\title{
C8-Arylguanine Modified Hairpin Oligonucleotides: Synthesis, Conformational Analysis, and Tools for the Investigation of Z-DNA Formation
}

\author{
Brian C. Train \\ West Virginia University
}

Follow this and additional works at: https://researchrepository.wvu.edu/etd

\footnotetext{
Recommended Citation

Train, Brian C., "C8-Arylguanine Modified Hairpin Oligonucleotides: Synthesis, Conformational Analysis, and Tools for the Investigation of Z-DNA Formation" (2014). Graduate Theses, Dissertations, and Problem Reports. 592.

https://researchrepository.wvu.edu/etd/592

This Dissertation is protected by copyright and/or related rights. It has been brought to you by the The Research Repository @ WVU with permission from the rights-holder(s). You are free to use this Dissertation in any way that is permitted by the copyright and related rights legislation that applies to your use. For other uses you must obtain permission from the rights-holder(s) directly, unless additional rights are indicated by a Creative Commons license in the record and/ or on the work itself. This Dissertation has been accepted for inclusion in WVU Graduate Theses, Dissertations, and Problem Reports collection by an authorized administrator of The Research Repository @ WVU. For more information, please contact researchrepository@mail.wvu.edu.
} 


\title{
C8-Arylguanine Modified Hairpin Oligonucleotides: Synthesis, Conformational Analysis, and Tools for the Investigation of Z-DNA Formation
}

\author{
Brian C. Train \\ Dissertation submitted \\ to the School of Pharmacy \\ at West Virginia University \\ in partial fulfillment of the requirements \\ for the degree of \\ Doctor of Philosophy in \\ Pharmaceutical and Pharmacological Sciences \\ Peter M. Gannett, PhD, Chair \\ Patrick S. Callery, $\mathrm{PhD}$ \\ Robert K. Griffith, PhD \\ Yongyut Rojanasakul, PhD \\ X. Michael Shi, PhD \\ Department of Pharmaceutical and Pharmacological Sciences
}

Morgantown, West Virginia

2014

Keywords: Z-DNA, Hairpin Oligonucleotides, Arylhydrazine, C8-arylguanine, Physiological Conditions

Copyright 2014 Brian C. Train 


\title{
ABSTRACT \\ C8-Arylguanine Modified Hairpin Oligonucleotides: Synthesis, Conformational Analysis, and Tools for the Investigation of Z-DNA Formation
}

\author{
Brian C. Train
}

Z-DNA is the only DNA conformation that has a left-handed helical twist. Z-DNA has been implicated in carcinogenesis from its role in gene expression. Z-DNA formation has been linked to mutagenesis since it may play a role in genetic instability and can induce gene deletions. However, the specific biological role for Z-DNA in vivo remains uncertain. Arylhydrazines are carcinogenic compounds that are known to form DNA adducts, although it is unknown how DNA adduct formation is related to their carcinogenicity. Previous work in our lab has demonstrated that the formation of C8-arylguanine DNA adducts, derived from arylhydrazines, shifts the B-/Z-DNA equilibrium toward the Z-DNA conformation in $\mathrm{d}(\mathrm{CG})_{5}$ sequences. However, our previous work examined the effect of two adducts in the duplex and it was unclear whether the two base modifications were working together to cause the equilibrium shift toward the Z-DNA conformation. Here we sought to determine the conformational effects of a hairpin oligonucleotide sequence $\left(\mathrm{d}(\mathrm{CG})_{5} \mathrm{~T}_{4}(\mathrm{CG})_{5}\right)$ containing only one $\mathrm{C} 8$-arylguanine modified base to compare with our previous results.

Synthesis of C8-arylguanine modified hairpin oligonucleotides began at the nucleoside level and then the C8-aryl-2'-deoxyguanosine phosphoramidite was incorporated into a hairpin sequence (d(5'CGCGCG*CGCGTTTTCGCGCGCGCG3') where $\mathbf{G}^{*}=\mathrm{C} 8$-arylguanine). The conformational effects of a single $\mathrm{C} 8$-arylguanine modification on the hairpin oligonucleotide were determined and quantitated by a combination of NMR, CD and molecular modeling. The unmodified hairpin and the previously studied unmodified double-stranded oligonucleotide were conformationally similar and each required $\sim 3 \mathrm{M} \mathrm{NaCl}$ to yield a B-/Z-DNA ratio of 1:1. The introduction of a single $\mathrm{C} 8$-arylguanine modification significantly reduced the $\mathrm{NaCl}$ concentration needed to produce a 1:1 B-/Z-DNA ratio in the hairpin. Further, the addition of $\mathrm{MgCl}_{2}$ and spermine to the $\mathrm{C} 8$-arylguanine modified hairpin shifts the B-/Z-DNA equilibrium such that the $\mathrm{Z}$ form predominated under physiological conditions. NMR and molecular modeling indicated the conformational effects produced by the $\mathrm{C} 8$-arylguanine modification occurred locally at the site of modification while $\mathrm{CD}$ data demonstrated that the $\mathrm{C} 8$-arylguanine modified base destabilized the $\mathrm{B}$ form. Additionally, the data show that adopting the Z-DNA conformation is preferred over denaturation to the single-stranded form. Finally, the conformational effects of the C8-arylguanine modifications were not additive and the introduction of any such modifications drive Z-DNA formation under physiological conditions, which may provide a novel carcinogenesis mechanism where DNA adducts confer their carcinogenicity through a Z-DNA mediated mechanism. 


\section{Acknowledgements}

I would like to thank my advisor, Dr. Peter M. Gannett, for helping me and guiding me throughout my dissertation work. His unyielding encouragement, patience, and understanding combined with his incredible intellect and knowledge facilitated and enhanced my comprehension of my research project. I will able to use the skills that I learned in graduate school not only in my next position but for the rest of my life. Thank you. Thank you to my dissertation committee members, Dr. Patrick S. Callery, Dr. Robert K. Griffith, Dr. Yongyut Rojanasakul, and Dr. X. Michael Shi, who have profoundly influenced me through their valuable suggestions for my work as well as volunteering their time to guide me during my graduate school experience.

I would like to thank the many members of Dr. Gannett's lab, especially Dr. Vorasit Vongsutilers and Dr. Lance A. Wollenberg, for helping me and working alongside me throughout my project. I would also like to thank all the undergraduate students that helped work with me on this project, specifically Suzan A. Bilgesü. Many acknowledgements to the PPS staff members, Penny Dailey, Donna Mathess, and Brad Rager, for all their help and assistance in the graduate school program. Thank you to Dr. Fred Minnear and the 2007 Biomedical Sciences search committee for taking a chance and giving me the opportunity to attend graduate school at West Virginia University. Thank you to Mrs. Claire Noel for making the transition from undergraduate to graduate school as seamless as possible and for being a very good friend.

Most importantly thank you to my family, all 52 Trains and all the Overtons, for all their relentless support and words of wisdom. I could be not successful without them. To my mother and father, Helena and Peter Train, for being the best parents in the entire world and always being there for me. To my younger brother, Kevin, for being my best friend and my favorite person in the world. To Dr. Sarah E. Bowen for being the love of my life, you are truly the most amazing woman in the entire world. 


\section{Table of Contents}

ABSTRACT I

ACKNOWLEDGEMENTS ...II

LIST OF FIGURES.

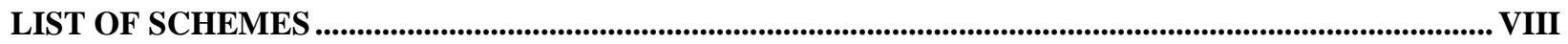

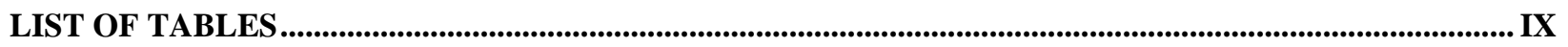

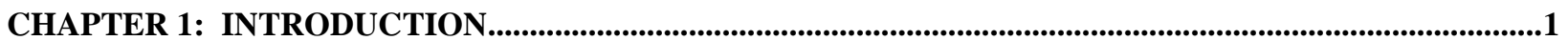

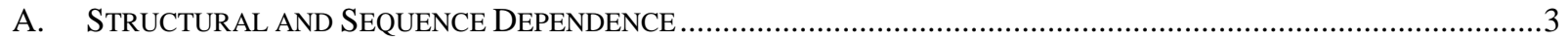

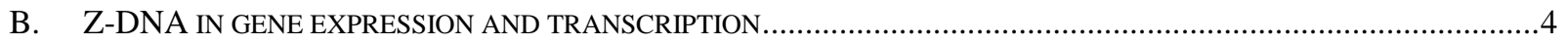

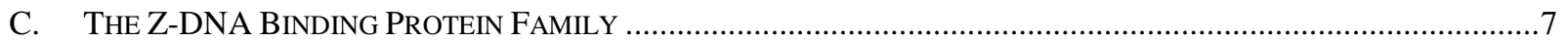

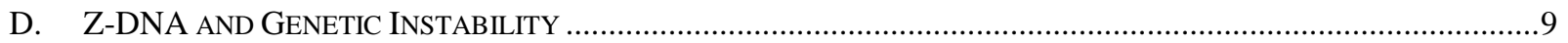

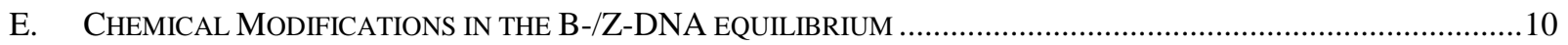

1. The Effect of Arylhydrazines on the B-/Z-DNA equilibrium ...........................................................12

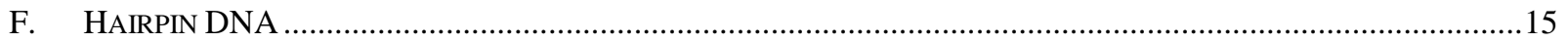

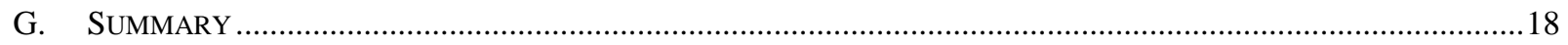

CHAPTER 2: EXPERIMENTAL TECHNIQUES AND APPROACH .............................................................20

A. SUZUKI COUPLING TO PRODUCE THE C8-ARYL-2'-DEOXYGUANOSINE …...................................................21

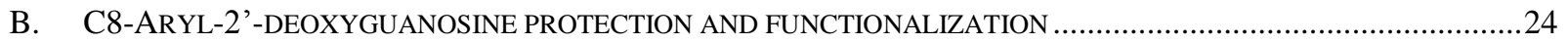

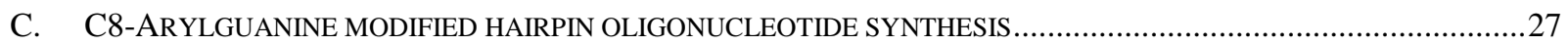

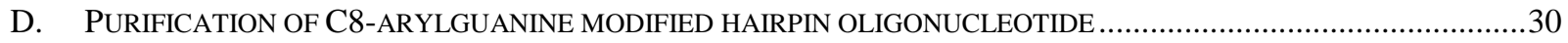

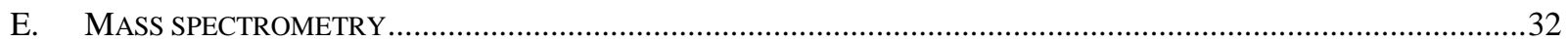

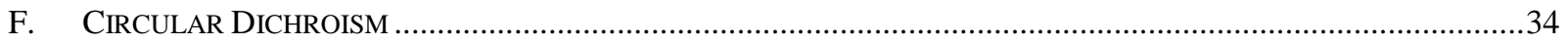

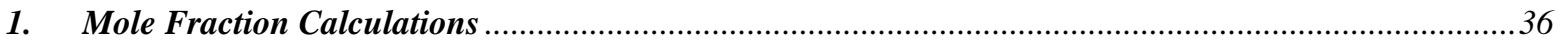

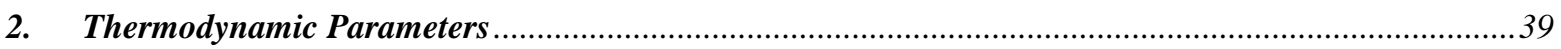

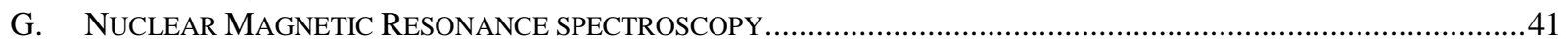

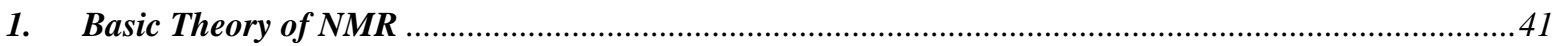

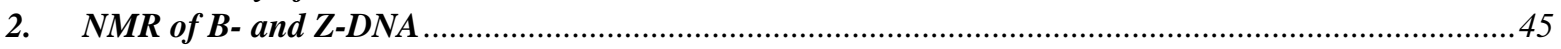

CHAPTER 3: EXPERIMENTAL TECHNIQUES AND RESULTS..................................................................50

PART I: C8-ARYL-2'-DEOXYGUANINE MODIFIED NUCLEOSIDE AND HAIRPIN

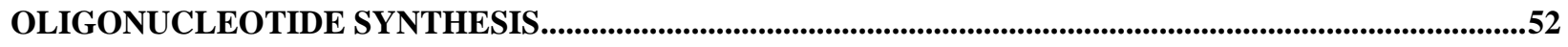

A. C8-ARYL-2'-DEOXYGUANOSINE NUCLEOSIDES AND PHOSPHORAMIDITE SYNTHESIS ......................................52

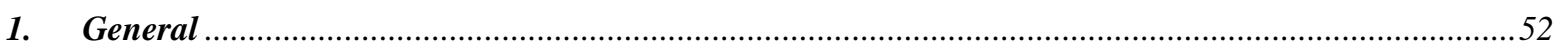

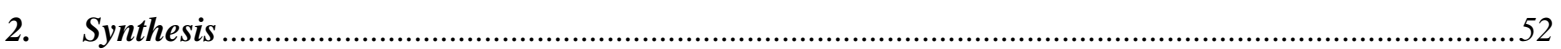

B. SYNTHESIS, PURIFICATION AND STRUCTURE CONFIRMATION OF HAIRPIN OLIGONUCLEOTIDES .......................68

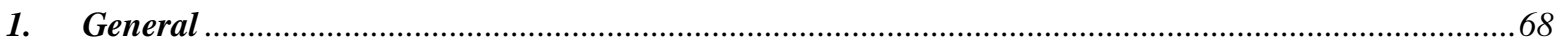

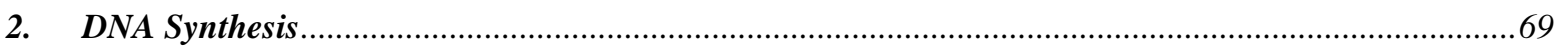

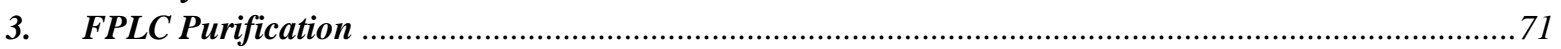

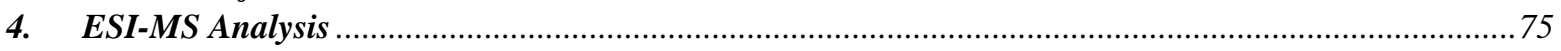

PART II: CONFORMATIONAL ANALYSIS OF C8-ARYLYGUANINE MODIFIED HAIRPIN

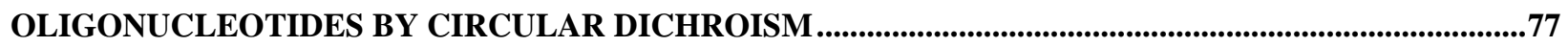

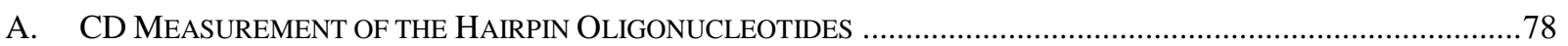

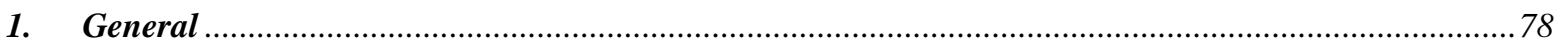

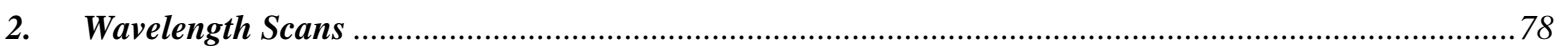

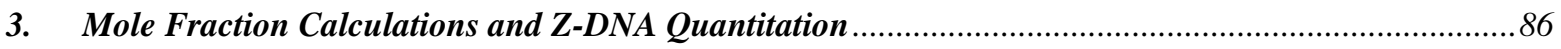

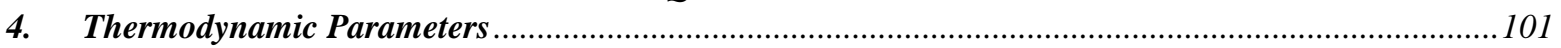




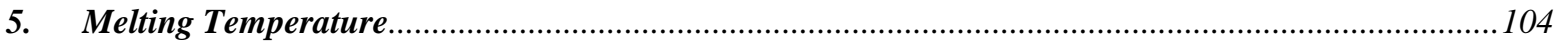

6. Conformational Preferences of the B-/Z-DNA Equilibrium under Physiological Conditions.............106

PART III: NMR ANALYSIS OF THE HAIRPIN OLIGONUCLEOTIDES ...................................................113

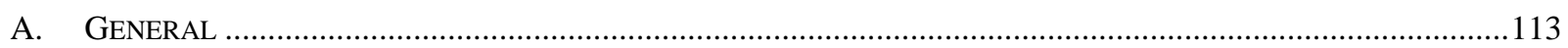

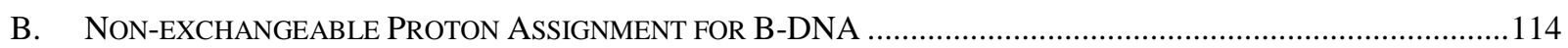

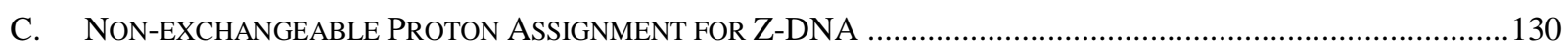

CHAPTER 4: MOLECULAR MODELING OF THE B- AND Z-DNA CONFORMATIONS OF THE

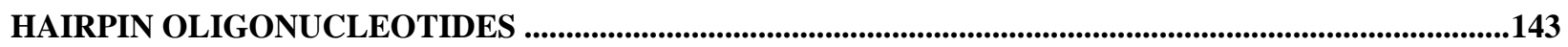

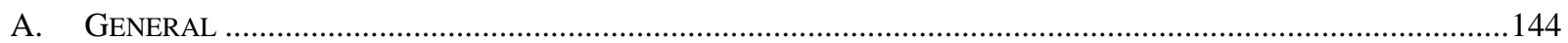

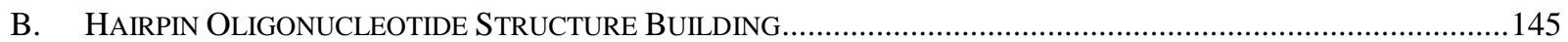

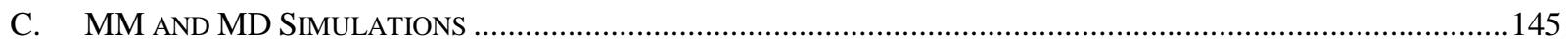

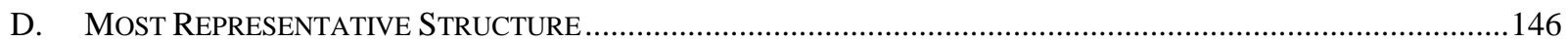

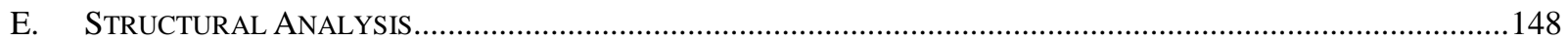

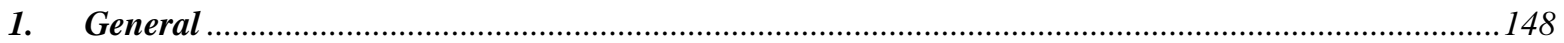

2. Hairpin Oligonucleotides in the B-DNA conformation ...........................................................150

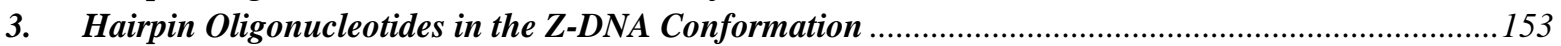

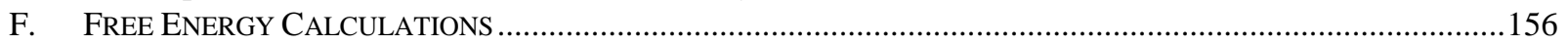

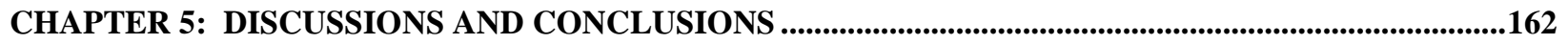

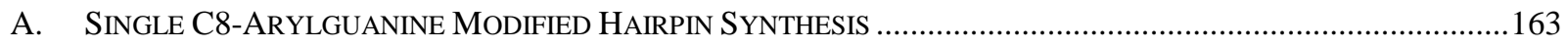

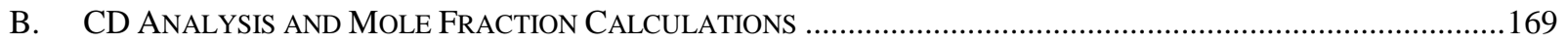

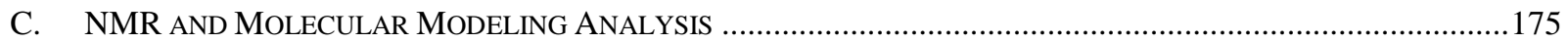

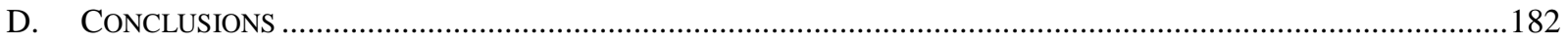

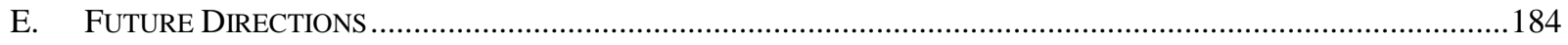

REFERENCE LIST ..........................................................................................................................................................188

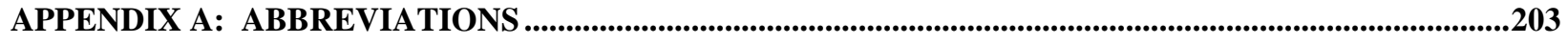

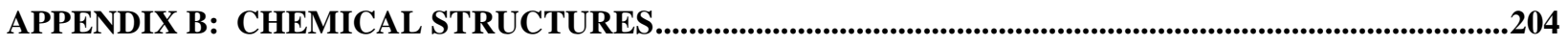

APPENDIX C: EXPERIMENTAL SPECTRA AND CHROMATOGRAMS......................................................214 


\section{List of Figures}

Figure 1.1 Depictions of the major conformations of DNA

Figure 1.2 Illustration of the syn and anti glycosidic bond in the deoxyguanosine nucleotide

Figure 1.3 Structure of C8-aryl-2'-deoxyguanosine

Figure 1.4 Comparison of double-stranded and hairpin oligonucleotides

Figure 2.1 Structures of the phosphoramidites used in the single modified C8-arylguanine hairpin oligonucleotide synthesis

Figure 2.2 Structure of the major synthetic products of the C8-arylguanine modified hairpins

Figure 2.3 CD spectrum of B-DNA and Z-DNA conformations of the hairpin oligonucleotides

Figure 2.4 Energy levels of nuclei with $I=1 / 2$ and relationship of $\Delta E$ and external magnetic field strength

Figure 2.5 1H NMR spectrum of the hairpin oligonucleotide (5'-CGCGCGCGCGTTTTCGCGCGCGCG-3')

Figure 2.6 Internucleotide and intranucleotide assignment strategy for oligonucleotides in the B-DNA conformation

Figure 3.1 FPLC chromatogram of the $\mathrm{HP}-\mathrm{CG}^{8 \mathrm{Ph}}$ hairpin oligonucleotide before purification

Figure 3.2 FPLC chromatogram of the $\mathrm{HP}-\mathrm{CG}^{8 \mathrm{Ph}}$ oligonucleotide purification run

Figure 3.3 FPLC chromatogram of the $\mathrm{HP}-\mathrm{CG}^{8 \mathrm{Ph}}$ after purification

Figure 3.4 CD spectra at $37^{\circ} \mathrm{C}$ wavelength scan for HP-CG

Figure 3.5 $\mathrm{CD}$ spectra at $37^{\circ} \mathrm{C}$ wavelength scan for $\mathrm{HP}-\mathrm{CG}^{8 \mathrm{Ph}}$

Figure 3.6 $\mathrm{CD}$ spectra at $37^{\circ} \mathrm{C}$ wavelength scan for $\mathrm{HP}-\mathrm{CG}^{8 \mathrm{Tol}}$

Figure 3.7 $\mathrm{CD}$ spectra at $37^{\circ} \mathrm{C}$ wavelength scan for $\mathrm{HP}-\mathrm{CG}^{8 \mathrm{HMPh}}$

Figure 3.8 CD spectra at $37^{\circ} \mathrm{C}$ wavelength scan for $\mathrm{HP}-\mathrm{CG}^{8 \mathrm{MMPh}} \quad 84$

Figure 3.9 $\mathrm{CD}$ spectra at $37^{\circ} \mathrm{C}$ wavelength scan for $\mathrm{HP}-\mathrm{CG}^{8 \mathrm{CPh}} \quad 85$

Figure 3.10 Mole fractions plots for HP-CG 89

Figure 3.11 Mole fractions plots for $\mathrm{HP}-\mathrm{CG}^{8 \mathrm{Ph}}$ 
Figure 3.12 Mole fractions plots for $\mathrm{HP}-\mathrm{CG}^{8 \mathrm{Tol}} \quad 93$

Figure 3.13 Mole fractions plots for HP-CG ${ }^{8 \mathrm{HMPh}} \quad 95$

Figure 3.14 Mole fractions plots for HP-CG ${ }^{8 \mathrm{MMPh}} \quad 97$

Figure 3.15 Mole fractions plots for $\mathrm{HP}-\mathrm{CG}^{8 \mathrm{CPh}} \quad 99$

Figure 3.16 van't Hoff plot of the hairpin mole fraction vs. temperature 103

Figure 3.17 Melting temperature profile for the unmodified and C8-arylguanine modified hairpin oligonucleotides as a function of salt concentration

Figure 3.18 HP-CG CD spectra under physiological conditions 107

Figure 3.19 $\mathrm{HP}-\mathrm{CG}^{8 \mathrm{Ph}} \mathrm{CD}$ spectra under physiological conditions 108

Figure 3.20 HP-CG ${ }^{8 \mathrm{Tol}} \mathrm{CD}$ spectra under physiological conditions 109

Figure 3.21 HP-CG ${ }^{8 \mathrm{HMPh}} \mathrm{CD}$ spectra under physiological conditions 110

Figure 3.22 $\mathrm{HP}-\mathrm{CG}^{8 \mathrm{MMPh}} \mathrm{CD}$ spectra under physiological conditions 111

Figure 3.23 $\mathrm{HP}-\mathrm{CG}^{8 \mathrm{CPh}} \mathrm{CD}$ spectra under physiological conditions 112

Figure 3.24 NMR assignment procedure for the hairpin oligonucleotides 116

Figure 3.25 Expansion of the aromatic region of the ${ }^{1} \mathrm{H}$ NMR spectrum 117

Figure 3.26 Expansion of the upfield region of the ${ }^{1} \mathrm{H}$ NMR spectrum 118

Figure 3.27 Expansion of the HP-CG ${ }^{8 \mathrm{MMPh}}$ gCOSY spectra 119

Figure 3.28 NOESY expansion of the HP-CG ${ }^{8 \mathrm{MMPh}} \quad 120$

Figure 3.29 NOESY expansion of the HP-CG ${ }^{8 M M P h}$ in the B-DNA conformation

Figure 3.30 Expansion of the HP-CG8HMPh aromatic region in the ${ }^{1} \mathrm{H}$ NMR spectrum in the Z-DNA conformation

Figure 3.31 Expansion of the HP-CG ${ }^{8 \mathrm{HMPh}}$ upfield region of the ${ }^{1} \mathrm{H} \mathrm{NMR}$ spectrum of the Z-DNA conformation

Figure 3.32 Expansion of the HP-CG ${ }^{8 \mathrm{HMPh}} \mathrm{gCOSY}$ spectra in the Z-DNA conformation

Figure 3.33 NOESY expansion of the HP-CG ${ }^{8 \mathrm{HMPh}}$ in the Z-DNA conformation

Figure 4.1 The most representative structures of the unmodified and

C8-arylguanine modified hairpin oligonucleotides in the B-DNA conformation 
Figure 4.2 The most representative structures of the unmodified and

Figure 4.3 Depiction of the base pair and base pair step helical parameters

Figure 5.1 FPLC chromatogram of the failed $\mathrm{HP}-\mathrm{CG}^{8 \mathrm{Ph}}$ synthesis and successful HP-CG ${ }^{8 \mathrm{Ph}}$ synthesis

Figure 5.2 Double-stranded and hairpin $\mathrm{C}_{5}-\mathrm{G}_{6}$ base step

Figure 5.3 CD spectra with DAI- $\beta$ in complex with unmodified HP-CG and $\mathrm{HP}-\mathrm{CG}^{8 \mathrm{MMPh}}$ 


\section{List of Schemes}

Scheme 1.1 Proposed mechanism of the Z-DNA binding protein mediated B-/Z-DNA transition

Scheme 1.2 Mechanistic scheme for the formation of aryl radicals

Scheme 2.1 Synthesis of the C8-aryl-2'-deoxguanosine modified phosphoramidite

Scheme 2.2 The general mechanism of the Suzuki coupling used to make

C8-aryl-2'-deoxgyanosine nucleosides

Scheme 2.3 The synthetic cycle of DNA synthesis

Scheme 5.1 Novel approach of the ZBP mediated B-/Z-DNA transition using C8-arylguanine modified oligonucleotides 


\section{List of Tables}

Table 3.1 FPLC analysis of the hairpin oligonucleotides

Table 3.2 Comparison of calculated and observed $\mathrm{m} / \mathrm{z}$ values for hairpin oligonucleotides

Table 3.3 Mole fractions HP-CG

$\begin{array}{ll}\text { Table 3.4 Mole fractions } \mathrm{HP}-\mathrm{CG}^{8 \mathrm{Ph}} & 90\end{array}$

Table 3.5 Mole fractions HP-CG ${ }^{8 \mathrm{Tol}} \quad 92$

Table 3.6 Mole fractions HP-CG ${ }^{8 \mathrm{HMPh}} 94$

Table 3.7 Mole fractions HP-CG ${ }^{8 M M P h} \quad 96$

$\begin{array}{ll}\text { Table 3.8 Mole fractions HP-CG8cph } & 98\end{array}$

Table 3.9 Transition concentration of the hairpin oligonucleotides at $37^{\circ} \mathrm{C} \quad 101$

Table 3.10 Thermodynamic parameters for the hairpin oligonucleotides 104

Table 3.11 Non-exchangeable proton assignment of the unmodified HP-CG in the $\mathrm{B}$ form

Table 3.12 Non-exchangeable proton assignment of the modified $\mathrm{HP}-\mathrm{CG}^{8 \mathrm{Ph}}$ in the B form

Table 3.13 Non-exchangeable proton assignment of the modified $\mathrm{HP}-\mathrm{CG}^{8 \mathrm{Tol}}$ in the B form

Table 3.14 Non-exchangeable proton assignment of the modified HP-CG ${ }^{8 \mathrm{HMPh}}$ in the $\mathrm{B}$ form

Table 3.15 Non-exchangeable proton assignment of the modified HP-CG ${ }^{8 \mathrm{MMPh}}$ in the B form

Table 3.16 Non-exchangeable proton assignment of the modified $\mathrm{HP}-\mathrm{CG}^{8 \mathrm{CPh}}$ in the $\mathrm{B}$ form

Table 3.17 Non-exchangeable proton assignment of the modified HP-CG ${ }^{8 \mathrm{Ph}}$ in the $\mathrm{Z}$ form

Table 3.18 Non-exchangeable proton assignment of the modified HP-CG ${ }^{8 T o l}$ in the $\mathrm{Z}$ form

Table 3.19 Non-exchangeable proton assignment of the modified HP-CG ${ }^{8 \mathrm{HMPh}}$ in the $\mathrm{Z}$ form 
Table 3.20 Non-exchangeable proton assignment of the modified $\mathrm{HP}_{-} \mathrm{CG}^{8 \mathrm{MMPh}}$ in the $\mathrm{Z}$ form

Table 3.21 Non-exchangeable proton assignment of the modified $\mathrm{HP}-\mathrm{CG}^{8 \mathrm{CPh}}$ in the $\mathrm{Z}$ form

Table 4.1 Helical parameters for the unmodified and modified hairpin oligonucleotides in the B-DNA conformation determined by X3DNA

Table 4.2 Major and minor groove widths for the unmodified and modified hairpin oligonucleotides in the B-DNA conformation determined by X3DNA

Table 4.3 Helical parameters for the unmodified and modified hairpin oligonucleotides in the Z-DNA conformation determined by X3DNA

Table 4.4 Major and minor groove widths for the unmodified and modified hairpin oligonucleotides in the Z-DNA conformation determined by X3DNA

Table 4.5. Free Energies of the Unmodified and C8-Arylguanine Modified Hairpin Oligonucleotides Calculated by the MM/GBSA Model in the B-DNA Conformation

Table 4.6. Free Energies of the Unmodified and C8-Arylguanine Modified Hairpin Oligonucleotides Calculated by the MM/GBSA Model in the Z-DNA Conformation

Table 4.7. Free Energy Difference between the B- and Z-DNA Conformations for the Unmodified and Modified Hairpins

Table 5.1 Synthetic yields of the C8-aryl-2'-deoxyguanosine analogs and protection reactions

Table 5.2 Transition and thermodynamic parameters for the B-/Z-DNA equilibrium of unmodified and modified double-stranded and hairpin oligonucleotides

Table 5.3 Salt dependence of the difference in TM between the unmodified hairpin and the $\mathrm{C} 8$-arylguanine modified hairpins

Table 5.4 Chemical shifts of the C8-aryl protons in double-stranded and hairpin oligonucleotides

Table 5.5 Key helical parameters of the most representative structures for the unmodified and modified double-stranded and hairpin oligonucleotides in the B-DNA conformation 


\section{Chapter 1: Introduction}

Deoxyribonucleic acid (DNA) has the structural flexibility to adopt many different conformations. The most well-known conformations of DNA are A-DNA, ${ }^{1} \mathrm{~B}-\mathrm{DNA},{ }^{2}$ and Z-DNA ${ }^{3}$ (Figure 1.1), although there are also several other biologically significant conformations including hairpin, ${ }^{4,5}$ cruciform, ${ }^{6}$ triplex ${ }^{7-9}$ and quadruplex DNA. ${ }^{10,11}$ All of the aforementioned DNA conformations adopt a right-handed helix except Z-DNA, which has a left-handed helix.

The initial discovery of Z-DNA was reported by Pohl and Jovin ${ }^{12}$ in 1972 though the structural nature of this conformation of DNA was unknown. In Pohl and Jovin's study, it was clear that the DNA conformation they produced gave CD spectral characteristics that were not consistent with A- or B-DNA. In 1979, the term Z-DNA was first used to describe a DNA XRAY structure obtained when DNA was crystallized under high salt conditions. These conditions produced a new form of DNA that had a 'zigzag' phosphate backbone and, hence, was named ZDNA. Later it was confirmed by Raman spectroscopy ${ }^{13}$ that the high salt structure of DNA determined by Pohl and Jovin in 1972 was analogous to the crystal structure by reported Wang et $a .^{3}$ 
A-DNA

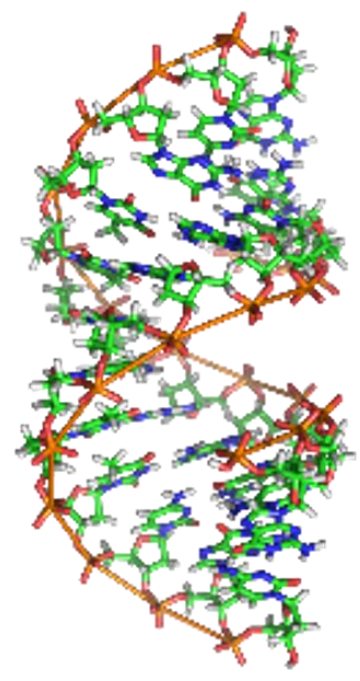

B-DNA

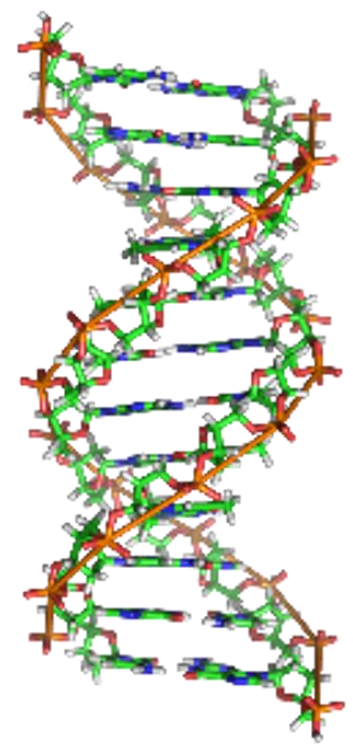

Z-DNA

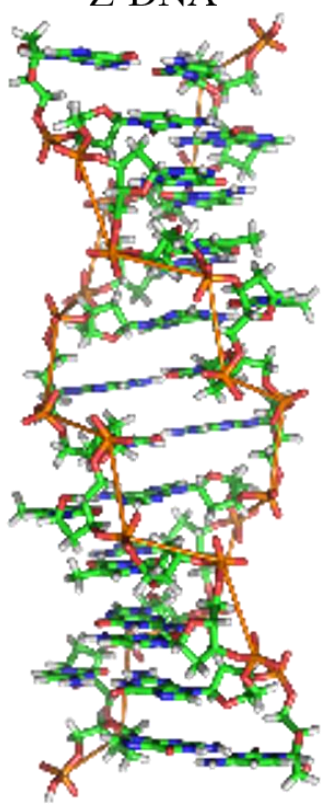

Figure 1.1. Depictions of the major conformations of DNA. A-DNA (left) and B-DNA (middle) adopt a right-handed left helix. Z-DNA (right) is the lone conformation of DNA that adopts of a left-handed helix twist.

In the 1980's, Z-DNA became the subject of extensive research and at the same time became the source of significant debate regarding the biological significance of this DNA conformation. Initially, all conditions where the $\mathrm{Z}$ conformation was favored over the $\mathrm{B}$ conformation were beyond the range thought to be physiologically relevant. Thus, Z-DNA became thought of as an artifact of experimental curiosity and an example of the polymorphic capacity of DNA. ${ }^{14}$ However, during the 35 years since the first crystal structure of Z-DNA, there have been more than 4,000 publications leading to over 70,000 citations on Z-DNA.

While controversy still surrounds the biological relevance of Z-DNA conformation, the review presented below and the original research presented herein, provides evidence in support of a biological role for Z-DNA and further supports a regulatory role during transcription for the 
left-handed conformer of DNA. Specifically, this work provides insight into the conformational effects generated by the introduction of $\mathrm{C} 8$-arylguanine modifications in oligonucleotides, the biological relevance of these adducts with respect to Z-DNA formation, and suggests a novel carcinogenic mechanism by which DNA adducts on the $\mathrm{C} 8$ position of guanine nucleotides confer their carcinogenicity through a Z-DNA mediated mechanism.

\section{A. Structural and Sequence Dependence}

The zigzag nature of the phosphate backbone of Z-DNA is a direct result of the configuration of the glycosidic group that alternates between the syn-and anti-conformation. ${ }^{3}$ A major structural requirement for Z-DNA formation is sequence and generally an alternating purine-pyrimidine (APP) repeat sequence is required. This requirement is derived from the purines ability to adopt the syn-conformation about the glycosidic bond while the pyrimidines predominantly adopt the anti-conformation (Figure 1.2). The $\mathrm{d}(\mathrm{CG})_{\mathrm{n}}$ repeat sequence has been

demonstrated to be the most favorable Z-DNA forming sequence, ${ }^{15,16}$ however the $\mathrm{d}(\mathrm{CA}): \mathrm{d}(\mathrm{TG})$ sequence ${ }^{17}$ can also form Z-DNA as well as some other non-APP sequences. ${ }^{18}$ 


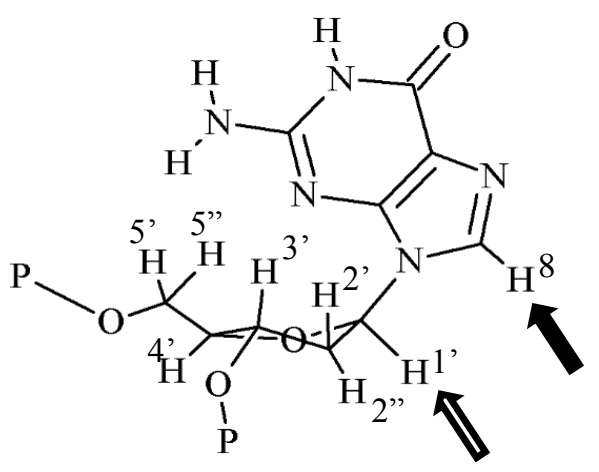

A) Syn

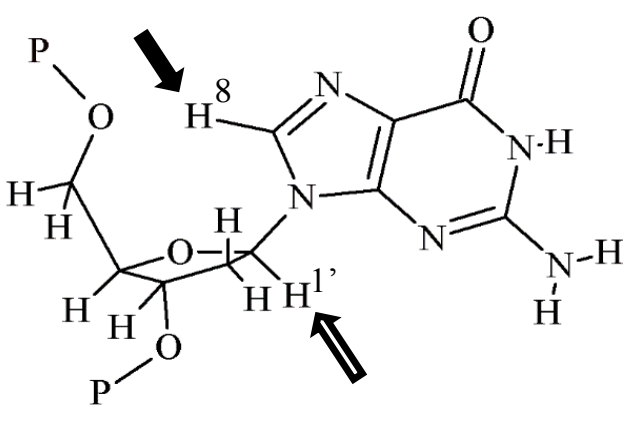

B) Anti

Figure 1.2. Illustration of the syn- (A) and anti-glycosidic bond in the deoxyguanosine nucleotide. The anticonformation is the preferred conformation for the DNA nucleotides in the B form where the $\mathrm{H} 1$ ' and $\mathrm{C} 8 \mathrm{H}$ are away from each other relative the glycosidic bond. C8-deoxyguanosine DNA adducts cause steric hindrance between the group at $\mathrm{C} 8$ and $\mathrm{H} 2$ ' that drives the deoxyguanosine syn-conformation where the $\mathrm{H} 1$ ' and $\mathrm{C} 8 \mathrm{H}$ are on the same side as the glycosidic bond.

The preference for B- over Z-DNA has been ascribed to electrostatic repulsion between adjacent phosphate oxygen anions which are approximately one angstrom closer in the $\mathrm{Z}$ form. Consequently, Z-DNA formation requires the stabilization by external conditions. For example, the unfavorable electrostatic interactions present in Z-DNA can be attenuated by screening the negative charges with high salt concentrations $(2-4 \mathrm{M} \mathrm{NaCl}),{ }^{19}$ magnesium or other divalent metal ions, ${ }^{20}$ spermidine and other polyamines,${ }^{21,22}$ and other positively charged species such as Z-DNA binding proteins $(\mathrm{ZBP}) .^{23,24}$

\section{B. Z-DNA in gene expression and transcription}

The most common occurrence of Z-DNA in vivo arises during transcription and is caused by the torsional stress produced during negative supercoiling ${ }^{25}$ though it was not until 1987 that this phenomena was demonstrated to have a potential biological role. Initially, it was thought that the RNA polymerase rotated around the DNA helix during transcription. ${ }^{26,27}$ However Liu and 
Wang $^{28}$ demonstrated that, in fact, the RNA polymerase drives through the middle of the DNA helix which in turn creates negative supercoiling behind the RNA polymerase complex. Relieving the torsional stress induced by negative supercoiling provides the energy required to stabilize DNA in the Z-DNA conformation and therefore a role for Z-DNA in transcription was suggested. Further, analysis of the human genome revealed many potential Z-DNA forming sequences that are non-randomly located near transcription start sites. ${ }^{29}$ Subsequent studies by Wittig et al. ${ }^{30,31}$ demonstrated that Z-DNA formation was correlated with the expression of the human oncogene c-MYC and Wolfl et al. ${ }^{32}$ also found Z-DNA during the transcription of human corticortopinreleasing hormone. ${ }^{33}$

Another major breakthrough was found by the Zhao lab at the NIH. These workers demonstrated that Z-DNA formation was required, along with the NF1/CTF transcription factors and SWI/SNF/BAF complex to the promoter region, to initiate transcription of the human colonystimulating factor 1 (CSF1). ${ }^{33}$ This group established that the ATP-dependent subunit of SWI/SNF complex, BRG1, was able to induce Z-DNA formation even in the absence of transcription and thus the torsional strain may be the result of the nucleosome remodeling before transcription and not necessarily the action of the transcribing polymerase. ${ }^{34}$ The SWI/SNF chromatin remodeling complex is thought to regulate genes during cell differentiation, proliferation, neural development, hematopoietic development, malignant processes, and specifically has been identified in transcriptional activation of solute carrier family 11 member $1(S L C 11 A 1)^{35}$ and HIV $-1 .{ }^{36}$ The SWI/SNF complexes were further shown to be recruited to target genes such as c-MYC ${ }^{37}$ and CCAAT/enhancer-binding protein ${ }^{38}$ or nuclear receptors ${ }^{39}$ like glucocorticoid receptor ${ }^{40}$ and 
estrogen receptor via transcription factors. These reports provide strong evidence for a regulatory role of Z-DNA in transcription.

More recently, Mulholland et al. ${ }^{41}$ demonstrated that Z-DNA formation can occur on nucleosomes, contrary to previous studies that suggest that Z-DNA creates a nucleosomal boundary. ${ }^{42}$ Z-DNA formation within the nucleosome structure enhances the argument that ZDNA plays a role in gene expression as this structure may provide additional opportunities for protein interactions regulating gene expression even at the chromatin level. ${ }^{41}$ Regardless of whether Z-DNA formation prevents nucleosome reformation or initiates gene transcription, both can lead to overexpression of genes, a hallmark of cancer (reviewed by Santarius et $a l .{ }^{43}$ ).

In another system, a Z-DNA forming negative regulatory element (NRE) has been identified in the 5'-UTR of ADAM-12 (a disintegrin and metalloprotease). Normal expression of ADAM-12 is very low but is upregulated in a number of disease states such as breast, liver, brain, and prostate cancer. ${ }^{44}$ In this report, the authors demonstrated that low levels of expression of ADAM-12 are correlated to high levels of Z-DNA-interacting protein activity with the ADAM-12 NRE. In contrast, low levels of Z-DNA-interacting protein activity with the NRE led to high levels of ADAM-12 expression. Thus the authors suggested that there are protein(s) involved in the transcriptional regulation of ADAM-12. More recently, this group confirmed the overexpression of ADAM-12 is correlated to the loss Z-DNA transcriptional suppression. ${ }^{45}$ These authors further established a novel epigenetic regulatory mechanism where a complex of three proteins, methylCpG-binding protein (MeCP2) and two members of the nuclear factor 1 transcription factors (NF1C and NF1X), interact with the NRE in ADAM-12 thereby regulating ADAM-12 expression. Interestingly, nuclear factor 1 transcription factor (NF1) has been shown to target genes as well as Z-DNA forming regions near transcription start sites. The NF1 was also shown to play a role in 
the activation of the CSF1 with the above mentioned SWI/SNF remodeling complex. Altogether these studies provide evidence that Z-DNA is involved in the activation of gene expression, which is a highly regulated, and thus when Z-DNA formation becomes dysregulated can lead to carcinogenic consequences.

\section{The Z-DNA Binding Protein Family}

Four proteins have been identified that belong to the Z-DNA binding protein (ZBP) family $\left(\mathrm{ADAR} 1,{ }^{24} \mathrm{ZBP} 1 / \mathrm{DLM} / \mathrm{DAI},{ }^{46} \mathrm{PKZ}^{47}\right.$ and $\left.\mathrm{E} 3 \mathrm{~L}^{48}\right)$. The ZBP family of proteins all display specificity for the $\mathrm{Z}$ conformation and share structural binding motifs in the Z-DNA binding region. The ZBP binding proteins have two Z-DNA binding domains, $\mathrm{Z} \alpha$ and $\mathrm{Z} \beta$, that interact with the DNA backbone. The ZBP Z-DNA binding domains contain several positively charged lysine and arginine residues that help to screen the negative charges of the phosphate backbone to stabilize the Z-DNA conformation. Three of the ZBPs are functionally related to the interferon system of the innate immune response: double stranded RNA adenosine deaminase (ADAR1), DNA-dependent activator of IFN-regulatory factors (DAI/ZBP1/DLM-1), and fish PKZ protein kinase. ADAR1 and PKZ activity have been demonstrated as host responses to viral infections. For example, ADAR1 is thought to alter viral replication by deaminating the viral duplex RNA. ${ }^{49}$ PKZ activates eIF2 $\alpha$ to halt protein synthesis, which eventually leads to cell death. ${ }^{50}$ DAI is believed to be a cytosolic DNA sensor that binds foreign DNA which recruits TANK-binding kinase 1 (TBK1) and further activates interferon regulatory factor 3 (IRF3) and nuclear factor- $\kappa \mathrm{B}$

$(\mathrm{NF}-\kappa \mathrm{B}) .{ }^{51-53}$ The fourth ZBP identified, E3L, is the virulence factor of the vaccinia virus and displays behavior similar to other oncogenic proteins of DNA viruses through inhibition of 
apoptosis of the host cell. ${ }^{54}$ Since these proteins all contain structural homology, Kim and coworkers propose that E3L can compete with DAI to suppress gene expression of the host's immune response. ${ }^{55}$

In addition to the biological roles for these ZBP proteins, the mechanism of how ZBPs convert B-DNA to Z-DNA is also of great interest. The ZBP mediated B- to Z-DNA transition, determined by NMR spectroscopy, was first reported for ADAR 1 in $2009 .{ }^{56}$ In this report, the authors claim that the Z $\alpha$ domain of ADAR1 converted B-DNA to Z-DNA through an active-mono mechanism; where a single ADAR1-Z $\alpha$ binds to a B-DNA $\left(\mathrm{d}(\mathrm{CG})_{3}\right)$, begins to convert it to the ZDNA conformation, and then a second ADAR1-Z $\alpha$ binds with full conversion to the $\mathrm{Z}$ form (Scheme 1.1). A similar mechanism was suggested for $\mathrm{E} 3 \mathrm{~L}-\mathrm{Z} \alpha^{57}$, however the mechanism was slightly different for DAI-Z $\beta{ }^{58}$ The mechanism for DAI-Z $\beta$ proposed, instead, two DAI-Z $\beta$ monomers binding concurrently to convert the B-DNA structure to Z-DNA (active-di mechanism).

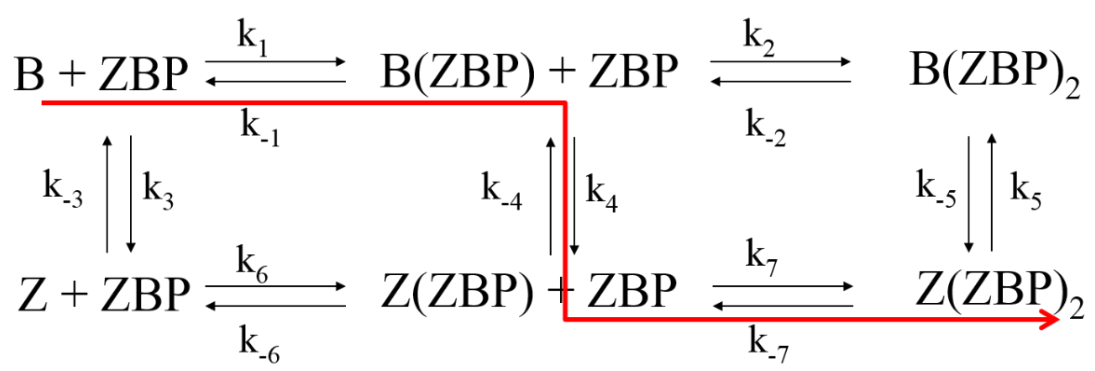

Scheme 1.1. Proposed mechanism of the Z-DNA binding protein (ZBP) mediated B-/Z-DNA transition. The currently proposed mechanism follows the red arrow and suggests that ZBPs actively induce and/or converm temp BDNA to the Z-DNA conformation.

More recently, studies ${ }^{59,60}$ have been performed on oligonucleotides that contain regions that are prone to Z-DNA formation and resistant to Z-DNA formation (i.e., non-APP B-DNA) and therefore a B-/Z-DNA junction can form. ${ }^{61}$ These studies provided a clearer picture of how ADAR1-Z $\alpha$ converts B-DNA into Z-DNA. Initially, a ZBP binds to the Z-prone $\mathrm{d}(\mathrm{GC})$ repeat 
dyad, in the $\mathrm{B}$ form, of the oligonucleotide. Binding of the ZBP to the Z-DNA forming region causes destabilization of the adjacent portion of the oligonucleotide. In the non-Z-DNA, B-DNA sequence a 'bubble' occurs which allows for the structural adjustments required for Z-DNA formation. In particular, the purine nucleotides need to rotate about the glycosidic bond. The purine nucleotides break their base pair and move outside of the helix. The purine base then rotates $180^{\circ}$ (i.e., flips over) and then rotates back into the helix. The above reports suggest that ZBPs bind B-DNA and actively convert it to Z-DNA, raising two intriguing questions. First, what is the evolutionary advantage of producing proteins that bind selectively to Z-DNA, yet recognize B-DNA, only to then convert it to the Z-DNA structure? Second, how does their biological function fit into their selectivity for Z-DNA structure especially in the context that the most common occurrence of Z-DNA arises from transcription, whether from negative supercoiling or nucleosome remodeling, where the ZBPs do not need to convert the B-DNA structure into the Z form?

\section{Z-DNA and Genetic Instability}

Genetic instability has been thought to play a role in diseases such as cancer or neurological disorders. However, only recently has it been considered that the genetic instability may be the result from alternative, non-B-DNA structures. ${ }^{62}$ Since Z-DNA, under physiological conditions, is a higher energy form of DNA, Z-DNA formation has been hypothesized to be a major source of genetic instability. In addition to the location of Z-DNA forming sequences at transcription start

sites, Z-DNA forming sequences are also found near genetic 'hotspots' or 'fragile sites'. These regions of the genome have been shown to readily undergo double-strand breaks (DSB), 
translocations, rearrangements and deletions. ${ }^{63}$ Initially, Z-DNA mediated genetic instability was observed in $E$. coli where incorporation of CG repeats into the bacterial DNA increased the gene deletion frequency. ${ }^{64}$ When CG repeats are incorporated into mammalian cells, they can stimulate DSBs around the Z-prone sequence which, subsequently, results in large-scale gene deletions. ${ }^{65}$ These types of gene deletions have been found to be replication independent and therefore thought to be initiated by inefficient repair processes of the cleavages surrounding the Z-DNA structure.

In addition to gene deletions, DSBs can also lead to chromosomal translocations near the DNA breakpoints that commonly occur in leukemia and lymphoma diseases. Specifically these translocation events can occur in $B C L-2,{ }^{66} c-M Y C^{67}$ and $S C L^{68}$ genes which have been described as some of the most commonly translocated genes in leukemia, lymphoma, and myeloma. Z-DNA forming sequences often occur at or near these breakage points on the chromosome, which are thought to play causative roles in acute lymphoblastic leukemia (ALL), ${ }^{69}$ non-Hodgkin's lymphomas, ${ }^{70}$ chronic lymphocytic leukemia, ${ }^{71,72}$ Brukitt's lymphomas, ${ }^{73}$ and T-cell ALL. ${ }^{68}$ Collectively these studies provide evidence of how Z-DNA formation can lead to mutagenic consequences that can be correlated with several disease states.

\section{E. Chemical Modifications in the B-/Z-DNA equilibrium}

This review has presented evidence of Z-DNA formation in the context of biological events, whether it be from negative supercoiling, chromosomal remodeling via DNA unwrapping from the nucleosome, or stabilization from endogenous Z-DNA binding proteins. However, naturally occurring or chemical modifications to the DNA bases can also alter the B-/Z-DNA

equilibrium. Methylation of the N7 position of guanine ${ }^{74}$ and/or C5 position of cytosine ${ }^{75}$ can 
have a profound effect on the B-/Z-DNA equilibrium. The methylation of N7 of guanine generates a positive charge which was described to help defray the negative charge repulsion in the zigzag phosphate backbone. DNA with the 5-methylcytosine modifications favors the $\mathrm{Z}$ form which is mainly due to hydrophobic interactions that occur in the B form where the methyl groups protrudes into the surrounding aqueous environment. In the $\mathrm{Z}$ form the methyl groups lie between the H1' and $\mathrm{H} 2$ ' of the adjacent 5'-guanine shielded from the solvent.

The presence of C8-purine adducts can also cause the equilibrium to shift toward the Z-DNA conformer. The DNA adducts such as bromine, ${ }^{76}$-aminobiphenyl, ${ }^{77} \mathrm{~N}$-methyl-4aminobenzene, ${ }^{77} \mathrm{~N}$-2-acetyl-aminofluorene ${ }^{78,79}$ or 2-aminofluorene, ${ }^{80}$ which most are formed from carcinogens, at the $\mathrm{C} 8$ position destabilize the B-DNA structure due to local steric interactions between the $\mathrm{C} 8$-adduct and the $\mathrm{H}-2$ ' proton of the pendant 2'-deoxyribose sugar in the anti-conformation. The steric strain is alleviated in the Z-DNA conformation when the purine is in the syn-conformation (see Figure 1.2). Generally, more than one of the above modifications are needed to destabilize the B-DNA conformation and drive Z-DNA formation. However, a single base modification of C8-methylguanine ${ }^{81}$ or incorporation of a single 8-methylguanosine ${ }^{82}$ into a $\mathrm{d}(\mathrm{CG})_{\mathrm{n}}$ sequence greatly stabilizes the Z-DNA conformation. The 8-methylguanosine modification stabilizes the $\mathrm{Z}$ conformation almost without any $\mathrm{NaCl}$ present. This result was explained by arguing that the energy needed to stabilize the Z-DNA form was afforded by the 2'$\mathrm{OH}$ hydrogen bonding with the solvent. In addition to the above C8-purine DNA adducts, alkylhydrazines and arylhydrazines can also produce DNA adducts and thus represent an important class of DNA adducts. These adducts are the primary focus of the work presented here, specifically C8-arylguanine DNA adducts. 


\section{The Effect of Arylhydrazines on the B-/Z-DNA equilibrium}

Arylhydrazines are class of biologically relevant compounds and while many are known carcinogens it is unclear how DNA adduct formation from arylhydrazines relates to their carcinogenicity. ${ }^{83}$ These chemicals are important due to their potential for human exposure since an arylhydrazine is found in the Agaricus bisporus mushroom ${ }^{84-86}$ and related compounds are also found in azo dyes, ${ }^{87}$ pharmacueticals,${ }^{88}$ and industrial areas. ${ }^{89}$ In 1996 , it was proposed that C8arylguanine adducts can form in DNA through production of aryl radicals after reduction of the corresponding arenediazonium ions (Scheme 1.2). ${ }^{90}$

$$
\begin{aligned}
& \mathrm{Ar}-\mathrm{N} \equiv \mathrm{N}^{+}+\mathrm{H}_{2} \mathrm{O} \rightleftharpoons \mathrm{Ar}-\mathrm{N} \equiv \mathrm{N}-\mathrm{OH}+\mathrm{H}^{+} \\
& \mathrm{Ar}-\mathrm{N} \equiv \mathrm{N}-\mathrm{OH} \rightleftharpoons \mathrm{Ar}-\mathrm{N}=\mathrm{N}^{\cdot}+{ }^{\cdot} \mathrm{OH} \\
& \mathrm{Ar}-\mathrm{N}=\mathrm{N}^{\cdot} \longrightarrow \mathrm{Ar}^{\cdot}+\mathrm{N}_{2} \\
& \mathrm{Ar}^{+}
\end{aligned}
$$

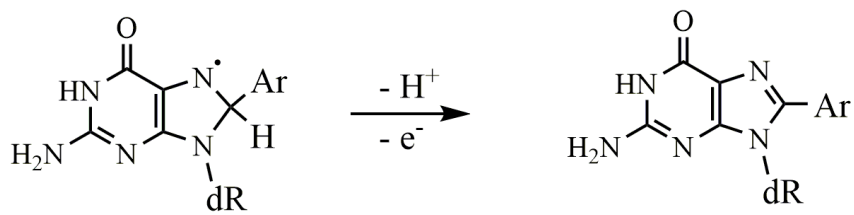

Scheme 1.2. Mechanistic scheme for the formation of aryl radicals from arylhydrazines. Here we will focus on the formation of C8-aryl-2'-deoxyguanosine modifications.

One year later it was shown that aryl radicals are indeed the result of arylhydrazine metabolism, supporting the initial proposal that $\mathrm{C} 8$-arylguanine adduct formation occurs directly from aryl radicals. ${ }^{91}$ In addition, it was reported that $\mathrm{C} 8$-arylguanine formation can also lead to significant depurination ${ }^{92}$ in calf thymus DNA. Kohda et al. showed that incorporation of the C8- 
phenyl modification can block DNA polymerase action, however it was also demonstrated that $\mathrm{G} \rightarrow \mathrm{T}$ and $\mathrm{G} \rightarrow \mathrm{C}$ transversions can occur in addition to two-base deletions. ${ }^{93}$ In addition to the $\mathrm{C} 8$ phenylguanine modification, several other C8-arylguanine DNA adducts have been found to have mutagenic and/or carcinogenic potential. ${ }^{90-92,94-97}$ Taken together, C8-arylguanine modifications, derived from exposure to arylhydrazines, bioactivation to arenediazoniums, and then to aryl radicals that readily react with DNA, may be related to their genotoxic and carcinogenic potential. However the specific mechanism(s) of action remains unclear. ${ }^{83}$

Recently we demonstrated that the C8-arylguanine modification shift the B-/Z-DNA equilibrium toward the Z-DNA conformation. ${ }^{98-100}$ This modification was incorporated into $\mathrm{d}(\mathrm{CG})_{5}$ sequences $\left(\mathrm{d}(\mathrm{CGCGCG} * \mathrm{CGCG})\right.$ where $\mathbf{G}^{*}=\mathrm{C} 8$-arylguanine, Figure 1.3). The modified bases were shown to drive Z-DNA formation because they generate unfavorable steric and/or electronic interactions with the phosphate backbone when in the B-DNA conformation.

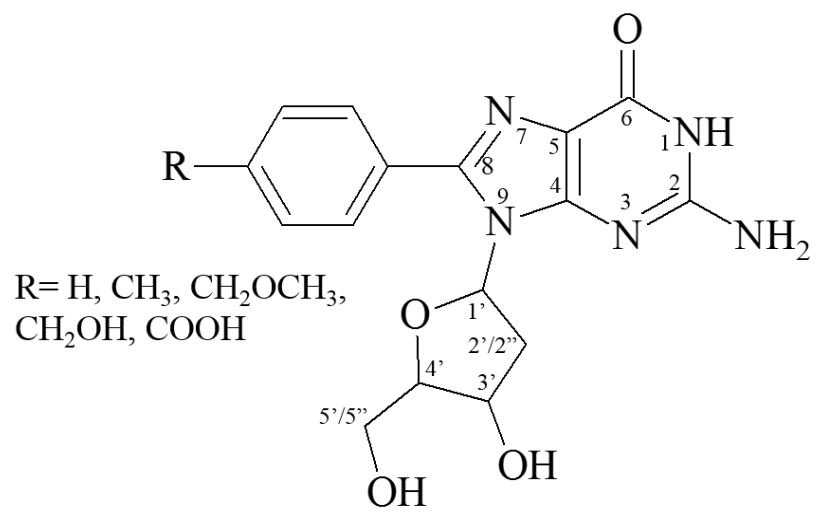

Figure 1.3. Structure of C8-aryl-2'-deoxyguanosine. Five C8-aryl-2'-deoxyguanosine were studied in this work: C8-phenyl-2'-deoxyguanosine ( $\mathrm{R}=\mathrm{H})$, C8-tolyl-2'-deoxyguanosine $\left(\mathrm{R}=\mathrm{CH}_{3}\right), \mathrm{C} 8$-methoxymethylphenyl-2'deoxyguanosine $\left(\mathrm{R}=\mathrm{CH}_{2} \mathrm{OCH}_{3}\right)$, $\mathrm{C}$-'hydroxymethylphenyl-2'-deoxyguanosine $\left(\mathrm{R}=\mathrm{CH}_{2} \mathrm{OH}\right)$, and $\mathrm{C} 8$ carboxyphenyl-2'-deoxyguanosine $(\mathrm{R}=\mathrm{COOH})$. 
Our previous studies revealed several key observations. First, C8-arylguanine modified bases in $(\mathrm{CG})_{5}$ oligonucleotides significantly reduces the sodium chloride concentration required to observe the Z-DNA conformation, although only the C8-carboxyphenyl modification rendered the oligonucleotides in the Z-DNA conformation under physiological sodium chloride concentrations. Second, the modified oligonucleotides displayed a much lower melting temperature $\left(\mathrm{T}_{\mathrm{M}}\right)$ than the unmodified $(\mathrm{CG})_{5}$ decamer when in the $\mathrm{B}$ form and further exhibited other unique $\mathrm{T}_{\mathrm{M}}$ behaviors. In particular, in response to increasing salt concentration the modified oligonucleotides displayed a further decrease in $\mathrm{T}_{\mathrm{M}}$ near the transition concentration $\left(\mathrm{T}_{\mathrm{c}}\right.$; the salt concentration required to for a 1:1 B-:Z-DNA ratio). Finally, the C8-arylguanine modified base stacks over the adjacent 5'-cytosine in the B form observed by noting the large upfield shifts of the C8-aryl protons of the modified base and the adjacent $\mathrm{C}_{5}-\mathrm{H} 5 / 6$ protons in the ${ }^{1} \mathrm{H}$ NMR spectrum. Molecular dynamics simulations supported the stacking geometry between the C8-aryl group and $\mathrm{C}_{5}$ and also between the purine components of the two modified bases. The latter interaction generates significant local distortion at the modified base step. Taken together these data suggested that the C8-arylguanine modified bases produce large conformational changes in the oligonucleotide structure when in the B form but does not alter the Z-DNA conformation.

The palindromic nature of these oligonucleotide sequences leads to two modified bases in the duplex. Therefore, it could not be determined if the conformational preferences these oligonucleotides displayed are due to one C8-arylguanine modification or if two modified bases generate additive or synergistic conformational effects. The work presented herein sought to clarify the conformational effects of the C8-arylguanine modifications. To accomplish this goal we utilized a DNA hairpin with the sequence 5'-CGCGCG*CGCGTTTTCGCGCGCGCG-3', where $\mathbf{G}^{*}=\mathrm{C} 8$-arylguanine. The hairpin forms an intramolecular double-stranded $\mathrm{d}(\mathrm{CG})_{5}$ stem 
connected by a loop of four thymidines and was prepared such that it contained only one C8arylguanine modified base. Thus, by determining the conformational preferences of this hairpin oligonucleotide, and in comparison to our previous work, the effect(s) of a single C8-arylguanine base modification can be assessed. The section below will describe how and why a hairpin DNA can be utilized to effectively compare the conformational effects of a modified oligonucleotide with one or two C8-arylguanine modified bases.

\section{F. Hairpin DNA}

Investigation of hairpins has focused on their significance in tRNA and therefore most of what is known regarding hairpins is RNA based. 5,101 Early studies concluded that hairpins were most stable with homonucleotide loop sizes of six or seven bases and it was proclaimed a rule for hairpin formation that the loop size contain greater than six nucleotides. However, as the knowledge of the field progressed it became more accepted that initial conclusions were more likely based on a unique case rather than the prevailing rule. ${ }^{102}$

Studies investigating DNA hairpins, initially discovered by Scheffler et al. in d(AT) $)_{\mathrm{n}}$ DNA oligomers, ${ }^{4}$ were rejuvenated as synthetic procedures for oligodeoxynucleotides evolved and commercially available automated DNA synthesizers became more widely available. Subsequent studies were performed to investigate the thermodynamic properties of DNA hairpins and duplexhairpin transitions. ${ }^{103}$ Attention has been given to the role of the loop size ${ }^{104}$ and composition ${ }^{105}$ in this dynamic process. ${ }^{106}$ Through the use of NMR spectroscopy the authors of these studies utilized two-dimensional techniques to determine the spatial relationships of the hairpin and duplex structures as well as the interconversion rates between the two forms as a function of temperature, salt concentration and strand concentration. ${ }^{107,108}$ It was found that DNA hairpin 
oligonucleotides generally exhibit a two-state transition where loops with four or five bases are the most stable. ${ }^{109,110}$ Subsequently a series of publications by Haasnoot et al. suggested a model for the prediction of the loop folding and overall stability of DNA hairpins, though this particular model was designed for loops comprised of only thymidines. ${ }^{111,112}$ Breslauer and coworkers ${ }^{113}$ later found that hairpins with tetraloops were most stable (i.e. $\mathrm{T}_{\mathrm{M}}$ ) when the loops were comprised of only thymidine bases and the rank order of stability was primarily a result of steric bulk of the nucleotides $(\mathrm{T}>\mathrm{C}>\mathrm{G}>\mathrm{A}) .{ }^{113}$ These studies further provided evidence that the presence of a hairpin loop does not have a significant impact on the duplex (stem) portion of the hairpin oligonucleotide and therefore provides a system to compare with double-stranded oligonucleotides.

While there was considerable investigation into the stability of the hairpin loop with respect to size and composition, there were also several groups that investigated the conformational preferences of the stem portion of the hairpin. In particular, Germann and van de Sande undertook a study to determine if the hairpin loop would provide an energy barrier that would prevent the Bto Z-DNA transition. ${ }^{114}$ In this study the authors determined that the hairpin $\left(\mathrm{d}(\mathrm{CG})_{5} \mathrm{~T}_{4}(\mathrm{CG})_{5}\right)$ was able to undergo a B- to Z-DNA conformational change and concluded that the loop $\left(\mathrm{T}_{4}\right)$ had only a small effect on the B-/Z-DNA equilibrium as the hairpin required slightly higher $\mathrm{NaCl}$ and $\mathrm{MgCl}_{2}$ concentrations to induce the Z-DNA conformation. Subsequent studies by van Boom and coworkers, ${ }^{115-118}$ confirmed that hairpins $\left(\mathrm{d}(\mathrm{CG})_{3} \mathrm{~T}_{\mathrm{n}}(\mathrm{CG})_{3}\right)$ were able to undergo a B-/Z-DNA transition and the presence of a $\mathrm{T}_{4}$ or $\mathrm{T}_{5}$ loops do not affect the conformational transition energy. Importantly their work provided a framework for quantifying the mole fractions of the major conformations in solution (B-, Z-, and ss-DNA). In turn, this information can be used to accurately determine the thermodynamic parameters for B- to Z-DNA oligonucleotide transitions. This 
experimental approach will be discussed in greater detail in the subsequent experimental techniques section. These reports helped further substantiate that hairpin stability is influenced not only by the loop composition but also by the composition of the stem sequence. ${ }^{107,117,119,120}$ Further these reports demonstrated that the thermodynamics in the B- to Z-DNA transition observed in the hairpin systems were similar to the double-stranded counterparts.

Around the time Wolk et al. determined structures for B- and Z-DNA loops by NMR, ${ }^{121}$ Chattopadhyaya et al. were able to solve the crystal structure of a DNA hairpin, which displayed a Z-DNA stem. ${ }^{122,123}$ In addition, Xodo et al. measured $\mathrm{T}_{\mathrm{M}}, \Delta \mathrm{H}, \Delta \mathrm{S}$ and $\Delta \mathrm{G}$ of the B- and Z-DNA forms of hairpins with loop sizes of two, three, and four thymidines and variable length CG palindromic stems $\left(\mathrm{d}(\mathrm{CG})_{\mathrm{n}} \mathrm{T}_{\mathrm{n}}(\mathrm{CG})_{\mathrm{n}}\right)$. The $\mathrm{B}$ and $\mathrm{Z}$ hairpin forms were found to be most energetically similar to the double-stranded forms when the loop contained four thymidines. Furthermore, a loop with four thymidines does not appear to alter the conformation of the doublestranded portion when compared to same sequence lacking the loop (e.g., $\left(\mathrm{d}(\mathrm{CG})_{5}\right)_{2}$ vs. $\left.\left.\mathrm{d}(\mathrm{CG})_{5} \mathrm{~T}_{4}(\mathrm{CG})_{5}\right)\right)^{118}$ Therefore, the hairpin oligonucleotides used here are expected to be a suitable model for determination of the conformational effects of a single base modification (Figure 1.4). 
A)

$$
\begin{aligned}
& \mathrm{C}_{1}-\mathrm{G}_{2}-\mathrm{C}_{3}-\mathrm{G}_{4}-\mathrm{C}_{5}-\mathbf{G}_{6}^{*}-\mathrm{C}_{7}-\mathrm{G}_{8}-\mathrm{C}_{9}-\mathrm{G}_{10} \\
& \mathrm{G}_{10}-\mathrm{C}_{9}-\mathrm{G}_{8}-\mathrm{C}_{7}-\mathrm{G}_{6}^{*}-\mathrm{C}_{5}-\mathrm{G}_{4}-\mathrm{C}_{3}-\mathrm{G}_{2}-\mathrm{C}_{1}
\end{aligned}
$$

B)

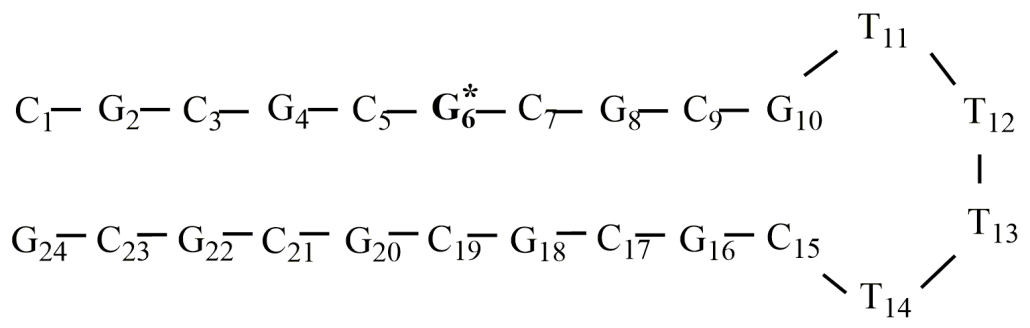

Figure 1.4. Comparison of double-stranded (A) and hairpin (B) oligonucleotides. The use of these two oligonucleotide systems enable the comparison of the conformational effects between one and two modified C8-arylguanine bases.

\section{G. Summary}

Z-DNA has been found in many biologically relevant events that suggest a role for Z-DNA in gene expression that may be related to carcinogenesis and genetic instability leading to mutagenesis. Further, several chemical modifications from known carcinogens can to lead to C8guanine adducts in DNA though it is unclear how C8-guanine DNA adduct formation relates to their carcinogenicity. Here the conformational analysis of a hairpin oligonucleotide modified with a single C8-arylguanine and compare to previous results by our group will be described. Further, these oligonucleotides are stable in the $\mathrm{Z}$ form near or at physiological salt conditions and therefore can be utilized to further clarify the Z-DNA binding protein mediated B-/Z-DNA transition enabling experiments that, to date, cannot and have not been performed. Together these results may suggest a role for Z-DNA in arylhydrazine carcinogenesis. Subsequent chapters will describe the experimental techniques used to obtain the experimental and computational results that allow for a discussion of how the C8-arylguanine DNA adduct drives the B-/Z-DNA equilibrium toward 
the Z-DNA conformation which may result in carcinogenic and/or mutagenic consequences in vivo. 


\section{Chapter 2: Experimental Techniques and Approach}

C8-aryl-2'-deoxyguanine modified bases are not commercially available. The single C8arylguanine modified hairpin requires synthesis beginning at the nucleoside level. The modified nucleoside is subsequently converted to the functionalized C8-aryl-2'-deoxyguanine modified phosphoramidite used in the hairpin oligonucleotide synthesis. In this chapter, the synthetic steps for production of the C8-aryl-2'-deoxyguanine modified phosphoramidite and how it is used in oligonucleotide synthesis by the DNA synthesizer will be described.

After oligonucleotide synthesis, the hairpin requires purification before structural characterization. In addition, the experimental techniques used to characterize the $\mathrm{C} 8$-arylguanine modified hairpin oligonucleotide including electrospray ionization-mass spectrometry (ESI-MS), circular dichroism (CD) and nuclear magnetic resonance (NMR) will also be described. Using these techniques, one can compare the conformational effects of one versus two C8-arylguanine modified bases on an oligonucleotide sequence.

The synthesis of the C8-aryl-2'-deoxyguanine modified nucleoside has been reviewed extensively by Thomsen et al. ${ }^{124}$ The C8-aryl-2'-deoxyguanine phosphoramidites synthesis begins with 2'-deoxyguanosine and in five steps is converted to the C8-aryl-2'-deoxyguanosine modified phosphoramidite (Scheme 2.1). ${ }^{125}$ This product is then incorporated into the hairpin oligonucleotide sequence. The conversion of the 2'-deoxyguanosine to 8-bromo-2'-deoxyguanosine (1) is achieved via reaction with N-bromosuccinimde (NBS). Compound (1) is then converted to C8-aryl-2'-deoxyguanosine (2) using the Suzuki coupling reaction. The exocyclic amine is then converted to a $N, N$-dimethylformamidine to yield $\mathbf{3}$. The 5'-hydroxyl is protected as the dimethoxyltrityl (DMTr) ether, 4. Finally the 3'-hydroxyl is phosphitylated to give the C8-aryl-2'-deoxyguanine phosphoramidite $\mathbf{5}$. 


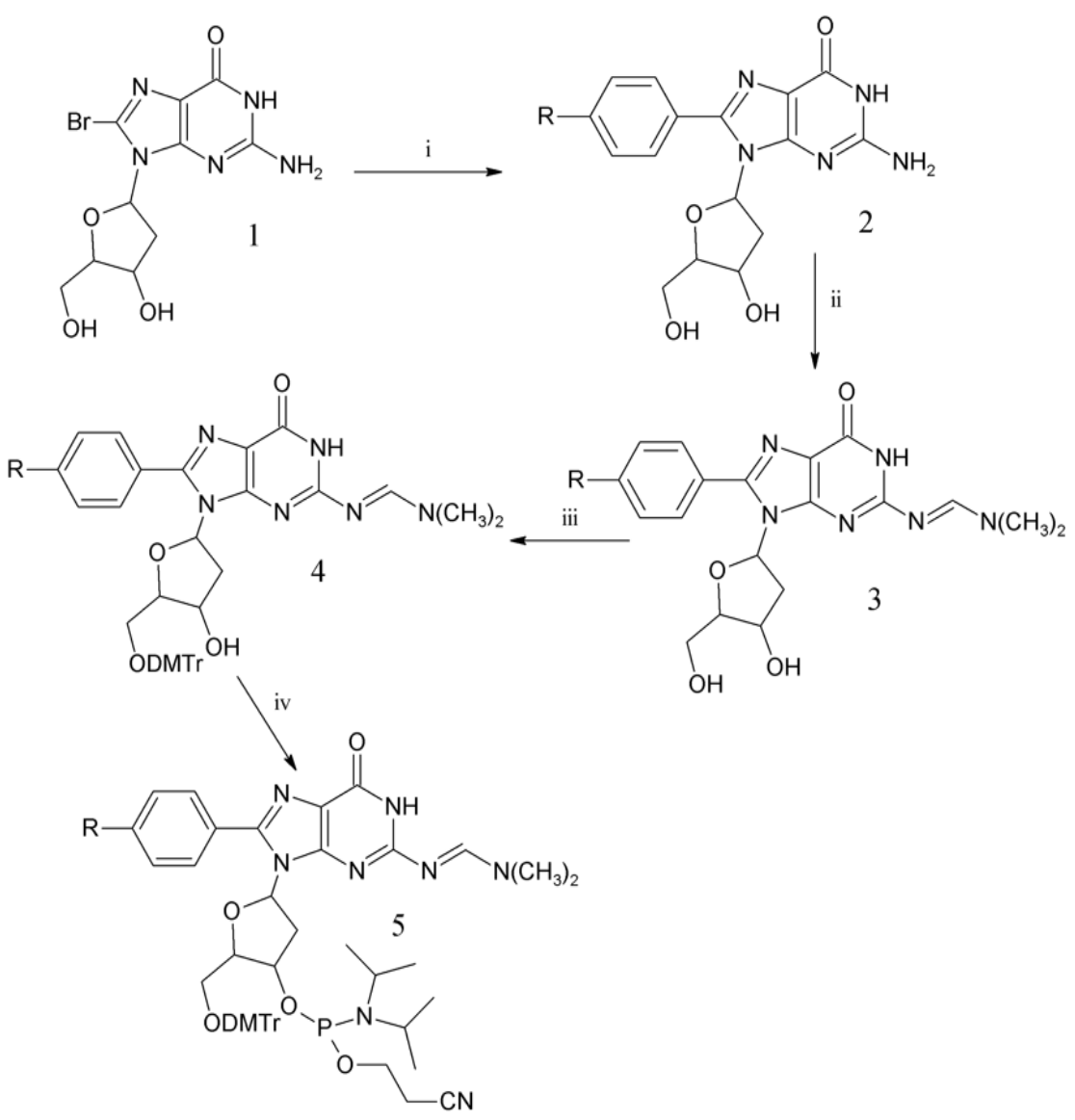

Scheme 2.1: Synthesis of the C8-aryl-2'-deoxyguanosine modified phosphoramidite. i) Arylboronic acid, $\mathrm{Pd}(\mathrm{OAc})_{2}$, TPPTS, $\mathrm{Na}_{2} \mathrm{CO}_{3}, 2: 1 \mathrm{H}_{2} \mathrm{O}$ :Acetonitrile at $80^{\circ} \mathrm{C}$. ii) $N, N$-Dimethylformamide dimethyl acetal in methanol. iii) 4,4'-Dimethoxytrityl chloride in pyridine and triethylamine. iv) 2-Cyanoethyldiisopropylchlorophosphoramidite in methylene chloride and triethylamine.

\section{A. Suzuki coupling to produce the C8-aryl-2'-deoxyguanosine}

The C8-aryl-2'-deoxyguanosine modified base is readily produced via the Suzuki coupling, however this was not always the case. Initial studies involving C8-arylguanine DNA modifications,${ }^{90}$ such as the one performed by Kodha et al. ${ }^{93}$ required the use of hazardous conditions to make the carcinogenic arenediazonium ions to transfer the aryl group to the 2'-deoxyguanosine. In this study, the benzenediazonium ion was produce via reaction of aniline and $\mathrm{NaNO}_{2}$, which was further reacted with the 2'-deoxyguanosine to generate the 
C8-phenyl-2'-deoxyguanosine. In addition to the necessity of working with carcinogenic chemicals in this synthetic route, nitrogen is a by-product making the reaction mixture difficult to contain due to foaming and, after workup, produced relatively low yields $(<40 \%)$. Further this procedure may not be compatible with a variety of phenyl substituted derivatives and therefore an alternative approach was desirable.

It had been known from the extensive work of Suzuki and coworkers that palladium catalyzed cross-coupling reactions, the Suzuki ${ }^{126,127}$ coupling reaction, can be utilized to generate new carbon-carbon bonds. However, this procedure was not utilized to generate modified nucleosides until late 1990s. More recently, this coupling has been extensively used to sitespecifically incorporate DNA modifications into DNA sequences as a model to examine the carcinogenic consequences of DNA adducts. ${ }^{128}$ Since the Suzuki coupling works by connecting the carbon atoms between an organoboron species and organohalide species, it is expected to be readily applicable to the cross-coupling of a C8-halonucleoside (1) and arylboronic acid compound to produce our desired C8-aryl-2'-deoxyguanosine (2). Since the synthesis of 8-bromo-2'-deoxyguanosine has been reported ${ }^{129}$ and a variety of arylboronic acids are commercially, this reaction makes a logical choice for the production of C8-aryl-2'-deoxyguanosine nucleosides.

The major obstacle to the success of this reaction is the proper choice of catalysts, which we have established through our work with collaborators at the University of Alabama. ${ }^{128,130}$ Based on previous studies by the Shaughnessy $l a b^{131}$ it was determined that palladium acetate $\left(\mathrm{Pd}(\mathrm{OAc})_{2}\right)$, in combination with tris-(3-sulfonatophenyl)phosphine (TPPTS) catalyst, in a biphasic solvent system ( $2: 1$ water: acetonitrile) at $80^{\circ} \mathrm{C}$ resulted in excellent yields for a variety 
of C8-aryl-2'-deoxyguanine modified nucleosides. These conditions were used here in the first synthetic step, shown in Scheme 2.1.

The general mechanism of the Suzuki couple reaction is depicted in Scheme 2.2. The reaction cycle begins with the halonucleoside reacting with the $\operatorname{Pd}(0)$ catalyst by oxidative addition to form an aryl palladium (II) halide intermediate. The nucleophilic base can react with the arylpalladium (II) halide to generate an arylpalladium (II) hydroxide. The basic component of the reaction mixture, here a hydroxide, also attacks the boron of the arylboronic acid to produce an arylboron-ate complex. The arylboron-ate and the arylpalladium (II) hydroxide then reacts to form a diarylpalladium (II) complex. After reductive-elimination, the desired biaryl product (C8-aryl2'-deoxyguanosine) and results regeneration of the $\operatorname{Pd}(0)$ catalyst occurs and the Suzuki coupling catalytic cycle can begin again.

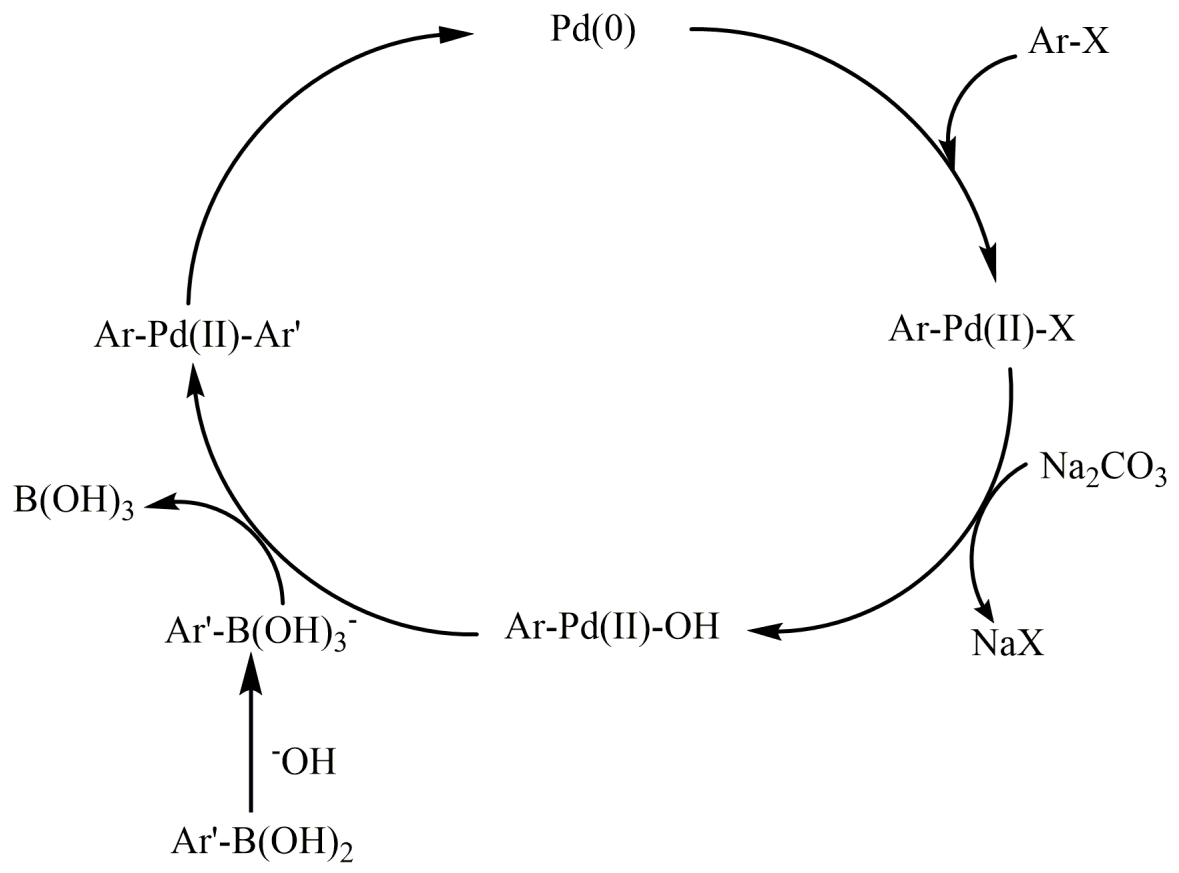

Scheme 2.2: The general mechanism of the Suzuki coupling used to make C8-aryl-2'-deoxyguanosine nucleosides. 


\section{B. C8-Aryl-2'-deoxyguanosine protection and functionalization}

As depicted earlier in Scheme 2.1, after adding the desired aryl group onto the $\mathrm{C} 8$ position of the 2'-deoxyguanosine there are several functional groups that need to be protected and/or functionalized before it can be used in the DNA synthesizer for oligonucleotide synthesis. The first step protects the exocyclic amine group. There have been several amine protecting groups that have been used to protect the free amine group on the guanine ring and standard guanine phosphoramidites use an isobutyryl moiety. However the addition of a C8-aryl group onto the 2'deoxyguanosine renders the nucleoside more susceptible to acid cleavage and our group, along

with another group, have demonstrated that protection using a $N, N$-dimethylformamidine ${ }^{100,125,130}$ creates a more stable C8-aryl-2'-deoxyguanosine nucleoside, which is important in subsequent nucleosidic functionalization reactions as well as during DNA synthesis. Reaction with C8-aryl2'-deoxyguanosine to form $\mathrm{N} 2-(N, N$-dimethylformamidine)-C8-aryl-2'-deoxyguanosine (3) is performed under inert conditions (nitrogen or argon) in dry methanol. This reaction as well as all subsequent nucleoside reactions are all performed under anhydrous conditions because water can compete with the nucleoside for the reactants and create undesired side products decreasing the yield. In this particular case, water will hydrolyze the $N, N$-dimethylformamide acetal reactant into an inactive species for the $\mathrm{N} 2$-amine protection reaction. The yields of this reaction are very good and the product does not need further purification after solvent removal.

After the amine protection reaction, the 5'-hydroxyl group is functionalized to a dimethoxytrityl (DMTr) ether compound 4. This reaction serves a dual purpose of blocking the 5'-OH during the next reaction (phosphitylation) as well as generating the 5'-DMTr functional group that is customary in DNA synthesis. The 5'-hydroxyl protection follows a $\mathrm{S}_{\mathrm{N}} 1$ mechanism, where the nucleoside hydroxyl group is the nucleophile that attacks the electrophilic carbon of the 
DMTr- $\mathrm{Cl}$ compound replacing the $\mathrm{Cl}$ atom to produce the 5'-DMTr-N2-dimethylformamidineC8-aryl-2'-deoxyguanosine (4). Since the by-product is $\mathrm{HCl}$, this reaction is conducted in the basic solvents, pyridine and triethylamine (TEA), to neutralize the acid that would otherwise destroy the C8-aryl-2'-deoxyguanine derivative. In addition, both of these solvents are dried and purified from lithium aluminum hydride (LAH) to remove any residual water that can also react with the DMTr-Cl reactant reducing the yield of the desired DMTr-C8-aryl-2'-deoxyguanosine product. The progress of the reaction is monitored by neutral alumina thin layer chromatography (TLC) where one can observe the formation of the DMTr-C8-aryl-2'-deoxyguanine by washing the TLC strip with $\mathrm{HCl}$ which renders the DMTr-C8-aryl-2'-deoxyguanine spot an orange color. The orange spot is likely due to the formation of DMTr-OH, since the DMTr- moiety is susceptible to acid cleavage. The reaction is deemed complete when the N2-dimethylformamidine-C8-aryl2'-deoxyguanine spot disappears and only the DMTr-C8-aryl-2'-deoxyguanosine spot is present on the TLC. After the reaction is complete the excess of DMTr-Cl is inactivated with the addition of methanol and then the solvents are removed in vacuo to yield the crude 5'-DMTr protected C8aryl-2'-deoxyguanosine (4).

Unlike the previous two reactions in the C8-aryl-2'-deoxyguanine phosphoramidite synthetic scheme, this reaction product requires purification before the phosphitylation reaction. The DMTr-C8-aryl-2'-deoxyguanosine is purified using column chromatography on basic alumina as the stationary phase. Alumina is chosen over the more commonly used silica stationary phase because the acidic nature of the silica leads to breakdown of the C8-aryl-2'-deoxyguanosine base and the yields are much lower versus the alumina stationary phase. The mobile phase used in the purification is a mixture of methylene chloride and methanol $\left(\mathrm{CH}_{2} \mathrm{Cl}_{2}: \mathrm{CH}_{3} \mathrm{OH}\right)$. Initially 99:1 $\mathrm{CH}_{2} \mathrm{Cl}_{2}: \mathrm{CH}_{3} \mathrm{OH}$ is used to separate the less polar DMTr-OH from the DMTr-C8-aryl-2'- 
deoxyguanosine, which requires a greater percentage of methanol to elute from the column. Typically after column purification the DMTr protected C8-aryl-2'-deoxyguanosine nucleosides are obtained in 40 to $60 \%$ yields (two steps).

The final step of the C8-aryl-2'-deoxyguanine phosphoramidite synthesis functionalizes, forming compound (5), the 3'-hydroxyl into the phosphoramidite using the 2-cyanoethyl $N, N$-diisopropylchlorophosphoramidite phosphitylating agent. ${ }^{132-134}$ The nucleophilic 3'hydroxyl reacts on the electrophilic nitrogen of the phosphoramidite reactant displacing the $\mathrm{Cl}$ atom. Again, this reaction must occur under anhydrous conditions because of the high reactivity of the phosphitylating agent with water which can inactivate the reagent for the phosphitylation reaction. The reaction is performed in $\mathrm{CH}_{2} \mathrm{Cl}_{2}$ with TEA so that the $\mathrm{HCl}$ produced throughout the course of the reaction is neutralized. The reaction progress is monitored by the TLC, monitoring the disappearance of the DMTr-C8-aryl-2'-deoxyguanosine spot from the reaction mixture. While the modified phosphoramidite can be purified via column chromatography, this purification step is not necessary, and generally tends to lead to product degradation. Further, purification does not enhance the overall yield of the phosphoramidite coupling in DNA synthesis. Instead, the TEAhydrochloride salts are precipitated from the C8-aryl-2'-deoxyguanine phosphoramidite using a 4:1 benzene: tetrahydrofuran solvent mixture that can be filtered from solution. The C8-aryl-2'deoxyguanine phosphoramidite is obtained after solvent removal and is further dried by washing with dry benzene. Finally, before the modified phosphoramidite is used in DNA synthesis, the desired product is dried in vacuo over phosphorus pentoxide $\left(\mathrm{P}_{2} \mathrm{O}_{5}\right)$. 


\section{C8-Arylguanine modified hairpin oligonucleotide synthesis}

Single C8-arylguanine modified hairpin oligonucleotide synthesis was conducted on an ABI 394 DNA synthesizer using phosphoramidite chemistry pioneered by Caruthers and coworkers. ${ }^{135,136}$ This method has become the method of choice and the standard chemistry, phosphoramidite chemistry, utilized by commercial DNA synthesizers. The standard phosphoramidites along with the synthesized C8-aryl-2'-deoxyguanine phosphoramidites are depicted in Figure 2.1. Although the $\mathrm{C} 8$-aryl-2'-deoxyguanine modified phosphoramidites require multi-step synthesis before use in the DNA synthesizer, the other phosphoramidites, in this case dG CE-PA, dC CE-PA, and dT CE-PA, are commercially available. In this section the chemistry of DNA synthesis will be reviewed (and references therein). ${ }^{137}$
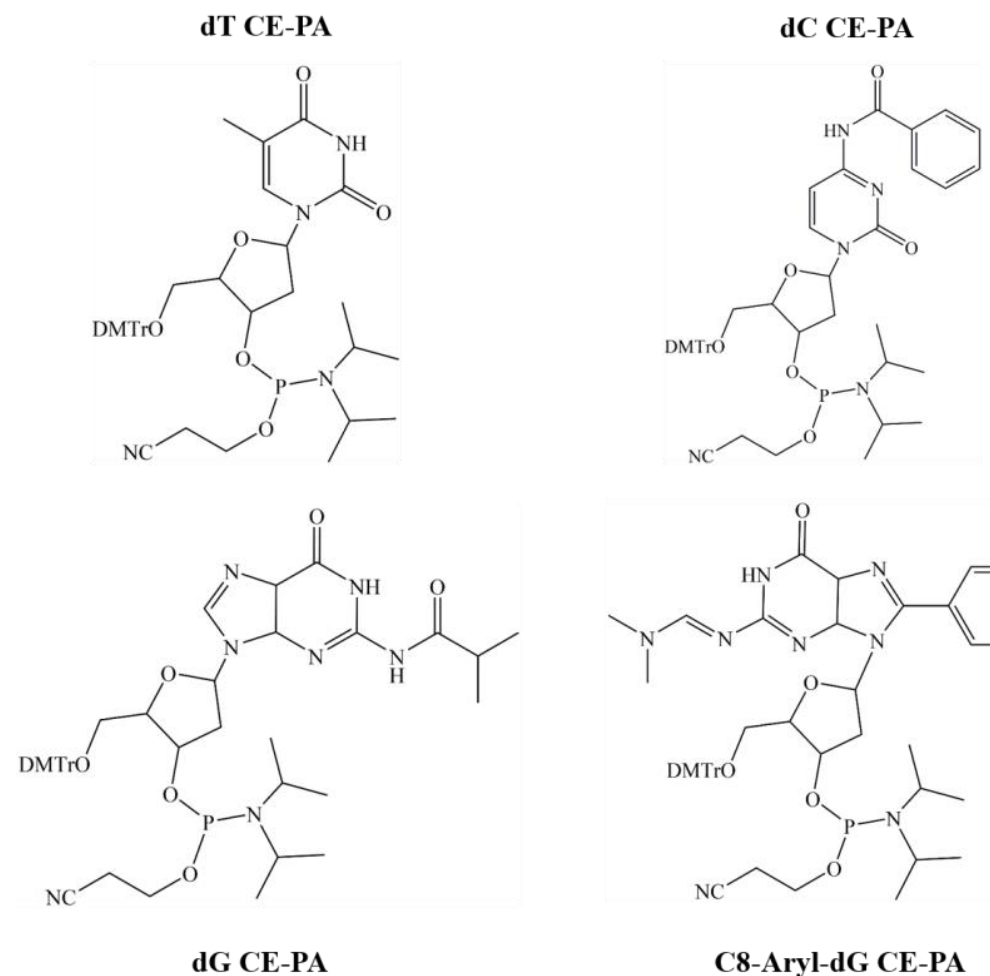

dG CE-PA

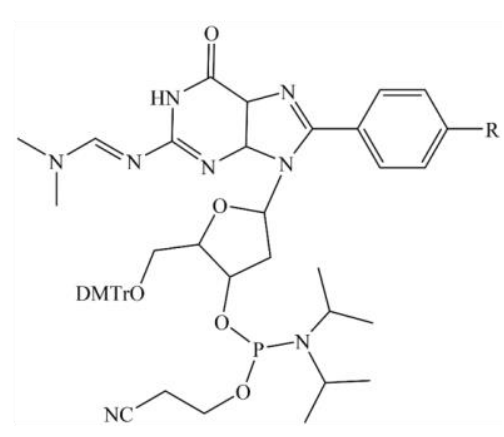

C8-Aryl-dG CE-PA

Figure 2.1. Structures of the phosphoramidites used in the single modified C8-arylguanine hairpin oligonucleotide synthesis. 
Although a complex macromolecule, the chemistry of DNA synthesis is quite simple. DNA sequences are written and read in the $5^{\prime}$ to $3^{\prime}$ direction, however synthesis occurs in the $3^{\prime}$ to 5 ' direction. Synthesis begins on a controlled pore glass (CPG) solid support with the 3'-nucletoide already attached to the column. Oligonucleotide synthesis occurs one monomer nucleotide unit at time through a four-step synthetic cycle (Scheme 2.3). After each step in the cycle excess reactants are removed, which is another advantage in the design of the CPG support, so purification is not necessary. In addition, each step in the oligonucleotide synthesis occurs under anhydrous conditions, to minimize side reactions, by washing the growing oligonucleotide chain with anhydrous acetonitrile and then dried under a stream of argon.

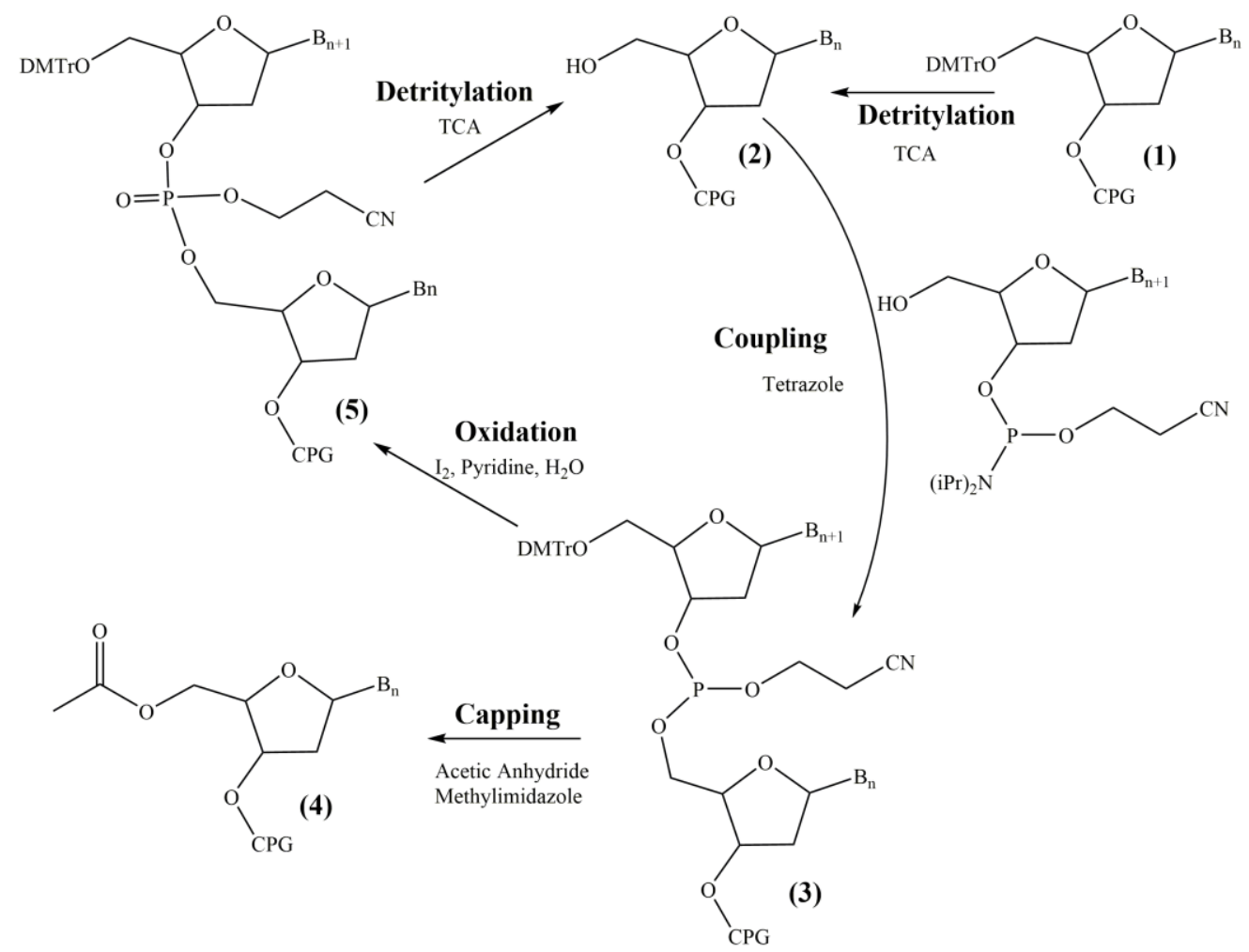

Scheme 2.3: The synthetic cycle of DNA synthesis. 
The first step in DNA synthesis begins with detritylation of the DMTr moiety of the nucleoside (1) attached to the CPG support by treatment with trichloroacetic acid (TCA) in $\mathrm{CH}_{2} \mathrm{Cl}_{2}$. Cleavage of the acid labile DMTr generates a free, nucleophilic 5'-OH (2). After the removal of any residual TCA with an acetonitrile $(\mathrm{ACN})$ wash, the next base in the desired sequence is delivered to the column simultaneously with the tetrazole activator. Tetrazole protonates the nitrogen of the incoming phosphoramidite which renders this phosphoramidite moiety more electrophilic and thus more susceptible to nucleophilic attack. Tetrazole attacks the phosphoramidite producing a tetrazolyl phosphoramidite intermediate, which then reacts with the 5'-OH of the nucleoside on the CPG support. Since there is still a DMTr group on the incoming phosphoramidite, the reaction is directed towards coupling the 5'-OH on the CPG to the 3'phosphoramidite creating an internucleotide linkage (3).

The coupling reaction is not $100 \%$ efficient and therefore the third step in the synthetic cycle inactivates any free 5'-OH from participating in any further chain extension reactions (4). This step is necessary to prevent the accumulation of undesired oligonucleotide products which ultimately makes DNA synthesis more efficient. The 5'-OH is 'capped' using acetic anhydride in the presence of methylimidazole to produce a 5'-acetylated group that is inactive in any further synthetic cycles. After the capping reaction the trivalent phosphite internucleotide linkage is oxidized to the pentavalent phosphodiester linkage characteristic of DNA (5). Iodine is used as the oxidizing agent and water as the oxygen donor from a solution of aqueous iodine, pyridine and tetrahydrofuran.

Now that the growing oligonucleotide chain has been extended by one base, this base can begin the next synthetic cycle again via detritylation of the 5'-DMTr of the oligonucleotide. This four step process is repeated until the desired sequence has been synthesized, which is controlled 
by the user. Using these conditions the addition of each base addition is $\sim 98 \%$ efficient, and therefore automated DNA synthesis is an ideal technique in the study of synthetic oligonucleotide sequences. Afterwards, the oligonucleotide can be cleaved from the CPG support using aqueous ammonium hydroxide $\left(30 \% \mathrm{NH}_{3}\right)$ and the exocyclic protecting groups, shown in Figure 2.1, are removed by heating the ammonium hydroxide solution at $55^{\circ} \mathrm{C}$ overnight $(\leq 18 \mathrm{~h})$

\section{Purification of C8-arylguanine modified hairpin oligonucleotide}

There are several factors that can affect the efficiency of the C8-arylguanine modified hairpin oligonucleotide synthesis, including the purity of the aforementioned C8-aryl-2'-deoxyguanine phosphoramidite, degradation of the modified oligonucleotide during synthesis, and/or inefficient coupling of the phosphoramidite to the growing oligonucleotide chain. Therefore it is necessary to purify the unmodified and modified hairpin oligonucleotides before structural characterization and determination of the conformational effects of the C8-arylguanine modified base. The method used in this study was Fast Protein Liquid Chromatography (FPLC), an application of High Performance Liquid Chromatography (HPLC).

FPLC is typically used to purify proteins, however it has also been utilized to purify DNA. FPLC uses aqueous buffers and separates its analyte of interest via ion-exchange, ${ }^{138}$ since both DNA and proteins are charged species. Ion-exchange chromatography is a convenient methodology to purify DNA since the phosphate backbone is negatively charged and can separate the DNA based on charge and, therefore, also on chain length. This is especially important in our hairpin oligonucleotides used in this study because both inefficient coupling and product degradation leads to two major products in the crude oligonucleotide solution forming. One is the 18-mer, where the C8-aryl-2'-deoxyguanine does not get coupled to the oligonucleotide chain, and 
the other is the full length 24-mer hairpin oligonucleotide (Figure 2.2). The longer 24-mer hairpin oligonucleotide is more negatively charged and will absorb to the positively charged stationary phase more strongly than the 18 -mer thus the 24 -mer will have a longer retention time than the 18 mer. In addition to the charge separation in the ion-exchange chromatography there is also some dependence of retention time on the hydrophobicity of the individual nucleosides that comprise an oligonucleotide, especially after incorporation of the C8-aryl modification, where the increase in hydrophobicity decreases the retention time of the oligonucleotide relative to the unmodified oligonucleotide.

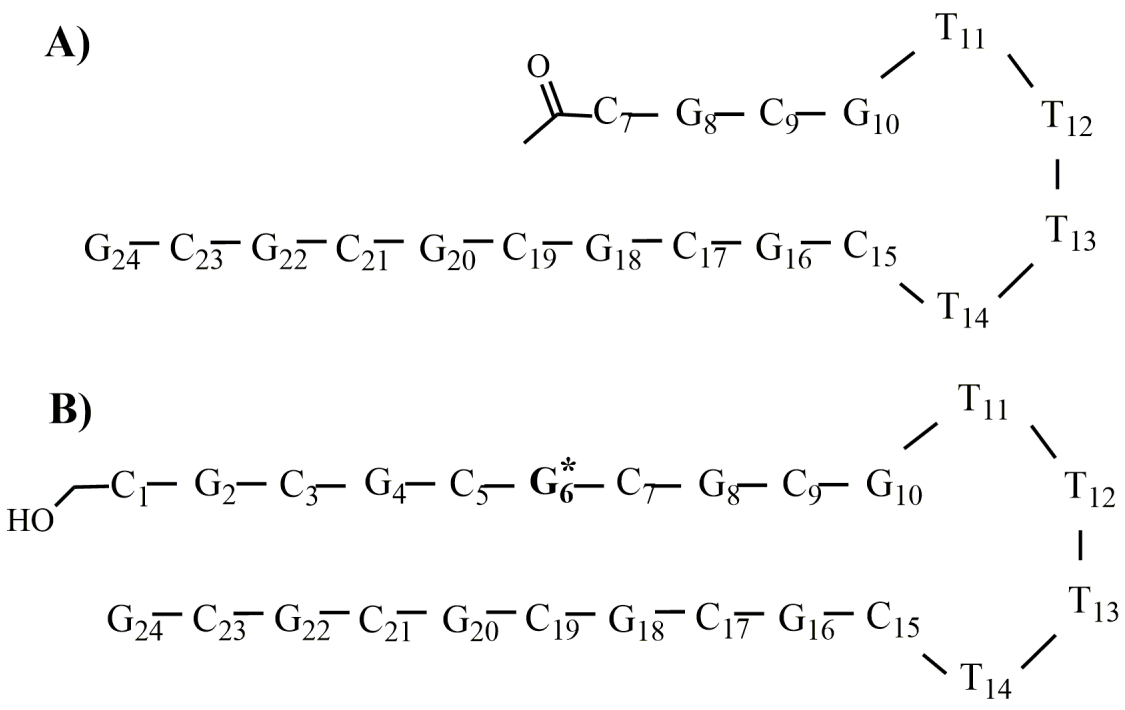

Figure 2.2. Structures of the major synthetic products of the $\mathrm{C} 8$-arylguanine modified hairpins. A) Displays the acetylated (capped) 18-mer structure and B) depicts the full length 24-mer structure.

Anion exchange chromatography requires a cationic stationary phase. The diethylaminoethyl (DEME) modified resin used here to purify the hairpin oligonucleotides contains a quaternary ammonium ion. ${ }^{138}$ The quaternary ammonium ion requires a counter ion, here hydroxide ion, to maintain the electrical neutrality of the stationary phase. When the hairpin oligonucleotides are loaded onto the column, the negatively charged residues of the 
oligonucleotide phosphate backbone will bind more tightly to the DEME matrix and replaces the counter ions. The mobile phase used to elute the oligonucleotides (mobile phase B) is comprised of sodium hydroxide and sodium chloride solutions. Increasing the concentration of the $\mathrm{Cl}^{-}$atoms causes the oligonucleotides to elute from the DEME stationary phase. The full-length oligonucleotide sequence will have the longest sequence in the crude mixture and, consequently, will have the longest retention time. DNA purification is monitored using an ultraviolet (UV) detector at $260 \mathrm{~nm}$ where nucleic acids typically have the highest absorbtivities.

After the desired full-length oligonucleotide is obtained, the oligonucleotides must be desalted to remove the sodium chloride salts present in the eluent solution. This final desalting step is accomplished using reverse-phase C18 solid phase extraction (SPE) cartridges. The hydrophobic purine and pyrimidine components of the oligonucleotides will interact with the lipophilic hydrocarbon chain of the stationary phase of the SPE more strongly than the more polar salts. Therefore the salts can be removed from the oligonucleotides after washing the SPE cartridge with water and the oligonucleotides can be eluted from the SPE cartridge with aqueous methanol. After removing the solvent, the purity of the modified oligonucleotides can be determined by a single peak in the FPLC chromatogram.

\section{E. Mass spectrometry}

Mass spectrometry (MS) is an analytical technique that can be used to determine the molecular weight of molecule of interest. During MS measurements the sample is ionized and may also break down into ionized fragments. ${ }^{139}$ These ionized products are produced in a vacuum and separated by a magnetic or electric field based on their mass to charge ratio $(\mathrm{m} / \mathrm{z})$. The ions are directed towards a detector which can convert the number of ions into a signal that is reported 
in the mass spectrum. Some techniques produce the ionized molecule with electrons in electron ionization (EI) or with other ions such as a protonated methane $\left(\mathrm{CH}_{5}^{+}\right)$or ammonium ion $\left(\mathrm{NH}_{4}^{+}\right)$ in chemical ionization (CI). However, these techniques were not reliable and/or sufficient for analysis of large, high molecular weight biomolecules, such as proteins or DNA, that are nonvolatile and thermally unstable. ${ }^{140}$ Electrospray ionization (ESI) provides a solution to this problem that has enabled tremendous advancement of the field of mass spectrometry for the investigation of DNA. ${ }^{141}$

In ESI, a solution of analyte is injected into the mass spectrometer through a capillary tube that is held a high potential. ${ }^{142}$ This produces a mist or ion spray of charged solution droplets which are directed towards the mass analyser. As the analyte droplets flow down a potential and pressure gradient the droplets become smaller due to evaporation of the solvent, eventually resulting in 'Coulomb explosion' (solvent droplets shrink in size). Solvent evaporation is aided by a nebulizer gas which is typically nitrogen. ${ }^{140}$ In general, the process employed in ESI can be described in three stages: droplet formation, droplet shrinkage and gaseous ion formation.

ESI is a desorption technique that produces multiply charged, quasi-molecular ions without fragmentation and therefore allows for the characterization of significantly larger molecules of interest that have a much higher molecular weight than the mass detector but the resultant ions have $\mathrm{m} / \mathrm{z}$ values within the detector range. In the case of DNA, this allows for the characterization of DNA samples with molecular weights between 200 Da to $200 \mathrm{kDa} .{ }^{141} \mathrm{In} \mathrm{ESI}$, the mass spectrum of a DNA sample contains a series of peaks that result from several different charge states associated with the DNA molecule.

DNA ionization is typically observed in the negative ion mode due to the polyanionic nature of the phosphodiester backbone $(\mathrm{pKa} \sim 1)$. To assist with the ionization of the DNA sample 
volatile counter ions (e.g. $\mathrm{NH}_{4}^{+}$) are used to replace the more common non-volatile counter ions (e.g. $\mathrm{Na}^{+}$or $\mathrm{K}^{+}$). In addition, non-volatile solvents and salts are typically avoided to prevent their accumulation which will lead to decreased resolution and may lead to machine malfunction. To ensure non-volatile salts are not in the sample, several methods have been used for inline desalting. For example, the ESI-MS can be coupled to an HPLC system (LC-MS or LC-MS/MS). However, prior desalting with C18 SPE and direct injection analysis, used here, provided excellent results and confirmed the identity of the synthetic products of the unmodified and C8-arylguanine modified hairpin oligonucleotides.

\section{F. Circular Dichroism}

Circular dichroism (CD) is an optical spectroscopic technique that uses circularly polarized right- $\left(\varepsilon_{\mathrm{R}}\right)$ and left-handed $\left(\varepsilon_{\mathrm{L}}\right)$ light. Optically active molecules absorb right- and left-handed light differently and that difference is called $\mathrm{CD}\left(\Delta \varepsilon=\varepsilon_{\mathrm{L}}-\varepsilon_{\mathrm{R}}\right) .{ }^{143} \mathrm{CD}$ has been mathematically predicted though the computational result does not always correlate with the experimental CD spectrum. A CD spectrum is generally referred to as a characteristic spectrum, especially in the case for the spectrum of DNA. The purine and pyrimidine components of nucleic acids are chromophoric due to the aromaticity of their $\pi$ systems, however their planar $\mathrm{sp}^{2}$ system renders them optically inactive and thus CD inactive. The base-pendant deoxyribose sugars, on the other hand, are chiral and therefore active in CD. However, given that the chromophoric and chiral unit are attached, the CD intensity of a nucleoside is low. Fortunately the interactions within the double helix of a DNA molecule, such as hydrogen bonding, base stacking, hydrophobic and electronic interactions, provide a super asymmetric molecule with a high CD intensity. ${ }^{143}$ 
CD was used here to distinguish between the right-handed (B) and the left-handed (Z) tertiary DNA structures. $\mathrm{CD}$ can differentiate between $\mathrm{B}$ - and Z-DNA since B-DNA has characteristic positive ellipticity around $280 \mathrm{~nm}$ and negative ellipticity around $250 \mathrm{~nm}$ whereas Z-DNA has negative ellipticity at approximately $295 \mathrm{~nm}$ with positive ellipticity at approximately $250 \mathrm{~nm}$ (Figure 2.3). ${ }^{12} \mathrm{CD}$ has been used to characterize the B- to Z-DNA transition in several different studies including modified oligonucleotides as well as hairpin oligonucleotides. ${ }^{12,114,117}$ In general, increasing salt concentration, typically $\mathrm{NaCl}$ or $\mathrm{NaClO}_{4}$, will drive the $\mathrm{B}-/ \mathrm{Z}-\mathrm{DNA}$ equilibrium favor the Z-DNA conformation at approximately $3 \mathrm{M} \mathrm{Na}^{+}$. Divalent cations ${ }^{144}$ such as $\mathrm{Mg}^{2+}$ and other polycationic species such as the polyamines spermine $\mathrm{e}^{21}$ and spermidine ${ }^{22}$ are more effective at stabilizing the Z-DNA conformation at significantly lower salt concentrations and, in some cases, within the range of physiological conditions. This is especially important in the work discussed here to examine the conformational effects of the C8-arylguanine modified base on the B-/Z-DNA equilibrium.

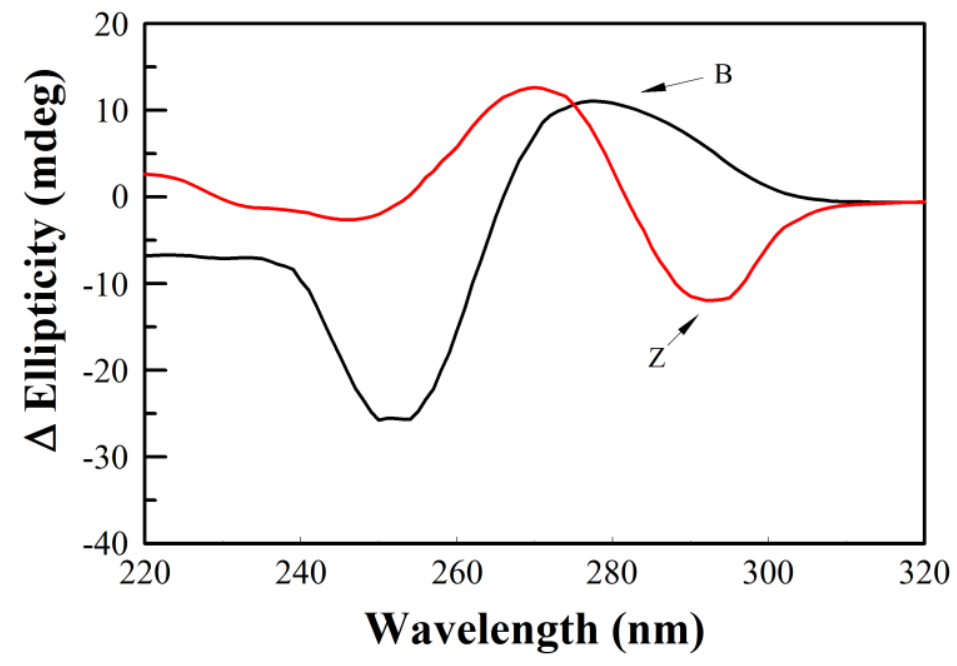

Figure 2.3. CD spectrum of B-DNA (black) and Z-DNA (red) conformations of the hairpin oligonucleotides. 
The CD spectra can be used to estimate the magnitude of the conformational effects caused by the C8-arylguanine modified base where a lower salt concentration required to drive Z-DNA formation is indicative of the relative amount the modified base destabilizes B-DNA and/or stabilizes Z-DNA. This can be accomplished by acquiring $\mathrm{CD}$ data as a function of salt concentration. Acquiring $\mathrm{CD}$ at a single temperature will provide data appropriate for an initial estimation of the effects on the B-/Z-DNA equilibrium. A more accurate method to compare the conformational effects between the unmodified and modified hairpin oligonucleotides requires the quantitation of the mole fractions of the DNA conformations (B-, Z-, and ss-DNA) in solution. Therefore by acquiring CD data as a function of both salt concentration and temperature one can make a quantitative determination of the effect on conformation by the C8-aryl modification.

\section{Mole Fraction Calculations}

The conformational effects of the C8-arylguanine modified base(s) can be quantitated by determining the molar fractions of B- $\left(f_{\mathrm{B}}\right), \mathrm{Z}-\left(f_{\mathrm{Z}}\right)$, and ss-DNA $\left(f_{\mathrm{ss}}\right)$ as a function of temperature and salt concentration. This analysis enables a more accurate evaluation of the conformational effects of the C8-arylguanine modification on the hairpin oligonucleotide stability in comparison to the unmodified hairpin. The mathematical determination of the mole fractions with respect to the B-/Z-DNA equilibrium was first developed by Xodo et al. ${ }^{117}$ This approach assumes that the only DNA conformations in solution are the B-, Z- and ss-DNA forms and that they are rapidly equilibrating. Thus, at all wavelengths acquired in the CD spectrum, the total molar ellipticity $(\Delta \varepsilon)$ is equal to the sum of the molar ellipticities of all the oligonucleotide conformations in solution, weighted by the mole fraction of each species (eq 2.1). Since the CD at $295 \mathrm{~nm}$ correlates 
strongly with the Z-DNA but not the B-DNA conformation, the $\Delta \varepsilon^{295}$ is used to determine $f_{\mathrm{B}}, f_{\mathrm{Z}}$ and $f_{\text {Ss. }}$ Therefore, for each temperature data were acquired, eqs 2.1 and 2.2 apply:

$$
\begin{gathered}
\Delta \varepsilon^{295}=\Delta \varepsilon_{\mathrm{B}}{ }^{295 *} f_{\mathrm{B}}+\Delta \varepsilon_{\mathrm{Z}}{ }^{295 *} f_{\mathrm{Z}}+\Delta \varepsilon_{\mathrm{SS}}{ }^{295 *} f_{\mathrm{SS}} \\
1=f_{\mathrm{B}}+f_{\mathrm{Z}}+f_{\mathrm{SS}}
\end{gathered}
$$

where $f$ is the mole fraction of one of the three possible oligonucleotide conformations and $\Delta \varepsilon$ is the corresponding ellipticity of the oligonucleotide in that particular conformation. However the mole fractions cannot be determined solely from eqs 2.1 and 2.2 and thus eq 2.1 is modified to eq 2.3 .

$$
\mathrm{CD}^{295}=\Delta \varepsilon_{\mathrm{B}}^{295 *} \mathrm{C}_{\mathrm{B}}+\Delta \varepsilon_{\mathrm{Z}}{ }^{295} * \mathrm{C}_{\mathrm{Z}}+\Delta \varepsilon_{\mathrm{SS}}{ }^{295} * \mathrm{C}_{\mathrm{SS}}
$$

The $\Delta \varepsilon$ values for each of the three possible conformations were estimated from the CD at a) low salt $(0-250 \mathrm{mM} \mathrm{NaCl})$ at $30{ }^{\circ} \mathrm{C}\left(\Delta \varepsilon_{\mathrm{B}}\right)$, b) high salt $(1000-4000 \mathrm{mM} \mathrm{NaCl})$ at $10{ }^{\circ} \mathrm{C}\left(\Delta \varepsilon_{\mathrm{Z}}\right)$, and c) low salt $(0-500 \mathrm{mM} \mathrm{NaCl})$ at $99{ }^{\circ} \mathrm{C}\left(\Delta \varepsilon_{\mathrm{SS}}\right)$. However to determine $\mathrm{C}_{\mathrm{B}}$ and $\mathrm{C}_{\mathrm{Z}}$, one must first determine $\mathrm{C}_{\mathrm{ss}}$.

An isosbestic point was observed at $274 \mathrm{~nm}$ corresponding to the case where $\Delta \varepsilon$ for the B and $\mathrm{Z}$ forms are equal $\left(\Delta \varepsilon_{\mathrm{B}}=\Delta \varepsilon_{\mathrm{Z}}=\Delta \varepsilon_{\mathrm{ds}}\right)$. Therefore eqs 2.4 and 2.5 can be used to determine $f_{\mathrm{ss}}$ and $f_{\text {ds. }}$.

$$
\begin{aligned}
& \Delta \varepsilon^{274}=\Delta \varepsilon_{\mathrm{ds}}^{274 * f_{\mathrm{ds}}}+\Delta \varepsilon_{\mathrm{ss}}^{274 *} f_{\mathrm{ss}} \\
& 1=f_{\mathrm{ds}}+f_{\mathrm{ss}}
\end{aligned}
$$


As with eq 2.3, eq 2.4 is modified to eq 2.6 however the observed UV absorbance $\left(\mathrm{A}^{274}\right)$ was used rather than $\mathrm{CD}$.

$$
\mathrm{A}^{274}=\varepsilon_{\mathrm{ds}}{ }^{274} * \mathrm{C}_{\mathrm{ds}}+\varepsilon_{\mathrm{ss}}{ }^{274} * \mathrm{C}_{\mathrm{ss}}
$$

The molar absorptivities of ds- and ss-DNA can be estimated in a similar manner as $\Delta \varepsilon_{\mathrm{B}}$ and $\Delta \varepsilon_{\mathrm{Z}}$. At low temperatures $\left(10{ }^{\circ} \mathrm{C}\right) \varepsilon_{\mathrm{ds}}{ }^{274}$ can be estimated and at high temperatures $\left(99{ }^{\circ} \mathrm{C}\right) \varepsilon_{\mathrm{ss}}{ }^{274} \mathrm{can}$ be estimated. However the concentration of ds-DNA $\left(\mathrm{C}_{\mathrm{ds}}\right)$ requires additional calculations based on the ss-DNA and ds-DNA equilibrium. While the amount of ss-DNA and ds-DNA varies based on the conditions, the total amount of DNA $\left(\mathrm{C}_{\text {total }}\right)$ remains constant and, therefore, at the lowest temperature at which experiments were conducted $\left(10^{\circ} \mathrm{C}\right)$, one can assume that DNA denaturation is minimal and all DNA is in the double-stranded form. Thus, to quantitate the ds-DNA and ssDNA equilibrium eqs 2.7 and 2.8 are applied:

$$
\begin{gathered}
\mathrm{C}_{\text {total }}=\mathrm{C}_{\mathrm{ds}}+\mathrm{C}_{\mathrm{ss}} / 2 \\
\mathrm{C}_{\mathrm{ds}}=\mathrm{C}_{\text {total }}-\left(\mathrm{C}_{\mathrm{ss}} / 2\right)
\end{gathered}
$$

Substitution of $\mathrm{C}_{\mathrm{ds}}$ with eq $2.8, \mathrm{C}_{\mathrm{ss}}$ can be determined from eq 2.13 derived below:

$$
\begin{gathered}
\mathrm{A}^{274}=\left(\varepsilon_{\mathrm{ds}}{ }^{274 *}\left(\mathrm{C}_{\text {total }}-\mathrm{C}_{\mathrm{ss}} / 2\right)\right)+\varepsilon_{\mathrm{ss}}{ }^{274} * \mathrm{C}_{\mathrm{ss}} \\
\left.\mathrm{A}^{274}=\left(\varepsilon_{\mathrm{ds}}{ }^{274 *} \mathrm{C}_{\text {total }}\right)+\left(\varepsilon_{\mathrm{ss}}{ }^{274 *} \mathrm{C}_{\mathrm{ss}}\right)-\left(\varepsilon_{\mathrm{ds}}{ }^{274} / 2\right) * \mathrm{C}_{\mathrm{ss}}\right) \\
\mathrm{A}^{274}=\left(\varepsilon_{\mathrm{ds}}{ }^{274 *} \mathrm{C}_{\text {total }}\right)+\left(\left(\varepsilon_{\mathrm{ss}}{ }^{274}-\left(\varepsilon_{\mathrm{ds}}{ }^{274} / 2\right)\right)^{*} \mathrm{C}_{\mathrm{ss}}\right) \\
\mathrm{A}^{274}-\left(\varepsilon_{\mathrm{ds}}{ }^{274 *} \mathrm{C}_{\text {total }}\right)=\left(\left(\varepsilon_{\mathrm{ss}}{ }^{274}-\left(\varepsilon_{\mathrm{ds}}{ }^{274} / 2\right)\right)^{*} \mathrm{C}_{\mathrm{ss}}\right) \\
\mathrm{C}_{\mathrm{ss}}=\frac{\mathrm{A}^{274}-\left(\varepsilon_{\mathrm{ds}}{ }^{274 *} \mathrm{C}_{\mathrm{total}}\right)}{\left(\left(\varepsilon_{\mathrm{ss}}{ }^{274}-\left(\varepsilon_{\mathrm{ds}}{ }^{274} / 2\right)\right)\right.}
\end{gathered}
$$

Eq 2.3 can be manipulated to solve for $C_{B}$ when substituting $C_{d s}-C_{B}$ for $C_{Z}$ since $\mathrm{C}_{\mathrm{ds}}=\mathrm{C}_{\mathrm{B}}+\mathrm{C}_{\mathrm{Z}}$. This provides eq 2.19, derived below: 


$$
\begin{aligned}
& \mathrm{CD}^{295}=\left(\Delta \varepsilon_{\mathrm{B}}{ }^{295 *} \mathrm{C}_{\mathrm{B}}\right)+\left(\Delta \varepsilon_{\mathrm{Z}}{ }^{295 *}\left(\mathrm{C}_{\mathrm{ds}}-\mathrm{C}_{\mathrm{B}}\right)\right)+\left(\Delta \varepsilon_{\mathrm{Ss}}{ }^{295 *} \mathrm{C}_{\mathrm{SS}}\right) \\
& \mathrm{CD}^{295}=\left(\Delta \varepsilon_{\mathrm{B}}{ }^{295 *} \mathrm{C}_{\mathrm{B}}\right)+\left(\Delta \varepsilon_{\mathrm{Z}}{ }^{295 *} \mathrm{C}_{\mathrm{ds}}\right)-\left(\Delta \varepsilon_{\mathrm{Z}}{ }^{295 *} \mathrm{C}_{\mathrm{B}}\right)+\left(\Delta \varepsilon_{\mathrm{SS}}{ }^{295 *} \mathrm{C}_{\mathrm{SS}}\right) \\
& \mathrm{CD}^{295}=\left(\Delta \varepsilon_{\mathrm{SS}}{ }^{295 *} \mathrm{C}_{\mathrm{SS}}\right)+\left(\Delta \varepsilon_{\mathrm{Z}}{ }^{295 *} \mathrm{C}_{\mathrm{ds}}\right)+\left(\Delta \varepsilon_{\mathrm{B}}{ }^{295 *} \mathrm{C}_{\mathrm{B}}\right)-\left(\Delta \varepsilon_{\mathrm{Z}}{ }^{295 *} \mathrm{C}_{\mathrm{B}}\right)
\end{aligned}
$$

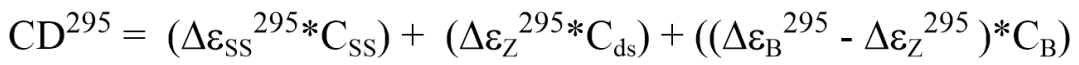

$$
\begin{aligned}
& \mathrm{CD}^{295}-\left(\Delta \varepsilon_{\mathrm{SS}}{ }^{295 *} \mathrm{C}_{\mathrm{SS}}\right)+\left(\Delta \varepsilon_{\mathrm{Z}}{ }^{295 * \mathrm{C}_{\mathrm{ds}}}\right)=\left(\left(\Delta \varepsilon_{\mathrm{B}}{ }^{295}-\Delta \varepsilon_{\mathrm{Z}}{ }^{295}\right) * \mathrm{C}_{\mathrm{B}}\right) \\
& \mathrm{C}_{\mathrm{B}}=\frac{\mathrm{CD}^{295}-\left(\Delta \varepsilon_{\mathrm{SS}}{ }^{295 *} \mathrm{C}_{\mathrm{SS}}\right)+\left(\Delta \varepsilon_{\mathrm{Z}}{ }^{295 *} \mathrm{C}_{\mathrm{ds}}\right)}{\Delta \varepsilon_{\mathrm{B}}{ }^{295}-\Delta \varepsilon_{\mathrm{Z}}{ }^{295}}
\end{aligned}
$$

$\mathrm{C}_{\mathrm{Z}}$ can be determined from $\mathrm{C}_{\mathrm{ds}}-\mathrm{C}_{\mathrm{B}}$ once $\mathrm{C}_{\mathrm{B}}$ is determined; and once $\mathrm{C}_{\mathrm{B}}, \mathrm{C}_{\mathrm{Z}}$ and $\mathrm{C}_{\mathrm{ss}}$ have been calculated the mole fractions $f_{\mathrm{B}}, f_{\mathrm{Z}}$ and $f_{\mathrm{SS}}$ can be calculated from eqs 2.20-2.22.

$$
\begin{aligned}
& f_{\mathrm{B}}=\left(\mathrm{C}_{\mathrm{B}} / \mathrm{C}_{\mathrm{ds}}\right) * f_{\mathrm{ds}} \\
& f_{\mathrm{Z}}=f_{\mathrm{ds}}-f_{\mathrm{B}} \\
& f_{\mathrm{SS}}=1-\left(f_{\mathrm{B}}+f_{\mathrm{Z}}\right)
\end{aligned}
$$

The mole fraction data from the variable temperature and salt concentration $\mathrm{CD}$ experiments allows for a quantitative comparison amongst the hairpin (unmodified vs. modified) oligonucleotides. This data can also be used to compare the hairpin to double-stranded (single vs. doubly modified) oligonucleotides. The mole fraction plots can also be used to determine the melting temperature $\left(\mathrm{T}_{\mathrm{M}}\right)$ of the $\mathrm{C} 8$-arylguanine modified oligonucleotides where the temperature that corresponds to $\left(f_{\mathrm{B}}+f_{\mathrm{Z}}\right) / f_{\mathrm{SS}}=1$ was taken as the $\mathrm{T}_{\mathrm{M}}$.

\section{Thermodynamic Parameters}

The mole fraction data can also be used to derive thermodynamic data of the C8-arylguanine modified oligonucleotides including the transition concentration $\left(\mathrm{T}_{\mathrm{c}}\right)$, transition free energy $\left(\Delta \mathrm{G}_{\mathrm{t}}\right), \Delta \mathrm{G}, \Delta \mathrm{H}$, and $\Delta \mathrm{S}$. The $\mathrm{T}_{\mathrm{c}}$ is the concentration of salt required such that the B- 
/Z-DNA ratio is 1 . This can be estimated by interpolation from the CD data and the ratios obtained by the methods described above.

An alternative method to determine the transition salt concentration has been described and was also used here. ${ }^{145}$ The effect of salt on the B-/Z-DNA transition can be described as written in eq 2.23:

$$
\mathrm{B}+\mathrm{c}[\mathrm{NaCl}] \stackrel{\mathrm{K}_{\mathrm{eq}}}{\rightleftharpoons} \mathrm{Z}
$$

where $\mathrm{c}[\mathrm{NaCl}]$ represents the interactions of salt between the $\mathrm{B}$ - and Z-DNA conformations and $\mathrm{c}$ stands for the transition specific constant coefficient. The observed equilibrium constant ( $\left.\mathrm{K}_{\mathrm{obs}}\right)$ (calculated from $f_{\mathrm{Z}} / f_{\mathrm{B}}$ ), for a given salt concentration, is defined as shown in eqs 2.24 and 2.25.

$$
\begin{gathered}
\mathrm{K}_{\mathrm{obs}}=\mathrm{K}_{\mathrm{eq}} *[\mathrm{NaCl}]^{\mathrm{c}} \\
\ln \left(\mathrm{K}_{\mathrm{obs}}\right)=\ln \left(\mathrm{K}_{\mathrm{eq}}\right)+\mathrm{c} \ln [\mathrm{NaCl}]
\end{gathered}
$$

A plot of $\ln \left(\mathrm{K}_{\mathrm{obs}}\right)$ versus $\ln [\mathrm{NaCl}]$ yields the values of $\mathrm{c}$ and $\ln \left(\mathrm{K}_{\mathrm{eq}}\right)$, determined from the slope and y-intercept. In turn, the transition energy can be calculated from eq 2.26.

$$
\Delta \mathrm{G}_{\mathrm{t}}=-\mathrm{RT} \ln \left(\mathrm{K}_{\mathrm{eq}}\right)
$$

Finally $\Delta \mathrm{G}, \Delta \mathrm{H}$, and $\Delta \mathrm{S}$ can be determined by fitting the data to the van't Hoff equation. ${ }^{118} \mathrm{CD}$ spectroscopy is an extremely useful technique to evaluate the conformational effects of the C8arylguanine modified bases on the oligonucleotide stability for the hairpin or double-stranded oligonucleotides as well as comparison between the single and double modified systems. 


\section{G. Nuclear Magnetic Resonance spectroscopy}

Nuclear Magnetic Resonance (NMR) is a powerful technique for the structural characterization of chemical compounds and, in this case, the B- and Z-DNA structures of the C8-arylguanine modified hairpin oligonucleotides. ${ }^{146,147}$ While CD is an excellent technique for the conformational analysis of the $\mathrm{C} 8$-arylguanine modified oligonucleotides, $\mathrm{CD}$ only provides information on the global structure of the hairpin oligonucleotides, whereas, NMR provides detailed structural information of the local conformation of the $\mathrm{C} 8$-arylguanine modified base. NMR was used here to confirm the conformation of the hairpin oligonucleotides seen in the CD experiments and to examine the local environment of the modified base. The principles of NMR and how NMR has been used previously to study the B- and Z-DNA conformation are discussed below.

\section{Basic Theory of NMR}

Atomic nuclei may have magnetic properties, the physical characteristic required for the NMR phenomenon. The general requirement for nuclei to be magnetically active is they must have the property called spin. Nuclei will have spin if it does not have an even atomic mass and even number of neutrons. A spinning charge generates a magnetic field and the magnetic spin properties are characterized by the spin quantum number $I$. The atomic nuclei that have spin most important in DNA NMR have a spin $=1 / 2(\mathrm{I}=1 / 2)$ such as ${ }^{1} \mathrm{H},{ }^{13} \mathrm{C},{ }^{31} \mathrm{P}$, and in some cases ${ }^{15} \mathrm{~N}$. Atomic nuclei with $I=1 / 2$ give the simplest spectra because when placed in a magnetic field $\left(\mathrm{B}_{0}\right)$ the nuclei will orient themselves either with (parallel) or against (antiparallel) the external 
magnetic field. In turn, this gives rise to two possible spin or energy states, $+1 / 2$ and $-1 / 2$. These two spin states are separated by an energy difference $(\Delta \mathrm{E})$ shown in Figure 2.4.

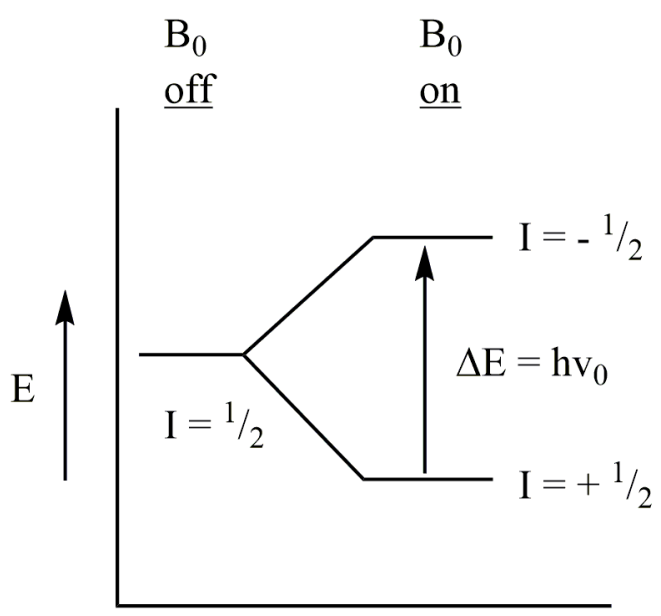

Figure 2.4. Energy levels of nuclei with $\mathrm{I}=1 / 2$ and relationship of $\Delta \mathrm{E}$ and external magnetic field strength. $I=$ quantum spin number, $\mathrm{B}_{0}=$ external magnetic field, $\mathrm{h}=$ Planck's constant, and $\mathrm{v}_{0}=$ Larmor frequency.

An observable signal in NMR occurs when the nuclei from the lower energy state are excited to the higher energy state and if there is a difference in the number of electrons occupying the two spin states. This can also be described as a spin flip where the nuclei reorient themselves relative to the direction of $\mathrm{B}_{0}$. The Larmor equation (eq 2.27) can be used to calculate the energy gap between the two energy states of the nuclei which is based on the Larmor or rotation frequency $\left(\mathrm{v}_{0}\right)$ of the nuclei relative to the gyromagnetic ratio $(\gamma)$ and the external magnetic field strength $\left(\mathrm{B}_{0}\right)$.

$$
\mathrm{v}_{0}=(\gamma / 2 \pi) \mathrm{B}_{0}
$$

When the electromagnetic frequency is tuned to match the value of $\mathrm{v}_{0}$ for a given nuclei like ${ }^{1} \mathrm{H}$ or ${ }^{13} \mathrm{C}$ then the nuclei can be promoted from the lower energy state to the higher energy state are come into resonance, which is where the terminology NMR is derived. Using a programmable 
radio frequency ( $\mathrm{RF}$ in $\mathrm{MHz}$ for $\mathrm{NMR}$ ) transmitter, one can adjust the frequency from the RF (v) to bring the nuclei under study into resonance. As the nuclei from the higher energy state transition back to the lower energy state the absorption energy can be detected and translated into the NMR peaks of the NMR spectrum.

The relationship above describes the effect of nuclei in an applied magnetic field under the assumption that all the nuclei in a molecule are identical. However, nuclei of the same type in a molecule will have slightly different chemical environments that arise from the electron cloud density of a given nuclei. These nuclei absorb energy at slightly different frequencies and, when compared to a reference sample (e.g., tetramethylsilane (TMS) for $\left.{ }^{1} \mathrm{H}\right)$, the difference in resonance frequency between the resonance of interest and TMS, is termed the chemical shift $(\delta)$ (eq 2.28). The resonance frequency difference between the reference resonance and the resonance of interest divided by the NMR spectrometer frequency yields the chemical shift in parts per million (ppm). In NMR the absorption peaks or signals are plotted in the form of intensity as a function of their chemical shift. Finally, the peak area is proportional to the number of nuclei giving rise to the peak.

$$
\delta=\frac{\mathrm{v}_{\text {ref }}-\mathrm{v}_{\text {sample }}}{\mathrm{v}_{\text {ref }}} \times 10^{6}
$$

Another important phenomenon seen in NMR occurs when a nucleus in the sample interact with nearby nuclei. Spin-spin coupling occurs when a particular nucleus has a magnetic moment induced from the applied RF and then transfers the energy to other nuclei in the same molecule. This interaction can result in splitting of the NMR signal that produces a multiplicity of the absorption peak separated by the coupling constant ( $J$-coupling). In particular, for nuclei with 
$I=1 / 2$ scalar coupling follow the $2 \mathrm{n} I+1$ rule where $\mathrm{n}$ is the number of magnetically equivalent nuclei surrounding the nucleus of interest. For example, when a nucleus has only one neighboring nucleus a doublet is observed. The most commonly studied nuclei in NMR are ${ }^{1} \mathrm{H}$ and ${ }^{13} \mathrm{C}$ because all organic molecules contain these nuclei and since $I=1 / 2$ produce spectra that are relatively straightforward to analyze. Thus, by acquiring ${ }^{1} \mathrm{H}$ and ${ }^{13} \mathrm{C}$ spectra and determining from them peak areas (integrations), chemical shifts, multiplicities and coupling constants, one can assign the structure and conformation of a compound.

Normally, one dimensional (1D) ${ }^{1} \mathrm{H}$ and ${ }^{13} \mathrm{C}$ spectra acquisition is sufficient to determine the structure of simple organic molecules. Macromolecules, such as proteins or DNA, require additional experiments to determine structure as there is usually insufficient dispersion to resolve all the signals. In particular, 2D experiments, such correlation spectroscopy (COSY) and nuclear Overhauser effect correlation spectroscopy (NOESY), provide additional information relevant to the structure determination of a molecule of interest. These experiments, provide additional information making it possible to assign the many NMR signals of proteins or DNA by utilizing additional dimensions. COSY experiments provide through bond connectivities from spin coupling and NOESY provides through space information arising from dipole-dipole interactions.

The proton-proton coupling correlation, ${ }^{1} \mathrm{H}-{ }^{1} \mathrm{H}$ COSY, experiment reveals the bond connectivities of a molecule. In a COSY spectra, the diagonal corresponds to the $1 \mathrm{D}{ }^{1} \mathrm{H}$ spectrum, which is typically displayed on both the top and side of the spectral plot. The off-diagonal signals represent $J$-coupling correlations and are used to determine which nuclei are adjacent to each other in the molecule. COSY spectra were used here in this study to assign the nucleoside protons (e.g., $\mathrm{H} 1$ ' to $\mathrm{H} 2$ ' and $\mathrm{H} 2$ ') as well as the pyrimidine protons, dC $\mathrm{H} 6$ to $\mathrm{H} 5$ and $\mathrm{dT} \mathrm{H} 6$ to $\mathrm{CH}_{3}$. 
NOESY is based on the nuclear Overhauser effect (NOE) which provides information of protons interacting through space and in close proximity $(<\sim 4 \AA) .{ }^{148,149}$ In NOESY, when the protons promoted to the higher energy relax back to lower energy state they interact with nearby protons through dipole-dipole interactions which results in an enhancement of the NMR signal. Similar to COSY, the diagonal in a NOESY plot corresponds to the ${ }^{1} \mathrm{H}$ reference spectrum where off-diagonal correlations are due to spatial interactions of the protons in the sample. The intensity of the cross-peaks that form are distance dependent and are proportional to the inverse of $\mathrm{r}^{-6}$ where $\mathrm{r}$ is the distance between interacting protons. NMR experiments ( ${ }^{1} \mathrm{H}, \mathrm{gCOSY}$ and NOESY) were used in this study to confirm the presence of the C8-arylguanine modified base and its local geometry in the hairpin oligonucleotides, aid in the assignment of the spectra, and to corroborate the $\mathrm{CD}$ results relative to the $\mathrm{B}-/ \mathrm{Z}-\mathrm{DNA}$ equilibrium.

\section{NMR of B- and Z-DNA}

DNA is a polymer composed of many monomeric units ( $\mathrm{dA}, \mathrm{dG}, \mathrm{dC}$, or $\mathrm{dT}$ nucleobases) and in the hairpin oligonucleotide studied here, $10 \mathrm{dG}, 10 \mathrm{dC}$, and four $\mathrm{dT}$ bases are present. Although each $\mathrm{dG}, \mathrm{dC}$ or $\mathrm{dT}$ bases has the same atomic identity, the NMR data show each base has a slightly different chemical environment resulting in slightly different chemical shifts of the same nuclei. This results in the ${ }^{1} \mathrm{H}$ spectrum of the hairpin oligonucleotides with many overlapping signals (Figure 2.5) and hence there is a need for 2D experiments to derive structural information of the C8-arylguanine modified base in the B-and Z-DNA conformation. There have been several NMR studies comparing the NMR of the $\mathrm{B}$ and $\mathrm{Z}$ forms of the same sequence that provide the framework for the conformational and therefore spectral differences observed by NMR 
spectroscopy. These reports guided our assignment of the NMR of the C8-arylguanine modified hairpin oligonucleotides studied in this work. ${ }^{120,121,150,151}$

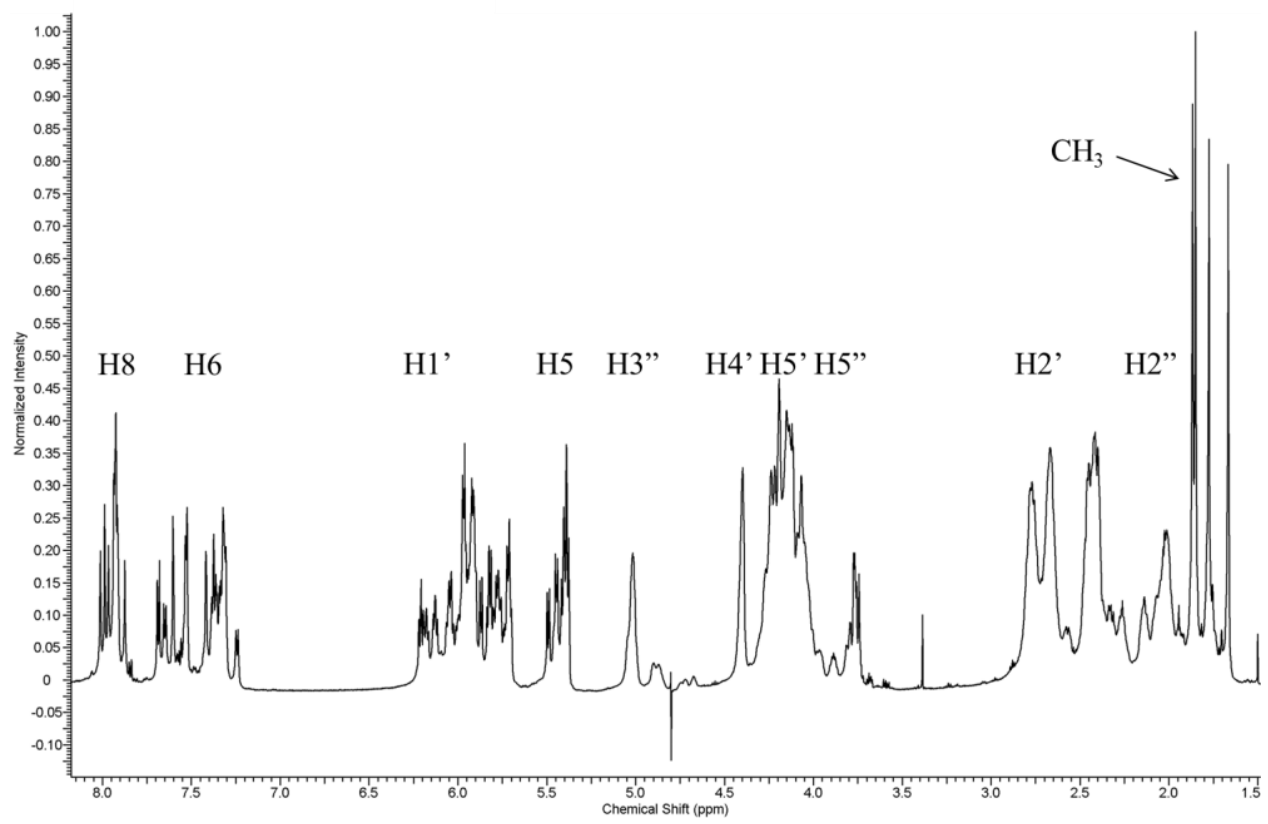

Figure 2.5. ' $\mathrm{H}$ NMR spectrum of the hairpin oligonucleotide d(5'-CGCGCGCGCGTTTTCGCGCGCGCG-3'). The sugar proton resonances of the nucleotide bases overlap extensively and are not resolved. To fully assign the protons of each individual nucleotide, more advanced 2D (COSY and NOESY) experiments are required.

Patel and coworkers ${ }^{150}$ were the first to observe the effect of conformational changes of an alternating dG-dC oligonucleotide (B- to Z-DNA) in high salt solution using NMR, at that time this sequence was still referred to as 'alternating B-DNA'. In this work the authors demonstrated that as the salt concentration was increased to $4 \mathrm{M} \mathrm{NaCl}$ the $\mathrm{H1}$ ' proton of the $\mathrm{dG}$ residues shifted downfield, this corresponds to less influence from adjacent base-pairs (shielding) and a change in glycosidic torsional angle. However the exact identity of which H1' was most affected could not ascertained from the 1D ${ }^{1} \mathrm{H}$ spectrum alone. Three years later Patel and another group of coworkers ${ }^{151}$ used 2D NOESY experiments to confirm that this $\mathrm{H} 1$ ' proton belonged to the $\mathrm{dG}$ base through NOE correlations between $\mathrm{H} 8$ and $\mathrm{H1}$ ', indicative of the syn-glycosidic bond 
conformation. Further it was demonstrated that NOEs were seen only under high salt conditions (i.e., Z-DNA conformation) and were not present under conditions where only the B-DNA conformation was present. Therefore, using NOESY, combined with COSY 2D data, one can often assign the nucleoside protons as well as distinguish between the B- and Z-DNA conformations.

In the early 1980s, two groups established a set of rules for the sequential assignment of the non-exchangeable protons of DNA bases. ${ }^{152,153}$ In DNA, the only aromatic scalar coupled protons are the $\mathrm{H} 6$ and $\mathrm{H} 5$ of $\mathrm{dC}$, although it is possible to see four bond coupling between the $\mathrm{H} 6$ and $\mathrm{CH}_{3}$ of $\mathrm{dT}$ bases, and therefore are readily identifiable in the COSY spectra of an oligonucleotide. Hare and Reid ${ }^{153}$ demonstrated that every H8 and H6 proton will display NOEs to their own H1' and with the H1' of the 3'-base in the sequence $(\mathrm{n}+1)$. In addition, the H8/H6 base protons are also close enough to display NOEs to the H2" of the 5'-base, which is scalar coupled to the $\mathrm{H} 1$ ' of the 5'-base. This provides a checkpoint where the COSY spectra can be used to verify the NOEs seen in the NOESY spectra. In addition, this work also demonstrated that the $\mathrm{H} 5$ of the pyrimidines will have NOEs to the $\mathrm{H} 6$ or $\mathrm{H} 8$ of the 3'-base and the H1' of any base will have an NOE to H5 proton of a 5'-pyrimidine. Further these authors explained that in a NOESY spectrum the H2" should always have a stronger intensity cross-peak with the H1' of the same base than with the H2' since the H2" is always closer in space than the H2' ${ }^{153}$ Scheek et $a{ }^{152}$ reported a similar assignment procedure where the resonance signals of the purine/pyrimidine components of the nucleotides do not display direct NOEs to adjacent bases, however the H1', H2' and H2" of any given nucleotide should display NOEs cross-peaks to both their own base (purine/pyrimidine) proton(s) and also to the 3'-base proton(s). Using these two 
reports, one can follow their assignment procedures to readily assign the base and nucleoside protons of any DNA sequence in the B-DNA conformation (Figure 2.6).

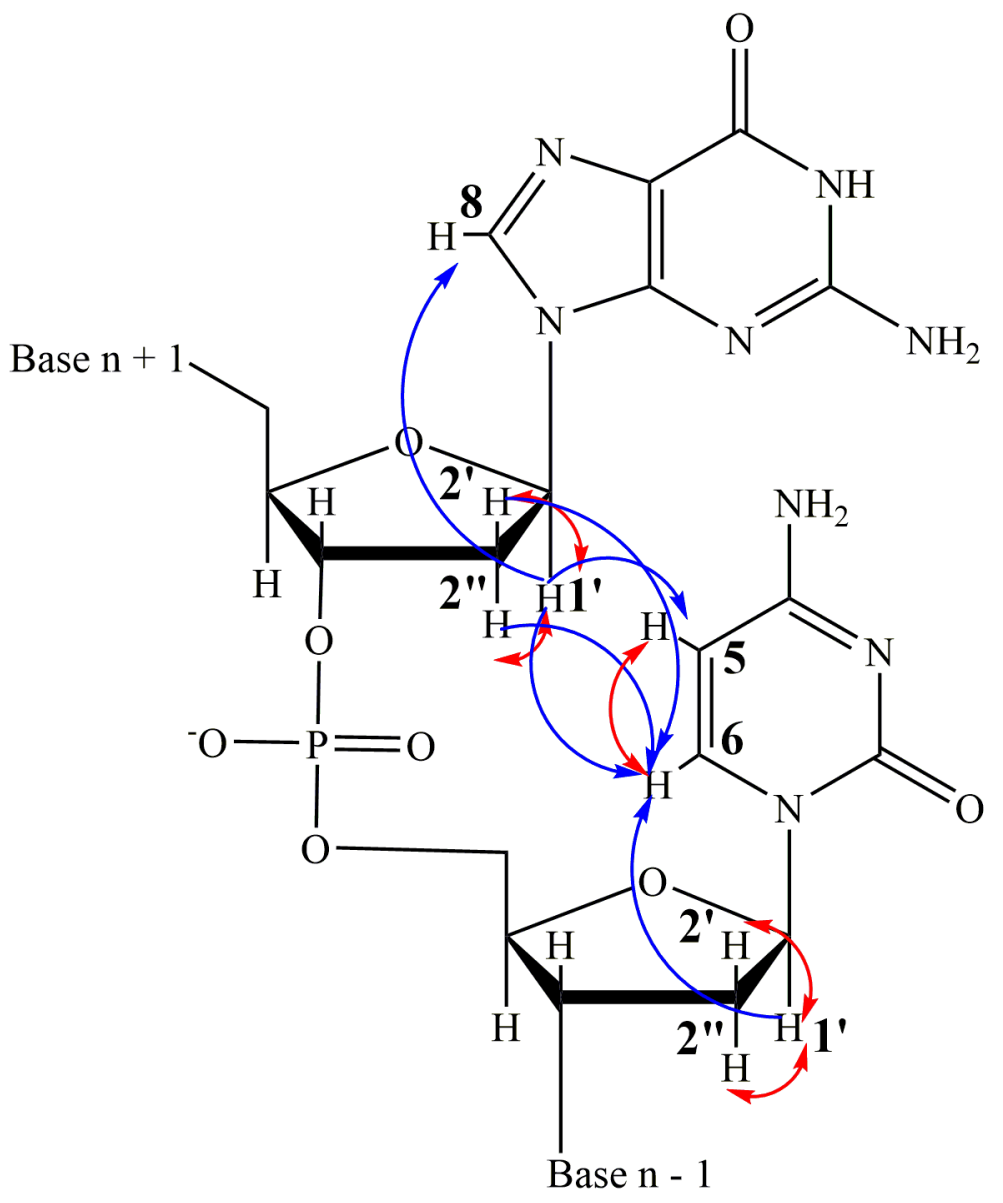

Figure 2.6. Intranucleotide and internucleotide assignment procedure for oligonucleotides in the B-DNA conformation. The red double-tip arrows show the protons that can be assigned from the COSY spectra: dC H6 to $\mathrm{H} 5, \mathrm{H} 1$ ' to H2' and H1' to H2". The blue single-tip arrows show the NOE correlations that can be assigned from the NOESY spectra: $\mathrm{H} 1$ ' to the 5'-base protons $(\mathrm{H} 8 / \mathrm{H} 6 / \mathrm{H} 5)$ and $\mathrm{H} 2$ '/H2' to the 5'-base protons.

The structural differences between B-DNA and Z-DNA are substantial and arise from the glycosidic bond conformation which alternates from syn for the purine bases to anti for the pyrimidines in the Z-DNA conformation whereas in B-DNA, all the nucleotides have the 
anti-glycosidic bond conformation. As a result there is also a substantial difference in the ${ }^{1} \mathrm{H}$ NMR spectrum, which has the most effect on the chemical shift of the H1' proton. ${ }^{151,154-156}$ One of the most important characteristics of the Z-DNA conformation in the NOESY spectra is a strong NOE cross-peak between the $\mathrm{H} 8$ proton of purines, here $\mathrm{dG}$ bases, and their own $\mathrm{H} 1$ ' proton (see Figure 2.6). The syn-conformation brings the H8 proton significantly closer in space than when in the anti-conformation and is therefore diagnostic of the Z-DNA conformation. This is also useful in the study described here where the aromatic protons of the $\mathrm{C} 8$-arylguanine modified base show strong NOE correlations to its H1' proton, which has also been observed for C8-methylguanine modified oligonucleotides. ${ }^{157,158}$

NMR is a very powerful technique to determine the conformational effects of the C8-arylguanine modified base on the hairpin oligonucleotide as well as for comparison to the previously studied doubly modified double-stranded oligonucleotide. The combination of the COSY and NOESY NMR experiments can be used to assign the resonances of the B-DNA and Z-DNA conformations of C8-arylguanine modified hairpin oligonucleotides in a fashion similar to previously studied double-stranded oligonucleotides. ${ }^{98,100}$ Hairpin oligonucleotides have also been studied in both the B- and Z-DNA conformations ${ }^{120,121}$ and have been shown to behave similarly to their double-stranded oligonucleotides without a loop (e.g., $\left(\mathrm{d}(\mathrm{CG})_{\mathrm{n}}\right)_{2}$ vs. $\left.\left.\mathrm{d}(\mathrm{CG})_{\mathrm{n}} \mathrm{T}_{4}(\mathrm{CG})_{\mathrm{n}}\right)\right)$. Therefore using hairpin oligonucleotides similar to those previous studies provide a good system for comparison one and two C8-arylguanine modified bases. 


\section{Chapter 3: Experimental Techniques and Results}

It is well known that DNA base modifications in alternating purine-pyrimidine (APP) sequences can shift the B-/Z-DNA equilibrium toward the Z-DNA conformation. ${ }^{16,159}$ In addition many of these C8-purine modifications are derived from carcinogens. ${ }^{77,83,88,90}$ APP sequences have been shown to play a role in gene expression, specifically in relation to these sequences being able to adopt Z-DNA. Therefore, it is possible that the base modifications that drive Z-DNA formation in a region of the genome that regulates gene expression may amplify the role of ZDNA in gene expression. Therefore it is important to understand how base modifications can alter the B-/Z-DNA equilibrium to drive Z-DNA formation.

Previous work in our laboratory has investigated the conformational effects of C8arylguanine modified bases on the B-/Z-DNA equilibrium. ${ }^{98-100}$ In addition our group has also demonstrated expertise in the synthesis of C8-aryl-2'-deoxyguanine modified nucleoside to produce C8-aryl-2'-deoxyguanine analogs with various para-substituents on the C8-aryl modification that can be incorporated into oligonucleotide sequences. ${ }^{125}$ In general, the C8-aryl2'-deoxyguanine modified nucleoside synthesis begins with 8-bromo-2'-deoxyguanosine synthesis prepared from 2'-deoxyguanosine and NBS which is further used in the Suzuki coupling reaction with an arylboronic acid to make C8-aryl-2'-deoxyguanosine. Subsequently, the exocyclic amine is converted to a dimethylformamidine and then the 5'-hydroxyl is converted to the dimethoxy trityl ether. Finally, the 3'-hydroxyl group was converted to the phosphoramidite and used in the modified hairpin oligonucleotide synthesis (see Scheme 2.1).

Although we have confirmed that the presence of the C8-arylguanine modified base shifts the B-/Z-DNA equilibrium towards the Z-DNA conformation in $\mathrm{d}(\mathrm{CG})_{5}$ oligonucleotides, our 
previous studies used oligonucleotides that contained two modified bases, one on each strand and in successive base pairs. ${ }^{98,100}$ Consequently, we could not determine if the conformational effects of the doubly modified $\mathrm{d}(\mathrm{CG})_{5}$ oligonucleotides were due to the modifications acting independently or in combination. Further, since it is unlikely that two adducts would form adjacent to one another in vivo, we sought to determine the effect of a single C8-arylguanine modification on the B-/Z-DNA equilibrium. To accomplish this goal we utilized a DNA hairpin with the sequence 5'-CGCGCG*CGCGTTTTCGCGCGCGCG-3', where $\mathbf{G}^{*}=$ C8-arylguanine (see Figure 1.4). Thus, by determining the conformational preferences of this hairpin oligonucleotide we can determine the effect of a single modification directly. In turn, by comparison to our previous work, the effect of a double modification can be assessed as to whether the effect is additive or that the two modifications are acting independently. ${ }^{100}$ This also allows us determine if, when multiple adducts are present, their effects are independent of one another.

In this section the experimental procedures and results of the synthesis of the C8-aryl-2'-deoxyguanine modified nucleosides will be reported. In addition the modified hairpin oligonucleotide synthesis and purification will be presented. Finally a detailed description of the conformational analysis experiments (NMR and CD) will be provided. 


\section{Part I: C8-Aryl-2'-deoxyguanine Modified Nucleoside and Hairpin Oligonucleotide Synthesis}

\section{A. C8-Aryl-2'-deoxyguanosine Nucleosides and Phosphoramidite Synthesis}

\section{General}

All chemicals used were purchased from Aldrich (Milwaukee, WI) unless otherwise noted. 4-Carboxyphenyl boronic acid (4-CPhBA) and 4-methoxymethylphenyl boronic acid (4-MMPhBA) were purchased from Frontier Scientific (Logan, UT). Tris-(3-sulfantophenyl) phosphine (TPPTS) was purchased from Strem Chemicals (Newburyport, MA). Other than the Suzuki coupling reaction, the following reactions en route to the production of the C8-aryl-2'-deoxyguanine phosphoramidite require anhydrous conditions and thus the solvents were dried and distilled before use. Methanol $\left(\mathrm{CH}_{3} \mathrm{OH}\right)$ and dimethylformamide (DMF) were

dried over molecular sieves $(3 \AA)$. Methylene chloride $\left(\mathrm{CH}_{2} \mathrm{Cl}_{2}\right)$ was dried by distillation from phosphorus pentoxide $\left(\mathrm{P}_{2} \mathrm{O}_{5}\right)$. Benzene and toluene were dried by distillation from calcium hydride. Triethylamine (TEA), tetrahydrofuran (THF), and pyridine were dried by distillation from lithium aluminum hydride. The structure of the synthetic C8-aryl-2'-deoxyguanine modified nucleosides (structures shown in Appendix B) were consistent with ${ }^{1} \mathrm{H}$ NMR spectra obtained on either a Varian 300 or 600 spectrometers (Palo Alto, CA) and are displayed in Appendix C.

\section{Synthesis}

8-Bromo-2'-deoxyguanosine, $\mathbf{C 1 1 0 H}_{12} \mathrm{O}_{4} \mathbf{N}_{5} \mathrm{Br}$ (1): 2'-Deoxyguanosine (dG; 2.86 g, $\left.10 \mathrm{mmol}\right)$ was suspended in a 4:1 mixture of acetonitrile $(\mathrm{ACN})$ and water $(125 \mathrm{~mL})$. N-Bromosuccinimide (NBS) (freshly recrystallized from water and hot filtration) was added to the $\mathrm{dG}$ suspension (2.67 
$\mathrm{g}, 15 \mathrm{mmol}$ ) which resulted in a yellow-orange precipitate. The reaction mixture was stirred for $30 \mathrm{~min}$ at $\mathrm{rm}$ temp and then filtered. The filter cake was resuspended in acetone $(50 \mathrm{~mL})$, stirred from $2 \mathrm{~h}$, sealed and then stored at $-20{ }^{\circ} \mathrm{C}$ freezer overnight. The precipitate was isolated by vacuum filtration and dried in a vacuum desiccator for additional $24 \mathrm{~h}(2.94 \mathrm{~g}, 8.5 \mathrm{mmol}, 85 \%$ yield).

${ }^{1} \mathrm{H}$ NMR (300 MHz, DMSO-d 6 ): $\delta$ ppm $10.78(1 \mathrm{H}, \mathrm{s}, \mathrm{NH}), 6.47\left(2 \mathrm{H}, \mathrm{s}, \mathrm{NH}_{2}\right), 6.16(1 \mathrm{H}, \mathrm{t}, J=7.5$ Hz, H1'), 5.23 (1H, d, J = 6.0 Hz 3'-OH), 4.83 (1H, s, 5'-OH), 4.39 (1H, m, H3'), 3.80 (1H, m, H4'), 3.62 and $3.50\left(2 \mathrm{H}, \mathrm{m}, \mathrm{H} 5^{\prime} / 5^{\prime}\right), 3.16\left(1 \mathrm{H}, \mathrm{m}, \mathrm{H} 2^{\prime \prime}\right)$ and $2.10(1 \mathrm{H}, \mathrm{ddd}, J=3.0,6.0,9.0 \mathrm{~Hz}$, H2').

4-(tert-butyldimethylsilyl-O-methyl)-phenyl bromide, $\mathrm{C}_{12} \mathrm{H}_{21} \mathrm{OSiBr}$ (2): 4-Bromobenzyl alcohol (756 mg, $4.0 \mathrm{mmol}$ ), tert-butyldimethylsilyl (TBS) chloride (1.30 mg, $8.0 \mathrm{mmol})$, and imidazole (freshly sublimed, $605 \mathrm{mg}, 8.8 \mathrm{mmol})$ were dissolved in DMF (10 mL). The reaction was stirred at $\mathrm{rm}$ temp for $24 \mathrm{~h}$ under argon. The reaction solvent was removed using Rotovap with heating at $90{ }^{\circ} \mathrm{C}$. The residue was extracted with hexane $(30 \mathrm{~mL})$, the hexane then washed with water ( $3 \times 30 \mathrm{~mL})$, and the organic layer dried over sodium sulfate. The desired product, 2 , was isolated after solvent removal and further dried in vacuo overnight in a desiccator.

${ }^{1} \mathrm{H}$ NMR $\left(300 \mathrm{MHz}, \mathrm{CDCl}_{3}-\mathrm{d}_{1}\right): \delta$ ppm $7.46(2 \mathrm{H}, \mathrm{d}, J=9.0 \mathrm{~Hz}, \operatorname{aryl}), 7.21(2 \mathrm{H}, \mathrm{d}, J=9.0 \mathrm{~Hz}$, aryl), $4.69\left(2 \mathrm{H}, \mathrm{s}, \mathrm{CH}_{2}\right), 0.95$ (9H, s, t-butyl), and 0.11 (6H, s, dimethylsilyl). 
4-(TBS-O-methyl)-phenyl boronic acid, $\mathrm{C}_{13} \mathrm{H}_{23} \mathrm{O}_{3} \mathrm{BSi}$ (3): A previously reported procedure ${ }^{160}$ of this compound was modified and used here. Compound 2 ( $5 \mathrm{~g}, 16.6 \mathrm{mmol})$ was dissolved in dry THF $(50 \mathrm{~mL})$ and toluene $(10 \mathrm{~mL})$ and combined with triisopropyl borate $(5.5 \mathrm{~mL}, 23.8 \mathrm{mmol})$. The organic mixture was sparged with nitrogen at $-78{ }^{\circ} \mathrm{C}$ (acetone and dry ice bath) for $30 \mathrm{~min}$ and then n-butyl lithium (1.6 M in hexane, $20 \mathrm{~mL}, 32 \mathrm{mmol}$ ) added, over $20 \mathrm{~min}$, through an addition funnel. The reaction was stirred for $10 \mathrm{~min}$, the dry ice bath was removed and replaced with a wet ice bath, and the temperature raised from $-78{ }^{\circ} \mathrm{C}$ to $0{ }^{\circ} \mathrm{C}$ over $30 \mathrm{~min}$. Concentrated $\mathrm{HCl}$ was then added $(17.5 \mathrm{~mL}, 2 \mathrm{M})$, the mixture stirred for $30 \mathrm{~min}$, ethyl acetate $(27.5 \mathrm{~mL})$ added and stirring for additional $30 \mathrm{~min}$. The organic layer was collected and washed with a $5 \%$ sodium bicarbonate and $10 \%$ sodium chloride solution $(25 \mathrm{~mL})$, dried over magnesium sulfate, filtered and concentrated to dryness in vacuo. The crude product was suspended in ACN and collected by filtration to yield the final TBS-protected boronic acid $\mathbf{3}$.

${ }^{1} \mathrm{H}$ NMR $\left(300 \mathrm{MHz}, \mathrm{CDCl}_{3}-\mathrm{d}_{1}\right): \delta \mathrm{ppm} 8.23(2 \mathrm{H}, \mathrm{d}, J=7.5 \mathrm{~Hz}$, aryl), $7.48(2 \mathrm{H}, \mathrm{d}, J=7.8 \mathrm{~Hz}$, aryl), $4.86\left(2 \mathrm{H}, \mathrm{s}, \mathrm{CH}_{2}\right), 0.99$ (9H, s, t-butyl), and 0.14 (6H, s, dimethylsilyl).

8-(Phenyl)-2'-deoxyguanosine $\mathbf{C}_{16} \mathrm{H}_{17} \mathbf{O}_{4} \mathbf{N}_{5}$ (4): Phenylboronic acid (301 mg, $2.47 \mathrm{mmol}$ ), 1 (692 mg, $2.0 \mathrm{mmol}), \mathrm{Na}_{2} \mathrm{CO}_{3}(421 \mathrm{mg}, 3.97 \mathrm{mmol})$, TPPTS ( $80 \mathrm{mg}, 0.14 \mathrm{mmol}$ ) were added to the reaction flask and sparged with argon for $5 \mathrm{~min}$. Then, palladium (II) acetate $\left(\mathrm{Pd}(\mathrm{OAc})_{2} ; 11.6 \mathrm{mg}\right.$, $0.053 \mathrm{mmol}$ ) was added to the reaction flask and sparged with argon for an additional $10 \mathrm{~min}$. The reactants were dissolved in aqueous $\mathrm{ACN}\left(2: 1 \mathrm{H}_{2} \mathrm{O}: \mathrm{ACN}, 20 \mathrm{~mL}\right)$, sparged with argon for $30 \mathrm{~min}$ and then heated at $80{ }^{\circ} \mathrm{C}$. The reaction was stirred for $2.5 \mathrm{~h}$ or until reverse-phase TLC (RP-TLC; 
C18, 1:1 $\mathrm{H}_{2} \mathrm{O}: \mathrm{CH}_{3} \mathrm{OH}$, UV detection) indicated complete consumption of $\mathbf{1}$, which typically was accompanied by the reaction mixture changing from a clear, yellowish color to an opaque, black color. The reaction mixture was cooled to rm temp by the addition of ice and diluted with $\mathrm{H}_{2} \mathrm{O}$ $(10 \mathrm{~mL})$ and further cooled with an ice bath. The $\mathrm{pH}$ was adjusted to 6-7 by the drop-wise addition of $10 \% \mathrm{HCl}$. The resulting precipitate was isolated via vacuum filtration and the filter cake was dried in vacuo to yield 4 (665 mg, $1.94 \mathrm{mmol}, 96.9 \%$ yield).

${ }^{1} \mathrm{H}$ NMR (300 MHz, DMSO-d $\left.{ }_{6}\right): \delta$ ppm $10.80(1 \mathrm{H}, \mathrm{s}, \mathrm{NH}), 7.65(2 \mathrm{H}, \mathrm{m}), 7.53(3 \mathrm{H}, \mathrm{m}), 6.40(2 \mathrm{H}$, s, $\left.\mathrm{NH}_{2}\right), 6.05\left(1 \mathrm{H}, \mathrm{t}, J=6.8 \mathrm{~Hz}, \mathrm{H1}\right.$ '), $5.12\left(1 \mathrm{H}, \mathrm{brs}, 3^{\prime}-\mathrm{OH}\right), 4.99$ (1H, brs, 5'-OH), 4.34 (1H, m, H3'), 3.79 (1H, m, H4'), 3.65 and 3.54 (2H, m, H5'/H5"), 3.17 (1H, m, H2"), and 2.03 (1H, ddd, $\left.J=3.0,6.0,9.0 \mathrm{~Hz}, \mathrm{H} 2^{\prime}\right)$.

8-p-Tolyl-2'-deoxyguanosine $\mathbf{C}_{17} \mathbf{H}_{18} \mathbf{O}_{4} \mathbf{N}_{5}$ (5): $p$-Tolylboronic acid (336 mg, $2.47 \mathrm{mmol}$ ), $\mathbf{1}$ (692 $\mathrm{mg}, 2.0 \mathrm{mmol}), \mathrm{Na}_{2} \mathrm{CO}_{3}(421 \mathrm{mg}, 3.97 \mathrm{mmol})$, TPPTS $(80 \mathrm{mg}, 0.14 \mathrm{mmol})$ were added to the reaction flask and sparged with argon for $5 \mathrm{~min}$. Then $\mathrm{Pd}(\mathrm{OAc})_{2}(11.6 \mathrm{mg}, 0.053 \mathrm{mmol})$ was added to the reaction flask and sparged with argon for an additional 10 min. The reactants were dissolved in aqueous $\mathrm{ACN}\left(2: 1 \mathrm{H}_{2} \mathrm{O}: \mathrm{ACN}, 20 \mathrm{~mL}\right)$ sparged with argon for $30 \mathrm{~min}$ and then heated at $80{ }^{\circ} \mathrm{C}$. The reaction was stirred for $2.5 \mathrm{~h}$ or until reverse-phase TLC (RP-TLC; C18, 1:1 $\mathrm{H}_{2} \mathrm{O}: \mathrm{CH}_{3} \mathrm{OH}$, UV detection) indicated complete consumption of $\mathbf{1}$, which typically was accompanied by the reaction mixture changing from a clear, yellowish color to an opaque, black color. The reaction mixture was cooled to rm temp by the addition of ice and diluted with $\mathrm{H}_{2} \mathrm{O}$ $(10 \mathrm{~mL})$ and further cooled with an ice bath. The $\mathrm{pH}$ was adjusted to 6-7 by the drop-wise addition 
of $10 \% \mathrm{HCl}$. The precipitate was isolated via vacuum filtration and the filter cake was dried in vacuo to yield 5 (704 mg, $1.84 \mathrm{mmol}, 92.0 \%)$.

${ }^{1} \mathrm{H}$ NMR (300 MHz, DMSO-d $): \delta$ ppm $7.52(2 \mathrm{H}, \mathrm{d}, J=8.1 \mathrm{~Hz}, \operatorname{aryl}), 7.34(2 \mathrm{H}, \mathrm{d}, J=8.1 \mathrm{~Hz}$, aryl), $6.70\left(2 \mathrm{H}\right.$, brs, $\left.\mathrm{NH}_{2}\right), 6.07(1 \mathrm{H}, \mathrm{dd}, J=8.6,6.3 \mathrm{~Hz}, \mathrm{H} 1$ '), 5.69 (1H, brs, 3'-OH), 4.13 (1H, brs, 5'-OH), 4.36 (1H, m, H3'), 3.82 (1H, m, H4'), 3.68 and 3.55 (2H, m, H5'/H5’), 3.17 (1H, m, H2”), 2.39 (3H, s, $\left.\mathrm{CH}_{3}\right)$, and $2.02(1 \mathrm{H}, \mathrm{ddd}, J=2.7,6.0,88 \mathrm{~Hz}, \mathrm{H} 2$ ').

8-(4-(TBS-O-methyl)phenyl)-2'-deoxyguanosine $\mathrm{C}_{23} \mathrm{H}_{33} \mathrm{O}_{5} \mathrm{~N}_{5} \mathrm{Si}$ (6): Compound 3 (293 mg, $1.10 \mathrm{mmol}), 1$ (346 mg, $1.0 \mathrm{mmol}), \mathrm{Na}_{2} \mathrm{CO}_{3}(292 \mathrm{mg}, 2.75 \mathrm{mmol})$, TPPTS (80 mg, $\left.0.14 \mathrm{mmol}\right)$ were added to the reaction flask and sparged with argon for $5 \mathrm{~min}$. Then $\mathrm{Pd}(\mathrm{OAc})_{2}(22 \mathrm{mg}, 0.10$ mmol) was added to the reaction flask and sparged with argon for an additional $10 \mathrm{~min}$. The reactants were dissolved in aqueous $\mathrm{ACN}\left(2: 1 \mathrm{H}_{2} \mathrm{O}: \mathrm{ACN}, 10 \mathrm{~mL}\right)$ sparged with argon for $30 \mathrm{~min}$ and then heated to $80{ }^{\circ} \mathrm{C}$. The reaction was stirred for $2.5 \mathrm{~h}$ or until reverse-phase TLC (RP-TLC; $\mathrm{C} 18,1: 1 \mathrm{H}_{2} \mathrm{O}: \mathrm{CH}_{3} \mathrm{OH}$, UV detection) indicated complete consumption of $\mathbf{1}$, which typically was accompanied by the reaction mixture changing from a clear, yellowish color to an opaque, black color. The reaction mixture was cooled to rm temp, diluted with $\mathrm{H}_{2} \mathrm{O}(5 \mathrm{~mL})$ and further cooled with an ice bath. The $\mathrm{pH}$ was not adjusted unlike the other $\mathrm{C} 8$-aryl-2'-deoxyguanosine derivatives and the precipitate was isolated via vacuum filtration, washed with water and then ethyl acetate, and the filter cake was dried in vacuo to yield 6 (365 mg, $0.75 \mathrm{mmol}, 74.9 \%$ ). 
${ }^{1} \mathrm{H}$ NMR (300 MHz, DMSO-d 6 ): $\delta$ ppm $7.60(2 \mathrm{H}, \mathrm{d}, 8.4 \mathrm{~Hz}), 7.45(2 \mathrm{H}, \mathrm{d}, 8.1 \mathrm{~Hz}), 6.65(2 \mathrm{H}, \mathrm{s}$, $\left.\mathrm{NH}_{2}\right), 6.08\left(1 \mathrm{H}, \mathrm{t}, J=7.5 \mathrm{~Hz}, \mathrm{H} 1^{\prime}\right), 5.83$ (1H, brs, 3'-OH), 5.12 (1H, brs, 5'-OH), 4.80 (2H, s, $\mathrm{CH}_{2}$ 4.37 (1H, m, H3'), 3.83 (1H, m, H4'), 3.67 and 3.54 (2H, m, H5'/H5”), 3.15 (1H, m, H2"), and $2.03(1 \mathrm{H}, \mathrm{dd}, J=6.0,12.0 \mathrm{~Hz}, \mathrm{H} 2$ '), 0.94 (9H, s, t-butyl), and 0.12 (6H, s, dimethylsilyl).

8-(4-Methoxymethylphenyl)-2'-deoxyguanosine $\mathrm{C}_{18} \mathrm{H}_{21} \mathrm{O}_{5} \mathrm{~N}_{5}$ (7): 4-MPhBA (410 mg, 2.47 mmol), 1 (692 mg, $2.0 \mathrm{mmol}), \mathrm{Na}_{2} \mathrm{CO}_{3}(421 \mathrm{mg}, 3.97 \mathrm{mmol})$, TPPTS (80 mg, $\left.0.14 \mathrm{mmol}\right)$ were added to the reaction flask and sparged with argon for $5 \mathrm{~min}$. Then $\mathrm{Pd}(\mathrm{OAc})_{2}(11.6 \mathrm{mg}, 0.053$ mmol) was added to the reaction flask and sparged with argon for an additional 10 min. The reactants were dissolved in aqueous $\mathrm{ACN}\left(1: 1 \mathrm{H}_{2} \mathrm{O}: \mathrm{ACN}, 20 \mathrm{~mL}\right)$ sparged with argon for $30 \mathrm{~min}$ and then heated to $80^{\circ} \mathrm{C}$. The reaction was stirred for $2.5 \mathrm{~h}$ or until reverse-phase TLC (RP-TLC; C18, 1:1 $\mathrm{H}_{2} \mathrm{O}: \mathrm{CH}_{3} \mathrm{OH}$, UV detection) indicated complete consumption of $\mathbf{1}$, which typically was accompanied by the reaction mixture changing from a clear, yellowish color to an opaque, black color. The reaction mixture was cooled to rm temp by the addition of ice and diluted with $\mathrm{H}_{2} \mathrm{O}$ $(10 \mathrm{~mL})$ and further cooled with an ice bath. The $\mathrm{pH}$ was adjusted to 6-7 by the drop-wise addition of $10 \% \mathrm{HCl}$. The precipitate was isolated via vacuum filtration and the filter cake was dried in vacuo to 7 (708 $\mathrm{mg}, 1.83 \mathrm{mmol}, 91.5 \%$ yield).

${ }^{1} \mathrm{H}$ NMR (300 MHz, DMSO-d $)$ ): $\delta$ ppm $10.76(1 \mathrm{H}, \mathrm{s}, \mathrm{NH}), 7.64(2 \mathrm{H}, \mathrm{d}, 9.0 \mathrm{~Hz}), 7.47$ (2H, d, 9.0 Hz), 6.39 (2H, s, $\left.\mathrm{NH}_{2}\right), 6.07$ (1H, t, $J=7.5 \mathrm{~Hz}, \mathrm{H1}$ '), $5.12\left(1 \mathrm{H}, \mathrm{d}, J=6.0 \mathrm{~Hz}, 3^{\prime}-\mathrm{OH}\right), 4.99(1 \mathrm{H}$, d, $\left.J=6.0 \mathrm{~Hz}, 5^{\prime}-\mathrm{OH}\right), 4.33$ (1H, m, H3'), 3.78 (1H, m, H4'), 3.65 and 3.54 (2H, m, H5'/H5'), 3.32 $\left(3 \mathrm{H}, \mathrm{s}, \mathrm{OCH}_{3}\right), 3.15(1 \mathrm{H}, \mathrm{m}, \mathrm{H} 2 ”)$, and $2.02\left(1 \mathrm{H}, \mathrm{ddd}, J=3.0,6.0,9.0 \mathrm{~Hz}, \mathrm{H} 2{ }^{\prime}\right)$. 
8-(4-Carboxyphenyl)-2'-deoxyguanosine $\mathbf{C}_{17} \mathrm{H}_{17} \mathrm{O}_{6} \mathbf{N}_{5}$ (8): 4-CPhBA (410 mg, $\left.2.47 \mathrm{mmol}\right), 1$ (8-Br2dG; $692 \mathrm{mg}, 2.0 \mathrm{mmol}$ ), $\mathrm{Na}_{2} \mathrm{CO}_{3}$ (421 mg, $3.97 \mathrm{mmol}$ TPPTS (80 mg, $0.14 \mathrm{mmol}$ ) were added to the reaction flask and sparged with argon for $5 \mathrm{~min}$. Then $\mathrm{Pd}(\mathrm{OAc})_{2}(11.6 \mathrm{mg}, 0.053$ mmol) was added to the reaction flask and sparged with argon for an additional 10 min. The reactants were dissolved in aqueous $\mathrm{ACN}\left(1: 1 \mathrm{H}_{2} \mathrm{O}: \mathrm{ACN}, 20 \mathrm{~mL}\right)$ sparged with argon for $30 \mathrm{~min}$ and then heated to $80{ }^{\circ} \mathrm{C}$. The reaction was stirred for $2.5 \mathrm{~h}$ or until reverse-phase TLC (RP-TLC; $\mathrm{C} 18,1: 1 \mathrm{H}_{2} \mathrm{O}: \mathrm{CH}_{3} \mathrm{OH}$, UV detection) indicated complete consumption of $\mathbf{1}$, which typically was accompanied by the reaction mixture changing from a clear, yellowish color to an opaque, black color. The reaction mixture was gradually cooled to rm temp without an ice bath before diluted with $\mathrm{H}_{2} \mathrm{O}(10 \mathrm{~mL})$ and the $\mathrm{pH}$ was adjusted to $6-7$ by the drop-wise addition of $10 \% \mathrm{HCl}$. The precipitate was isolated via vacuum filtration and the filter cake was dried in vacuo to yield $\mathbf{8}$ (704 $\mathrm{mg}, 1.84 \mathrm{mmol}, 92.0 \%)$.

${ }^{1} \mathrm{H}$ NMR (300 MHz, DMSO-d 6 ): $\delta$ ppm 10.83 (1H, s, NH), 8.07 (2H, d, $\left.8.3 \mathrm{~Hz}\right), 7.80$ (2H, d, 8.4 Hz), 6.49 (2H, s, NH 2$), 6.10$ (1H, t, $J=7.5$ Hz, H1'), 5.12 (1H, brs, 3'-OH), 4.95 (1H, brs, 5'-OH), 4.34 (1H, m, H3'), 3.80 (1H, m, H4'), 3.66 and 3.55 (2H, m, H5'/H5”), 3.11 (1H, m, H2”), and 2.04 (1H, ddd, $J=3.0,6.0,9.0 \mathrm{~Hz}, \mathrm{H} 2^{\prime}$ ).

N2-(N,N-Dimethylformamidine)-8-phenyl-2'-deoxyguanosine, $\mathrm{C}_{19} \mathrm{H}_{22} \mathrm{O}_{6} \mathrm{~N}_{6}$ (9): Compound 4 (350 mg, $1.02 \mathrm{mmol}$ ) was suspended in methanol $(7 \mathrm{~mL})$ and $N, N$-dimethylformamide dimethyl acetal $(625 \mu \mathrm{L}, 5.0 \mathrm{mmol})$ was added to the reaction. The suspension was stirred at $\mathrm{rm}$ temp for 
24-48 $\mathrm{h}$. The solvent was removed in vacuo to yield 9 which was used without further purification (382 mg, $0.96 \mathrm{mmol}, 94.0 \%$ yield)

${ }^{1} \mathrm{H}$ NMR (300 MHz, DMSO-d 6$): \delta$ ppm $11.48(1 \mathrm{H}, \mathrm{s}, \mathrm{NH}), 8.53(1 \mathrm{H}, \mathrm{s}, \mathrm{HC}=\mathrm{N}), 7.68(2 \mathrm{H}, \mathrm{m})$, $7.58(3 \mathrm{H}, \mathrm{m}), 6.14(1 \mathrm{H}, \mathrm{t}, J=7.4 \mathrm{~Hz}, \mathrm{H1}$ '), 5.23 (1H, brs, 3'-OH), 4.94 (1H, brs, 5'-OH), 4.46 (1H, m, H3'), 3.84 (1H, m, H4'), 3.70 and 3.61 (2H, m, H5'/H5”), 3.23 (1H, m, H2"), 3.17 and $3.07\left(3 \mathrm{H}\right.$ each, s, $\left.\mathrm{N}\left(\mathrm{CH}_{3}\right)_{2}\right)$ and $2.08(1 \mathrm{H}, \mathrm{ddd}, J=3.0,6.0,9.0 \mathrm{~Hz}, \mathrm{H} 2$ ').

N2-(N,N-Dimethylformamidine)-8-p-tolyl-2'-deoxyguanosine, $\mathrm{C}_{20} \mathrm{H}_{24} \mathrm{O}_{4} \mathrm{~N}_{6}$ (10): Compound 5 (365 mg, $1.02 \mathrm{mmol})$ was suspended in methanol $(7 \mathrm{~mL})$ and $N, N$-dimethylformamide dimethyl acetal $(625 \mu \mathrm{L}, 5.0 \mathrm{mmol})$ was added to the reaction mixture. The suspension was stirred at $\mathrm{rm}$ temp for 24-48 $\mathrm{h}$. The solvent was removed in vacuo to yield $\mathbf{1 0}$ which was used without further purification (405 mg, $0.98 \mathrm{mmol}, 96.3 \%$ yield)

${ }^{1} \mathrm{H}$ NMR (300 MHz, DMSO-d 6$): \delta$ ppm $11.44(1 \mathrm{H}, \mathrm{s}, \mathrm{NH}), 8.50(1 \mathrm{H}, \mathrm{s}, \mathrm{HC}=\mathrm{N}), 7.54(2 \mathrm{H}, \mathrm{d}, J=$ $8.0 \mathrm{~Hz}$, aryl), $7.58(2 \mathrm{H}, \mathrm{d}, J=8.0 \mathrm{~Hz}$, aryl), $6.10(1 \mathrm{H}, \mathrm{t}, J=7.4 \mathrm{~Hz}, \mathrm{H1}$ '), $5.20(1 \mathrm{H}$, brs, 3'-OH), $4.98(1 \mathrm{H}$, brs, 5'-OH), 4.43 (1H, m, H3'), 3.81 (1H, m, H4'), 3.67 and 3.56 (2H, m, H5'/H5”), $3.22\left(1 \mathrm{H}, \mathrm{m}, \mathrm{H} 2\right.$ ”), 3.15 and 3.05 (3H each, s, $\left.\mathrm{N}\left(\mathrm{CH}_{3}\right)_{2}\right), 2.40\left(3 \mathrm{H}, \mathrm{s}, \mathrm{CH}_{3}\right)$, and $2.08(1 \mathrm{H}$, ddd, $J$ $\left.=2.7,6.6,9.2 \mathrm{~Hz}, \mathrm{H} 2^{\prime}\right)$. 


\section{N2-(N,N-Dimethylformamidine)-8-(4-(TBS-O-methyl)phenyl-2'-deoxyguanosine,}

$\mathrm{C}_{26} \mathrm{H}_{38} \mathrm{O}_{5} \mathrm{~N}_{6} \mathrm{Si}$ (11): Compound 6 (497 mg, $1.02 \mathrm{mmol}$ ) was suspended in methanol (7 mL). The addition of $N, N$-dimethylformamide dimethyl acetal $(625 \mu \mathrm{L}, 5.0 \mathrm{mmol})$ created the reaction solution, which was stirred at rm temp for 24-48 h. The solvent was removed in vacuo to yield 11 and was used without further purification (485 mg, $0.89 \mathrm{mmol}, 84.6 \%$ yield)

${ }^{1} \mathrm{H}$ NMR $\left(300 \mathrm{MHz}, \mathrm{DMSO}-\mathrm{d}_{6}\right): \delta \mathrm{ppm} 8.51(1 \mathrm{H}, \mathrm{s}, \mathrm{HC}=\mathrm{N}), 7.63(2 \mathrm{H}, \mathrm{d}, J=8.0 \mathrm{~Hz}$, aryl $), 7.58$ $(2 \mathrm{H}, \mathrm{d}, J=8.0 \mathrm{~Hz}$, aryl $), 6.10\left(1 \mathrm{H}, \mathrm{t}, J=7.2 \mathrm{~Hz}, \mathrm{H1}\right.$ ') $, 4.81\left(2 \mathrm{H}, \mathrm{s}, \mathrm{CH}_{2}\right), 4.44(1 \mathrm{H}, \mathrm{m}, \mathrm{H} 3$ '), 3.81 (1H, m, H4'), 3.66 and 3.57 (2H, m, H5'/H5”), 3.24 (1H, m, H2”), 3.15 and 3.05 (3H each, s, $\left.\mathrm{N}\left(\mathrm{CH}_{3}\right)_{2}\right)$ and $2.08\left(1 \mathrm{H}\right.$, ddd, $\left.J=3.0,6.0,9.0 \mathrm{~Hz}, \mathrm{H} 2^{\prime}\right) 0.94(9 \mathrm{H}, \mathrm{s}, \mathrm{t}$-butyl), and $0.12(6 \mathrm{H}, \mathrm{s}$, dimethylsilyl).

N2-( $N, N$-Dimethylforamidine)-8-(4-methoxymethylphenyl)-2'-deoxyguanosine, $\mathrm{C}_{21} \mathrm{H}_{26} \mathrm{O}_{5} \mathrm{~N}_{6}$ (12): Compound $7(395 \mathrm{mg}, 1.02 \mathrm{mmol})$ was suspended in methanol $(7 \mathrm{~mL})$ and $N, N-$ dimethylformamide dimethyl acetal $(625 \mu \mathrm{L}, 5.0 \mathrm{mmol})$ was added to the reaction mixture. The suspension was stirred at rm temp for 24-48 h. The solvent was removed in vacuo to yield $\mathbf{1 2}$ and was used without further purification (430 mg, $0.97 \mathrm{mmol}, 95.2 \%$ yield)

${ }^{1} \mathrm{H}$ NMR (300 MHz, DMSO-d 6 ): $\delta$ ppm $11.44(1 \mathrm{H}, \mathrm{s}, \mathrm{NH}), 8.49(1 \mathrm{H}, \mathrm{s}, \mathrm{HC}=\mathrm{N}), 7.63(2 \mathrm{H}, \mathrm{d}, J=$ $8.3 \mathrm{~Hz}$, aryl), 7.49 (2H, d, $J=8.3 \mathrm{~Hz}$, aryl), 6.11 (1H, t, $J=7.5 \mathrm{~Hz}, \mathrm{H} 1$ '), 5.20 (1H, brs, 3'-OH), 4.50 (2H, s, $\left.\mathrm{CH}_{2}\right), 4.43$ (1H, m, H3'), 3.82 (1H, m, H4'), 3.66 and 3.58 (2H, m, H5'/H5’), 3.35 
(3H, s, $\left.\mathrm{OCH}_{3}\right), 3.22(1 \mathrm{H}, \mathrm{m}, \mathrm{H} 2 "), 3.14$ and 3.04 (3H each, $\left.\mathrm{s}, \mathrm{N}\left(\mathrm{CH}_{3}\right)_{2}\right)$ and $2.08(1 \mathrm{H}, \mathrm{ddd}, J=3.0$, $\left.6.0,9.0 \mathrm{~Hz}, \mathrm{H} 2{ }^{\prime}\right)$.

N2-(N,N-Dimethylformamidine)-8-(4-carboxyphenyl)-2'-deoxyguanosine, $\mathrm{C}_{20} \mathrm{H}_{22} \mathrm{O}_{6} \mathrm{~N}_{6}$ (13): Compound 8 (395 mg, $1.02 \mathrm{mmol})$ was suspended in methanol $(7 \mathrm{~mL})$. The addition of $N, N$ dimethylformamide dimethyl acetal $(625 \mu \mathrm{L}, 5.0 \mathrm{mmol})$ created the reaction solution, which was stirred at rt for 24-48h. The solvent was removed in vacuo to yield $\mathbf{1 3}$ and used without further purification (422 mg, $0.95 \mathrm{mmol}, 93.5 \%$ yield)

${ }^{1} \mathrm{H}$ NMR (300 MHz, DMSO-d 6$): \delta$ ppm $8.57(1 \mathrm{H}, \mathrm{s}, \mathrm{HC}=\mathrm{N}), 8.03(2 \mathrm{H}, \mathrm{d}, J=8.3 \mathrm{~Hz}$, aryl), 7.62 (dH, d, $J=8.3 \mathrm{~Hz}$, aryl), $6.18\left(1 \mathrm{H}, \mathrm{t}, J=7.9 \mathrm{~Hz}, \mathrm{H} 1^{\prime}\right), 4.52(1 \mathrm{H}, \mathrm{m}, \mathrm{H} 3$ '), 3.85 (1H, m, H4'), 3.71 and $3.62\left(2 \mathrm{H}, \mathrm{m}, \mathrm{H} 5\right.$ '/H5"), 3.22 (1H, m, H2"), 3.14 and $3.06\left(3 \mathrm{H}\right.$ each, $\left.\mathrm{s}, \mathrm{N}\left(\mathrm{CH}_{3}\right)_{2}\right)$ and $2.14(1 \mathrm{H}$, ddd, $\left.J=3.0,6.0,9.0 \mathrm{~Hz}, \mathrm{H} 2^{\prime}\right)$.

\section{5'-O-(4,4'-Dimethoxytrityl)-N2-(N,N-dimethylformamidine)-8-phenyl-2'-deoxyguanosine,}

$\mathbf{C}_{40} \mathbf{H}_{40} \mathbf{O}_{6} \mathbf{N}_{6}$ (14): Compound 9 (398 $\left.\mathrm{mg}, 1.0 \mathrm{mmol}\right)$ was dissolved in pyridine (8 $\mathrm{mL}$ ) and then 4,4'-dimethoxytrityl chloride (DMTr-Cl; $501 \mathrm{mg}, 1.48 \mathrm{mmol}$ ) was added, which resulted in a deep red reaction mixture. TEA $(0.175 \mathrm{~mL})$ was then added to the reaction vessel, the reaction was stirred at rm temp, under argon, and the reaction progress was monitored by normal phase TLC (neutral alumina, $\left.5 \% \mathrm{CH}_{3} \mathrm{OH}: \mathrm{CH}_{2} \mathrm{Cl}_{2}\right)$. TLC confirmed complete consumption of $9(10 \% \mathrm{HCl}$ solution to develop the TLC) indicated by an orange spot on the TLC strip. Once the reaction is complete, methanol $(8 \mathrm{~mL})$ was added to the reaction mixture to destroy the remaining DMTr-Cl. 
The solvents were removed in vacuo and the product dried in a desiccator $\left(\mathrm{P}_{2} \mathrm{O}_{5}\right)$. Crude $\mathbf{1 4}$ was purified by low pressure column chromatography (neutral alumina, $0-5 \% \mathrm{CH}_{3} \mathrm{OH}: \mathrm{CH}_{2} \mathrm{Cl}_{2}$ ) to give the pure 14 ( $350 \mathrm{mg}, 0.5 \mathrm{mmol}, 50.0 \%$ yield).

${ }^{1} \mathrm{H}$ NMR (300 MHz, DMSO-d 6$): \delta$ ppm $11.42(1 \mathrm{H}, \mathrm{s}, \mathrm{NH}), 8.30(1 \mathrm{H}, \mathrm{s}, \mathrm{HC}=\mathrm{N}), 7.75(2 \mathrm{H}, \mathrm{m})$, $7.33(3 \mathrm{H}, \mathrm{m}), 7.33-6.73(13 \mathrm{H}, \mathrm{m}, \mathrm{DMTr}-\mathrm{H}), 6.17\left(1 \mathrm{H}, \mathrm{dd}, J=5.3,7.8 \mathrm{~Hz}, \mathrm{H} 1^{\prime}\right), 5.27(1 \mathrm{H}, \mathrm{d}, J=$ $\left.4.8 \mathrm{~Hz}, 3^{\prime}-\mathrm{OH}\right), 4.58\left(1 \mathrm{H}, \mathrm{m}, \mathrm{H} 3\right.$ '), $3.92\left(1 \mathrm{H}, \mathrm{m}, \mathrm{H} 4\right.$ '), 3.71 and 3.70 (3H each, s, $\left.\mathrm{OCH}_{3}\right), 3.31$ and $3.14\left(2 \mathrm{H}, \mathrm{m}, \mathrm{H} 5\right.$ '/H5”), $3.22(1 \mathrm{H}, \mathrm{m}, \mathrm{H} 2 "), 3.03$ and $2.98\left(3 \mathrm{H}\right.$ each, s, $\left.\mathrm{N}\left(\mathrm{CH}_{3}\right)_{2}\right)$ and $2.18(1 \mathrm{H}, \mathrm{m}$, H2').

\section{5'-O-(4,4'-Dimethoxytrityl)-N2-(N,N-dimethylformamidine)-8-p-tolyl-2'-deoxyguanosine,}

$\mathrm{C}_{41} \mathrm{H}_{42} \mathrm{O}_{6} \mathrm{~N}_{6}$ (15): Compound 10 (412 $\mathrm{mg}, 1.0 \mathrm{mmol}$ ) was dissolved in pyridine ( $8 \mathrm{~mL}$ ) and then DMTr-Cl (501 mg, $1.48 \mathrm{mmol})$ was added to the reaction solution, which resulted in a deep red reaction mixture. TEA $(0.175 \mathrm{~mL})$ was then added to the reaction vessel, the reaction was stirred at rm temp, under argon, and the reaction progress was monitored by normal phase TLC (neutral alumina, $\left.5 \% \mathrm{CH}_{3} \mathrm{OH}: \mathrm{CH}_{2} \mathrm{Cl}_{2}\right)$. TLC confirmed complete consumption of $\mathbf{1 0}(10 \% \mathrm{HCl}$ solution to develop the TLC) indicated by an orange spot on the TLC strip. Once the reaction was complete, methanol $(8 \mathrm{~mL})$ was added to the reaction mixture to destroy the remaining DMTr-Cl. The solvents were removed in vacuo and the product dried in a desiccator $\left(\mathrm{P}_{2} \mathrm{O}_{5}\right)$. Crude $\mathbf{1 5}$ was purified by low pressure column chromatography (neutral alumina, 0-5\% $\left.\mathrm{CH}_{3} \mathrm{OH}: \mathrm{CH}_{2} \mathrm{Cl}_{2}\right)(341 \mathrm{mg}, 0.49$ mmol, $48.5 \%$ yield). 
${ }^{1} \mathrm{H}$ NMR (300 MHz, DMSO-d 6 ): $\delta$ ppm $11.40(1 \mathrm{H}, \mathrm{s}, \mathrm{NH}), 8.30(1 \mathrm{H}, \mathrm{s}, \mathrm{HC}=\mathrm{N}), 7.64(2 \mathrm{H}, \mathrm{d}, J=$ $7.8 \mathrm{~Hz}, \operatorname{aryl}), 7.33(4 \mathrm{H}, \mathrm{m}, \operatorname{aryl} / \mathrm{DMTr}-\mathrm{H}), 7.20-6.72(11 \mathrm{H}, \mathrm{m}, \mathrm{DMTr}-\mathrm{H}), 6.15(1 \mathrm{H}, \mathrm{dd}, J=5.1$, $\left.7.8 \mathrm{~Hz}, \mathrm{H} 1^{\prime}\right), 5.27\left(1 \mathrm{H}, \mathrm{d}, J=5.1 \mathrm{~Hz}, 3^{\prime}-\mathrm{OH}\right), 4.57(1 \mathrm{H}, \mathrm{m}, \mathrm{H} 3$ '), $3.91(1 \mathrm{H}, \mathrm{m}, \mathrm{H} 4$ '), 3.71 and 3.70 (3H each, s, $\left.\mathrm{OCH}_{3}\right), 3.28$ and $3.14(2 \mathrm{H}, \mathrm{m}, \mathrm{H} 5$ '/H5”), 3.21 (1H, m, H2"), 3.02 and 2.97 (3H each, s, $\left.\mathrm{N}\left(\mathrm{CH}_{3}\right)_{2}\right), 2.39\left(3 \mathrm{H}, \mathrm{s}, \mathrm{CH}_{3}\right)$, and $2.16\left(1 \mathrm{H}, \mathrm{m}, \mathrm{H} 2^{\prime}\right)$.

\section{5'-O-(4,4'-Dimethoxytrityl)-N2-(N,N-dimethylformamidine)-8-(4-(TBS-O-methyl)phenyl-} 2'-deoxyguanosine, $\mathbf{C}_{51} \mathbf{H}_{56} \mathrm{O}_{7} \mathbf{N}_{6} \mathrm{Si}$ (16): Compound $\mathbf{1 1}$ (543 mg, $\left.1.0 \mathrm{mmol}\right)$ was dissolved in pyridine $(8 \mathrm{~mL})$ and then $\mathrm{DMTr}-\mathrm{Cl}(501 \mathrm{mg}, 1.48 \mathrm{mmol})$ was added to the reaction solution, which resulted in a deep red reaction mixture. TEA $(0.175 \mathrm{~mL})$ was then added to the reaction vessel, the reaction was stirred at $\mathrm{rm}$ temp, under argon, and the reaction progress was monitored by normal phase TLC (neutral alumina, $5 \% \mathrm{CH}_{3} \mathrm{OH}: \mathrm{CH}_{2} \mathrm{Cl}_{2}$ ). TLC confirmed complete consumption of $\mathbf{1 1}(10 \% \mathrm{HCl}$ solution to develop the TLC) indicated by an orange spot on the TLC strip. Once the reaction was complete, methanol $(8 \mathrm{~mL})$ was added to the reaction mixture to destroy the remaining DMTr-Cl. The solvents were removed in vacuo and the product dried in a desiccator $\left(\mathrm{P}_{2} \mathrm{O}_{5}\right)$. Crude $\mathbf{1 6}$ was purified by low pressure column chromatography (neutral alumina, 0-5\% $\mathrm{CH}_{3} \mathrm{OH}: \mathrm{CH}_{2} \mathrm{Cl}_{2}$ ) (332 mg, $0.32 \mathrm{mmol}, 39.3 \%$ yield).

${ }^{1} \mathrm{H}$ NMR (300 MHz, DMSO-d 6$): \delta$ ppm $11.43(1 \mathrm{H}, \mathrm{s}, \mathrm{NH}), 8.33(1 \mathrm{H}, \mathrm{s}, \mathrm{HC}=\mathrm{N}), 7.75(2 \mathrm{H}, \mathrm{d}, J=$ $7.8 \mathrm{~Hz}, \operatorname{aryl}), 7.48(2 \mathrm{H}, \mathrm{d}, J=7.8 \mathrm{~Hz}, \operatorname{aryl}), 7.35-6.74(13 \mathrm{H}, \mathrm{m}, \mathrm{DMTr}-\mathrm{H}), 6.19(1 \mathrm{H}, \mathrm{t}, J=6.2 \mathrm{~Hz}$ H1'), 5.29 (1H, d, J = $4.7 \mathrm{~Hz}, 3$ '-OH), 4.83 (2H, s, CH $), 4.59$ (1H, m, H3'), 3.94 (1H, m, H4'), 
3.73 and 3.72 ( $3 \mathrm{H}$ each, $\left.\mathrm{s}, \mathrm{OCH}_{3}\right), 3.31$ and 3.17 (2H, m, H5'/H5”), $3.24(1 \mathrm{H}, \mathrm{m}, \mathrm{H} 2 "), 3.05$ and 3.00 (3H each, s, $\left.\mathrm{N}\left(\mathrm{CH}_{3}\right)_{2}\right), 2.19$ (1H, m, H2'), 0.99 (9H, s, t-butyl), and 0.14 (6H, s, dimethylsilyl).

5'-O-(4,4'-Dimethoxytrityl)-N2-(N,N-dimethylformamidine)-8-(4-methoxymethylphenyl)2'-deoxyguanosine, $\mathbf{C}_{42} \mathrm{H}_{44} \mathrm{O}_{7} \mathbf{N}_{6}$ (17): Compound 12 (442 mg, $1.0 \mathrm{mmol}$ ) was dissolved in pyridine ( $8 \mathrm{~mL}$ ) and then DMTr-Cl (501 $\mathrm{mg}, 1.48 \mathrm{mmol})$ was added to the reaction solution, which resulted in a deep red reaction mixture. TEA $(0.175 \mathrm{~mL})$ was then added to the reaction vessel, the reaction was stirred at $\mathrm{rm}$ temp, under argon, and the reaction progress was monitored by normal phase TLC (neutral alumina, $5 \% \mathrm{CH}_{3} \mathrm{OH}: \mathrm{CH}_{2} \mathrm{Cl}_{2}$ ). TLC confirmed complete consumption of $12(10 \% \mathrm{HCl}$ solution to develop the TLC) indicated by an orange spot on the TLC strip. Once the reaction was complete, methanol $(8 \mathrm{~mL})$ was added to the reaction mixture to destroy the remaining DMTr-Cl. The solvents were removed in vacuo and the product dried in a desiccator $\left(\mathrm{P}_{2} \mathrm{O}_{5}\right)$. Crude 17 was purified by low pressure column chromatography (neutral alumina, 0-5\% $\mathrm{CH}_{3} \mathrm{OH}: \mathrm{CH}_{2} \mathrm{Cl}_{2}, 399 \mathrm{mg}, 0.54 \mathrm{mmol}, 53.5 \%$ yield).

${ }^{1} \mathrm{H}$ NMR $\left(300 \mathrm{MHz}, \mathrm{DMSO}-\mathrm{d}_{6}\right): \delta \mathrm{ppm} 11.41(1 \mathrm{H}, \mathrm{s}, \mathrm{NH}), 8.30(1 \mathrm{H}, \mathrm{s}, \mathrm{HC}=\mathrm{N}), 7.74(2 \mathrm{H}, \mathrm{d}, J=$ $8.1 \mathrm{~Hz}, \operatorname{aryl}), 7.33(2 \mathrm{H}, \mathrm{d}, J=8.1 \mathrm{~Hz}, \operatorname{aryl}), 7.33-6.72(13 \mathrm{H}, \mathrm{m}, \mathrm{DMTr}-\mathrm{H}), 6.17(1 \mathrm{H}, \mathrm{dd}, J=5.3$, $8.0 \mathrm{~Hz}, \mathrm{H1}$ '), 5.27 (1H, d, J = 4.8 Hz, 3'-OH), 4.55 (1H, m, H3'), 4.50 (2H, s, $\left.\mathrm{CH}_{2}\right), 3.91$ (1H, m, $\left.\mathrm{H} 4^{\prime}\right), 3.71$ and $3.70\left(3 \mathrm{H}\right.$ each, s, $\left.\mathrm{OCH}_{3}\right), 3.50\left(3 \mathrm{H}, \mathrm{s}, \mathrm{OCH}_{3}\right), 3.30$ and $3.16\left(2 \mathrm{H}, \mathrm{m}, \mathrm{H}{ }^{\prime} / \mathrm{H} 5\right.$ ”), $3.22(1 \mathrm{H}, \mathrm{m}, \mathrm{H} 2 "), 3.03$ and $2.98\left(3 \mathrm{H}\right.$ each, $\left.\mathrm{s}, \mathrm{N}\left(\mathrm{CH}_{3}\right)_{2}\right)$ and $2.17\left(1 \mathrm{H}, \mathrm{m}, \mathrm{H} 2^{\prime}\right)$. 


\section{5'-O-(4,4'-Dimethoxytrityl)-N2-(N,N-dimethylformamidine)-8-(4-carboxyphenyl)-2'-}

deoxyguanosine, $\mathrm{C}_{41} \mathrm{H}_{40} \mathrm{O}_{8} \mathbf{N}_{6}$ (18): Compound 13 (398 $\mathrm{mg}, 1.0 \mathrm{mmol}$ ) was dissolved in pyridine $(8 \mathrm{~mL})$ and then DMTr-Cl (501 mg, $1.48 \mathrm{mmol})$ was added to the reaction solution, which resulted in a deep red reaction mixture. TEA $(0.175 \mathrm{~mL})$ was then added to the reaction vessel, the reaction was stirred at rt, under argon, and the reaction progress was monitored by reverse-phase TLC (C18, $5 \% \mathrm{CH}_{3} \mathrm{OH}: \mathrm{CH}_{2} \mathrm{Cl}_{2}$ ). TLC confirmed complete consumption of $\mathbf{1 3}$ (10\% $\mathrm{HCl}$ solution to develop the TLC) indicated by an orange spot on the TLC strip. Once the reaction was complete, methanol $(8 \mathrm{~mL})$ was added to the reaction mixture to destroy the remaining DMTr-Cl. The solvents were removed in vacuo and the product dried overnight in a desiccator $\left(\mathrm{P}_{2} \mathrm{O}_{5}\right)$. The crude DMTr$8 \mathrm{CPh} 2 \mathrm{dG}$ was suspended in freshly distilled $\mathrm{CH}_{2} \mathrm{Cl}_{2}(100 \mathrm{~mL})$ and stored at $-20{ }^{\circ} \mathrm{C}$ for $24-48 \mathrm{~h}$. The precipitate was isolated via vacuum filtration and the filtrate was stored at $-20{ }^{\circ} \mathrm{C}$ for additional 24h. This process was repeated again to maximize yield of the final DMTr-protected 18 (505 mg, $0.68 \mathrm{mmol}, 67.8 \%$ yield).

${ }^{1} \mathrm{H}$ NMR $\left(300 \mathrm{MHz}, \mathrm{DMSO}-\mathrm{d}_{6}\right): \delta$ ppm $11.46(1 \mathrm{H}, \mathrm{s}, \mathrm{NH}), 8.32(1 \mathrm{H}, \mathrm{s}, \mathrm{HC}=\mathrm{N}), 8.07(2 \mathrm{H}, \mathrm{d}, J=$ 8.3 Hz, aryl), 7.89 (2H, d, $J=8.3 \mathrm{~Hz}$, aryl), 7.33-6.72 (13H, m, DMTr-H), $6.20(1 \mathrm{H}, \mathrm{dd}, J=5.4$, 7.8 Hz, H1'), 5.20 (1H, brs, 3'-OH), 4.59 (1H, m, H3'), 3.92 (1H, m, H4'), 3.71 and 3.70 (3H each, s, $\left.\mathrm{OCH}_{3}\right), 3.30$ and 3.14 (2H, m, H5'/H5”), 3.19 (1H, m, H2”), 3.03 and $\left.2.99(3 \mathrm{H} \text { each, s, N(CH})_{2}\right)$ and $2.20\left(1 \mathrm{H}, \mathrm{m}, \mathrm{H} 2{ }^{\prime}\right)$.

3'-O-[2-Cyanoethoxy)(diisopropylamino)phosphine]-5'-O-(4,4'-dimethoxytrityl)-N2-(N,Ndimethylformamidine)-8-phenyl-2'-deoxyguanosine, $\mathrm{C}_{49} \mathrm{H}_{57} \mathrm{O}_{7} \mathrm{~N}_{8} \mathrm{P}$ (19): Compound 14 (203 
mg, $0.29 \mathrm{mmol})$ was dissolved in $\mathrm{CH}_{2} \mathrm{Cl}_{2}(3 \mathrm{~mL})$ and TEA $(80 \mu \mathrm{L})$ before 2-cyanoethyl diisopropylchlorophosphoramidite (CEDCIP; $65 \mu \mathrm{L}, 0.29 \mathrm{mmol}$ ) was added. The reaction was allowed to stir at rm temp for $30 \mathrm{~min}$ and then another aliquot of CEDCIP (14 $\mu \mathrm{L}, 0.14 \mathrm{mmol})$ was added and stirred for $30 \mathrm{~min}$ at rm temp. The reaction progress was monitored with normal phase TLC (neutral alumina, $5 \% \mathrm{CH}_{3} \mathrm{OH}: \mathrm{CH}_{2} \mathrm{Cl}_{2}$ ) and once TLC indicated complete consumption of 14 the reaction solvents were removed in vacuo. Then, benzene:THF (4:1, $4 \mathrm{~mL})$ was added, briefly mixed, and filtered under argon. The filtrate was concentrated in vacuo in individual vials ( 250 $\mu \mathrm{L} /$ vial) to produce $\mathbf{1 9}$, which is ready for DNA synthesis.

\section{3'-O-[2-Cyanoethoxy)(diisopropylamino)phosphine]-5'-O-(4,4'-dimethoxytrityl)-N2-(N,N-} dimethylformamidine)-8-p-tolyl-2'-deoxyguanosine, $\mathrm{C}_{50} \mathrm{H}_{59} \mathrm{O}_{7} \mathbf{N}_{8} \mathbf{P}$ (20): Compound 15 (207 mg, $0.29 \mathrm{mmol})$ was dissolved in $\mathrm{CH}_{2} \mathrm{Cl}_{2}(3 \mathrm{~mL})$ and TEA $(80 \mu \mathrm{L})$ before 2-cyanoethyl diisopropylchlorophosphoramidite (CEDCIP; $65 \mu \mathrm{L}, 0.29 \mathrm{mmol}$ ) was added. The reaction was allowed to stir at rm temp for $30 \mathrm{~min}$ and then another aliquot of CEDCIP (14 $\mu \mathrm{L}, 0.14 \mathrm{mmol})$ was added and stirred for $30 \mathrm{~min}$ at $\mathrm{rm}$ temp. The reaction progress was monitored with normal phase TLC (neutral alumina, $5 \% \mathrm{CH}_{3} \mathrm{OH}: \mathrm{CH}_{2} \mathrm{Cl}_{2}$ ) and once TLC indicated complete consumption of 15 the reaction solvents were removed in vacuo. Then, benzene:THF (4:1, $4 \mathrm{~mL})$ was added, briefly mixed, and filtered under argon. The filtrate was concentrated in vacuo in individual vials ( 250 $\mu \mathrm{L} / v i a l)$ to produce $\mathbf{2 0}$, which is ready for DNA synthesis.

3'-O-[2-Cyanoethoxy)(diisopropylamino)phosphine]-5'-O-(4,4'-dimethoxytrityl)-N2-(N,Ndimethylformamidine)-8-(4-(TBS-O-methyl)phenyl)-2'-deoxyguanosine, $\quad \mathrm{C}_{56} \mathrm{H}_{73} \mathrm{O}_{8} \mathrm{~N}_{8} \mathrm{SiP}$ 
(21): Compound 16 (245 mg, $0.29 \mathrm{mmol})$ was dissolved in $\mathrm{CH}_{2} \mathrm{Cl}_{2}(3 \mathrm{~mL})$ and TEA ( $\left.80 \mu \mathrm{L}\right)$ before 2-cyanoethyl diisopropylchlorophosphoramidite (CEDCIP; $65 \mu \mathrm{L}, 0.29$ mmol) was added. The reaction was allowed to stir at rm temp for $30 \mathrm{~min}$ and then another aliquot of CEDCIP (14 $\mu \mathrm{L}, 0.14 \mathrm{mmol}$ ) was added and stirred for $30 \mathrm{~min}$ at $\mathrm{rm}$ temp. The reaction progress was monitored with normal phase TLC (neutral alumina, $5 \% \mathrm{CH}_{3} \mathrm{OH}: \mathrm{CH}_{2} \mathrm{Cl}_{2}$ ) and once TLC indicated complete consumption of $\mathbf{1 6}$ the reaction solvents were removed in vacuo. Then, benzene:THF (4:1, $4 \mathrm{~mL})$ was added, briefly mixed, and filtered under argon. The filtrate was concentrated in vacuo in individual vials ( $250 \mu \mathrm{L} /$ vial $)$ to produce $\mathbf{2 1}$, which is ready for DNA synthesis.

\section{3'-O-[2-Cyanoethoxy)(diisopropylamino)phosphine]-5'-O-(4,4'-dimethoxytrityl)-N2-(N,N-} dimethylformamidine)-8-(4-methoxymethylphenyl)-2'-deoxyguanosine, $\mathrm{C}_{49} \mathrm{H}_{57} \mathrm{O}_{7} \mathrm{~N}_{8} \mathrm{P}$ (22): Compound 17 (216 mg, $0.29 \mathrm{mmol})$ was dissolved in $\mathrm{CH}_{2} \mathrm{Cl}_{2}(3 \mathrm{~mL})$ and TEA $(80 \mu \mathrm{L})$ before 2cyanoethyl diisopropylchlorophosphoramidite (CEDCIP; $65 \mu \mathrm{L}, 0.29 \mathrm{mmol}$ ) was added. The reaction was allowed to stir at rm temp for $30 \mathrm{~min}$ and then another aliquot of CEDCIP (14 $\mu \mathrm{L}$, $0.14 \mathrm{mmol}$ ) was added and stirred for $30 \mathrm{~min}$ at $\mathrm{rm}$ temp. The reaction progress was monitored with normal phase TLC (neutral alumina, $5 \% \mathrm{CH}_{3} \mathrm{OH}: \mathrm{CH}_{2} \mathrm{Cl}_{2}$ ) and once TLC indicated complete consumption of $\mathbf{1 7}$ the reaction solvents were removed in vacuo. Then, benzene:THF (4:1, $4 \mathrm{~mL})$ was added, briefly mixed, and filtered under argon. The filtrate was concentrated in vacuo in individual vials ( $250 \mu \mathrm{L} /$ vial) to produce 22 , which is ready for DNA synthesis.

\section{3'-O-[2-Cyanoethoxy)(diisopropylamino)phosphine]-5'-O-(4,4'-dimethoxytrityl)-N2-(N,N- dimethylformamidine)-8-(4-carboxyphenyl)-2'-deoxyguanosine, $\quad \mathrm{C}_{50} \mathrm{H}_{57} \mathrm{O}_{9} \mathrm{~N} 8 \mathrm{P} \quad$ (23):}


Compound $18(216 \mathrm{mg}, 0.29 \mathrm{mmol})$ was suspended in $\mathrm{CH}_{2} \mathrm{Cl}_{2}(3 \mathrm{~mL})$ and TEA $(80 \mu \mathrm{L})$. The addition of 2-cyanoethyl diisopropylchlorophosphoramidite (CEDCIP; $65 \mu \mathrm{L}, 0.29 \mathrm{mmol}$ ) created the reaction solution. The reaction was allowed to stir at $\mathrm{rm}$ temp for $30 \mathrm{~min}$ and then another aliquot of CEDCIP $(14 \mu \mathrm{L}, 0.14 \mathrm{mmol})$ was added and stirred for $30 \mathrm{~min}$ at rm temp. The reaction progress was monitored with reverse phase TLC $\left(\mathrm{C} 18,5 \% \mathrm{CH}_{3} \mathrm{OH}: \mathrm{CH}_{2} \mathrm{Cl}_{2}\right)$ and once TLC indicated complete consumption of $\mathbf{1 8}$ the reaction solvents were removed in vacuo. Then, benzene:THF (4:1, $4 \mathrm{~mL})$ was added, briefly mixed, and filtered under argon. The filtrate was concentrated in vacuo in individual vials $(\sim 250 \mu \mathrm{L} /$ vial $)$ to produce $\mathbf{2 3}$, which is ready for DNA synthesis.

\section{B. Synthesis, Purification and Structure Confirmation of Hairpin Oligonucleotides}

\section{General}

The unmodified hairpin oligonucleotide $\mathrm{dG}$ (HP-CG) and modified hairpin

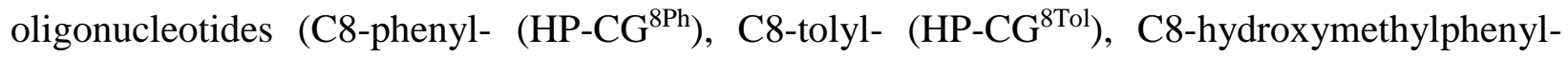

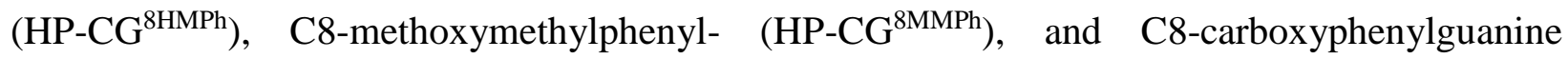
$\left(\mathrm{HP}-\mathrm{CG}^{8 \mathrm{CPh}}\right)$ ) were synthesized on an ABI-394 DNA synthesizer (Foster City, CA). DNA synthesizer phosphoramidites (dG CE-PA, dC CE-PA and dT CE-PA) and CPG (dG, $1 \mu \mathrm{mol}, 500$

$\AA$ A pore size) columns were purchased from Glen Research (Sterling, VA). DNA synthesizer reagents: phosphoramidite diluent (anhydrous $\mathrm{ACN}$ ), activator (0.45 M tetrazole in $\mathrm{ACN})$, cap mix A (THF, pyridine, and acetic anhydride), cap mix B (16\% 1-methylimidazole in THF), oxidizing solution (0.02 $\mathrm{M} \mathrm{I}_{2}$ in THF, pyridine, and water), and deblocking mix (3\% 
trichloroacetic acid (TCA) in $\mathrm{CH}_{2} \mathrm{Cl}_{2}$ ) were also purchased from Glen Research. Anhydrous acetonitrile (4 L) was purchased from Fisher Scientific (Waltham, MA).

The FPLC system used in the purification of the synthetic hairpin oligonucleotides employed a Waters U6K loop injector, HPLC 510 pump, and a 2487 dual absorbance detector (Milford, MA). The anion exchange columns (DEAE-5PW) were purchased from Tosoh Bioscience (Montgomeryville, PA). Maxi-Clean ${ }^{\mathrm{TM}}$ reversed-phase solid phase extraction (SPE) cartridges were purchased from Fisher Scientific (Waltham, MA). The amount of hairpin oligonucleotide in the crude and purified samples were quantified using a Beckman DU640 spectrophotometer (Somerset, NJ) and the OD, measured at $260 \mathrm{~nm}$, was converted into a concentration using OligoCalc. ${ }^{161}$ ESI-MS spectra were recorded on a Q-Exactive (Thermo Scientific, West Palm Beach, FL).

\section{DNA Synthesis}

The hairpin oligonucleotides (unmodified and modified) were synthesized on a $1 \mu \mathrm{mol}$ scale. Reagents were used according to the shelf life specified by the ABI DNA synthesizer manual. DNA synthesis is performed 3' to 5' and therefore the C8-aryl-2'-deoxyguanine modified base was located closer to the 5'-end of the hairpin sequence $\left(\mathrm{d}\left(5^{\prime}-\right.\right.$ CGCGCG $^{*}$ CGCGTTTTCGCGCGCGCG-3' $\left.\left.^{\prime}\right)\right)$ to minimize exposure of the C8-aryl-2'-deoxyguanine modified base to TCA, used in the detritylation step in base extension. In general, the synthesis followed standard protocols for the $1.0 \mu \mathrm{M} \mathrm{CE}$ cycle using the four major steps of detritylation, coupling, capping, and oxidation (see Scheme 2.3). The major exception here is the C8-aryl-2'-deoxyguanine modified base was manually coupled to the growing 
oligonucleotide chain because the C8-aryl-2'-deoxyguanine phosphoramidites form insoluble gels, rapidly, after dissolution with ACN.

Compounds 19 - 23 were used to make HP-CG ${ }^{8 \mathrm{Ph}}, \mathrm{HP}-\mathrm{CG}^{8 \mathrm{Tol}}, \mathrm{HP}-\mathrm{CG}^{8 \mathrm{HMPh}}, \mathrm{HP}-\mathrm{CG}^{8 \mathrm{MMPh}}$, or $\mathrm{HP}-\mathrm{CG}^{8 \mathrm{CPh}}$, respectively. After detritylation of the $3^{\prime}-\mathrm{dC}$ base $\left(\mathrm{C}_{7}, 18^{\text {th }}\right.$ base $)$ the synthesizer was paused and the column was removed from the DNA synthesizer and sealed with Luer-Lok (3 $\mathrm{mL}$ ) syringes, previously purged with argon to prevent the exposure of the growing oligonucleotide chain to air or moisture. Using a $1 \mathrm{~mL}$ syringe, the activator solution $(100 \mu \mathrm{L})$ was placed in the Luer-Lok fitting above the dG CPG synthesis column. The C8-aryl-2'deoxyguanine modified phosphoramidites $(15-25 \mathrm{mg}, 15-25 \mu \mathrm{mol})$ were dissolved in anhydrous ACN $(100 \mu \mathrm{L})$, drawn up into a $1 \mathrm{~mL}$ syringe, and then fitted to the bottom Luer-Lok fitting below the dG-CPG synthesis column. The activator solution was pushed through the synthesis column into the $\mathrm{C} 8$-arylguaine phosphoramidite solution, briefly mixed, before returning the solution back into the CPG column. The C8-aryl-2'-deoxyguanine solution is mixed repeatedly back and forth (above and below) through the CPG column by pushing and pulling the top and bottom syringes connected to the CPG column. This process was repeated 3 times every 5 min ( 15 min total) for the first addition of the C8-aryl-2'-deoxyguanine phosphoramidite. After 15 min, the solution was removed and the CPG column was washed with fresh activator $(0.5 \mathrm{~mL})$. Then fresh activator $(100 \mu \mathrm{L})$ was placed above the column in a $1 \mathrm{~mL}$ syringe and the second addition of modified phosphoramidite $(15-25 \mathrm{mg}, 15-25 \mu \mathrm{mol})$ was dissolved in anhydrous ACN $(100 \mu \mathrm{L})$, drawn up into a $1 \mathrm{~mL}$ syringe, and fitted below the CPG column. Again the activator is pushed through the CPG column to the phosphoramidite solution below the column, mixed, and the activated phosphoramidite solution is added back to the CPG column. The solution is repeatedly mixed above and below the column before allowing to remain in the column for $5 \mathrm{~min}$ and the process is 
repeated three more times ( $15 \mathrm{~min}$ total). After the reaction is complete, the phosphoramidite solution is removed from the column the column is washed and rinsed with fresh anhydrous ACN ( $1 \mathrm{~mL}$ ) before returning the column back to the DNA synthesizer. Once placed back on the DNA synthesizer the coupling steps are skipped resuming with the capping step in the DNA synthetic cycle.

Once DNA synthesis is complete, the hairpin oligonucleotides are cleaved from the CPG column using ammonium hydroxide $\left(30 \% \mathrm{NH}_{3}, 1 \mathrm{~mL}\right)$. Cleavage occurs by pushing the ammonium hydroxide $(0.3 \mathrm{~mL})$ from syringe above the $\mathrm{CPG}$ column into the syringe below the column every $20 \mathrm{~min}(1 \mathrm{~h}$ total). The cleaved oligonucleotides were transferred to a centrifuge tube and deprotected by heating the ammonium hydroxide solution at $55^{\circ} \mathrm{C}$ overnight $(\leq 18 \mathrm{~h})$. After deprotection, the centrifuge tube is cooled to rm temp and then concentrated to dryness in the SpeedVac ${ }^{\mathrm{TM}}$ to yield the crude hairpin oligonucleotide.

\section{FPLC Purification}

The crude hairpin oligonucleotides contain unwanted products which are mainly incomplete oligonucleotide sequences but may also contain residual protecting groups that will confound the conformational analysis experiments (Figure 3.1). Therefore, all of the hairpin oligonucleotides require purification before characterization and conformational analysis. The crude hairpins (100 OD) were dissolved in deionized (DI) water (500 $\mu \mathrm{L})$ and purified using a gradient of 50\%-80\% mobile phase B over 30 min (mobile phase: A: $10 \mathrm{mM} \mathrm{NaOH}$, mobile phase B: $10 \mathrm{mM} \mathrm{NaOH} / 1 \mathrm{M} \mathrm{NaCl}$ ) at a flow rate of $6 \mathrm{~mL} / \mathrm{min}$ on the DEAE-5PW preparative column (21.5 mm ID x $15 \mathrm{~cm})$. Oligonucleotide separation was monitored by UV detection at $260 \mathrm{~nm}$ and 
the major peaks of the crude solution were collected (Figure 3.2). The majority of the time the signal that gives the largest absorbance is the desired sequence of interest.

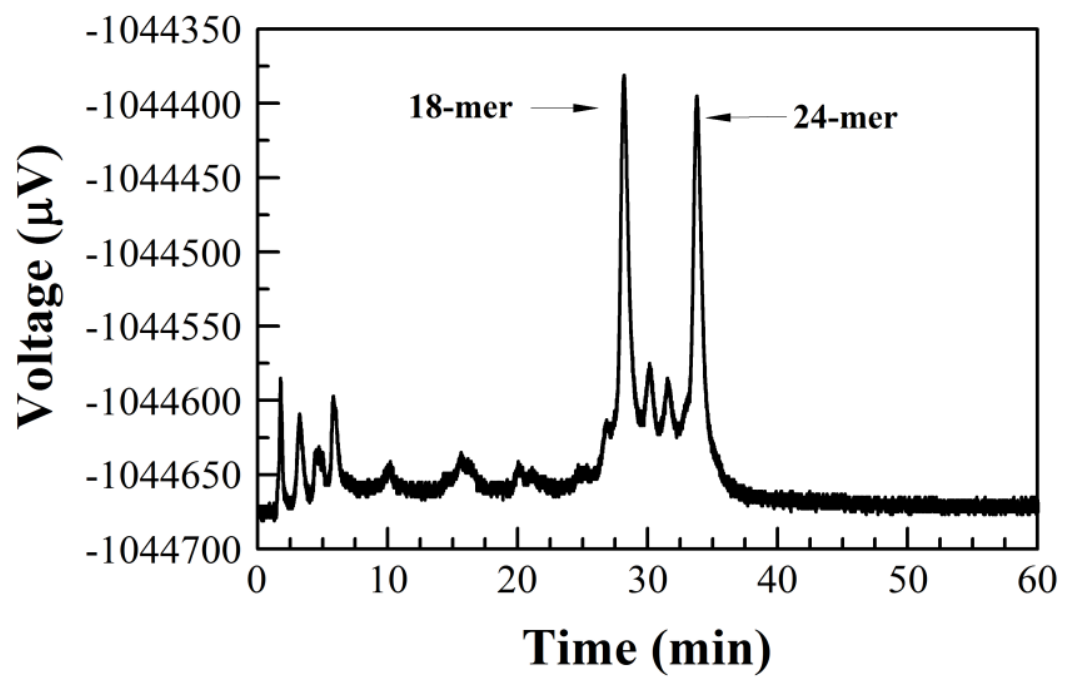

Figure 3.1. FPLC chromatogram of the $\mathrm{HP}-\mathrm{CG}^{8 \mathrm{Ph}}$ hairpin oligonucleotide before purification. 


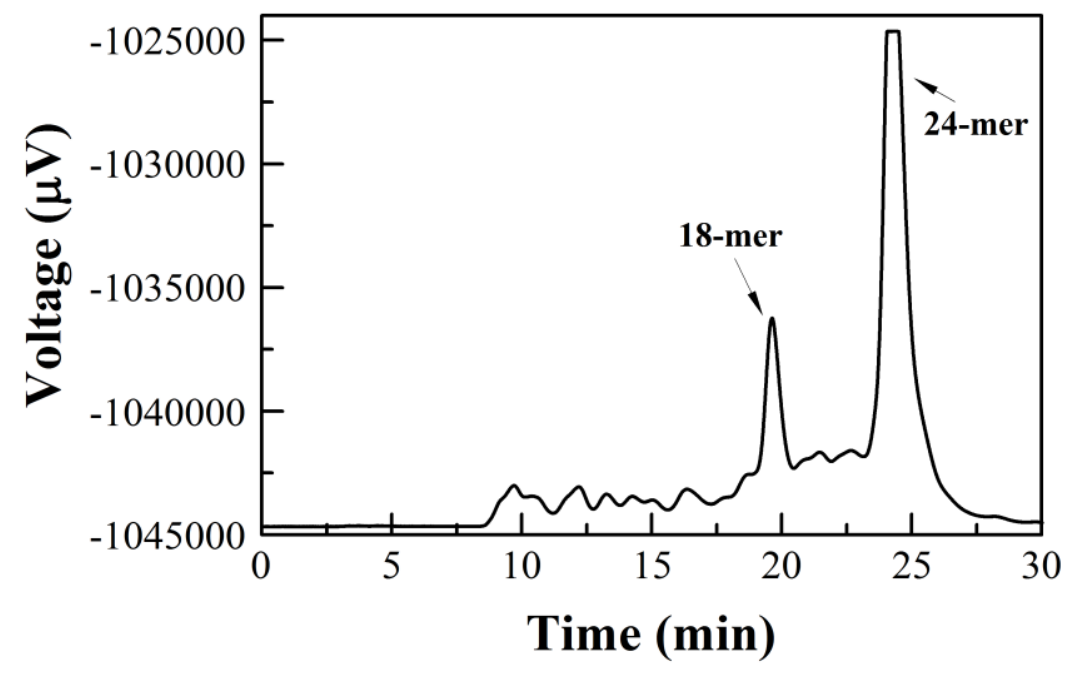

Figure 3.2. FPLC chromatogram of the HP-CG ${ }^{8 \mathrm{Ph}}$ oligonucleotide purification run.

After purification, the collected fractions need to be desalted to remove the salt used in the mobile phase. The fractions were desalted using C18 SPE cartridges rinsed with methanol (6 mL) and then conditioned with water $(6 \mathrm{~mL})$. The desired fraction was loaded on the SPE under conditions where the hairpin oligonucleotide is absorbed to the $\mathrm{C} 18$ packing material and the sodium chloride is not. The SPE was washed with water $(6 \mathrm{~mL})$ to rinse off the salts, and the hairpin oligonucleotide was eluted from the SPE cartridge using aqueous methanol $(60 \%, 4 \times 1.5$ $\mathrm{mL}$ ). The samples were concentrated to dryness in a SpeedVac ${ }^{\mathrm{TM}}$ to give the pure hairpin oligonucleotide.

The success of the purification was confirmed by FPLC using an analytical DEAE-5PW column $(5.0 \mathrm{~mm} \mathrm{ID} \times 5 \mathrm{~cm})$. The major objective of this experiment is to demonstrate that the purified hairpin oligonucleotide sample contains a single peak in the FPLC chromatogram. The hairpin sample ( $\sim$ OD in deionized water) was injected into the FPLC and run using a gradient 
of $30-90 \%$ mobile phase $\mathrm{B}$ over 30 or $60 \mathrm{~min}$. The existence of a single peak in the chromatogram verifies that there was only one oligonucleotide species detected in the purified sample solution (Figure 3.3). The retention times of all the hairpin oligonucleotides are presented in Table 3.1 and the FPLC chromatograms for the purified hairpin oligonucleotides are presented in Appendix C.

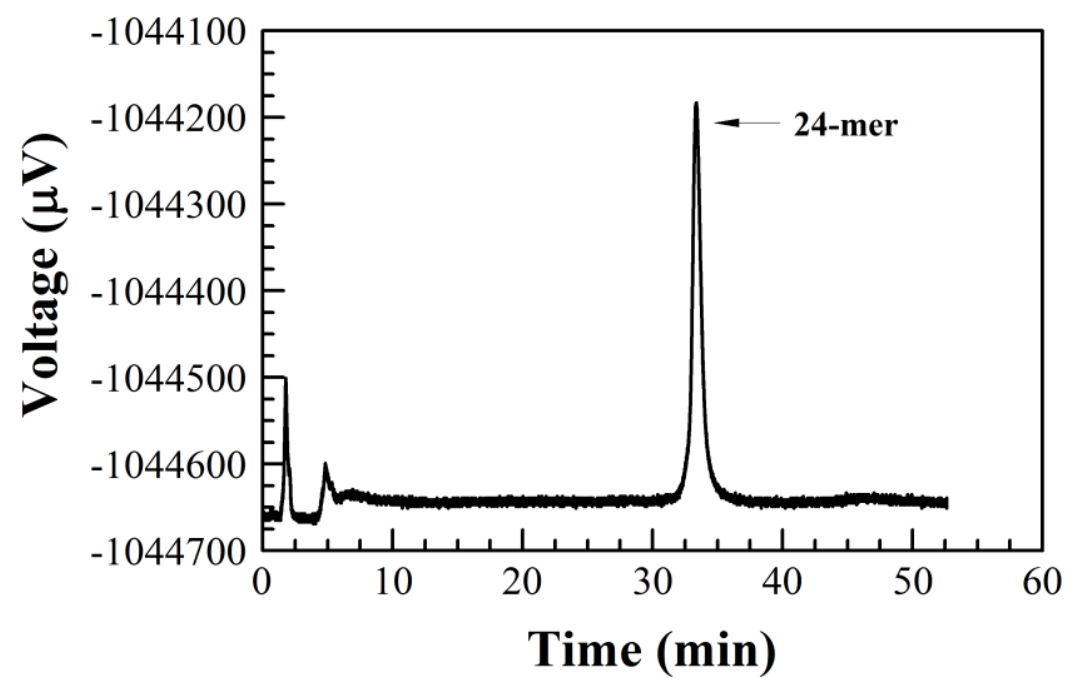

Figure 3.3. FPLC chromatogram of the $\mathrm{HP}-\mathrm{CG}^{8 \mathrm{Ph}}$ after purification. 
Table 3.1. FPLC Analysis of Hairpin Oligonucleotides ${ }^{\mathrm{a}}$

\begin{tabular}{|c|c|}
\hline Oligonucleotide & Retention Time (min) \\
\hline HP-CG & 18.68 \\
\hline HP-CG ${ }^{8 P h}$ & 19.16 \\
\hline HP-CG ${ }^{8 T o l}$ & 19.64 \\
\hline HP-CG ${ }^{8 H M P h}$ & 19.37 \\
\hline HP-CG ${ }^{8 M M P h}$ & 19.37 \\
\hline HP-CG ${ }^{8 \mathrm{CPh}}$ & 20.20 \\
\hline
\end{tabular}

${ }^{a}$ Retention time determined using FPLC gradient $30-90 \%$ mobile phase B over $30 \mathrm{~min}$ at $1 \mathrm{~mL} / \mathrm{min}$.

\section{ESI-MS Analysis}

The FPLC analysis is consistent with the hairpin oligonucleotide samples containing a single molecule but do not unequivocally confirm the identity of the DNA synthesis and purification products. Therefore, the purified synthetic hairpin oligonucleotides was verified using by ESI-MS in negative ion mode. Before analysis, however, samples were further desalted using Poly-Pak (Glen Research) C18 SPE cartridges. The SPE cartridges were rinsed with ACN (2 mL) and conditioned with triethylammonium acetate (TEAA; $2 \mathrm{~mL}, 2 \mathrm{M}$ ). Then the hairpin oligonucleotides are loaded onto the SPE column in water $(<50$ OD). The SPE column was washed with TEAA $(3 \mathrm{~mL}, 0.1 \mathrm{M})$ and then the oligonucleotides were eluted with $50 \%$ aqueous ACN $(1 \mathrm{~mL})$. The samples were concentrated to dryness in a SpeedVac ${ }^{\mathrm{TM}}$. The desalted oligonucleotide samples $(25 \mu \mathrm{M})$ were dissolved in ammonium acetate $(300 \mu \mathrm{M})$ in methanol and water (1:1). Samples were analyzed via direct injection of solution of the oligonucleotide at a rate of $5 \mu \mathrm{L} / \mathrm{min}$ and with a scan range of $600-2,000 \mathrm{~m} / \mathrm{z}$. Spectra were consistent with the desired 
products (< $0.01 \%$ error), which confirms the synthesis of the C8-arylguanine hairpin oligonucleotides (Table 3.2). ESI-MS spectra for all the hairpin oligonucleotides are displayed in Appendix C.

Table 3.2 Comparison of calculated and observed $\mathrm{m} / \mathrm{z}$ values for hairpin oligonucleotides

\begin{tabular}{|l|c|c|c|}
\hline Hairpin & MW (g/mol) & Calculated $^{\mathbf{a}}$ & Observed $^{\mathbf{b}}$ \\
\hline CG & 7338.7 & $916.3,814.4,732.8,666.2$ & $916.3,814.5,732.7,666.0$ \\
\hline CG $^{\text {8Ph }}$ & 7414.8 & $925.8,822.9,740.5,673.1$ & $925.8,822.8,740.4,673.0$ \\
\hline CG $^{\mathbf{8 T o l}}$ & 7428.8 & $927.6,824.4,741.9,674.3$ & $927.5,824.3,741.8,674.3$ \\
\hline CG $^{\text {8MMPh }}$ & 7458.9 & $931.4,827.8,744.9,677.1$ & $931.2,827.8,744.8,677.0$ \\
\hline CG $^{\text {8HMPh }}$ & 7444.8 & $929.6,826.2,743.5,675.8$ & $929.4,826.1,743.4,675.7$ \\
\hline CG $^{\text {8CPh }}$ & 7458.8 & $931.4,827.8,744.9,677.1$ & $931.3,827.8,744.8,677.0$ \\
\hline
\end{tabular}

${ }^{a}$ Molecular weights calculated based on $\mathrm{M}^{-8}, \mathrm{M}^{-9}, \mathrm{M}^{-10}$, and $\mathrm{M}^{-11}$ charge state.

${ }^{b}$ Molecular weights observed based on the charge state corresponding $\mathrm{M}^{-8}, \mathrm{M}^{-9}, \mathrm{M}^{-10}$, and $\mathrm{M}^{-11}$. 


\section{Part II: Conformational Analysis of C8-Arylyguanine Modified Hairpin Oligonucleotides by Circular Dichroism}

After the hairpin oligonucleotide (unmodified and C8-arylguanine modified) had been synthesized, purified and the structures confirmed, the hairpin oligonucleotides were analyzed using circular dichroism (CD) and nuclear magnetic resonance spectroscopy (NMR) (see Part III). Using these two techniques, the conformational preferences of the single $\mathrm{C} 8$-arylguanine modified hairpin oligonucleotides, in comparison to the unmodified hairpin oligonucleotide were determined, as a function of variety of sample conditions. This section will focus on the CD experiments. In addition, the conformational effects of a single or double modified oligonucleotides will be compared and this will be presented in the Discussion section.

Previous work in our group has demonstrated that the $\mathrm{C} 8$-aryguanine modifications shift the B-/Z-DNA equilibrium toward the Z-DNA conformation. ${ }^{98,100}$ Our previous studies examined $\mathrm{d}\left(\mathrm{CGCGCG}\right.$ (CGCG) sequences where $\mathbf{G}^{*}$ is the $\mathrm{C} 8$-arylguanine modified base $\left(\mathrm{G}^{8 \mathrm{Ph}}, \mathrm{G}^{8 \mathrm{Tol}}\right.$, $\mathrm{G}^{8 \mathrm{HMPh}}, \mathrm{G}^{8 \mathrm{MMPh}}$, or $\left.\mathrm{G}^{8 \mathrm{CPh}}\right)$. Since the previous oligonucleotides are palindromes, the resulting duplex structure contains two modified bases and, therefore, it was unclear whether the two modified bases produced conformational effects independent of one another or if the effects were additive or synergistic. To clarify this ambiguity, hairpin oligonucleotides can be designed to contain the $\mathrm{d}(\mathrm{CG})_{5}$ structure correspond to the ds-DNA, and synthesized to contain only one modified base since they are derived from one DNA strand. Finally the original duplex oligonucleotides were analyzed by $\mathrm{CD}$ and NMR and the same techniques were used here and the data used to compare the conformational effects between one and two C8-arylguanine modified bases. 


\section{A. CD Measurement of the Hairpin Oligonucleotides}

\section{General}

$\mathrm{CD}$ of the hairpin oligonucleotide samples $(25 \mu \mathrm{M})$ of $\mathrm{HP}-\mathrm{CG}, \mathrm{HP}-\mathrm{CG}^{8 \mathrm{Ph}}, \mathrm{HP}-\mathrm{CG}^{8 \mathrm{Tol}}$, HP$\mathrm{CG}^{8 \mathrm{HMPh}}, \mathrm{HP}-\mathrm{CG}^{8 \mathrm{MMPh}}$, and $\mathrm{HP}-\mathrm{CG}^{8 \mathrm{CPh}}$ were acquired in sodium phosphate $(10 \mathrm{mM}, \mathrm{pH} 7.0)$ as a function of sodium chloride $(0-4000 \mathrm{mM})$ and temperature $\left(0-99{ }^{\circ} \mathrm{C}\right)$ or on oligonucleotide solutions $(25 \mu \mathrm{M})$ in physiological salt conditions ( $\mathrm{pH} 7.4)$ : $\mathrm{NaCl}(10 \mathrm{mM}), \mathrm{KCl}(140 \mathrm{mM}), \mathrm{MgCl}_{2}$ (2 or $10 \mathrm{mM}$ ) with or without spermine $(1 \mathrm{mM})$. Hairpin oligonucleotides were annealed at $90{ }^{\circ} \mathrm{C}$ for 5 min then slowly cooled to rt over $1.5 \mathrm{~h}$. CD spectra were acquired on hairpin oligonucleotide samples using a Jasco J-810 spectropolarimeter (Easton, MD) and data were smoothed using the Jasco Spectra Analysis software. CD spectra were measured from 350 to $220 \mathrm{~nm}$ using the continuous scanning mode $(50 \mathrm{~nm} / \mathrm{min})$. In addition, the CD spectra were recorded with a band width of $1 \mathrm{~nm}$, a response rate of $1 \mathrm{sec}$ and at a data pitch of $1 \mathrm{~nm}$. CD data are reported as an average of triplicate experiments. CD spectra obtained as function of salt concentration and temperature were acquired using a temperature pitch of $1{ }^{\circ} \mathrm{C} / \mathrm{min}$.

\section{Wavelength Scans}

$\mathrm{CD}$ is an excellent technique to distinguish between the tertiary structures of B- and Z-DNA. The CD spectrum of B-DNA exhibits positive ellipticity at approximately $280 \mathrm{~nm}$ and negative ellipticity at approximately $250 \mathrm{~nm}$. The CD spectrum of Z-DNA exhibits negative ellipticity at approximately $295 \mathrm{~nm}$ and positive ellipticity at approximately $250 \mathrm{~nm}$. The CD spectra of the unmodified hairpin and the C8-arylguanine modified hairpin oligonucleotides were

acquired at $37^{\circ} \mathrm{C}$ at various sodium chloride concentrations (0, 25, 50, 100, 250, 500, 1000, 2000 
and $4000 \mathrm{mM}$ ) are presented in Figures 3.4-3.9. At low salt concentrations the B-DNA conformation is the predominant form in solution, however as the salt concentration is increased the amount Z-DNA also increases.

The CD results here with the hairpin oligonucleotides are in good agreement with our previous studies ${ }^{98,100}$ as well as other studies with CG oligomers ${ }^{12}$ and hairpins. ${ }^{114}$ The unmodified hairpin (Figure 3.4) transition from B-DNA to Z-DNA between $2 \mathrm{M} \mathrm{NaCl}$ and $4 \mathrm{M} \mathrm{NaCl}$ whereas the $\mathrm{C} 8$-arylguanine modified hairpins require significantly less $\mathrm{NaCl}$ for the $\mathrm{Z}$ form to become predominant. The CD spectra for HP-CG ${ }^{8 \mathrm{Ph}}$ (Figure 3.5), $\mathrm{HP}_{-\mathrm{CG}}{ }^{8 \mathrm{Tol}}$ (Figure 3.6), HP-CG ${ }^{8 \mathrm{HMPh}}$ (Figure 3.7), $\mathrm{HP}-\mathrm{CG}^{8 \mathrm{MMPh}}$ (Figure 3.8), and $\mathrm{HP}-\mathrm{CG}^{8 \mathrm{CPh}}$ (Figure 3.9) indicate that the transition from B-DNA to Z-DNA occurs between $500-1000 \mathrm{mM} \mathrm{NaCl}$. The $\mathrm{CD}$ at a single temperature with varying $\mathrm{NaCl}$ concentrations demonstrate the $\mathrm{C} 8$-arylguanine modified hairpins shift the $\mathrm{B}$ /Z-DNA equilibrium toward the Z-DNA conformation better than the unmodified hairpin. However, to make a quantitative comparison between the hairpin oligonucleotides or with the double-stranded oligonucleotides, the mole fractions must be calculated (see Chapter 2.F.1). 


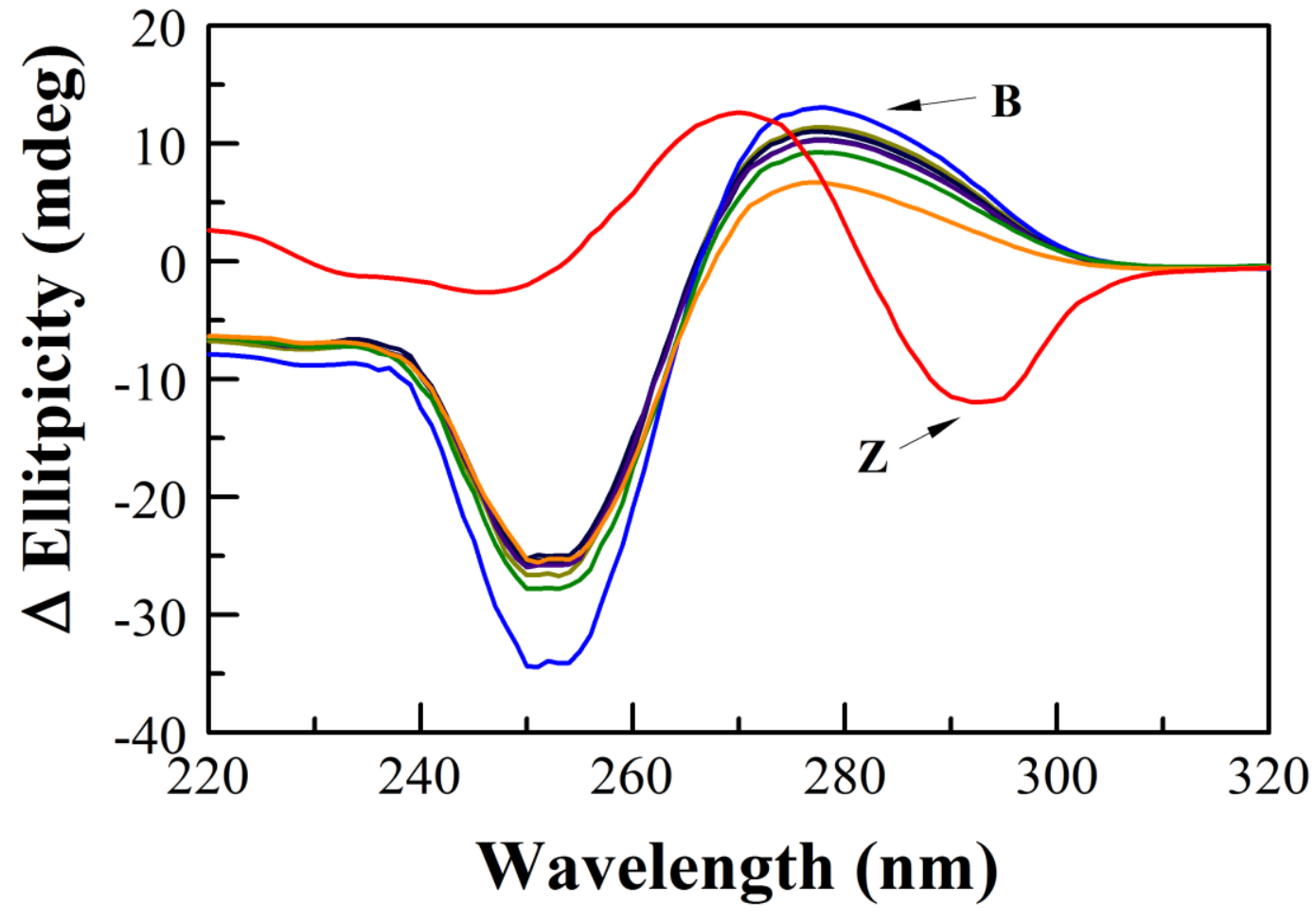

Figure 3.4. CD spectra of HP-CG with 0 (black), 25 (gold), 50 (violet), 100 (light blue), 250 (indigo), 500 (blue), 1000 (green), 2000 (orange), and 4000 (red) $\mathrm{mM} \mathrm{NaCl}$ at $37^{\circ} \mathrm{C}$. 


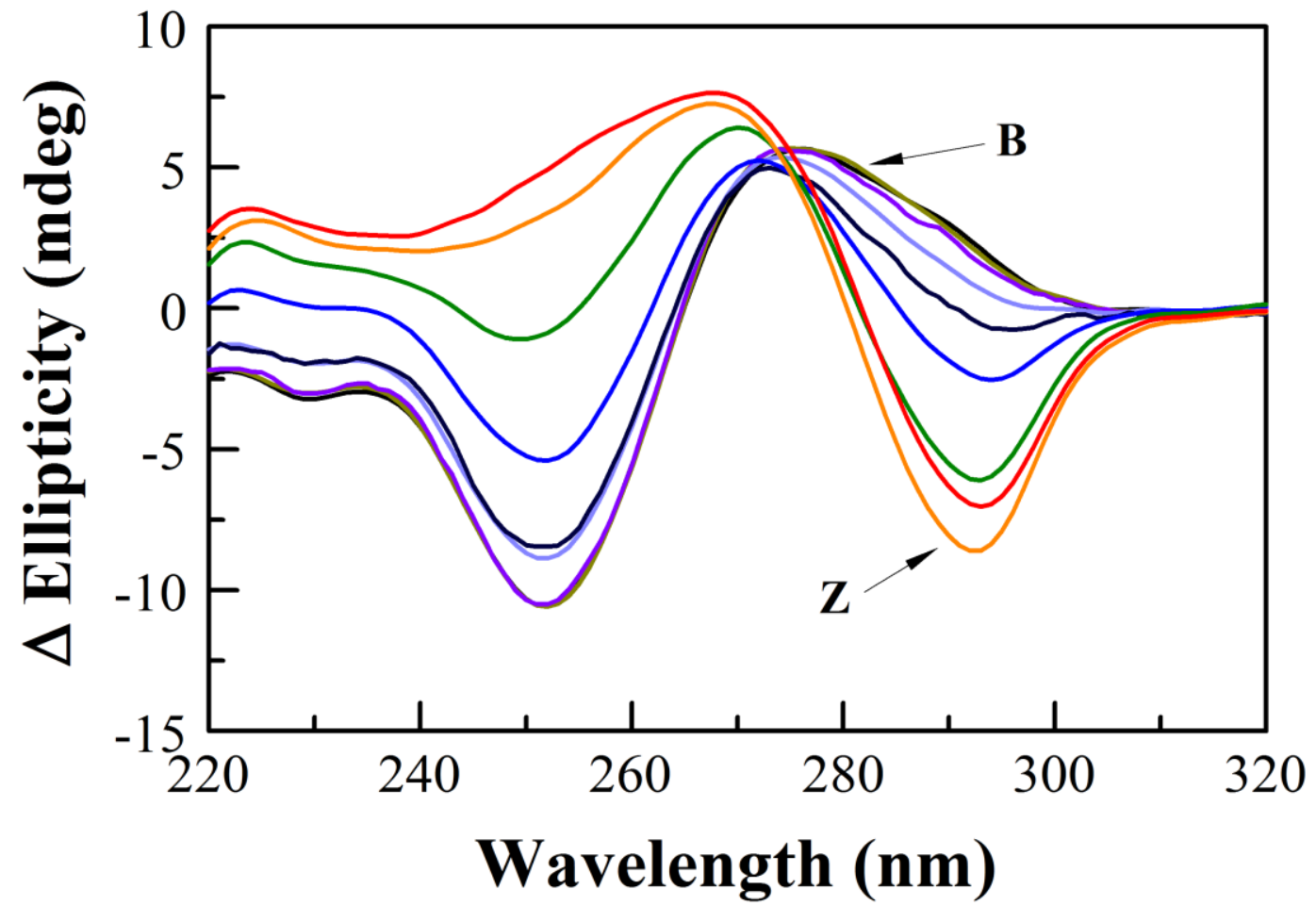

Figure 3.5. CD spectra of HP-CG ${ }^{8 \mathrm{Ph}}$ with 0 (black), 25 (gold), 50 (violet), 100 (light blue), 250 (indigo), 500 (blue), 1000 (green), 2000 (orange), and 4000 (red) $\mathrm{mM} \mathrm{NaCl}$ at $37^{\circ} \mathrm{C}$. 


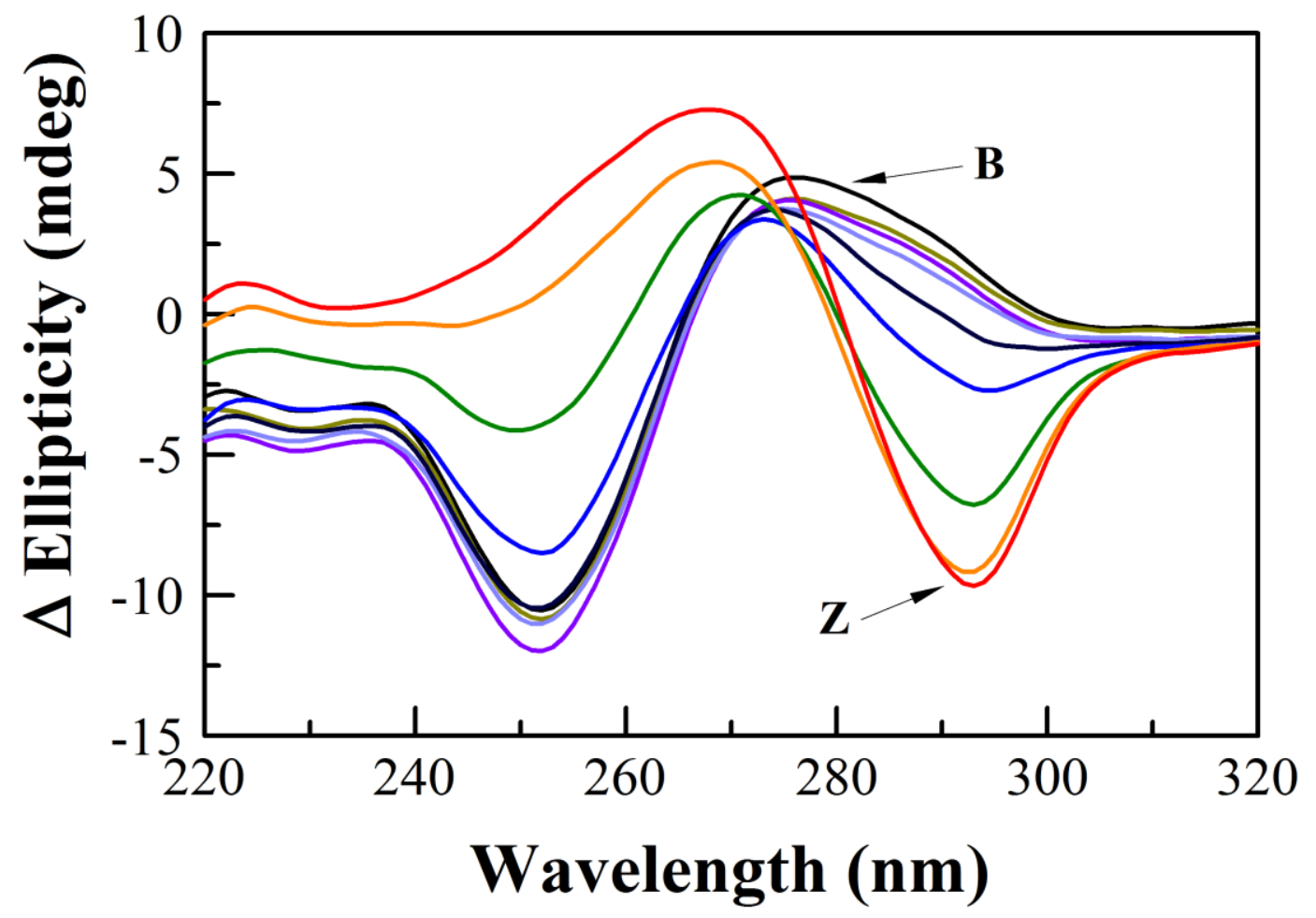

Figure 3.6. CD spectra of $\mathrm{HP}-\mathrm{CG}^{8 \mathrm{Tol}}$ with 0 (black), 25 (gold), 50 (violet), 100 (light blue), 250 (indigo), 500 (blue), 1000 (green), 2000 (orange), and 4000 (red) $\mathrm{mM} \mathrm{NaCl}$ at $37^{\circ} \mathrm{C}$. 


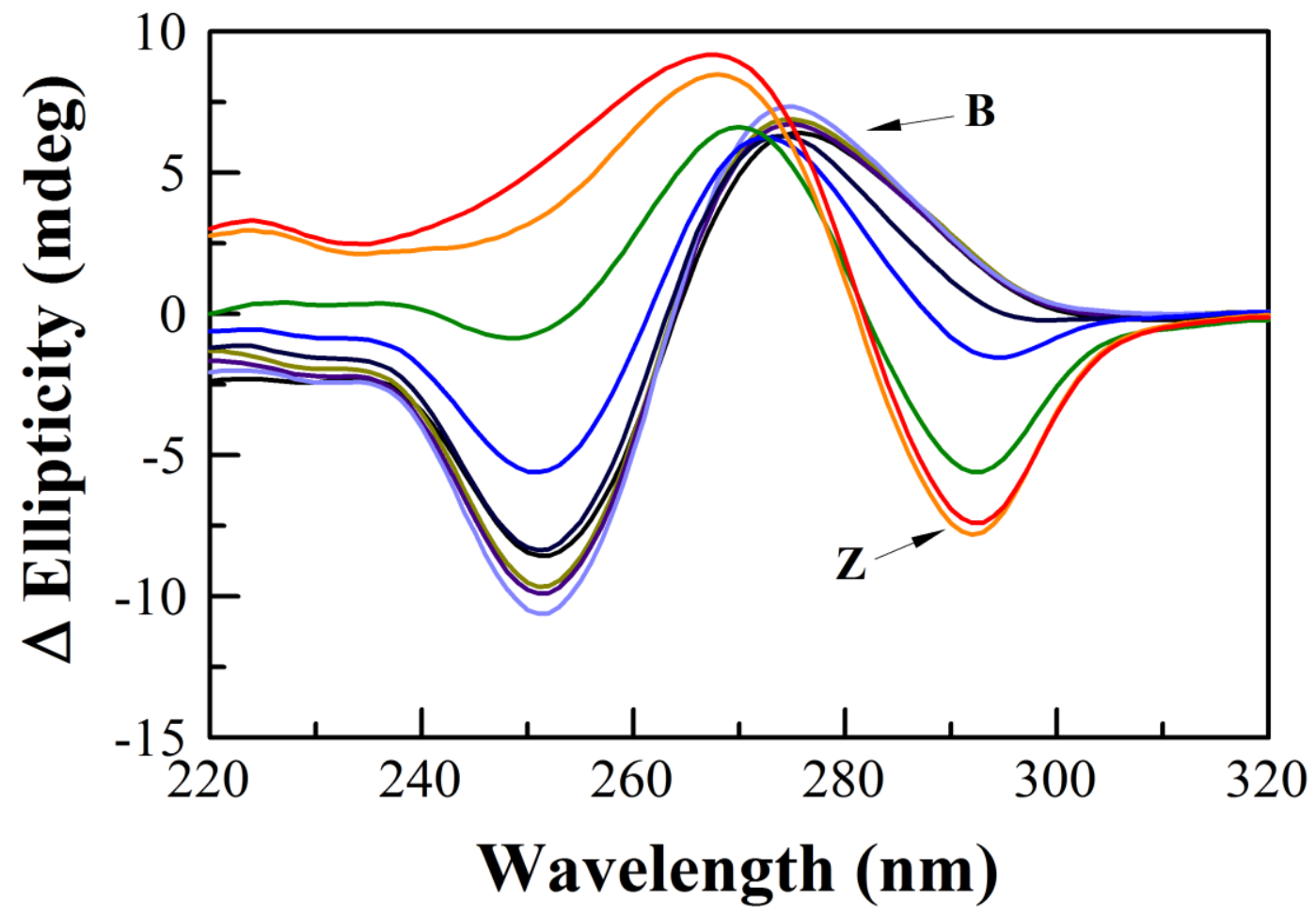

Figure 3.7. CD spectra of HP-CG ${ }^{8 H M P h}$ with 0 (black), 25 (gold), 50 (violet), 100 (light blue), 250 (indigo), 500 (blue), 1000 (green), 2000 (orange), and 4000 (red) $\mathrm{mM} \mathrm{NaCl}$ at $37^{\circ} \mathrm{C}$. 


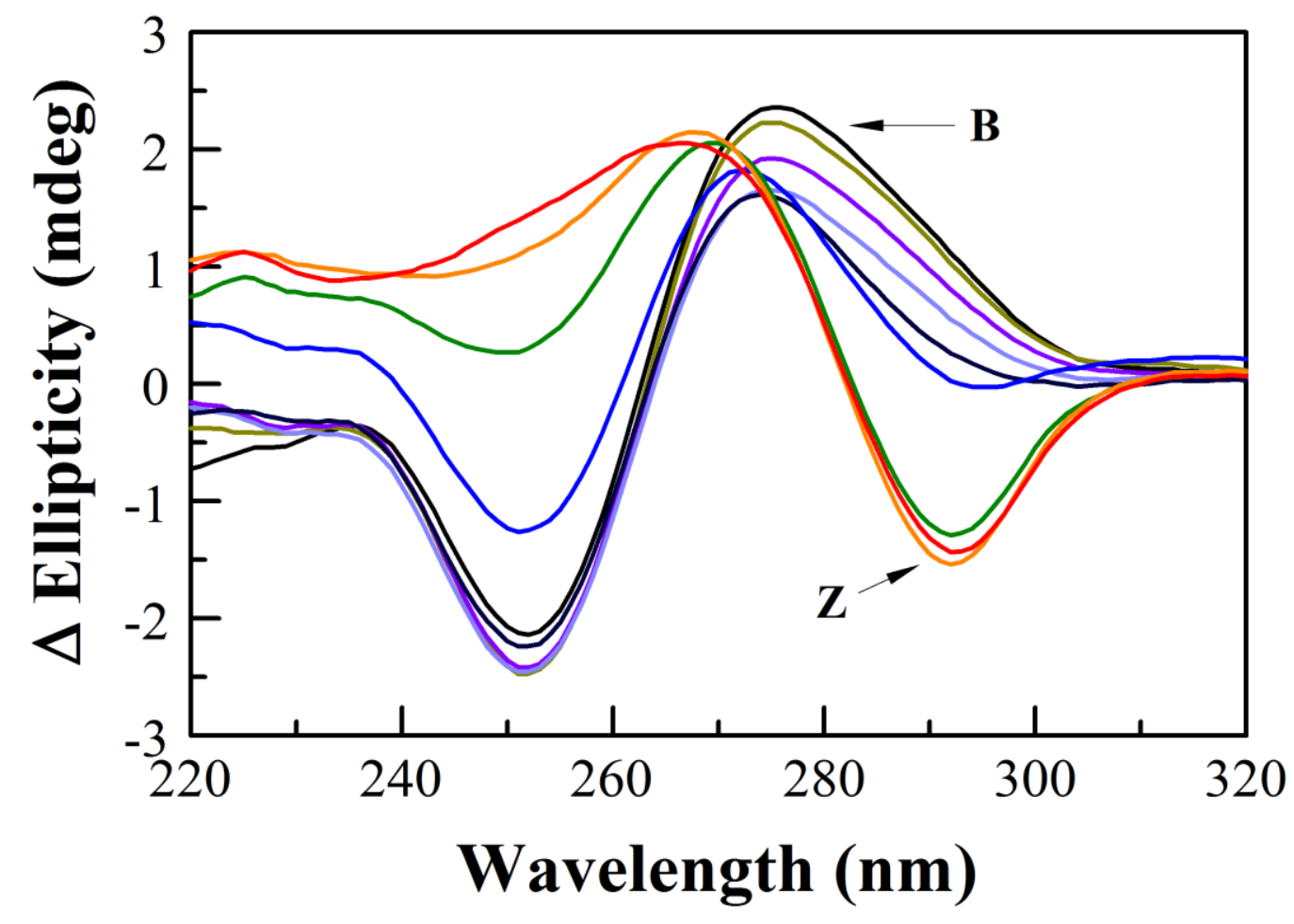

Figure 3.8. CD spectra of HP-CG ${ }^{8 \mathrm{MMPh}}$ with 0 (black), 25 (gold), 50 (violet), 100 (light blue), 250 (indigo), 500 (blue), 1000 (green), 2000 (orange), and 4000 (red) $\mathrm{mM} \mathrm{NaCl}$ at $37^{\circ} \mathrm{C}$. 


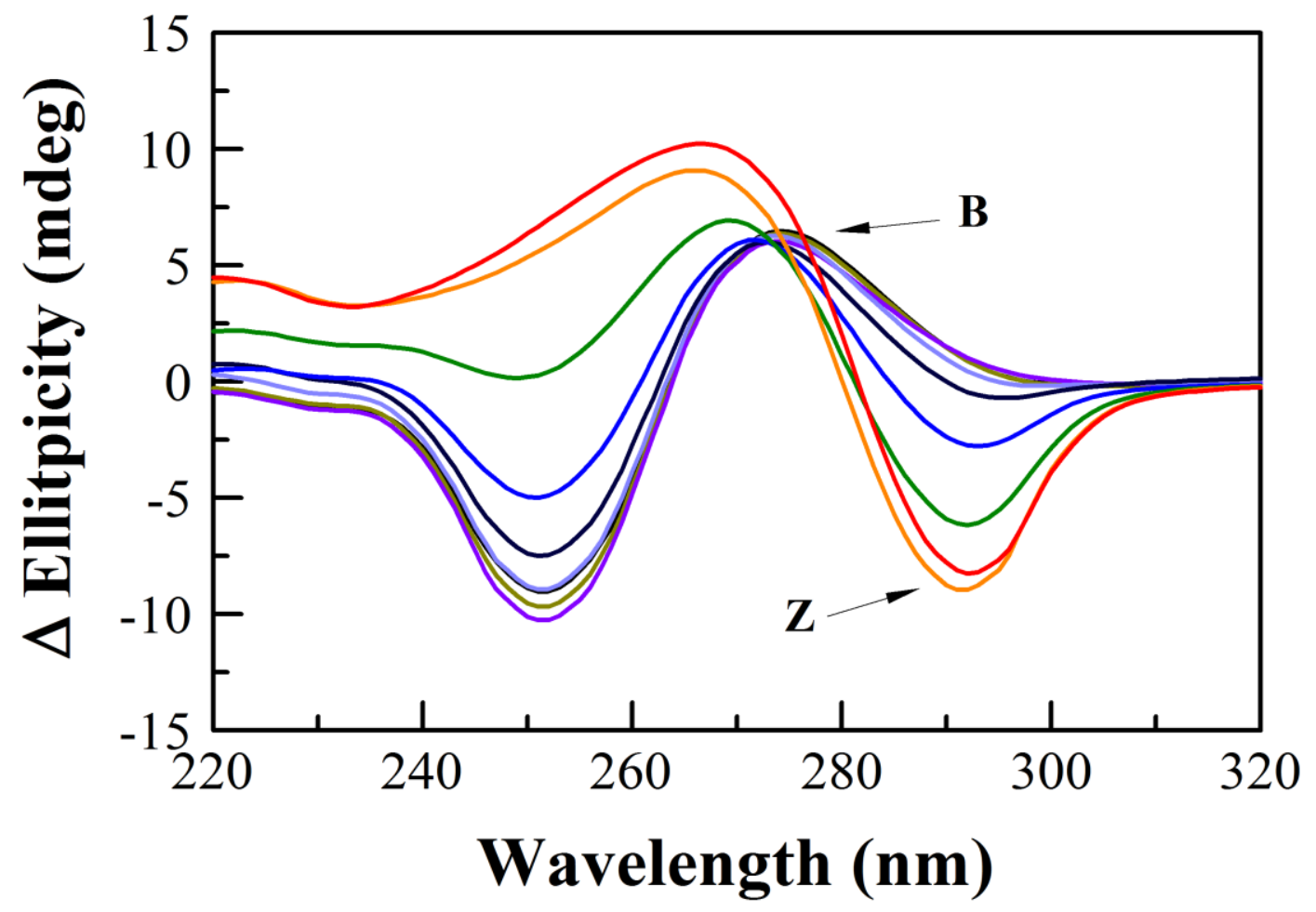

Figure 3.9. CD spectra of $\mathrm{HP}-\mathrm{CG}^{8 \mathrm{CPh}}$ with 0 (black), 25 (gold), 50 (violet), 100 (light blue), 250 (indigo), 500 (blue), 1000 (green), 2000 (orange), and 4000 (red) $\mathrm{mM} \mathrm{NaCl}$ at $37^{\circ} \mathrm{C}$. 


\section{Mole Fraction Calculations and Z-DNA Quantitation}

When $\mathrm{CD}$ spectra are acquired using variable $\mathrm{NaCl}$ concentrations and variable temperatures, along with the assumption that the only conformations of DNA in solution are B-, Z-, and ss-DNA and that they are rapidly equilibrating, the mole fractions of each can be determined. ${ }^{117}$ The approach utilizes eqs 3.1 and 3.2:

$$
\begin{gathered}
\Delta \varepsilon^{295}=\Delta \varepsilon_{\mathrm{B}}{ }^{295}{ }^{29} f_{\mathrm{B}}+\Delta \varepsilon_{\mathrm{Z}}{ }^{295} * f_{\mathrm{Z}}+\Delta \varepsilon_{\mathrm{SS}}{ }^{295} * f_{\mathrm{SS}} \\
1=f_{\mathrm{B}}+f_{\mathrm{Z}}+f_{\mathrm{SS}}
\end{gathered}
$$

where $f$ is the mole fraction of one of the three possible oligonucleotide conformations and $\Delta \varepsilon$ is the corresponding ellipticity of the oligonucleotide in that particular conformation. The $\Delta \varepsilon$ values corresponding to each of the three possible conformations were estimated from CD data obtained at a) low salt at room temperature $\left(30^{\circ} \mathrm{C}\right)\left(\Delta \varepsilon_{\mathrm{B}}\right)$, b) high salt and low temperature $\left(10^{\circ} \mathrm{C}\right)\left(\Delta \varepsilon_{\mathrm{Z}}\right)$, and c) low salt and high temperature $\left(99^{\circ} \mathrm{C}\right)\left(\Delta \varepsilon_{\mathrm{ss}}\right)$. An isosbestic point was observed at $274 \mathrm{~nm}$ corresponding to the case where $\Delta \varepsilon$ for the $\mathrm{B}$ and $\mathrm{Z}$ forms are equal and therefore $f_{\mathrm{B}}+f_{\mathrm{Z}}=f_{\mathrm{ds}}$. Thus, $f_{\mathrm{ss}}$ could be determined using equations 3.3 and 3.4 and then $f_{\mathrm{B}}$ and $f_{\mathrm{Z}}$ were solved from equations $3.1,3.2$, and $f_{\mathrm{ss}}$.

$$
\begin{gathered}
\Delta \varepsilon^{274}=\Delta \varepsilon_{\mathrm{ds}}^{274 *} f_{\mathrm{ds}}+\Delta \varepsilon_{\mathrm{ss}}^{274 *} f_{\mathrm{ss}} \\
1=f_{\mathrm{ds}}+f_{\mathrm{ss}}
\end{gathered}
$$


The $f_{\mathrm{B}}, f_{\mathrm{Z}}$, and $f_{\mathrm{SS}}$ for all the hairpin oligonucleotides are shown in Tables 3.3-3.8. The data in these tables were used to generate the mole fraction plots (Figure 3.10-3.15). The mole fraction plots were consistent with the known behavior of DNA where the B-DNA conformation is predominate at low salt concentrations and elevated temperatures while the Z-DNA conformation is favored at high salt concentrations and lower temperatures. As the temperature increases the BDNA or ss-DNA form is favored. Depending on the particular temperature in relation to the melting temperature $\left(\mathrm{T}_{\mathrm{M}}\right)$ either the B-DNA or ss-DNA will predominate. 
Table 3.3. Mole fractions of B-DNA, Z-DNA, and ss-DNA of HP-CG with $0-4000 \mathrm{mM} \mathrm{NaCl}$ at temperatures $10-99{ }^{\circ} \mathrm{C}$.

\begin{tabular}{|c|c|c|c|c|c|c|c|c|c|c|}
\hline \multirow{2}{*}{$\begin{array}{l}\mathrm{NaCl} \\
(\mathrm{mM})\end{array}$} & \multicolumn{10}{|c|}{$f_{\mathrm{B}}$ at temperature $\left({ }^{\circ} \mathrm{C}\right)$} \\
\hline & 10 & 20 & 30 & 37 & $\mathbf{5 0}$ & 60 & $\mathbf{7 0}$ & 80 & 90 & 99 \\
\hline $\mathbf{0}$ & 1.00 & 1.00 & 1.00 & 0.97 & 0.91 & 0.87 & 0.76 & 0.59 & 0.07 & 0.00 \\
\hline 25 & 1.00 & 0.96 & 0.91 & 0.90 & 0.82 & 0.80 & 0.70 & 0.59 & 0.25 & 0.00 \\
\hline 50 & 1.00 & 0.95 & 0.88 & 0.88 & 0.83 & 0.81 & 0.73 & 0.66 & 0.34 & 0.00 \\
\hline 100 & 1.00 & 0.95 & 0.89 & 0.91 & 0.83 & 0.84 & 0.78 & 0.72 & 0.46 & 0.00 \\
\hline 250 & 0.98 & 0.91 & 0.86 & 0.81 & 0.76 & 0.72 & 0.63 & 0.57 & 0.37 & 0.00 \\
\hline 500 & 0.96 & 0.90 & 0.83 & 0.80 & 0.80 & 0.78 & 0.71 & 0.59 & 0.40 & 0.00 \\
\hline 1000 & 1.00 & 0.94 & 0.83 & 0.81 & 0.73 & 0.78 & 0.62 & 0.53 & 0.36 & 0.00 \\
\hline 2000 & 0.89 & 0.86 & 0.83 & 0.78 & 0.75 & 0.74 & 0.69 & 0.55 & 0.36 & 0.00 \\
\hline 4000 & 0.00 & 0.06 & 0.12 & 0.14 & 0.21 & 0.29 & 0.32 & 0.31 & 0.19 & 0.00 \\
\hline \multirow{2}{*}{$\begin{array}{l}\mathrm{NaCl} \\
(\mathrm{mM})\end{array}$} & \multicolumn{10}{|c|}{$f \mathrm{z}$ at temperature $\left({ }^{\circ} \mathrm{C}\right)$} \\
\hline & 10 & 20 & 30 & 37 & 50 & 60 & 70 & 80 & 90 & 99 \\
\hline 0 & 0.00 & 0.00 & 0.00 & 0.00 & 0.00 & 0.00 & 0.00 & 0.00 & 0.03 & 0.00 \\
\hline 25 & 0.00 & 0.00 & 0.00 & 0.00 & 0.00 & 0.00 & 0.00 & 0.00 & 0.00 & 0.00 \\
\hline 50 & 0.00 & 0.00 & 0.01 & 0.00 & 0.00 & 0.00 & 0.00 & 0.00 & 0.00 & 0.00 \\
\hline 100 & 0.00 & 0.00 & 0.00 & 0.00 & 0.00 & 0.00 & 0.00 & 0.00 & 0.00 & 0.00 \\
\hline 250 & 0.02 & 0.02 & 0.01 & 0.02 & 0.00 & 0.00 & 0.00 & 0.00 & 0.00 & 0.00 \\
\hline 500 & 0.04 & 0.02 & 0.01 & 0.00 & 0.00 & 0.00 & 0.00 & 0.01 & 0.00 & 0.00 \\
\hline 1000 & 0.00 & 0.00 & 0.04 & 0.02 & 0.02 & 0.04 & 0.01 & 0.01 & 0.00 & 0.00 \\
\hline 2000 & 0.11 & 0.10 & 0.08 & 0.09 & 0.07 & 0.05 & 0.04 & 0.04 & 0.02 & 0.00 \\
\hline 4000 & 1.00 & 0.92 & 0.82 & 0.77 & 0.71 & 0.59 & 0.51 & 0.39 & 0.24 & 0.00 \\
\hline \multirow{2}{*}{$\begin{array}{l}\mathrm{NaCl} \\
(\mathrm{mM})\end{array}$} & \multicolumn{10}{|c|}{$f_{\text {SS }}$ at temperature $\left({ }^{\circ} \mathrm{C}\right)$} \\
\hline & 10 & 20 & 30 & 37 & 50 & 60 & 70 & 80 & 90 & 99 \\
\hline $\mathbf{0}$ & 0.00 & 0.00 & 0.00 & 0.03 & 0.09 & 0.13 & 0.24 & 0.41 & 0.90 & 1.00 \\
\hline 25 & 0.00 & 0.04 & 0.09 & 0.10 & 0.18 & 0.20 & 0.30 & 0.41 & 0.75 & 1.00 \\
\hline 50 & 0.00 & 0.05 & 0.11 & 0.12 & 0.17 & 0.19 & 0.27 & 0.34 & 0.66 & 1.00 \\
\hline 100 & 0.00 & 0.05 & 0.11 & 0.09 & 0.17 & 0.16 & 0.22 & 0.28 & 0.54 & 1.00 \\
\hline 250 & 0.00 & 0.07 & 0.14 & 0.17 & 0.25 & 0.28 & 0.37 & 0.43 & 0.63 & 1.00 \\
\hline 500 & 0.00 & 0.08 & 0.16 & 0.20 & 0.20 & 0.22 & 0.29 & 0.40 & 0.60 & 1.00 \\
\hline 1000 & 0.00 & 0.06 & 0.12 & 0.18 & 0.25 & 0.02 & 0.37 & 0.47 & 0.64 & 1.00 \\
\hline 2000 & 0.00 & 0.05 & 0.10 & 0.13 & 0.18 & 0.21 & 0.28 & 0.42 & 0.62 & 1.00 \\
\hline 4000 & 0.00 & 0.02 & 0.06 & 0.09 & 0.08 & 0.12 & 0.17 & 0.30 & 0.56 & 1.00 \\
\hline
\end{tabular}


A)

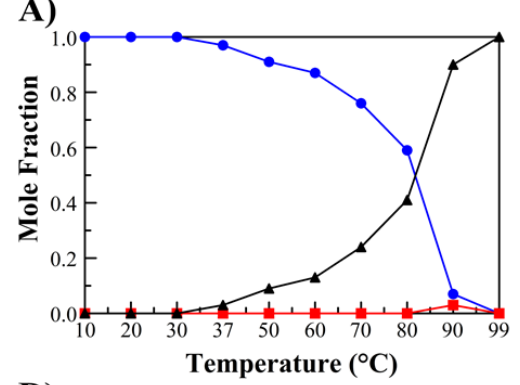

D)
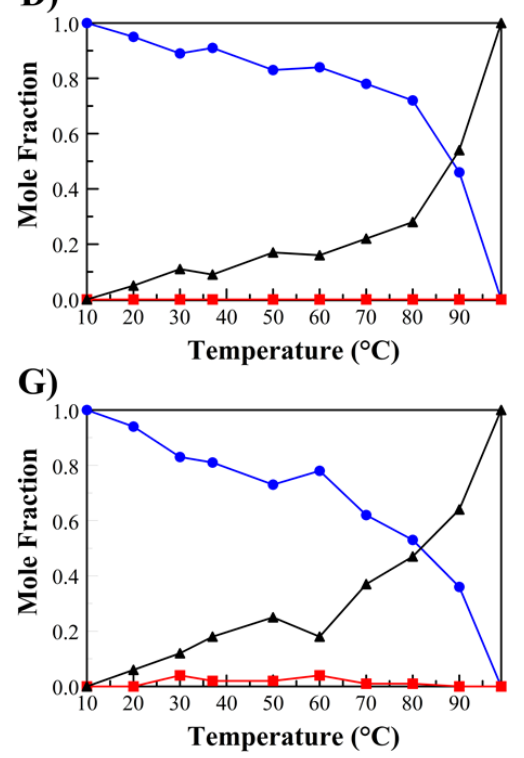

B)

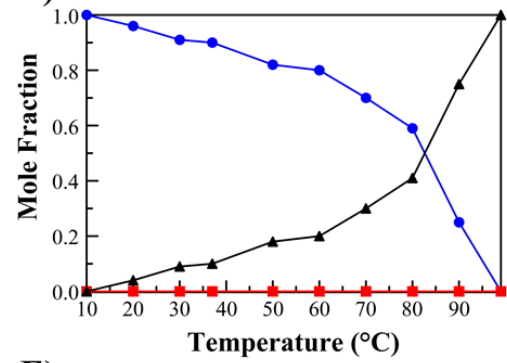

E)

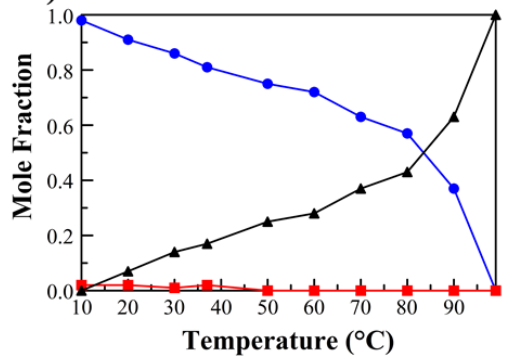

H)

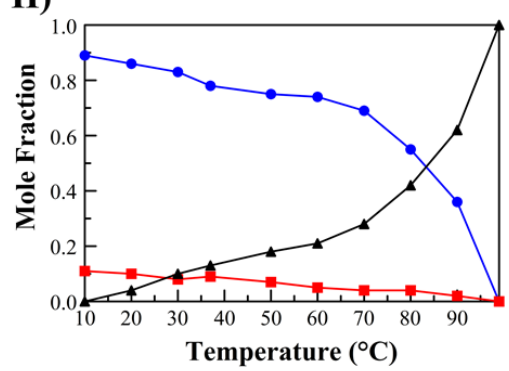

C)

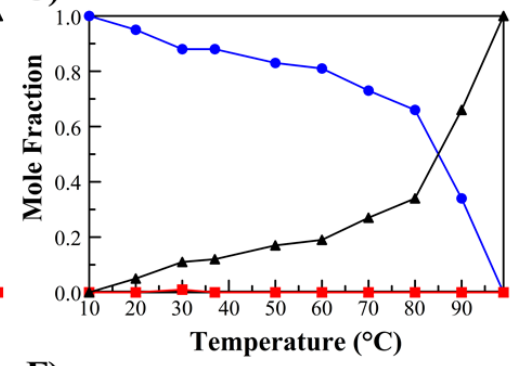

F)

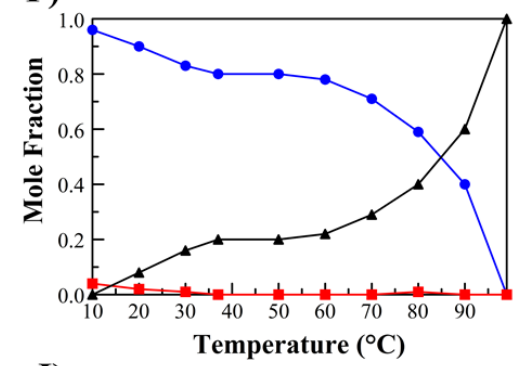

I)

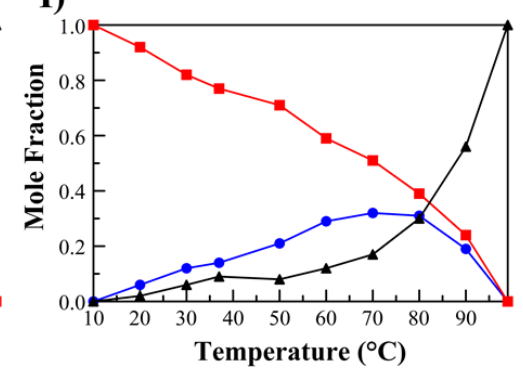

Figure 3.10. Mole fraction plots of the HP-CG calculated at 0, 25, 50, 100, 250, 500, 1000, 2000, and $4000 \mathrm{mM}$ $\mathrm{NaCl}$ (A-I) over $10-99{ }^{\circ} \mathrm{C}$. B-DNA is displayed in the blue circles, Z-DNA in red squares and ss-DNA in black triangles. 
Table 3.4. Mole fractions of B-DNA, Z-DNA, and ss-DNA of HP-CG ${ }^{8 \mathrm{Ph}}$ with $0-4000 \mathrm{mM}$ $\mathrm{NaCl}$ at temperatures $10-99{ }^{\circ} \mathrm{C}$.

\begin{tabular}{|c|c|c|c|c|c|c|c|c|c|c|}
\hline \multirow{2}{*}{$\begin{array}{l}\mathrm{NaCl} \\
(\mathrm{mM})\end{array}$} & \multicolumn{10}{|c|}{$f_{\mathrm{B}}$ at temperature $\left({ }^{\circ} \mathrm{C}\right)$} \\
\hline & 10 & 20 & 30 & 37 & 50 & 60 & $\mathbf{7 0}$ & 80 & 90 & 99 \\
\hline 0 & 0.96 & 0.93 & 0.89 & 0.85 & 0.76 & 0.66 & 0.38 & 0.11 & 0.02 & 0.00 \\
\hline 25 & 1.00 & 0.96 & 0.91 & 0.87 & 0.77 & 0.70 & 0.51 & 0.21 & 0.05 & 0.00 \\
\hline 50 & 0.98 & 0.96 & 0.92 & 0.87 & 0.85 & 0.78 & 0.60 & 0.28 & 0.05 & 0.00 \\
\hline 100 & 0.94 & 0.88 & 0.85 & 0.85 & 0.83 & 0.80 & 0.63 & 0.26 & 0.04 & 0.00 \\
\hline 250 & 0.94 & 0.88 & 0.82 & 0.80 & 0.71 & 0.61 & 0.51 & 0.32 & 0.09 & 0.00 \\
\hline 500 & 0.70 & 0.71 & 0.73 & 0.75 & 0.76 & 0.75 & 0.69 & 0.46 & 0.14 & 0.00 \\
\hline 1000 & 0.17 & 0.24 & 0.30 & 0.37 & 0.46 & 0.54 & 0.51 & 0.46 & 0.16 & 0.00 \\
\hline 2000 & 0.00 & 0.00 & 0.02 & 0.05 & 0.11 & 0.14 & 0.20 & 0.18 & 0.08 & 0.00 \\
\hline 4000 & 0.00 & 0.00 & 0.03 & 0.07 & 0.08 & 0.13 & 0.14 & 0.09 & 0.01 & 0.00 \\
\hline \multirow{2}{*}{$\begin{array}{l}\mathrm{NaCl} \\
(\mathrm{mM})\end{array}$} & \multicolumn{10}{|c|}{$f \mathrm{z}$ at temperature $\left({ }^{\circ} \mathrm{C}\right)$} \\
\hline & 10 & 20 & 30 & 37 & 50 & 60 & 70 & 80 & 90 & 99 \\
\hline 0 & 0.04 & 0.01 & 0.00 & 0.00 & 0.00 & 0.00 & 0.00 & 0.00 & 0.01 & 0.00 \\
\hline 25 & 0.00 & 0.00 & 0.00 & 0.00 & 0.00 & 0.00 & 0.00 & 0.00 & 0.00 & 0.00 \\
\hline 50 & 0.02 & 0.01 & 0.01 & 0.00 & 0.00 & 0.00 & 0.00 & 0.00 & 0.00 & 0.00 \\
\hline 100 & 0.06 & 0.04 & 0.02 & 0.00 & 0.00 & 0.00 & 0.00 & 0.00 & 0.01 & 0.00 \\
\hline 250 & 0.06 & 0.04 & 0.03 & 0.02 & 0.00 & 0.00 & 0.00 & 0.00 & 0.00 & 0.00 \\
\hline 500 & 0.30 & 0.25 & 0.20 & 0.15 & 0.11 & 0.05 & 0.00 & 0.00 & 0.00 & 0.00 \\
\hline 1000 & 0.83 & 0.76 & 0.69 & 0.61 & 0.50 & 0.40 & 0.28 & 0.14 & 0.03 & 0.00 \\
\hline 2000 & 1.00 & 0.99 & 0.93 & 0.91 & 0.83 & 0.76 & 0.63 & 0.47 & 0.18 & 0.00 \\
\hline 4000 & 1.00 & 1.00 & 0.96 & 0.90 & 0.87 & 0.77 & 0.70 & 0.56 & 0.33 & 0.00 \\
\hline \multirow{2}{*}{$\begin{array}{l}\mathrm{NaCl} \\
(\mathrm{mM})\end{array}$} & \multicolumn{10}{|c|}{ fss at temperature $\left({ }^{\circ} \mathrm{C}\right)$} \\
\hline & 10 & 20 & 30 & 37 & 50 & 60 & 70 & 80 & 90 & 99 \\
\hline $\mathbf{0}$ & 0.00 & 0.06 & 0.11 & 0.15 & 0.24 & 0.34 & 0.62 & 0.89 & 0.97 & 1.00 \\
\hline 25 & 0.00 & 0.04 & 0.09 & 0.13 & 0.23 & 0.30 & 0.49 & 0.79 & 0.95 & 1.00 \\
\hline 50 & 0.00 & 0.03 & 0.08 & 0.13 & 0.15 & 0.22 & 0.40 & 0.72 & 0.95 & 1.00 \\
\hline 100 & 0.00 & 0.08 & 0.13 & 0.15 & 0.17 & 0.20 & 0.37 & 0.75 & 0.95 & 1.00 \\
\hline 250 & 0.00 & 0.08 & 0.15 & 0.18 & 0.29 & 0.39 & 0.49 & 0.68 & 0.91 & 1.00 \\
\hline 500 & 0.00 & 0.04 & 0.07 & 0.09 & 0.13 & 0.20 & 0.30 & 0.54 & 0.87 & 1.00 \\
\hline 1000 & 0.00 & 0.00 & 0.01 & 0.02 & 0.04 & 0.06 & 0.21 & 0.41 & 0.80 & 1.00 \\
\hline 2000 & 0.00 & 0.01 & 0.04 & 0.04 & 0.06 & 0.10 & 0.18 & 0.35 & 0.74 & 1.00 \\
\hline 4000 & 0.00 & 0.00 & 0.01 & 0.03 & 0.05 & 0.11 & 0.16 & 0.36 & 0.66 & 1.00 \\
\hline
\end{tabular}


A)

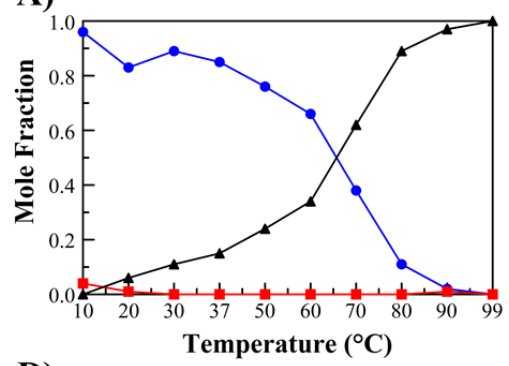

D)

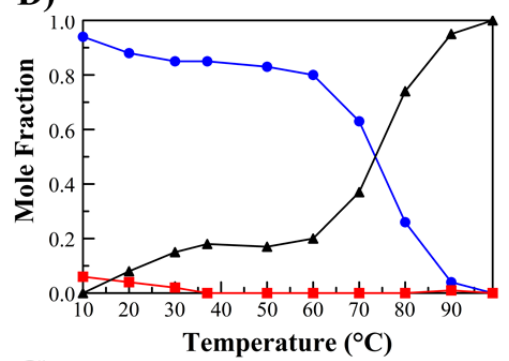

G)

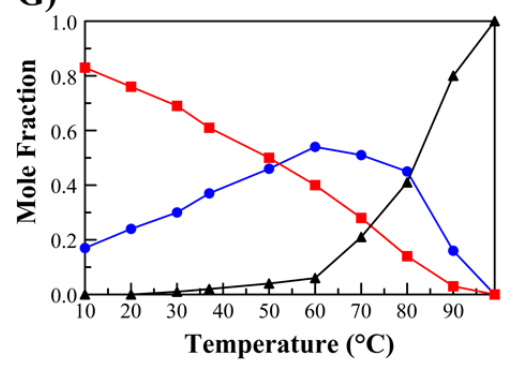

B)

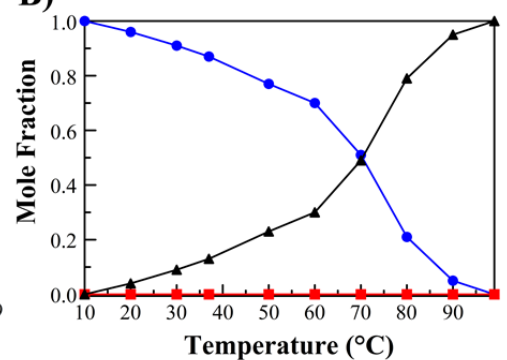

E)

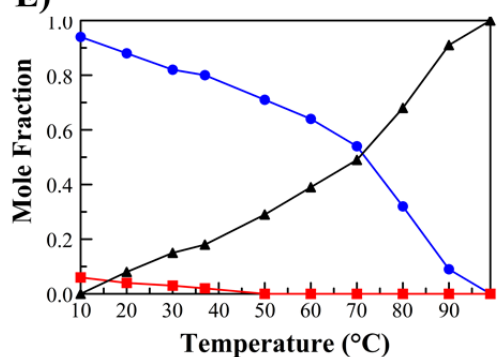

H)

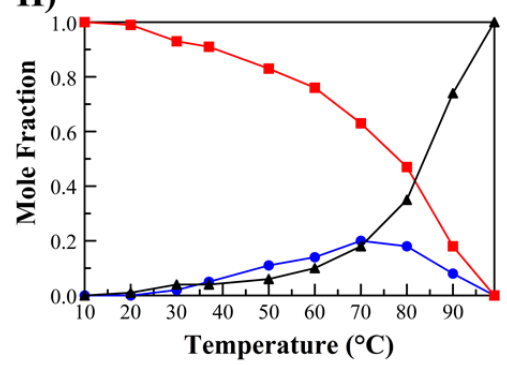

C)

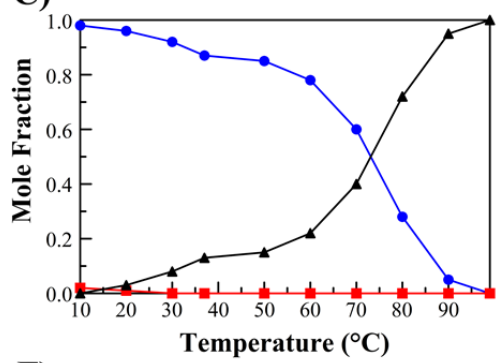

F)

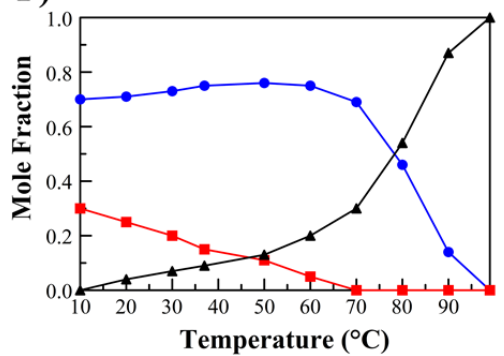

I)

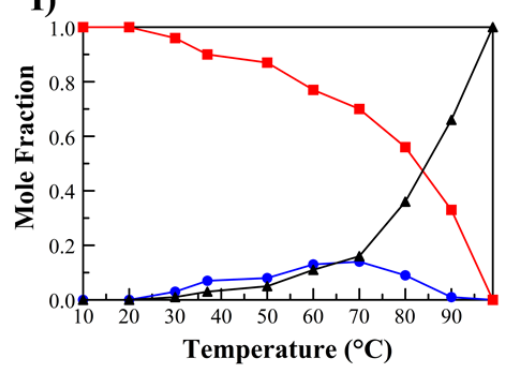

Figure 3.11. Mole fraction plots of the HP-CG ${ }^{8 \mathrm{Ph}}$ calculated at $0,25,50,100,250,500,1000,2000$, and $4000 \mathrm{mM}$ $\mathrm{NaCl}$ (A-I) over $10-99^{\circ} \mathrm{C}$. B-DNA is displayed in the blue circles, Z-DNA in red squares and ss-DNA in black triangles. 
Table 3.5. Mole fractions of B-DNA, Z-DNA, and ss-DNA of HP-CG ${ }^{8 \mathrm{Tol}}$ with $0-4000 \mathrm{mM}$ $\mathrm{NaCl}$ at temperatures $10-99{ }^{\circ} \mathrm{C}$.

\begin{tabular}{|c|c|c|c|c|c|c|c|c|c|c|}
\hline \multirow{2}{*}{$\begin{array}{l}\mathrm{NaCl} \\
(\mathrm{mM})\end{array}$} & \multicolumn{10}{|c|}{$f_{\mathrm{B}}$ at temperature $\left({ }^{\circ} \mathrm{C}\right)$} \\
\hline & 10 & 20 & 30 & 37 & $\mathbf{5 0}$ & 60 & $\mathbf{7 0}$ & 80 & 90 & 99 \\
\hline $\mathbf{0}$ & 0.98 & 1.00 & 1.00 & 1.00 & 0.95 & 0.88 & 0.53 & 0.13 & 0.02 & 0.00 \\
\hline 25 & 0.96 & 0.97 & 0.93 & 0.94 & 0.86 & 0.83 & 0.65 & 0.27 & 0.04 & 0.00 \\
\hline 50 & 0.96 & 0.94 & 0.94 & 0.90 & 0.80 & 0.82 & 0.63 & 0.22 & 0.02 & 0.00 \\
\hline 100 & 0.93 & 0.91 & 0.90 & 0.88 & 0.86 & 0.86 & 0.73 & 0.31 & 0.05 & 0.00 \\
\hline 250 & 0.86 & 0.86 & 0.87 & 0.84 & 0.83 & 0.85 & 0.77 & 0.53 & 0.14 & 0.00 \\
\hline 500 & 0.63 & 0.68 & 0.70 & 0.73 & 0.76 & 0.80 & 0.75 & 0.57 & 0.21 & 0.00 \\
\hline 1000 & 0.17 & 0.24 & 0.28 & 0.37 & 0.52 & 0.62 & 0.64 & 0.54 & 0.19 & 0.00 \\
\hline 2000 & 0.00 & 0.00 & 0.00 & 0.04 & 0.09 & 0.14 & 0.27 & 0.26 & 0.14 & 0.00 \\
\hline 4000 & 0.00 & 0.01 & 0.04 & 0.07 & 0.12 & 0.20 & 0.19 & 0.16 & 0.05 & 0.00 \\
\hline \multirow{2}{*}{$\begin{array}{l}\mathrm{NaCl} \\
(\mathrm{mM})\end{array}$} & \multicolumn{10}{|c|}{ fz at temperature $\left({ }^{\circ} \mathrm{C}\right)$} \\
\hline & 10 & 20 & 30 & 37 & 50 & 60 & 70 & 80 & 90 & 99 \\
\hline 0 & 0.02 & 0.00 & 0.00 & 0.00 & 0.00 & 0.00 & 0.00 & 0.00 & 0.01 & 0.00 \\
\hline 25 & 0.04 & 0.00 & 0.00 & 0.00 & 0.00 & 0.00 & 0.00 & 0.00 & 0.00 & 0.00 \\
\hline 50 & 0.04 & 0.02 & 0.01 & 0.00 & 0.00 & 0.00 & 0.00 & 0.00 & 0.02 & 0.00 \\
\hline 100 & 0.07 & 0.03 & 0.00 & 0.00 & 0.00 & 0.00 & 0.00 & 0.00 & 0.01 & 0.00 \\
\hline 250 & 0.14 & 0.11 & 0.07 & 0.08 & 0.00 & 0.00 & 0.00 & 0.00 & 0.00 & 0.00 \\
\hline 500 & 0.37 & 0.29 & 0.24 & 0.18 & 0.12 & 0.04 & 0.00 & 0.00 & 0.00 & 0.00 \\
\hline 1000 & 0.83 & 0.74 & 0.71 & 0.63 & 0.46 & 0.34 & 0.22 & 0.10 & 0.04 & 0.00 \\
\hline 2000 & 1.00 & 0.97 & 0.96 & 0.91 & 0.82 & 0.75 & 0.59 & 0.41 & 0.13 & 0.00 \\
\hline 4000 & 1.00 & 0.98 & 0.92 & 0.86 & 0.82 & 0.76 & 0.72 & 0.58 & 0.32 & 0.00 \\
\hline \multirow{2}{*}{$\begin{array}{l}\mathrm{NaCl} \\
(\mathrm{mM})\end{array}$} & \multicolumn{10}{|c|}{$f_{\text {ss }}$ at temperature $\left({ }^{\circ} \mathrm{C}\right)$} \\
\hline & 10 & 20 & 30 & 37 & 50 & 60 & 70 & 80 & 90 & 99 \\
\hline 0 & 0.00 & 0.00 & 0.00 & 0.00 & 0.05 & 0.12 & 0.47 & 0.87 & 0.97 & 1.00 \\
\hline 25 & 0.00 & 0.03 & 0.07 & 0.06 & 0.15 & 0.17 & 0.35 & 0.73 & 0.96 & 1.00 \\
\hline 50 & 0.00 & 0.04 & 0.06 & 0.10 & 0.20 & 0.18 & 0.37 & 0.78 & 0.96 & 1.00 \\
\hline 100 & 0.00 & 0.06 & 0.09 & 0.12 & 0.14 & 0.14 & 0.27 & 0.69 & 0.94 & 1.00 \\
\hline 250 & 0.00 & 0.03 & 0.06 & 0.09 & 0.17 & 0.15 & 0.23 & 0.47 & 0.86 & 1.00 \\
\hline 500 & 0.00 & 0.03 & 0.07 & 0.09 & 0.12 & 0.16 & 0.25 & 0.43 & 0.79 & 1.00 \\
\hline 1000 & 0.00 & 0.02 & 0.01 & 0.01 & 0.02 & 0.04 & 0.14 & 0.37 & 0.78 & 1.00 \\
\hline 2000 & 0.00 & 0.03 & 0.04 & 0.05 & 0.09 & 0.10 & 0.14 & 0.32 & 0.73 & 1.00 \\
\hline 4000 & 0.00 & 0.01 & 0.04 & 0.07 & 0.06 & 0.05 & 0.09 & 0.26 & 0.63 & 1.00 \\
\hline
\end{tabular}


A)

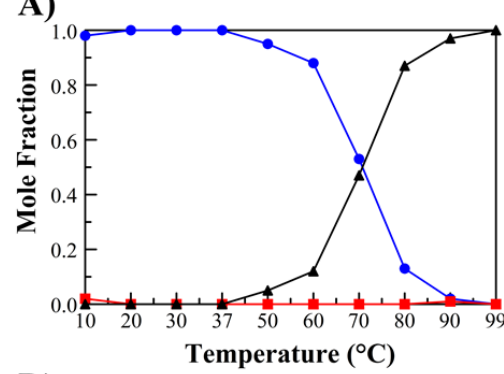

D)

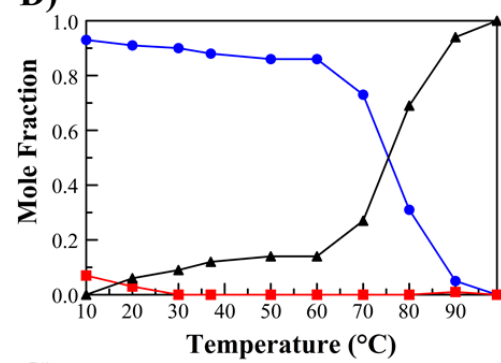

G)

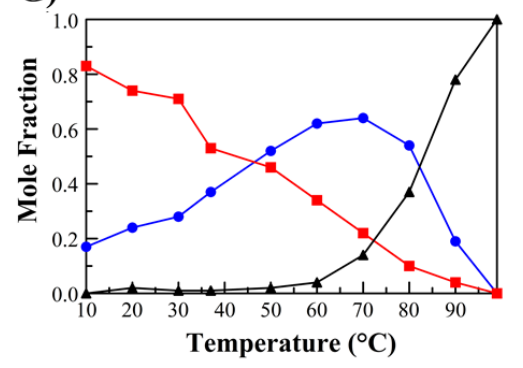

B)

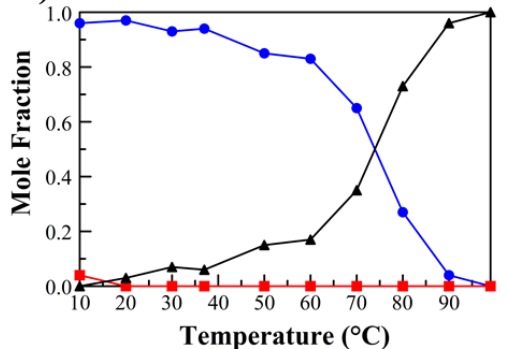

E)

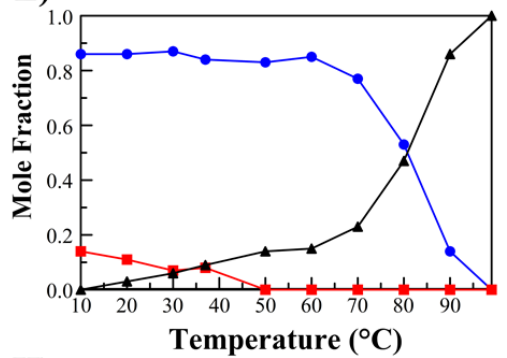

H)

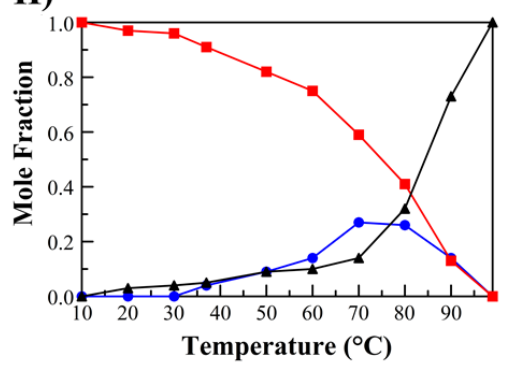

C)

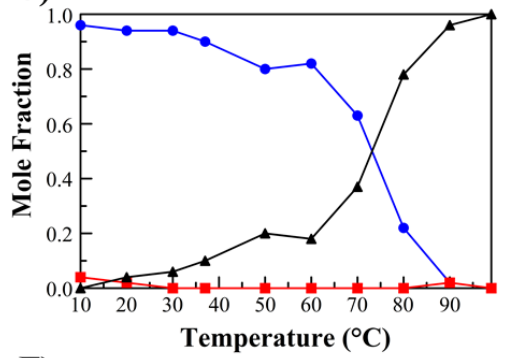

F)

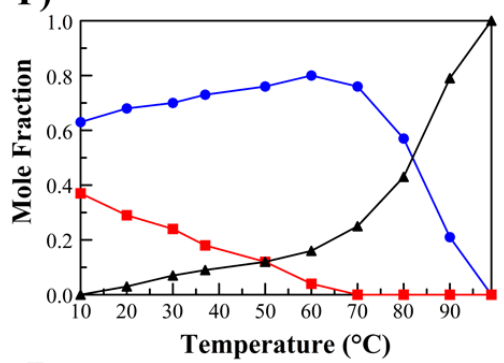

I)

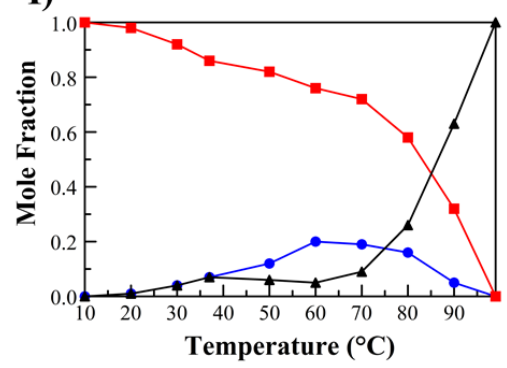

Figure 3.12. Mole fraction plots of the HP-CG ${ }^{8 T o l}$ calculated at 0, 25, 50, 100, 250, 500, 1000, 2000, and 4000 $\mathrm{mM} \mathrm{NaCl}$ (A-I) over $10-99{ }^{\circ} \mathrm{C}$. B-DNA is displayed in the blue circles, Z-DNA in red squares and ss-DNA in black triangles. 
Table 3.6. Mole fractions of B-DNA, Z-DNA, and ss-DNA of HP-CG ${ }^{8 H M P h}$ with $0-4000 \mathrm{mM}$ $\mathrm{NaCl}$ at temperatures $10-99{ }^{\circ} \mathrm{C}$.

\begin{tabular}{|c|c|c|c|c|c|c|c|c|c|c|}
\hline \multirow{2}{*}{$\begin{array}{l}\mathrm{NaCl} \\
(\mathbf{m M})\end{array}$} & \multicolumn{10}{|c|}{$f_{\mathrm{B}}$ at temperature $\left({ }^{\circ} \mathrm{C}\right)$} \\
\hline & 10 & 20 & 30 & 37 & $\mathbf{5 0}$ & 60 & $\mathbf{7 0}$ & 80 & 90 & 99 \\
\hline 0 & 1.00 & 1.00 & 0.96 & 1.00 & 0.95 & 0.73 & 0.25 & 0.08 & 0.00 & 0.00 \\
\hline 25 & 1.00 & 0.96 & 0.93 & 0.88 & 0.73 & 0.64 & 0.43 & 0.04 & 0.00 & 0.00 \\
\hline 50 & 0.96 & 0.92 & 0.87 & 0.84 & 0.79 & 0.74 & 0.62 & 0.29 & 0.06 & 0.00 \\
\hline 100 & 0.99 & 0.93 & 0.90 & 0.86 & 0.78 & 0.76 & 0.65 & 0.34 & 0.07 & 0.00 \\
\hline 250 & 0.88 & 0.88 & 0.86 & 0.83 & 0.75 & 0.74 & 0.64 & 0.43 & 0.08 & 0.00 \\
\hline 500 & 0.73 & 0.76 & 0.75 & 0.75 & 0.74 & 0.74 & 0.66 & 0.46 & 0.16 & 0.00 \\
\hline 1000 & 0.21 & 0.26 & 0.32 & 0.36 & 0.44 & 0.51 & 0.47 & 0.40 & 0.16 & 0.00 \\
\hline 2000 & 0.00 & 0.00 & 0.03 & 0.04 & 0.13 & 0.16 & 0.23 & 0.19 & 0.11 & 0.00 \\
\hline 4000 & 0.00 & 0.00 & 0.00 & 0.01 & 0.01 & 0.09 & 0.06 & 0.05 & 0.00 & 0.00 \\
\hline \multirow{2}{*}{$\begin{array}{l}\mathrm{NaCl} \\
(\mathbf{m M})\end{array}$} & \multicolumn{10}{|c|}{$f \mathrm{z}$ at temperature $\left({ }^{\circ} \mathrm{C}\right)$} \\
\hline & 10 & 20 & 30 & 37 & 50 & 60 & 70 & 80 & 90 & 99 \\
\hline 0 & 0.00 & 0.00 & 0.00 & 0.00 & 0.00 & 0.00 & 0.00 & 0.00 & 0.02 & 0.00 \\
\hline 25 & 0.00 & 0.00 & 0.00 & 0.00 & 0.00 & 0.00 & 0.00 & 0.00 & 0.00 & 0.00 \\
\hline 50 & 0.04 & 0.01 & 0.00 & 0.00 & 0.00 & 0.00 & 0.00 & 0.00 & 0.02 & 0.00 \\
\hline 100 & 0.01 & 0.01 & 0.00 & 0.00 & 0.00 & 0.00 & 0.00 & 0.00 & 0.01 & 0.00 \\
\hline 250 & 0.12 & 0.08 & 0.07 & 0.07 & 0.00 & 0.00 & 0.00 & 0.00 & 0.00 & 0.00 \\
\hline 500 & 0.27 & 0.21 & 0.17 & 0.14 & 0.09 & 0.03 & 0.00 & 0.00 & 0.00 & 0.00 \\
\hline 1000 & 0.79 & 0.72 & 0.66 & 0.59 & 0.46 & 0.38 & 0.27 & 0.14 & 0.03 & 0.00 \\
\hline 2000 & 1.00 & 0.97 & 0.94 & 0.91 & 0.79 & 0.72 & 0.61 & 0.45 & 0.14 & 0.00 \\
\hline 4000 & 1.00 & 1.00 & 0.96 & 0.93 & 0.87 & 0.72 & 0.65 & 0.52 & 0.28 & 0.00 \\
\hline \multirow{2}{*}{$\begin{array}{l}\mathrm{NaCl} \\
(\mathrm{mM})\end{array}$} & \multicolumn{10}{|c|}{$f_{\text {Ss at }}$ temperature $\left({ }^{\circ} \mathrm{C}\right)$} \\
\hline & 10 & 20 & 30 & 37 & 50 & 60 & 70 & 80 & 90 & 99 \\
\hline $\mathbf{0}$ & 0.00 & 0.00 & 0.04 & 0.00 & 0.05 & 0.27 & 0.75 & 0.92 & 0.97 & 1.00 \\
\hline 25 & 0.00 & 0.04 & 0.07 & 0.12 & 0.27 & 0.36 & 0.57 & 0.96 & 1.00 & 1.00 \\
\hline 50 & 0.00 & 0.07 & 0.13 & 0.16 & 0.21 & 0.26 & 0.38 & 0.71 & 0.94 & 1.00 \\
\hline 100 & 0.00 & 0.06 & 0.10 & 0.14 & 0.22 & 0.24 & 0.35 & 0.66 & 0.93 & 1.00 \\
\hline 250 & 0.00 & 0.04 & 0.08 & 0.10 & 0.25 & 0.26 & 0.36 & 0.57 & 0.92 & 1.00 \\
\hline 500 & 0.00 & 0.03 & 0.08 & 0.11 & 0.18 & 0.23 & 0.34 & 0.54 & 0.84 & 1.00 \\
\hline 1000 & 0.00 & 0.02 & 0.00 & 0.00 & 0.00 & 0.10 & 0.27 & 0.46 & 0.81 & 1.00 \\
\hline 2000 & 0.00 & 0.03 & 0.04 & 0.05 & 0.08 & 0.12 & 0.16 & 0.36 & 0.75 & 1.00 \\
\hline 4000 & 0.00 & 0.00 & 0.04 & 0.06 & 0.12 & 0.19 & 0.29 & 0.43 & 0.72 & 1.00 \\
\hline
\end{tabular}


A)

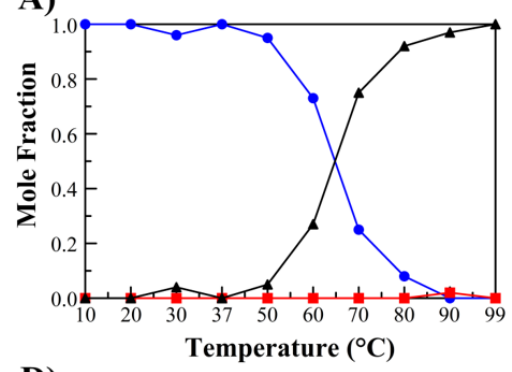

D)

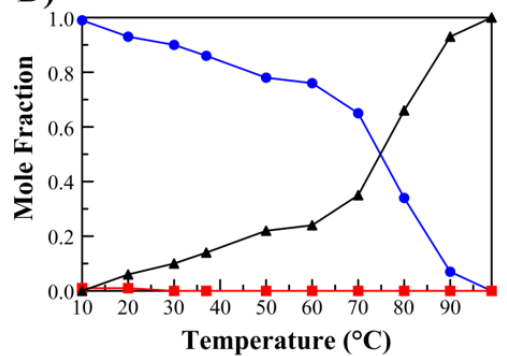

G)

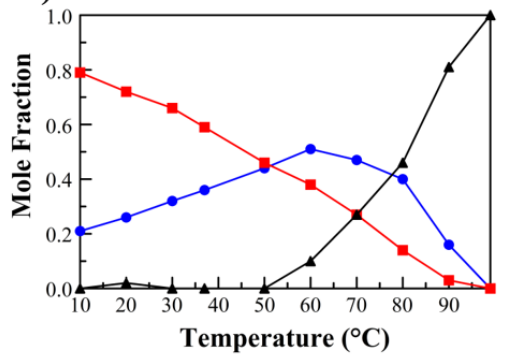

B)

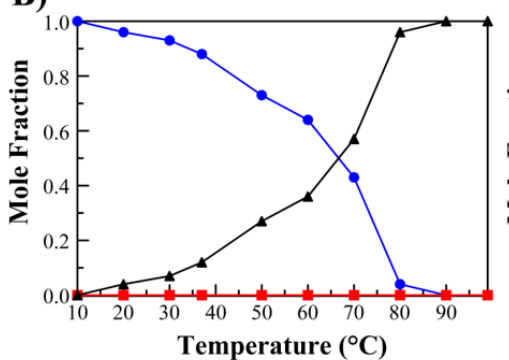

E)

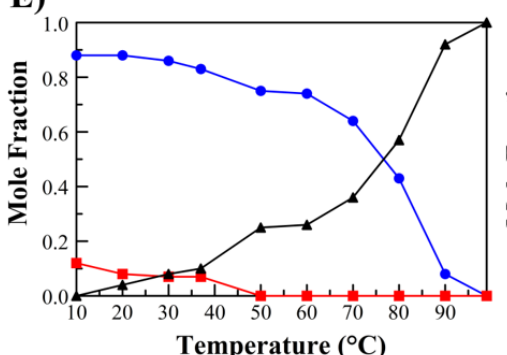

H)

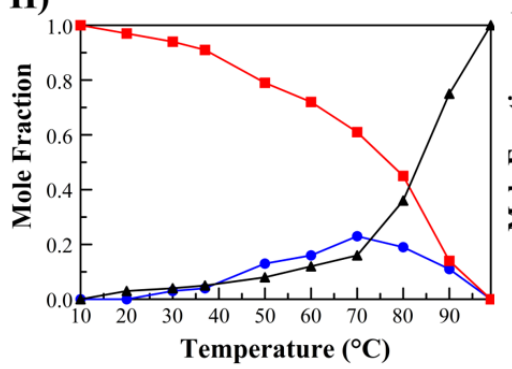

C)

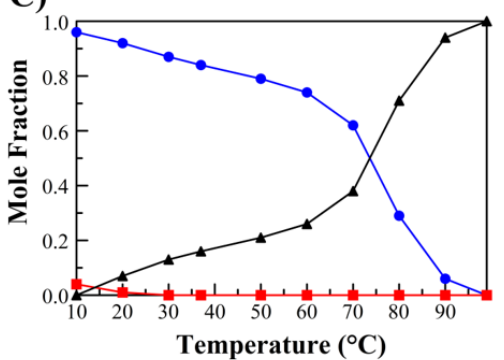

F)

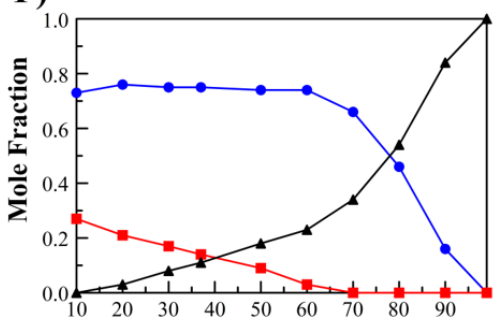

I)

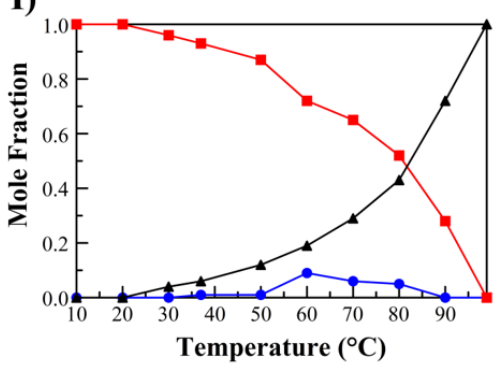

Figure 3.13. Mole fraction plots of the HP-CG ${ }^{8 \mathrm{HMPh}}$ calculated at $0,25,50,100,250,500,1000,2000$, and 4000 $\mathrm{mM} \mathrm{NaCl}$ (A-I) over $10-99{ }^{\circ} \mathrm{C}$. B-DNA is displayed in the blue circles, Z-DNA in red squares and ss-DNA in black triangles. 
Table 3.7. Mole fractions of B-DNA, Z-DNA, and ss-DNA of HP-CG ${ }^{8 M M P h}$ with $0-4000 \mathrm{mM}$ $\mathrm{NaCl}$ at temperatures $10-99{ }^{\circ} \mathrm{C}$.

\begin{tabular}{|c|c|c|c|c|c|c|c|c|c|c|}
\hline \multirow{2}{*}{$\begin{array}{l}\mathrm{NaCl} \\
(\mathbf{m M})\end{array}$} & \multicolumn{10}{|c|}{$f_{\mathrm{B}}$ at temperature $\left({ }^{\circ} \mathrm{C}\right)$} \\
\hline & 10 & 20 & 30 & 37 & 50 & 60 & $\mathbf{7 0}$ & 80 & 90 & 99 \\
\hline $\mathbf{0}$ & 1.00 & 1.00 & 1.00 & 1.00 & 0.96 & 0.87 & 0.58 & 0.21 & 0.08 & 0.00 \\
\hline 25 & 1.00 & 0.98 & 0.94 & 0.94 & 0.87 & 0.88 & 0.71 & 0.31 & 0.07 & 0.00 \\
\hline 50 & 0.92 & 0.92 & 0.94 & 0.89 & 0.90 & 0.85 & 0.72 & 0.34 & 0.05 & 0.00 \\
\hline 100 & 0.93 & 0.92 & 0.91 & 0.91 & 0.87 & 0.87 & 0.76 & 0.47 & 0.10 & 0.00 \\
\hline 250 & 0.83 & 0.84 & 0.83 & 0.81 & 0.80 & 0.77 & 0.72 & 0.53 & 0.15 & 0.00 \\
\hline 500 & 0.60 & 0.66 & 0.69 & 0.72 & 0.76 & 0.77 & 0.74 & 0.58 & 0.24 & 0.00 \\
\hline 1000 & 0.16 & 0.23 & 0.30 & 0.37 & 0.50 & 0.59 & 0.65 & 0.55 & 0.20 & 0.00 \\
\hline 2000 & 0.00 & 0.00 & 0.02 & 0.06 & 0.11 & 0.17 & 0.18 & 0.20 & 0.10 & 0.00 \\
\hline 4000 & 0.00 & 0.00 & 0.03 & 0.06 & 0.10 & 0.15 & 0.17 & 0.15 & 0.07 & 0.00 \\
\hline \multirow{2}{*}{$\begin{array}{l}\mathrm{NaCl} \\
(\mathbf{m M})\end{array}$} & \multicolumn{10}{|c|}{$f_{\mathrm{Z}}$ at temperature $\left({ }^{\circ} \mathrm{C}\right)$} \\
\hline & 10 & 20 & 30 & 37 & 50 & 60 & 70 & 80 & 90 & 99 \\
\hline 0 & 0.00 & 0.00 & 0.00 & 0.00 & 0.00 & 0.00 & 0.00 & 0.00 & 0.00 & 0.00 \\
\hline 25 & 0.00 & 0.00 & 0.00 & 0.00 & 0.00 & 0.00 & 0.00 & 0.00 & 0.00 & 0.00 \\
\hline 50 & 0.08 & 0.06 & 0.00 & 0.00 & 0.00 & 0.00 & 0.00 & 0.00 & 0.02 & 0.00 \\
\hline 100 & 0.07 & 0.05 & 0.02 & 0.00 & 0.00 & 0.00 & 0.00 & 0.00 & 0.01 & 0.00 \\
\hline 250 & 0.17 & 0.12 & 0.08 & 0.08 & 0.00 & 0.00 & 0.00 & 0.00 & 0.00 & 0.00 \\
\hline 500 & 0.40 & 0.32 & 0.27 & 0.22 & 0.15 & 0.09 & 0.00 & 0.00 & 0.00 & 0.00 \\
\hline 1000 & 0.84 & 0.76 & 0.71 & 0.64 & 0.50 & 0.40 & 0.26 & 0.13 & 0.04 & 0.00 \\
\hline 2000 & 1.00 & 0.98 & 0.95 & 0.91 & 0.83 & 0.75 & 0.64 & 0.44 & 0.17 & 0.00 \\
\hline 4000 & 1.00 & 0.98 & 0.93 & 0.90 & 0.84 & 0.78 & 0.74 & 0.58 & 0.33 & 0.00 \\
\hline \multirow{2}{*}{$\begin{array}{l}\mathrm{NaCl} \\
(\mathrm{mM})\end{array}$} & \multicolumn{10}{|c|}{$f_{\text {SS }}$ at temperature $\left({ }^{\circ} \mathrm{C}\right)$} \\
\hline & 10 & 20 & 30 & 37 & 50 & 60 & 70 & 80 & 90 & 99 \\
\hline $\mathbf{0}$ & 0.00 & 0.00 & 0.00 & 0.00 & 0.04 & 0.13 & 0.42 & 0.79 & 0.93 & 1.00 \\
\hline 25 & 0.00 & 0.02 & 0.06 & 0.06 & 0.13 & 0.12 & 0.29 & 0.69 & 0.93 & 1.00 \\
\hline 50 & 0.00 & 0.02 & 0.06 & 0.11 & 0.10 & 0.15 & 0.28 & 0.66 & 0.93 & 1.00 \\
\hline 100 & 0.00 & 0.03 & 0.07 & 0.09 & 0.13 & 0.13 & 0.24 & 0.53 & 0.90 & 1.00 \\
\hline 250 & 0.00 & 0.04 & 0.09 & 0.12 & 0.20 & 0.23 & 0.28 & 0.47 & 0.85 & 1.00 \\
\hline 500 & 0.00 & 0.02 & 0.04 & 0.06 & 0.10 & 0.14 & 0.26 & 0.42 & 0.76 & 1.00 \\
\hline 1000 & 0.00 & 0.01 & 0.00 & 0.00 & 0.00 & 0.01 & 0.09 & 0.33 & 0.76 & 1.00 \\
\hline 2000 & 0.00 & 0.02 & 0.02 & 0.03 & 0.06 & 0.08 & 0.18 & 0.36 & 0.73 & 1.00 \\
\hline 4000 & 0.00 & 0.02 & 0.04 & 0.04 & 0.06 & 0.07 & 0.09 & 0.24 & 0.60 & 1.00 \\
\hline
\end{tabular}


A)

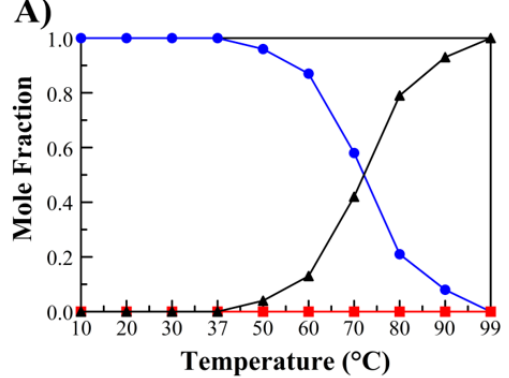

D)

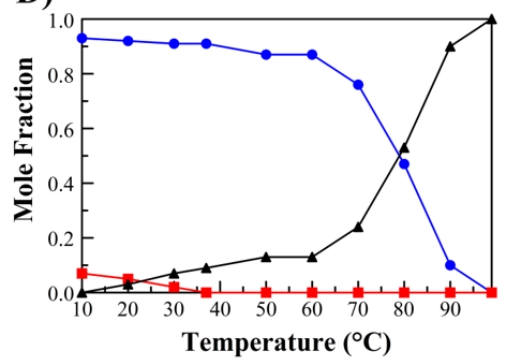

G)

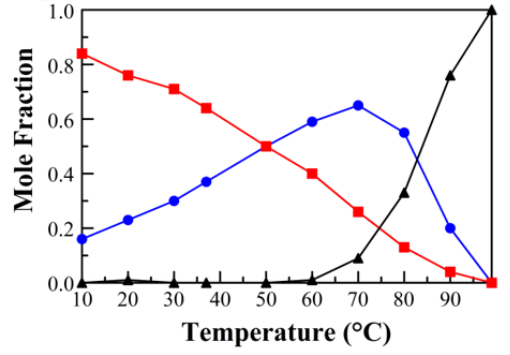

B)

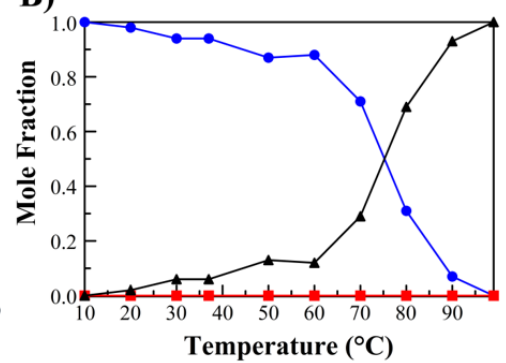

E)

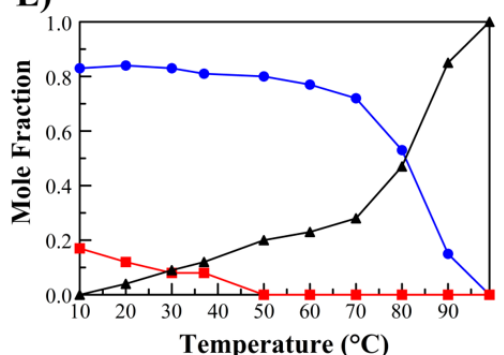

H)

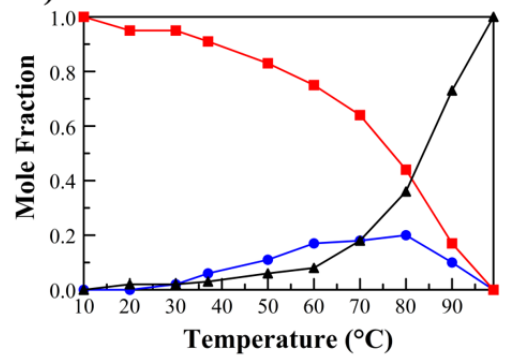

C)

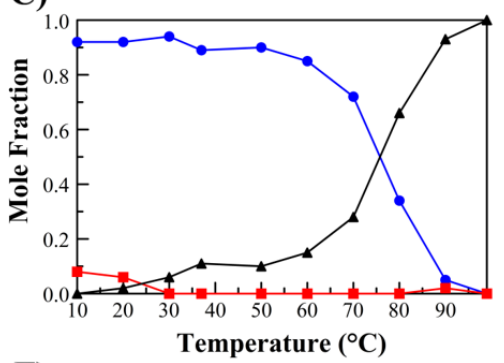

F)

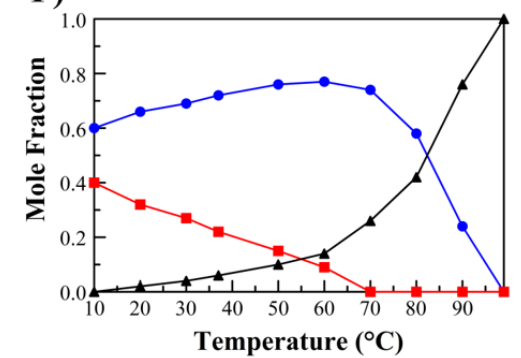

I)

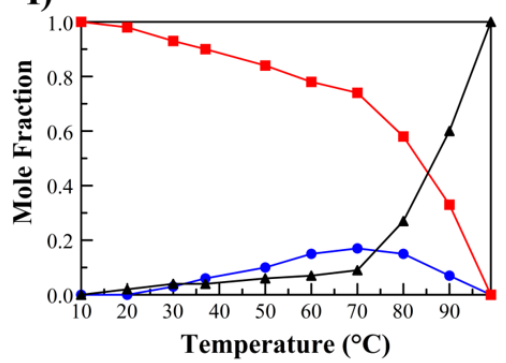

Figure 3.14. Mole fraction plots of the HP-CG ${ }^{8 M M P h}$ calculated at 0, 25, 50, 100, 250, 500, 1000, 2000, and $4000 \mathrm{mM} \mathrm{NaCl}$ (A-I) over $10-99{ }^{\circ} \mathrm{C}$. B-DNA is displayed in the blue circles, Z-DNA in red squares and ss-DNA in black triangles. 
Table 3.8. Mole fractions of B-DNA, Z-DNA, and ss-DNA of HP-CG ${ }^{8 \mathrm{CPh}}$ with $0-4000 \mathrm{mM}$ $\mathrm{NaCl}$ at temperatures $10-99{ }^{\circ} \mathrm{C}$.

\begin{tabular}{|c|c|c|c|c|c|c|c|c|c|c|}
\hline \multirow{2}{*}{$\begin{array}{l}\mathrm{NaCl} \\
(\mathbf{m M})\end{array}$} & \multicolumn{10}{|c|}{$f_{\mathrm{B}}$ at temperature $\left({ }^{\circ} \mathrm{C}\right)$} \\
\hline & 10 & 20 & 30 & 37 & 50 & 60 & $\mathbf{7 0}$ & 80 & 90 & 99 \\
\hline $\mathbf{0}$ & 0.96 & 0.97 & 1.00 & 0.97 & 0.91 & 0.82 & 0.49 & 0.14 & 0.04 & 0.00 \\
\hline 25 & 0.98 & 0.97 & 0.93 & 0.91 & 0.85 & 0.80 & 0.62 & 0.18 & 0.04 & 0.00 \\
\hline 50 & 0.93 & 0.91 & 0.89 & 0.86 & 0.83 & 0.80 & 0.66 & 0.27 & 0.04 & 0.00 \\
\hline 100 & 0.91 & 0.90 & 0.91 & 0.89 & 0.87 & 0.86 & 0.70 & 0.24 & 0.04 & 0.00 \\
\hline 250 & 0.81 & 0.84 & 0.86 & 0.81 & 0.76 & 0.75 & 0.69 & 0.48 & 0.10 & 0.00 \\
\hline 500 & 0.50 & 0.57 & 0.61 & 0.63 & 0.62 & 0.65 & 0.61 & 0.47 & 0.14 & 0.00 \\
\hline 1000 & 0.09 & 0.15 & 0.18 & 0.24 & 0.33 & 0.41 & 0.38 & 0.36 & 0.14 & 0.00 \\
\hline 2000 & 0.00 & 0.00 & 0.04 & 0.04 & 0.08 & 0.13 & 0.17 & 0.18 & 0.12 & 0.00 \\
\hline 4000 & 0.00 & 0.04 & 0.08 & 0.13 & 0.11 & 0.17 & 0.17 & 0.15 & 0.05 & 0.00 \\
\hline \multirow{2}{*}{$\begin{array}{l}\mathrm{NaCl} \\
(\mathbf{m M})\end{array}$} & \multicolumn{10}{|c|}{$f_{\mathrm{z}}$ at temperature $\left({ }^{\circ} \mathrm{C}\right)$} \\
\hline & 10 & 20 & 30 & 37 & 50 & 60 & 70 & 80 & 90 & 99 \\
\hline 0 & 0.04 & 0.02 & 0.00 & 0.00 & 0.00 & 0.00 & 0.00 & 0.00 & 0.00 & 0.00 \\
\hline 25 & 0.02 & 0.00 & 0.00 & 0.00 & 0.00 & 0.00 & 0.00 & 0.00 & 0.00 & 0.00 \\
\hline 50 & 0.07 & 0.04 & 0.00 & 0.00 & 0.00 & 0.00 & 0.00 & 0.00 & 0.00 & 0.00 \\
\hline 100 & 0.09 & 0.04 & 0.00 & 0.00 & 0.00 & 0.00 & 0.00 & 0.00 & 0.00 & 0.00 \\
\hline 250 & 0.19 & 0.12 & 0.07 & 0.10 & 0.04 & 0.00 & 0.00 & 0.00 & 0.00 & 0.00 \\
\hline 500 & 0.50 & 0.42 & 0.35 & 0.29 & 0.23 & 0.14 & 0.09 & 0.06 & 0.01 & 0.00 \\
\hline 1000 & 0.91 & 0.83 & 0.77 & 0.70 & 0.60 & 0.52 & 0.41 & 0.27 & 0.08 & 0.00 \\
\hline 2000 & 1.00 & 0.93 & 0.87 & 0.88 & 0.81 & 0.76 & 0.69 & 0.56 & 0.27 & 0.00 \\
\hline 4000 & 1.00 & 0.90 & 0.83 & 0.77 & 0.75 & 0.66 & 0.61 & 0.53 & 0.35 & 0.00 \\
\hline \multirow{2}{*}{$\begin{array}{l}\mathrm{NaCl} \\
(\mathbf{m M})\end{array}$} & \multicolumn{10}{|c|}{$f_{\text {ss }}$ at temperature $\left({ }^{\circ} \mathrm{C}\right)$} \\
\hline & 10 & 20 & 30 & 37 & 50 & 60 & 70 & 80 & 90 & 99 \\
\hline $\mathbf{0}$ & 0.00 & 0.01 & 0.00 & 0.03 & 0.09 & 0.18 & 0.51 & 0.86 & 0.96 & 1.00 \\
\hline 25 & 0.00 & 0.03 & 0.07 & 0.09 & 0.15 & 0.20 & 0.38 & 0.82 & 0.96 & 1.00 \\
\hline 50 & 0.00 & 0.06 & 0.11 & 0.14 & 0.17 & 0.20 & 0.34 & 0.73 & 0.96 & 1.00 \\
\hline 100 & 0.00 & 0.06 & 0.09 & 0.11 & 0.13 & 0.14 & 0.30 & 0.76 & 0.96 & 1.00 \\
\hline 250 & 0.00 & 0.04 & 0.07 & 0.09 & 0.20 & 0.25 & 0.31 & 0.52 & 0.90 & 1.00 \\
\hline 500 & 0.00 & 0.02 & 0.04 & 0.07 & 0.15 & 0.21 & 0.30 & 0.47 & 0.85 & 1.00 \\
\hline 1000 & 0.00 & 0.02 & 0.04 & 0.06 & 0.07 & 0.07 & 0.21 & 0.37 & 0.78 & 1.00 \\
\hline 2000 & 0.00 & 0.07 & 0.08 & 0.08 & 0.10 & 0.11 & 0.14 & 0.26 & 0.61 & 1.00 \\
\hline 4000 & 0.00 & 0.06 & 0.09 & 0.10 & 0.13 & 0.17 & 0.22 & 0.32 & 0.60 & 1.00 \\
\hline
\end{tabular}


A)

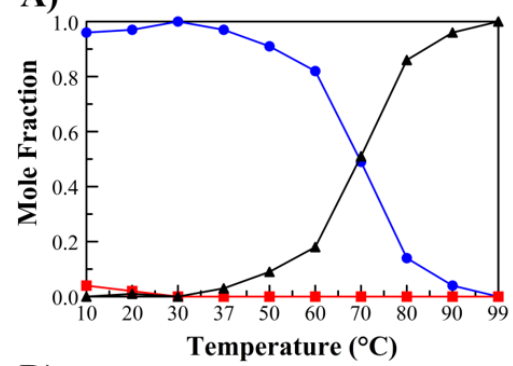

D)

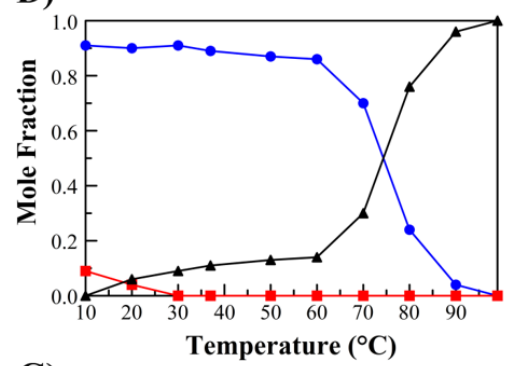

G)

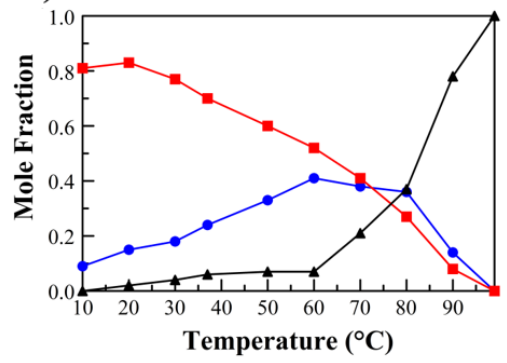

B)

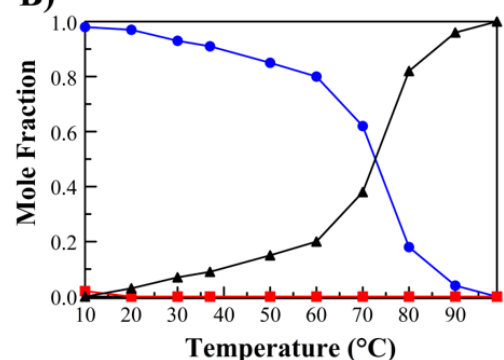

E)

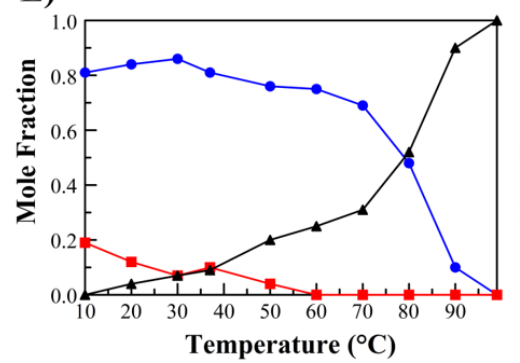

H)

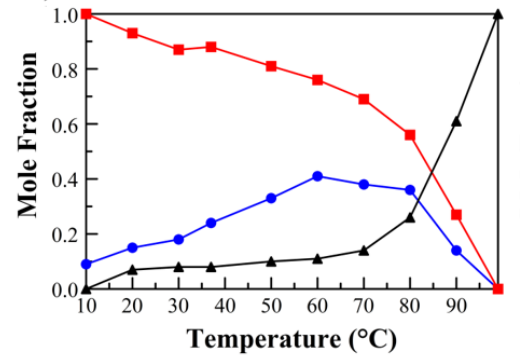

C)

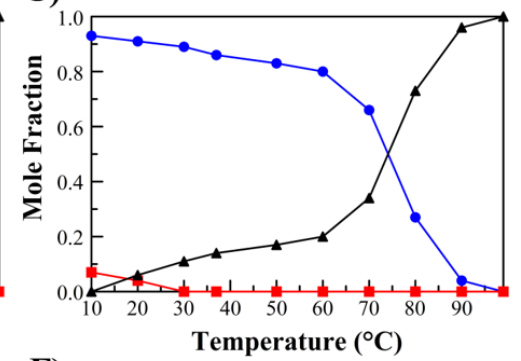

F)

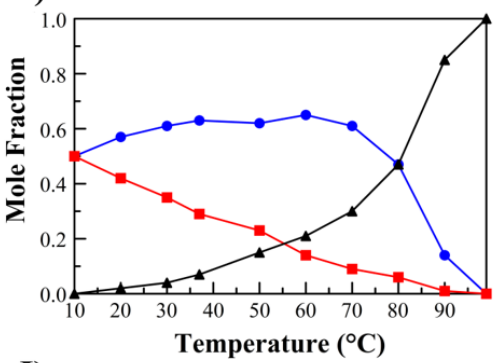

I)

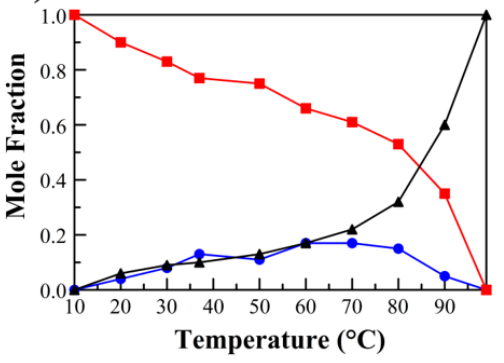

Figure 3.15. Mole fraction plots of the $\mathrm{HP}-\mathrm{CG}^{8 \mathrm{CPh}}$ calculated at $0,25,50,100,250,500,1000,2000$, and 4000 $\mathrm{mM} \mathrm{NaCl}(\mathrm{A}-\mathrm{I})$ over $10-99^{\circ} \mathrm{C}$. B-DNA is displayed in the blue circles, Z-DNA in red squares and ss-DNA in black triangles. 
The CD spectra can be used to show that the single C8-arylguanine modification shifts the B-/Z-DNA equilibrium toward the Z-DNA conformation. However, acquiring CD spectra at only a single temperature provides data that can only be used to qualitatively determine the conformational effects of the C8-arylguanine modified base. Quantitation requires CD spectra to be acquired over a range of salt concentrations and temperatures and then the mole fractions of B, Z-, and ss-DNA, in solution, be calculated.

The mole fraction data can be used, also, to estimate and/or calculate the transition concentration $\left(\mathrm{T}_{\mathrm{c}}\right.$; the salt concentration required such that the B-/Z-DNA ratio is 1$)$. The calculation of the transition salt concentration begins by considering the equilibrium in eq 3.5

$$
\mathrm{B}+\mathrm{c}[\mathrm{NaCl}] \stackrel{\mathrm{K}_{\mathrm{eq}}}{\rightleftharpoons} \mathrm{Z}
$$

where $\mathrm{c}[\mathrm{NaCl}]$ represents the interactions of salt between the $\mathrm{B}$ - and Z-DNA conformations and c stands for the transition specific constant coefficient. ${ }^{145}$ The observed equilibrium constant (Kobs) (calculated from $f_{\mathrm{Z}} / f_{\mathrm{B}}$ ), for a given salt concentration, is defined as shown by eqs 3.6 and 3.7 .

$$
\begin{gathered}
\mathrm{K}_{\mathrm{obs}}=\mathrm{K}_{\mathrm{eq}} *[\mathrm{NaCl}]^{\mathrm{c}} \\
\ln \left(\mathrm{K}_{\mathrm{obs}}\right)=\ln \left(\mathrm{K}_{\mathrm{eq}}\right)+\mathrm{c} \ln [\mathrm{NaCl}]
\end{gathered}
$$

Fitting a plot of $\ln \left(\mathrm{K}_{\mathrm{obs}}\right)$ versus $\ln [\mathrm{NaCl}]$ yields the values of $\mathrm{c}$ and $\mathrm{K}_{\mathrm{eq}}$, determined from the slope (c) and y-intercept $\left(\ln \left(\mathrm{K}_{\mathrm{eq}}\right)\right)$. In turn, the transition energy can be calculated from eq 3.8 .

$$
\Delta \mathrm{G}_{\mathrm{t}}=-\mathrm{RT} \ln \left(\mathrm{K}_{\mathrm{eq}}\right)
$$


The rank-order (Table 3.9) for the hairpin oligonucleotides with respect to the $\mathrm{T}_{\mathrm{c}}$ is $\mathrm{HP}-\mathrm{CG}^{8 \mathrm{CPh}}<$ $\mathrm{HP}-\mathrm{CG}^{8 \mathrm{Tol}}<\mathrm{HP}-\mathrm{CG}^{8 \mathrm{MMPh}}<\mathrm{HP}-\mathrm{CG}^{8 \mathrm{HMPh}}<\mathrm{HP}-\mathrm{CG}^{8 \mathrm{Ph}}<<\mathrm{HP}-\mathrm{CG}$. The mole fraction calculations demonstrate that the $\mathrm{C} 8$-arylguanine modified hairpin oligonucleotides require much less $\mathrm{NaCl}$ to drive Z-DNA formation. In addition the mole fraction data can also be used to determine thermodynamic data for the hairpin oligonucleotides $(\Delta \mathrm{G}, \Delta \mathrm{H}$, and $\Delta \mathrm{S})$.

Table 3.9. Transition concentration of the hairpin oligonucleotides at $37{ }^{\circ} \mathrm{C}$

\begin{tabular}{|l|c|c|}
\hline \multicolumn{1}{|c|}{ Hairpin } & $\begin{array}{c}\text { Transition Concentration } \\
(\mathrm{mM} \mathrm{NaCl})\end{array}$ & $\Delta \mathrm{G}_{\mathrm{t}}{ }^{\mathrm{a}}$ \\
\hline $\mathrm{CG}$ & 2978 & 18.4 \\
\hline $\mathrm{CG}^{8 \mathrm{Ph}}$ & 822 & 12.7 \\
\hline $\mathrm{CG}^{8 \mathrm{Tol}}$ & 708 & 10.9 \\
\hline $\mathrm{CG}^{8 \mathrm{HMPh}}$ & 744 & 11.1 \\
\hline $\mathrm{CG}^{8 \mathrm{MMPh}}$ & 730 & 10.0 \\
\hline $\mathrm{CG}^{8 \mathrm{CPh}}$ & 621 & 9.9 \\
\hline
\end{tabular}

${ }^{\mathrm{a} C a l c u l a t e d}$ for $\mathrm{T}=310 \mathrm{~K}, \mathrm{~K}_{\mathrm{B} / \mathrm{Z}}=1 . \Delta \mathrm{G}_{\mathrm{t}}$ are in $\mathrm{kcal} \mathrm{mol}^{-1}$

\section{Thermodynamic Parameters}

Using the mole fraction data, the thermodynamic parameters $(\Delta \mathrm{G}, \Delta \mathrm{H}$, and $\Delta \mathrm{S})$ which can be used to quantitatively compare the $\mathrm{C} 8$-arylguanine modified hairpins to the unmodified hairpin as well to the previously studied doubly modified double-stranded $(\mathrm{CG})_{5}$ oligonucleotides (see Discussion). The van't Hoff equation has been previously used to calculate the thermodynamic parameters for the B-/Z-DNA equilibrium and was also used here. ${ }^{117,157,158}$ The van't Hoff equation can be derived using the Gibbs free energy (eq 3.9) combined with the Gibbs free energy 
isotherm equation (eq 3.10) to yield the van't Hoff equation, eq 3.11. The van't Hoff equation can be modified, replacing $\mathrm{K}_{\mathrm{eq}}$ with $f_{Z} / f_{B}$ resulting in eq. 3.12 or, by multiplying through by -1 , to provide eq 3.13. The mole fraction data can then be fit to the van't Hoff equation to yield the $\Delta \mathrm{G}$, $\Delta \mathrm{H}$, and $\Delta \mathrm{S}$ (Figure 3.16). The values of $\Delta \mathrm{G}_{\mathrm{t}}, \Delta \mathrm{G}, \Delta \mathrm{H}$, and $\Delta \mathrm{S}$ for the hairpin oligonucleotides are listed in Table 3.10.

$$
\begin{gathered}
\Delta \mathrm{G}=\Delta \mathrm{H}-\mathrm{T} \Delta \mathrm{S} \\
\Delta \mathrm{G}=-\mathrm{RT} \ln \mathrm{K}_{\mathrm{eq}} \\
\ln \mathrm{K}_{\mathrm{eq}}=-\Delta \mathrm{H} / \mathrm{RT}+\Delta \mathrm{S} / \mathrm{R} \\
\ln \left(f_{\mathrm{Z}} / f_{\mathrm{B}}\right)=-\Delta \mathrm{H} / \mathrm{RT}+\Delta \mathrm{S} / \mathrm{R} \\
\ln \left(f_{\mathrm{B}} / f_{\mathrm{Z}}\right)=\Delta \mathrm{H} / \mathrm{RT}-\Delta \mathrm{S} / \mathrm{R}
\end{gathered}
$$




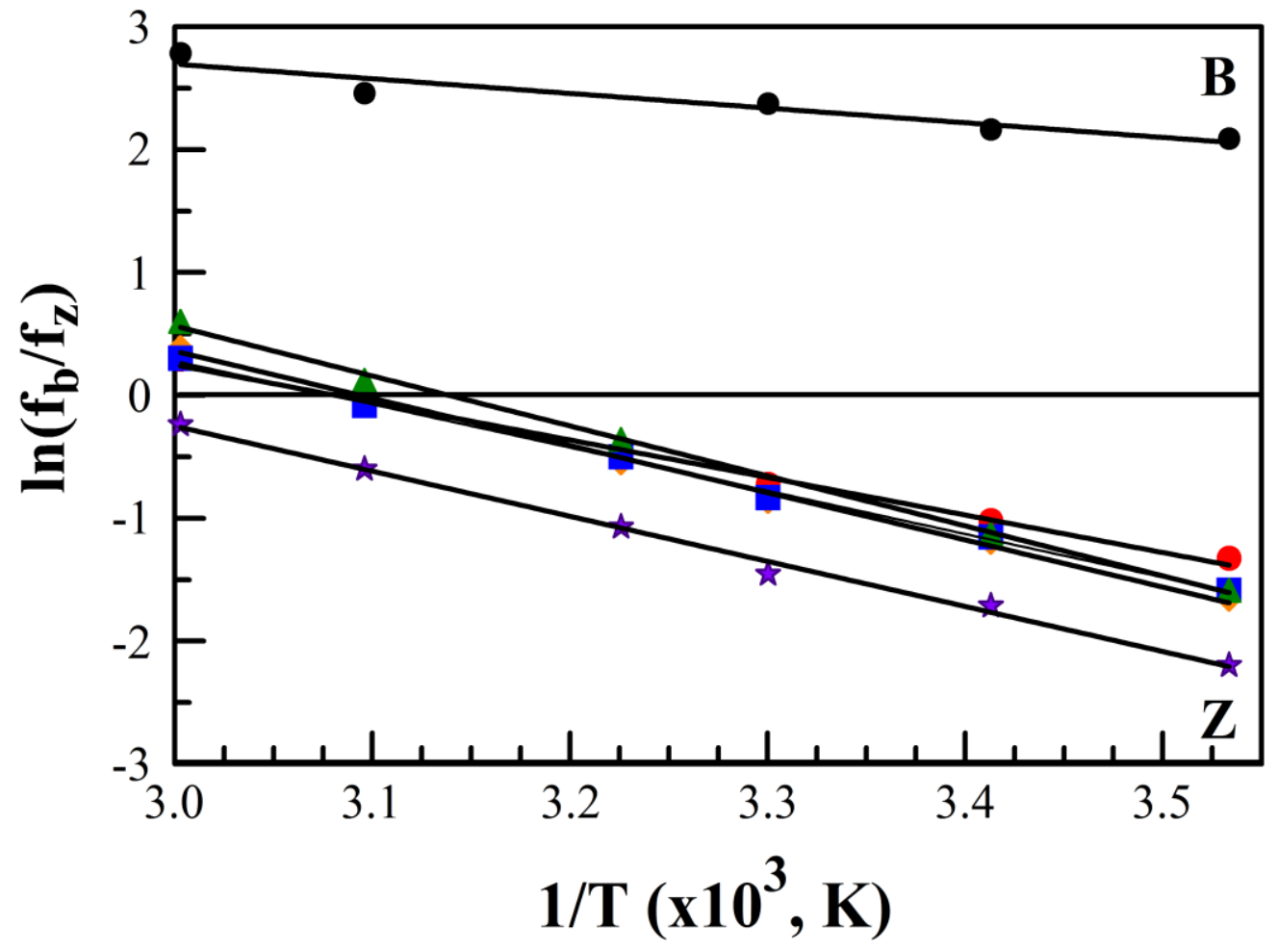

Figure 3.16. Van't Hoff plot of the hairpin mole fraction vs. temperature. Displayed are the unmodified HP-CG (black circles), $\mathrm{HP}_{-\mathrm{CG}}{ }^{8 \mathrm{Ph}}$ (blue squares), $\mathrm{HP}^{-\mathrm{CG}^{8 \mathrm{Tol}}}$ (green triangles), $\mathrm{HP}^{-\mathrm{CG}^{8 \mathrm{HMPh}}}$ (red circles), $\mathrm{HP}^{-\mathrm{CG}^{8 \mathrm{MMPh}}}$ (orange diamonds) and HP-CG ${ }^{8 \mathrm{CPh}}$ (purple stars) in sodium phosphate (10 mM, pH 7.0) in $2000 \mathrm{mM} \mathrm{NaCl}$ for the unmodified hairpin and $1000 \mathrm{mM} \mathrm{NaCl}$ for the $\mathrm{C} 8$-arylguanine modified hairpins. 
Table 3.10. Thermodynamic parameters for the hairpin oligonucleotides

\begin{tabular}{|l|c|c|c|}
\hline \multicolumn{1}{|c|}{ Hairpin } & $\Delta \mathrm{G}^{\mathrm{a}}$ & $\Delta \mathrm{H}^{\mathrm{a}}$ & $\Delta \mathrm{S}^{\mathrm{a}}$ \\
\hline $\mathrm{CG}$ & 1.4 & -2.1 & -11.4 \\
\hline $\mathrm{CG}^{8 \mathrm{Ph}}$ & -0.58 & -6.99 & -21.5 \\
\hline $\mathrm{CG}^{8 \mathrm{Tol}}$ & -0.52 & -8.08 & -25.4 \\
\hline $\mathrm{CG}^{8 \mathrm{HMPh}}$ & -0.50 & -6.07 & -18.7 \\
\hline $\mathrm{CG}^{8 \mathrm{MMPh}}$ & -0.60 & -7.63 & -23.6 \\
\hline $\mathrm{CG}^{8 \mathrm{CPh}}$ & -0.92 & -7.30 & -21.4 \\
\hline
\end{tabular}

${ }^{a}$ Thermodynamic parameters were obtained from oligonucleotide solutions $(25 \mu \mathrm{M})$ in sodium phosphate (10 mm, $\mathrm{pH} 7.0)$ and $\mathrm{NaCl}(1000 \mathrm{mM}$ (modified hairpins) and $2000 \mathrm{mM}$ (unmodified hairpin)) at $298 \mathrm{~K} . \Delta \mathrm{G}$ and $\Delta \mathrm{H}$ are in $\mathrm{kcal} \mathrm{mol}^{-1}$ $\mathrm{K}^{-1}$ and $\Delta \mathrm{S}$ is in cal $\mathrm{mol}^{-1} \mathrm{~K}^{-1}$.

\section{Melting Temperature}

The melting temperature $\left(\mathrm{T}_{\mathrm{M}}\right)$ of the unmodified and $\mathrm{C} 8$-arylguanine modified hairpins were determined from the mole fraction data. $\mathrm{T}_{\mathrm{M}}$ is the temperature at which ([B-DNA] $+[\mathrm{Z}-$ DNA $]) /[$ ss-DNA $]=1$, or, equivalently, when $\left(f_{B}+f_{\mathrm{Z}}\right) / f_{\mathrm{ss}}=1$. The $\mathrm{T}_{\mathrm{M}}$ data was measured as function of the concentration of sodium chloride are presented in Figure 3.17. The C8-arylguanine modification reduced the $\mathrm{T}_{\mathrm{M}}$ (up to $16^{\circ} \mathrm{C}$ ) relative to the unmodified hairpin when in the B-DNA conformation. The differences observed in $\mathrm{T}_{\mathrm{M}}$ diminished as the salt concentration increased and the $\mathrm{Z}$ form became the dominant species. 


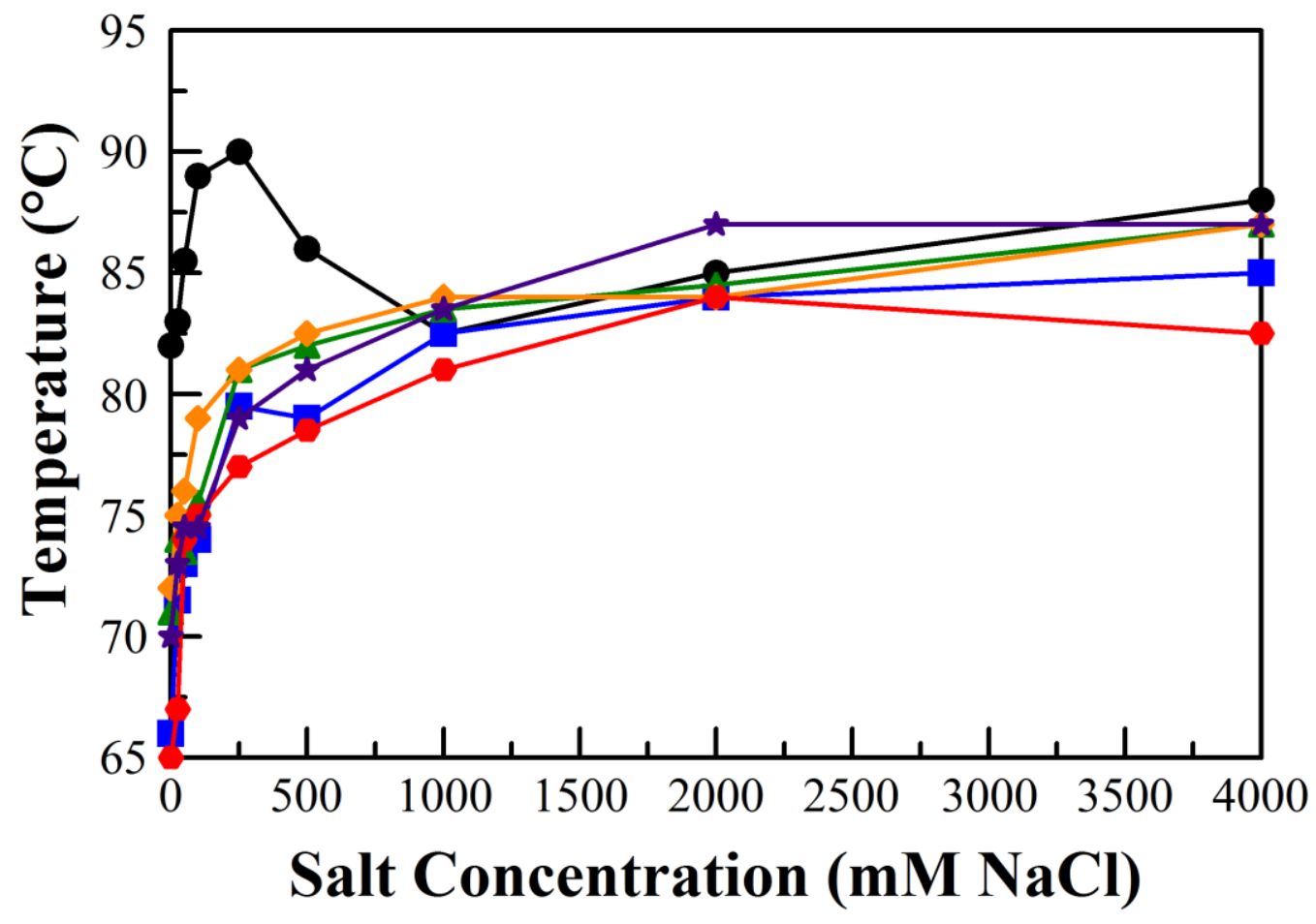

Figure 3.17. Melting temperature profile for unmodified and $\mathrm{C} 8$-arylguanine modified hairpin oligonucleotides as a function of salt concentration $(\mathrm{mM} \mathrm{NaCl})$. The melting temperature at the corresponding salt concentration for unmodified HP-CG (black circles), HP-CG ${ }^{8 \mathrm{Ph}}$ (blue squares), $\mathrm{HP}_{-\mathrm{CG}}{ }^{8 \mathrm{Tol}}$ (green triangles), $\mathrm{HP}-\mathrm{CG}^{8 \mathrm{HMPh}}$ (red hexagons), $\mathrm{HP}-\mathrm{CG}^{8 \mathrm{MMPh}}$ (orange diamonds), and $\mathrm{HP}-\mathrm{CG}^{8 \mathrm{CPh}}$ (purple stars) modified hairpins $(25 \mu \mathrm{M})$ were acquired in solutions of sodium phosphate $(10 \mathrm{mM}, \mathrm{pH}=7.0)$ and the indicated $\mathrm{NaCl}$ concentration over a temperature range of $10-99^{\circ} \mathrm{C}$. 


\section{Conformational Preferences of the B-/Z-DNA Equilibrium under Physiological Conditions}

The conformational effects of the C8-arylguanine modifications were examined in

physiological salt conditions. ${ }^{23,162-164}$ In particular, CD spectra were obtained on the unmodified and the $\mathrm{C} 8$-arylguanine modified hairpins in the presence of $\mathrm{MgCl}_{2}, \mathrm{KCl}, \mathrm{NaCl}$, and spermine. In samples containing $10 \mathrm{mM} \mathrm{MgCl}_{2}, 10 \mathrm{mM} \mathrm{NaCl}$, and $140 \mathrm{mM} \mathrm{KCl}$, with or without spermine, the $\mathrm{CD}$ indicated the $\mathrm{C} 8$-arylguanine modified hairpin (Figure 3.19, $\mathrm{HP}-\mathrm{CG}^{8 \mathrm{Ph}}$; Figure 3.20, HP-CG ${ }^{8 \mathrm{Tol}}$; Figure 3.21, $\mathrm{HP}-\mathrm{CG}^{8 \mathrm{HMPh}}$; Figure 3.22, $\mathrm{HP}_{-\mathrm{CG}}{ }^{8 \mathrm{MMPh}}$; Figure 3.23, $\mathrm{HP}-\mathrm{CG}^{8 \mathrm{CPh}}$ ) was in $\sim 100 \%$ Z-DNA conformation. Reducing the $\mathrm{MgCl}_{2}$ concentration (10 to $2 \mathrm{mM}$ ) in the presence of spermine had no effect on the B-/Z-DNA equilibrium and the modified hairpin oligonucleotides remained in the Z-DNA conformation. In contrast, the unmodified hairpin (Figure 3.18) was unaffected by any of these conditions and remained in the B-DNA conformation. 


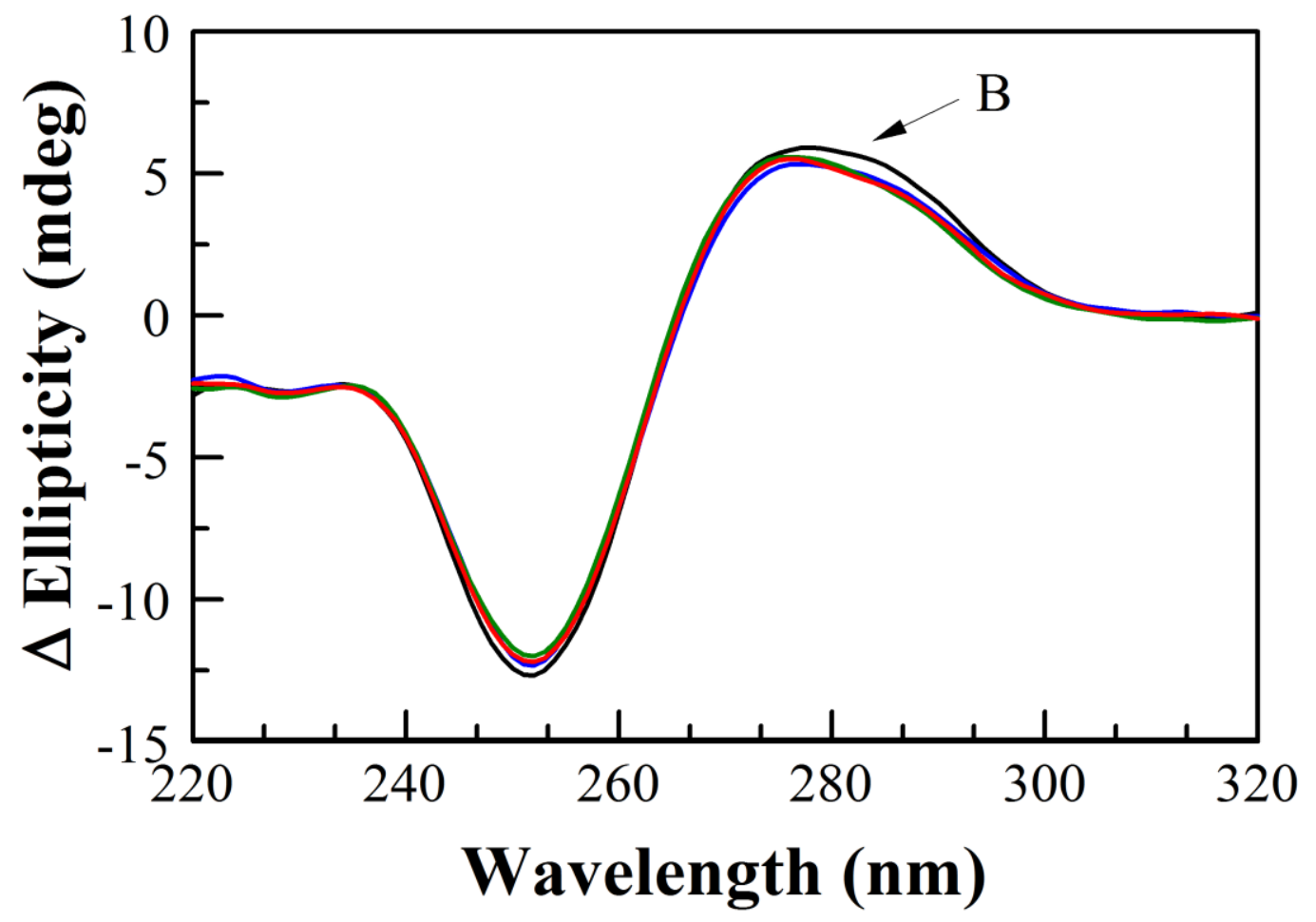

Figure 3.18. Unmodified hairpin HP-CG CD spectra under physiological salt conditions. CD spectra of the unmodified hairpin $(25 \mu \mathrm{M})$ at $37{ }^{\circ} \mathrm{C}(\mathrm{pH} 7.4)$ in $2 \mathrm{mM} \mathrm{MgCl}_{2}, 10 \mathrm{mM} \mathrm{NaCl}$ and $140 \mathrm{mM} \mathrm{KCl}$ (black), $10 \mathrm{mM}$ $\mathrm{MgCl}_{2}, 10 \mathrm{mM} \mathrm{NaCl}, 140 \mathrm{mM} \mathrm{KCl}$ (blue), $2 \mathrm{mM} \mathrm{MgCl}_{2}, 10 \mathrm{mM} \mathrm{NaCl}, 140 \mathrm{KCl}$ and $1 \mathrm{mM}$ spermine (green) and 10 $\mathrm{mM} \mathrm{MgCl} 2,10 \mathrm{mM} \mathrm{NaCl}, 140 \mathrm{mM} \mathrm{KCl}$ and $1 \mathrm{mM}$ spermine (red). 


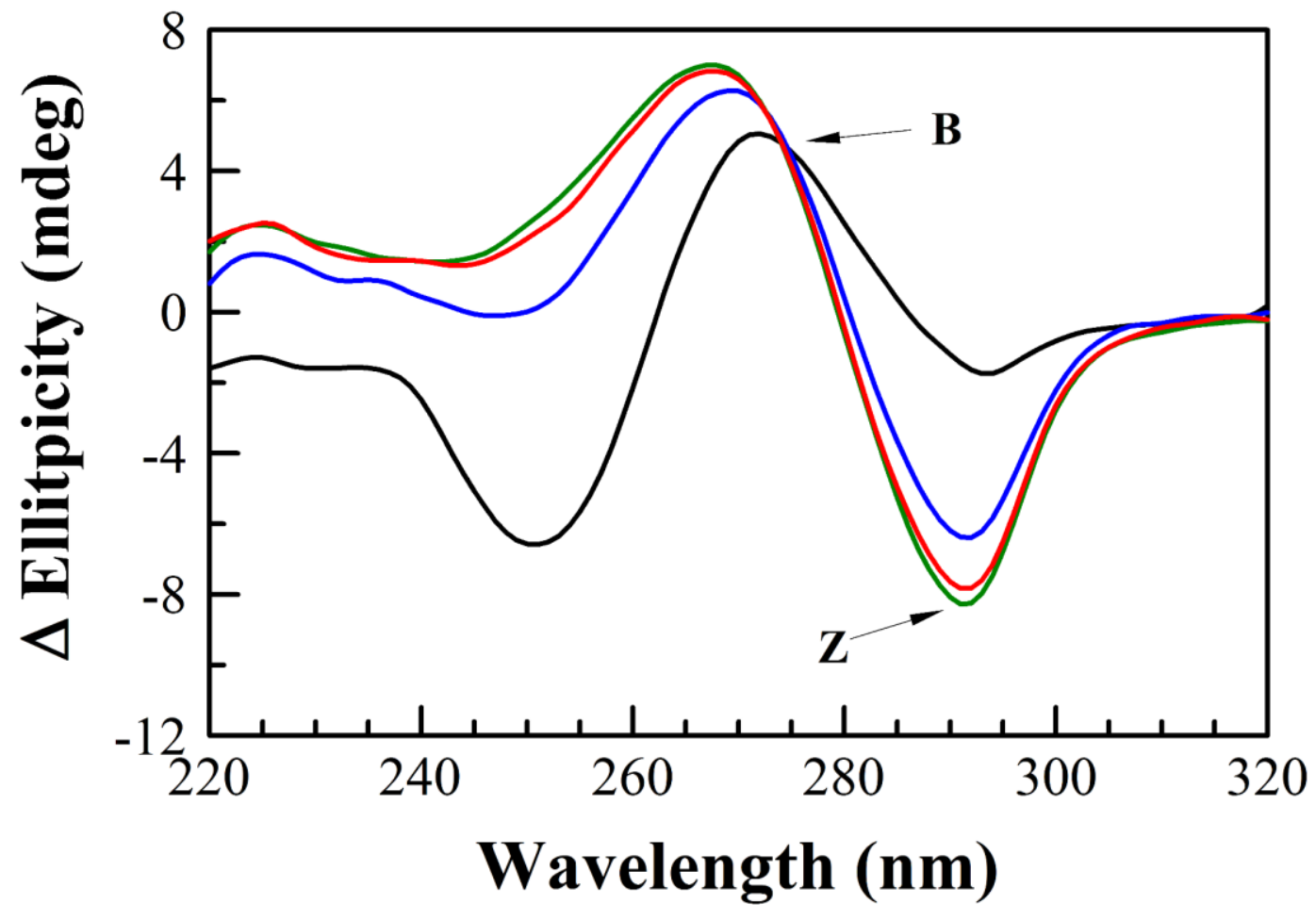

Figure 3.19. Modified hairpin $\mathrm{HP}-\mathrm{CG}^{8 \mathrm{Ph}} \mathrm{CD}$ spectra under physiological salt conditions. CD spectra of the unmodified hairpin $(25 \mu \mathrm{M})$ at $37^{\circ} \mathrm{C}(\mathrm{pH} 7.4)$ in $2 \mathrm{mM} \mathrm{MgCl} 2,10 \mathrm{mM} \mathrm{NaCl}$ and $140 \mathrm{mM} \mathrm{KCl}$ (black), $10 \mathrm{mM}$ $\mathrm{MgCl}_{2}, 10 \mathrm{mM} \mathrm{NaCl}, 140 \mathrm{mM} \mathrm{KCl}$ (blue), $2 \mathrm{mM} \mathrm{MgCl}_{2}, 10 \mathrm{mM} \mathrm{NaCl}, 140 \mathrm{KCl}$ and $1 \mathrm{mM}$ spermine (green) and 10 $\mathrm{mM} \mathrm{MgCl} 2,10 \mathrm{mM} \mathrm{NaCl}, 140 \mathrm{mM} \mathrm{KCl}$ and $1 \mathrm{mM}$ spermine (red). 


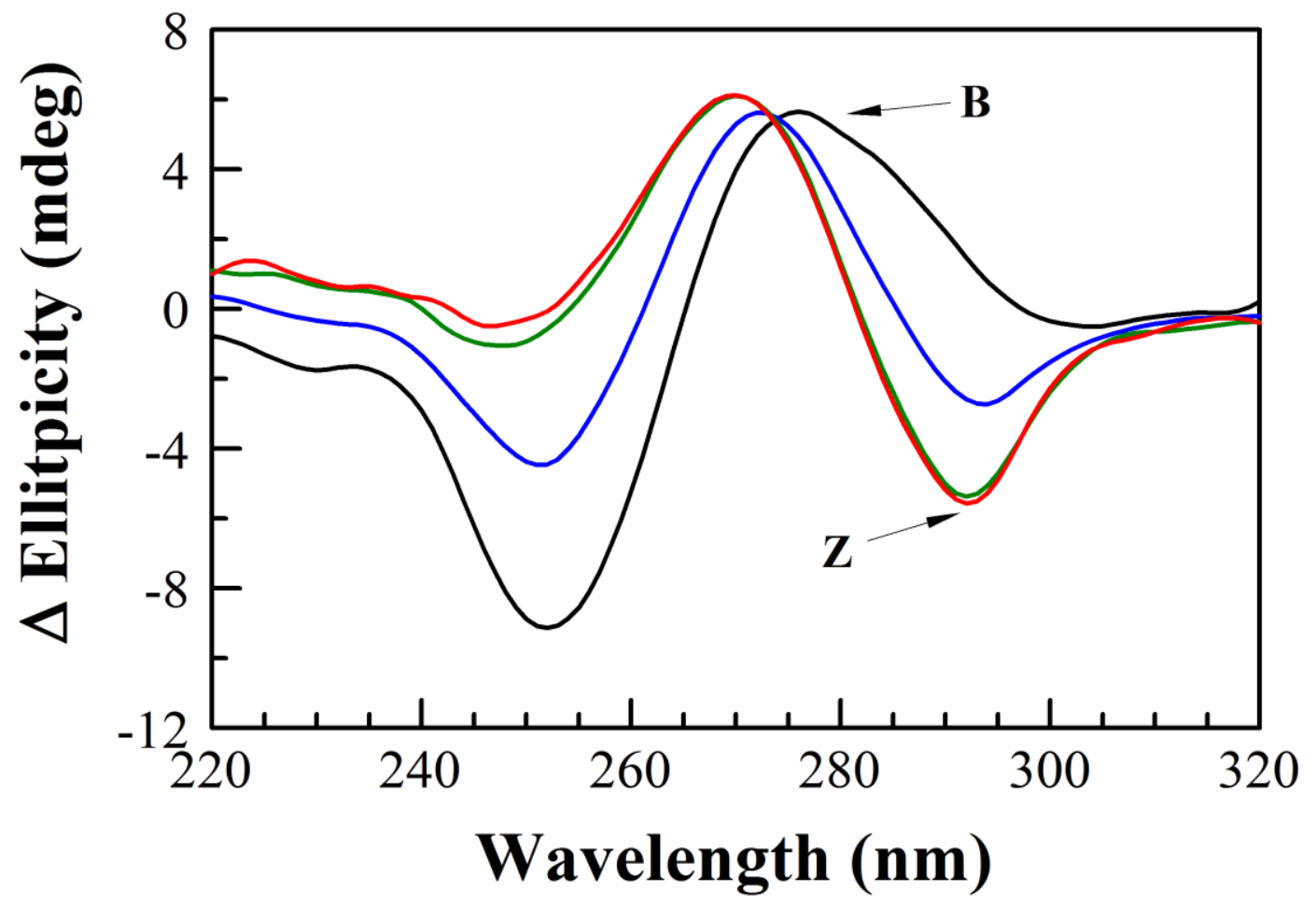

Figure 3.20. Modified hairpin HP-CG ${ }^{8 T o l} \mathrm{CD}$ spectra under physiological salt conditions. CD spectra of the unmodified hairpin $(25 \mu \mathrm{M})$ at $37{ }^{\circ} \mathrm{C}(\mathrm{pH} 7.4)$ in $2 \mathrm{mM} \mathrm{MgCl}_{2}, 10 \mathrm{mM} \mathrm{NaCl}$ and $140 \mathrm{mM} \mathrm{KCl}$ (black), $10 \mathrm{mM}$ $\mathrm{MgCl}_{2}, 10 \mathrm{mM} \mathrm{NaCl}, 140 \mathrm{mM} \mathrm{KCl}$ (blue), $2 \mathrm{mM} \mathrm{MgCl}_{2}, 10 \mathrm{mM} \mathrm{NaCl}, 140 \mathrm{KCl}$ and $1 \mathrm{mM}$ spermine (green) and 10 $\mathrm{mM} \mathrm{MgCl} 2,10 \mathrm{mM} \mathrm{NaCl}, 140 \mathrm{mM} \mathrm{KCl}$ and $1 \mathrm{mM}$ spermine (red). 


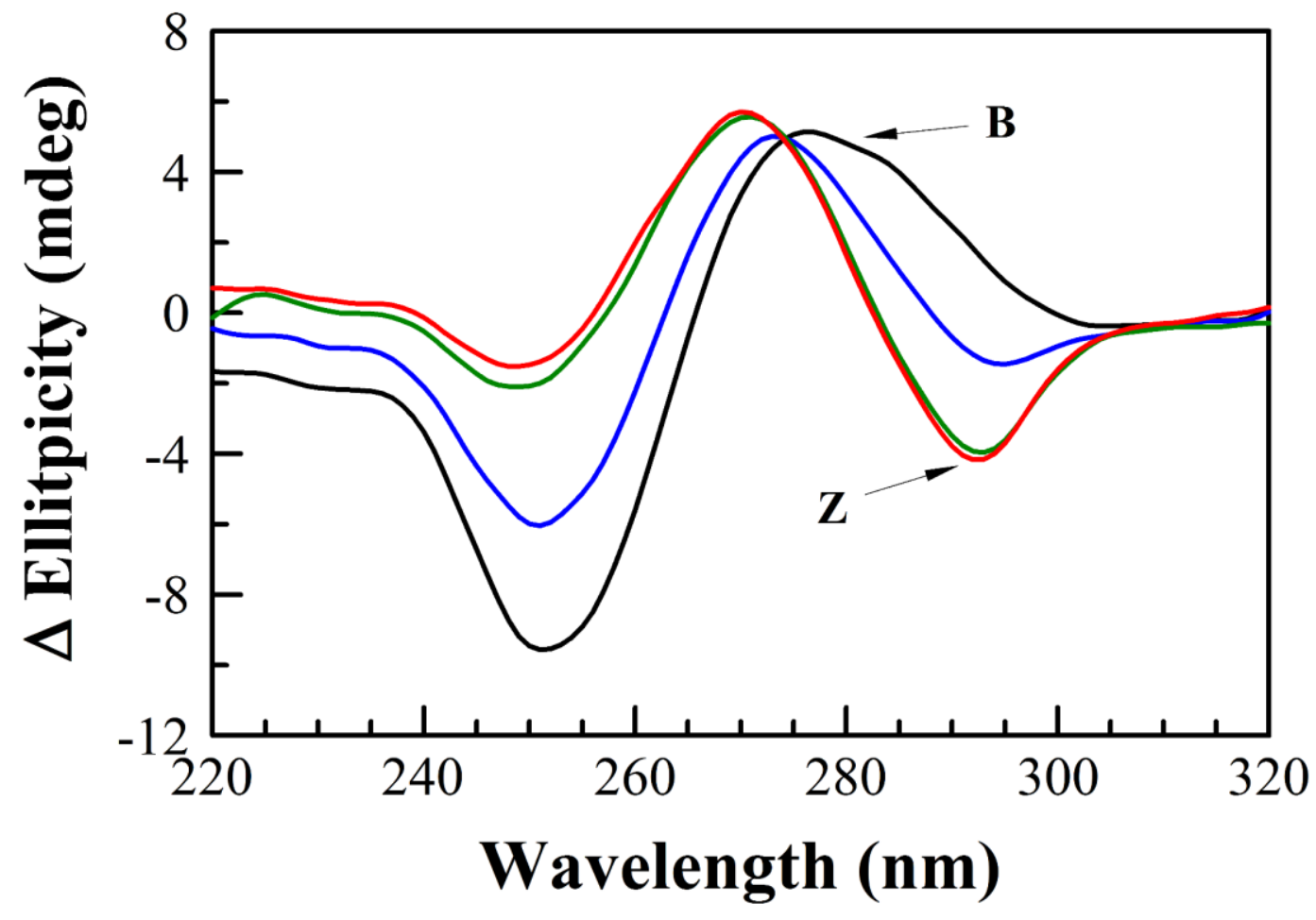

Figure 3.21. Modified hairpin HP-CG ${ }^{8 H M P h} C D$ spectra under physiological salt conditions. $\mathrm{CD}$ spectra of the unmodified hairpin $(25 \mu \mathrm{M})$ at $37{ }^{\circ} \mathrm{C}(\mathrm{pH} 7.4)$ in $2 \mathrm{mM} \mathrm{MgCl}_{2}, 10 \mathrm{mM} \mathrm{NaCl}$ and $140 \mathrm{mM} \mathrm{KCl}$ (black), $10 \mathrm{mM}$ $\mathrm{MgCl}_{2}, 10 \mathrm{mM} \mathrm{NaCl}, 140 \mathrm{mM} \mathrm{KCl}$ (blue), $2 \mathrm{mM} \mathrm{MgCl}_{2}, 10 \mathrm{mM} \mathrm{NaCl}, 140 \mathrm{KCl}$ and $1 \mathrm{mM}$ spermine (green) and 10 $\mathrm{mM} \mathrm{MgCl} 2,10 \mathrm{mM} \mathrm{NaCl}, 140 \mathrm{mM} \mathrm{KCl}$ and $1 \mathrm{mM}$ spermine (red). 


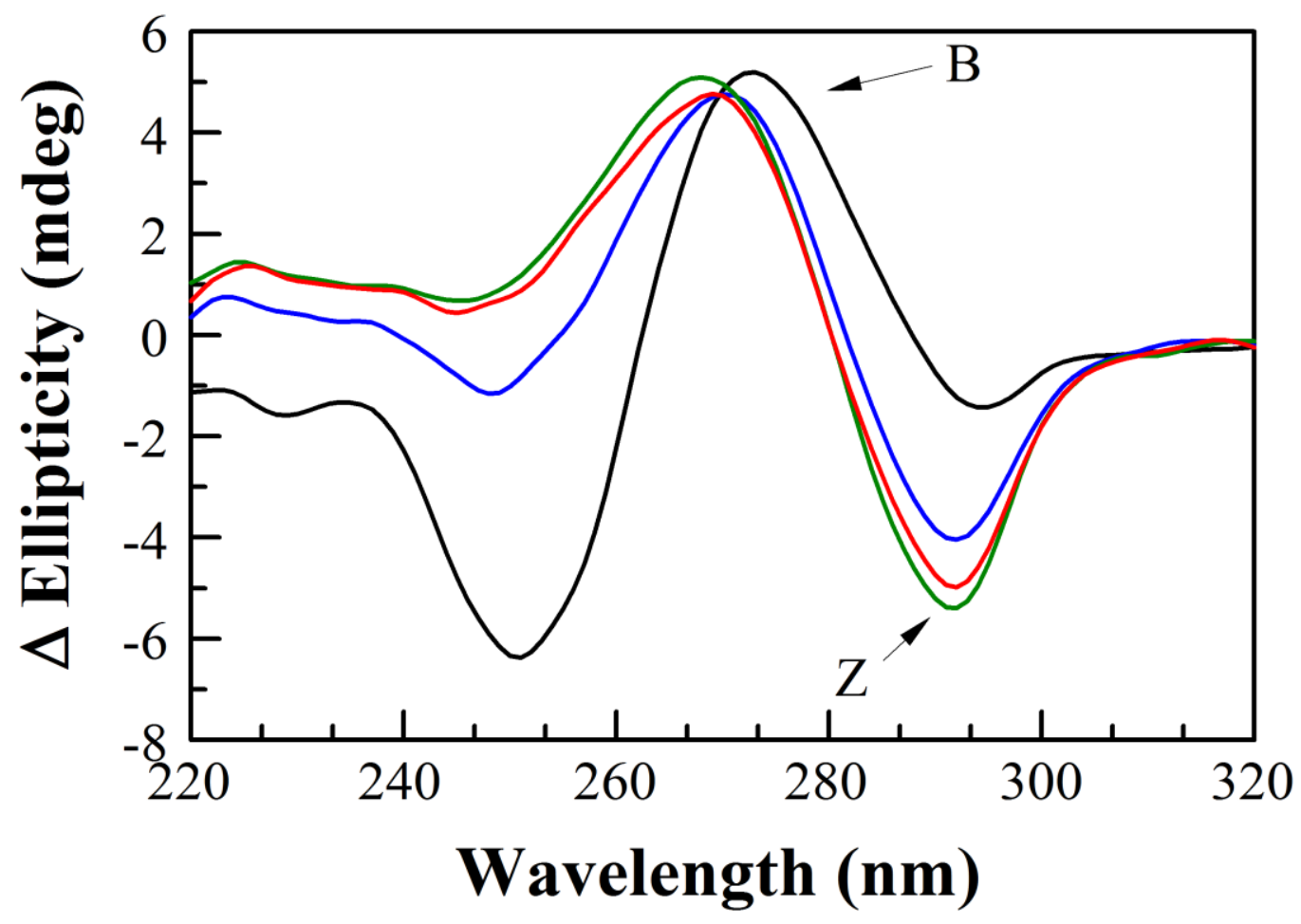

Figure 3.22. Modified hairpin $\mathrm{HP}-\mathrm{CG}^{8 \mathrm{MMPh}} \mathrm{CD}$ spectra under physiological salt conditions. CD spectra of the unmodified hairpin $\left(25 \mu \mathrm{M}\right.$ ) at $37{ }^{\circ} \mathrm{C}(\mathrm{pH} 7.4)$ in $2 \mathrm{mM} \mathrm{MgCl}_{2}, 10 \mathrm{mM} \mathrm{NaCl}$ and $140 \mathrm{mM} \mathrm{KCl}$ (black), $10 \mathrm{mM}$ $\mathrm{MgCl}_{2}, 10 \mathrm{mM} \mathrm{NaCl}, 140 \mathrm{mM} \mathrm{KCl}$ (blue), $2 \mathrm{mM} \mathrm{MgCl}_{2}, 10 \mathrm{mM} \mathrm{NaCl}, 140 \mathrm{KCl}$ and $1 \mathrm{mM}$ spermine (green) and $10 \mathrm{mM} \mathrm{MgCl} 2,10 \mathrm{mM} \mathrm{NaCl}, 140 \mathrm{mM} \mathrm{KCl}$ and $1 \mathrm{mM}$ spermine (red). 


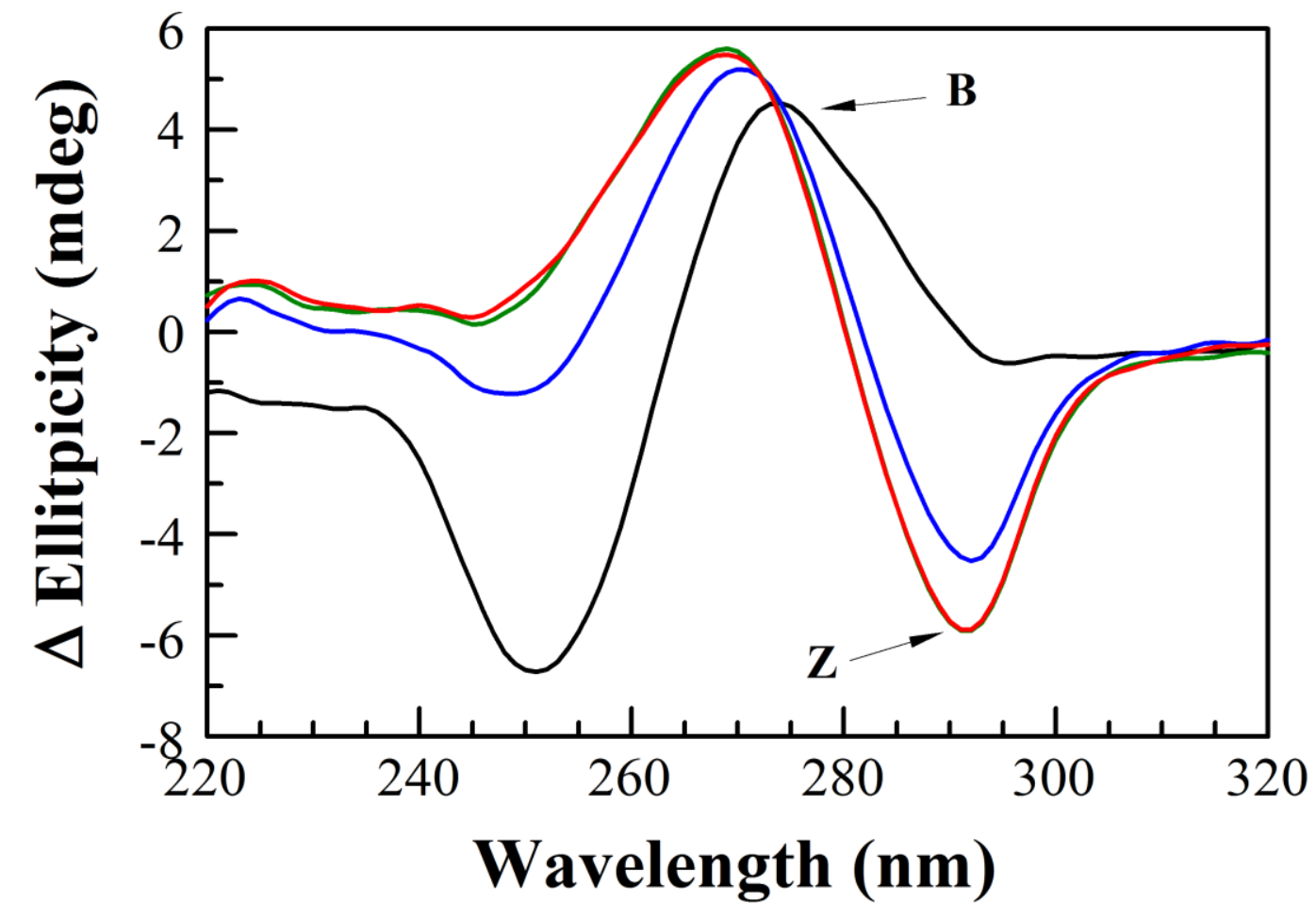

Figure 3.23. Modified hairpin $\mathrm{HP}-\mathrm{CG}^{8 \mathrm{CPh}} \mathrm{CD}$ spectra under physiological salt conditions. $\mathrm{CD}$ spectra of the unmodified hairpin $(25 \mu \mathrm{M})$ at $37^{\circ} \mathrm{C}(\mathrm{pH} 7.4)$ in $2 \mathrm{mM} \mathrm{MgCl}_{2}, 10 \mathrm{mM} \mathrm{NaCl}$ and $140 \mathrm{mM} \mathrm{KCl}$ (black), $10 \mathrm{mM}$ $\mathrm{MgCl}_{2}, 10 \mathrm{mM} \mathrm{NaCl}, 140 \mathrm{mM} \mathrm{KCl}$ (blue), $2 \mathrm{mM} \mathrm{MgCl}_{2}, 10 \mathrm{mM} \mathrm{NaCl}, 140 \mathrm{KCl}$ and $1 \mathrm{mM}$ spermine (green) and 10 $\mathrm{mM} \mathrm{MgCl} 2,10 \mathrm{mM} \mathrm{NaCl}, 140 \mathrm{mM} \mathrm{KCl}$ and $1 \mathrm{mM}$ spermine (red). 


\section{Part III: NMR Analysis of the Hairpin Oligonucleotides}

The CD experiments described in Part II provide partial information regarding the conformational preferences for the B-/Z-DNA conformation preferences of the C8-arylguanine modified hairpin oligonucleotides relative to the unmodified hairpin. However, CD data only provides information about the global conformation of the oligonucleotides in solution and, therefore, to determine the local environment of the C8-arylguanine modification, NMR was used. NMR has been extensively used to determine the conformation of nucleic acids primarily through two-dimensional (2D) techniques such as COSY and NOESY. ${ }^{121,150,151}$ We have applied these techniques to examine the B- and Z-DNA conformations of the C8-arylguanine modified

oligonucleotides. ${ }^{98,100}$ The techniques used here follow the previously reported assignment procedures of the non-exchangeable protons in oligonucleotides by Scheek et al. ${ }^{152}$ and Hare and Reid. $^{119,153}$

\section{A. General}

NMR spectra were acquired on samples containing deuterated sodium phosphate $(10 \mathrm{mM}$, apparent pD 7.0, $0.5 \mathrm{~mL}$ ) in $\mathrm{D}_{2} \mathrm{O}$ on a Varian $600 \mathrm{MHz}$ spectrometer (Paolo Alto, Ca). Deuterated sodium phosphate solutions were prepared by drying down the sodium phosphate in vacuo in a SpeedVac ${ }^{\mathrm{TM}}$ and then re-dissolving the solute in an equal volume of "100\%" deuterium oxide $\left(\mathrm{D}_{2} \mathrm{O}, 99.996 \%, 0.5 \mathrm{~mL}\right)$. This process was repeated three times to prepare the deuterated sodium phosphate. The hairpin oligonucleotides $(\sim 1.5 \mathrm{mM})$ were dissolved in deuterated sodium phosphate $(10 \mathrm{mM})$ and sodium chloride $(25 \mathrm{mM})$ for the $\mathrm{B}$ form and the addition of $\mathrm{MgCl}_{2}$ (50 $\mathrm{mM}$ ) was used for the $\mathrm{Z}$ form. Hairpin oligonucleotides samples were annealed at $90{ }^{\circ} \mathrm{C}$ for $5 \mathrm{~min}$ 
then slowly cooled to $\mathrm{rt}$ over $1.5 \mathrm{~h}$. Samples were filtered using Fisherbrand ${ }^{\mathrm{TM}}$ syringe filters (Nylon, pore size: $0.45 \mu \mathrm{m}$, Waltham, MA) then transferred to a Shigemi NMR tube (5 mm, Allison Park, PA). NMR spectra were acquired at $\mathrm{rt}\left(25^{\circ} \mathrm{C}\right) .{ }^{1} \mathrm{H}$ NMR spectra (1D) were obtained acquiring 128 transients (nt). ${ }^{1} \mathrm{H}^{-1} \mathrm{H}$ gCOSY spectra were collected with $16 \mathrm{nt}$ and $512 \mathrm{t}_{1}$ increments. Data were zero-filled by transforming the data with $2048 \mathrm{t}_{2}$ complex points. NOESY spectra were acquired with mixing time of $100 \mathrm{~ms}$ (B form) and $600 \mathrm{~ms}$ ( $\mathrm{Z}$ form) and data collected with $512 \mathrm{t}_{1}$ increments, $16 \mathrm{nt}$ each. Data was transformed with $2048 \mathrm{t}_{2}$ complex points.

\section{B. Non-exchangeable Proton Assignment for B-DNA}

The non-exchangeable protons of the hairpin oligonucleotides in the B-DNA conformation were assigned using data from ${ }^{1} \mathrm{H}$ 1D NMR, gCOSY and NOESY 2D NMR experiments. 1D spectra of the hairpin oligonucleotides can be used to determine the general location of the base and sugar protons of the individual nucleotides in the hairpin. The non-exchangeable protons of the oligonucleotides are found in the $0-9$ ppm range of the ${ }^{1} \mathrm{H}$ NMR spectrum; where the base protons are the most downfield $(5.30-8.0 \mathrm{ppm})$ and the sugar protons exhibit a broad chemical shift range $(1.46-6.20 \mathrm{ppm})$. The $\mathrm{C} 8$-aryl protons are also downfield in the aromatic region $(7.52$ $-8.07 \mathrm{ppm})$. The base, the $\mathrm{C} 8$-aryl protons, and the $\mathrm{dT}-\mathrm{CH}_{3}$ protons can be loosely assigned based on their relative location and multiplicity in the ${ }^{1} \mathrm{H}$ spectrum. The dG-H8 and dT-H6 protons exhibit singlets in the aromatic region $(\sim 6.0-8.0 \mathrm{ppm})$ where the $\mathrm{dC}-\mathrm{H} 6$ protons $(7.01-7.68$ ppm) should appear as doublets in this region and the $\mathrm{dC}-\mathrm{H} 5$ protons are upfield $(5.23-5.97 \mathrm{ppm})$. The C8-aryl protons, except the C8-phenylguanine derivative, also exhibit doublets in the aromatic region. Unfortunately, the deoxyribose sugar protons have a similar chemical environment relative to the other identical deoxyribose residues in the hairpin oligonucleotide sequence $(10 \mathrm{dG}, 10 \mathrm{dC}$, 
and four dT) and are not well resolved. This is a problem also shared by the base protons which leads to large clusters of multiplets or otherwise unresolved peaks. Complete assignment of the chemical shifts in the $1 \mathrm{D}{ }^{1} \mathrm{H}$ spectral data was generally possible using a combination of the $2 \mathrm{D}$ gCOSY and NOESY data.

gCOSY (gradient COSY) (see Experimental 2.G) provides $J$-coupling correlations based on scalar coupling (i.e., on adjacent nuclei). In the case of the hairpin oligonucleotides, only the $\mathrm{dC}-\mathrm{H} 6 / \mathrm{H} 5$ protons and the protons of the $\mathrm{C} 8$-arylguanine group show scalar coupling in the aromatic region. The H6-H5 coupling exhibit correlations further from the diagonal since the H6 and $\mathrm{H} 5{ }^{1} \mathrm{H}$ chemical shift differences are larger. The $\mathrm{C} 8$-arylguanine protons are the only protons that give rise to correlations between $7-8 \mathrm{ppm}$. In addition, the dT-H6 and dT- $\mathrm{CH}_{3}$ exhibit unique four-bond coupling and off-diagonal correlations can be see between these protons and are in a region where no other protons will have correlations (1.65 to $7.60 \mathrm{ppm})$. The H1' $\rightarrow \mathrm{H} 2{ }^{\prime} / \mathrm{H} 2^{\prime}$ ' correlations can also be observed and assigned in the gCOSY spectra because their relatively large chemical shift difference. However these proton resonances cannot be assigned to a particular nucleotide in the sequence and therefore one must also acquire NOESY spectra for assignment of these protons to a particular base in the sequence.

NOESY spectra shows correlations between protons that are close in space $(\sim 4 \AA)$ which is very useful in the assignment of the non-exchangeable protons in the hairpin oligonucleotides because several protons within the same nucleotide such as ArH/H8/H5/6 $\rightarrow \mathrm{H} 1$ ', $\mathrm{ArH} / \mathrm{H} 8 / \mathrm{H} 5 / 6 \rightarrow \mathrm{H} 2$ ' and $\mathrm{ArH} / \mathrm{H} 8 / \mathrm{H} 5 / 6 \rightarrow \mathrm{H} 2$ " can be observed, which were used to confirm the assignments made for the gCOSY spectra. In addition, several of the protons of any given nucleotide are close enough to show NOEs to the adjacent nucleotide(s). Thereby, using these NOE correlations with the already determined intranucleotide resonances, one can sequentially 
assign the protons of one nucleotide to the adjacent nucleotide(s) in the sequence. Figure 3.24 summarizes the assignment procedure for the hairpin oligonucleotides used here.

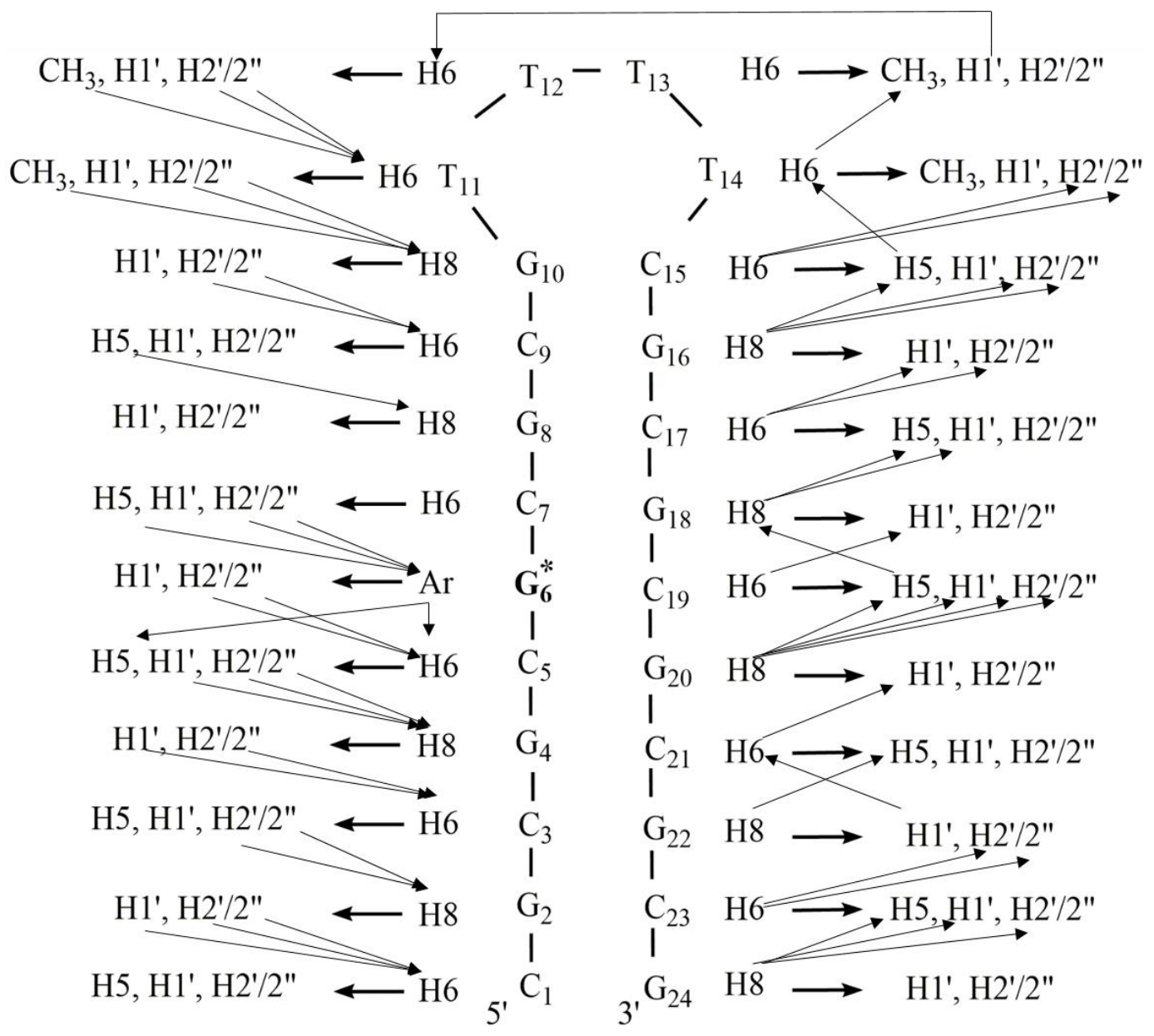

Figure 3.24. NMR assignment procedure for the hairpin oligonucleotides. The arrows show the NOEs used for the assignment of the intranucleotide and internucleotide resonances.

The assignment procedure of the non-exchangeable protons will be described for the HP-CG ${ }^{8 M M P h}$ as a representative model for the unmodified and other $\mathrm{C} 8$-arylguanine modified hairpins in the B-DNA conformation (NMR spectra $\left({ }^{1} \mathrm{H}, \mathrm{gCOSY}, \mathrm{NOESY}\right)$ for the other hairpin oligonucleotides are shown in Appendix C). Initial inspection of the ${ }^{1} \mathrm{H}$ spectrum between $5.2-$ 8.1 ppm (Figure 3.25) reveals extensive signal overlap, especially between $5.72-6.22 \mathrm{ppm}$, which 
likely corresponds to $24 \mathrm{H} 1$ ' protons and a couple dC-H5 protons. The five furthest downfield peaks and probably correspond to nine dG-H8 protons. Between $7.63-7.83 \mathrm{ppm}$ are a series of multiplets, which correspond to the $\mathrm{C} 8-$ aryl- $\mathrm{dG}_{6}$ protons as well as a couple of $\mathrm{dC}-\mathrm{H} 6$ protons. The four singlets $(7.42-7.61 \mathrm{ppm})$ are likely the $\mathrm{dT}-\mathrm{H} 6$ resonances as they are expected to be further upfield than the dG-H8 singlets. The remaining series of peaks between $(7.02-7.38 \mathrm{ppm})$ can be then assumed to correspond to the remaining $\mathrm{dC}-\mathrm{H} 6$ protons that mostly likely correlate to the series of peaks between $(5.27-5.51 \mathrm{ppm})$. At this point the ${ }^{1} \mathrm{H}$ spectrum can only be used to further locate the $\mathrm{C} 8 \mathrm{MMPh}-\mathrm{OCH}_{3}$ at $\delta 3.51 \mathrm{ppm}$ and the $\mathrm{dT}-\mathrm{CH}_{3}$ protons at $\delta 1.65,1.76,1.84$ and $1.85 \mathrm{ppm}$ (Figure 3.26). Therefore one must use the gCOSY spectra to assign the dC-H6-H5, dT-H6- $\mathrm{CH}_{3}$, and all the $\mathrm{H}^{\prime}{ }^{\prime}-\mathrm{H} 2^{\prime} / \mathrm{H} 2$ '” pairs.

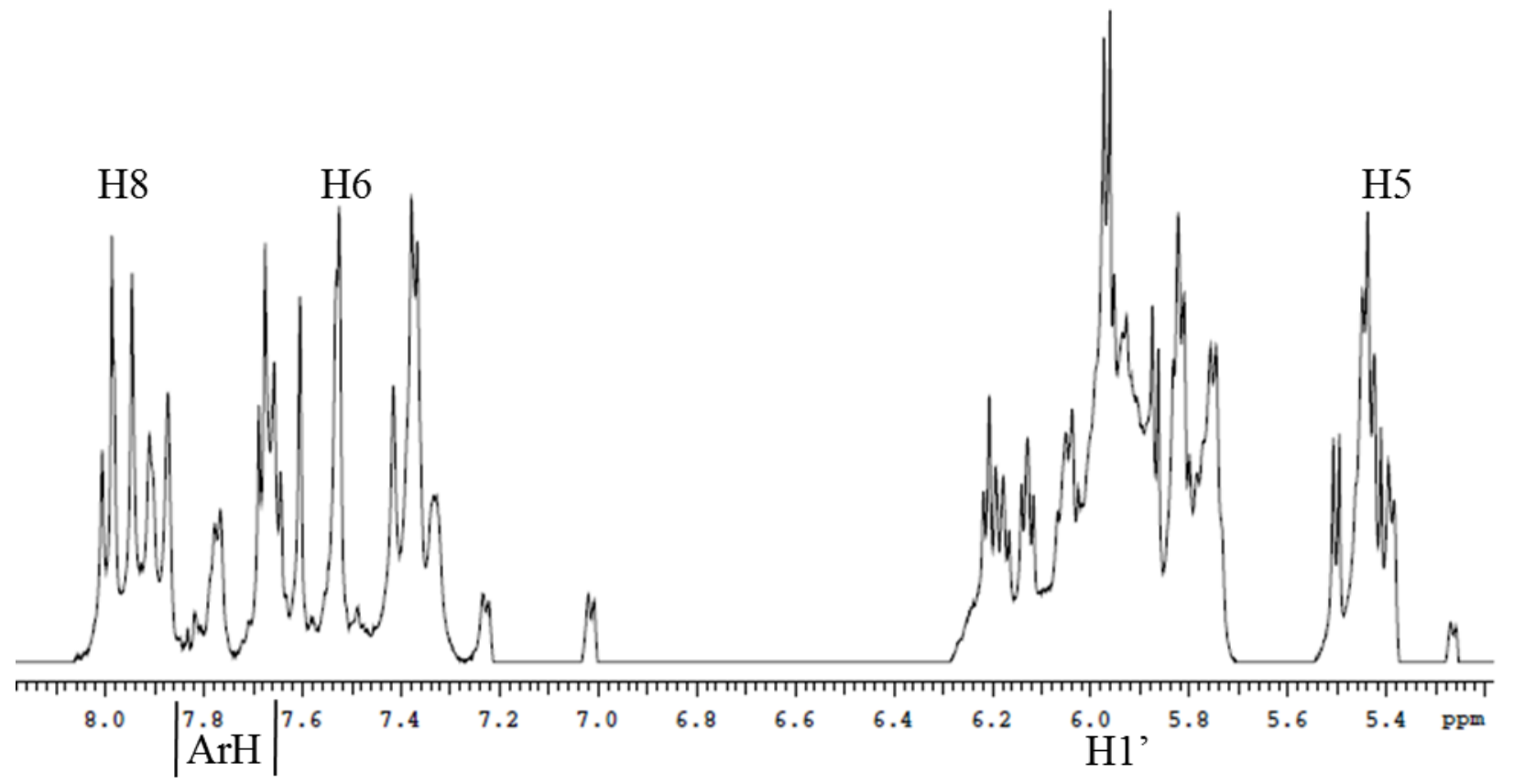

Figure 3.25. Expansion of the aromatic region of the ${ }^{1} \mathrm{H}$ NMR spectrum. The dG-H8, dG-C8-aryl (ArH), dT-H6, dC-H6/H5 and the H1' are labeled above and below the frequency axis (ppm). 


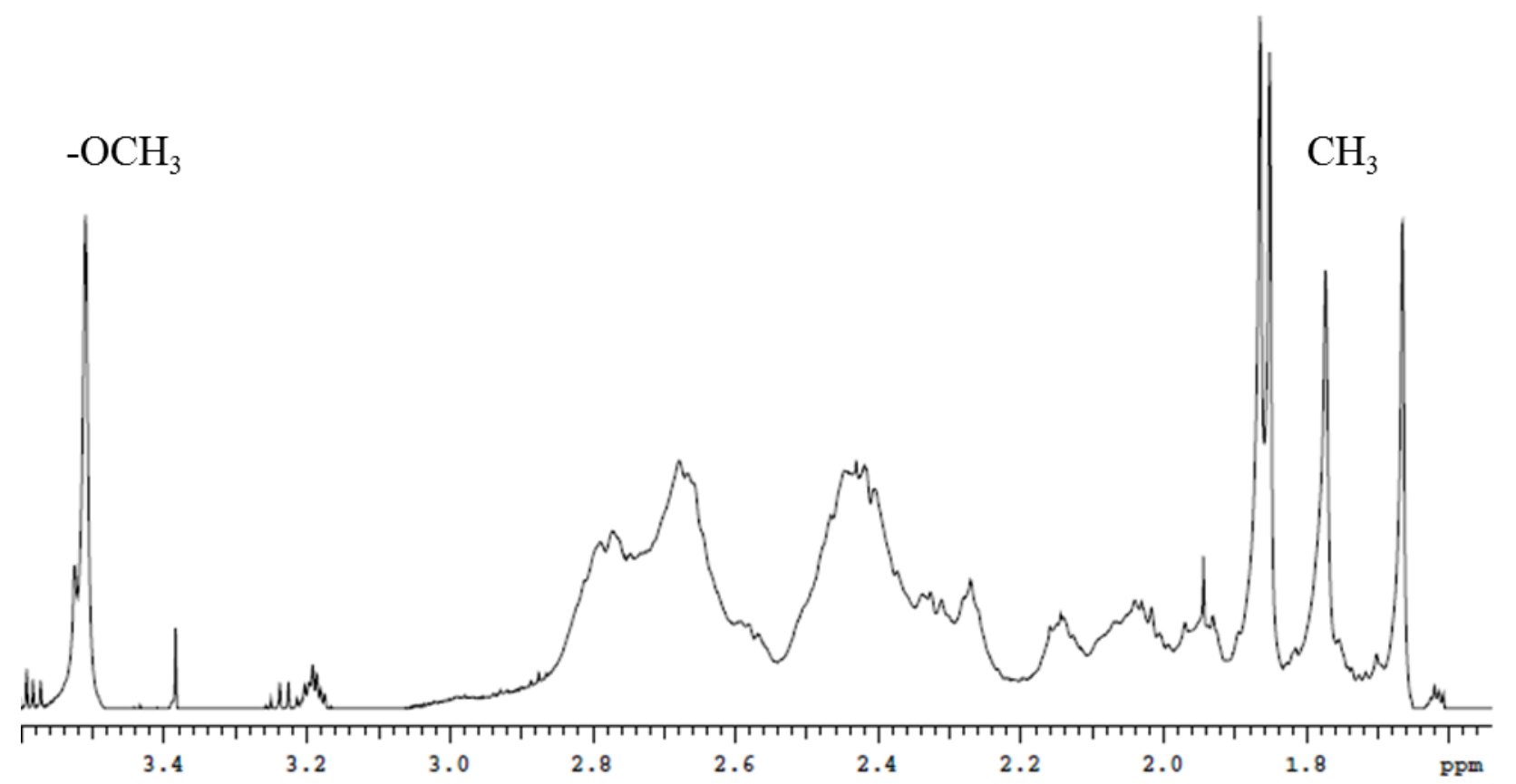

Figure 3.26. Expansion of the upfield region of the ${ }^{1} \mathrm{H}$ NMR spectrum. The dG-MMPh- $-\mathrm{OCH}_{3}$ and dT- $\underline{\mathrm{CH}_{3}}$ are labeled above the spectrum.

The gCOSY spectra support the initial assumptions made in the ${ }^{1} \mathrm{H}$ spectrum. The furthest downfield singlets do not show any correlations with other protons, which confirms these singlets correspond to dG-H8 protons. The multiplets at 7.77 and $7.82 \mathrm{ppm}$ show correlations to 7.67 and $7.54 \mathrm{ppm}$, respectively, and are most likely the $\mathrm{C} 8 \mathrm{-MMPh}$ aromatic protons (Figure 3.27a). Further the multiplet at $7.64-7.69 \mathrm{ppm}$ show correlations to 5.97 and $5.87 \mathrm{ppm}$, which correspond to dC-H6-H5 protons. The series of peaks between $\delta 7.02-7.38$ ppm show correlations to $5.27-$ $5.51 \mathrm{ppm}$ confirming our initial assumption that these resonances belong to the $\mathrm{dC}$ nucleotides (H6-H5 pairs). The final two unique upfield doublets in the $\delta 7-8$ ppm range exhibit correlations 5.39 to $7.23 \mathrm{ppm}$ and 5.27 to $7.01 \mathrm{ppm}$ (Figure $3.27 \mathrm{~b}$ ). The four singlets at 7.41, 7.52, 7.53 and $7.60 \mathrm{ppm}$ show correlations to the upfield singlets at $1.76,1.65,1.85$ and $1.84 \mathrm{ppm}$, respectively, confirming these resonances are due to the dT nucleotides (Figure 3.27c). Finally Figure 3.27d shows the $\mathrm{H} 1$ ' to $\mathrm{H} 2$ '/ $\mathrm{H} 2$ ' ' correlations. The $24 \mathrm{H} 1$ ' protons correlate to $24 \mathrm{H} 2$ ' and $24 \mathrm{H} 2$ " over 
the range of $1.46-2.81 \mathrm{ppm}$. The gCOSY spectra was used to assign the $J$ correlated resonances such as the $\mathrm{dG}_{6}-\mathrm{MMPh}-\mathrm{Ar} / \mathrm{Ar}$, dC-H6/H5 and $\mathrm{dT}-\mathrm{H} 6 / \mathrm{CH}_{3}$ however, deoxyribose sugar proton resonances cannot be assigned to a particular nucleotide. Using the NOESY spectra the H1' can be assigned to either a $\mathrm{dG}, \mathrm{dC}$ or $\mathrm{dT}$ nucleotide.

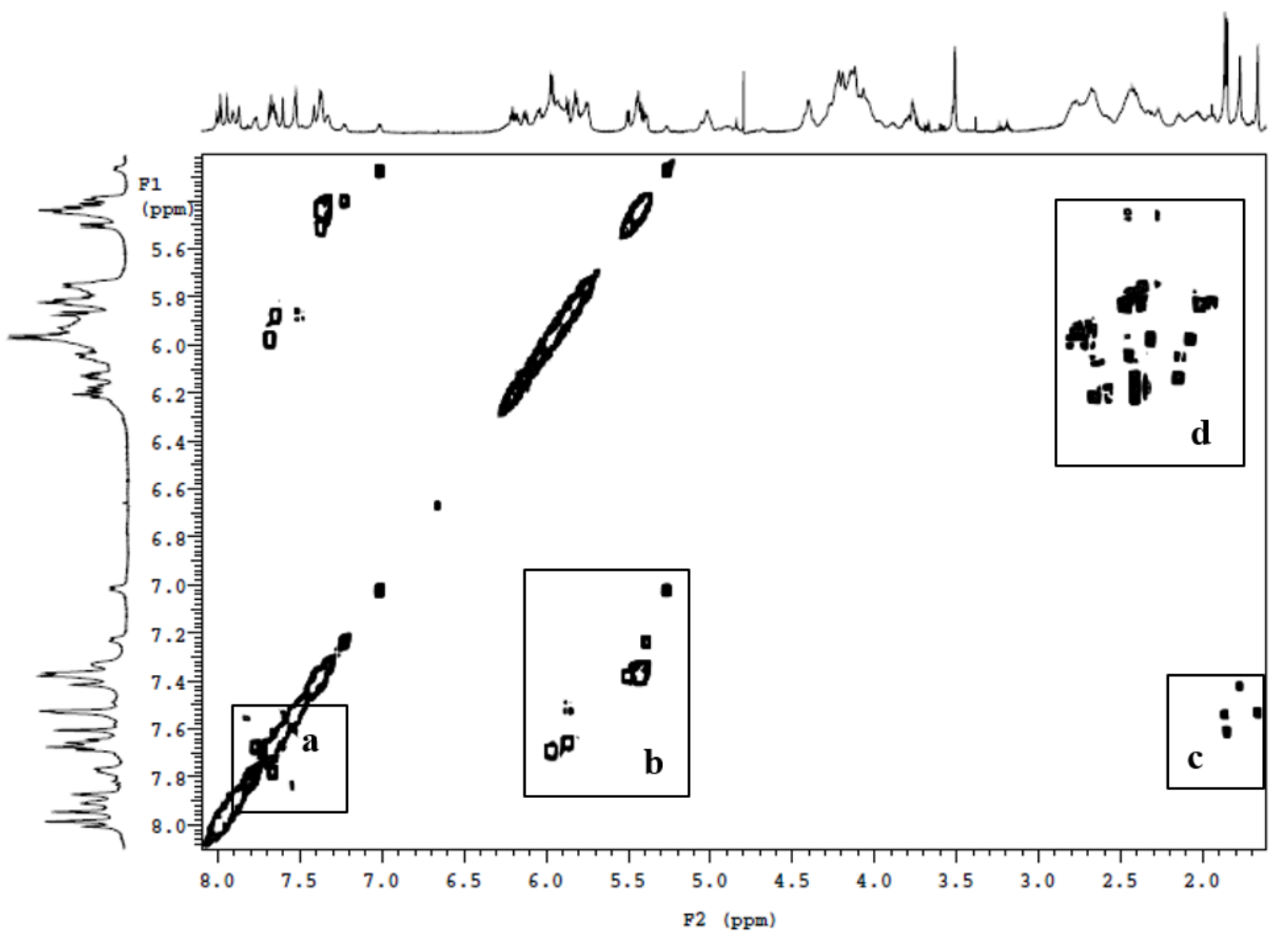

Figure 3.27. Expansion of the HP-CG ${ }^{8 M M P h}$ gCOSY spectra. The boxed areas show a) $\mathrm{G}_{6}-\mathrm{MMPh} \mathrm{Ar} / \mathrm{Ar}$ b) dCH6/H5 correlations c) dT-H6/ $\mathrm{CH}_{3}$ and d) $\mathrm{H} 1$ '/H2'H2" cross-peaks. 


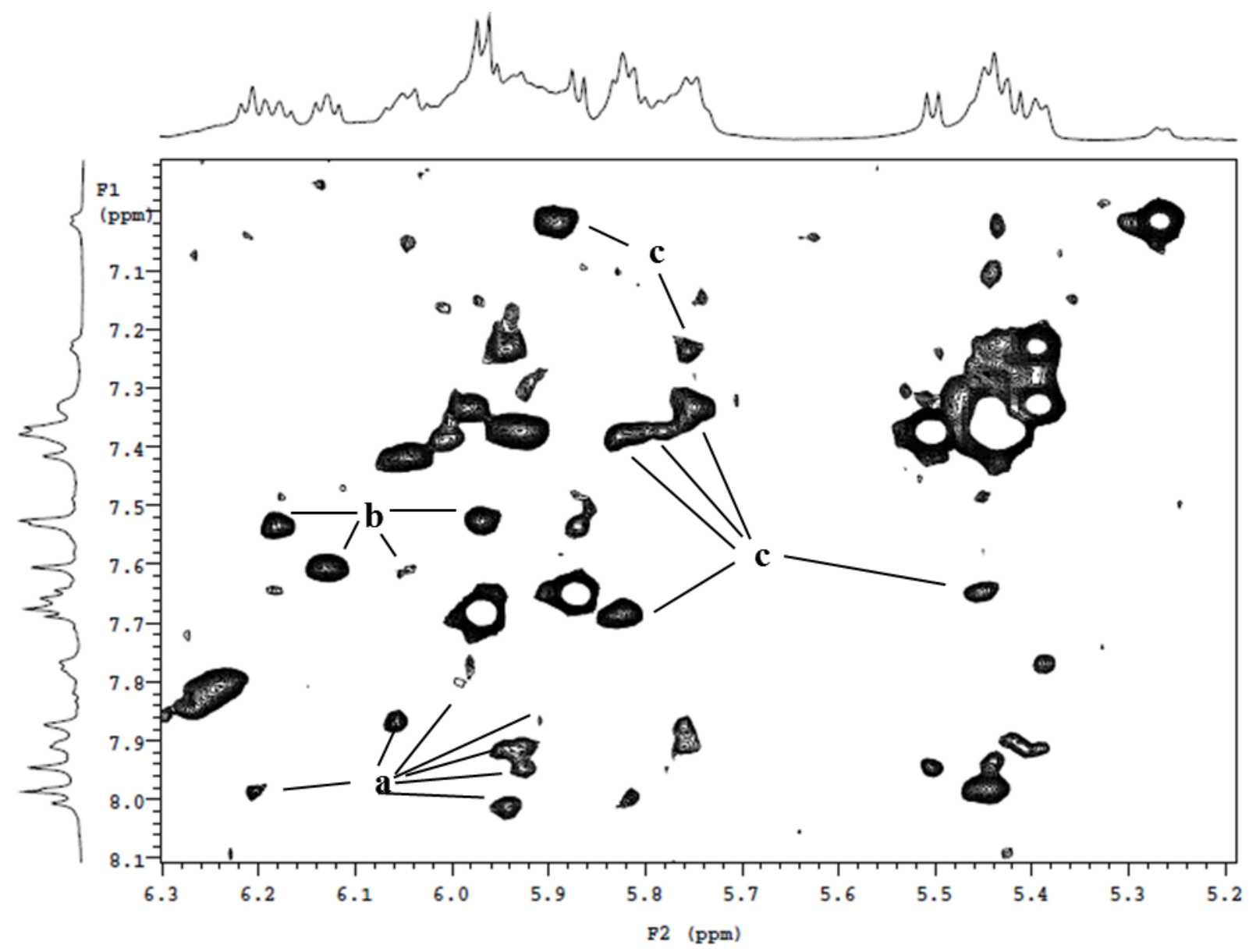

Figure 3.28. NOESY expansion of the HP-CG ${ }^{8 M M P h}$. The lines from the letters a, b, or c show the a) dG-H8-H1'or dGAr-H1', b) dT-H6-H1' and c) dC-H6-H1' correlations.

The H1' of any given nucleotide is close enough in space $(\sim 3-5 \AA)$ to show NOE correlations to $\mathrm{H} 8$ of $\mathrm{dG}, \mathrm{H} 6$ of $\mathrm{dC}$ or the $\mathrm{C} 8$-aryl protons in the same nucleotide (Figure 3.28). Therefore the $24 \mathrm{H1}$ ' protons observed from the gCOSY spectra can be assigned to their respective nucleotide residues. Further, the $\mathrm{H} 1$ ', $\mathrm{H} 2$ ' and $\mathrm{H} 2$ " also show NOE correlations to each other which can be used to confirm the assignments made in the gCOSY spectra. The combination of the gCOSY and NOESY spectra allow for assignment of the $\mathrm{H} 8, \mathrm{H} 6$, or C8-aryl $\rightarrow \mathrm{H} 1^{\prime} \rightarrow \mathrm{H} 2^{\prime} \rightarrow$ H2" of all 24 nucleotides in the hairpin oligonucleotides. These assignments can then be used to 
determine the cross-peaks in the NOESY spectra that correspond to the internucleotide connectivities that can be used in the sequential resonance assignments of the hairpin oligonucleotides.

In our previous studies with the doubly modified double-stranded oligonucleotide the $\mathrm{C} 1$ residue was generally the starting point given that its $\mathrm{H} 6$ resonance is furthest downfield in comparison to the $\mathrm{dC}$ residues, here it is actually easier to start the assignment procedures at the $\mathrm{T}_{4}$ loop because $\mathrm{T}_{11}$ will have a correlation(s) with only $\mathrm{G}_{10}$ and $\mathrm{T}_{14}$ will have a correlation(s) with only $\mathrm{C}_{15}\left(\mathrm{C}_{1} \mathrm{G}_{2} \mathrm{C}_{3} \mathrm{G}_{4} \mathrm{C}_{5} \mathrm{G}_{6}{ }^{*} \mathrm{C}_{7} \mathrm{G}_{8} \mathrm{C}_{9} \mathrm{G}_{10} \mathrm{~T}_{11} \mathrm{~T}_{12} \mathrm{~T}_{13} \mathrm{~T}_{14} \mathrm{C}_{15} \mathrm{G}_{16} \mathrm{C}_{17} \mathrm{G}_{18} \mathrm{C}_{19} \mathrm{G}_{20} \mathrm{C}_{21} \mathrm{G}_{22} \mathrm{C}_{23} \mathrm{G}_{24}\right)$. This easily distinguishes the 5' and 3' dT residues of the $\mathrm{T}_{4}$ loop. Then, the remaining $\mathrm{d}(\mathrm{CG})_{5}$ stem component of the hairpin oligonucleotides can be sequentially assigned.

Starting from $\mathrm{T}_{11}$, the dT-H6 $\delta .41 \mathrm{ppm}$ shows $J$ correlations to its $\mathrm{CH}_{3}$ at $1.76 \mathrm{ppm}$ (Figure 3.29A, the ' $A$ ' refers to the correlation labeled ' $A$ '), which was further used to assign the $\mathrm{G}_{10}$ based on the observed NOE correlation to 7.87 ppm (Figure 3.29B). The H1', H2' and H2" (5.76, 2.27, and $1.74 \mathrm{ppm}$, respectively) of $\mathrm{C}_{9}$ are correlated to $\mathrm{G}_{10}-\mathrm{H} 8$ (Figure 3.29D). The $\mathrm{H} 1$ '/ $\mathrm{H} 2^{\prime}$ ' of $\mathrm{G}_{8}$ correlate to the $\mathrm{C}_{9}$ - $\mathrm{H} 5$ (Figure 3.29F), and, in addition, the $\mathrm{G}_{8}$ displays cross-peaks with the $\mathrm{C}_{7}$ $\mathrm{H} 2$ '/H2" (Figure $3.29 \mathrm{H}$ ). The $\mathrm{C}_{7}-\mathrm{H} 5$ shows NOE correlations to the H1' and H2" of the MMPh$\mathrm{G}_{6}$ (Figure 3.29J). The modified $\mathrm{MMPh}-\mathrm{G}_{6} \mathrm{H}_{2}$ ' and $\mathrm{H}_{2}$ " protons are further correlated to the $\mathrm{H} 5 / \mathrm{H} 2$ '/H2" of $\mathrm{C}_{5}$ which is easily distinguishable because the $\mathrm{H} 2$ " protons of $\mathrm{C}_{5}$ is the furthest signal upfield (Figure 3.29L). The $\mathrm{C}_{5}-\mathrm{H} 6$ is correlated to the $\mathrm{H} 2$ ' $/ \mathrm{H} 2$ " of $\mathrm{G}_{4}$ (Figure $3.29 \mathrm{~N}$ ). $\mathrm{G}_{4}$ shows correlations to $\mathrm{C}_{3}$ from NOEs between the $\mathrm{G}_{4}-\mathrm{H} 1$ ' and $\mathrm{C}_{3}-\mathrm{H} 6$ and of $\mathrm{G}_{4}-\mathrm{H} 8$ and $\mathrm{C}_{3}-\mathrm{H} 2$ " (Figure 3.29P). $\mathrm{C}_{3}$ shows NOEs from its $\mathrm{H} 2$ '/H2" protons to the $\mathrm{G}_{2}-\mathrm{H} 8$ (Figure 3.29R), which shows correlations to the $\mathrm{H}^{\prime}$ '/H2'/H2" of $\mathrm{C}_{1}(5.82 / 2.46 / 2.02 \mathrm{ppm})$ (Figure 3.29T). This completes the assignment of one strand of the $\mathrm{d}(\mathrm{CG})_{5}$ stem. 
Beginning at $\mathrm{T}_{11}$, the $\mathrm{T}_{12}-\mathrm{CH}_{3}$ as well as $\mathrm{T}_{12}-\mathrm{H} 2$ " show NOE correlations to $\mathrm{T}_{11}-\mathrm{H} 6$ (Figure 3.29V). The $\mathrm{T}_{12}-\mathrm{H} 2$ ' and $\mathrm{T}_{12}-\mathrm{CH}_{3}$ show correlations to the $\mathrm{T}_{13}-\mathrm{H} 6$ (Figure 3.29X). $\mathrm{T}_{12}$ shows a NOE correlation to $\mathrm{T}_{13}-\mathrm{CH}_{3}$ which distinguishes $\mathrm{T}_{13}-\mathrm{H} 6$ and $\mathrm{T}_{14}-\mathrm{H} 6$ (7.52 and $7.53 \mathrm{ppm}$ ). Further, $\mathrm{T}_{14}$ can be assigned based on its NOEs to $\mathrm{C}_{15}$ where the $\mathrm{T}_{14}$ shows a NOE to $\mathrm{C}_{15}$ - $\mathrm{H} 1$ ' and $\mathrm{C}_{15}$ shows a NOE to $\mathrm{T}_{14}-\mathrm{H} 2$ ' and to $\mathrm{T}_{14}-\mathrm{CH}_{3} . \mathrm{G}_{16}-\mathrm{H} 8$ is assigned from the NOE to the distinct $\mathrm{C}_{15}$ H1' (Figure 3.29CC). $\mathrm{C}_{17}$ is assigned through correlations to $\mathrm{G}_{16}-\mathrm{H} 1$ ' and NOEs from $\mathrm{G}_{16}-\mathrm{H} 8$ to $\mathrm{C}_{17}-\mathrm{H} 2 ” \cdot \mathrm{G}_{18}$ is assigned via NOEs between $\mathrm{C}_{17-\mathrm{H} 1}$ ' and $-\mathrm{H} 5 . \mathrm{C}_{19}$ is assigned through NOEs with $\mathrm{G}_{18}-\mathrm{H} 2^{\prime} / \mathrm{H} 2^{\prime \prime}$ and a $\mathrm{NOE}$ from $\mathrm{G}_{18}-\mathrm{H} 1^{\prime}$ to $\mathrm{C}_{19}$. $\mathrm{C}_{19}-\mathrm{H} 1^{\prime} / \mathrm{H} 2^{\prime} / \mathrm{H} 2^{\prime \prime}$ shows correlations to $\mathrm{G}_{20}-\mathrm{H} 8$ and $\mathrm{C}_{21}$ shows correlations to the $\mathrm{G}_{20}-\mathrm{H} 1{ }^{\prime}$. $\mathrm{C}_{21}-\mathrm{H} 5$ show a correlation to the $\mathrm{G}_{22}-\mathrm{H} 8$ and $\mathrm{G}_{22}-\mathrm{H} 8$ shows a NOE to $\mathrm{C}_{23}-\mathrm{H} 5$, that also shows a $\mathrm{NOE}$ to $\mathrm{G}_{22}-\mathrm{H} 1$ '. Finally the $\mathrm{G}_{24}-\mathrm{H} 8$ can be assigned through a NOE to $\mathrm{C}_{23}-\mathrm{H} 1$ '. Figure 3.28 shows the NOE cross-peaks that were used in the assignment procedure. Using this assignment procedure the individual nucleotides $\left(\mathrm{H} 8 / \mathrm{H} 6 / \mathrm{C} 8\right.$-aryl $\rightarrow \mathrm{H} 1^{\prime} \rightarrow \mathrm{H} 2$ ' $\rightarrow \mathrm{H} 2$ ”) of unmodified and modified hairpins can be sequentially assigned (Table $3.11-3.16$ ). 


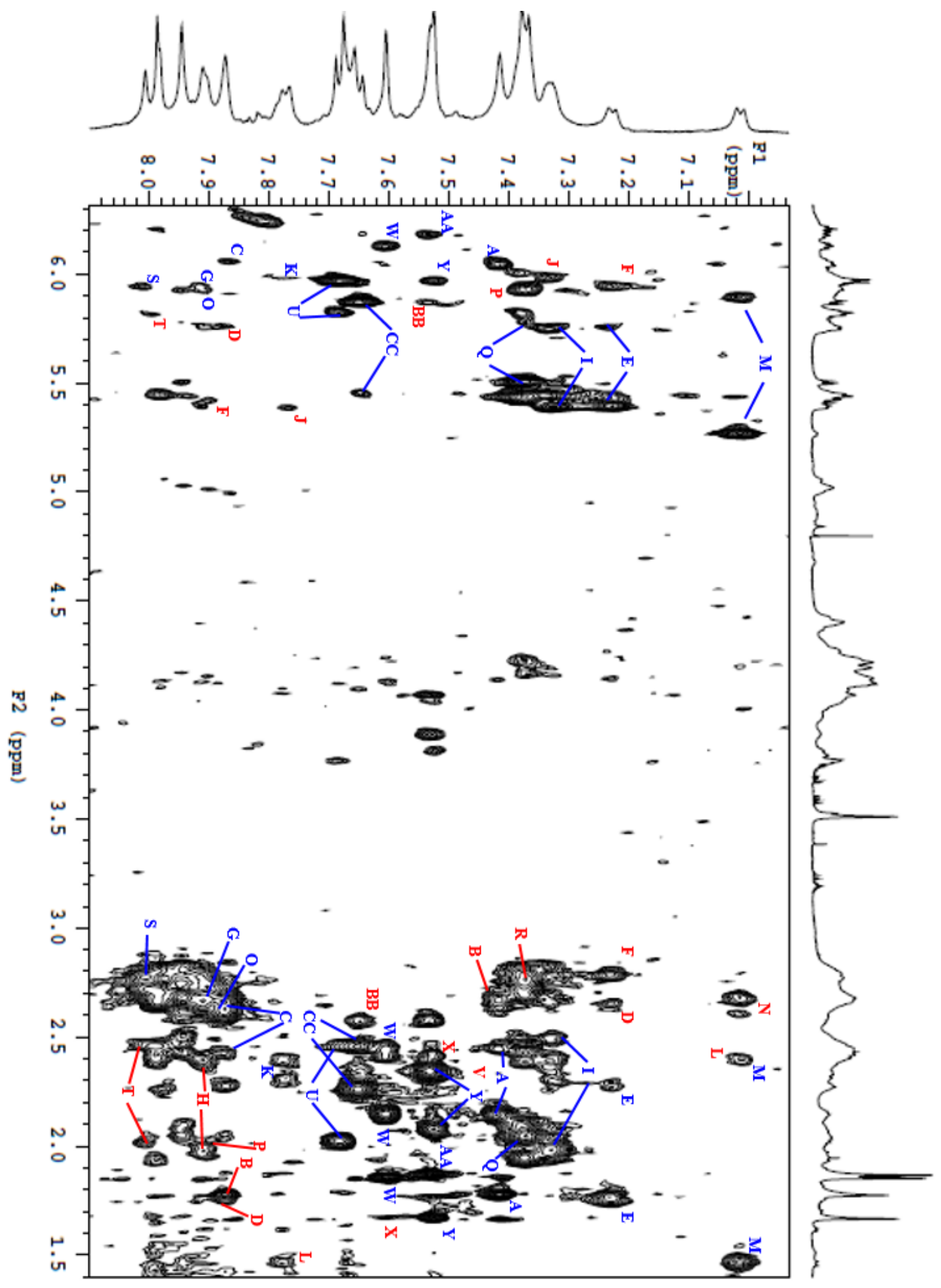

Figure 3.29. NOESY expansion of the HP-CG ${ }^{8 M M P h}$ in the B-DNA conformation. The blue letters correspond to the intranucleotide correlations and the red letters correspond to the correlations that are internucleotide. The assignment labels begin with $\mathrm{T}_{11}(\mathrm{~A})$ through $\mathrm{C}_{1}(\mathrm{U})$. The $\mathrm{T}_{4}$ loop is also labeled starm temping from $\mathrm{T}_{11}(\mathrm{~A})$ to $\mathrm{T}_{12}(\mathrm{~V})$ as well as $\mathrm{C}_{15}(\mathrm{CC})$. 
Table 3.11. Non-exchangeable proton assignment of the unmodified $\mathrm{HP}-\mathrm{CG}$ in the $\mathrm{B}$ form ${ }^{\mathrm{a}}$

\begin{tabular}{|c|c|c|c|c|c|}
\hline \multirow{2}{*}{ base no. } & \multicolumn{5}{|c|}{$\mathbf{1}^{\mathbf{H}}$ Chemical Shifts (ppm) } \\
\cline { 2 - 6 } & $\mathbf{H 8 / H 6}$ & $\mathbf{H 5 / C H}$ & $\mathbf{H 1}^{\prime}$ & $\mathbf{H 2}^{\prime}$ & $\mathbf{H 2}^{\prime}$ \\
\hline C1 & 7.67 & 5.96 & 5.83 & 2.46 & 2.02 \\
\hline G2 & 8.00 & & 5.96 & 2.75 & 2.72 \\
\hline C3 & 7.33 & 5.43 & 5.77 & 2.44 & 2.03 \\
\hline G4 & 7.92 & & 5.97 & 2.75 & 2.73 \\
\hline C5 & 7.30 & 5.37 & 5.70 & 2.39 & 2.01 \\
\hline G6 & 7.91 & & 5.91 & 2.75 & 2.64 \\
\hline C7 & 7.35 & 5.42 & 5.78 & 2.38 & 2.02 \\
\hline G8 & 7.92 & & 5.91 & 2.75 & 2.64 \\
\hline C9 & 7.24 & 5.41 & 5.74 & 2.26 & 1.75 \\
\hline G10 & 7.87 & & 6.04 & 2.68 & 2.63 \\
\hline T11 & 7.41 & 1.77 & 6.03 & 2.43 & 2.13 \\
\hline T12 & 7.60 & 1.84 & 6.12 & 2.40 & 2.14 \\
\hline T13 & 7.52 & 1.66 & 5.96 & 2.30 & 2.07 \\
\hline T14 & 7.53 & 1.86 & 6.16 & 2.56 & 2.38 \\
\hline C15 & 7.64 & 5.85 & 5.44 & 2.43 & 2.24 \\
\hline G16 & 7.96 & & 5.99 & 2.77 & 2.74 \\
\hline C17 & 7.33 & 5.39 & 5.71 & 2.39 & 1.99 \\
\hline G18 & 7.98 & & 5.98 & 2.72 & 2.70 \\
\hline C19 & 7.38 & 5.40 & 5.80 & 2.36 & 1.92 \\
\hline G20 & 7.91 & & 5.90 & 2.71 & 2.67 \\
\hline C21 & 7.37 & 5.44 & 5.82 & 2.44 & 2.05 \\
\hline G22 & 7.93 & & 5.93 & 2.75 & 2.67 \\
\hline C23 & 7.36 & 5.48 & 5.76 & 2.38 & 1.94 \\
\hline G24 & 7.98 & & 6.20 & 2.64 & 2.40 \\
\hline NR & 14 & & \\
\hline
\end{tabular}

${ }^{a} \mathrm{NMR}$ spectra $(1 \mathrm{H}, \mathrm{gCOSY}$ and NOESY) were acquired on oligonucleotide solutions $(\sim 1.5 \mathrm{mM})$ in deuterated sodium phosphate (10 $\mathrm{mM}, \mathrm{pD} 7.0)$ and sodium chloride $(25 \mathrm{mM})$ and at $25^{\circ} \mathrm{C}$. 
Table 3.12. Non-exchangeable proton assignment of the modified $\mathrm{HP}-\mathrm{CG}^{8 \mathrm{Ph}}$ in the $\mathrm{B}$ form ${ }^{\mathrm{a}}$

\begin{tabular}{|c|c|c|c|c|c|}
\hline \multirow{2}{*}{ base no. } & \multicolumn{5}{|c|}{${ }^{1}$ H Chemical Shifts (ppm) } \\
\hline & H8/H6 & $\mathrm{H} 5 / \mathrm{CH}_{3}$ & H1' & H2' & H2" \\
\hline C1 & 7.68 & 5.96 & 5.81 & 2.46 & 2.02 \\
\hline G2 & 8.00 & & 5.94 & 2.76 & 2.68 \\
\hline $\mathrm{C3}$ & 7.37 & 5.43 & 5.79 & 2.41 & 2.02 \\
\hline G4 & 7.87 & & 5.89 & 2.65 & 2.60 \\
\hline C5 & 7.01 & 5.24 & 5.88 & 2.40 & 1.55 \\
\hline G6 & \multicolumn{2}{|c|}{$7.84,7.52,7.74,7.68,7.62$} & 5.95 & 2.44 & 2.29 \\
\hline C7 & 7.33 & 5.39 & 5.75 & 2.40 & 1.95 \\
\hline G8 & 7.91 & & 5.92 & 2.76 & 2.64 \\
\hline C9 & 7.22 & 5.39 & 5.74 & 2.40 & 1.95 \\
\hline G10 & 7.87 & & 6.05 & 2.65 & 2.41 \\
\hline T11 & 7.41 & 1.75 & 6.02 & 2.43 & 2.13 \\
\hline T12 & 7.60 & 1.84 & 6.12 & 2.40 & 2.14 \\
\hline T13 & 7.53 & 1.66 & 6.17 & 2.55 & 2.34 \\
\hline T14 & 7.54 & 1.85 & 5.96 & 2.30 & 2.07 \\
\hline C15 & 7.65 & 5.86 & 5.44 & 2.44 & 2.26 \\
\hline G16 & 7.98 & & 6.00 & 2.80 & 2.71 \\
\hline C17 & 7.37 & 5.43 & 5.79 & 2.41 & 2.02 \\
\hline G18 & 7.94 & & 5.91 & 2.74 & 2.69 \\
\hline C19 & 7.38 & 5.50 & 5.81 & 2.48 & 2.08 \\
\hline G20 & 7.93 & & 5.97 & 2.80 & 2.72 \\
\hline C21 & 7.33 & 5.39 & 5.75 & 2.33 & 1.95 \\
\hline G22 & 7.91 & & 5.92 & 2.80 & 2.74 \\
\hline $\mathrm{C23}$ & 7.37 & 5.43 & 5.80 & 2.36 & 1.93 \\
\hline G24 & 7.98 & & 6.20 & 2.63 & 2.40 \\
\hline
\end{tabular}

${ }^{a}$ NMR spectra $(1 \mathrm{H}$, gCOSY and NOESY) were acquired on oligonucleotide solutions $(\sim 1.5 \mathrm{mM})$ in deuterated sodium phosphate $(10 \mathrm{mM}, \mathrm{pD} 7.0)$ and sodium chloride $(25$ $\mathrm{mM})$ and at $25^{\circ} \mathrm{C}$. 
Table 3.13. Non-exchangeable proton assignment of the modified $\mathrm{HP}-\mathrm{CG}^{8 \mathrm{Tol}}$ in the $\mathrm{B}$ form ${ }^{\mathrm{a}}$

\begin{tabular}{|c|c|c|c|c|c|}
\hline \multirow{2}{*}{ base no. } & \multicolumn{5}{|c|}{${ }^{1} \mathrm{H}$ Chemical Shifts (ppm) } \\
\hline & H8/H6 & $\mathrm{H} 5 / \mathrm{CH}_{3}$ & H1' & H2' & H2" \\
\hline C1 & 7.68 & 5.96 & 5.82 & 2.46 & 2.02 \\
\hline G2 & 8.01 & & 5.94 & 2.76 & 2.72 \\
\hline $\mathrm{C3}$ & 7.38 & 5.41 & 5.76 & 2.46 & 2.04 \\
\hline G4 & 7.87 & & 5.88 & 2.61 & 2.42 \\
\hline C5 & 7.01 & 5.24 & 5.89 & 2.42 & 1.53 \\
\hline $\mathbf{G 6}^{\mathrm{b}}$ & \multicolumn{2}{|c|}{$7.81,7.53,7.65$} & 5.39 & 2.66 & 2.42 \\
\hline C7 & 7.33 & 5.41 & 5.76 & 2.39 & 1.97 \\
\hline G8 & 7.91 & & 5.93 & 2.76 & 2.65 \\
\hline C9 & 7.23 & 5.39 & 5.74 & 2.26 & 1.75 \\
\hline G10 & 7.87 & & 6.05 & 2.65 & 2.40 \\
\hline T11 & 7.42 & 1.77 & 6.04 & 2.44 & 2.14 \\
\hline T12 & 7.60 & 1.84 & 6.13 & 2.41 & 2.14 \\
\hline T13 & 7.52 & 1.66 & 5.96 & 2.32 & 2.07 \\
\hline T14 & 7.53 & 1.86 & 6.18 & 2.58 & 2.34 \\
\hline C15 & 7.66 & 5.87 & 5.45 & 2.45 & 2.27 \\
\hline G16 & 7.98 & & 6.00 & 2.80 & 2.70 \\
\hline C17 & 7.38 & 5.44 & 5.78 & 2.35 & 1.95 \\
\hline G18 & 7.95 & & 5.96 & 2.81 & 2.72 \\
\hline C19 & 7.33 & 5.39 & 5.72 & 2.39 & 2.02 \\
\hline G20 & 7.99 & & 5.44 & 2.45 & 2.27 \\
\hline C21 & 7.38 & 5.50 & 5.81 & 2.37 & 1.94 \\
\hline G22 & 7.95 & & 5.92 & 2.75 & 2.68 \\
\hline $\mathrm{C23}$ & 7.38 & 5.50 & 5.82 & 2.42 & 2.04 \\
\hline G24 & 7.99 & & 6.20 & 2.65 & 2.41 \\
\hline
\end{tabular}

${ }^{a}$ NMR spectra $(1 \mathrm{H}, \mathrm{gCOSY}$ and NOESY) were acquired on oligonucleotide solutions $(\sim 1.5 \mathrm{mM})$ in deuterated sodium phosphate $(10 \mathrm{mM}, \mathrm{pD} 7.0)$ and sodium chloride $(25 \mathrm{mM})$ and at $25{ }^{\circ} \mathrm{C} .{ }^{\mathrm{b}} \mathrm{C} 8-\mathrm{Tol}-\mathrm{CH}_{3}=2.55 \mathrm{ppm}$. 
Table 3.14. Non-exchangeable proton assignment of the modified $\mathrm{HP}-\mathrm{CG}^{8 \mathrm{HMPh}}$ in the $\mathrm{B}$ form ${ }^{\mathrm{a}}$

\begin{tabular}{|c|c|c|c|c|c|}
\hline \multirow{2}{*}{ base no. } & \multicolumn{5}{|c|}{${ }^{1} \mathrm{H}$ Chemical Shift (ppm) } \\
\hline & H8/H6 & $\mathrm{H5} / \mathrm{CH}_{3}$ & H1' & H2' & H2" \\
\hline C1 & 7.68 & 5.96 & 5.82 & 2.46 & 2.02 \\
\hline G2 & 8.01 & & 5.93 & 2.78 & 2.69 \\
\hline C3 & 7.37 & 5.45 & 5.76 & 2.42 & 2.04 \\
\hline G4 & 7.88 & & 5.90 & 2.67 & 2.61 \\
\hline $\mathrm{C5}$ & 7.02 & 5.24 & 5.90 & 2.35 & 1.56 \\
\hline G6 $^{\mathbf{a}}$ & \multicolumn{2}{|c|}{$7.84 / 7.73,7.67 / 7.53$} & 6.21 & 2.65 & 2.43 \\
\hline C7 & 7.33 & 5.39 & 5.76 & 2.40 & 2.00 \\
\hline G8 & 7.90 & & 5.93 & 2.79 & 2.65 \\
\hline C9 & 7.23 & 5.39 & 5.75 & 2.26 & 1.76 \\
\hline G10 & 7.88 & & 6.05 & 2.65 & 2.39 \\
\hline T11 & 7.42 & 1.77 & 6.05 & 2.45 & 2.14 \\
\hline T12 & 7.60 & 1.85 & 6.13 & 2.42 & 2.13 \\
\hline T13 & 7.52 & 1.67 & 5.97 & 2.33 & 2.07 \\
\hline T14 & 7.53 & 1.86 & 6.18 & 2.57 & 2.34 \\
\hline $\mathrm{C15}$ & 7.65 & 5.86 & 5.45 & 2.44 & 2.26 \\
\hline G16 & 7.98 & & 6.00 & 2.81 & 2.71 \\
\hline $\mathrm{C17}$ & 7.38 & 5.49 & 5.82 & 2.46 & 1.94 \\
\hline G18 & 7.95 & & 5.96 & 2.81 & 2.72 \\
\hline C19 & 7.33 & 5.43 & 5.78 & 2.38 & 1.98 \\
\hline G20 & 7.92 & & 5.94 & 2.74 & 2.71 \\
\hline $\mathrm{C21}$ & 7.37 & 5.40 & 5.78 & 2.46 & 2.02 \\
\hline G22 & 7.95 & & 5.99 & 2.75 & 2.70 \\
\hline $\mathrm{C23}$ & 7.38 & 5.49 & 5.82 & 2.49 & 2.10 \\
\hline G24 & 7.99 & & 6.20 & 2.65 & 2.41 \\
\hline
\end{tabular}

${ }^{\mathrm{a}} \mathrm{NMR}$ spectra (1H, gCOSY and NOESY) were acquired on oligonucleotide solutions $(\sim 1.5 \mathrm{mM})$ in deuterated sodium phosphate $(10 \mathrm{mM}, \mathrm{pD} 7.0)$ and sodium chloride $(25 \mathrm{mM})$ and at $25^{\circ} \mathrm{C}$. 
Table 3.15. Non-exchangeable proton assignment of the modified $\mathrm{HP}-\mathrm{CG}^{8 \mathrm{MMPh}}$ in the B form ${ }^{\mathrm{a}}$

\begin{tabular}{|c|c|c|c|c|c|}
\hline \multirow{2}{*}{ base no. } & \multicolumn{5}{|c|}{${ }^{1}$ H Chemical Shifts (ppm) } \\
\hline & H8/H6 & $\mathrm{H} 5 / \mathrm{CH}_{3}$ & H1' & H2' & H2" \\
\hline C1 & 7.68 & 5.96 & 5.82 & 2.46 & 2.02 \\
\hline G2 & 8.01 & & 5.93 & 2.78 & 2.69 \\
\hline C3 & 7.37 & 5.45 & 5.76 & 2.42 & 2.04 \\
\hline G4 & 7.88 & & 5.90 & 2.67 & 2.61 \\
\hline C5 & 7.02 & 5.24 & 5.90 & 2.35 & 1.56 \\
\hline G6 $^{\mathbf{b}}$ & \multicolumn{2}{|c|}{$7.84 / 7.73,7.67 / 7.53$} & 6.21 & 2.65 & 2.43 \\
\hline C7 & 7.33 & 5.39 & 5.76 & 2.40 & 2.00 \\
\hline G8 & 7.90 & & 5.93 & 2.79 & 2.65 \\
\hline C9 & 7.23 & 5.39 & 5.75 & 2.26 & 1.76 \\
\hline G10 & 7.88 & & 6.05 & 2.65 & 2.39 \\
\hline T11 & 7.42 & 1.77 & 6.05 & 2.45 & 2.14 \\
\hline T12 & 7.52 & 1.67 & 5.97 & 2.33 & 2.07 \\
\hline T13 & 7.53 & 1.86 & 6.18 & 2.57 & 2.34 \\
\hline T14 & 7.60 & 1.85 & 6.13 & 2.42 & 2.13 \\
\hline C15 & 7.65 & 5.86 & 5.45 & 2.44 & 2.26 \\
\hline G16 & 7.98 & & 6.00 & 2.81 & 2.71 \\
\hline C17 & 7.38 & 5.49 & 5.82 & 2.46 & 1.94 \\
\hline G18 & 7.95 & & 5.96 & 2.81 & 2.72 \\
\hline C19 & 7.33 & 5.43 & 5.78 & 2.38 & 1.98 \\
\hline G20 & 7.92 & & 5.94 & 2.74 & 2.71 \\
\hline C21 & 7.37 & 5.40 & 5.78 & 2.46 & 2.02 \\
\hline G22 & 7.95 & & 5.99 & 2.75 & 2.70 \\
\hline $\mathrm{C23}$ & 7.38 & 5.49 & 5.82 & 2.49 & 2.10 \\
\hline G24 & 7.99 & & 6.20 & 2.65 & 2.41 \\
\hline
\end{tabular}

${ }^{a}$ NMR spectra (1H, gCOSY and NOESY) were acquired on oligonucleotide solutions $(\sim 1.5 \mathrm{mM})$ in deuterated sodium phosphate $(10 \mathrm{mM}, \mathrm{pD} 7.0)$ and sodium chloride $(25 \mathrm{mM})$ and at $25^{\circ} \mathrm{C} .{ }^{\mathrm{b}} \mathrm{C} 8-\mathrm{MMPh}-\mathrm{OCH}_{3}=3.51 \mathrm{ppm}$. 
Table 3.16. Non-exchangeable proton assignment of the modified $\mathrm{HP}_{-} \mathrm{CG}^{8 \mathrm{CPh}}$ in the $\mathrm{B}$ form ${ }^{\mathrm{a}}$

\begin{tabular}{|c|c|c|c|c|c|}
\hline \multirow{2}{*}{ base no. } & \multicolumn{5}{|c|}{${ }^{1}$ H Chemical Shifts (ppm) } \\
\hline & H8/H6 & $\mathrm{H} 5 / \mathrm{CH}_{3}$ & H1' & H2' & H2" \\
\hline C1 & 7.68 & 5.97 & 5.83 & 2.46 & 2.02 \\
\hline G2 & 8.01 & & 5.95 & 2.75 & 2.72 \\
\hline C3 & 7.37 & 5.43 & 5.77 & 2.42 & 2.27 \\
\hline G4 & 7.88 & & 5.88 & 2.66 & 2.60 \\
\hline C5 & 7.06 & 5.32 & 5.90 & 2.43 & 1.46 \\
\hline G6 & \multicolumn{2}{|c|}{$8.03 / 7.84,7.76 / 7.56$} & 6.01 & 2.51 & 2.27 \\
\hline C7 & 7.32 & 5.41 & 5.74 & 2.38 & 1.99 \\
\hline G8 & 7.91 & & 5.94 & 2.77 & 2.63 \\
\hline C9 & 7.23 & 5.39 & 5.75 & 2.27 & 1.75 \\
\hline G10 & 7.88 & & 6.05 & 2.65 & 2.45 \\
\hline T11 & 7.43 & 1.77 & 6.04 & 2.44 & 2.14 \\
\hline T12 & 7.61 & 1.85 & 6.13 & 2.41 & 2.14 \\
\hline T13 & 7.54 & 1.87 & 5.97 & 2.32 & 2.09 \\
\hline T14 & 7.53 & 1.67 & 6.17 & 2.57 & 2.34 \\
\hline C15 & 7.65 & 5.87 & 5.46 & 2.45 & 2.25 \\
\hline G16 & 7.99 & & 6.00 & 2.80 & 2.70 \\
\hline C17 & 7.39 & 5.50 & 5.81 & 2.38 & 1.94 \\
\hline G18 & 7.95 & & 5.92 & 2.81 & 2.65 \\
\hline C19 & 7.39 & 5.46 & 5.82 & 2.47 & 2.07 \\
\hline G20 & 7.95 & & 5.96 & 2.78 & 2.68 \\
\hline $\mathrm{C21}$ & 7.35 & 5.45 & 5.73 & 2.33 & 1.94 \\
\hline G22 & 7.93 & & 5.92 & 2.77 & 2.67 \\
\hline $\mathrm{C23}$ & 7.37 & 5.43 & 5.78 & 2.44 & 2.04 \\
\hline G24 & 7.99 & & 6.20 & 2.65 & 2.41 \\
\hline
\end{tabular}

${ }^{a}$ NMR spectra $(1 \mathrm{H}, \mathrm{gCOSY}$ and NOESY) were acquired on oligonucleotide solutions $(\sim 1.5 \mathrm{mM})$ in deuterated sodium phosphate $(10 \mathrm{mM}, \mathrm{pD} 7.0)$ and sodium chloride $(25 \mathrm{mM})$ and at $25^{\circ} \mathrm{C}$. 


\section{Non-exchangeable Proton Assignment for Z-DNA}

The non-exchangeable protons of the Z-DNA conformation of the C8-arylguanine modified hairpin oligonucleotides were assigned using a similar approach as for the B-DNA conformation, therefore ${ }^{1} \mathrm{H}, \mathrm{gCOSY}$, and NOESY spectra were acquired (full spectra for the C8-arylguanine modified hairpin oligonucleotides are shown in Appendix C). The ${ }^{1} \mathrm{H}$ spectrum displays resonances in the chemical shift range of the aromatic base protons and the deoxyribose sugar protons similar to the B-DNA form. However unlike the B-DNA spectra, the spectra of the modified hairpins in the Z-DNA conformation had much lower resolution, which can be generally ascribed to line broadening from the increase salt concentrations used to drive the B-/Z-DNA equilibrium toward the Z-DNA conformation. The line broadening also leads to reduced resolution spectra. As a result the gCOSY spectra does not provide the same level of structural detail for the $\mathrm{Z}$ forms of the modified hairpins compared to when they are in the B-DNA conformation. Although the $\mathrm{dG}_{6}-\mathrm{Ar} / \mathrm{Ar}, \mathrm{dC}-\mathrm{H} 6 / \mathrm{H} 5$ and $\mathrm{dT}-\mathrm{H} 6 / \mathrm{CH}_{3}$ correlations can still be observed, there are less $\mathrm{H} 1^{\prime} / \mathrm{H} 2^{\prime} / \mathrm{H} 2^{\prime}$ " pairs observable. The NOESY spectra of the $\mathrm{Z}$ form can still be used to assign the $\mathrm{H} 8 / \mathrm{H} 6$ to their respective $\mathrm{H} 1^{\prime} / \mathrm{H} 2^{\prime} / \mathrm{H} 2^{\prime \prime}$ pairs as was the case for the $\mathrm{B}$ form. Further the NOESY spectra is diagnostic of the Z-DNA conformation since the dG-H8/H1' protons exhibit very strong NOE cross-peaks, characteristic of the dG bases in the synconformation in the $\mathrm{Z}$ form.

The assignment strategy for Z-DNA is slightly different than that used for B-DNA. Previously established assignment strategies ${ }^{156}$ and reports on Z-DNA hairpins ${ }^{120,121}$ combined with our previous work with $\mathrm{C} 8$-arylguanine modified oligonucleotides ${ }^{98,100}$ in the $\mathrm{Z}$ form, was used to assign the protons of the C8-arylguanine modified hairpin oligonucleotides in the Z-DNA

conformation. In general, the literature shows that any given $\mathrm{dG}(\mathrm{n})-\mathrm{H} 8$ are close enough in 
proximity to show NOE cross-peaks with a $\mathrm{dC}(\mathrm{n}+1)-\mathrm{H} 6 / \mathrm{H} 5$. Further the $\mathrm{dG}(\mathrm{n})-\mathrm{H} 2^{\prime} / \mathrm{H} 2$ " will also show NOE correlations to the $\mathrm{dC}(\mathrm{n}+1)-\mathrm{H} 2$ '/H2'. Therefore, the assignment strategy utilizes the $d G(n)$ and $d C(n+1)$ pairs combined with the assignment of the $\mathrm{G}_{10}$ and $C_{15}$ based on NOE crosspeaks with $\mathrm{T}_{11}$ and $\mathrm{T}_{14}$, respectively. In addition, the $\mathrm{C} 8$-aryl-G 6 also display $\mathrm{Ar} / \mathrm{H} 1$ ' cross-peaks distinct from the rest of the $\mathrm{dG}-\mathrm{H} 8 / \mathrm{H} 1$ ' NOE cross-peaks. Therefore through a process of elimination the final $\mathrm{C}_{1}$ and $\mathrm{G}_{24}$ resonances can be assigned.

As a representative example the $\mathrm{HP}-\mathrm{CG}^{8 \mathrm{HMPh}}$ resonance assignment for the Z-DNA conformation will be described. In the $\mathrm{Z}$ form there is less dispersion of the resonances in the aromatic region; the nine dG-H8 protons are assumed to be the singlet resonances furthest downfield and located between $7.78-7.87 \mathrm{ppm}$, the four dT-H6 protons are probably the three singlets between $7.47-7.61 \mathrm{ppm}$ and the $10 \mathrm{dC}-\mathrm{H} 6$ resonances are likely to be the overlapping signals between $7.38-7.49 \mathrm{ppm}$. The $\mathrm{C} 8$-aryl- $\mathrm{dG}_{6}$ proton resonances can then be assumed to be the set of doublets between $7.65-7.70 \mathrm{ppm}$ (Figure 3.30). The H1' protons range from $5.76-$ $6.31 \mathrm{ppm}$, where there is extensive overlap of the resonances $(6.24-6.31 \mathrm{ppm})$. Figure 3.31 shows the upfield region of the ${ }^{1} \mathrm{H}$ spectrum which is where the $\mathrm{H} 2$ '/ $\mathrm{H} 2$ " and the $\mathrm{dT}-\mathrm{CH}_{3}$ resonances are located. As with B-DNA conformation, the assignment of the ${ }^{1} \mathrm{H}$ chemical shifts requires $2 \mathrm{D}$ gCOSY and NOESY data sets. 


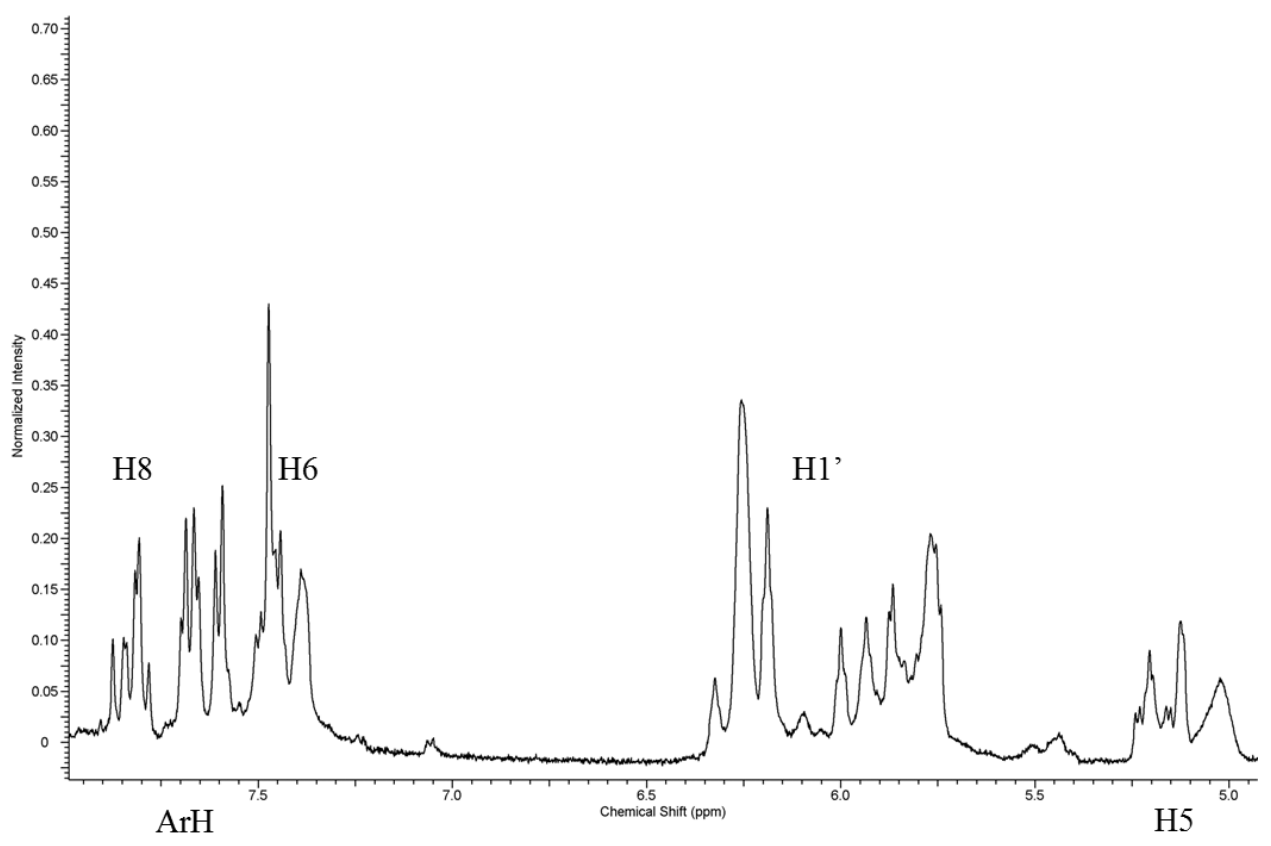

Figure 3.30. Expansion of the HP-CG ${ }^{8 \mathrm{HMPh}}$ aromatic region of the ${ }^{1} \mathrm{H}$ NMR spectrum in the Z-DNA conformation. The dG-H8, dG-C8-aryl (ArH), dT-H6, dC-H6/H5 and the H1' proton resonances are labeled above and below the frequency axis (ppm).

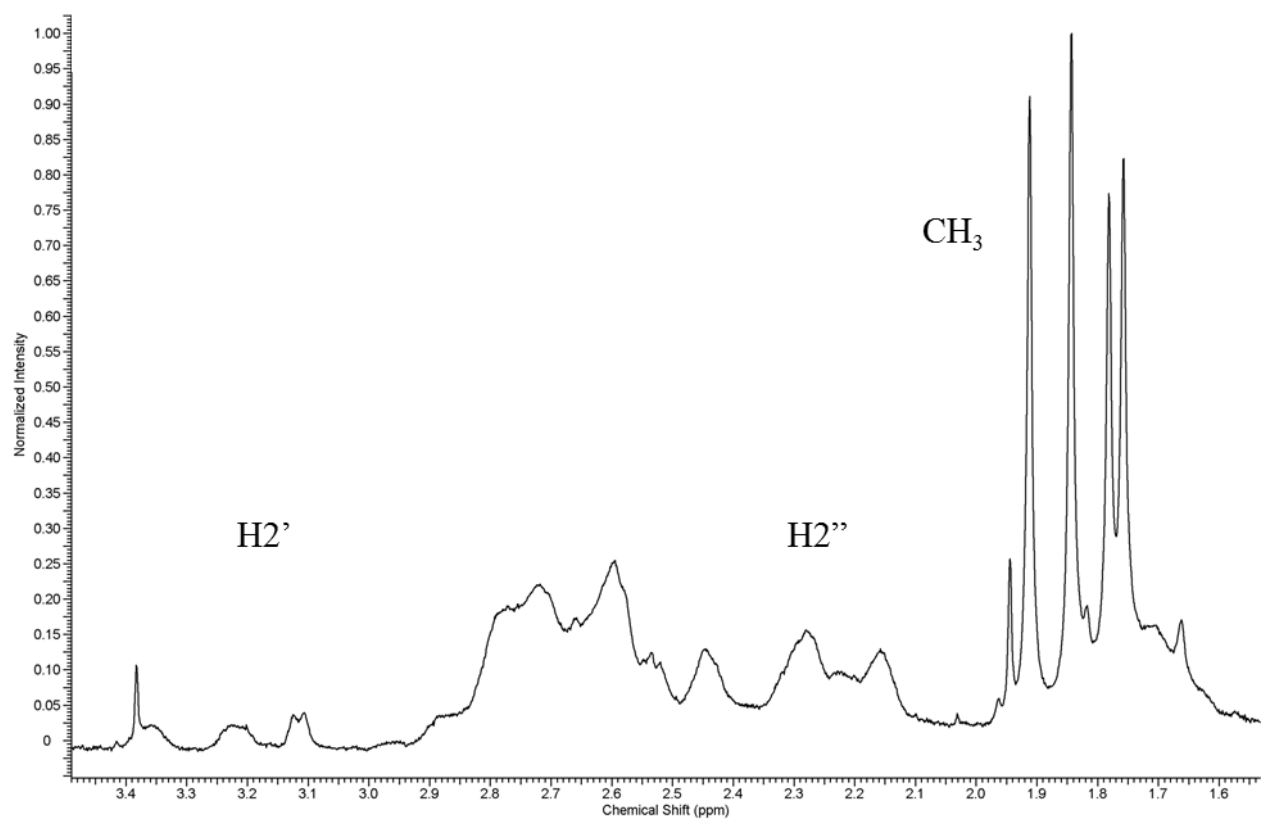

Figure 3.31. Expansion of the HP-CG ${ }^{8 H M P h}$ upfield region of the ${ }^{1} \mathrm{H}$ NMR spectrum of the Z-DNA conformation. The $\mathrm{H}_{2}$, $\mathrm{H} 2$ " and $\mathrm{dT}-\mathrm{CH}_{3}$ are labeled above the frequency axis (ppm). 
The $\mathrm{gCOSY}$ data set of the HP-CG ${ }^{8 \mathrm{HMPh}}$ oligonucleotide in the $\mathrm{Z}$ form was used in a similar manner as described for the B-DNA data. Figure 3.32 shows an expansion of the gCOSY spectra of the HP-CG ${ }^{8 \mathrm{HMPh}}$ in the Z-DNA conformation. The gCOSY spectrum confirms the assumptions made in the ${ }^{1} \mathrm{H}$ NMR spectrum. The furthest downfield resonances do not show any off-diagonal correlations which is expected for the $\mathrm{dG}-\mathrm{H} 8$ protons. Since the $\mathrm{C} 8$-aryl- $\mathrm{dG}_{6}$ resonances are close in proximity the off-diagonal correlations shown in Figure 3.32a are so close to the diagonal that they are not as easily distinguishable as in the B form, however they are present with further expansion. Figure $3.32 \mathrm{~b}$ displays the dC-H6-H5 cross-peaks between the 7.38 to the $5.12 \mathrm{ppm}$. In addition, the downfield cross-peaks are likely to correspond to the $\mathrm{dC}_{1}$ and $\mathrm{dC}_{15}$ residues. Unlike the B-DNA conformation, the dC-H5 are much further upfield 5.12 - 5.87 ppm with a difference between $0.10-0.40 \mathrm{ppm}$ relative to the $\mathrm{B}$ form. Figure $3.32 \mathrm{c}$ displays the dT- $\mathrm{H} 6$ to $\mathrm{dT}-\mathrm{CH}_{3}$ four bond couplings, confirming the upfield singlets observed in the aromatic region correspond to the dT residues. Although there is considerable overlap amongst the H1' resonances of the hairpin oligonucleotides in the $\mathrm{B}$ form, most, if not all, of the $\mathrm{H} 1$ ' had two distinct correlations corresponding to the two different $\mathrm{H} 2$ ' and $\mathrm{H} 2$ " protons. The gCOSY Z-DNA spectra shows fewer $\mathrm{H} 1{ }^{\prime} \rightarrow \mathrm{H} 2$ '/H2" pairs (Figure 3.32d). Although the gCOSY spectra can be used to confirm the initial assumptions from the ${ }^{1} \mathrm{H}$ spectrum, the NOESY spectral data are required to assign the proton resonances to a particular nucleotide in the hairpin sequence. 


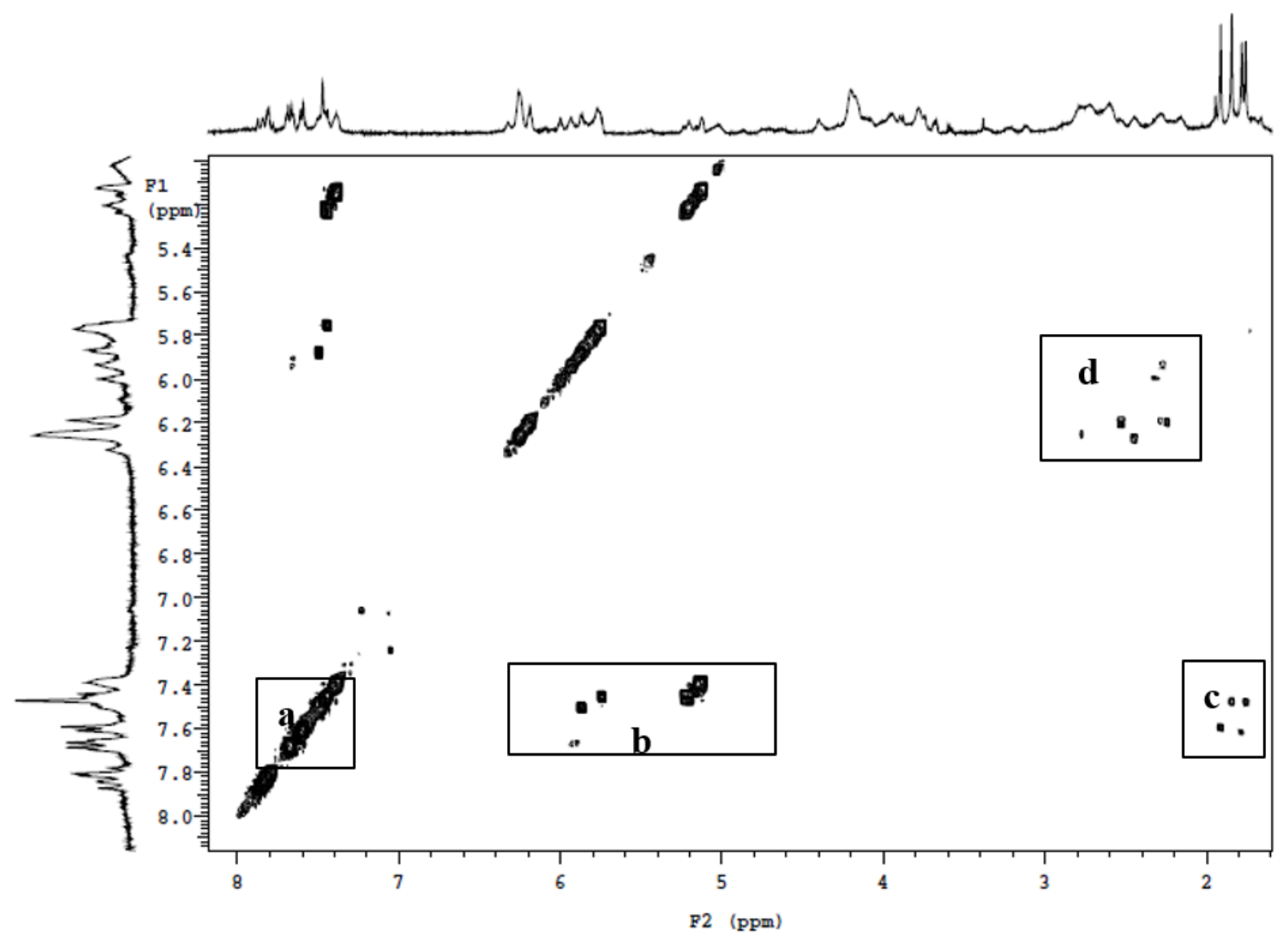

Figure 3.32. Expansion of the HP-CG ${ }^{8 \mathrm{HMPh}} \mathrm{gCOSY}$ spectra in the Z-DNA conformation. The boxed areas show a) G6-HMPh Ar/Ar b) dC-H6/H6 c) dT-H6/CH 3 and d) H1'/H2'/H2” cross-peaks.

NOESY expansion of the aromatic region to the $\mathrm{H} 1$ ' region indicates that the $\mathrm{dG}-\mathrm{H} 8$ display very strong NOEs to their H1' (Figure 3.33a), which is expected for the Z-DNA conformation. Further these dG-H1' resonances show strong cross-peaks to the cluster of dC-H6 resonances between $7.38-7.45 \mathrm{ppm}$. Figure $3.33 \mathrm{~b}$ labels the dT-H1' resonances that are correlated to the upfield dT singlets in the aromatic region. The $10 \mathrm{dC}-\mathrm{H} 1$ ' resonances are labeled in Figure 3.33c, which show considerable overlap between $5.76-5.84 \mathrm{ppm}$. Wolk et al. ${ }^{121}$ reported that the stem component of Z-DNA hairpins contained six equivalent $\mathrm{dC}$ bases and it was concluded that these nucleotides were in the interior of the $(\mathrm{CG})_{5}$ stem $\left(\mathrm{C}_{3}, \mathrm{C}_{5}, \mathrm{C}_{7}, \mathrm{C}_{17}, \mathrm{C}_{19}\right.$ and 
$\mathrm{C}_{21}$ ). In agreement with these results, there are several equivalent $\mathrm{dC}$ and $\mathrm{dG}$ residues based on the overlap of dC-H6/H1' and dG-H8/H1' NOE cross-peaks that also display dG-H1'/dC-H6 and dG-H8/dC-H6 cross-peaks. From these NOEs the H8, H6, or C8-aryl protons can be identified and paired with their $\mathrm{H}^{\prime}$ as well as their $\mathrm{H} 2^{\prime} / \mathrm{H} 2$ " protons $\left(\mathrm{H} 8 / \mathrm{H} 6\left(\mathrm{H} 5 / \mathrm{CH}_{3}\right) / \mathrm{ArH} \rightarrow \mathrm{H} 1^{\prime} \rightarrow \mathrm{H} 2\right.$ ' $/ \mathrm{H} 2$ '). For the dG nucleotides, $7.87 \rightarrow 6.31 \rightarrow 3.25 / 2.65 \mathrm{ppm}$, $7.85 \rightarrow 6.26 \rightarrow 2.78 / 2.58$ ppm, $\quad 7.83 \rightarrow 6.26 \rightarrow 2.78 / 2.58 \quad \mathrm{ppm}, \quad 7.82 \rightarrow 6.24 \rightarrow 2.78 / 2.58 \quad \mathrm{ppm}$, $7.81 \rightarrow 6.24 \rightarrow 2.78 / 2.74 \mathrm{ppm}, 7.81 \rightarrow 6.24 \rightarrow 3.21 / 2.44 \mathrm{ppm}$ and $7.78 \rightarrow 6.24 \rightarrow 2.78 / 2.74 \mathrm{ppm}$ were identified. For the $\mathrm{dC}$ nucleotides, 7.49(5.87) $\rightarrow 5.84 \rightarrow 2.66 / 1.78$ ppm, 7.44(5.74) $\rightarrow 5.81 \rightarrow 2.43 / 1.64 \quad$ ppm, $\quad 7.47(5.20) \rightarrow 5.82 \rightarrow 2.60 / 1.74 \quad$ ppm, $\quad 7.44(5.23)$ $\rightarrow 5.86 \rightarrow 2.64 / 1.74 \mathrm{ppm}, 7.39(5.15) \rightarrow 5.76 \rightarrow 2.60 / 1.69 \mathrm{ppm}$ and $7.38(5.12) \rightarrow 5.76 \rightarrow 2.60 / 1.69 \mathrm{ppm}$ were identified. Finally for the four dT nucleotides, $7.47(1.75) \rightarrow 5.99 \rightarrow 2.31 / 2.15 \mathrm{ppm}, 7.47(1.83)$ $\rightarrow 5.92 \rightarrow 2.26 / 2.15,7.59(1.90) \rightarrow 6.18 \rightarrow 2.52 / 2.27 \mathrm{ppm}$ and $7.61(1.78) \rightarrow 6.18 \rightarrow 2.52 / 2.22 \mathrm{ppm}$ were identified. 


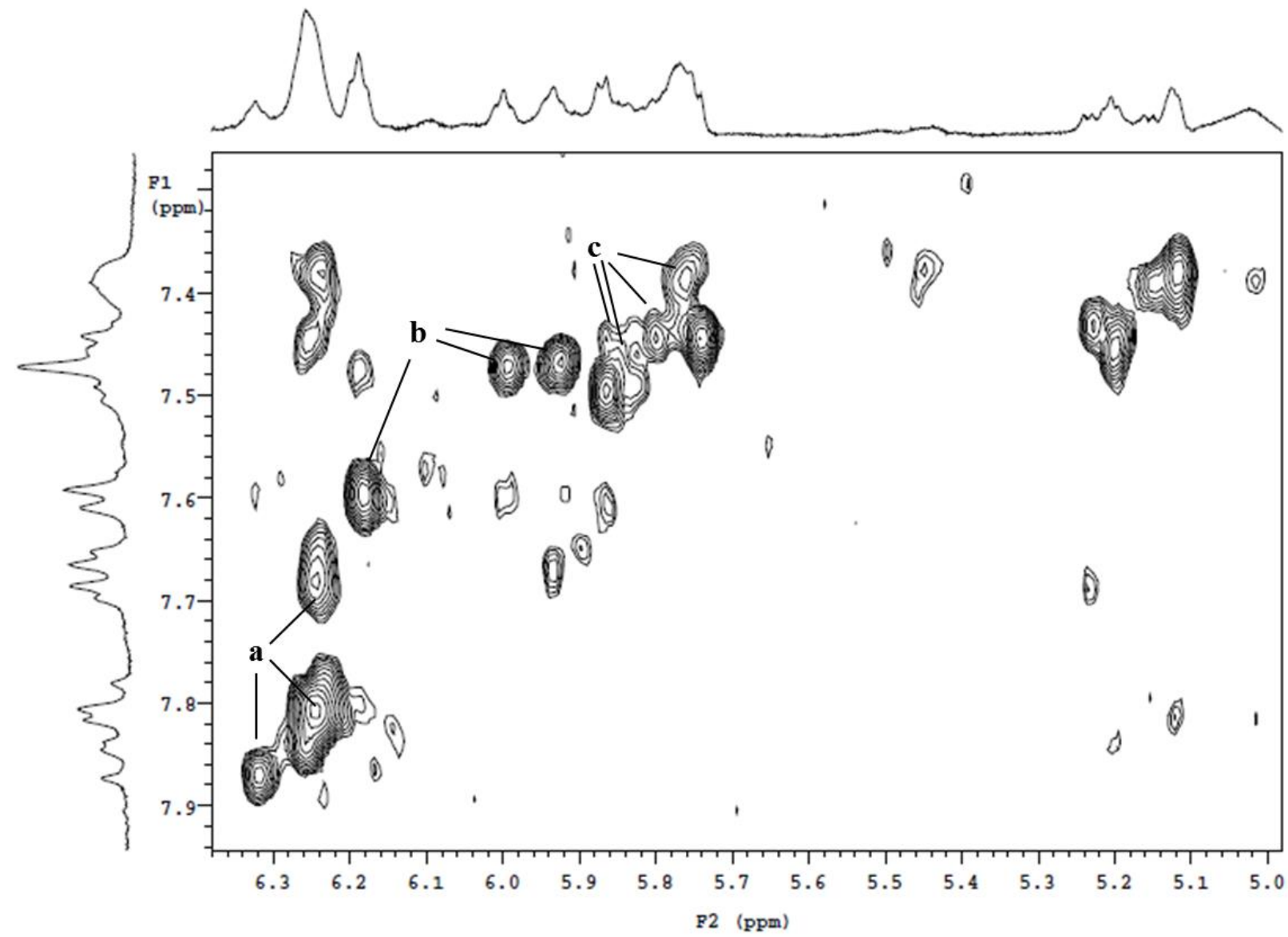

Figure 3.33. NOESY expansion of the HP-CG ${ }^{8 \mathrm{HMPh}}$ in the Z-DNA conformation. The lines from the letters a, b, or c show the a) dG-H8/H1' or dG-Ar-H1', b) dT-H6/H1' and c) dC-H6/H1' correlations.

Now that the intranucleotide NOE correlations have been assigned, the internucleotide assignment requires the identification of $\mathrm{dG}(\mathrm{n}) / \mathrm{dC}(\mathrm{n}+1), \mathrm{G}_{6}-\mathrm{Ar} / \mathrm{C}_{7}, \mathrm{G}_{10} / \mathrm{T}_{11}$ and $\mathrm{T}_{14} / \mathrm{C}_{15} \mathrm{NOE}$ correlations. $\mathrm{G}_{10}-\mathrm{H} 1$ ' (the furthest downfield $\mathrm{H} 1$ ' at $6.31 \mathrm{ppm}$ ) displays a NOE cross-peak to a dT at $7.61 \mathrm{ppm}$, which can be assumed to be $\mathrm{T}_{11}$. Another $\mathrm{dT}$ at $7.59 \mathrm{ppm}$ shows a cross-peak to a dC-H6 at $7.49 \mathrm{ppm}$ and therefore can be assigned as $\mathrm{C}_{15}$. Further the $\mathrm{C}_{15}-\mathrm{H} 6$ also shows a crosspeak with the dT- $\mathrm{CH}_{3}$ at $1.90 \mathrm{ppm}$ and thus the dT-H6 at $7.59 \mathrm{ppm}$ can be assigned as $\mathrm{T}_{14}$. Then, based on the NOE cross-peaks between dG-H8 (7.82 and $7.81 \mathrm{ppm})$ as well as the dG-H1' at 6.24 
ppm to $\mathrm{dC}-\mathrm{H} 6$ resonances at $7.38 \mathrm{ppm}$ the interior $\mathrm{dG}(\mathrm{n})$ to $\mathrm{dC}(\mathrm{n}+1)$ nucleotides are assigned yielding $\mathrm{G}_{2}-\mathrm{C}_{3}, \mathrm{G}_{4}-\mathrm{C}_{5}, \mathrm{G}_{16}-\mathrm{C}_{17}, \mathrm{G}_{18}-\mathrm{C}_{19}$ and $\mathrm{G}_{20}-\mathrm{C}_{21}$ pairs. Unlike the previous reports, our hairpin oligonucleotides contain a $\mathrm{G}_{6}-\mathrm{C} 8$-aryl modification which displays a unique $\mathrm{G}_{6}-\mathrm{H} 1$ ' to dC-H6 and G6-Ar to dC-H5 cross-peaks (6.24 to $7.44 \mathrm{ppm}$ and 7.69 to $5.23 \mathrm{ppm}$ ) that can be used to assign $\mathrm{G}_{6}$ and $\mathrm{C}_{7}$. Then $\mathrm{G}_{8}$ and $\mathrm{C}_{9}$ are assigned from $\mathrm{H} 8$ to $\mathrm{H} 6$ and $\mathrm{H} 5$ cross-peaks at 7.83 to 7.45 and $5.20 \mathrm{ppm}$. The remaining $\mathrm{dG}(\mathrm{n}) / \mathrm{dC}(\mathrm{n}+1)$ pair $\left(\mathrm{G}_{22}\right.$ to $\left.\mathrm{C}_{23}\right)$ is assigned from the cross-peak to the most upfield dG-H2” (2.44 ppm) to $\mathrm{dC}-\mathrm{H} 6$ at $7.45 \mathrm{ppm}$. Thus, the remaining $\mathrm{C}_{1}$ and $\mathrm{G}_{24}$ nucleotides are assigned to $7.47 / 5.20 \mathrm{ppm}$ and $7.85 \mathrm{ppm}$, respectively. The $\mathrm{T}_{4}$ loop is assigned based on NOE cross-peaks from $\mathrm{T}_{11}-\mathrm{H} 1^{\prime}(6.18 \mathrm{ppm})$ to $\mathrm{T}_{12}-\mathrm{H} 6$ at $7.47 \mathrm{ppm}$. $\mathrm{T}_{12}-\mathrm{CH}_{3}$ also has NOE correlations to $\mathrm{T}_{13}-\mathrm{H} 6$ at $7.47 \mathrm{ppm}$. This general procedure was used to assign the chemical shifts of the five C8-arylguanine modified hairpin oligonucleotides in the $\mathrm{Z}$ form (Table 3.17 3.21). The Z-DNA conformation of the unmodified hairpin was not assigned because the HP-CG was resistant to the salt Z-DNA conformation at the conditions used to assign the C8-arylguanine modified hairpins. 
Table 3.17. Non-exchangeable proton assignment of the modified $\mathrm{HP}-\mathrm{CG}^{8 \mathrm{Ph}}$ in the $\mathrm{Z}$ form ${ }^{\mathrm{a}}$

\begin{tabular}{|c|c|c|c|c|c|}
\hline \multirow{2}{*}{$\begin{array}{c}\text { base } \\
\text { no. }\end{array}$} & \multicolumn{5}{|c|}{${ }^{1} \mathbf{H}$ Chemical Shifts (ppm) } \\
\hline & H8/H6 & H5/CH3 & H1' & H2' & H2" \\
\hline C1 & 7.45 & 5.20 & 5.83 & 2.62 & 1.74 \\
\hline G2 & 7.79 & & 6.24 & 2.77 & 2.72 \\
\hline C3 & 7.38 & 5.12 & 5.76 & 2.60 & 1.70 \\
\hline G4 & 7.81 & & 6.24 & 2.77 & 2.72 \\
\hline C5 & 7.38 & 5.12 & 5.76 & 2.60 & 1.70 \\
\hline G6 & \multicolumn{2}{|c|}{$7.84 / 7.56$} & 6.23 & 2.83 & 2.68 \\
\hline C7 & 7.43 & 5.23 & 5.76 & 2.57 & 2.42 \\
\hline G8 & 7.82 & & 6.25 & 2.77 & 2.72 \\
\hline C9 & 7.42 & 5.20 & 5.76 & 2.60 & 1.70 \\
\hline G10 & 7.86 & & 6.31 & 3.33 & 2.63 \\
\hline T11 & 7.61 & 1.77 & 6.18 & 2.51 & 2.21 \\
\hline T12 & 7.46 & 1.83 & 5.92 & 2.26 & 2.14 \\
\hline T13 & 7.46 & 1.74 & 5.98 & 2.30 & 2.14 \\
\hline T14 & 7.58 & 1.90 & 6.18 & 2.51 & 2.26 \\
\hline C15 & 7.48 & 5.86 & 5.82 & 2.62 & 1.74 \\
\hline G16 & 7.81 & & 6.24 & 2.77 & 2.64 \\
\hline C17 & 7.38 & 5.12 & 5.76 & 2.60 & 1.70 \\
\hline G18 & 7.81 & & 6.25 & 2.77 & 2.72 \\
\hline $\mathrm{C19}$ & 7.38 & 5.12 & 5.76 & 2.60 & 1.70 \\
\hline G20 & 7.77 & & 6.23 & 2.77 & 2.74 \\
\hline C21 & 7.38 & 5.15 & 5.76 & 2.6 & 1.7 \\
\hline G22 & 7.79 & & 6.24 & 3.21 & 2.44 \\
\hline C23 & 7.43 & 5.73 & 5.80 & 2.43 & 1.63 \\
\hline G24 & 7.83 & & 6.25 & 2.77 & 2.72 \\
\hline
\end{tabular}

${ }^{a}$ NMR spectra (1H, gCOSY and NOESY) were acquired on

oligonucleotide solutions $(\sim 1.5 \mathrm{mM})$ in deuterated sodium phosphate $(10$ $\mathrm{mM}, \mathrm{pD} 7.0)$ sodium chloride $(25 \mathrm{mM})$ and magnesium chloride $(50 \mathrm{mM})$ and at $25^{\circ} \mathrm{C}$. 
Table 3.18. Non-exchangeable proton assignment of the modified $\mathrm{HP}-\mathrm{CG}^{8 \mathrm{Tol}}$ in the $\mathrm{Z}$ form ${ }^{\mathrm{a}}$

\begin{tabular}{|c|c|c|c|c|c|}
\hline \multirow{2}{*}{$\begin{array}{c}\text { base } \\
\text { no. }\end{array}$} & \multicolumn{5}{|c|}{${ }^{1}$ H Chemical Shifts (ppm) } \\
\hline & H8/H6 & $\mathrm{H} 5 / \mathrm{CH}_{3}$ & H1' & H2' & H2" \\
\hline C1 & 7.46 & 5.20 & 5.80 & 2.62 & 1.66 \\
\hline G2 & 7.80 & & 6.24 & 2.77 & 2.72 \\
\hline $\mathbf{C 3}$ & 7.38 & 5.11 & 5.76 & 2.60 & 1.69 \\
\hline G4 & 7.81 & & 6.24 & 2.77 & 2.72 \\
\hline C5 & 7.38 & 5.11 & 5.76 & 2.60 & 1.69 \\
\hline G6 $^{b}$ & \multicolumn{2}{|c|}{$7.57 / 7.51$} & 6.22 & 2.85 & 2.69 \\
\hline C7 & 7.42 & 5.22 & 5.80 & 2.43 & 1.62 \\
\hline G8 & 7.83 & & 6.26 & 2.74 & 2.58 \\
\hline C9 & 7.43 & 5.19 & 5.86 & 2.64 & 1.71 \\
\hline G10 & 7.87 & & 6.32 & 3.35 & 2.66 \\
\hline T11 & 7.61 & 1.77 & 6.18 & 2.52 & 2.22 \\
\hline T12 & 7.47 & 1.83 & 5.92 & 2.27 & 2.15 \\
\hline T13 & 7.47 & 1.75 & 5.99 & 2.31 & 2.15 \\
\hline T14 & 7.59 & 1.90 & 6.18 & 2.52 & 2.27 \\
\hline C15 & 7.49 & 5.86 & 5.83 & 2.62 & 1.71 \\
\hline G16 & 7.80 & & 6.24 & 2.77 & 2.72 \\
\hline C17 & 7.38 & 5.11 & 5.76 & 2.60 & 1.69 \\
\hline G18 & 7.81 & & 6.24 & 2.77 & 2.72 \\
\hline C19 & 7.38 & 5.11 & 5.76 & 2.60 & 1.69 \\
\hline G20 & 7.77 & & 6.25 & 2.74 & 2.72 \\
\hline $\mathrm{C21}$ & 7.39 & 5.15 & 5.76 & 2.60 & 1.69 \\
\hline G22 & 7.79 & & 6.24 & 3.22 & 2.44 \\
\hline $\mathrm{C23}$ & 7.44 & 5.73 & 5.80 & 2.43 & 1.63 \\
\hline G24 & 7.84 & & 6.26 & 2.79 & 2.74 \\
\hline
\end{tabular}

${ }^{a}$ NMR spectra $(1 \mathrm{H}, \mathrm{gCOSY}$ and NOESY) were acquired on oligonucleotide solutions $(\sim 1.5 \mathrm{mM})$ in deuterated sodium phosphate $(10 \mathrm{mM}, \mathrm{pD} 7.0)$ sodium chloride $(25 \mathrm{mM})$ and magnesium chloride $(50 \mathrm{mM})$ and at $25^{\circ} \mathrm{C}$. ${ }^{\mathrm{b}} \mathrm{C} 8-\mathrm{Tol}-\mathrm{CH}_{3}=2.50 \mathrm{ppm}$. 
Table 3.19. Non-exchangeable proton assignment of the modified $\mathrm{HP}-\mathrm{CG}^{8 \mathrm{HMPh}}$ in the $\mathrm{Z}$ form ${ }^{\mathrm{a}}$

\begin{tabular}{|c|c|c|c|c|c|}
\hline \multirow{2}{*}{$\begin{array}{c}\text { base } \\
\text { no. }\end{array}$} & \multicolumn{5}{|c|}{${ }^{1}$ H Chemical Shifts (ppm) } \\
\hline & H8/H6 & $\mathrm{H} 5 / \mathrm{CH}_{3}$ & H1' & H2' & H2' \\
\hline C1 & 7.47 & 5.20 & 5.82 & 2.60 & 1.74 \\
\hline G2 & 7.81 & & 6.24 & 2.78 & 2.74 \\
\hline C3 & 7.38 & 5.12 & 2.76 & 2.60 & 1.69 \\
\hline G4 & 7.82 & & 6.24 & 2.78 & 2.58 \\
\hline C5 & 7.38 & 5.12 & 2.76 & 2.60 & 1.69 \\
\hline G6 & \multicolumn{2}{|c|}{$7.69 / 7.66$} & 6.24 & 2.85 & 2.69 \\
\hline C7 & 7.44 & 5.23 & 5.86 & 2.64 & 1.74 \\
\hline G8 & 7.83 & & 6.26 & 2.78 & 2.58 \\
\hline C9 & 7.47 & 5.20 & 5.82 & 2.60 & 1.74 \\
\hline G10 & 7.87 & & 6.31 & 3.35 & 2.65 \\
\hline T11 & 7.59 & 1.90 & 6.18 & 2.52 & 2.27 \\
\hline T12 & 7.47 & 1.83 & 5.92 & 2.26 & 2.15 \\
\hline T13 & 7.47 & 1.75 & 5.99 & 2.31 & 2.15 \\
\hline T14 & 7.61 & 1.78 & 6.18 & 2.52 & 2.22 \\
\hline C15 & 7.49 & 5.87 & 5.84 & 2.66 & 1.78 \\
\hline G16 & 7.81 & & 6.24 & 2.78 & 2.74 \\
\hline $\mathrm{C17}$ & 7.38 & 5.12 & 2.76 & 2.60 & 1.69 \\
\hline G18 & 7.82 & & 2.64 & 2.78 & 2.58 \\
\hline C19 & 7.38 & 5.12 & 2.76 & 2.60 & 1.69 \\
\hline G20 & 7.78 & & 6.24 & 2.78 & 2.74 \\
\hline $\mathrm{C21}$ & 7.39 & 5.15 & 5.76 & 2.60 & 1.69 \\
\hline G22 & 7.80 & & 6.24 & 3.21 & 2.44 \\
\hline $\mathrm{C} 23$ & 7.44 & 5.74 & 5.80 & 2.43 & 1.64 \\
\hline G24 & 7.85 & & 6.26 & 2.78 & 2.72 \\
\hline
\end{tabular}

${ }^{a}$ NMR spectra (1H, gCOSY and NOESY) were acquired on oligonucleotide solutions $(\sim 1.5 \mathrm{mM})$ in deuterated sodium phosphate $(10 \mathrm{mM}, \mathrm{pD} 7.0)$

sodium chloride $(25 \mathrm{mM})$ and magnesium chloride $(50 \mathrm{mM})$ and at $25^{\circ} \mathrm{C}$. 
Table 3.20. Non-exchangeable proton assignment of the modified $\mathrm{HP}-\mathrm{CG}^{8 \mathrm{MMPh}}$ in the $\mathrm{Z}$ form ${ }^{\mathrm{a}}$

\begin{tabular}{|c|c|c|c|c|c|}
\hline \multirow{2}{*}{$\begin{array}{c}\text { base } \\
\text { no. }\end{array}$} & \multicolumn{5}{|c|}{${ }^{1}$ H Chemical Shifts (ppm) } \\
\hline & H8/H6 & $\mathrm{H} 5 / \mathrm{CH}_{3}$ & H1' & H2' & H2" \\
\hline C1 & 7.45 & 5.19 & 5.84 & 2.64 & 1.75 \\
\hline G2 & 7.80 & & 6.22 & 2.76 & 2.73 \\
\hline C3 & 7.00 & 5.12 & 5.75 & 2.60 & 1.69 \\
\hline G4 & 7.80 & & 6.22 & 2.76 & 2.73 \\
\hline C5 & 7.37 & 5.12 & 5.75 & 2.60 & 1.69 \\
\hline G6 & \multicolumn{2}{|c|}{$7.69 / 7.65$} & 6.22 & 2.85 & 2.69 \\
\hline C7 & 7.42 & 5.22 & 5.77 & 2.43 & 1.63 \\
\hline G8 & 7.82 & & 6.22 & 2.70 & 2.57 \\
\hline C9 & 7.42 & 5.19 & 5.77 & 2.43 & 1.63 \\
\hline G10 & 7.86 & & 6.31 & 3.35 & 2.65 \\
\hline T11 & 7.58 & 1.90 & 6.18 & 2.51 & 2.22 \\
\hline T12 & 7.46 & 1.83 & 5.99 & 2.30 & 2.15 \\
\hline T13 & 7.46 & 1.75 & 5.92 & 2.26 & 2.15 \\
\hline T14 & 7.60 & 1.77 & 6.18 & 2.51 & 2.27 \\
\hline C15 & 7.48 & 5.85 & 5.82 & 2.70 & 1.66 \\
\hline G16 & 7.80 & & 6.22 & 3.22 & 2.44 \\
\hline C17 & 7.37 & 5.12 & 5.75 & 2.60 & 1.69 \\
\hline G18 & 7.80 & & 6.22 & 2.76 & 2.73 \\
\hline C19 & 7.38 & 5.14 & 5.75 & 2.60 & 1.69 \\
\hline G20 & 7.79 & & 6.22 & 2.76 & 2.73 \\
\hline C21 & 7.37 & 5.12 & 5.75 & 2.60 & 1.69 \\
\hline G22 & 7.82 & & 6.22 & 2.70 & 2.57 \\
\hline $\mathrm{C23}$ & 7.42 & 5.70 & 5.77 & 2.43 & 1.63 \\
\hline G24 & 7.83 & & 6.25 & 2.76 & 2.73 \\
\hline
\end{tabular}

${ }^{a}$ NMR spectra $(1 \mathrm{H}, \mathrm{gCOSY}$ and NOESY) were acquired on oligonucleotide solutions $(\sim 1.5 \mathrm{mM})$ in deuterated sodium phosphate $(10 \mathrm{mM}, \mathrm{pD} 7.0)$ sodium chloride $(25 \mathrm{mM})$ and magnesium chloride $(50 \mathrm{mM})$ and at $25^{\circ} \mathrm{C}$. ${ }^{\mathrm{b}} \mathrm{C} 8-\mathrm{MMPh}-\mathrm{OCH}_{3}=3.51 \mathrm{ppm}$. 
Table 3.21. Non-exchangeable proton assignment of the modified $\mathrm{HP}-\mathrm{CG}^{8 \mathrm{CPh}}$ in the $\mathrm{Z}$ form ${ }^{\mathrm{a}}$

\begin{tabular}{|c|c|c|c|c|c|}
\hline \multirow{2}{*}{$\begin{array}{c}\text { base } \\
\text { no. }\end{array}$} & \multicolumn{5}{|c|}{${ }^{1}$ H Chemical Shifts (ppm) } \\
\hline & H8/H6 & $\mathrm{H} 5 / \mathrm{CH}_{3}$ & H1' & H2' & H2" \\
\hline C1 & 7.42 & 5.70 & 5.76 & 2.43 & 1.62 \\
\hline G2 & 7.80 & & 6.24 & 2.76 & 2.71 \\
\hline $\mathbf{C 3}$ & 7.38 & 5.10 & 5.75 & 2.59 & 1.57 \\
\hline G4 & 7.80 & & 6.24 & 2.76 & 2.71 \\
\hline C5 & 7.38 & 5.10 & 5.75 & 2.59 & 1.57 \\
\hline G6 & \multicolumn{2}{|c|}{$7.84 / 7.56$} & 6.23 & 2.83 & 2.68 \\
\hline C7 & 7.43 & 5.22 & 5.78 & 2.43 & 1.62 \\
\hline G8 & 7.80 & & 6.24 & 2.76 & 2.71 \\
\hline C9 & 7.42 & 5.20 & 5.76 & 2.60 & 1.70 \\
\hline G10 & 7.86 & & 6.31 & 3.34 & 2.65 \\
\hline T11 & 7.59 & 1.77 & 6.17 & 2.51 & 2.27 \\
\hline T12 & 7.46 & 1.82 & 5.91 & 2.26 & 2.15 \\
\hline T13 & 7.46 & 1.74 & 5.98 & 2.29 & 2.15 \\
\hline T14 & 7.57 & 1.89 & 6.17 & 2.51 & 2.27 \\
\hline C15 & 7.49 & 5.85 & 5.83 & 2.60 & 1.71 \\
\hline G16 & 7.80 & & 6.24 & 2.76 & 2.71 \\
\hline C17 & 7.38 & 5.10 & 5.75 & 2.59 & 1.57 \\
\hline G18 & 7.80 & & 6.24 & 2.76 & 2.71 \\
\hline C19 & 7.39 & 5.14 & 5.75 & 2.59 & 1.57 \\
\hline G20 & 7.80 & & 6.24 & 2.76 & 2.71 \\
\hline C21 & 7.38 & 5.10 & 5.75 & 2.59 & 1.57 \\
\hline G22 & 7.80 & & 6.24 & 3.20 & 2.44 \\
\hline $\mathrm{C23}$ & 7.45 & 5.20 & 5.84 & 2.64 & 1.73 \\
\hline G24 & 7.83 & & 6.24 & 2.76 & 2.71 \\
\hline
\end{tabular}

${ }^{a}$ NMR spectra $(1 \mathrm{H}$, gCOSY and NOESY) were acquired on oligonucleotide solutions $(\sim 1.5 \mathrm{mM})$ in deuterated sodium phosphate $(10 \mathrm{mM}, \mathrm{pD} 7.0)$ sodium chloride $(25 \mathrm{mM})$ and magnesium chloride $(50 \mathrm{mM})$ and at $25^{\circ} \mathrm{C}$. 


\section{Chapter 4: Molecular Modeling of the B- and Z-DNA Conformations of the Hairpin Oligonucleotides}

Molecular modeling is a computational approach used to study biological molecules of interest. It uses mathematical equations to approximate the fundamental laws of physical chemistry. Through the combination of molecular mechanics (MM) and molecular dynamics (MD) simulations the conformation(s) of oligonucleotides can be investigated. Molecular modeling can also be used to calculate the free energy of the oligonucleotide systems. The computational approach used here was applied to the $\mathrm{B}$ and $\mathrm{Z}$ forms of the unmodified and $\mathrm{C} 8$ arylguanine modified hairpins studied by CD and NMR. Molecular modeling can be used to generate computational models that are useful for interpreting the experimental results, especially the NMR data. In addition, the simulation data provides a breakdown of the contributing factors (van der Waal interactions, electrostatics, etc.) that drive the oligonucleotide conformation.

The unmodified and C8-arylguanine hairpin oligonucleotides in both the B-DNA and ZDNA conformation were subjected to MM/MD simulations. This is required to compare the conformational effects of the $\mathrm{C} 8$-arylguanine base modification to the unmodified hairpin as well as on the local and global helicoidal parameters relative to the hairpin oligonucleotide conformation (B vs. $\mathrm{Z}$ form). A description of the base pair and helical parameters has been previously reported and this terminology will be used here. ${ }^{165}$ In addition, free energy calculations were used to predict which conformation of the unmodified and C8-arylguanine modified hairpin oligonucleotides was most stable. These calculations also yield an analysis of the individual components that compose the overall free energies for each conformation. Although the computational method, here MM-PB(GB)SA, was originally designed for work with proteins, we have used them here for the B-and Z-DNA conformations of the hairpin oligonucleotides. 
The computational studies described below were also used to compare the hairpin oligonucleotides with our previous computational studies with doubly modified double-stranded (CG) 5 decamers. ${ }^{99,100}$ In this section, the focus will be on the hairpin oligonucleotides: HP-CG, $\mathrm{HP}-\mathrm{CG}^{8 \mathrm{Ph}}, \mathrm{HP}-\mathrm{CG}^{8 \mathrm{Tol}}, \mathrm{HP}-\mathrm{CG}^{8 \mathrm{HMPh}}, \mathrm{HP}-\mathrm{CG}^{8 \mathrm{MMPh}}$ and $\mathrm{HP}-\mathrm{CG}^{8 \mathrm{CPh}}$. In the following chapter comparison between the doubly modified and singly modified hairpins will be described.

\section{A. General}

The computational studies require the hairpin oligonucleotides to be built and generally follows the protocol established by Heavner and Gannett. ${ }^{99}$ All the parameters for the C8arylguanine modified bases were generated either through the work of Heavner ${ }^{166}$ or Vongsutilers ${ }^{167}$ and were used in the Amber suite of programs such as xLEAP, sander, ptraj, and $\mathrm{MM} / \mathrm{PB}(\mathrm{GB}) \mathrm{SA}$. The hairpin oligonucleotides were built using the previously constructed $(\mathrm{CG})_{5}$ decamers and the coordinate file of hairpin oligonucleotide with a $\mathrm{T}_{4}$ loop using Moil-View. ${ }^{168}$ Once the hairpin oligonucleotides are created then the input files are written for the MM calculations, which is applied to relax the hairpin oligonucleotide and the solvent molecules using sander. Sander is further used in the MD simulations to produce trajectories that can be analyzed using ptraj and $\mathrm{MM}-\mathrm{PB}(\mathrm{GB}) \mathrm{SA}$ to generate the most representative structures and determine the free energy of the hairpin systems, respectively. The most representative structures were then analyzed using X3DNA ${ }^{169}$ to yield the base pair and helical parameters. 


\section{B. Hairpin Oligonucleotide Structure Building}

Previous work with a RNA hairpin had a -UUUU- tetraloop, here the U bases were changed to dT bases and aligned with our previously constructed $(\mathrm{CG})_{5}$ decamer. The hairpin oligonucleotides were constructed using MOIL-View. In MOIL-View, both structures ((-T⿰亻 $4^{-}$and $(\mathrm{CG})_{5}$ decamer) can be loaded into the same window and then two atoms that are supposed to be the 'same' are picked (i.e. the dT-5'-Oxygen connected to the $\mathrm{T}_{4}$ loop and 3'-dG-5'-Oxygen of the $(\mathrm{CG})_{5}$ decamer). A root mean square deviation (RMSd) fit can be run on the two structures to align the two structures, which can then be saved as one coordinate file. The resulting coordinate file requires manual editing to re-label the nucleotide residues 1 through 24 . This coordinate file is loaded into xLEAP and the required sander files generated. The B- and Z-DNA conformations were created using the previously generated $\mathrm{B}$ and $\mathrm{Z}$ forms of the unmodified $(\mathrm{CG})_{5}$ decamer. To create the $\mathrm{C} 8$-arylguanine modified hairpin oligonucleotide the $\mathrm{G}_{6}$ residue was modified using the text editor with the appropriate C8-arylguanine modification, and the structure was loaded into xLEAP, the appropriate C8-arylguanine force field files (frcmod file and prep file), and the sander files written. The $\mathrm{B}$ and $\mathrm{Z}$ forms of the unmodified and five $\mathrm{C} 8$-arylguanine modified hairpin oligonucleotides (12 structures total) were the starting structures for the MM simulations and the resulting structures used for the MD simulations.

\section{MM and MD Simulations}

The MM and MD simulations were performed using the sander program of Amber $11^{170}$ and the parm99.dat of the Cornell force field. ${ }^{171}$ The B- and Z-DNA hairpin structures were loaded into xLEAP and the negatively charged residues of the phosphate backbone were neutralized by the addition of 23 sodium counter ions (24 for the $\mathrm{HP}-\mathrm{CG}^{8 \mathrm{CPh}}$ analog). The hairpin 
oligonucleotides were solvated by the addition of water box (TIP3) with a box size in any direction being a minimum of $10 \AA$ from the oligonucleotide and counter ions. Then the topology (top) and coordinate (crd) were created for the initial MM simulations.

The computational studies begin with MM to minimize the energy of the system. First a MM simulation is performed with the DNA fixed by $500 \mathrm{kcal} / \mathrm{mol} \AA$ of positional restraints on all the hairpin oligonucleotide atoms for 1000 steps. Then the atom positional restraints are removed and the entire system is minimized for 2500 steps. In the following MD simulation (20 ps) the oligonucleotide is fixed again while the solvent box and counter ions are equilibrated and the system warmed to $300 \mathrm{~K}$. Then production MD simulations were performed at constant temperature $(300 \mathrm{~K})$ and pressure $(1 \mathrm{~atm})$ for $10 \mathrm{~ns}$.

\section{Most Representative Structure}

The most representative structure is the structure with the smallest RMSd to all of the other structures in the trajectory. This structure is used to determine the base pair and helical parameters as well as well as the major and minor groove widths which were then used to compare between the unmodified and modified hairpin oligonucleotides. The most representative structure is determined using the cluster option in the Amber program ptraj. The ptraj program reads the 3D coordinates of the MD trajectories based on the similarity of RMSd. ptraj can also be used to strip the water and ions out of the coordinate files before creating the most representative pdb.

The most representative structure is a model that can be used to help interpret the NMR data, especially with respect to the non-exchangeable proton assignment. These models are used to predict NOE correlations seen in the NOESY spectra, since this data is distance dependent. The 
most representative structures all the hairpin oligonucleotides in the B-DNA conformation are shown in Figure 4.1. The most representative structures for the hairpin oligonucleotides in the Z-DNA conformation are shown in Figure 4.2. Initial inspection of the most representative structures show that the single C8-arylguanine modification has the most effect on the B-DNA conformation, when the modified base is contained within the DNA helix, but has little effect on the Z-DNA conformation when the base modification is outside the DNA helix. A more quantitative analysis of the $\mathrm{C} 8$-arylguanine modification on the hairpin conformation is provided from the X3DNA, which can be used to determine the base pair and helical parameters.

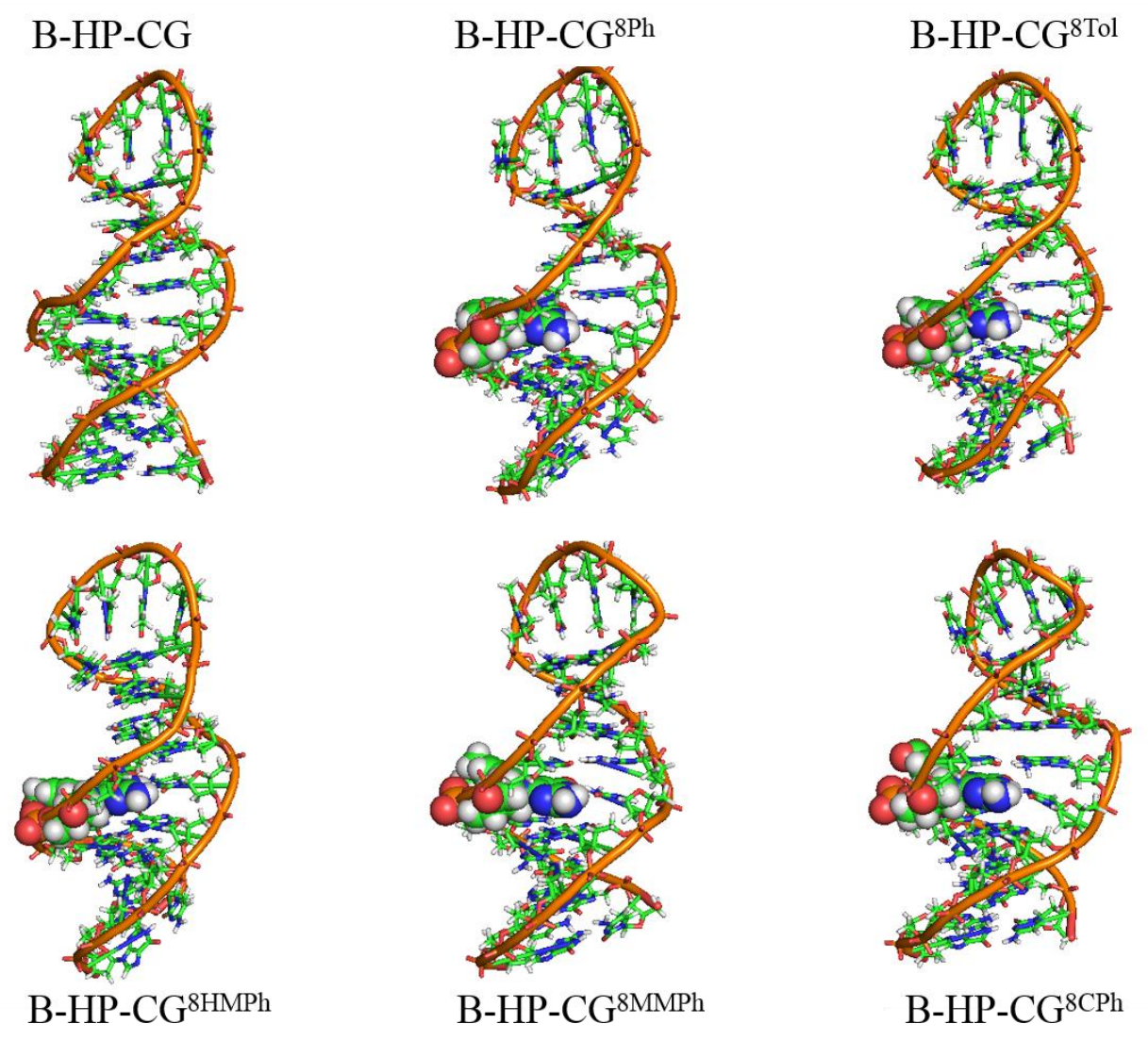

Figure 4.1. The most representative structures of the unmodified and $C 8$-arylguanine modified hairpin oligonucleotides in the B-DNA conformation. The gold ribbon represents the phosphate backbone, the bases are drawn with stick bonds except for the modified base which rendered with spheres. 

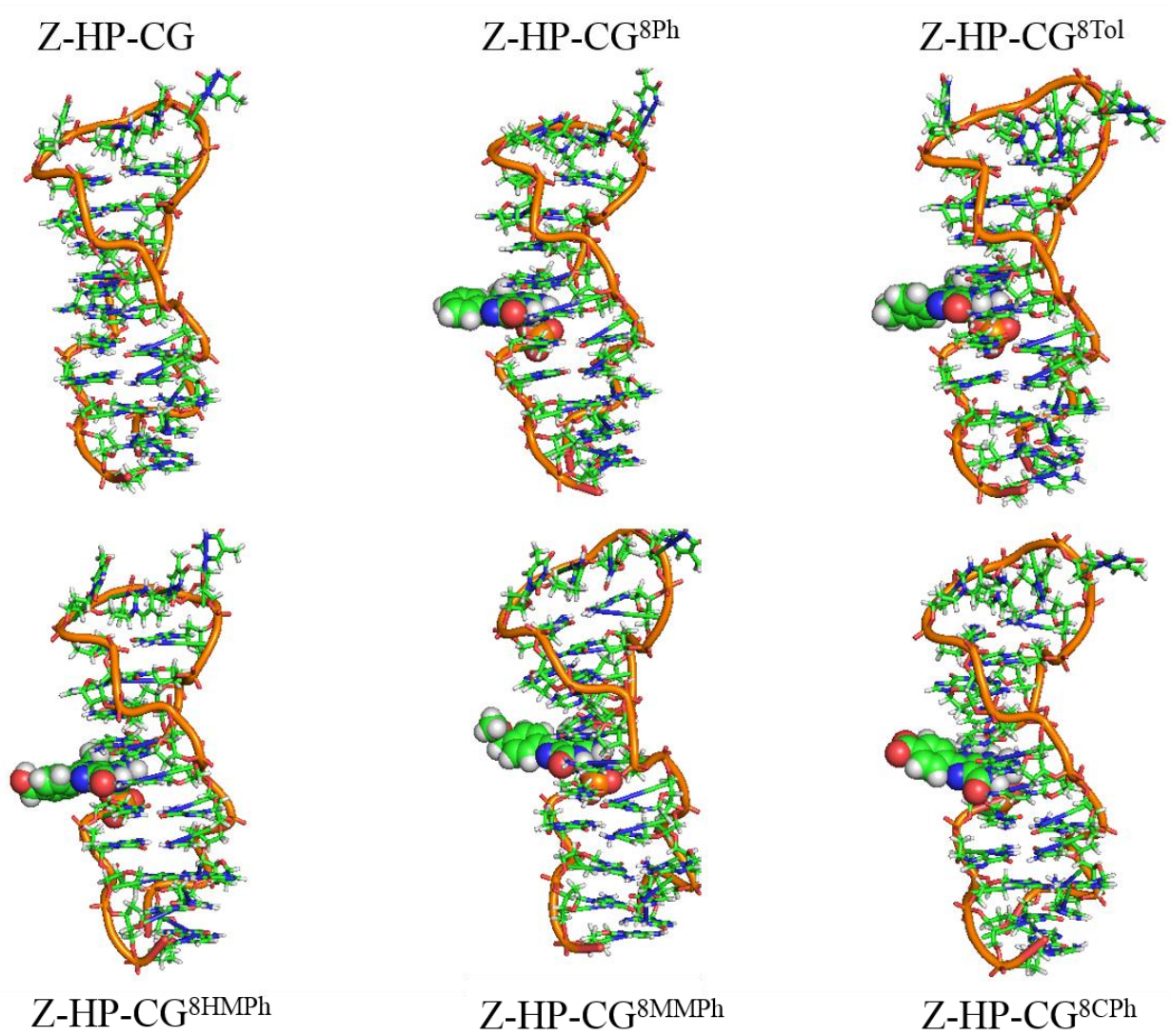

Figure 4.2. The most representative structures of the unmodified and $\mathrm{C} 8$-arylguanine modified hairpin oligonucleotides in the Z-DNA conformation. The gold ribbon represents the phosphate backbone, the bases are drawn with stick bonds except for the modified base which rendered with spheres.

\section{E. Structural Analysis}

\section{General}

The computational structural analysis of the C8-arylguanine modified hairpin oligonucleotides was performed by X3DNA. ${ }^{169}$ This software program is used to determine the helicoidal parameters of the $\mathrm{C} 8$-arylguanine modified hairpin structure relative to the unmodified hairpin in both the B- and Z-DNA conformations. The coordinate file of the most representative structure from the MD simulations is analyzed to determine the base pair $\left(\mathrm{G}_{6} / \mathrm{C} 19\right)$ and base step $\left(\mathrm{C}_{5} / \mathrm{G}_{6}\right)$ geometries that comprise the hairpin structure and to provide the major and minor groove 
dimensions. In general, the base pair and helical parameters that were analyzed were previously described and illustrated in Figure 4.3. ${ }^{169}$

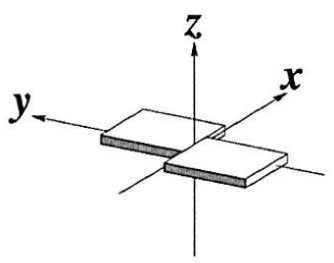

Shear $(S x)$

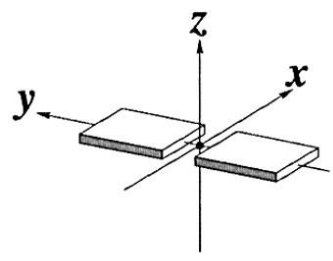

Stretch (Sy)

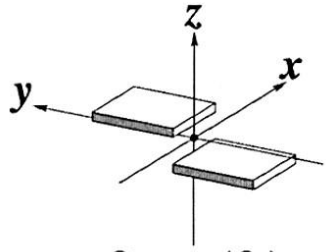

Stagger $(S z)$

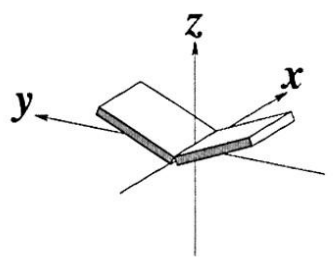

Buckle $(\kappa)$

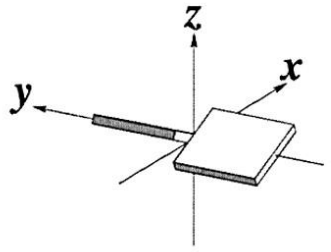

Propeller $(\pi)$

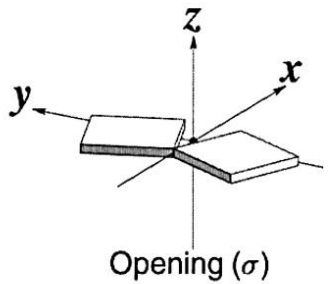

Opening $(\sigma)$

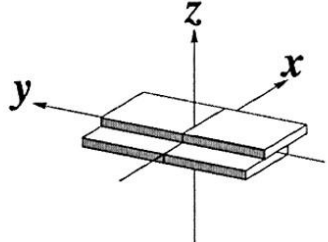

Shift $(D x)$

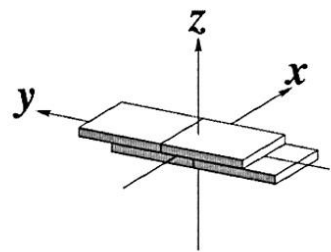

Slide $(D y)$

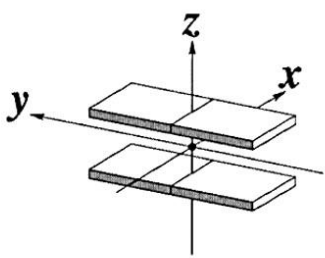

Rise $(D z)$

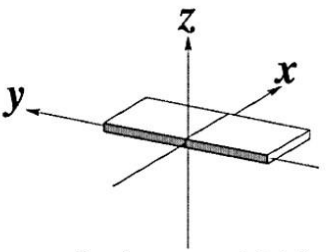

$x$-displacement $(d x)$

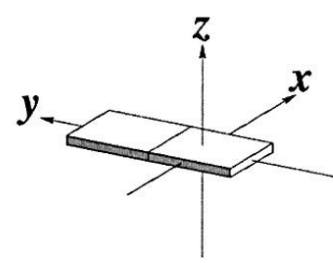

$y$-displacement (dy)

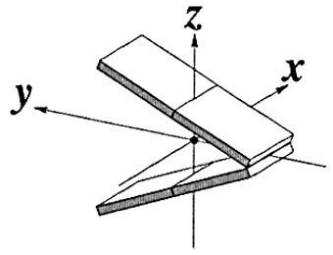

Tilt $(\tau)$
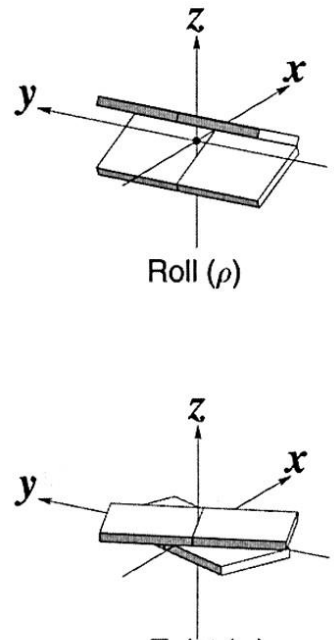

Twist $(\omega)$
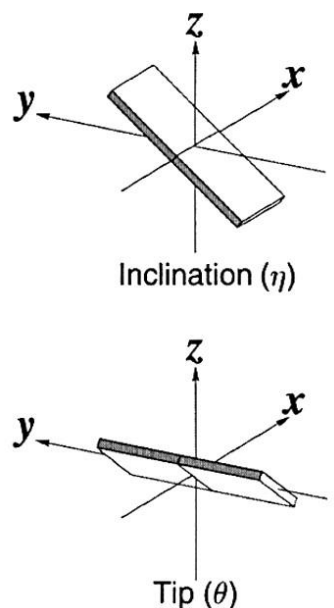

Figure 4.3. Depiction of the base pairand base pairstep helical parameters. Reprinted with permission from Dr. Xiang-Jun Lu and Nucleic Acids Research (ref 168). 


\section{Hairpin Oligonucleotides in the B-DNA conformation}

The C8-arylguanine modification has a significant conformational effect in the hairpin oligonucleotide in the B-DNA conformation. Since the C8-arylguanine modified base is contained within the DNA helix in the B form the local base pair and helical parameters are altered relative to the unmodified hairpin. Table 4.1 presents the base helicoidal parameters of the most representative structures determined by X3DNA.

Although the intra-base pair values of the $\mathrm{C} 8$-arylguanine modified hairpins varied relative to the unmodified hairpin, there were no obvious trends for any given parameter with the exception of buckle (BKL). The BKL value for the modified hairpins were all negative relative to the unmodified $\mathrm{G}_{6}-\mathrm{C}_{19}$ base pair with the greatest difference seen for the $\mathrm{HP}-\mathrm{CG}^{8 \mathrm{Tol}}$ derivative $\left(\Delta 37.4^{\circ}\right)$. The inter-base values for slide (SLD) were all slightly more negative relative to the unmodified hairpin. The values for shift (SHF) between the $\mathrm{G}_{6}$ modified base and the 5'-cytosine $\left(\mathrm{C}_{5}\right)$ base pair step are somewhat more negative than in the unmodified hairpin, especially for the HP-CG ${ }^{8 \mathrm{CPh}}$ analog $(\Delta 0.82 \AA)$, however the $\mathrm{HP}-\mathrm{CG}^{8 \mathrm{Ph}}$ and $\mathrm{HP}-\mathrm{CG}^{8 \mathrm{Tol}}$ are slightly more positive $(<\Delta 0.25 \AA)$. One consequence of the C8-arylguanine modification is an increase in rise (RIS), except for the HP-CG ${ }^{8 \mathrm{Ph}}$ which exhibits a slight decrease in RIS, where the HP-CG ${ }^{8 \mathrm{CPh}}$ displays the largest deviation relative to the unmodified $\mathrm{C}_{5}-\mathrm{G}_{6}$ inter-base step. In addition, there is an increase in roll (ROL) for all the modified hairpins. While there is a general increase in rise (RIS) and ROL, there is a general decrease in helical twist (TWT) for the all the C8-arylguanine modifications in the hairpin conformation with up to a $12.1^{\circ}$ difference for the HP-CG ${ }^{8 T o l}$ derivative. 
The base pair axis parameters for modified hairpins show a large increase for inclination (INC) with a difference of $36.7^{\circ}$ in $\mathrm{HP}-\mathrm{CG}^{8 \mathrm{MMPh}}$ relative to the unmodified hairpin oligonucleotide. The X-displacement (XDP) parameter for all the modified hairpins show a negative shift from the helical axis relative to the unmodified $\mathrm{G}_{6}-\mathrm{C}_{19}$ base pair. The Y-displacement (YDP) parameters show modest changes with no obvious trends and all of the TIP values for the modified hairpins are more negative than the TIP value for the unmodified hairpin. 
Table 4.1. Helical parameters for the unmodified and modified hairpin oligonucleotides in the B-DNA conformation determined by X3DNA.

\begin{tabular}{|c|c|c|c|c|c|c|}
\hline \multicolumn{7}{|c|}{ Intra-Base Pair ${ }^{\mathrm{a}}$} \\
\hline & CG & $\mathrm{CG}^{8 \mathrm{Ph}}$ & $\mathrm{CG}^{8 \mathrm{Tol}}$ & $\mathrm{CG}^{8 \mathrm{HMPh}}$ & CG $^{8 M M P h}$ & $\mathrm{CG}^{8 \mathrm{CPh}}$ \\
\hline & G6/C19 & G6/C19 & G6/C19 & G6/C19 & G6/C19 & G6/C19 \\
\hline SHR $^{b}$ & 0.60 & 0.15 & 0.05 & 0.01 & -0.12 & 0.32 \\
\hline STR $^{b}$ & 0.07 & -0.15 & -0.08 & -0.06 & -0.11 & 0.00 \\
\hline STG $^{\mathbf{b}}$ & -0.03 & -0.15 & -0.53 & 0.34 & -0.76 & -0.77 \\
\hline BKL ${ }^{c}$ & 11.7 & -12.6 & -25.7 & -13.5 & -3.19 & -16.3 \\
\hline PRP $^{c}$ & -2.89 & -20.9 & -13.9 & -12.7 & -16.6 & -3.51 \\
\hline OPNc & -3.50 & -0.07 & 2.71 & -1.84 & -0.58 & -5.02 \\
\hline \multicolumn{7}{|c|}{ Inter-Base Pair $^{\mathbf{a}}$} \\
\hline & CG & $\mathrm{CG}^{8 \mathrm{Ph}}$ & $\mathrm{CG}^{8 \mathrm{Tol}}$ & $\mathrm{CG}^{8 \mathrm{HMPh}}$ & $\mathrm{CG}^{8 \mathrm{MMPh}}$ & $\mathrm{CG}^{8 \mathrm{CPh}}$ \\
\hline & $\mathrm{C} 5 / \mathrm{G} 6$ & C5/G6 & C5/G6 & C5/G6 & C5/G6 & C5/G6 \\
\hline SHF $^{b}$ & 0.75 & 1.00 & 0.93 & 0.74 & 0.61 & -0.07 \\
\hline SLD $^{\mathbf{b}}$ & -0.16 & -1.02 & -1.74 & -1.15 & -2.07 & -1.43 \\
\hline $\mathbf{R I S}^{\mathbf{b}}$ & 3.56 & 3.2 & 3.92 & 3.49 & 3.79 & 4.12 \\
\hline TLT $^{\mathrm{c}}$ & 0.38 & 10.9 & 8.4 & 0.83 & 5.12 & 4.15 \\
\hline ROL $^{\mathrm{c}}$ & -2.43 & 15.5 & 10.9 & 7.46 & 15.6 & 14.2 \\
\hline TWT $^{\mathrm{c}}$ & 35.8 & 29.3 & 23.7 & 27.4 & 24.2 & 27.9 \\
\hline \multicolumn{7}{|c|}{ Base Pair-Helical Axis ${ }^{d}$} \\
\hline & CG & $\mathrm{CG}^{8 \mathrm{Ph}}$ & CG $^{8 T o l}$ & CG ${ }^{8 H M P h}$ & $\mathrm{CG}^{8 \mathrm{MMPh}}$ & $\mathrm{CG}^{8 \mathrm{CPh}}$ \\
\hline & G6/C19 & G6/C19 & G6/C19 & G6/C19 & G6/C19 & G6/C19 \\
\hline $\mathbf{X D P}^{\mathbf{b}}$ & 0.12 & -3.99 & -6.75 & -4.09 & -7.51 & -5.71 \\
\hline YDP & -1.16 & -0.07 & 0.40 & -1.31 & -0.09 & 1.03 \\
\hline$I^{\prime N C} C^{c}$ & -3.95 & 27.3 & 24.1 & 15.4 & 32.8 & 27.1 \\
\hline TIPc & -0.61 & -19.2 & -18.6 & -1.70 & -10.8 & -7.94 \\
\hline
\end{tabular}

${ }^{a}$ Values reported are for the $\mathrm{C}_{5} / \mathrm{G}_{20}-\mathrm{G}_{6} / \mathrm{C}_{19}$ base pair step. ${ }^{b}$ Values are in units of $\AA$. ${ }^{c}$ Values are in unites of degrees. ${ }^{d}$ Values reported are the average of both $\mathrm{C}_{5} / \mathrm{G}_{20}$ and $\mathrm{G}_{6} / \mathrm{C}_{19}$ base pair-axis values.

The differences in the helical parameters noted, produced some changes in the widths of the major and minor grooves. Relative to the unmodified oligonucleotide, the major groove in the modified oligonucleotides (B form) increases in size if the para-substituent is non-polar (- $\mathrm{H}$ or - 
$\mathrm{CH}_{3}$ ) but is more narrow with polar (- $\mathrm{COO}^{-}$or $-\mathrm{CH}_{2} \mathrm{OH}$ ) substituents. In addition, the minor groove width increases for the C8-arylguanine hairpin oligonucleotides.

Table 4.2. Major and minor groove widths for the unmodified and modified hairpin oligonucleotides in the B-DNA conformation determined by X3DNA.

\begin{tabular}{|c|c|c|c|c|c|c|}
\hline \multicolumn{7}{|c|}{ Major Groove Width $(\AA)^{\mathbf{a}}$} \\
\hline $\begin{array}{l}\text { Base } \\
\text { No. }\end{array}$ & CG & $\mathrm{CG}^{8 \mathrm{Ph}}$ & $\mathrm{CG}^{8 \mathrm{~T} o l}$ & $\mathrm{CG}^{8 \mathrm{CPh}}$ & $\mathrm{CG}^{8 \mathrm{MMPh}}$ & CG $^{8 H M P h}$ \\
\hline 4 & 16.9 & 16.6 & 19.2 & 16.7 & 16.3 & 18.0 \\
\hline 5 & 20.3 & 20.6 & 21.6 & 19.4 & 17.2 & 16.9 \\
\hline 6 & 16.2 & 19.3 & 21.6 & 15.9 & 18.3 & 18.0 \\
\hline 7 & & & & & & \\
\hline Average & 17.8 & 18.8 & 20.8 & 17.3 & 17.3 & 17.6 \\
\hline \multicolumn{7}{|c|}{ Minor Groove Width $(\AA)^{\mathbf{a}}$} \\
\hline $\begin{array}{l}\text { Base } \\
\text { No. }\end{array}$ & $\mathbf{C G}$ & $\mathrm{CG}^{8 \mathrm{Ph}}$ & $\mathrm{CG}^{8 \mathrm{~T} o \mathrm{l}}$ & $\mathrm{CG}^{8 \mathrm{CPh}}$ & CG $^{8 M M P h}$ & CG $^{8 \mathrm{HMPh}}$ \\
\hline 4 & 12.3 & 13.8 & 13.8 & 12.6 & 13.8 & 12.9 \\
\hline 5 & 11.3 & 12.6 & 12.7 & 12.7 & 12.7 & 12.7 \\
\hline 6 & 11.8 & 12.7 & 12.0 & 15.4 & 13.1 & 12.7 \\
\hline 7 & & & & & & \\
\hline Average & 11.8 & 13.0 & 12.8 & 13.6 & 13.2 & 12.8 \\
\hline
\end{tabular}

${ }^{a}$ Values reported correspond to the average taken over $\mathrm{G}_{4}-\mathrm{C}_{7} / \mathrm{G}_{18}-\mathrm{C}_{21}$.

\section{Hairpin Oligonucleotides in the Z-DNA Conformation}

The C8-arylguanine modification has less of a conformational effect on the Z-DNA conformation than was shown for the B-DNA conformation. Based on the similarity of the representative structures (unmodified and modified) presented in Figure 4.2, this result was expected. While there are distinct differences in the inter-base and base pair helical axis parameters for all of the $\mathrm{C} 8$-arylguanine modified hairpins relative to the unmodified hairpin in 
the B form, there were no significant deviations observed between the unmodified and modified hairpins in the $\mathrm{Z}$ form. Table 4.3 presents the helical parameters of the hairpin oligonucleotides in the Z-DNA conformation.

The majority of the intra-base pair parameters were similar for all of the hairpins, however, there are some minor deviations in the BKL and propeller (PRP) parameters. The inter-base pair parameters for the modified hairpins were also similar to the unmodified hairpin and only a few parameters showed large differences relative to the unmodified hairpin. The tilt (TLT) parameters for the $\mathrm{HP}-\mathrm{CG}^{8 \mathrm{Ph}}, \mathrm{HP}-\mathrm{CG}^{8 \mathrm{MMPh}}$ and $\mathrm{HP}-\mathrm{CG}^{8 \mathrm{CPh}}$ were more positive relative to the unmodified value while the $\mathrm{HP}-\mathrm{CG}^{8 \mathrm{Tol}}$ and $\mathrm{HP}-\mathrm{CG}^{8 \mathrm{HMPh}}$ showed a decrease in values relative to the unmodified hairpin. The base pair helical axis parameters were also very similar for all of the hairpin series and although there was some variation from the modified hairpins to unmodified hairpin, the variations did not show any consistent trends. For example, the INC for the HP-CG ${ }^{8 M M P h}$ is nearly double the value of the unmodified INC value, but the $\mathrm{HP}-\mathrm{CG}^{8 \mathrm{Ph}}$ and $\mathrm{HP}-\mathrm{CG}^{8 \mathrm{CPh}}$ are nearly the same and the $\mathrm{HP}-\mathrm{CG}^{8 \mathrm{Tol}}$ and $\mathrm{HP}-\mathrm{CG}^{8 \mathrm{HMPh}}$ values are smaller than that of the HP-CG value. Further the major and minor groove widths are nearly identical between the unmodified and modified hairpin oligonucleotides (Table 4.4). Overall, the variation seen amongst the $\mathrm{Z}$ forms of the hairpin oligonucleotide series is not likely due to the C8-arylguanine modification as was the case in the B-DNA conformation and may be due the zigzag phosphate backbone in the Z-DNA conformation. 
Table 4.3. Helical parameters for the unmodified and modified hairpin oligonucleotides in the Z-DNA conformation determined by X3DNA.

\begin{tabular}{|c|c|c|c|c|c|c|}
\hline \multicolumn{7}{|c|}{ Intra-Base Pair ${ }^{\mathrm{a}}$} \\
\hline & CG & $\mathrm{CG}^{8 \mathrm{Ph}}$ & $\mathrm{CG}^{8 \mathrm{TTol}}$ & $\mathrm{CG}^{8 \mathrm{HMPh}}$ & $\mathrm{CG}^{\mathrm{8MMPh}}$ & $\mathrm{CG}^{8 \mathrm{CPh}}$ \\
\hline & G6/C19 & G6/C19 & G6/C19 & G6/C19 & G6/C19 & G6/C19 \\
\hline SHR $^{\mathbf{b}}$ & 0.16 & 0.26 & -0.11 & 0.46 & 0.16 & 0.34 \\
\hline STR $^{b}$ & -0.06 & -0.18 & -0.06 & -0.04 & -0.33 & -0.23 \\
\hline STG $^{b}$ & -0.25 & -0.22 & 0.00 & 0.11 & -0.77 & -0.17 \\
\hline$B K^{c}$ & -16.6 & -1.77 & -5.21 & 3.51 & 2.95 & 4.73 \\
\hline $\mathbf{P R P}^{\mathbf{c}}$ & 4.82 & -5.68 & 6.15 & -2.84 & -12.0 & -19.3 \\
\hline OPN & 5.53 & 0.52 & 2.41 & -2.80 & 9.34 & 2.94 \\
\hline \multicolumn{7}{|c|}{ Inter-Base Pair ${ }^{\mathrm{a}}$} \\
\hline & CG & $\mathrm{CG}^{8 \mathrm{Ph}}$ & $\mathrm{CG}^{8 \mathrm{TTol}}$ & $\mathrm{CG}^{8 \mathrm{HMPh}}$ & $\mathrm{CG}^{\mathrm{8MMPh}}$ & $\mathrm{CG}^{8 \mathrm{CPh}}$ \\
\hline & C5/G6 & C5/G6 & C5/G6 & C5/G6 & C5/G6 & C5/G6 \\
\hline SHF $^{b}$ & 0.16 & -0.5 & 0.34 & -0.31 & 0.39 & 0.60 \\
\hline SLD $^{b}$ & 5.39 & 5.70 & 5.30 & 5.10 & 5.11 & 5.38 \\
\hline $\mathbf{R I S}^{\mathbf{b}}$ & 4.04 & 3.65 & 3.63 & 3.38 & 3.21 & 3.59 \\
\hline TLT $^{\mathrm{c}}$ & 2.04 & 5.05 & -1.33 & 0.84 & 8.64 & 11.6 \\
\hline ROL $^{c}$ & -5.39 & -5.88 & -3.13 & -2.51 & -14.9 & -7.69 \\
\hline TWT $^{\mathrm{c}}$ & -10.2 & -10.9 & -10.8 & -7.42 & -10.1 & -9.82 \\
\hline \multicolumn{7}{|c|}{ Base Pair-Helical Axis ${ }^{d}$} \\
\hline & CG & $\mathrm{CG}^{8 \mathrm{Ph}}$ & $\mathrm{CG}^{8 \mathrm{TTol}}$ & $\mathrm{CG}^{8 \mathrm{HMPh}}$ & $\mathrm{CG}^{\mathrm{8MMPh}}$ & $\mathrm{CG}^{8 \mathrm{CPh}}$ \\
\hline & G6/C19 & G6/C19 & G6/C19 & G6/C19 & G6/C19 & G6/C19 \\
\hline XDPb & -14.3 & -14.8 & -20.7 & -27.3 & -2.67 & -10.8 \\
\hline YDPb & 5.34 & 6.20 & -0.90 & 1.08 & 8.17 & 13.2 \\
\hline INC $^{\mathrm{c}}$ & 27.7 & 27.0 & 16.1 & 18.6 & 51.7 & 30.4 \\
\hline TIPc & 10.5 & 23.2 & -6.84 & 6.27 & 30.1 & 45.8 \\
\hline
\end{tabular}

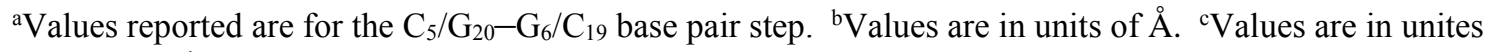
of degrees. ${ }^{d}$ Values reported are the average of both $\mathrm{C}_{5} / \mathrm{G}_{20}$ and $\mathrm{G}_{6} / \mathrm{C}_{19}$ base pair-axis values. 
Table 4.4. Major and minor groove widths for the unmodified and modified hairpin oligonucleotides in the Z-DNA conformation determined by X3DNA.

\begin{tabular}{|c|c|c|c|c|c|c|}
\hline \multicolumn{7}{|c|}{ Major Groove Width $(\AA)^{\mathbf{a}}$} \\
\hline Base No. & $\mathbf{C G}$ & $\mathrm{CG}^{8 \mathrm{Ph}}$ & $\mathrm{CG}^{8 \mathrm{TOl}}$ & $\mathrm{CG}^{8 \mathrm{CPh}}$ & $\mathbf{C G}^{8 M M P h}$ & $\mathrm{CG}^{8 \mathrm{HMPh}}$ \\
\hline 4 & 15.0 & 14.6 & 15.1 & 16.8 & - & 15.5 \\
\hline 5 & 19.3 & 18.7 & 19.1 & 19.2 & - & 18.3 \\
\hline 6 & 14.6 & 14.2 & 14.2 & 14.1 & - & 15.0 \\
\hline \multicolumn{7}{|l|}{7} \\
\hline Average & 16.3 & 15.8 & 16.1 & 16.7 & - & 16.3 \\
\hline \multicolumn{7}{|c|}{ Minor Groove Width $(\AA)^{\mathbf{a}}$} \\
\hline Base No. & CG & $\mathrm{CG}^{8 \mathrm{Ph}}$ & $\mathrm{CG}^{8 \mathrm{Tol}}$ & $\mathrm{CG}^{8 \mathrm{CPh}}$ & $\mathrm{CG}^{8 \mathrm{MMPh}}$ & $\mathrm{CG}^{8 \mathrm{HMPh}}$ \\
\hline 4 & 11.8 & 11.7 & 11.4 & 13.4 & - & 13.1 \\
\hline 5 & 11.4 & 11.0 & 11.3 & 12.9 & - & 12.3 \\
\hline 6 & 12.0 & 10.9 & 11.3 & 13.7 & - & 11.2 \\
\hline \multicolumn{7}{|l|}{7} \\
\hline Average & 11.7 & 11.2 & 11.3 & 13.3 & - & 12.2 \\
\hline
\end{tabular}

${ }^{\text {a}}$ Values reported correspond to the average taken over $\mathrm{G}_{4}-\mathrm{C}_{7} / \mathrm{G}_{18}-\mathrm{C}_{21}$.

\section{F. Free Energy Calculations}

The Molecular Mechanics/Poisson Boltzmann (generalized Born) Surface Area (MM/PB(GB)SA) program within Amber was used to calculate the absolute free energies of the unmodified and C8-arylguanine modified hairpin oligonucleotides from the MD trajectories. ${ }^{172}$ $\mathrm{MM} / \mathrm{PB}(\mathrm{GB}) \mathrm{SA}$ can be used to calculate the free energy difference between two different conformations. Since the hairpin oligonucleotides are negatively charged molecules, their solvation energies are directly related to their electrostatic interactions with the solvent. Here we used two different models that combine molecular mechanics calculations and continuum solvation models (PB and GB models) to determine and compare the free energies of the $\mathrm{B}$ and $\mathrm{Z}$ 
forms of the unmodified and modified hairpins. In the PB model, the free energies are derived by solving the linearized Poisson Boltzmann equation. The GB model is a calculation that uses the generalized Born model to derive the free energies, which has been described as alternative and comparable model for the PB model. ${ }^{172}$ The following set of equations (eq 4.1-4.5) show the breakdown of the individual components used to obtain the free energies from MM/PB(GB)SA.

$$
\begin{aligned}
\mathrm{G}_{\mathrm{GAS}}= & \mathrm{BOND}+\text { ANGLE }+ \text { DIHED }+ \text { VDWAALS } \\
& +\mathrm{EEL}+1-4 \mathrm{VDW}+1-4 \mathrm{EEL} \\
\mathrm{G}_{\mathrm{SOLV}}= & \mathrm{E}_{\mathrm{GB}}+\mathrm{E}_{\mathrm{SURF}} \\
\mathrm{GB}_{\mathrm{TOT}}= & \mathrm{G}_{\mathrm{GAS}}+\mathrm{G}_{\mathrm{SOLV}} \\
\mathrm{TS}_{\mathrm{TOT}}= & \mathrm{TS}_{\mathrm{TRA}}+\mathrm{TS}_{\mathrm{ROT}}+\mathrm{TS}_{\mathrm{VIB}} \\
\Delta \mathrm{G}_{\mathrm{GB}}= & \mathrm{GB}_{\mathrm{TOT}}-\mathrm{TS}_{\mathrm{TOT}}
\end{aligned}
$$

The GB model was used as the primary comparison between the unmodified and modified hairpin oligonucleotides since this methodology for oligonucleotides is more firmly established. ${ }^{173,174}$ The $\mathrm{GB}$ free energy $\left(\Delta \mathrm{G}_{\mathrm{GB}}\right)$ is derived from the sum of the molecular mechanical energy in the gas phase $\left(\mathrm{G}_{\mathrm{GAS}}\right)$ and the solvation energy (GSOLv) minus the total entropy term (TS energy arising from the bond terms (BOND), the angle terms (ANGLE), the dihedral terms (DIHED) from the MM force field as well as the van der Waals contributions (VDWAALS), the electrostatic energy (EEL), van der Waals contributions (1-4 VDW) and electrostatic energy (1-4 EEL) derived from interactions of atoms separated by 3 bonds (1-4 pairs) derived from the MM calculations (eq 4.1). The solvation energy (GsoLv) is the sum of the electrostatic contribution to the solvation free energy using the $\mathrm{GB}$ model $\left(\mathrm{E}_{\mathrm{GB}}\right)$ and the non-polar contribution to the solvation free energy calculated by an empirical model (ESURF) to yield eq 4.2. The total entropy term 
(TS $\mathrm{TSOT}_{\text {) }}$ is derived from the summation of the translational $\left(\mathrm{TS}_{\mathrm{TRA}}\right)$, rotational $\left(\mathrm{TS}_{\mathrm{ROT}}\right)$, and vibrational (TS $\mathrm{VIB}_{\mathrm{V}}$ ) entropies calculated using the ptraj module in Amber (eq 4.4).

The free energy calculations were performed on both the B- and Z-DNA conformations of the unmodified and C8-arylguanine modified hairpin oligonucleotides and by subtracting free energy of the Z-DNA conformation $\left(\Delta \mathrm{G}_{\mathrm{GB}_{-} \mathrm{Z}}\right)$ from the free energy of the B-DNA conformation

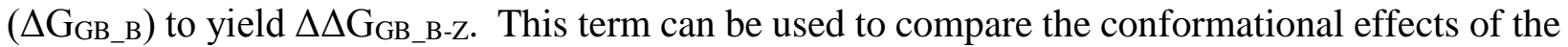
C8-arylguanine modification of the relative stabilities of the $\mathrm{B}$ and $\mathrm{Z}$ forms of the hairpin oligonucleotides as well as to compare the unmodified hairpin to the modified hairpins. Tables 4.5 and 4.6 show the individual components used to derive the free energies of the $\mathrm{B}$ and $\mathrm{Z}$ forms of the hairpins, respectively. Table 4.7 displays the difference between free energies of the B and $\mathrm{Z}$ forms as determined by the GB model. 
Table 4.5. Free Energies of the Unmodified and C8-Arylguanine Modified Hairpin Oligonucleotides Calculated by the MM/GBSA Model in the B-DNA Conformation. ${ }^{\text {a }}$

\begin{tabular}{|c|c|c|c|c|c|c|}
\hline & $\mathbf{C G}$ & $\mathbf{C G}^{\mathbf{8 P h}}$ & $\mathbf{C G}^{\mathbf{8 T o l}}$ & $\mathbf{C G}^{\mathbf{8 H M P h}}$ & $\mathbf{C G}^{\mathbf{8 M M P h}}$ & $\mathbf{C G}^{\mathbf{8 C P}}$ \\
\hline BOND & 204.21 & 207.88 & 207.32 & 208.65 & 209.74 & 212.93 \\
\hline ANGLE & 407.94 & 417.22 & 418.15 & 416.09 & 520.08 & 667.46 \\
\hline DIHED & 517.45 & 515.22 & 522.31 & 518.06 & 461.68 & 626.67 \\
\hline VDWAALS & -406.76 & -411.85 & -412.99 & -410.95 & -392.06 & -387.80 \\
\hline EEL & 4141.28 & 4116.06 & 4116.74 & 4088.99 & 4237.49 & 4710.80 \\
\hline $\mathbf{1 - 4}$ VDW & 200.40 & 204.37 & 205.78 & 203.84 & 223.87 & 212.90 \\
\hline 1-4 EEL & -3738.43 & -3733.08 & -3745.09 & -3705.05 & -3883.96 & -3794.14 \\
\hline EGB & -6514.73 & -6484.90 & -6487.88 & -6370.77 & -6512.15 & -7130.71 \\
\hline ESURF & 31.36 & 31.93 & 31.94 & 31.96 & 32.55 & 32.68 \\
\hline GGAS & 1326.09 & 1315.81 & 1312.22 & 1319.64 & 1376.86 & 2248.82 \\
\hline GsOLV & -6483.37 & -6452.97 & -6455.94 & -6338.81 & -6479.60 & -7098.03 \\
\hline GBTOT & -5157.28 & -5137.16 & -5143.72 & -5019.18 & -5102.74 & -4849.22 \\
\hline TSTRA & 15.65 & 15.66 & 15.66 & 15.66 & 15.66 & 15.66 \\
\hline TSROT & 15.52 & 15.52 & 15.54 & 15.50 & 15.55 & 15.53 \\
\hline TSVIB & 374.80 & 323.62 & 515.12 & 608.18 & 378.59 & 389.58 \\
\hline TS & 405.96 & 354.79 & 546.31 & 639.34 & 409.80 & 420.77 \\
\hline$\Delta$ GGB_B & -5563.24 & -5491.51 & -5690.03 & -5536.66 & -5511.26 & -5269.99 \\
\hline
\end{tabular}

${ }^{\text {a}}$ Energy values are in $\mathrm{kcal} / \mathrm{mol}$. 
Table 4.6. Free Energies of the Unmodified and C8-Arylguanine Modified Hairpin Oligonucleotides Calculated by the MM/GBSA Model in the Z-DNA Conformation. ${ }^{\text {a }}$

\begin{tabular}{|c|c|c|c|c|c|c|}
\hline & $\mathbf{C G}$ & $\mathbf{C G}^{\mathbf{8 P h}}$ & $\mathbf{C G}^{\mathbf{8 T o l}}$ & $\mathbf{C G}^{\mathbf{8 H M P h}}$ & $\mathbf{C G}^{\mathbf{8 M M P h}}$ & $\mathbf{C G}^{\mathbf{8 C P h}}$ \\
\hline BOND & 205.94 & 208.92 & 208.43 & 209.27 & 210.61 & 213.63 \\
\hline ANGLE & 406.68 & 410.42 & 408.32 & 409.83 & 509.00 & 656.48 \\
\hline DIHED & 529.59 & 535.47 & 543.20 & 537.58 & 505.26 & 660.52 \\
\hline VDWAALS & -431.51 & -431.53 & -430.42 & -438.99 & -413.10 & -402.15 \\
\hline EEL & 5054.74 & 5043.57 & 4974.77 & 4933.27 & 4749.82 & 5019.31 \\
\hline $\mathbf{1 - 4}$ VDW & 198.58 & 203.09 & 203.69 & 203.38 & 223.51 & 216.06 \\
\hline $\mathbf{1 - 4}$ EEL & -3724.13 & -3709.81 & -3721.08 & -3678.08 & -3855.23 & -3758.74 \\
\hline EGB & -7408.49 & -7404.92 & -7340.81 & -7199.06 & -7026.43 & -7460.05 \\
\hline ESURF & 30.19 & 30.96 & 31.09 & 31.09 & 31.54 & 32.11 \\
\hline GGAS & 2239.91 & 2260.14 & 2186.90 & 2176.24 & 1929.88 & 2605.12 \\
\hline GSOLV & -7378.30 & -7373.96 & -7309.72 & -7167.97 & -6994.89 & -7427.94 \\
\hline GB & -5138.39 & -5113.82 & -5122.82 & -4991.73 & -5065.01 & -4822.82 \\
\hline TSTRA & 15.65 & 15.66 & 15.66 & 15.66 & 15.66 & 15.66 \\
\hline TSROT & 15.47 & 15.48 & 15.49 & 15.50 & 15.55 & 15.53 \\
\hline TSVIB & 419.09 & 653.09 & 674.87 & 673.31 & 689.06 & 704.80 \\
\hline TSTOT & 450.20 & 684.22 & 706.01 & 704.47 & 720.27 & 735.98 \\
\hline$\Delta$ GGB_Z & -5588.59 & -5798.04 & -5828.83 & -5696.19 & -5785.28 & -5558.80 \\
\hline
\end{tabular}

${ }^{\mathrm{a}}$ Energy values are in $\mathrm{kcal} / \mathrm{mol}$.

Table 4.7. Free Energy Difference between the B- and Z-DNA Conformations for the Unmodified and Modified Hairpins. ${ }^{\mathrm{a}, \mathrm{b}}$

\begin{tabular}{|c|c|c|c|c|c|c|}
\hline & $\mathbf{C G}$ & $\mathbf{C G}^{\mathbf{8 P h}}$ & $\mathbf{C G}^{\text {8Tol }}$ & $\mathbf{C G}^{\text {8HMPh }}$ & $\mathbf{C G}^{\mathbf{8 M M P h}}$ & $\mathbf{C G}^{\mathbf{8 C P h}}$ \\
\hline $\boldsymbol{\Delta} \boldsymbol{\Delta}$ GG__B-Z & -18.89 & -23.34 & -20.90 & -27.45 & -37.73 & -26.40 \\
\hline
\end{tabular}

a Determined from $\Delta \mathrm{G}_{\mathrm{GB}_{-} \mathrm{B}}-\Delta \mathrm{G}_{\mathrm{GB} \_\mathrm{Z}}$. ${ }^{\mathrm{b}}$ Energy values are in $\mathrm{kcal} / \mathrm{mol}$. 
The $\Delta \Delta \mathrm{G}_{\mathrm{GB}} \mathrm{B}-\mathrm{Z}$ values demonstrate whether the $\mathrm{B}$ or $\mathrm{Z}$ form is energetically more favorable, however from inspection Table 4.7 all the hairpin forms prefer the $\mathrm{Z}$ form since all the $\Delta \Delta \mathrm{G}_{\mathrm{GB}} \mathrm{B}-\mathrm{Z}$ values are negative. This result does not agree with the $\mathrm{CD}$ and NMR experimental results since the unmodified HP-CG should prefer the B-DNA conformation. This may be a 'zero' point issue and if the value for the unmodified hairpin were normalized to reflect the experimental results where the $\mathrm{B}$ form is preferred then the other $\mathrm{C} 8$-arylguanine modified hairpins are in the right direction. However the rank order as predicted by the MM/GBSA are not in agreement with the experimental results. The MM/GBSA method predicts the free energies of the modified hairpin series to be $\mathrm{HP}-\mathrm{CG}^{8 \mathrm{MMPh}}<\mathrm{HP}-\mathrm{CG}^{8 \mathrm{HMPh}}<\mathrm{HP}-\mathrm{CG}^{8 \mathrm{CPh}}<\mathrm{HP}-\mathrm{CG}^{8 \mathrm{Ph}}<\mathrm{HP}-\mathrm{CG}^{8 \mathrm{Tol}}$. The energy value determined for the $\mathrm{HP}-\mathrm{CG}^{8 \mathrm{MMPh}}$ is too negative in comparison to the other $\mathrm{C} 8$-arylguanine modifications, which may be the result of the overall system not being in equilibrium at the end of the simulations. The individual components used to derive the free energies of HP-CG ${ }^{8 M M P h}$ and HP-CG ${ }^{8 \mathrm{CPh}}$ often show differences relative to the other $\mathrm{C} 8$-arylguanine derivatives which suggests a systematic error, however the $\mathrm{HP}-\mathrm{CG}^{8 \mathrm{HMPh}}$ also shows differences from the relative trends several values such as 1-4 EEL, EGB, GsoLv and GB 


\section{Chapter 5: Discussions and Conclusions}

Several DNA modifications, specifically C8-substituted guanines, have been previously shown to alter the B-/Z-DNA equilibrium including C8-bromoguanine, ${ }^{130,175}$ C8methylguanine, ${ }^{157,158}$ and C8-arylguanine. ${ }^{98,100}$ Our research focuses on C8-arylguanine modifications derived from carcinogenic arylhydrazines. ${ }^{90,176}$ These compounds are part of an important class of carcinogens that have a large potential for human exposure and produce DNA adducts. ${ }^{83,177}$ Although it is known that arylhydrazines generate DNA adducts in vivo, ${ }^{91,92}$ it is unclear how DNA adduct formation is related to their carcinogenicity. ${ }^{83}$ Recent research in our laboratory group has demonstrated that the incorporation of several different C8-arylguanine modifications drive the B-/Z-DNA equilibrium toward the Z-DNA conformation at or near physiological conditions. Therefore it may be possible that arylhydrazine DNA adducts may confer their carcinogenicity through a Z-DNA mediated mechanism.

Our previous studies investigated, first, the C8-phenylguanine modification, ${ }^{98}$ derived from the metabolism/bioactivation of phenylhydrazine, and subsequent studies examined C8-phenylguanine modifications with various para-substituents, also derived from known carcinogenic arylhydrazines. ${ }^{100}$ These studies incorporated the C8-arylguanine modifications into $(\mathrm{CG})_{5}$ decamer sequences $(\mathrm{d}(\mathrm{CGCGCG} * \mathrm{CGCG}))_{2}$ where $\mathbf{G}^{*}$ is the $\mathrm{C} 8$-arylguanine modified base. The palindromic nature of these sequences produces two base modifications in the oligonucleotide double helix that are in consecutive base steps. In this system, it is unclear if the conformational effects of the C8-arylguanine modifications were due to the modifications acting independently or in combination (additive or synergistic). Further the biological significance of our previous results are questionable since it is highly unlikely for two C8-arylguanine modifications to occur in 
successive base pairs, one on each strand, in vivo. The work presented here sought to determine if the conformations effects of this modification are similar or significantly diminished if only a single C8-arylguanine adduct is present. To address this question, a hairpin oligonucleotide $\left(\mathrm{d}(\mathrm{CG})_{5} \mathrm{~T}_{4}(\mathrm{CG})_{5}\right)$ containing an intramolecular $(\mathrm{CG})_{5}$ duplex was synthesized permitting the incorporation of only one C8-arylguanine modification.

The single C8-arylguanine modified hairpin oligonucleotides were prepared by first synthesizing the C8-aryl-2'-deoxyguanosine modified phosphoramidite and then incorporating the modified phosphoramidite into the hairpin sequence. The synthetic hairpin products require purification (FPLC) and confirmation (ESI-MS) before conformational analysis by CD and NMR. The hairpin oligonucleotides were also analyzed using computational methods to help interpret the experimental results. A thorough discussion of the results obtained with the single modified hairpins as well as comparison to the doubly modified double-stranded oligonucleotides will be presented here.

\section{A. Single C8-Arylguanine Modified Hairpin Synthesis}

The synthetic procedure used to synthesize the $\mathrm{C} 8$-arylguanine modified hairpins requires the synthesis of the C8-aryl-2'-doexyguanosine phosphoramidite since they are not commercially available. In general, the synthetic procedure used here followed the work by Vongsutilers et al. ${ }^{125}$ which provides for a broad range of conditions that can accommodate several different parasubstituted C8-aryl-2'-deoxyguanosine analogs. Most of the starting materials in the synthetic procedure are commercially available with the exception of 4-(TBS-O-methyl)-phenyl boronic acid however the work of Zheng et al. ${ }^{160}$ and Vongsutilers ${ }^{167}$ provided protocols for synthetic procedures of the C8-hydroxymethylphenyl-2'-deoxyguanosine derivative. All the reactions en 
route the C8-aryl-2'-deoxyguanosine phosphoramidites provided acceptable yields which led to successful incorporation of the C8-arylguanine modified base into the hairpin oligonucleotide sequence.

The synthetic scheme (Scheme 2.1) begins with the Suzuki coupling reaction from 8-bromo-2'-deoxyguanosine and the appropriate arylboronic acid. Table 5.1 summarizes the synthetic yields of the various C8-aryl-2'-deoxyguanosine coupling and subsequent protection reactions. The next step of the synthetic procedure converts the exocylic amine to a dimethylformamidine. Table 5.1 demonstrates that the first two steps in the synthetic scheme produce good yields and further the ${ }^{1} \mathrm{H}$ NMR spectrum of these products showed they do not require purification. In the case of the $\mathrm{NH}_{2}$-protection reaction the excess $\mathrm{DMF}$ leftover from the reaction does not interfere with the 5'-OH tritylation reaction and therefore purification is not necessary. However the crude product from the tritylation reaction does require purification before use in the phosphitylation reaction.

Table 5.1. Synthetic Yields of the C8-Aryl-2'-deoxyguanosine Analogs and Protection Reactions.

\begin{tabular}{|l|c|c|c|}
\hline $\begin{array}{c}\text { C8-Aryl-2'-deoxguanosine } \\
\text { Modification }\end{array}$ & $\begin{array}{c}\text { Suzuki } \\
\text { Coupling }\end{array}$ & $\begin{array}{c}\text { Dimethylformamidine } \\
\text { Protection }\end{array}$ & $\begin{array}{c}\text { 5'-OH } \\
\text { Tritylation }\end{array}$ \\
\hline 8-Phenyl & 96.9 & 94.0 & 50.0 \\
\hline 8-Tolyl & 92.0 & 96.3 & 48.5 \\
\hline 8-Hydroxymethylphenyl & 74.9 & 84.6 & 39.3 \\
\hline 8-Methoxymethylphenyl & 91.5 & 95.2 & 53.5 \\
\hline 8-Carboxyphenyl & 92.0 & 93.5 & 67.8 \\
\hline
\end{tabular}

*Synthetic conditions from in Scheme 2.1 and described in Chapter 3, Parm temp I, A.2. 
Unlike the yields of the previous reactions, the yields from the tritylation reaction were relatively low $(39.3-67.8 \%)$, which is probably the result of several factors including product degradation, additional side reactions and sample loss during chromatography. Since the glycosidic bond is more prone to acid cleavage after the addition of the aryl substituent to the $\mathrm{C} 8$ position of guanine relative to the unmodified 2'-deoxyguanosine, sample degradation is likely even though basic alumina was used in the column chromatography over the conventional silica stationary phase. Further the DMTr functional group itself is also an acid labile functional group which can also be degraded during synthesis and/or column purification.

The final step in the synthetic scheme functionalizes the 3'-hydroxyl into the phosphoramidite used in DNA synthesis. The method established by Vongsutilers et al. ${ }^{125}$ was used to produce the modified C8-aryl-2'-deoxyguanosine phosphoramidites in sufficient quantity and purity to make the $\mathrm{C} 8$-arylguanine modified hairpin oligonucleotides. While the modified phosphoramidites can be purified as with the tritylated products, this does not seem to be necessary as the crude phosphoramidites can be used for effective DNA synthesis as demonstrated by ESIMS. The tradeoff between purity versus quantity favors having more phosphoramidite material because our DNA synthesis procedure uses nearly twice the phosphoramidite used in the standard DNA coupling reaction, which already uses an excess of phosphoramidite to ensure effective coupling. ${ }^{1} \mathrm{H}$ NMR analysis can be used as a quick check of the crude phosphoramidite material, however the ${ }^{1} \mathrm{H}$ NMR spectrum becomes significantly more complicated with the addition of the 3'-phosphoramidite functional group and the water sensitive nature of this compound makes it difficult to acquire a suitable spectrum. In the method used here, the phosphitylation reaction was monitored by TLC versus a standard of pure DMTr-protected starting material, where the disappearance of the DMTr spot indicated the reaction was complete. In addition, during the 
solvent removal of the reaction material on the Rotaevap if the crude material produced a solid, crystalline like material, versus a gelatinous material, then the reaction was assumed to be successful. This assumption was reinforced based on the knowledge that each time the crystalline material was used in DNA coupling reaction successful C8-arylguanine modified hairpin synthesis resulted (i.e. the major DNA synthesis product was the full-length 24-mer sequence) as demonstrated by FPLC.

The C8-arylguanine phosphoramidites display an unfortunate characteristic with regard to DNA synthesis because they do not have the same solubility as unmodified phosphoramidites in ACN, which is the solvent used in DNA synthesis. The C8-arylguanine modified phosphoramidites precipitate out of solution shortly after dissolution with ACN into gel-like material, and we hypothesize that this may be due to G-quartet formation. In general, G-quartet formation requires the presence of cations to stabilize the G-quartet structure, however there has been at least one report that has demonstrated G-quartets without a metal cation. ${ }^{178}$ Regardless of the cause and the composition of the gelatinous material, this material is no longer sufficient for use in DNA synthesis. Therefore the C8-arylguanine modified phosphoramidites were manual coupled to the growing hairpin oligonucleotide chain.

Initial hairpin oligonucleotide synthesis was largely unsuccessful (Figure 5.1A). Originally in the manual coupling of the $\mathrm{C} 8$-arylguanine modified phosphoramidite, the solid phosphoramidite was dissolved with $\mathrm{ACN}$ and then mixed with activator before being introduced into the CPG synthetic column. This procedure mainly resulted in the production of the 18 -mer product rather than the full-length 24-mer hairpin sequence $(>80 \%)$. This result can be explained since the activated phosphoramidite is extremely sensitive water and therefore when the already highly reactive phosphoramidite is exposed to an open atmosphere, the C8-arylguanine 
phosphoramidite may be inactivated toward DNA coupling before introduction into the CPG DNA column. However when the coupling procedure was adapted to better match the protocol used by the DNA synthesizer, ${ }^{137}$ more successful C8-arylguanine hairpin oligonucleotide products ( $>80$ $\%$ ) were achieved (Figure 5.1B). As described in the experimental section, the dissolved modified phosphoramidite was delivered to the CPG column at nearly the same time as the activator solution, which enhances the coupling reaction. Further rather than mixing and letting the activated phosphoramidite solution sit and react in the CPG column, the activated phosphoramidite was repeatedly mixed through the $\mathrm{CPG}$ column which helped to bring fresh $\mathrm{C} 8$-arylguanine phosphoramidite to the site of reaction.

A)

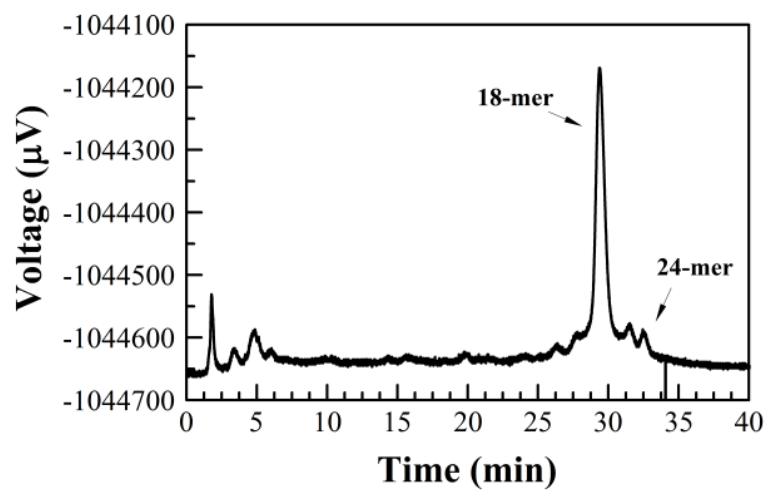

B)

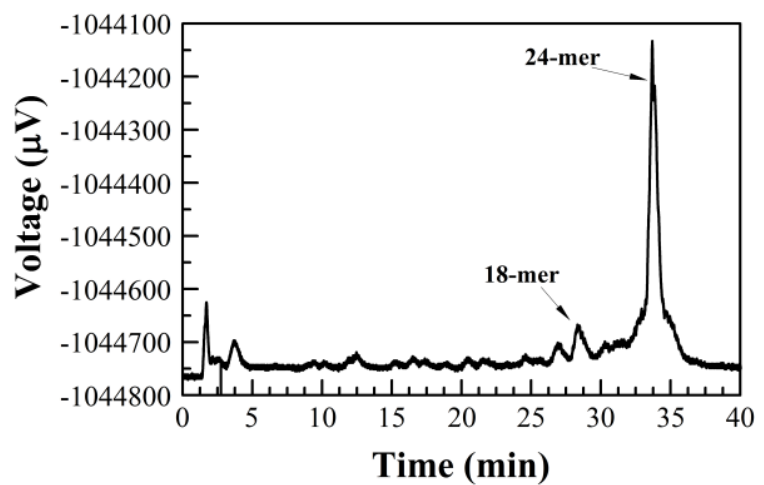

Figure 5.1. FPLC chromatograms of A) failed $\mathrm{HP}-\mathrm{CG}^{8 \mathrm{Ph}}$ synthesis and $\mathrm{B}$ ) successful $\mathrm{HP}-\mathrm{CG}^{8 \mathrm{Ph}}$ synthesis. Failed syntheses resulted in the major product as the 18-mer sequence and successful syntheses produced the full-length 24-mer sequence. 
Since the manual coupling procedure is not $100 \%$ percent efficient and incomplete extension as well as decomposition may occur during hairpin oligonucleotide synthesis, the hairpin oligonucleotide products require FPLC purification before the conformational analysis experiments. Initial DNA synthesis products demonstrated that there are several incomplete sequences with the major side product being the incomplete 18-mer sequence where coupling of the C8-arylguanine phosphoramidite was unsuccessful. The main objective of the FPLC purification was purify out all hairpin oligonucleotide products that were not the full-length 24-mer sequence and then check to make sure that the purification run was successful by confirming the purification product was a single molecular species. After ESI-MS successfully confirmed the unmodified and C8-arylguanine modified hairpin oligonucleotide products then the postpurification analysis used the aliquots of ESI-MS confirmed hairpin oligonucleotides as internal standards to confirm the purified synthetic product.

All five C8-arylguanine modified hairpin oligonucleotides were prepared successfully using a standardized approach. ${ }^{100}$ The modified hairpins were obtained in relatively low yield when compared to the unmodified hairpin, which is likely due to the susceptibility of the glycosidic bond of the $\mathrm{C} 8$-arylguanine modified base to acid cleavage that may occur during the detritylation step in DNA synthesis subsequent to the addition of the C8-aryl modification. Since DNA synthesis is performed in the 3' to the 5' direction, locating the C8-arylguanine modification closer to the 5' end of the hairpin minimizes this problem. FPLC and ESI-MS confirmed that the synthetic products were sufficiently pure before structural and conformational analysis by $\mathrm{CD}$ and NMR. 


\section{B. CD Analysis and Mole Fraction Calculations}

$\mathrm{CD}$ analysis can be used to determine the global conformation of the hairpin oligonucleotides. By acquiring $\mathrm{CD}$ over a range of salt concentrations the conformational effects of the C8-arylguanine modification(s) on the B-/Z-DNA equilibrium can be evaluated. CD analysis demonstrated that the presence of a single C8-arylguanine modification will shift the B-/Z-DNA equilibrium toward the Z-DNA conformation. Initial experiments at a single temperature $\left(37^{\circ} \mathrm{C}\right)$ can be used to qualitatively examine the salt concentration where the single C8-arylguanine modified hairpins transition from B- to Z-DNA relative to the unmodified hairpin. However the $\mathrm{CD}$ experiments acquired over a range of salt concentrations and temperature can also be used to quantitatively determine the conformational effects on the B-/Z-DNA equilibrium and calculating the mole fractions of the B-, Z-, and ss-DNA in solution. The mole fraction data can be used to determine the transition concentration $\left(T_{c}\right)$, the transition free energy $\left(\Delta \mathrm{G}_{t}\right)$ and the thermodynamic parameters $(\Delta \mathrm{G}, \Delta \mathrm{H}$, and $\Delta \mathrm{S})$ which can be used to more accurately compare the conformational effects of the single $\mathrm{C} 8$-arylguanine modification relative to the unmodified hairpin as well as to our previously studied doubly modified double-stranded oligonucleotides.

There have been many studies that have examined hairpin stability as a function of loop composition or size. Loops of four-to-five bases were found to yield the most stable hairpins and did not significantly affect the B-/Z-DNA equilibrium. In addition, Xodo et al. compared $\mathrm{T}_{\mathrm{M}}, \Delta \mathrm{H}$, $\Delta \mathrm{S}$ and $\Delta \mathrm{G}$ of the B- and Z-DNA forms of hairpins with loop sizes of two, three, and four thymidines and $\mathrm{CG}$ palindromic stems $\left(\mathrm{d}(\mathrm{CG})_{\mathrm{n}} \mathrm{T}_{\mathrm{n}}(\mathrm{CG})_{\mathrm{n}}\right)$. They determined that the $\mathrm{B}$ and $\mathrm{Z}$ forms were most similar to the double-stranded CG counterpart when the loop contained four thymidines. Furthermore, a loop with four thymidines does not appear to alter the conformation of the 
double-stranded portion as compared to the same sequence but lacking the loop (e.g., $\left(\mathrm{d}(\mathrm{CG})_{\mathrm{n}}\right)_{2}$ vs. $\left.\left.\mathrm{d}(\mathrm{CG})_{\mathrm{n}} \mathrm{T}_{4}(\mathrm{CG})_{\mathrm{n}}\right)\right)^{118,120}$ Therefore the loop should not bias the system and should closely resemble the previously studied double-stranded oligonucleotides. ${ }^{14,116,117,119,121}$

The unmodified hairpin and double-stranded oligonucleotides were found to be quite similar with respect to the effect on the B-/Z-DNA equilibrium as demonstrated by the similar transition concentrations and free energies (Table 1). Both unmodified oligonucleotides required approximately $3 \mathrm{M} \mathrm{NaCl}$ to obtain B-/Z-DNA ratio of one and their free energies differed by only $0.3 \mathrm{kcal} / \mathrm{mol}$, which further demonstrates that the modified hairpins can be used to compare the conformational effects of the one or two C8-arylguanine bases. The relative enthalpic and entropic contributions to the free energy do differ and both terms for the hairpin were reduced four- to five-fold relative to the double-stranded system. A difference in entropy between the two systems is expected since the hairpin loop holds the two strands of the double-stranded stem in close proximity. The entropy effect is offset by the more positive enthalpy of the hairpin system resulting in the net effect of similar free energies. 
Table 5.2. Transition and Thermodynamic Parameters for the B/Z-DNA Equilibrium of Unmodified and Modified Double-Stranded and Hairpin Oligonucleotides.

\begin{tabular}{|c|c|c|c|c|c|c|}
\hline \multirow{2}{*}{ Oligonucleotide } & Form & $\begin{array}{c}\text { Transition } \\
\text { Concentration } \\
(\mathbf{m} \mathbf{M} \mathbf{N a C l})^{\mathbf{a}}\end{array}$ & $\Delta \mathbf{G}^{\mathbf{b}}$ & $\Delta \mathbf{G}^{\mathbf{c}}$ & $\Delta \mathbf{H}^{\mathbf{c}}$ & $\Delta \mathbf{S}^{\mathbf{c}}$ \\
\hline \multirow{2}{*}{$\mathrm{CG}$} & $\mathrm{ds}$ & 3180 & 14.4 & 1.1 & -11.6 & -42.3 \\
\cline { 2 - 7 } & $\mathrm{hp}$ & 2978 & 18.4 & 1.4 & -2.1 & -11.4 \\
\hline \multirow{2}{*}{$\mathrm{CG}^{8 \mathrm{Tol}}$} & $\mathrm{ds}$ & 926 & 9.1 & -1.41 & -30.6 & -97.9 \\
\cline { 2 - 7 } & $\mathrm{hp}$ & 708 & 10.9 & -0.52 & -8.08 & -25.4 \\
\hline \multirow{2}{*}{$\mathrm{CG}^{8 \mathrm{HMPh}}$} & $\mathrm{ds}$ & 710 & 9.5 & -1.72 & -27.8 & -87.5 \\
\cline { 2 - 7 } & $\mathrm{hp}$ & 744 & 11.1 & -0.5 & -6.07 & -18.7 \\
\hline \multirow{2}{*}{$\mathrm{CG}^{8 \mathrm{MMPh}}$} & $\mathrm{ds}$ & 675 & 8.5 & -1.96 & -29.9 & -93.8 \\
\cline { 2 - 7 } & $\mathrm{hp}$ & 730 & 10.0 & -0.6 & -7.63 & -23.6 \\
\hline \multirow{2}{*}{$\mathrm{CG}^{8 \mathrm{Ph}}$} & $\mathrm{ds}$ & 585 & 7.0 & -2.13 & -29.9 & -93.2 \\
\cline { 2 - 7 } & $\mathrm{hp}$ & 822 & 12.7 & -0.58 & -6.99 & -21.5 \\
\hline \multirow{2}{*}{$\mathrm{CG}^{8 \mathrm{CPh}}$} & $\mathrm{ds}$ & 121 & 4.0 & -1.98 & -14.8 & -42.9 \\
& $\mathrm{hp}$ & 621 & 9.9 & -0.92 & -7.30 & -21.4 \\
\hline
\end{tabular}

${ }^{a}$ Determined from plots of $\ln \left(\mathrm{K}_{\mathrm{obs}}\right)$ vs $\ln [\mathrm{NaCl}](\mathrm{mM})$. Similar values were determined by interpolation of the mole fraction data obtained by $\mathrm{CD}$ (see experimental). ${ }^{\mathrm{b}}$ Calculated for $\mathrm{T}=310 \mathrm{~K}, \mathrm{~K}_{\mathrm{B} / \mathrm{Z}}=1$. ${ }^{\mathrm{c}}$ Thermodynamic parameters were calculated from data obtained on oligonucleotide solutions $(25 \mu \mathrm{M})$ dissolved in sodium phosphate (10 mM, pH 7.0) and $\mathrm{NaCl}(1000 \mathrm{mM}$ (modified hairpins) and $2000 \mathrm{mM}$ (unmodified hairpin)) at $298 \mathrm{~K}\left(25^{\circ} \mathrm{C}\right) . \Delta \mathrm{G}, \Delta \mathrm{G}_{\mathrm{t}}$, and $\Delta \mathrm{H}$ are in kcal mol ${ }^{-1} \mathrm{~K}^{-1}, \Delta \mathrm{S}$ is in cal $\mathrm{mol}^{-1} \mathrm{~K}^{-1}$.

Substitution of the C8-guanine position has been shown to reduce the salt concentration required to obtain a 1:1 B-:Z-DNA ratio. Examples include C8-bromoguanine, ${ }^{130,175} \mathrm{C} 8$ methylguanine, ${ }^{157,158}$ and C8-arylguanine ${ }^{98,179}$ containing oligonucleotides. Consistent with these results we find that the presence of only one $\mathrm{C} 8$-arylguanine modified base in the hairpin oligonucleotides reduces the transition concentration $\left(\mathrm{T}_{\mathrm{c}}\right)$ approximately four-fold relative to the unmodified hairpin with the specific transition concentration being dependent upon the identity of 
the para-substituent on the C8-aryl group. At the same time the data in Table 1 indicate there are some differences between the C8-arylguanine modified hairpins and double-stranded (CG) 5 oligonucleotides. The rank-order for the hairpin oligonucleotides with respect to the $\mathrm{T}_{\mathrm{c}}$ is C8-carboxyphenyl- $\left(\mathrm{HP}-\mathrm{CG}^{8 \mathrm{CPh}}\right)>\mathrm{C} 8$-tolyl- $\left(\mathrm{HP}-\mathrm{CG}^{8 \mathrm{Tol}}\right)>\mathrm{C} 8$-methoxymethylphenyl$\left(\mathrm{HP}-\mathrm{CG}^{8 \mathrm{MMPh}}\right) \sim \mathrm{C} 8$-hydroxymethylphenyl- $\left(\mathrm{HP}-\mathrm{CG}^{8 \mathrm{HMPh}}\right)>\mathrm{C} 8$-phenylguanine $\left(\mathrm{HP}-\mathrm{CG}^{8 \mathrm{Ph}}\right)$. This order differs from the double-stranded as the $\mathrm{G}^{8 \mathrm{Tol}}$ and $\mathrm{G}^{8 \mathrm{Ph}}$ are reversed. In addition, the $\mathrm{G}^{8 \mathrm{CPh}}$ in the hairpin system does not shift the B-/Z-DNA equilibrium toward the Z-DNA conformation to the same extent as in the double stranded system $\left(\mathrm{T}_{\mathrm{c}}=659 \mathrm{mM} \mathrm{NaCl}\right.$ for the hairpin and $121 \mathrm{mM} \mathrm{NaCl}$ for the double-stranded oligonucleotide). The dramatic conformational effect in the double modified oligonucleotides can be ascribed to the close proximity of the negatively charged carboxy groups to the phosphate backbone in the $\mathrm{B}$ form ${ }^{179}$ as well as the energy compensation of this hydrophilic group interacting with the solvent in the $\mathrm{Z}$ form. ${ }^{158}$ Regardless, on average, the doubly modified oligonucleotides require $600 \mathrm{mM} \mathrm{NaCl}$ concentration for a 1:1 B-/Z-DNA ratio while for the hairpins the value is quite similar $(760 \mathrm{mM} \mathrm{NaCl})$. The lower number for the double-stranded system is driven largely by the $T_{c}$ of the $\mathrm{G}^{8 \mathrm{CPh}}$ derivative. If the data for the $\mathrm{G}^{8 \mathrm{CPh}}$ modified oligonucleotides were not included then the average $\mathrm{T}_{\mathrm{c}}$ for the two systems are nearly identical $\left(\mathrm{T}_{\mathrm{c}}=751 \mathrm{mM} \mathrm{NaCl}\right.$ for the hairpins and $724 \mathrm{mM} \mathrm{NaCl}$ for the double-stranded oligonucleotides). Overall, the similarity in the transition concentrations indicate that the conformational effect of the C8-aryl modification is largely independent of whether there are one or two modified bases.

The $\mathrm{T}_{\mathrm{M}}$ trends seen in the single modified hairpin oligonucleotides were similar as the trends for the doubly modified double-stranded oligonucleotides with the main exception that the $\mathrm{T}_{\mathrm{M}}$ is much higher for the hairpin oligonucleotides relative to the double-stranded oligonucleotides 
which was based on previous reports with hairpin oligonucleotides. ${ }^{114,118,121}$ Comparison of the $\mathrm{T}_{\mathrm{M}}$ between unmodified and modified hairpin oligonucleotides provides some insight as to why the C8-arylguanine modification causes a shift in the B-/Z-DNA equilibrium. Table 2 lists, for each of the indicated salt concentrations, the difference in the $\mathrm{T}_{\mathrm{M}}$ between the unmodified and C8arylguanine modified hairpins. At low salt concentrations where the B form is predominant (25$250 \mathrm{mM} \mathrm{NaCl}$ ), the modified hairpins have a $\mathrm{T}_{\mathrm{M}}$ that are $4-16{ }^{\circ} \mathrm{C}$ lower than the unmodified hairpin. At salt concentrations where the $\mathrm{Z}$ form is predominant $(1000-4000 \mathrm{mM} \mathrm{NaCl})$, the difference is small $\left(1-3{ }^{\circ} \mathrm{C}\right)$. The data suggest that in the modified oligonucleotides, the C8arylguanine modified base is responsible for destabilization of the $\mathrm{B}$ form but not the $\mathrm{Z}$ form. ${ }^{179}$ The molecular modeling results suggest that there is some perturbation in structure where the modified hairpins show increased RIS and decreased TWT (local unwinding) to accommodate the changes in INC at the modified base-step. These changes are likely due to steric interactions in the $\mathrm{B}$ form which are non-existent in the $\mathrm{Z}$ form. The only penalty the $\mathrm{Z}$ form should experience is the unfavorable interaction between water and the C8-aryl group that is fully exposed outside the DNA helix in the $\mathrm{Z}$ form. 
Table 5.3. Salt Dependence of the Difference in $T_{M}$ between the Unmodified Hairpin and the C8-Arylguanine Modified Hairpins. ${ }^{\text {a }}$

\begin{tabular}{|l|c|c|c|c|c|c|c|c|}
\hline Hairpin & \multicolumn{7}{|c|}{ NaCl Concentration (mM) } \\
\hline & $\mathbf{2 5}$ & $\mathbf{5 0}$ & $\mathbf{1 0 0}$ & $\mathbf{2 5 0}$ & $\mathbf{5 0 0}$ & $\mathbf{1 0 0 0}$ & $\mathbf{2 0 0 0}$ & $\mathbf{4 0 0 0}$ \\
\hline $\mathrm{CG}^{8 \mathrm{Ph}}$ & 12 & 12 & 15 & 14 & 7 & 0 & 1 & 3 \\
\hline $\mathrm{CG}^{8 \mathrm{Tol}}$ & 9 & 12 & 14 & 4 & 4 & -1 & 1 & 1 \\
\hline $\mathrm{CG}^{8 \mathrm{MMPh}}$ & 8 & 10 & 10 & 4 & 4 & -2 & 1 & 1 \\
\hline $\mathrm{CG}^{8 \mathrm{HMPh}}$ & 16 & 12 & 14 & 8 & 8 & 2 & 1 & 2 \\
\hline $\mathrm{CG}^{8 \mathrm{CPh}}$ & 10 & 11 & 15 & 6 & 5 & -1 & -2 & 1 \\
\hline
\end{tabular}

${ }^{a}$ The values correspond to the difference of the $T_{M}$ of the unmodified hairpin minus the $\mathrm{T}_{\mathrm{M}}$ of the modified hairpin. The table entries are in ${ }^{\circ} \mathrm{C}$.

In our previous research, the conformational effects of the C8-arylguanine modifications on the B-/Z-DNA equilibrium were only evaluated in the presence of $\mathrm{NaCl}$. However, the effect of divalent cations on the B/Z-DNA equilibrium has been reported and is much stronger than that of monovalent cations. For example, poly $(\mathrm{dG}-\mathrm{dC})$ requires $2.7 \mathrm{M} \mathrm{NaCl}$ to exist as a 1:1 mixture of B-/Z-DNA but only $0.7 \mathrm{M} \mathrm{MgCl}_{2}$ is required to achieve the same equilibrium. ${ }^{13}$ Similar results have been obtained in smaller oligonucleotides $\left(\mathrm{d}(\mathrm{CG})_{13}\right)$ and hairpins $\left(\mathrm{d}(\mathrm{CG})_{5} \mathrm{~T}_{4}(\mathrm{CG})_{5}\right)$ with a 1:1 B-/Z-DNA ratio at $0.66 \mathrm{M}$ and $0.94 \mathrm{M} \mathrm{MgCl}_{2}$, respectively. ${ }^{12,13,114}$ The effect is believed to be, at least in part, that $\mathrm{Mg}^{2+}$ and other positively charged species such as spermine are more effective at screening the negative charge of the phosphate backbone and thereby stabilize the $\mathrm{Z}$ form better than monovalent cations. ${ }^{163,180}$ In addition, the coordination geometry is complementary to the arrangement of the phosphate oxygens in DNA when it is in the $\mathrm{Z}$ form. Specifically, $\mathrm{Mg}^{2+}$ ions have been demonstrated to coordinate to oxygens of two phosphate residues as well as to the $\mathrm{N}^{7}$ of guanine. ${ }^{144,181}$ Spermine is a ubiquitous tetravalent polyamine that has been demonstrated to stabilize the Z-DNA conformation. ${ }^{21,163}$ Spermine is involved in many cellular processes notably 
in the regulation of transcription and translation as well as nucleic acid structure and stability. ${ }^{182}$ Further spermine can alter the gene expression levels and thought to have a role in the MAPK pathway. ${ }^{183,184}$ Thus spermine may have a regulatory role in Z-DNA formation in vivo. The effect of $\mathrm{Mg}^{2+}$ and spermine on the $\mathrm{C} 8$-arylguanine modified hairpins with respect to the $\mathrm{B}$-/Z-DNA equilibrium is quite profound. While there is no effect on the unmodified hairpin, the presence of $\mathrm{Mg}^{2+}$ and spermine renders the $\mathrm{C} 8$-arylguanine modified hairpin oligonucleotides stable in the $\mathrm{Z}$ form under physiological conditions $\left(2 \mathrm{mM} \mathrm{MgCl}_{2}, 10 \mathrm{mM} \mathrm{NaCl}, 140 \mathrm{mM} \mathrm{KCl}\right.$ and $1 \mathrm{mM}$ spermine). To the best of our knowledge this is the first hairpin oligonucleotide stable in the ZDNA conformation under physiological conditions.

\section{NMR and Molecular Modeling Analysis}

The NMR of a hairpin containing a $\mathrm{T}_{4}$ loop with an alternating $\mathrm{CG}$ stem $\left(\mathrm{d}(\mathrm{CG})_{2} \mathrm{~T}_{4}(\mathrm{CG})_{2}\right)$ has been reported. ${ }^{119}$ NMR of hairpin oligonucleotides in the B- and Z-DNA conformation has been previously reported in particular with the sequence used here $\left(\mathrm{d}(\mathrm{CG})_{5} \mathrm{~T}_{4}(\mathrm{CG})_{5}\right){ }^{121}$ In these reports the main concern was whether the presence of the loop would present an energy barrier to the B-/Z-DNA transition. The chemical shifts of the unmodified and single C8-arylguanine modified hairpins were very similar and in qualitative agreement with the previously reported chemical shifts, especially for the $\mathrm{T}_{4}$ loop, which indicates the overall conformations are largely similar. The obvious exception is at the $\mathrm{C}_{5}-\mathrm{C} 8$-aryl- $\mathrm{G}_{6}$ base step, which indicates the conformational effects of the C8-arylguanine modification occur locally and do not affect the global conformation of the hairpin structure relative to the unmodified hairpin in the B-DNA

conformation. As demonstrated by the most representative structures and $\mathrm{T}_{\mathrm{M}}$ of the $\mathrm{Z}$ forms of the 
hairpin oligonucleotides the C8-arylguanine modification has little to no effect on the hairpin structure. Since the C8-arylguanine modification is outside the DNA helix in the Z-DNA conformation, the steric and/or electronic interactions of the $\mathrm{C} 8$-arylguanine modification in the $\mathrm{B}$ form with the phosphate backbone are no longer present and alleviating these unfavorable interactions is likely the driving force for Z-DNA formation.

Previous NMR studies of the doubly modified oligonucleotides found that the C8-aryl protons in the $\mathrm{B}$ form were shifted upfield, by up to $1.2 \mathrm{ppm}$, of the free nucleoside while in the $\mathrm{Z}$ form they were shifted downfield of the corresponding nucleoside (Table 5.4). This suggested the oligonucleotide was in a conformation such that the $\mathrm{C} 8$-aromatic ring of the modified base was located over the adjacent 5 '-cytosine $\left(\mathrm{C}_{5}\right)$ thereby shielding the aromatic protons (see Figure 5.2B). In contrast, in the $\mathrm{Z}$ form, the aromatic protons shift downfield which is expected since the aromatic group is outside of the helix and cannot be shielded. 
Table 5.4. Chemical Shifts of the C8-Aryl Protons in Double-Stranded and Hairpin Oligonucleotides.

\begin{tabular}{|c|c|c|c|c|c|c|c|c|c|}
\hline \multirow[t]{2}{*}{ DNA } & \multirow[t]{2}{*}{ Form } & \multicolumn{2}{|c|}{ Nucleoside $^{a}$} & \multicolumn{3}{|c|}{ B-DNA ${ }^{b}$} & \multicolumn{3}{|c|}{ Z-DNA ${ }^{c}$} \\
\hline & & $2 / 6^{d}$ & $3 / 5^{\mathrm{e}}$ & $2 / 6$ & $3 / 5$ & $4^{\mathrm{f}}$ & $2 / 6$ & $3 / 5$ & $4^{\mathrm{f}}$ \\
\hline \multirow{2}{*}{$C G^{8 \mathrm{Tol}}$} & ds & \multirow{2}{*}{7.53} & \multirow{2}{*}{7.34} & 6.28 & 6.86 & - & 7.64 & 7.69 & - \\
\hline & $\mathrm{hp}$ & & & 7.52 & $7.81 / 7.65$ & - & 7.51 & 7.57 & - \\
\hline \multirow{2}{*}{$\mathrm{CG}^{8 \mathrm{HMPh}}$} & ds & \multirow{2}{*}{$7.62^{\mathrm{g}}$} & \multirow{2}{*}{$7.46^{\mathrm{g}}$} & 6.37 & 7.07 & - & 7.73 & 7.76 & - \\
\hline & $\mathrm{hp}$ & & & 7.73 & $7.84 / 7.67$ & - & 7.66 & 7.69 & - \\
\hline \multirow{2}{*}{$\mathrm{CG}^{8 \mathrm{MMPh}}$} & ds & \multirow{2}{*}{7.47} & \multirow{2}{*}{7.63} & 6.38 & 7.07 & - & 7.74 & 7.78 & - \\
\hline & hp & & & 7.77 & $7.82 / 7.67$ & - & 7.65 & 7.69 & - \\
\hline \multirow{2}{*}{$\mathrm{CG}^{8 \mathrm{Ph}}$} & ds & \multirow{2}{*}{$7.55^{\mathrm{h}}$} & \multirow{2}{*}{$7.64^{\mathrm{h}}$} & $6.35 / 7.28$ & $7.04 / 7.32$ & 7.33 & 7.55 & 7.65 & 7.84 \\
\hline & $\mathrm{hp}$ & & & $7.53 / 7.74$ & $7.82 / 7.68$ & 7.62 & 7.56 & 7.68 & 7.84 \\
\hline \multirow{2}{*}{$\mathrm{CG}^{8 \mathrm{CPh}}$} & ds & \multirow{2}{*}{7.80} & \multirow{2}{*}{8.07} & 6.72 & 7.79 & - & 7.81 & 8.16 & - \\
\hline & $\mathrm{hp}$ & & & $7.83 / 7.55$ & $8.07 / 7.64$ & - & 7.72 & 8.07 & - \\
\hline
\end{tabular}

${ }^{\mathrm{a}}$ In dmso- $\mathrm{d}_{6} .{ }^{\mathrm{b}} \mathrm{All}$ samples were in $25 \mathrm{mM} \mathrm{NaCl}$ and $10 \mathrm{mM}$ sodium phosphate, $\mathrm{pD} 7.0$ at $25^{\circ} \mathrm{C}$. ${ }^{\mathrm{c}}$ Measured on samples that with the addition of $50 \mathrm{mM} \mathrm{MgCl}_{2}$. ${ }^{\mathrm{d}} 2 / 6$ protons are orm tempho to $\mathrm{C} 8$-atom of guanine, e $3 / 5$ protons are meta to $\mathrm{C} 8$-atom of guanine, ${ }^{\mathrm{f}} 4$ proton is para to $\mathrm{C} 8$-atom of guanine. ${ }^{\mathrm{g}} \mathrm{As}$ the TBS ether.

hoth resonances were multiplets, the downfield resonance integrated to two protons.

The chemical shift behavior of the C8-aryl protons of the hairpins in the B form were quite different (Table 5.4). Instead of upfield shifts, the chemical shifts were similar to those of the free nucleoside or shifted slightly downfield. Consequently, the C8-aryl group of the modified base is not stacking over the adjacent base. In addition, unlike in the doubly modified double-stranded oligonucleotides where the C8-aryl resonances displayed a typical AA'XX' pattern characteristic of a 1,4-disubstituted benzene ring the $\mathrm{C} 8$-arylguanine resonances in the single modified hairpin oligonucleotide exhibited at least three distinct chemical shifts (HP-CG ${ }^{8 \mathrm{Tol}}, \mathrm{HP}-\mathrm{CG}^{8 \mathrm{HMPh}}$ and 
$\mathrm{HP}-\mathrm{CG}^{8 \mathrm{MMPh}}$ ) while in the $\mathrm{HP}-\mathrm{CG}^{8 \mathrm{Ph}}$ and $\mathrm{HP}^{8 \mathrm{CPh}}$ hairpins all the $\mathrm{C} 8$-aryl protons displayed distinct resonances. When the $\mathrm{C} 8$-arylguanine modified base has restricted free rotation about the aryl-dG bond the ortho and meta protons become magnetically equivalent, which was ascribed to the constraints of imposed by the $\mathrm{C} 5$ and $\mathrm{C} 8$-aryl-G6 stacking interactions. However this is not the case in the single modified hairpin systems since the stacking interactions are less pronounced as they are in the double modified system. Figure 5.2 demonstrates that while the stacking interactions between $\mathrm{C}_{5}-\mathrm{G}_{6}$ vary between the double and single modified systems, the location and geometry of the $\mathrm{C} 8$-aryl modification relative to the phosphate backbone is similar, which could also impede the free rotation of the C8-aryl moiety based on steric and/or electronic interactions when contained in the DNA helix in the B-DNA conformation.

As in the case of the doubly modified double-stranded oligonucleotides, the protons of $\mathrm{C}_{5}$ in the hairpin oligonucleotides are upfield shifted $(0.24-0.29 \mathrm{ppm})$ relative to their location in the unmodified hairpin. This upfield shift suggests that the adjacent $\mathrm{C}_{5} \mathrm{H} 5$ and $\mathrm{H} 6$ protons are located under the C8-aryl ring and thereby shielded (see Figure 5.2D). Both of these results are in agreement with the molecular modeling results. Furthermore, this orientation is expected to result in NOE correlations between the $\mathrm{C} 8$-arylguanine aromatic protons and the $\mathrm{H} 5 / 6$ protons of the $\mathrm{C}_{5}$ as observed. Also, it is the NOEs between the H5/6 cytosine protons and the C8-aromatic ring protons that allowed the assignment of the aromatic ring protons. In the $\mathrm{Z}$ form the aromatic protons of the modified base are shifted downfield relative to the free nucleoside and are nearly the same as those in the doubly modified double-stranded oligonucleotides.

Figure 5.2 displays the $\mathrm{C}_{5}-\mathrm{G}_{6}$ base step for both the double-stranded and hairpin unmodified $\mathrm{CG}$ and modified $\mathrm{CG}^{8 \mathrm{HMPh}}$ oligonucleotides. The changes in the relative orientation between $\mathrm{C}_{5}$ and $\mathrm{G}_{6}$ produced by the $\mathrm{G}_{6}-\mathrm{C} 8$-aryl group (B and $\mathrm{D}$ ) can be seen by comparison with 
the unmodified base step (A and C). In particular, the differences in SLD and SHF cause $\mathrm{G}_{6}$ to be shifted toward the helical axis in the modified double-stranded oligonucleotides, though to a lesser extent for the hairpin oligonucleotides. In turn, the $\mathrm{C} 8$-aromatic ring is drawn over and partially stacks on $\mathrm{C}_{5}$. The twist of the aromatic ring attached to $\mathrm{G}_{6}$ is readily apparent. Finally, unlike the B forms, there were few differences seen in the helical parameters of the $\mathrm{Z}$ forms for the modified C8-arylguanine hairpin oligonucleotides relative to the unmodified hairpin CG (Figure 4.2), which is also true for the double-stranded oligonucleotides.

A)

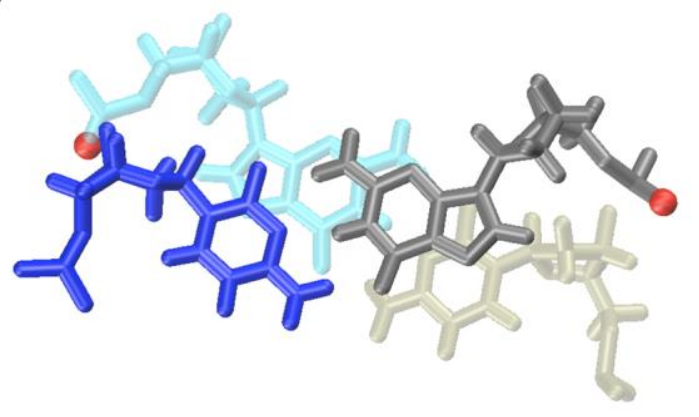

B)

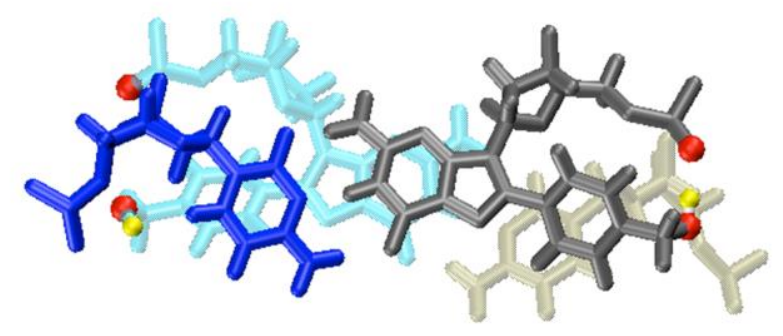

C)

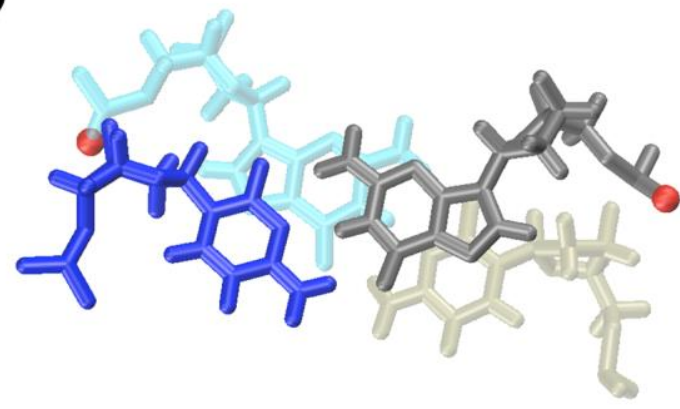

D)

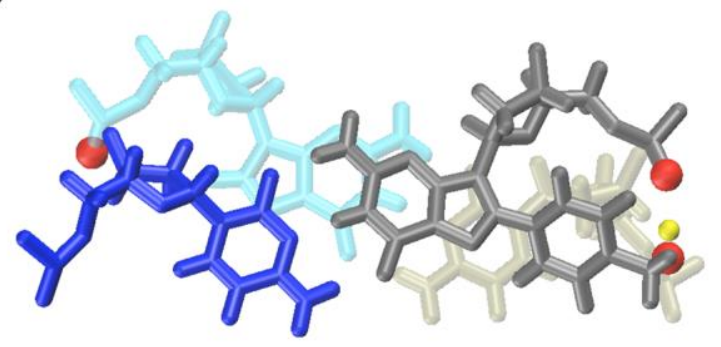

Figure 5.2. Double-stranded and hairpin $\mathrm{C}_{5}-\mathrm{G}_{6}$ base step. The unmodified or modified $\mathrm{G}_{6}$ is shown in gray, its base-paired $\mathrm{dC}$ in blue, $\mathrm{C}_{5}$ is tan and its base-paired unmodified or modified $\mathrm{dG}$, cyan. Shown are A) unmodified double-stranded CG, B) $\mathrm{CG}^{8 \mathrm{HMPh}}$ modified double-stranded, C) unmodified hairpin CG and D) $\mathrm{CG}^{8 \mathrm{HMPh}}$ modified hairpin. Also shown for the modified duplex and hairpin is the hydroxyl methyl hydrogen (yellow) and one of the phosphate oxygens (red) of the modified base. 
Molecular modeling can also be used to compare the individual helical parameters that most affect the oligonucleotide conformation and/or drive Z-DNA formation. Generally, the C8-arylguanine modifications in the doubly modified double-stranded oligonucleotides significantly distort the B-DNA conformation. The major factor ascribed to affect the oligonucleotide conformation was the stacking interactions between the $\mathrm{C}_{5}-\mathrm{G}_{6}$ as well as the purine component of the two modified bases $\left(\mathrm{G}_{6} / \mathrm{G}_{16}\right)$ (Figure 5.2B). Since this result is not possible in the single C8-arylguanine modified hairpin system, there must other factors that drive Z-DNA formation, especially in light of the $\mathrm{CD}$ results which generally suggest that the $\mathrm{T}_{\mathrm{c}}$ for the single and double modified oligonucleotides are nearly identical (excluding the $\mathrm{G}^{8 \mathrm{CPh}}$ derivatives). Table 5.5 displays the comparison of the helicoidal parameters that had the most significant differences between the unmodified and modified oligonucleotides in the B-DNA form. 
Table 5.5. Key Helical Parameters of the Most Representative Structure for Unmodified and Modified Double-Stranded and Hairpin Oligonucleotides in the B-DNA Conformation.

\begin{tabular}{|c|c|c|c|c|c|c|c|}
\hline & & \multicolumn{6}{|c|}{ Inter-Base Pair ${ }^{a}$} \\
\hline & & CG & $\mathrm{CG}^{8 \mathrm{Ph}}$ & CG ${ }^{8 T o l}$ & $\mathrm{CG}^{8 \mathrm{HMPh}}$ & $\mathrm{CG}^{8 \mathrm{MMPh}}$ & $\mathrm{CG}^{8 \mathrm{CPh}}$ \\
\hline \multirow{2}{*}{$\mathbf{S H F}^{\mathbf{d}}$} & ds & 0.67 & 0.41 & 0.24 & -0.31 & -0.12 & 1.09 \\
\hline & hp & 0.75 & 1.00 & 0.93 & 0.74 & 0.61 & -0.07 \\
\hline \multirow{2}{*}{ SLD $^{d}$} & ds & -1.27 & -3.01 & -3.57 & -2.67 & -0.09 & 1.05 \\
\hline & hp & -0.16 & -1.02 & -1.74 & -1.15 & -2.07 & -1.43 \\
\hline \multirow{2}{*}{$\mathbf{R I S}^{\mathbf{d}}$} & ds & 3.00 & 4.90 & 5.33 & 3.98 & 3.26 & 2.94 \\
\hline & $\mathrm{hp}$ & 3.56 & 3.20 & 3.92 & 3.49 & 3.79 & 4.12 \\
\hline \multirow{2}{*}{ TWT $^{\mathbf{e}}$} & ds & 30.9 & 19.0 & 16.1 & 20.5 & 28.8 & 25.1 \\
\hline & $\mathrm{hp}$ & 35.8 & 29.3 & 23.7 & 27.4 & 29.2 & 27.9 \\
\hline & & \multirow{2}{*}{\multicolumn{6}{|c|}{ Base Pair-Helical Axis ${ }^{b}$}} \\
\hline & & & & & & & \\
\hline & & CG & $\mathrm{CG}^{8 \mathrm{Ph}}$ & $\mathrm{CG}^{8 \mathrm{~T} o \mathrm{l}}$ & $\mathrm{CG}^{8 \mathrm{HMPh}}$ & $\mathrm{CG}^{\mathbf{8 M M P h}}$ & $\mathrm{CG}^{8 \mathrm{CPh}}$ \\
\hline \multirow{2}{*}{$\mathbf{X D P}^{\mathbf{d}}$} & ds & -3.56 & -8.85 & -1.39 & -8.97 & -0.82 & 2.24 \\
\hline & $\mathrm{hp}$ & 0.12 & -3.99 & -6.75 & -4.09 & -7.51 & -5.71 \\
\hline \multirow{2}{*}{$\mathbf{Y D P}^{\mathbf{d}}$} & ds & -1.76 & -2.71 & -8.65 & 2.99 & -1.93 & -3.11 \\
\hline & hp & -1.16 & -0.07 & 0.40 & -1.31 & -0.09 & 1.03 \\
\hline \multirow{2}{*}{$\mathbf{I N C}^{\mathrm{e}}$} & ds & 15.3 & -1.40 & -31.0 & 10.5 & 6.47 & 1.36 \\
\hline & hp & -3.95 & 27.3 & 24.1 & 15.4 & 32.8 & 27.1 \\
\hline & & \multicolumn{6}{|c|}{ Groove Width $^{c}(\AA)$} \\
\hline Groove & & $\mathbf{C G}$ & $\mathrm{CG}^{8 \mathrm{Ph}}$ & $\mathrm{CG}^{8 \mathrm{~T} o l}$ & $\mathrm{CG}^{8 \mathrm{HMPh}}$ & $\mathrm{CG}^{8 \mathrm{MMPh}}$ & $\mathrm{CG}^{8 \mathrm{CPh}}$ \\
\hline \multirow{2}{*}{ Major } & $\mathrm{ds}$ & 18.6 & 24.1 & 26.9 & 22.8 & 18.9 & - \\
\hline & hp & 17.8 & 18.8 & 20.8 & 17.6 & 17.3 & 17.3 \\
\hline \multirow{2}{*}{ Minor } & ds & 13.7 & 11.6 & 10.7 & 12.9 & - & - \\
\hline & hp & 11.8 & 13.0 & 12.8 & 12.8 & 13.2 & 13.6 \\
\hline
\end{tabular}

${ }^{a}$ Values reported are for the $\mathrm{C}_{5} / \mathrm{G}_{20}-\mathrm{G}_{6} / \mathrm{C}_{19}$ base pair step. ${ }^{b}$ Values reported are the average of both $\mathrm{C}_{5} / \mathrm{G}_{20}$ and $\mathrm{G}_{6} / \mathrm{C}_{19}$ base pair-axis values. ${ }^{\mathrm{c}}$ Values reported correspond to the average taken over $\mathrm{G}_{4}-\mathrm{C}_{7} / \mathrm{G}_{18}-\mathrm{C}_{21}$. ${ }^{\mathrm{d}}$ Values are in units of $\AA$. ${ }^{e}$ Values are in unites of degrees. 
The modified hairpin oligonucleotides yield similar trends as the double-stranded oligonucleotides but substantially attenuated at the modified base step $\left(\mathrm{C}_{5}-\mathrm{G}_{6}\right)$. For example, the decrease in the helical twist at the $\mathrm{C} 8$-arylguanine modified $\mathrm{C}_{5}-\mathrm{G}_{6}$ base step for the doubly modified double-stranded oligonucleotides was less than the value for unmodified $\mathrm{C}_{5}-\mathrm{G}_{6}$ base step. Although the TWT for the $\mathrm{C}_{5}-\mathrm{G}_{6}$ base step of all the modified hairpins was less than the value for the unmodified $\mathrm{C}_{5}-\mathrm{G}_{6}$ base step, there is considerably less variation at the $\mathrm{C}_{5}-\mathrm{G}_{6}$ base step in the hairpin system. In addition, the major and minor groove widths were affected more in the doubly modified double-stranded oligonucleotides that in the single modified hairpins in comparison to the unmodified counterparts.

\section{Conclusions}

The C8-arylguanine modifications in a double-stranded purine-pyrimidine repeat, one on each strand, was previously found to have large changes in the local base pair geometry, especially with respect to base pair location relative to the helical axis. These changes were ascribed to stacking interactions and were suggested to be responsible for the shift in the B/Z-DNA equilibrium. In the present case there is only one C8-arylguanine modified base and the modification causes only minimal changes in local conformation relative to the unmodified hairpin. Nevertheless, the single modification produces a shift in the B/Z-DNA equilibrium similar to the one observed in the doubly modified system. These results lead us to conclude that both single and double C8-arylguanine modifications destabilize the B form that produces a shift in the B/Z-DNA equilibrium toward the Z-DNA conformation. Further, destabilization of the B form is largely responsible for the observed conformational preferences. 
Destabilization of the B-DNA conformation can result in at least two different outcomes including adopting an alternative conformation or denaturation to the single-stranded form. Our results show that adopting the Z-DNA conformation is preferred over denaturation under physiological salt concentrations. This result is quite surprising as current dogma states that Z-DNA formation requires very high salt concentrations to screen the negative charges along the phosphate backbone. Here, the introduction of a single C8-arylguanine modification is sufficient to shift the B/Z-DNA equilibrium because the modification destabilizes the B form. In addition, our results also suggest that the $\mathrm{Z}$ form may be more favorable than previously thought and the reason that Z-DNA is not observed under physiological conditions is mainly due to the B form being much more energetically favorable.

Our results here have potential biological implications. It is well documented that Z-DNA forming sequences are most commonly found in promoter regions of the human genome where Z-DNA formation can regulate transcription and nucleosome positioning. ${ }^{29,41,63,185}$ Consequently, dysregulation in these sequences can lead to unregulated gene transcription. Furthermore, proteins that stabilize the Z-DNA conformation (Z-DNA binding proteins, ZBP) are thought to maintain control of transient Z-DNA formation in vivo. The virulence factor of the vaccinia virus (E3L) is believed to escape the host immune response by competing with the endogenous ZBPs (ADAR1 and DAI). ${ }^{53,54,186,187}$ In another example, the complex of methyl-CpG-binding protein (MeCP2) combined with two members of the nuclear factor 1 transcription factor family (NF1C and NF1X) maintain transcriptional suppression of the $A D A M-12$ gene through binding to a Z-DNA forming negative response element. ${ }^{45}$ Carcinogenic arylhydrazines are known to produce DNA adducts on the C8-position of guanine. In turn, these adducts are predicted to shift the B/Z-DNA equilibrium towards the Z-DNA conformer. ${ }^{79,179}$ Therefore, after exposure to these carcinogenic chemicals, 
Z-DNA formation may overwhelm the normal cellular response to Z-DNA formation and may produce the mutagenic or carcinogenic consequences associated with Z-DNA. ${ }^{31,65}$

\section{E. Future Directions}

Although this work in comparison with our previous results suggest a possible novel carcinogenic mechanism from DNA adduct formation, additional in vitro experiments are required to further support this hypothesis. Since the single C8-arylguanine modified hairpin oligonucleotides have been shown to adopt the Z-DNA conformation under physiological conditions, they should be used to investigate the interactions (protein: DNA interactions) with Z-DNA binding proteins (ZBP). In addition, C8-arylguanine modified oligonucleotides can be used as a tool to further investigate the proposed mechanism of the ZBP mediated B-/Z-DNA transition.

The relationship of DNA adduct formation and arylhydrazine carcinogenesis remains unclear, however Z-DNA formation may play an intermediary role between DNA adduct formation and arylhydrazine carcinogenesis. Since Z-DNA is thought to play a regulatory role in gene expression, the C8-arylguanine modified sequences used here could be further used in a reporter gene ${ }^{188}$ or promoter assays ${ }^{189}$ to determine if the presence C8-arylguanine modification enhances gene expression. In addition, it may also be possible to utilize the $\mathrm{C} 8$-arylguanine modifications to induce Z-DNA formation in a similar manner as was used to demonstrate the role of Z-DNA formation in negative supercoiling ${ }^{25,190,191}$ and gene deletions. ${ }^{65,192}$ Future, in vitro studies, will be required to properly ascertain the role of the $\mathrm{C} 8$-arylguanine modification in the

context of Z-DNA formation, even though there have been reports using Z-DNA antibodies ${ }^{32,193}$ to determine Z-DNA formation detection in vitro. 
Another possible use for the C8-arylguanine modified oligonucleotides is for the examination of the currently proposed mechanism of the B-/Z-DNA transition induced by ZBPs. The current hypothesis suggests that ZBPs, though known to bind Z-DNA with a stronger affinity than B-DNA, ${ }^{24}$ bind B-DNA and actively convert it to the Z-DNA conformation. ${ }^{56}$ However this has not been demonstrated in vivo. Further, the unmodified oligonucleotide sequences that have been studied are resistant to Z-DNA under physiological conditions. Although ZBPs have been investigated with brominated oligonucleotides ${ }^{23,24}$ or oligonucleotides stabilized by cobalt hexamine, ${ }^{194,195}$ neither of these conditions are considered to be physiologically relevant.

Preliminary CD data of the ZBP DNA-dependent activator of interferon-regulatory factors (DAI) and the unmodified HP-CG and single modified $\mathrm{HP}-\mathrm{CG}^{8 \mathrm{MMPh}}$ has been acquired (Figure 5.5). The modified HP-CG ${ }^{8 M M P h}$ is converted to Z-DNA between a 2:1 and 3:1 ZBP:HP-CG ${ }^{8 M M P h}$ ratio (10 $\mu \mathrm{M}$ ZBP: $5 \mu \mathrm{M}$ HP-CG ${ }^{8 M M P h}$ to $15 \mu \mathrm{M}$ ZBP: $5 \mu \mathrm{M}$ HP-CG ${ }^{8 M M P h}$ ) whereas the unmodified HP-CG requires $50 \mu \mathrm{M}$ ZBP to transition to the Z-DNA conformation (10:1 ZBP: HP-CG). The $\mathrm{CD}$ data suggest the $\mathrm{C} 8$-arylguanine does not impede the ZBP binding to the hairpin oligonucleotide. Moreover, the ZBPs may even prefer to bind to the Z-DNA prone modified hairpin oligonucleotides. $\mathrm{CD}$ should be obtained for all the $\mathrm{C} 8$-arylguanine modifications with both the DAI- $\alpha$ and DAI- $\beta$ proteins. 
B)
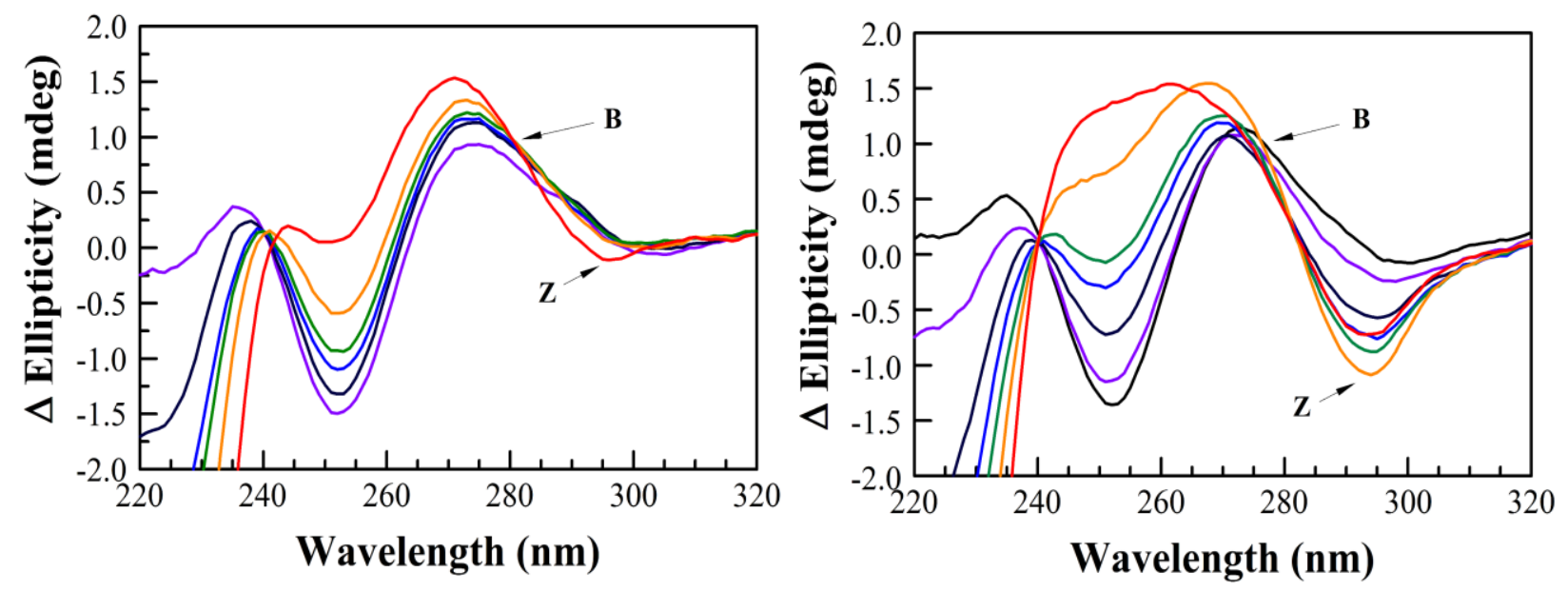

Figure 5.3. CD spectra with DAI- $\beta$ in complex with unmodified HP-CG (A) and $\mathrm{HP}^{-\mathrm{CG}^{8 M M P h}}(\mathrm{~B})$. CD was obtained with various DAI- $\beta$ concentrations, $0 \mu \mathrm{M}$ (black), $5 \mu \mathrm{M}$ (violet), $10 \mu \mathrm{M}$ (purple), $15 \mu \mathrm{M}$ (blue), 20 $\mu \mathrm{M}$ (green), $30 \mu \mathrm{M}$ (orange) and $50 \mu \mathrm{M}$ (red), in complex with oligonucleotide $(5 \mu \mathrm{M})$. CD was acquired at $20{ }^{\circ} \mathrm{C}$ in a buffer solutions ( $\left.\mathrm{pH} 7.4\right)$ of sodium phosphate $(10 \mathrm{mM})$ and sodium chloride $(150 \mathrm{mM})$.

Since the ZBP DAI- $\beta$ will bind the C8-arylguanine modified oligonucleotides, the ZBP B-/Z-DNA transition mechanism could be further evaluated with either the single or double C8-arylguanine modified oligonucleotides, which can be accomplished using surface plasmon resonance (SPR). SPR is an optical technique that can be used to provide equilibrium and kinetic information about biomolecular interactions, ${ }^{196,197}$ which can be specifically used in future studies of ZBP: C8-arylguanine modified oligonucleotide interactions. SPR requires a molecule of interest to be immobilized on a thin layer of a metal, typically gold, film. Then, analyte solutions are injected into the flow cell of the SPR instrument and introduced to the immobilized molecule where there interactions can be detected. These SPR experiments could follow previous SPR 
experiments ${ }^{24,198}$ which have immobilized the oligonucleotide onto the gold film and introduced varying concentrations of ZBP.

The phenomenon of SPR is based on the changes of the refractive index of the gold film, which is directly proportional to the amount of mas bound on the surface. When the ZBP meets the immobilized oligonucleotide, the ZBP binds to the oligonucleotide and changes the refractive index of the gold film or the SPR signal that can be translated into a response signal in the SPR sensorgram. In general, SPR is a way to detect the mass immobilized on the surface, which will change depending on the binding event, and by monitoring the amount of analyte (ZBP) injected into the SPR instrument over a period of time followed by a period of time that where only buffer solution $K_{o n}$ and $K_{\text {off }}$ can be determined, respectively, which can be used to derive $K_{D}\left(K_{D}=\right.$ $\mathrm{K}_{\mathrm{off}} / \mathrm{K}_{\mathrm{on}}$ ). Using SPR the ZBP mediate B-/Z-DNA transition can be fully elucidated, because the kinetics of ZBP binding to both the B- and Z-DNA conformations under physiological conditions (Scheme 5.1).

Unmodified Hairpin

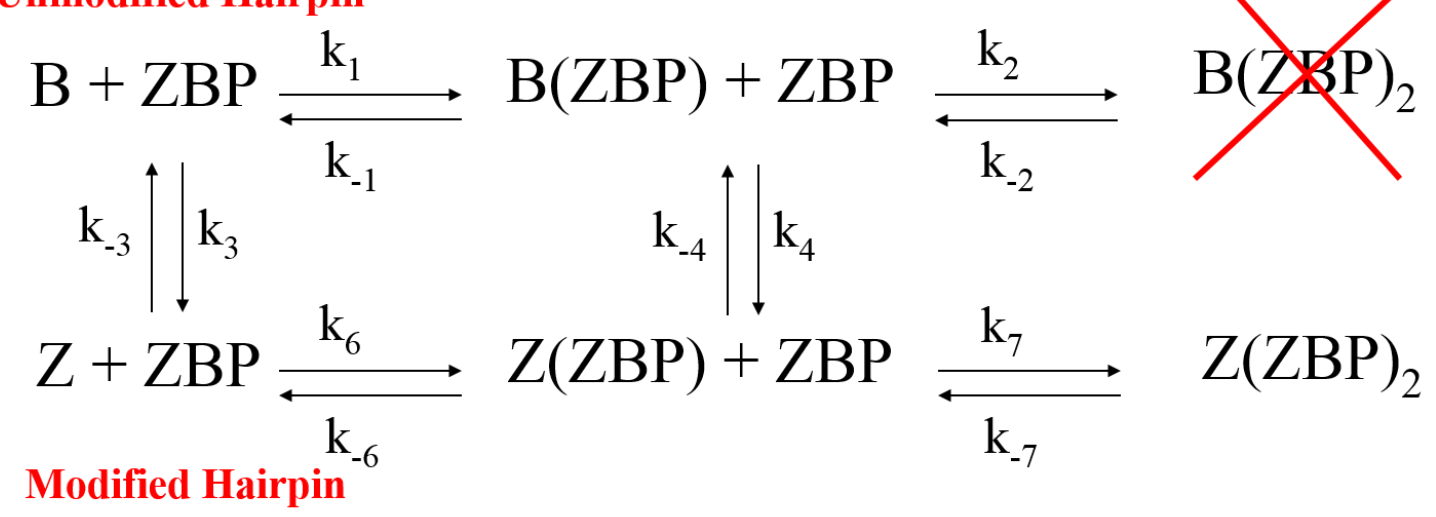

Scheme 5.1. Novel approach of the ZBP mediated B-/Z-DNA transition using C8-arylguanine modified oligonucleotides. Using the C8-arylguanine modified oligonucleotides, the ZBP kinetics of binding to both Band Z-DNA can be determined. 


\section{Reference List}

1. Ivanov, V. I.; Minchenkova, L. E.; Minyat, E. E.; Frank-Kamenetskii, M. D.; Schyolkina, A. K. The B to A transition of DNA in solution. J. Mol. Biol. 1974, 87, 817-833.

2. Watson, J. D.; Crick, F. H. Molecular structure of nucleic acids; a structure for dexoyribose nucleic acid. Nature 1953, 171 (4356), 737-738.

3. Wang, A. H. J.; Quigley, G. J.; Kolpak, F. J.; Crawford, J. L.; van Boom, J. H.; van der Marel, G.; Rich, A. Molecular structure of a left-handed double helical DNA fragment at atomic resolution. Nature 1979, 282, 680-686.

4. Scheffler, I. E.; Elson, E. L.; Baldwin, R. L. Helix formation by d(TA) oligomers: Analysis of Helix-Coil transitions of linear and circular oligomers. J. Mol. Biol. 1970, 48 (1), 145-171.

5. Tinoco, I.; Borer, P. N.; Dengler, B.; Levine, M. D.; Uhlenbecc, O. C.; Crothers, D. M.; Gralla, J. Improved estimation of secondary structure in ribonucleic-acids. Nature-New Biology 1973, 246 (150), 40-41.

6. Panayotatos, N.; Wells, R. D. Cruciform structures in supercoiled DNA. Nature 1981, 289 (5797), $466-470$

7. Arnott, S.; Selsing, E. Structures for the Polynucleotide Complexes Poly(dA) Poly(dT) and Poly(dT)·Poly(dA)·Poly(dT). J. Mol. Biol. 1974, 88, 509-521.

8. Arnott, S.; Bond, P. J.; Selsing, E.; Smith, P. J. C. Models of Triple-Stranded Polynucleotides with Optimised Stereochemistry. Nucl. Acids Res. 1976, 3, 2459-2470.

9. Felsenfeld, G.; Davies, D. R.; Rich, A. Formation of a Three-stranded Polynucleotide Molecule. $J$. Am. Chem. Soc. 1957, 79, 2023-2024.

10. Smith, F. W.; Feigon, J. Quadruplex Structure of Oxytricha Telomeric DNA Oligonucleotides. Nature 1992, 356, 164-168.

11. Wang, Y.; Patel, D. J. Guanine Residues in $d\left(T_{2} A_{3}\right)$ and $d\left(T_{2} G_{4}\right)$ Form Parallel- Stranded Potassium Cation Stabilized G-Quadruplexes with Anti Glycosidic Torsion Angles in Solution. Biochem. 1992, 31, 8112-8119.

12. Pohl, F. M.; Jovin, T. M. Salt-induced cooperative conformational change of a synthetic DNA: Equilibrium and kinetic studies with poly(dG-dC). J. Mol. Biol. 1972, 67 (3), 375-396.

13. Thamann, T. J.; Lord, R. C.; Wang, A. H. J.; Rich, A. The high salt form of poly(dG-dC): poly(dG$\mathrm{dC}$ ) is left-handed Z-DNA: Raman spectra of crystals and solutions. Nucl. Acids Res. 1981, 9 (20), 5443-5457.

14. Marx, J. L. Z-DNA: Still searching for a function. Science 1985, 230 (4727), 794-796.

15. Herbert, A.; Rich, A. Left-handed Z-DNA: Structure and Function. Genetica 1999, 106, 37-47. 
16. Rich, A.; Zhang, S. Z-DNA: The long road to biological function. Nature Reviews Genetics 2003, $4,566-573$.

17. Haniford, D. B.; Pulleybank, D. E. Facile Transition of Poly [d(TG) d(CA)] into a Left-Handed Helix in Physiological Conditions. Nature 1983, 302, 632-634.

18. Feigon, J.; Wang, A. H. J.; van der Marel, G. A.; van Boom, J. H.; Rich, A. Z-DNA forms without an alternating purine-pyrmidine sequence in solution. Science 1985, 230, 82-84.

19. Pohl, F. M.; Jovin, T. M. Salt-Induced Coperative Conformational Change of a Synthetic DNA: Equilibrium and Kinetic Studies with Poly (dG-dC). J. Mol. Biol. 1972, 67 (3), 375-396.

20. Behe, M.; Felsenfeld, G. Effects of Methylation on a Synthetic Polynucleotide: The B-Z Transition in Poly(dG-m5 dC) poly(dG-md ). Proc. Natl Acad. Sci,USA 1981, 78 (3), 1619-1623.

21. Thomas, T. J.; Messner, R. P. A Left-handed (Z) Conformation of Poly(dA-dC).poly(dG-dT) Induced by Polyamines. Nucl. Acids Res. 1986, 14, 6721-6733.

22. Thomas, T. J.; Bloomfield, V. A.; Canellakis, Z. N. Differential effects on the B-to-Z transition of poly(dG-me5dC):poly(dG-me5dC) produced by $\mathrm{N}$-1-acetyl and N8-acetyl spermidine. Biopoly. 1985, 24 (4), 725-729.

23. Herbert, A. G.; Rich, A. A method to identify and characterize Z-DNA binding proteins using a linear oligodeoxynucleotide. Nucl. Acids Res. 1993, 21 (11), 2669-2672.

24. Herbert, A.; Alfken, J.; Kim, Y.-G.; Mian, I. S.; Nishimoto, K.; Rich, A. A Z-DNA Binding Domain Present in the Human Editing Enzyme, Double-stranded RNA Adenosine Deaminase. Proc. Natl Acad. Sci. USA 1997, 94, 8421-8426.

25. Singleton, C. K.; Klysik, J.; Stirdivant, S. M.; Wells, R. D. Left-handed Z-DNA is induced by supercoiling in physiological ionic conditions. Nature 1982, 299 (5881), 312-316.

26. Wang, J. C. Interaction between DNA and an Escherichia coli protein $\omega$. J. Mol. Biol. 1971, 55 (3), 523-533.

27. Wang, J. C. DNA synthesis in Vitro. Wells, R. D., Inman, R. B., Eds.; University Park Press, Baltimore: 1973; pp 163-174.

28. Liu, L. F.; Wang, J. C. Supercoiling of the DNA template during transcription. Proc. Natl Acad. Sci,USA 1987, 84, 7024-7027.

29. Schroth, G. P.; Chou, P. J.; Ho, P. S. Mapping Z-DNA in the human genome. Computer-aided mapping reveals a nonrandom distribution of potential Z-DNA-forming sequences in human genes. J. Biol. Chem. 1992, 267 (17), 11846-11855.

30. Wittig, B.; Dorbic, T.; Rich, A. The Level of Z-DNA in Metabolically Active, Permeabilized Mammalian Cell Nuclei is Regulated by Torsional Strain. Journal of Cell Biology 1989, 108, 755-764. 
31. Wittig, B.; Wolfl, S.; Dorbic, T.; Vahrson, W.; Rich, A. Transcription of human c-myc in permeabilized nuclei is associated with formation of Z-DNA in three discrete regions of the gene. EMBO J 1992, 11, 4653-4663.

32. Wolfl, S.; Wittig, B.; Rich, A. Identification of Transcriptionally Induced Z-DNA Segments in the Human c-myc Gene. Biochim. Biophys. Acta 1995, 1264, 294-302.

33. Liu, R.; Liu, H.; Chen, X.; Kirby, M.; Brown, P. O.; Zhao, K. Regulation of CSF1 Promoter by the SWI/SNF-like BAF Complex. Cell 2001, 106, 309-318.

34. Liu, H.; Mulholland, N.; Fu, H. Q.; Zhao, K. Cooperative activity of BRG1 and Z-DNA formation in chromatin remodeling. Molec. Cellular Biol. 2006, 26 (7), 2550-2559.

35. Xu, Y. Z.; Thuraisingam, T.; Marino, R.; Radzioch, D. Recruitment of SWI/SNF Complex is Required for Transcriptional Activation of the SLC11A1 Gene during Macrophage Differentiation of HL-60 Cells. J. Biol. Chem. 2011, 286 (15), 12839-12849.

36. Henderson, A.; Holloway, A.; Reeves, R.; Tremethick, D. J. Recruitment of SWI/SNF to the human immunodeficiency virus type 1 promoter. Molec. Cellular Biol. 2004, 24 (1), 389-397.

37. Cheng, S. W. G.; Davies, K. P.; Yung, E.; Beltran, R. J.; Yu, J.; Kalpana, G. V. c-MYC interacts with INI1/hSNF5 and requires SWI/SNF complex for transactivation function. Nature Genetics 1999, 22 (1), 102-105.

38. Villagra, A.; Cruzat, F.; Carvallo, L.; Paredes, R.; Olate, J.; van Winjnen, A. J.; Stein, G. S.; Lian, J. B.; Stein, J. L.; Imbalzano, A. N.; Montecino, M. Chromatin remodeling and transcriptional activity of the bone-specific osteocalcin gene require CCAAT/enhancerbinding protein $\beta$-dependent Recruitment of SWI/SNF Activity. J. Biol. Chem. 2006, 281 (32), 22695-22706.

39. Debril, M. B.; Gelman, L.; Fayard, E.; Annicotte, J. S.; Rocchi, S.; Auwerx, J. Transcription factors and nuclear receptors interact with the SWI/SNF complex through the BAF60c subunit. $J$. Biol. Chem. 2004, 279 (16), 16677-16686.

40. Fryer, C. J.; Archer, T. K. Chromatin remodelling by the glucocorticoid receptor requires the BRG1 complex. Nature 1998, 393 (6680), 88-91.

41. Mulholland, N.; Xu, Y.; Sugiyama, H.; Zhao, K. J. SWI/SNF-mediated chromatin remodeling induces Z-DNA formation on a nucleosome. Cell and Biosci. 2012, 2, 7 pp. doi: 10.1186/2045-3701-2-3.

42. Wong, B.; Chen, S.; Kwon, J. A.; Rich, A. Characterization of Z-DNA as a nucleosome-boundary element in yeast Saccharomyces cerevisiae . Proc. Natl. Acad. Sci. USA 2007, 104 (7), 2229-2234.

43. Santarius, T.; Shipley, J.; Brewer, D.; Stratton, M. R.; Cooper, C. S. Epigenetics and Genetics: A census of amplified and overexpressed human cancer genes. Nature Reviews Cancer 2010, $10(1), 59-64$.

44. Ray, B. K.; Dhar, S.; Shakya, A.; Ray, A. Z-DNA forming silencer in the first exon regulates human ADAM-12 gene expression. Proc. Natl. Acad. Sci. USA 2011, 108 (1), 103-108. 
45. Ray, B. K.; Dhar, S.; Henry, C.; Rich, A.; Ray, A. Epigenetic regulation by Z-DNA silencer function controls cancer-associated ADAM-12 expression in breast cancer: Cross-talk between MeCP2 and NF1 transcription factor family. Cancer Res. 2013, 73 (2), 736-744.

46. Schwartz, T.; Behike, J.; Lowenhaupt, K.; Heinemann, U.; Rich, A. Structure of the DLM-1-ZDNA Complex Reveals a Conserved Family of Z-DNA-binding Proteins. Nature Structural Biology 2001, 8 (9), 761-765.

47. Rothenburg, S.; Deigendesch, N.; Dittmar, K.; Koch-Nolte, F.; Haag, F.; Lowenhaupt, K.; Rich, A. A PKR-like eukaryotic initiation factor 2 alpha kinase from zebrafish contains Z-DNA binding domains instead of dsRNA binding domains. Proc. Natl Acad. Sci,USA 2005, 102 (5), 1602-1607.

48. Kim, Y. G.; Muralinath, M.; Brandt, T.; Pearcy, M.; Hauns, K.; Lowenhaupt, K.; Jacobs, B. L.; Rich, A. A role for Z-DNA binding in vaccinia virus pathogenesis. Proc. Natl Acad. Sci,USA 2003, 100 (12), 6974-6979.

49. Patterson, J. B.; Samuel, C. E. Expression and regulation by interferon of a double-stranded-RNAspecific adenosine deaminase from human cells: evidence for two forms of the deaminase. Molec. Cellular Biol. 1995, 15 (10), 5376-5388.

50. Bergan, V.; Jagus, R.; Lauksund, S.; Kileng, O.; Robertson, B. The Atlantic salmon Z-DNA binding protein kinase phosphorylates translation initiation factor $2 \alpha$ and constitutes a unique orthologue to the mammalian dsRNA-activated protein kinase R. FEBS 2008, 275 (1), 184-197.

51. Dai, J.; Wright, M. W.; Manderville, R. A. Ochratoxin A Forms a Carbon-Bonded C8Deoxyguanosine Nucleoside Adduct: Implications for C8-Reactivity by a Phenolic Radical. J. Am. Chem. Soc. 2003, 125, 3716-3717.

52. Rebsamen, M.; Heinz, L. X.; Meylan, E.; Michallet, M. C.; Schroder, K.; Hofmann, K.; Vazquez, J.; Benedict, C. A.; Tschopp, J. DAI/ZBP1 recruits RIP1 and RIP3 through RIP homotypic interaction motifs to activate NF-кB. EMBO Reports 2009, 10 (8), 916-922.

53. Wang, Z. C.; Choi, M. K.; Ban, T.; Yanai, H.; Negishi, H.; Lu, Y.; Tamura, T.; Takaoka, A.; Nishikura, K.; Taniguchi, T. Regulation of innate immune responses by DAI (DLM1/ZBP1) and other DNA-sensing molecules. Proc. Natl. Acad. Sci. USA 2008, 105 (14), $5477-5482$.

54. Kwon, J. A.; Rich, A. Biological function of the vaccinia virus Z-DNA-binding protein E3L: Gene transactivation and antiapoptotic activity in HeLa cells. Proc. Natl. Acad. Sci. USA 2005, 102 (36), 12759-12764.

55. Kim, D.; Lee, Y. H.; Hwang, H. Y.; Kim, K. K.; Park, H. J. Z-DNA Binding Proteins as Targets for Structure-Based Virtual Screening. Current Drug Targets 2010, 11 (3), 335-344.

56. Kang, Y.-M.; Bang, J.; Lee, E. H.; Ahn, H.-C.; Seo, Y.-J.; Kim, K. K.; Kim, Y.-G.; Choi, B.-S.; Lee, J.-H. NMR spectroscopic elucidation of the B-Z transition of a DNA double helix induced by the Z $\alpha$ domain of human ADAR1. J. Am. Chem. Soc. 2009, 131, 11485-11491. 
57. Lee, E. H.; Seo, Y.-J.; Ahn, H.-C.; Kang, Y.-M.; Kim, H.-E.; Lee, Y.-M.; Choi, B.-S.; Lee, J.-H. NMR Study of Hydrogen Exchange During the B-Z Transition of a DNA Duplex Induced by the Z $\alpha$ Domains of Yatapoxvirus E3L. FEBS Lett. 2010, 584, 4453-4457.

58. Kim, H. E.; Ahn, H. C.; Lee, Y. M.; Lee, E. H.; Seo, Y. J.; Kim, Y. G.; Kim, K. K.; Choi, B. S.; Lee, J. H. The Z $\beta$ domain of human DAI binds to Z-DNA via a novel B-Z transition pathway. FEBS Letters 2011, 585 (5), 772-778.

59. Lee, Y. M.; Kim, H. E.; Park, C. J.; Lee, A. R.; Ahn, H. C.; Cho, S. J.; Choi, K. H.; Choi, B. S.; Lee, J. H. NMR study on the B-Z Junction Formation of DNA Duplexes Induced by ZDNA Binding Domain of Human ADAR1. J. Am. Chem. Soc. 2012, 134, 5276-5283.

60. Lee, Y. M.; Kim, H. E.; Lee, E. H.; Seo, Y. J.; Lee, A. R.; Lee, J. H. NMR Investigation on the DNA binding and B-Z transition pathway of the $\mathrm{Z} \alpha$ domain of human ADAR1. Biophysical Chemistry 2013, 172, 18-25.

61. Ha, S. C.; Lowenhaupt, K.; Rich, A.; Kim, Y.-G.; Kim, K. K. Crystal Structure of a Junction Between B-DNA and Z-DNA Reveals Two Extruded Bases. Nature 2005, 437, 1183-1186.

62. Bacolla, A.; Wells, R. D. Non-B-DN conformations, genomic rearrangements, and human disease. J. Biol. Chem. 2004, 279 (46), 47411-47414.

63. Wang, G.; Vasquez, K. M. Z-DNA, an active element in the genome. Frontiers in Bioscience 2007, $12,4424-4438$.

64. Klysik, J.; Stirdivant, S. M.; Wells, R. D. Cloning, characterization, and instability of inserts containing different lengths of $(\mathrm{dC}-\mathrm{dG})$ in Escherichia coli. J. Biol. Chem. 1982, 257, 10152-10158.

65. Wang, G.; Christensen, L. A.; Vasquez, K. M. Z-DNA-forming sequences generate large-scale deletions in mammalian cells. Proc. Natl. Acad. Sci. USA 2006, 103 (8), 2677-2682.

66. Adachi, M.; Tsujimoto, Y. Potential Z-DNA elements surround the breakpoints of chromosome translocation within the 5' flanking region of bcl-2 gene. Oncogene 1990, 5, 1653-1657.

67. Rimokh, R.; Rouault, J. P.; Wahbi, K.; Gadoux, M.; Lafage, M.; Archimbaud, E.; Charrin, C.; Gentilhomme, O.; Germain, D.; Samarut, J.; Magaud, J. P. A chromosome 12 coding region is juxtaposed to the MYC protooncogene locus in a $\mathrm{t}(8 ; 12)(\mathrm{q} 24 ; \mathrm{q} 22)$ translocation in a case of B-cell chronic lymphocyctic leukemia. Genes Chromosomes Cancer 1991, 3 (1), 24-36.

68. Xia, Y.; Brown, L.; Tsan, J. T.; Yang, C. Y.; Siciliano, M. J.; Crist, W. M.; Carroll, A. J.; Baer, R. The translocation $(1 ; 14)(\mathrm{p} 34 ; \mathrm{q} 11)$ in human T-cell leukemia: chromosome breakage 25 kilobase pairs downstream of the TAL1 protooncogene. Genes Chromosomes Cancer 1992, 4, 211-216.

69. Thandla, S. P.; Ploski, J. E.; Raza-Egilmez, S. Z.; Chhalliyil, P. P.; Block, A. W.; de Jong, P. J.; Aplan, P. D. ETV6-AML1 translocation breakpoints cluster near a purine/pyrimidine repeat region in the ETV6 gene. Blood 1999, 93 (293), 299. 
70. Yunis, J. J.; Frizzera, G.; Oken, M. M.; McKenna, J.; Theologides, A.; Arnesen, M. Multiple Recurrent genomic defects in follicular lymphoma: A possible model for cancer. New England Journal of Medicine 1987, 316, 79-84.

71. Tashiro, S.; Takechi, M.; Asou, H.; Takauchi, K.; Kyo, T.; Dohy, H.; Kikuchi, M.; Kamada, N.; Tsujimoto, Y. Cytogenetic 2; 18 and 18; 22 translocation in chronic lymphocytic leukemia with juxtaposition of bcl-2 and immunoglobulin ligh chain genes. Oncogene 1992, 7, 573577.

72. Seite, P.; Leroux, D.; Hillion, J.; Monteil, M.; Berger, R.; Mathieu-Mahul, D.; Larsen, C. J. Molecular analysis of a variant 18;22 translocation in a case of lymphocytic lymphoma. Genes Chromosomes Cancer 1993, 6, 39-44.

73. Rabbitts, T. H.; Boehm, T. Structural and functional chimerism results from chromosomal translocation in lymphoid tumors. Adv Immunol 1991, 50, 119-146.

74. Möller, A.; Nordheim, A.; Nichols, S. R.; Rich, A. 7-Methylguanine in poly(dG-dC)poly(dG-dC) facilitates Z-DNA formation. Proc. Natl Acad. Sci,USA 1981, 78 (8), 4777-4781.

75. Fujii, S.; Wang, A. H.; van der Marel, G.; van Boom, J. H.; Rich, A. Molecular structure of (m5 dC-dG)3: the role of the methyl group on 5-methyl cytosine in stabilizing Z-DNA. Nucl. Acids Res. 1982, 10 (23), 7879-7892.

76. Möller, A.; Nordheim, A.; Kozlowski, S. A.; Patel, D. J.; Rich, A. Bromination Stabilizes Poly(dG$\mathrm{dC}$ ) in the Z-DNA Form Under Low-Salt Conditions. Biochem. 1984, 23 (1), 54-62.

77. Abuaf, P.; Kadlubar, F. F.; Grunberger, D. Circular Dichroism of Poly(dG-dC) Modified by the Carcinogens N-Methyl-4-Aminoazobenzene or 4-Aminobiphenyl. Nucl. Acids Res. 1987, $15,7125-7136$.

78. Wells, R. D.; Miglietta, J. J.; Klysik, J.; Larson, J. E.; Stirdivant, S. M.; Zacharis, W. Spectroscopic Studies on Acetylaminofluorene-Modified $(\mathrm{dT}-\mathrm{dG})_{\mathrm{n}} \cdot(\mathrm{dC}-\mathrm{dA})_{\mathrm{n}}$ Suggest a Left Handed Conformation. J. Biol. Chem. 1982, 257, 10166-10171.

79. Santella, R. M.; Grunberger, D.; Weinstein, I. B.; Rich, A. Induction of the Z conformation in poly(dG-dC):poly(dG-dC) by binding of N-2-acteylaminofluorence to guanine residues. Proc. Natl. Acad. Sci. USA 1981, 78 (3), 1451-1455.

80. van Houte, L. P. A.; Westra, J. G.; van Grondelle, R. A Spectroscopic Study of the Conformation of Poly d(G-C).poly d(G-C) Modified with the Carcinogen 2-Aminofluorene. Carcingenesis 1988, 9, 1017-1027.

81. Sugiyama, H.; Kawai, K.; Matsunaga, A.; Fujimoto, K.; Saito, I.; Robinson, H.; Wang, A. H. J. Synthesis, Structure and Thermodynamic Properties of 8-Methylguanine-containing Oligonucleotides: Z-DNA Under Physiological Salt Conditions. Nucl. Acids Res. 1996, 24, 1272-1278.

82. Xu, Y.; Ikeda, R.; Sugiyama, H. 8-Methylguanosine: A Powerful Z-DNA Stabilizer. J. Am. Chem. Soc. 2003, 125, 13519-13524. 
83. Powell, J. H.; Gannett, P. M. Mechanisms of Carcinogenicity of Aryl Hydrazines, Aryl Hydrazides, and Arenediazonium Ions. J. Environ. Pathol. Toxicol. Oncol. 2002, 21 (1), 1-31.

84. Toth, B. Mushroom Hydrazines: Occurrence, Metabolism, Carcinogenesis and Environmental Implications. In Naturally Occurring Carcinogens-Mutagens and Modulators of Carcinogenesis, 1 ed.; Miller, E. C., Ed.; Japan Sci. Soc. Press: Tokyo/Univ. Park Press, Baltimore, 1979; pp 57-65.

85. Toth, B.; Patil, K.; Jae, H.-S. Carcinogenesis of 4-(Hydroxymethyl)benzenediazonium Ion (Tetrafluoroborate) of Agaricus Bisporus. Cancer Res. 1981, 41, 2444-2449.

86. Toth, B. Carcinogenesis by $\mathrm{N}^{2}-\gamma$-glutamyl-4-carboxyphenylhydrazine of Agaricus bisporus in mice. Anticancer Res. 1986, 6, 917-920.

87. Stiborova, M.; Asfaw, B.; Anzenbacher, P.; Hodek, P. A New Way to Carcinogenicity of Azo Dyes: The Benzenediazonium Ion formed from a Non-aminoazoDye, 1-Phenylazo-2hydroxynaphthalene (Sudan I) by Microsomal Enzymes Binds to Deoxyguanosine Residues of DNA. Cancer Lett. 1988, 40, 327-333.

88. Toth, B. A review of the natural occurrence, synthetic production and use of carcinogenic hydrazines and related chemicals. In Vivo 2000, 14, 299-320.

89. Hryhorczuk, D. O.; Aks, S. E.; Turk, J. W. Unusual occupational toxins. Occupational Medicine 1992, 7, 567-586.

90. Gannett, P. M.; Lawson, T.; Miller, M.; Thakkar, D. D.; Lord, J. W.; Yau, W.-M.; Toth, B. 8Arylguanine Adducts from Arenediazonium Ions and DNA. Chem. -Biol. Interact. 1996, 95, 1-25.

91. Gannett, P. M.; Shi, X.; Lawson, T.; Kolar, C.; Toth, B. Aryl Radical Formation During the Metabolism of Arylhydrazines by Microsomes. Chem. Res. Toxicol. 1997, 10 (12), 13721377.

92. Gannett, P. M.; Powell, J. H.; Rao, R.; Shi, X.; Lawson, T.; Kolar, C.; Toth, B. C'-Arylguanine and $\mathrm{C}^{8}$-Aryladenine Formation in Calf Thymus DNA from Arenediazonium Ions. Chem. Res. Toxicol. 1999, 12 (3), 297-304.

93. Kohda, K.; Tsunomoto, H.; Kasamatsu, T.; Sawamura, F.; Terashima, I.; Shibutani, S. Synthesis and Miscoding Specificity of Oligodeoxynucleotide Containing 8-Phenyl-2'deoxyguanosine. Chem. Res. Toxicol. 1997, 10, 1351-1358.

94. Gannett, P. M.; Shi, X.; Ye, J.; Powell, J. H.; Darian, E.; Daft, J. Activation of AP-1 through the MAP Kinase Pathway: A Potential Mechanism of the Carcinogenic Effect of Arenediazonium Ions. Chem. Res. Toxicol. 2000, 13, 1020-1027.

95. Toth, B.; Taylor, J.; Mattson, B.; Gannett, P. Tumor Induction by 4-(Methyl)Benzenediazonium Sulfate in Mice. In Vivo 1989, 3, 17-22.

96. Toth, B.; Gannett, P. Agaricus Bisporus: An Assessment of its Carcinogenic Potency. Mycopathologia 1993, 24, 73-77. 
97. Toth, B.; Erickson, J.; Gannett, P.; Patil, K. Carcinogenesis by the Cultivated Baked Agaricus bisporus Mushroom in Mice. Oncology Reports 1997, 4, 931-936.

98. Gannett, P. M.; Heavner, S.; Daft, J. R.; Shaughnessy, K. H.; Epperson, J. D.; Greenbaum, N. L. Synthesis, properties, and NMR studies of a C8-phenylguanine modified oligonucleotide that preferentially adopts the Z-DNA conformation. Chem. Res. Toxicol. 2003, 16, 13851394.

99. Heavner, S.; Gannett, P. M. Molecular dynamics and free energy calculations of the B and Z forms of C8-arylguanine modified oligonucleotides. J. Biomol. Str. Dyn. 2005, 23 (2), 203-219.

100. Vongsutilers, V.; Phillips, D. J.; Train, B. C.; McKelvey, G. R.; Thomsen, N. M.; Shaughnessy, K. H.; Lewis, J. P.; Gannett, P. M. The conformational effects of para-substituted C8arylguanine adducts the B/Z-DNA equilibrium. Biophy. Chem. 2011, 154, 41-48.

101. Uhlenbecc, O. C.; Borer, P. N.; Dengler, B.; Tinoco, I. Stability of RNA hairpin loops: $\mathrm{A}_{6}-\mathrm{C}_{\mathrm{m}}-\mathrm{U}_{6}$. J. Mol. Biol. 1973, 73, 483-496.

102. Woese, C. R.; Gutell, R. R.; Gutpa, R.; Noller, H. F. Detailed analysis of the higher order structure of 16S-like ribosomal ribonucleic acids. Microbiology Review 1983, 47, 621-669.

103. Haasnoot, C. A. G.; De Bruin, S. H.; Berendensen, R. G.; Janssen, H. G. J. M.; Binnedndijk, T. J. J.; Hilbers, C. W.; van der Marel, G. A.; van Boom, J. H. Strucutre, kinetics, and thermodynamics of DNA hairpin fragments in solution. J. Biomol. Str. Dyn. 1983, 1, 115129.

104. Hilbers, C. W.; Blommers, M. J. J. J.; van de Ven, F. J. M.; van Boom, J. H.; van der Marel, G. A. High resolution NMR studies of DNA hairpins with four nucleotides in the loop region. Nucleosides \& Nucleotides 1991, 10, 61-80.

105. Blommers, M. J. J. J.; Walters, J. A. L. I.; Haasnoot, C. A. G.; Aelen, J. M. A.; van der Marel, G. A.; van Boom, J. H.; Hilbers, C. W. Effects of base sequence on the loop folding in DNA hairpins. Bichemistry 1989, 28, 7491-7498.

106. Hilbers, C. W.; Heus, H. A.; van Dongen, M. J. P.; Wijmenga, S. S. The Hairpin Elements of Nucleic Acid Structure: DNA and RNA folding. In Nucleic Acids and Molecular Biology, 8 ed.; Eckstein, F., Lilley, D. M. J., Eds.; Springer: Berlin Heidelberg, 1994; pp 56-104.

107. Orbons, L. P. M.; van der Marel, G. A.; van Boom, J. H.; Altona, C. Hairpin and duplex formation of the DNA octamer d $\left(\mathrm{m}^{5} \mathrm{C}-\mathrm{G}-\mathrm{m}^{5} \mathrm{C}-\mathrm{T}-\mathrm{G}-\mathrm{m}^{5} \mathrm{C}-\mathrm{G}\right)$ in solution. An NMR study. Nucl. Acids Res. 1986, 14, 4187-4196.

108. Summers, M. F.; Byrd, R. A.; Gallo, K. A.; Samson, C. J.; Zon, G.; Egan, W. Nuclear Magnetic Resonance and Circular Dichroism Studies of a Duplex - Single-Stranded Hairpin Loop Equilibrium for the Oligodeoxyribonucleotide Sequence d(CGCGATTCGCG). Nucl. Acids Res. 1985, 13 (17), 6375-6386.

109. Haasnoot, C. A. G.; den Hartog, J. H. J.; de Rooij, J. M. F.; van Boom, J. H.; Altona, C. Local destabilisation of a DNA double helix by a T-T wobble pair. Nature 1979, 281, 235-236. 
110. Haasnoot, C. A. G.; den Hartog, J. H. J.; de Rooij, J. M. F.; van Boom, J. H.; Altona, C. Loopstructures in synthetic oligodeoxynucleotides. Nucl. Acids Res. 1980, 8, 169-181.

111. Haasnoot, C. A. G.; Hilbers, C. W.; van der Marel, G. A.; van Boom, J. H.; Singh, U. C.; Pattabiraman, N.; Kollman, P. A. On loopfolding in nucleic acid hairpin-type structures. $J$. Biomol. Str. Dyn. 1986, 3, 843-857.

112. Hilbers, C. W.; Haasnoot, C. A. G.; De Bruin, S. H.; Joordens, J. J. M.; van der Marel, G. A.; van Boom, J. H. Hairpin formation in synthetic oligonucleotides. Biochimie 1985, 67, 685-695.

113. Breslauer, K. J.; Frank, K.; Blöcker, H.; Marky, L. A. Predicting DNA duplex stability from the base sequence. Proc. Natl. Acad. Sci. ,USA 1986, 83, 3746-3750.

114. Germann, M. W.; Schoenwaelder, K. H.; van de Sande, J. H. Right-handed and left-handed (Z) helical conformations of the hairpin d(C-G)5T4(C-G)5 monomer and dimer. Biochem. 1985, 24 (21), 5698-5702.

115. Xodo, L. E.; Manzini, G.; Quadrifoglio, F.; van der Marel, G. A.; van Boom, J. H. Thermodynamic behavior of the heptadecadeoxynucleotide d(CGCGCGTTTTCGCGCG) forming Bhairpins and Z-hairpins in aqueous solution. Nucl. Acids Res. 1986, 14 (13), 5389-5398.

116. Xodo, L. E.; Manzini, G.; Quadrifoglio, F.; van der Marel, G. A.; van Boom, J. H. Oligodeoxynucleotide folding in solution: loop size and stability of B-hairpins. Biochem. 1988, 27, 6960-6967.

117. Xodo, L. E.; Manzini, G.; Quadrifoglio, F.; van der Marel, G. A.; van Boom, J. H. The B-Z conformational transition in folded oligodeoxynucleotides: Loop size and stability of Zhairpins. Biochem. 1988, 27, 6327-6331.

118. Xodo, L. E.; Manzini, G.; Quadrifoglio, F.; van der Marel, G. A.; van Boom, J. H. DNA hairpin loops in solution: Correlation between primary structure, thermostability and reactivity with single-strand-specific nuclease from mung bean. Nucl. Acids Res. 1991, 19 (7), 15051511.

119. Hare, D. R.; Reid, B. R. Three-dimensional structure of a DNA hairpin in solution: Twodimensional NMR studies and distance geometry calculations on d(CGCGTTTTCGCG). Biochem. 1986, 25, 5341-5350.

120. Benight, A. S.; Wang, Y.; Amaratunga, M.; Chattopadhyaya, R.; Henderson, J.; Hanlon, S.; Ikuta, S. Conformation and dynamics of a left-handed Z-DNA hairpin: Studies of d(CGCGCGTTTTCGCGCG) in solution. Biochem. 1989, 28, 3323-3332.

121. Wolk, S. K.; Hardin, C. C.; Germann, M. W.; van de Sande, J.; Tinoco, Jr. I. Comparison of the Band Z-form hairpin loop structures formed by $\mathrm{d}(\mathrm{CG})_{5} \mathrm{~T}_{4}(\mathrm{CG})_{5}$. Biochem. 1988, 27, 69606967.

122. Chattopadhyaya, R.; Ikuta, S.; Grzeskowiak, K.; Dickerson, R. E. X-ray structure of a DNA hairpin molecule. Nature 1988, 334, 175-179. 
123. Chattopadhyaya, R.; Grzeskowiak, K.; Dickerson, R. E. Structure of a T4 Hairpin Loop on a ZDNA Stem and Comparison with A-RNA and B-DNA Loops. J. Mol. Biol. 1990, 211 (1), 189-210.

124. Thomsen, N. M.; Vongsutilers, V.; Gannett, P. M. The synthesis of C8-Aryl Purines, Nucleosides, and Phosphoramidites. Critical Reviews in Eukaryotic Gene Expression 2011, 21 (2), 155176.

125. Vongsutilers, V.; Daft, J. R.; Shaughnessy, K. H.; Gannett, P. M. A general synthesis of C8arylpurine phosphoramidites. Molecules 2009, 14, 3339-3352.

126. Miyaura, N.; Suzuki, A. Stereoselective synthesis of arylated (E)-alkenes by the reaction of alk-1enylboranes with aryl halides in the presence of palladium catalyst. Journal of the Chemical Society, Chemical Communications 1979, (19), 866-867.

127. Miyaura, N.; Suzuki, A. Palladium-catalyzed Cross-coupling Reactions of Organoboron Compounds. Chem. Rev. 1995, 95, 2457-2483.

128. Western, E. C.; Daft, J. R.; Johnson, I. E. M.; Daft, J.; Gannett, P. M.; Shaughnessy, K. H. Efficient one-step Suzuki arylation of unprotected halonucleosides, using water-soluble palladium catalysts. J. Org. Chem. 2003, 68, 6767-6774.

129. Lin, T.-S.; Cheng, J.-C.; Ishiguro, K.; Sartorelli, A. C. 8-Substituted Guanosine and 2'Deoxyguanosine Derivatives as Potential Inducers of the Differentiation of Friend Erythroleukemia Cells. J. Med. Chem. 1985, 28, 1194-1198.

130. Fabrega, C.; Macias, M. J.; Eritja, R. Synthesis and properties of oligonucleotides containing 8bromo-2'-deoxyguanosine. Nucleosides, Nucleotides, and Nucleic Acids 2001, 20 (3), 251260.

131. Shaughnessy, K. H.; Booth, R. S. Sterically Demanding, Water-Soluble Alkylphosphines as Ligands for High Activity Suzuki Coupling of Aryl Bromides in Aqueous Solvents. Org. Lett. 2001, 3, 2757-2759.

132. Tan, W. T.; Iyer, R. P.; Jiang, Z. W.; Yu, D.; Agrawal, S. An efficient synthesis of radioisotopically labeled oligonucleotides through direct solid-phase 5'-phosphitylation. Tetrahed. lett. 1995, 36 (30), 5323-5326.

133. Xie, C. Y.; Staszak, M. A.; Quatroche, J. T.; Sturgill, C. D.; Khau, V. V.; Martinelli, M. J. Nucleosidic phosphoramidite synthesis via phosphitylation: Activator selection and process development. Organic Process Research \& Development 2005, 9 (6), 730-737.

134. Sinha, N. D. Phosphitylation process. Jul 24, 2007.

135. Beaucage, S. L.; Caruthers, M. H. Deoxynucleoside Phosphoramidites: A New Class of Key Intermediates for Deoxypolynucleotide Synthesis. Tetrahed. lett. 1981, 22 (20), 18591862.

136. Matteucci, M. D.; Caruthers, M. H. Synthesis of Deoxyoligonucleotides on a Polymer Support. $J$. Am. Chem. Soc. 1981, 103, 3185-3191. 
137. Chemistry for Automated DNA/RNA Synthesis. In Models 392 and 394: DNA/RNA Synthesizers, Applied Biosystems, Inc.: 1994.

138. McLaughlin, L. W. Mixed-mode chromatography of nucleic acds. Chem. Rev. 1989, 89, 309-319.

139. McLafferty, F. W. Interpretation of mass spectra; 2nd ed.; W. A. Benjamin, Inc.: Reading, Massachuetts, 1973.

140. Fenn, J. B.; Mann, M.; Meng, C. K.; Wong, S. F.; Whitehouse, C. M. Electrospray ionization for mass spectrometry of large biomolecules. Science 1989, 246 (4926), 64-71.

141. Banoub, J. H.; Newton, R. P.; Esmans, E.; Ewing, D. F.; Mackenzie, G. Recent developments in mass spectrometry for the characterization of nucleosides, nucleotides, oligonucleotides, and nucleic acids. Chem. Rev. 2005, 105, 1869-1915.

142. Gaskell, S. J. Electrospray: Principles and practice. J. Mass. Spectrom. 1997, 32, 677-688.

143. Johnson, W. C. CD of Nucleic Acids. In Circular Dichroism: Principles and Applications, Berova, N., Nakanishi, K., Woody, R. W., Eds.; John Wiley and Sons, Inc: New York, 2000; pp 703-718.

144. Gessner, R. V.; Quigley, G. J.; Wang, A. H. J.; van der Marel, G. A.; van Boom, J. H.; Rich, A. Structural basis for stabilization of Z-DNA by cobalt hexaamine and magnesium cations. Biochem. 1985, 24, 237-240.

145. Reich, Z.; Friedman, P.; Levin-Zaidman, S.; Minsky, A. Effects of adenine tracts on the B-Z transition. J. Biol. Chem. 1993, 268, 8261-8266.

146. Crews, P.; Rodríguez, J.; Jaspars, M. Organic structure analysis; Oxford University Press, Inc.: New York, New York, 1998.

147. James, T. L. NMR determination of oligonucleotide structure. In Current Protocols in Nucleic Acid Chemistry, John Wiley \& Sons, Inc.: Hoboken, New Jersey, 2000; pp 1-16.

148. Bachers, G. E.; Schaefer, T. Applications of the intramoelcular nuclear Overhauser effect in structural organic chemistry. Chem. Rev. 1971, 71, 617-626.

149. Kumar, A. Two-dimensional nuclear Overhauser effect in biomolecules. Proc. Indian Acad. Sci. 1985, $95,1-8$.

150. Patel, D. J.; Canuel, L. L.; Pohl, F. M. "Alternating B-DNA" conformation for the oligo(dG-dC) duplex in high-salt solution. Proc. Natl Acad. Sci. USA 1979, 76, 2508-2511.

151. Patel, D. J.; Kozlowski, S. A.; Nordheim, A.; Rich, A. Right-handed and left-handed DNA: Studies of B- and Z-DNA by using proton nuclear Overhauser effect and P NMR. Proc. Natl Acad. Sci,USA 1982, 79 (5), 1413-1417.

152. Scheek, R. M.; Boelens, R.; Russo, N.; van Boom, J. H.; Kaptein, R. Sequential resonance assignments in ${ }^{1} \mathrm{H}$ NMR spectra of oligonucleotides by two-dimensional NMR spectroscopy. Biochem. 1984, 23, 1371-1376. 
153. Hare, D. R.; Wemmer, D. E.; Chou, S.-H.; Drobny, G.; Reid, B. R. Assignment of the Nonexchangeable Proton Resonances of d(C-G-C- G-A-A-T-T-C-G-C-G) Using Twodimensional Nuclear Magnetic Resonance Methods. J. Mol. Biol. 1983, 171, 319-336.

154. Mitra, C. K.; Sarma, M. H.; Sarma, R. H. Left-Handed Deoxyribonucleic Acid Double Helix in Solution. Biochem. 1981, 20, 2036-2041.

155. Feigon, J.; Wang, A. H. J.; van der Marei, G. A.; van Boom, J. H.; Rich, A. A One- and Twodimensional NMR Study of the B to Z Transition of $\left(\mathrm{m}^{5} \mathrm{dC}-\mathrm{dG}\right)_{2}$ in Methanolic Solution. Nucl. Acids Res. 1984, 12, 1243-1263.

156. Orbons, L. P. M.; van der Marel, G. A.; van Boom, J. H.; Altona, C. The B and Z Forms of the $\mathrm{d}\left(\mathrm{m}^{5} \mathrm{C}-\mathrm{G}\right)_{3}$ and $\mathrm{d}\left(\mathrm{br}^{5} \mathrm{C}-\mathrm{G}\right)_{3}$ Hexamers in Solution. A $300-\mathrm{MHz}$ and $500-\mathrm{MHz}$ Two Dimensional NMR Study. Eur. J. Biochem. 1986, 160, 131-139.

157. Sugiyama, H.; Kawai, K.; Matsunaga, A.; Fujimoto, K.; Saito, I.; Robinson, H.; Wang, A. H. J. Synthesis, structure and thermodynamic properties of 8-methylguanine-containing oligonucleotides: Z-DNA under physiological salt conditions. Nucl. Acids Res. 1996, 24, 1272-1278.

158. Xu, Y.; Ikeda, R.; Sugiyama, H. 8-Methylguanosine: A powerful Z-DNA stabilizer. J. Am. Chem. Soc. 2003, 125, 13519-13524.

159. Rich, A.; Nordheim, A.; Wang, A. H. J. The Chemistry and Biology of Left-Handed Z-DNA. Ann. Rev. Biochem. 1984, 53, 791-846.

160. Zheng, N.; Armstrong, I. J. D.; Eng, K. K.; Keller, J.; Liu, T.; Purick, R.; Lynch, J.; Hartner, F. W.; Volante, R. P. A Convergent Asymmetric Synthesis of a Growth Hormone Secretagogue. Tetrahedron: Asymmetry 2003, 14, 3435-3446.

161. Kibbe, W. A. OligoCalc: an online oligonucleotide properties calculator. Nucleic Acids Res. 2007, 35 , W43-W46.

162. Pegg, A. E.; McCann, P. P. Polyamine metabolism and function. Am. J. Physiol. 1982, 243, 212221.

163. Thomas, T. J.; Gunnia, U. B.; Thomas, T. Polyamine-induced B-DNA to Z-DNA conformational transition of a plasmid DNA with (dG-dC) $)_{\mathrm{n}}$ insert. J. Biol. Chem. 1991, 266 (10), $6137-$ 6141.

164. Hartwig, A. Role of magnesium in genomic stability. Mutat. Res. 2001, 475, 113-121.

165. Lavery, R.; Zakrzewska, K. Base and base pair morphologies, helical parameters, and definitions. In Oxford Handbook of Nucleic Acid Structure, Neidle, S., Ed.; Oxford University Press: New York, New York, 1999; pp 39-76.

166. Heavner, S. Molecular modeling and experimental determination of the structure of C8-arylguanine modified oligonucleotides that preferentially adopt the Z-DNA conformation. Deparment of Basic Pharmaceutical Sciences, West Virginia University, 2004. 
167. Vongsutilers, V. The Effect of C8-Arylguanine Adducts on B/Z-DNA Equilbrium: Implications in Aryl Hydrazine Carcinogenesis. Deparment of Basic Pharmaceutical Sciences, West Virginia University, 2009.

168. Simmerling, C.; Elber, R.; Zhang, J. MOIL-View - A program for visualization of structure and dynamics of biomolecules and STO - A program for computing stochastic paths. In Modeling of Biomolecular Structure and Mechanisms, Pullman, A., Ed.; Kluwer: Netherlands, 1995; pp 241-265.

169. Lu, X.-J.; Olson, W. K. 3DNA: A software package for the analysis, rebuilding and visualization of three-dimensional nucleic acid structures. Nucl. Acids Res. 2003, 31 (17), 5108-5121.

170. Case, D. A.; Darden, T. A.; Cheatham, I. T. E.; Simmerling, C. L.; Wang, J.; Duke, R. E.; Luo, R.; Crowley, M.; Walker, R. C.; Zhang, W.; Merz, K. M.; Wang, B.; Hayik, S.; Roitberg, A.; Seabra, I.; Kolossvary, I.; Wong, K. F.; Paesani, F.; Vanicek, J.; Wu, X.; Brozell, S.; Stembrecher, T.; Gohlke, H.; Yang, L.; Tan, C.; Mongan, J.; Hornak, G.; Cui, G.; Mathews, D. H.; Seetin, M. G.; Sagui, C.; Babin, V.; Kollman, P. A. Amber 10 User's Manual; 2008.

171. Cornell, W. D.; Cieplak, P.; Bayly, C. I.; Gould, I. R.; Merz, Jr. K. M.; Ferguson, D. M.; Spellmeyer, D. C.; Fox, T.; Caldwell, J. W.; Kollman, P. A. A second generation force field for the simulation of proteins, nucleic acids, and organic molecules. J. Am. Chem. Soc. 1995, 117, 5179-5197.

172. Srinivasan, J.; Cheatham, I. T. E.; Cieplak, P.; Kollman, P. A.; Case, D. A. Continuum Solvent Studies of the Stability of DNA, RNA, and Phosphoramidate-DNA Helices. J. Am. Chem. Soc. 1998, 120, 9401-9409.

173. Cheatham, I. T. E.; Case, D. A. Twenty-Five years of nucleic acid simulations. Biopoly. 2013, 99, 969-977.

174. Tsui, V.; Case, D. A. Molecular dynamics simulations of nucleic acids with a generalized Born solvation model. J. Am. Chem. Soc. 2000, 122, 2489-2498.

175. Kimura, T.; Kawai, K.; Tojo, S.; Majima, T. One-electron attachment reaction of B- and Z-DNA modified by 8-bromo-2'-deoxyguanosine. J. Org. Chem. 2004, 69, 1169-1173.

176. Toth, B. Synthetic and naturally occurring hydrazines as possible cancer causative agents. Cancer Res. 1975, 35, 3693-3697.

177. Toth, B. Hydrazines and cancer: A guidebook on the carcinogenic activities of hydrazines, related chemicals, and hydrazine-containing natural products; Harwood Academic Publishers: The Netherlands, 2000.

178. Sessler, J. L.; Sathiosatham, M.; Doerr, K.; Lynch, V.; Abboud, K. A. A G-Quartet Formed in the Absence of a Templating Metal Cation: A New 8-(N,N-dimethylaniline)guanosine Derivative. Angew. Chem., Int. Ed. 2000, 39, 1300-1303.

179. Vongsutilers, V.; Phillips, D. J.; Train, B. C.; McKelvey, G. R.; Thomsen, N. M.; Shaughnessy, K. H.; Lewis, J. P.; Gannett, P. M. The conformational effect of para-substituted C8arylguanine adducts on the B/Z-DNA equilibrium. Biophy. Chem. 2011, 154, 41-48. 
180. Jovin, T. M.; Soumpasis, D. M. The transition between B-DNA and Z-DNA. Ann. Rev. Phys. Chem. 1987, 38, 521-560.

181. Malinina, L.; Tereshko, V.; Ivanova, E.; Subirana, J. A.; Zarytova, V.; Nekrascv, Y. Structural variability and new intermolecular interactions of Z-DNA in crystals of d(pCpGpCpGpCpG). Biophys. J. 1998, 74, 2482-2490.

182. Pegg, A. E. The function of spermine. International Union of Biochemistry and Molecular Biology 2014, 66, 8-18.

183. Manni, A.; Wechter, R.; Gilmour, S.; Verderame, M. F.; Mauger, D.; Demers, L. M. Ornithine decarboxylase over-expression stimulates mitogen-activated protein kinase and anchorageindependent growth of human breast epithelial cells. Int. J. Cancer 1997, 70, 175-182.

184. Thomas, T.; Thomas, T. J. Polyamine metabolism and cancer. J. Cell. Mol. Med. 2003, 7, 113-126.

185. Wong, B.; Chen, S.; Kwon, J. A.; Rich, A. Characterization of Z-DNA as a nucleosome-boundary element in yeast Saccharomyces cerevisiae. Proc. Natl Acad. Sci,USA 2007, 104 (7), 2229 2234.

186. Rebsamen, M.; Heinz, L. X.; Meylan, E.; Michallet, M. C.; Schroder, K.; Hofmann, K.; Vasquez, J.; Benedict, C. A.; Tschopp, J. DAI/ZBP1 recruits RIP1 and RIP3 through RIP homotypic interaction motifs to activate NF-kappaB. EMBO Reports 2009, 10 (8), 916-922.

187. Kim, D.; Lee, Y. H.; Hwang, H. Y.; Kim, K. K.; Park, H. J. Z-DNA binding proteins as targets for structure-based virtual screening. Current Drug Targets 2010, 11, 335-344.

188. Brasier, A. R.; Tate, J. E.; Habener, J. F. Optimized use of the firefly luciferase assay as a reporter gene in mammalian-cell lines. Biotechniques 1989, 7, 1116-1122.

189. Favata, M. F.; Horiuchi, K. Y.; Manos, E. J.; Daulerio, A. J.; Stradley, D. A.; Feeser, W. S.; Van Dyk, D. E.; Pitts, W. J.; Earl, R. A.; Hobbs, F.; Copeland, R. A.; Magolda, R. L.; Scherle, P. A.; Trzaskos, J. M. Identification of a novel inhibitor of mitogen-activated protein kinase kinase. J. Biol. Chem. 1998, 273, 18623-18632.

190. Peck, L. J.; Nordheim, A.; Rich, A.; Wand, J. C. Flipping of cloned d(pCpG) $\mathrm{d}(\mathrm{pCpG})_{\mathrm{n}} \mathrm{DNA}$ sequences from right to left-handed structure by salt, $\mathrm{Co}(\mathrm{III})$, or negative supercoiling . Proc. Natl Acad. Sci,USA 1982, 79, 4560-4564.

191. Tsao, Y. P.; Wu, H.-Y.; Liu, L. F. Transcription-driven Supercoiling of DNA: Direct Biochemical Evidence from in vitro Studies. Cell 1989, 56, 111-118.

192. Wang, G.; Carbajal, S.; Vijg, J.; DiGiovanni, J.; Vasquez, K. M. DNA Structure-induced Genomic Instability In Vivo. J. Natl Cancer Inst. 2008, 100, 1815-1817.

193. Hardin, C. C.; Zarling, D. A.; Puglisi, J. D.; Trulson, M. O.; Davis, P. W.; Tinoco, J. I. Stabilization of Z-RNA by Chemical Bromination and Its Recognition by Anti-Z-DNA Antibodies. Biochem. 1987, 26, 5191-5199. 
194. Kim, Y. G.; Lowenhaupt, K.; Oh, D. Y.; Kim, K. K.; Rich, A. Evidence that vaccinia virulece factor ER binds to Z-DNA in vivo: Implications for development of a therapy for poxvirus infection. Proc. Natl. Acad. Sci. ,USA 2004, 101, 1514-1518.

195. Rothenberg, S.; Deigendesch, N.; Dittmar, K.; Koch-Nolte, F.; Haag, F.; Lowenhaupt, K.; Rich, A. A PKR-like eukaryotic initation factor $2 \alpha$ kinase from zebrafish contains Z-DNA binding domains instead of dsRNA binding domains. Proc. Natl. Acad. Sci. ,USA 2005, 102, 16021607.

196. Katsamba, P. S.; Park, S.; Laird-Offringa, I. A. Kinetic studies of RNA-protein interactions using surface plasmon resonance. Methods 2002, 26, 95-104.

197. Manera, M. G.; Spadavecchia, J.; Leone, A.; Quaranta, F.; Rella, R.; Dell'atti, D.; Minunni, M.; Mascini, M.; Siciliano, P. Surface plasmon resonance imaging technique for nucleic acid detection. Sensors and Actuators B-Chemical 2008, 130, 82-87.

198. Schade, M.; Behlke, J.; Lowenhaupt, K.; Herbert, A.; Rich, A.; Oschkinat, H. A 6 bp Z-DNA hairpin binds two $\mathrm{Z} \alpha$ domains from the human RNA editing enzyme ADAR1. FEBS Letters 1999, 458, 27-31. 


\section{APPENDIX A: Abbreviations}

\section{Chemicals}

8-BrdG, 8-bromo-

2'-deoxyguanosine

4-CPhBA, 4-carboxyphenyl

boronic acid

4-MMPhBA, 4-

methoxymethyphenyl boronic

acid

ACN, Acetonitrile

CEDCIP, 2-cyanoethyl

diisopropylchloro-

phosphoramidite

CE-PA, cyanoethyl

phosphoramidites

dG, 2'-deoxyguanosine

$\mathrm{D}_{2} \mathrm{O}$, deuterium oxide

DEME, diethylaminoethyl

dG, 2'-deoxyguanosine

DMF, dimethylformamidine

DMTr-Cl, 4,4'-dimethoxytrityl

chloride

LAH, lithium aluminum

hydride

NBS, N-bromosuccinimide

$\operatorname{Pd}(\mathrm{OAc})_{2}$, palladium acetate

TBS, tert-butyldimethylsilyl

TCA, Trichloroacetic acid

THF, tetrahydrofuran

TEA, triethylamine

TEAA, triethylammonium

acetate

TMS, tetramethylsilane

TPPTS, Tris-(3-

sulfantophenyl)phosphine

\section{Experimental}

1D, one dimension

2D, two dimensions

COSY, correlation

spectroscopy

$\mathrm{CI}$, chemical ionization

CPG, controlled pore

glass

EI, electron ionization

ESI, electrospray

ionization

FPLC, fast protein liquid

chromatography

gCOSY, gradient

correlation spectroscopy

HPLC, high performance

liquid chromatography

$\mathrm{MD}$, molecular dynamics

$\mathrm{MM}$, molecular

mechanics

MS, mass spectrometry

MW, molecular weight

$\mathrm{m} / \mathrm{z}$, mass to charge ratio

NMR, nuclear magnetic

resonance spectroscopy

NOE, nuclear

Overhauser effect

NOESY, nuclear

Overhauser effect

correlation spectroscopy

nt, transients

ppm, parts per million

$\mathrm{R}$, gas constant

$\mathrm{RF}$, radio frequency

$\mathrm{RMSd}$, root mean square

deviation

RP-TLC, reverse phase- thin layer

chromatography

SPE, solid phase

extraction

TLC, thin layer

chromatography

$\mathrm{T}_{\mathrm{M}}$, melting temperature

UV, ultraviolet

$\Delta \mathrm{E}$, energy gap

$\Delta \mathrm{G}$, free energy

$\Delta \mathrm{H}$, enthalpy

$\Delta \mathrm{S}$, entropy

$A$, Absorbance

$B_{0}$, magnetic field

strength

$f_{B}$, mole fraction of

B-DNA

$f_{S S}$, mole fraction of

ss-DNA

$f_{Z}$, mole fraction of Z-

DNA

$h$, Planck's constant

$I$, spin number

$J$, coupling constant

$\mathrm{v}$, applied radio

frequency

$\mathrm{v}_{0}$, Larmor frequency

$\delta$, chemical shift

$\varepsilon$, molar absorptivity/

total ellipticity

$\Delta \varepsilon$, molar ellipticity

$\gamma$, gyromagnetic ratio 


\section{APPENDIX B: Chemical Structures}

1) 8-Bromo-2'-deoxyguanosine

2) 4-(TBS-O-methyl)-phenyl bromide

3) 4-(TBS-O-methyl) phenyl boronic acid

4) 8-phenyl-2'-deoxyguanosine

5) 8-p-tolyl-2'-deoxyguanosine

6) 8-(4-(TBS-O-methyl)phenyl)-2'-deoxyguanosine

7) 8-(4-methoxymethylphenyl)-2'-deoxyguanosine

8) 8-(4-carboxyphenyl)-2'-deoxyguanosine

9) $\mathrm{N} 2$-( $N, N$-Dimethylformamidine)-8-phenyl-2'-deoxyguanosine

10) $\mathrm{N} 2$-( $N, N$-Dimethylformamidine)-8- $p$-tolyl-2'-deoxyguanosine

11) N2-( $N, N$-Dimethylformamidine)-8-(4-(TBS-O-methyl)phenyl-2'-deoxyguanosine

12) N2-(N,N-Dimethylformamidine)-8-(4-methoxymethylphenyl)-2'-deoxyguanosine

13) N2-( $N, N$-Dimethylformamidine)-8-(4-carboxyphenyl)-2'-deoxyguanosine

14) 5'-O-(4,4'-Dimethoxytrityl)- N2-(N,N-Dimethylformamidine)-8-phenyl-2'-deoxyguanosine

15) 5'-O-(4,4'-Dimethoxytrityl)- N2-(N,N-Dimethylformamidine)-8- $p$-tolyl-2'-deoxyguanosine

16) 5'-O-(4,4'-Dimethoxytrityl)- N2-(N,N-Dimethylformamidine)-8-(4-(TBS-O-methyl)phenyl2'-deoxyguanosine

17) 5'-O-(4,4'-Dimethoxytrityl)- N2-(N,N-Dimethylformamidine)-8-(4-methoxymethylphenyl)2'-deoxyguanosine

18) 5'-O-(4,4'-Dimethoxytrityl)- N2-(N,N-Dimethylformamidine)-8-(4-carboxyphenyl)-2'deoxyguanosine 
19) 3'-O-[2-Cyanoethoxy)(diisopropylamino)phosphine]-5'-O-(4,4'-Dimethoxytrityl)-N2-( $N, N$ Dimethylformamidine)-8-phenyl-2'-deoxyguanosine

20) 3'-O-[2-Cyanoethoxy)(diisopropylamino)phosphine]-5'-O-(4,4'-Dimethoxytrityl)-N2-( $N, N$ Dimethylformamidine)-8-p-tolyl-2'-deoxyguanosine

21) 3'-O-[2-Cyanoethoxy)(diisopropylamino)phosphine]-5'-O-(4,4'-Dimethoxytrityl)-N2-( $N, N$ Dimethylformamidine)-8-(4-TBS-O-methyl)phenyl)-2'-deoxyguanosine

22) 3'-O-[2-Cyanoethoxy)(diisopropylamino)phosphine]-5'-O-(4,4'-Dimethoxytrityl)-N2-( $N, N$ Dimethylformamidine)-8-(4-methoxymethylphenyl)-2'-deoxyguanosine 23) 3'-O-[2-Cyanoethoxy)(diisopropylamino)phosphine]-5'-O-(4,4'-Dimethoxytrityl)-N2-( $N, N$ Dimethylformamidine)-8-(4-carboxyphenyl)-2'-deoxyguanosine 


\begin{tabular}{|l|l|l|}
\hline 1) & Formula & Molecular Weight \\
\hline 2) & & \\
\hline
\end{tabular}




\begin{tabular}{|c|c|c|}
\hline Compound & Formula & Molecular Weight \\
\hline 4) & 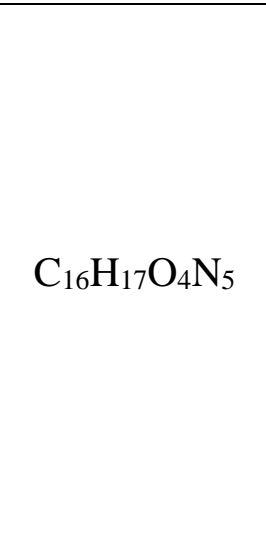 & 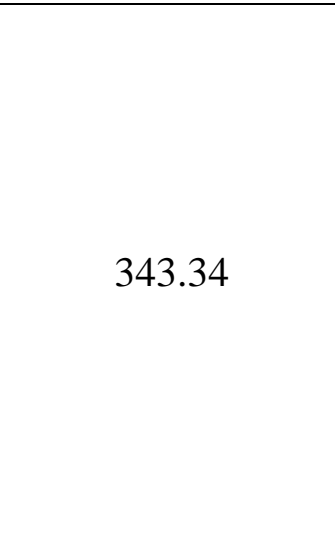 \\
\hline 5) & 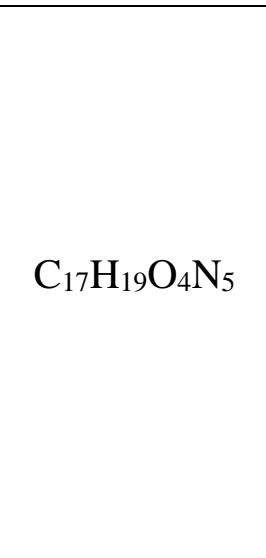 & 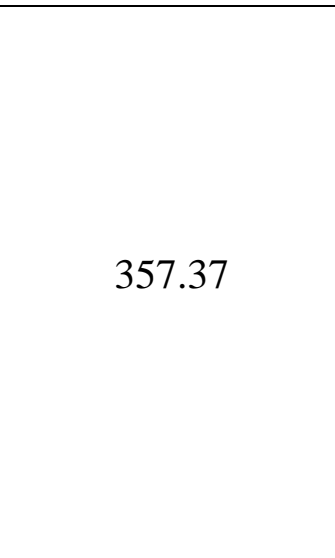 \\
\hline 6) & $\mathrm{C}_{23} \mathrm{H}_{33} \mathrm{O}_{5} \mathrm{~N}_{5} \mathrm{Si}$ & 更 \\
\hline
\end{tabular}




\begin{tabular}{|l|l|l|}
\hline 7 (2) & Formula & Molecular Weight \\
\hline 9
\end{tabular}




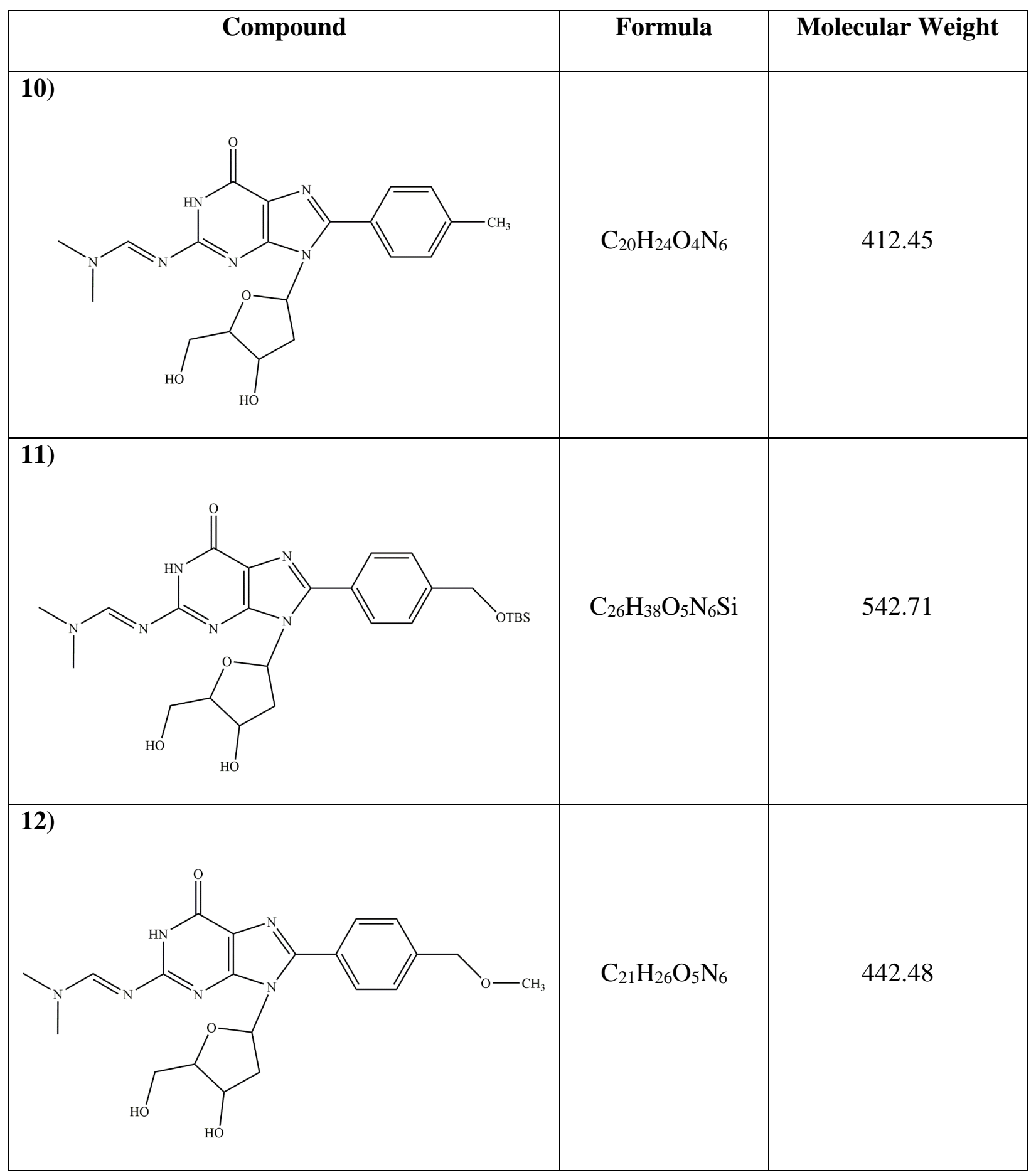




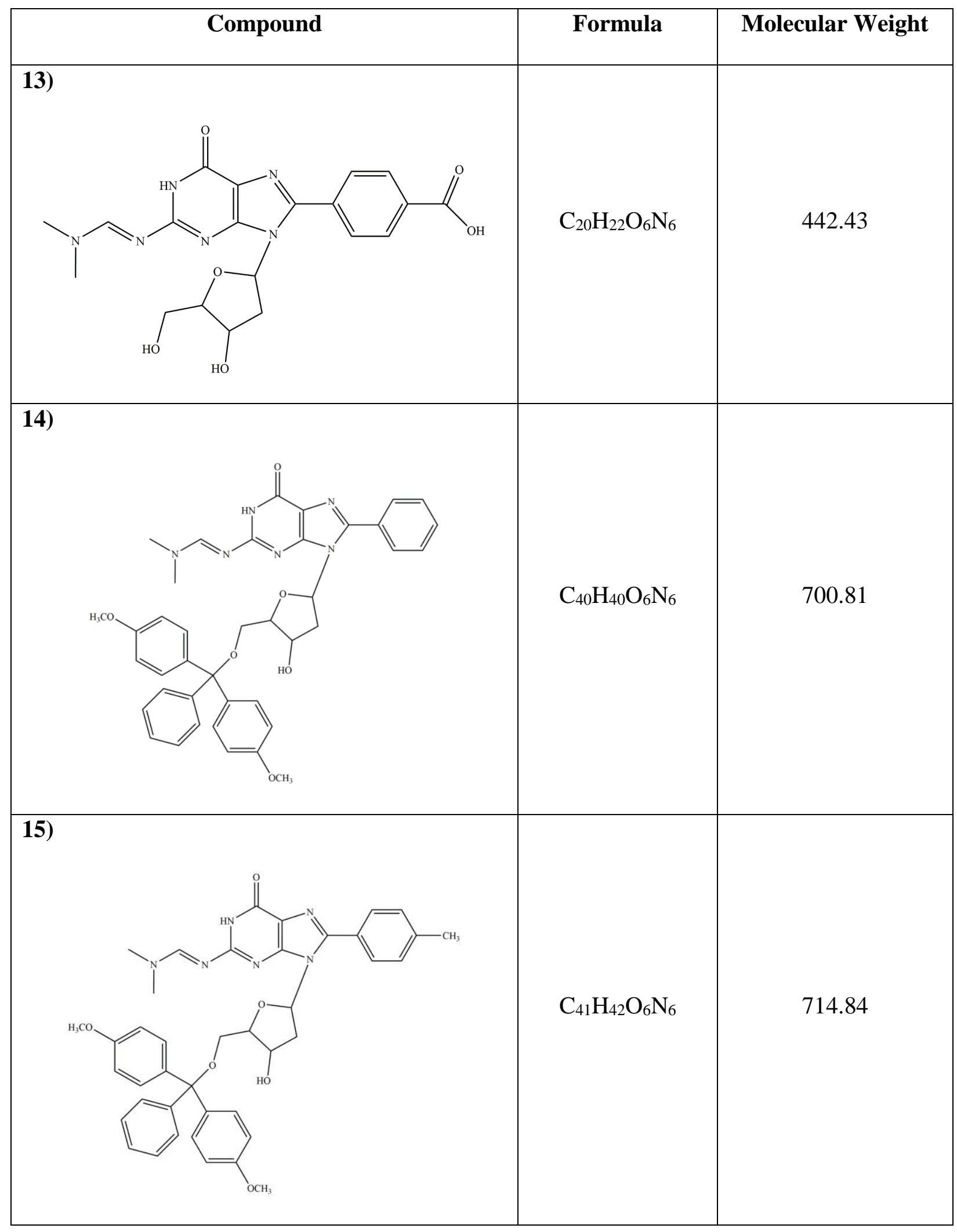




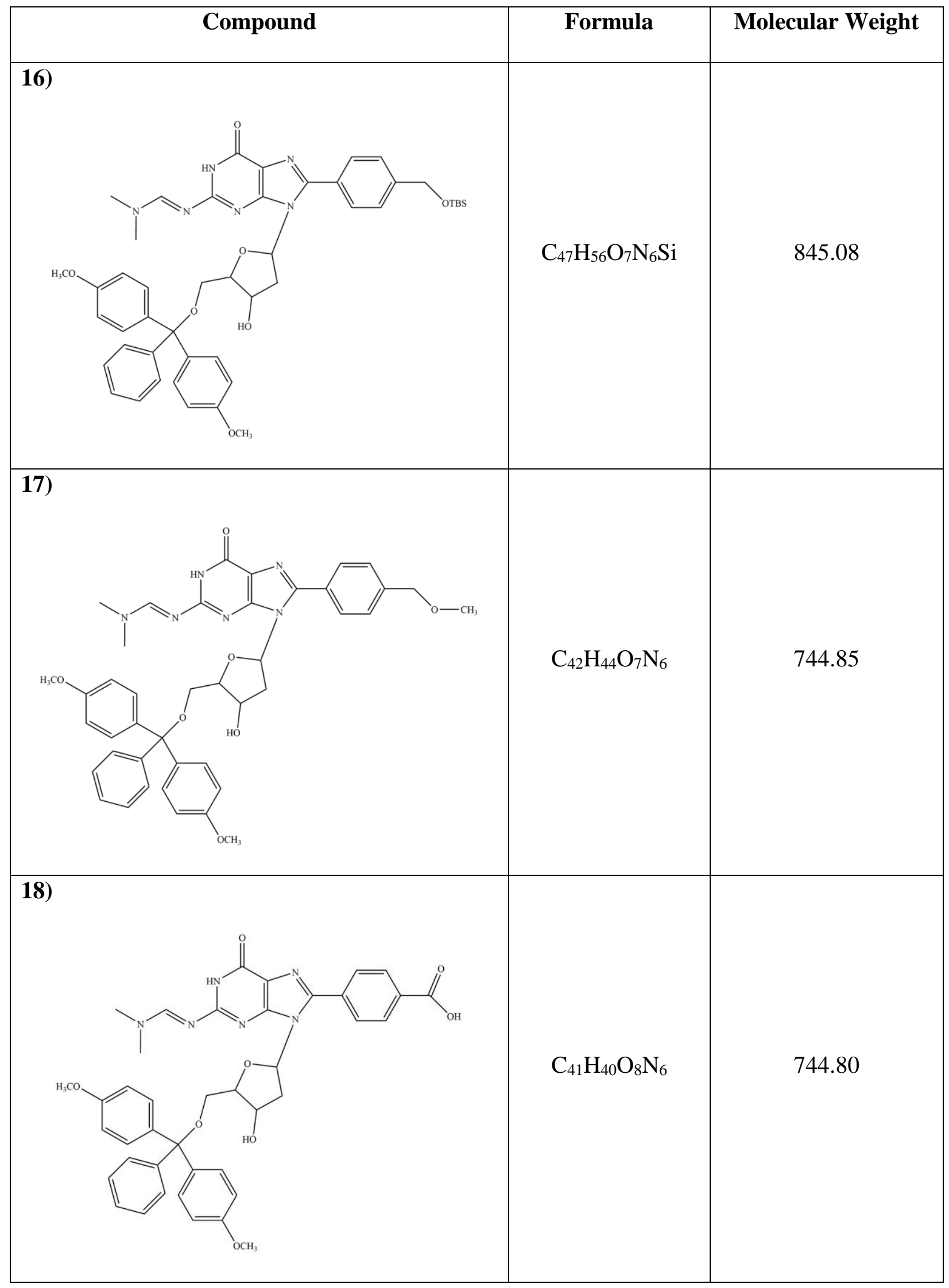




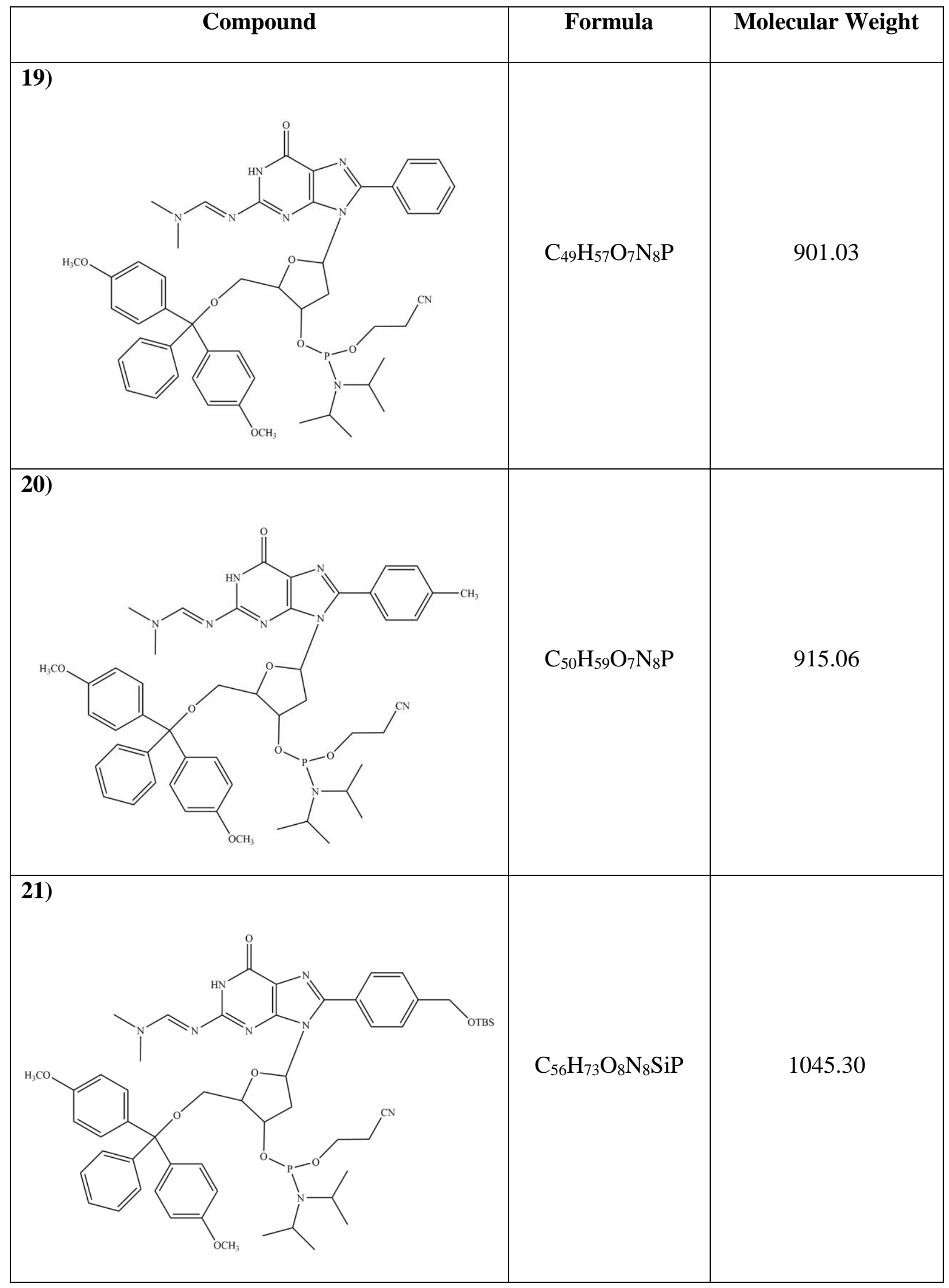




\begin{tabular}{|l|l|l|}
\hline 22 & Formula & Molecular Weight \\
\hline 23 &
\end{tabular}


Appendix C: Experimental Spectra and Chromatograms

${ }^{\mathbf{1}}$ H NMR of 8-Bromo-2'-deoxyguanosine (1) 217

${ }^{1}$ H NMR of 4-(TBS-O-methyl)-phenyl bromide (2) 218

${ }^{\mathbf{1}}$ H NMR of 4-(TBS-O-methyl) phenyl boronic acid (3) 219

$\begin{array}{ll}{ }^{1} H \text { NMR of 8-phenyl-2'-deoxyguanosine (4) } & 220\end{array}$

${ }^{1}$ H NMR of 8-p-tolyl-2'-deoxyguanosine (5) 221

${ }^{1}$ H NMR of 8-(4-(TBS-O-methyl)phenyl)-2'-deoxyguanosine (6) 222

${ }^{1}$ H NMR of 8-(4-methoxymethylphenyl)-2'-deoxyguanosine (7) 223

${ }^{1}$ H NMR of 8-(4-carboxyphenyl)-2'-deoxyguanosine (8) 224

${ }^{1}$ H NMR of N2-( $N, N$-Dimethylformamidine)-8-phenyl-2'-deoxyguanosine (9) 225

${ }^{1} \mathrm{H}$ NMR of N2-(N,N-Dimethylformamidine)-8-p-tolyl-2'-deoxyguanosine (10) 226

${ }^{1}$ H NMR of N2-( $N, N$-Dimethylformamidine)-8-(4-(TBS-O-methyl) phenyl-

2'-deoxyguanosine (11)

${ }^{1}$ H NMR of N2-(N,N-Dimethylformamidine)-8-(4-methoxymethylphenyl)-2'deoxyguanosine (12)

${ }^{1} \mathrm{H}$ NMR of N2-( $N, N$-Dimethylformamidine)-8-(4-carboxyphenyl)-

2'-deoxyguanosine (13)

${ }^{1}$ H NMR of 5'-O-(4,4'-Dimethoxytrityl)- N2-( $N, N$-Dimethylformamidine)-

8-phenyl-2'-deoxyguanosine (14)

${ }^{1}$ H NMR of 5'-O-(4,4'-Dimethoxytrityl)- N2-( $N, N$-Dimethylformamidine)8-p-tolyl-2'-deoxyguanosine (15)

${ }^{1} \mathrm{H}$ NMR of 5'-O-(4,4'-Dimethoxytrityl)- N2-( $N, N$-Dimethylformamidine)-8(4-(TBS-O-methyl)phenyl-2'-deoxyguanosine (16)

${ }^{1}$ H NMR of 5'-O-(4,4'-Dimethoxytrityl)- N2-( $N, N$-Dimethylformamidine)-8(4-methoxymethylphenyl)-2'-deoxyguanosine (17)

${ }^{1}$ H NMR of 5'-O-(4,4'-Dimethoxytrityl)- N2-( $N, N$-Dimethylformamidine)-8(4-carboxyphenyl)-2'-deoxyguanosine (18)

FPLC Chromatogram of the HP-CG 235

FPLC Chromatogram of the HP-CG ${ }^{\text {8Tol }} 236$

\begin{tabular}{ll} 
FPLC Chromatogram of the HP-CG & 8HMPh \\
\hline
\end{tabular}

\begin{tabular}{ll} 
FPLC Chromatogram of the HP-CG & 8MMPh \\
\hline
\end{tabular}

FPLC Chromatogram of the HP-CG ${ }^{8 \mathrm{CPh}} \quad 239$

$\begin{array}{ll}\text { MS- Spectrum of HP-CG } & 240\end{array}$ 
MS- Spectrum of HP-CG ${ }^{8 \mathrm{Ph}}$

\begin{tabular}{ll} 
MS- Spectrum of HP-CG & 8Tol \\
\hline
\end{tabular}

MS- Spectrum of HP-CG ${ }^{8 H M P h} \quad 243$

\begin{tabular}{ll} 
MS- Spectrum of HP-CG & 8MMPh \\
\hline
\end{tabular}

MS- Spectrum of HP-CG ${ }^{8 C P h} \quad 245$

${ }^{1}$ H NMR Spectrum of HP-CG in the B-DNA Conformation 246

${ }^{1} \mathrm{H}-{ }^{1} \mathrm{H}$ gCOSY NMR Spectra of HP-CG in the B-DNA Conformation 247

${ }^{1}$ H-1 ${ }^{1}$ NOESY NMR Spectra of HP-CG in the B-DNA Conformation 248

${ }^{1}$ H NMR Spectrum of HP-CG ${ }^{8 P h}$ in the B-DNA Conformation 249

${ }^{1} \mathrm{H}^{1} \mathrm{H}$ gCOSY NMR Spectra of HP-CG ${ }^{\mathbf{P P h}}$ in the B-DNA Conformation 250

${ }^{1} \mathrm{H}^{1}{ }^{1} \mathrm{H}$ NOESY NMR Spectra of HP-CG ${ }^{\mathbf{8 P h}}$ in the B-DNA Conformation 251

${ }^{\mathbf{1}} \mathrm{H}$ NMR Spectrum of HP-CG ${ }^{\mathbf{8 P h}}$ in the Z-DNA Conformation 252

${ }^{1} \mathrm{H}-{ }^{1} \mathrm{H}$ gCOSY NMR Spectra of HP-CG ${ }^{\mathbf{8 P h}}$ in the Z-DNA Conformation 253

${ }^{\mathbf{1}} \mathrm{H}^{\mathbf{1}} \mathrm{H}$ NOESY NMR Spectra of HP-CG ${ }^{\mathbf{8 P h}}$ in the Z-DNA Conformation 254

${ }^{1}$ H NMR Spectrum of HP-CG ${ }^{8 T o l}$ in the B-DNA Conformation 255

${ }^{1} \mathbf{H}-{ }^{1} \mathrm{H}$ gCOSY NMR Spectra of HP-CG ${ }^{\mathbf{8 T o l}}$ in the B-DNA Conformation 256

${ }^{1}{ }^{H}-{ }^{1} H$ NOESY NMR Spectra of HP-CG ${ }^{8 T o l}$ in the B-DNA Conformation 257

${ }^{1} \mathrm{H}$ NMR Spectrum of HP-CG ${ }^{\mathbf{8 T o l}}$ in the Z-DNA Conformation 258

${ }^{1} \mathrm{H}-{ }^{1} \mathrm{H}$ gCOSY NMR Spectra of HP-CG ${ }^{8 T o l}$ in the Z-DNA Conformation 259

${ }^{1}{ }^{H}-{ }^{1} H$ NOESY NMR Spectra of HP-CG ${ }^{8 T o l}$ in the Z-DNA Conformation 260

${ }^{1}$ H NMR Spectrum of HP-CG ${ }^{\text {8HMPh }}$ in the B-DNA Conformation 261

${ }^{1} \mathrm{H}-{ }^{1} \mathrm{H}$ gCOSY NMR Spectra of HP-CG ${ }^{\mathbf{H M P h}}$ in the B-DNA Conformation 262

${ }^{\mathbf{1}} \mathrm{H}^{\mathbf{1}} \mathrm{H}$ NOESY NMR Spectra of HP-CG ${ }^{\mathbf{8 H M P h}}$ in the B-DNA Conformation 263

${ }^{\mathbf{1}} \mathrm{H}$ NMR Spectrum of HP-CG ${ }^{\mathbf{8 H M P h}}$ in the Z-DNA Conformation 264

${ }^{1}{ }^{H}-{ }^{1} \mathrm{H}$ gCOSY NMR Spectra of HP-CG ${ }^{8 \mathrm{HMPh}}$ in the Z-DNA Conformation 265

${ }^{1}{ }^{H}-{ }^{1}$ H NOESY NMR Spectra of HP-CG ${ }^{\mathbf{8 H M P h}}$ in the Z-DNA Conformation 266

${ }^{1}$ H NMR Spectrum of HP-CG ${ }^{\text {8MMPh }}$ in the B-DNA Conformation 267

${ }^{1}{ }^{H}-{ }^{1} \mathrm{H}$ gCOSY NMR Spectra of HP-CG ${ }^{\mathbf{8 M M h}}$ in the B-DNA Conformation 268

${ }^{1} H_{-}{ }^{1}$ H NOESY NMR Spectra of HP-CG ${ }^{\mathbf{8 M M P h}}$ in the B-DNA Conformation 269

${ }^{1}$ H NMR Spectrum of HP-CG ${ }^{8 M M P h}$ in the Z-DNA Conformation 270 
${ }^{1} \mathrm{H}-{ }^{1} \mathrm{H}$ gCOSY NMR Spectra of HP-CG ${ }^{8 M M P h}$ in the Z-DNA Conformation

${ }^{1} \mathrm{H}^{1}{ }^{1} \mathrm{H}$ NOESY NMR Spectra of HP-CG ${ }^{8 M M P h}$ in the Z-DNA Conformation

${ }^{1}$ H NMR Spectrum of HP-CG ${ }^{8 \mathrm{CPh}}$ in the Z-DNA Conformation

${ }^{1} \mathrm{H}-{ }^{1} \mathrm{H}$ gCOSY NMR Spectra of HP-CG ${ }^{8 \mathrm{CPh}}$ in the B-DNA Conformation

${ }^{1} \mathrm{H}-{ }^{1} \mathrm{H}$ NOESY NMR Spectra of HP-CG ${ }^{8 \mathrm{CPh}}$ in the B-DNA Conformation

${ }^{1} \mathrm{H}$ NMR Spectrum of HP-CG ${ }^{8 \mathrm{CPh}}$ in the Z-DNA Conformation

${ }^{1} \mathrm{H}-{ }^{1} \mathrm{H}$ gCOSY NMR Spectra of HP-CG ${ }^{8 \mathrm{CPh}}$ in the Z-DNA Conformation

${ }^{1} \mathrm{H}-{ }^{1} \mathrm{H}$ NOESY NMR Spectra of HP-CG ${ }^{8 \mathrm{CPh}}$ in the Z-DNA Conformation 
${ }^{1}$ H NMR of 8-Bromo-2'-deoxyguanosine (1)

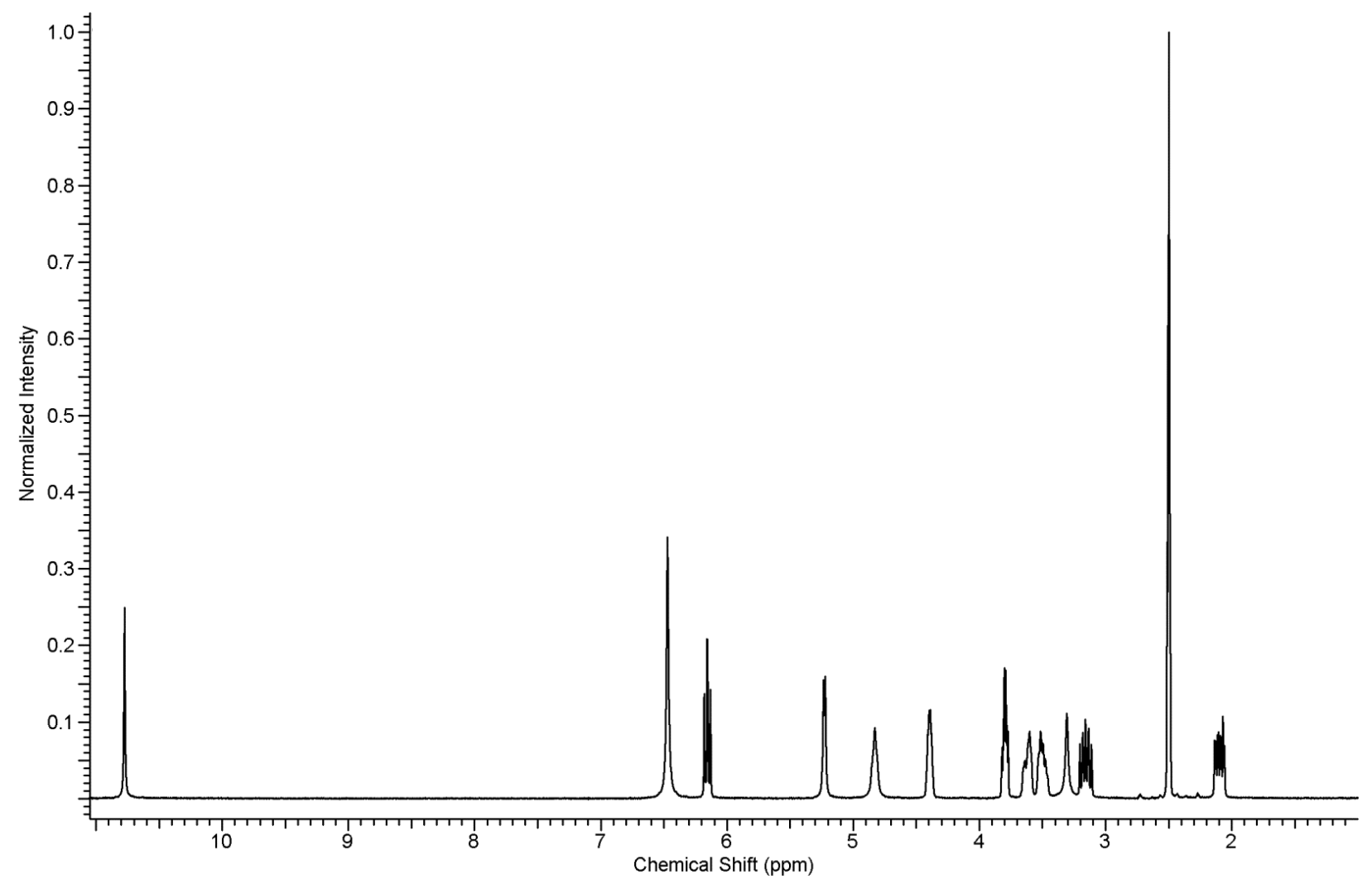


${ }^{1}$ H NMR of 4-(TBS-O-methyl)-phenyl bromide (2)

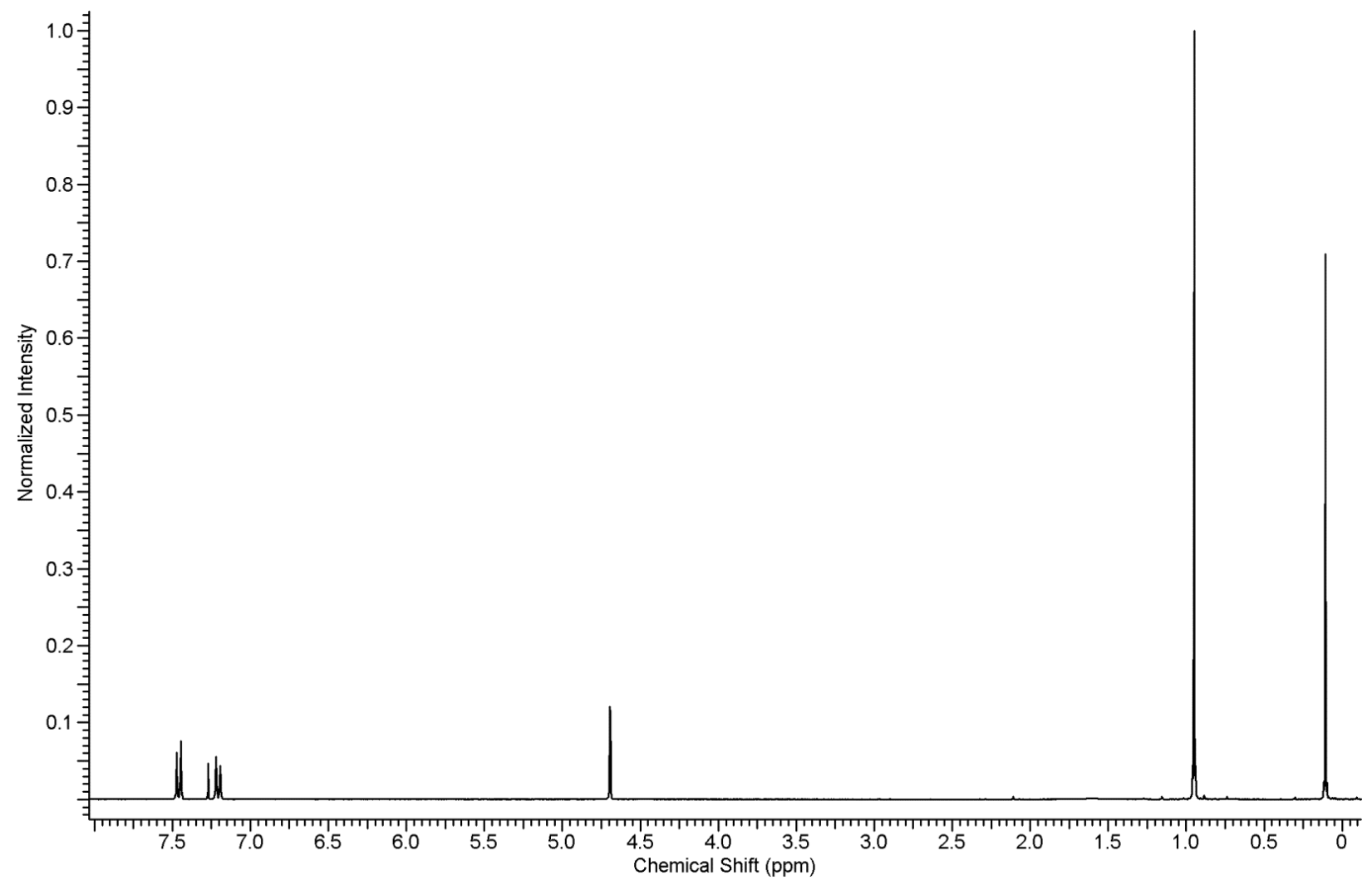


${ }^{1}$ H NMR of 4-(TBS-O-methyl) phenyl boronic acid (3)

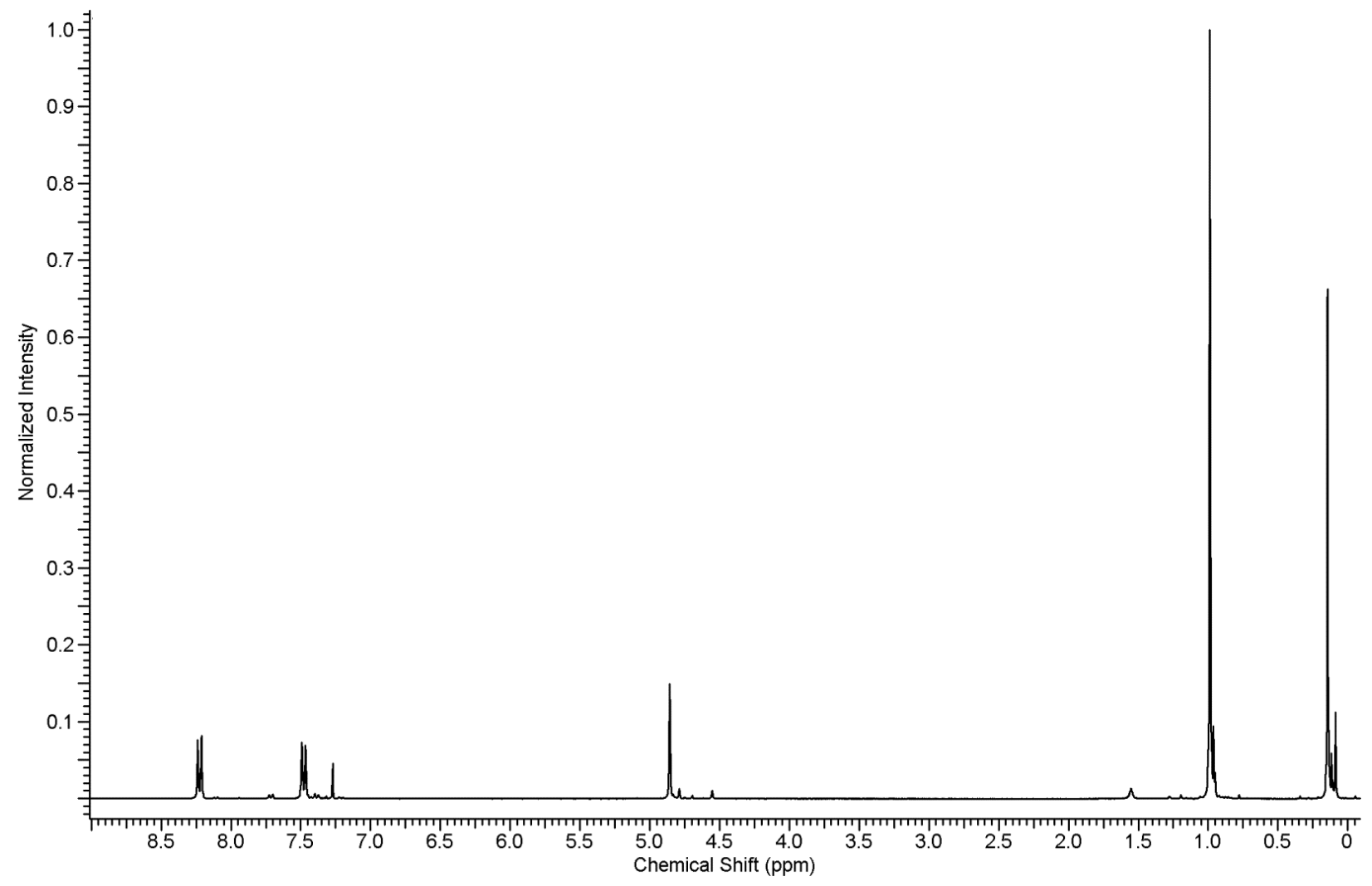


${ }^{1}$ H NMR of 8-phenyl-2'-deoxyguanosine (4)

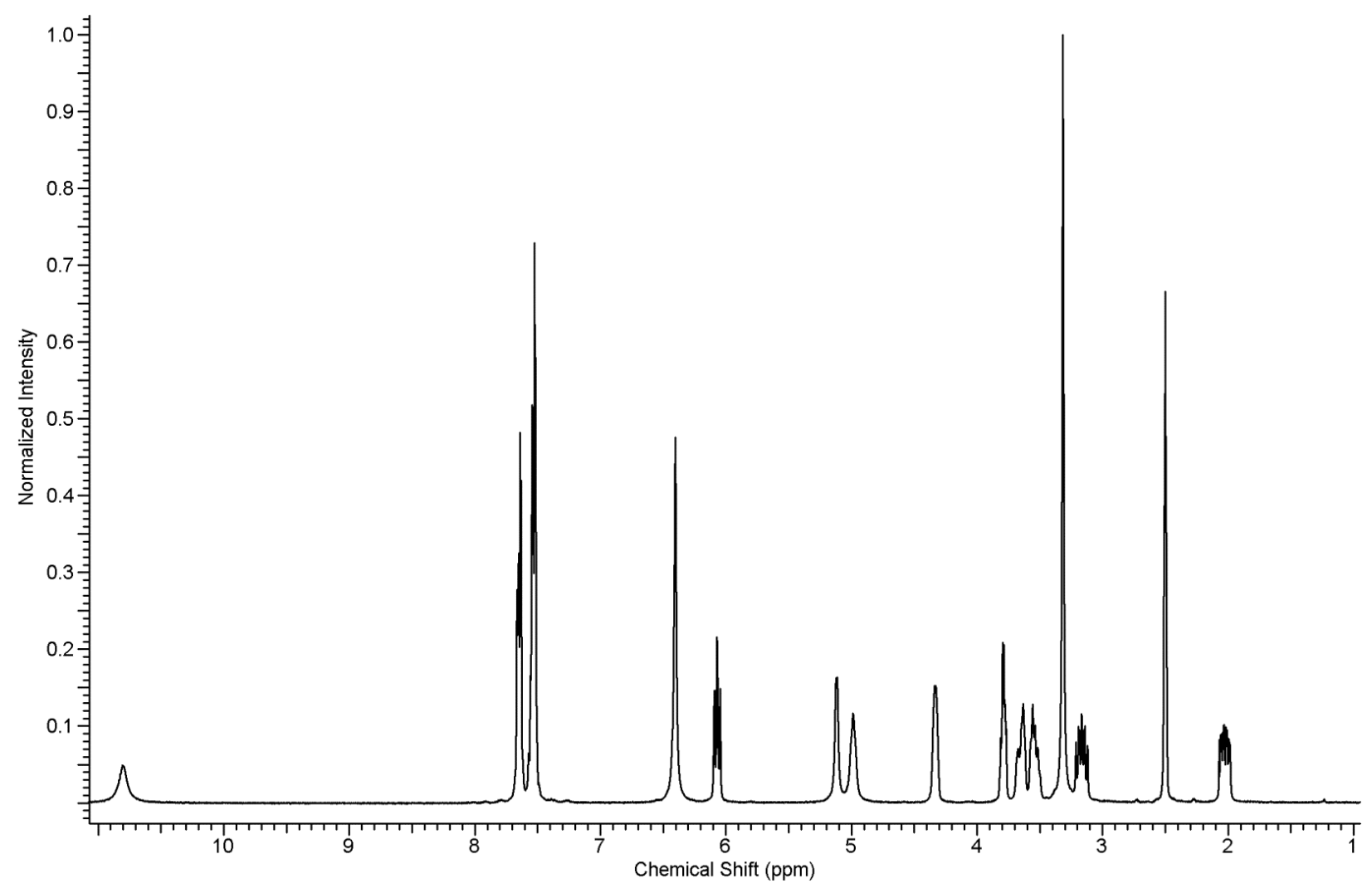


${ }^{1}$ H NMR of 8-p-tolyl-2'-deoxyguanosine (5)

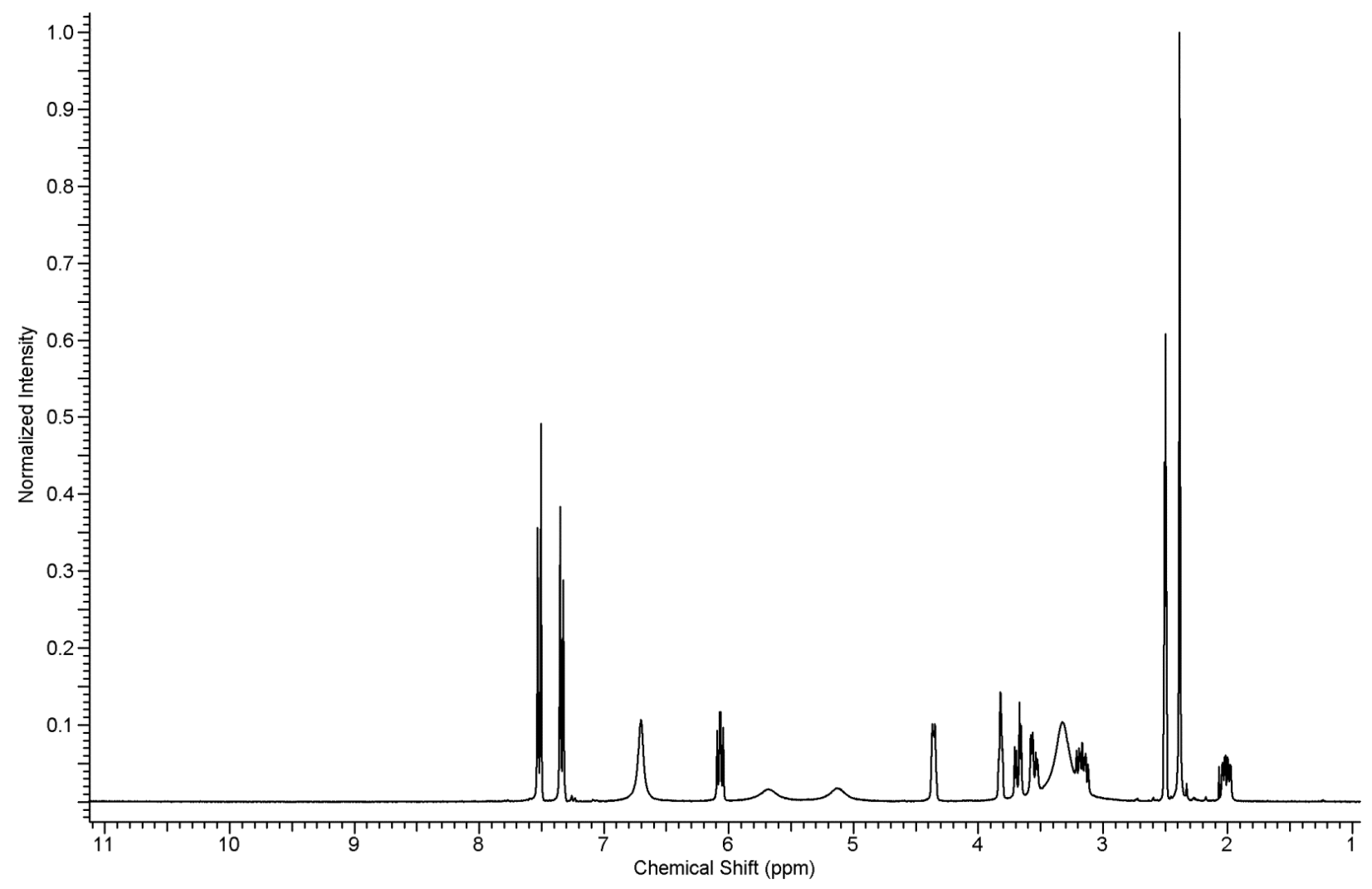


${ }^{1}$ H NMR of 8-(4-(TBS-O-methyl)phenyl)-2'-deoxyguanosine (6)

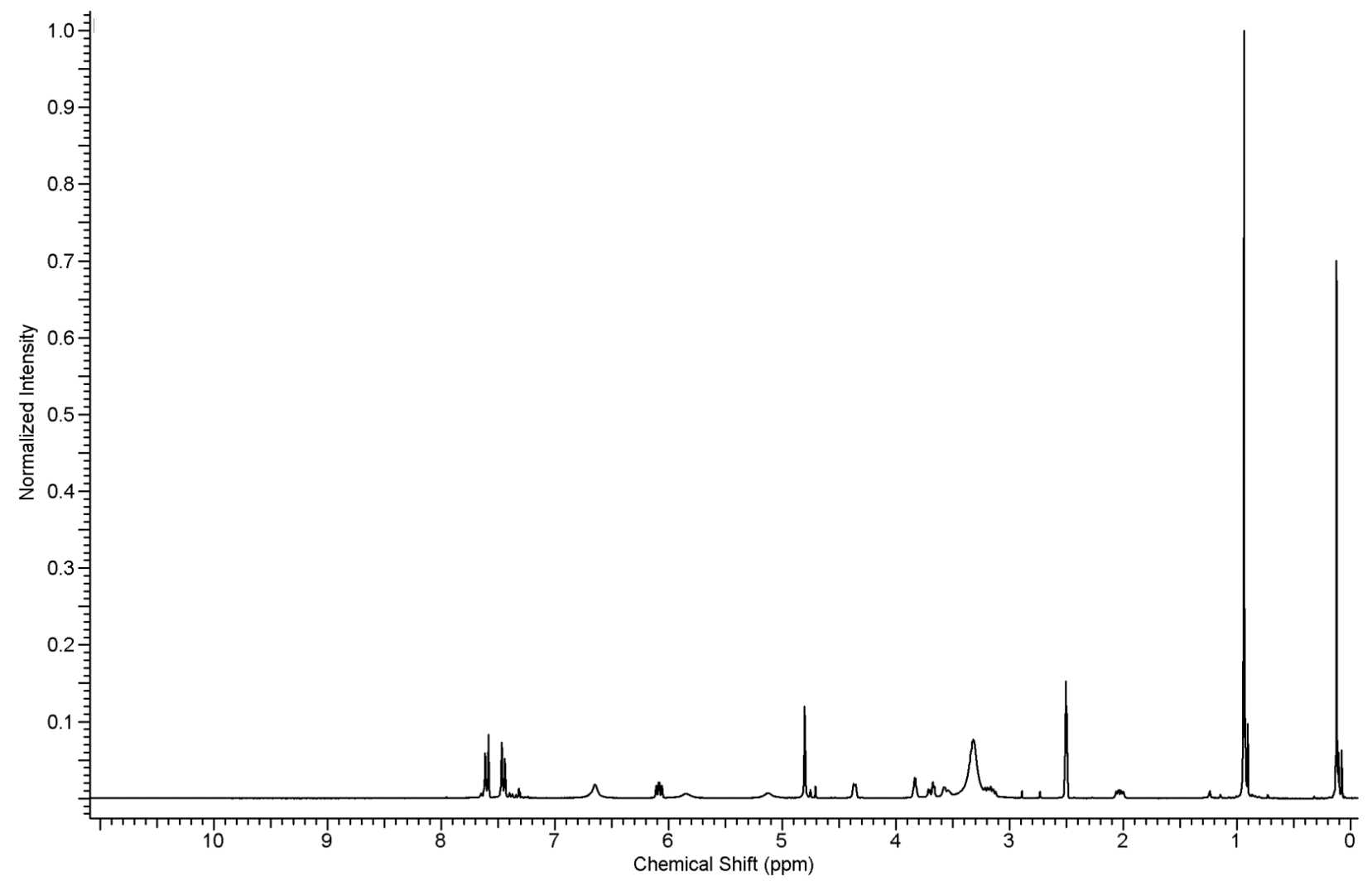


${ }^{1}$ H NMR of 8-(4-methoxymethylphenyl)-2'-deoxyguanosine (7)

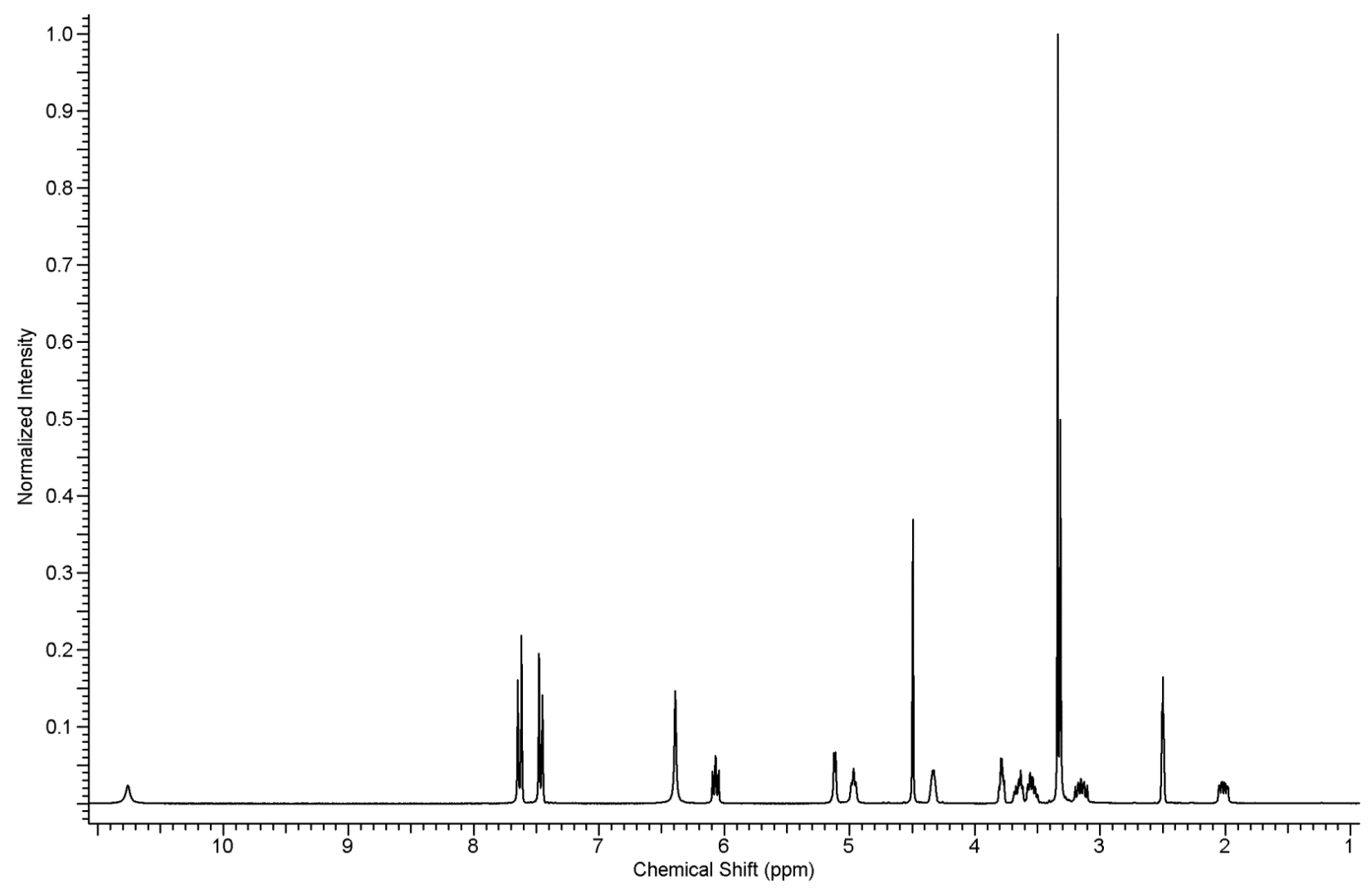


${ }^{1}$ H NMR of 8-(4-carboxyphenyl)-2'-deoxyguanosine (8)

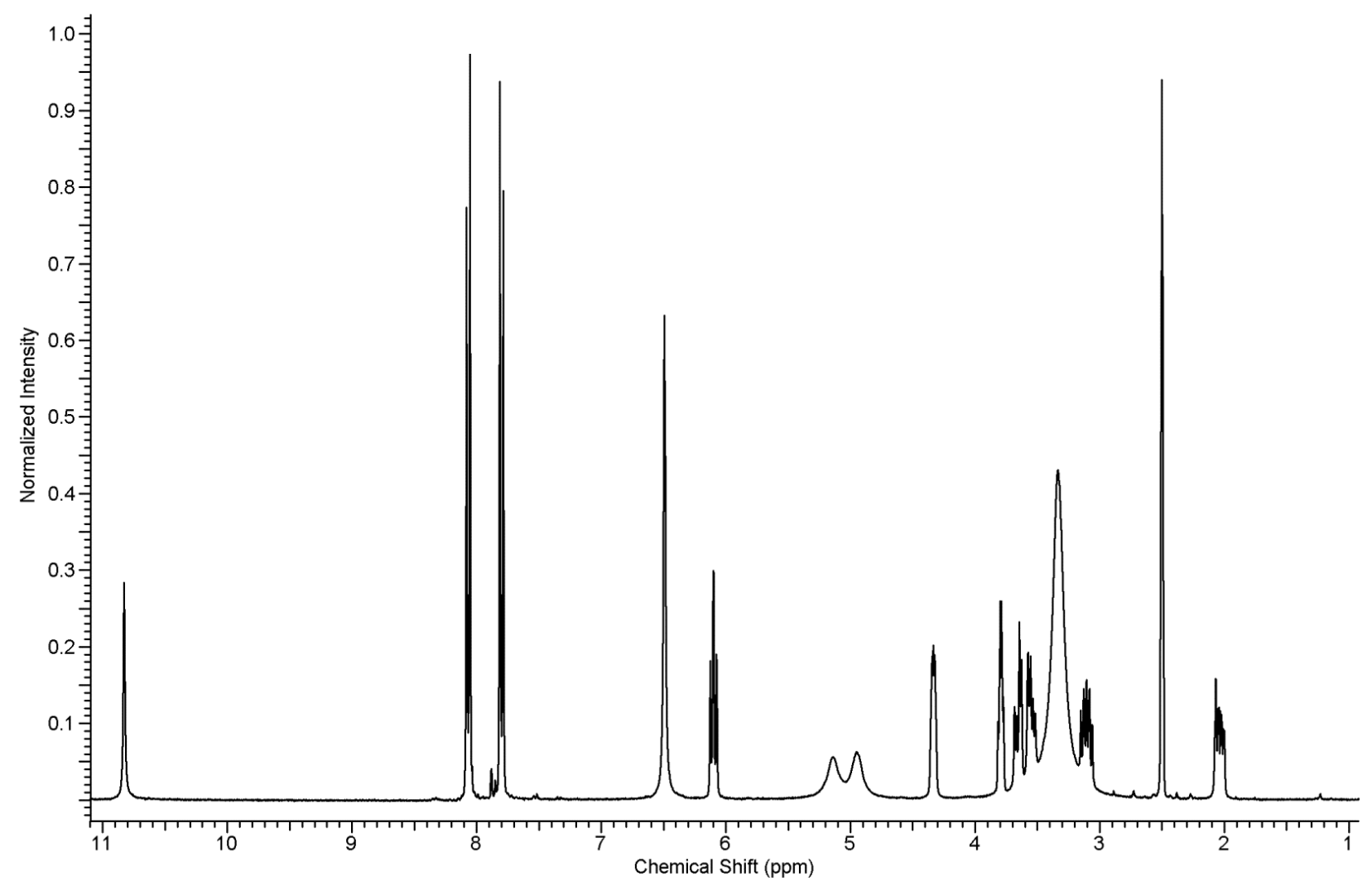


${ }^{1} \mathrm{H}$ NMR of N2-( $N, N$-Dimethylformamidine)-8-phenyl-2'-deoxyguanosine (9)

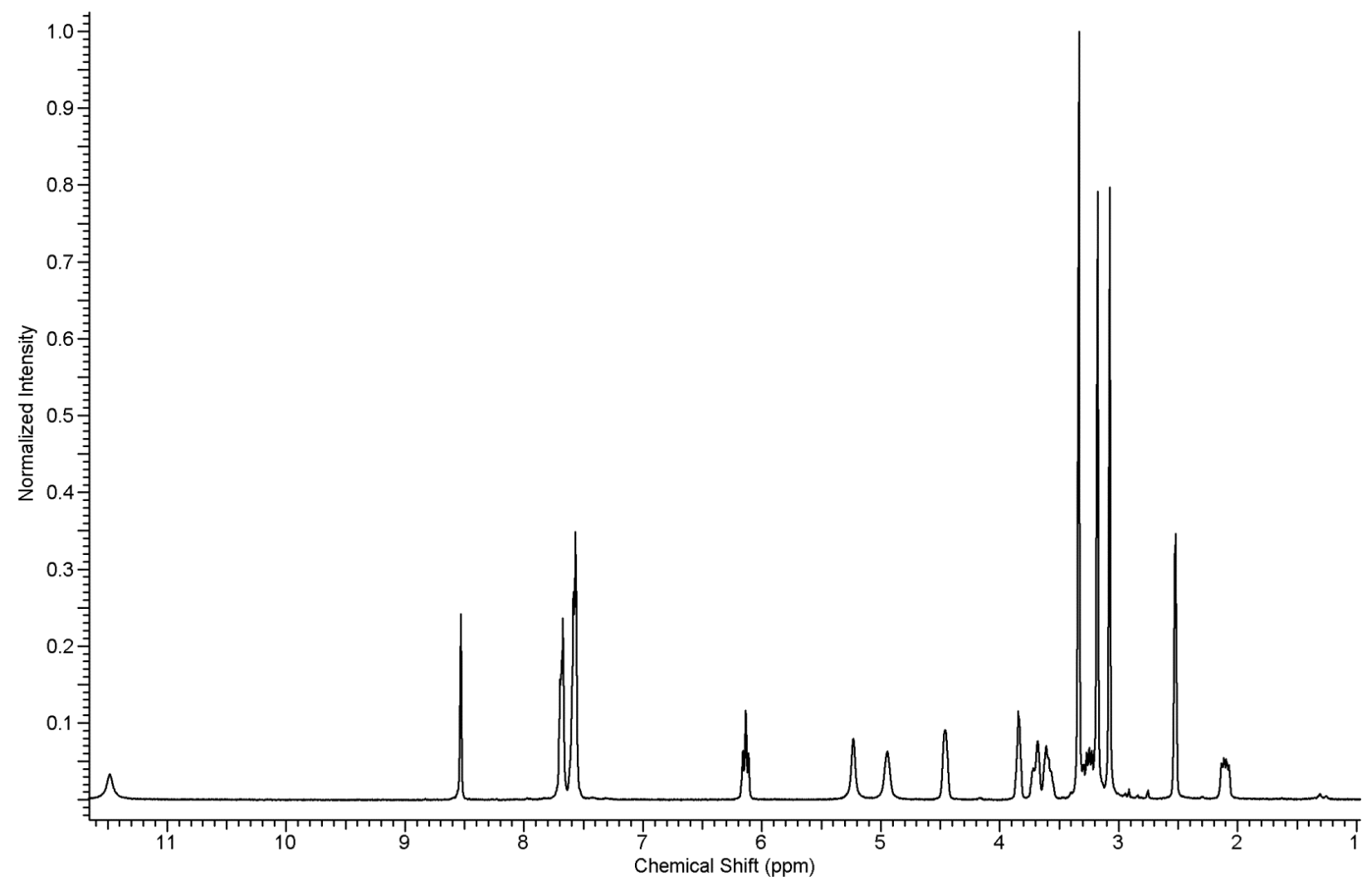


${ }^{1} \mathrm{H}$ NMR of N2-(N,N-Dimethylformamidine)-8-p-tolyl-2'-deoxyguanosine (10)

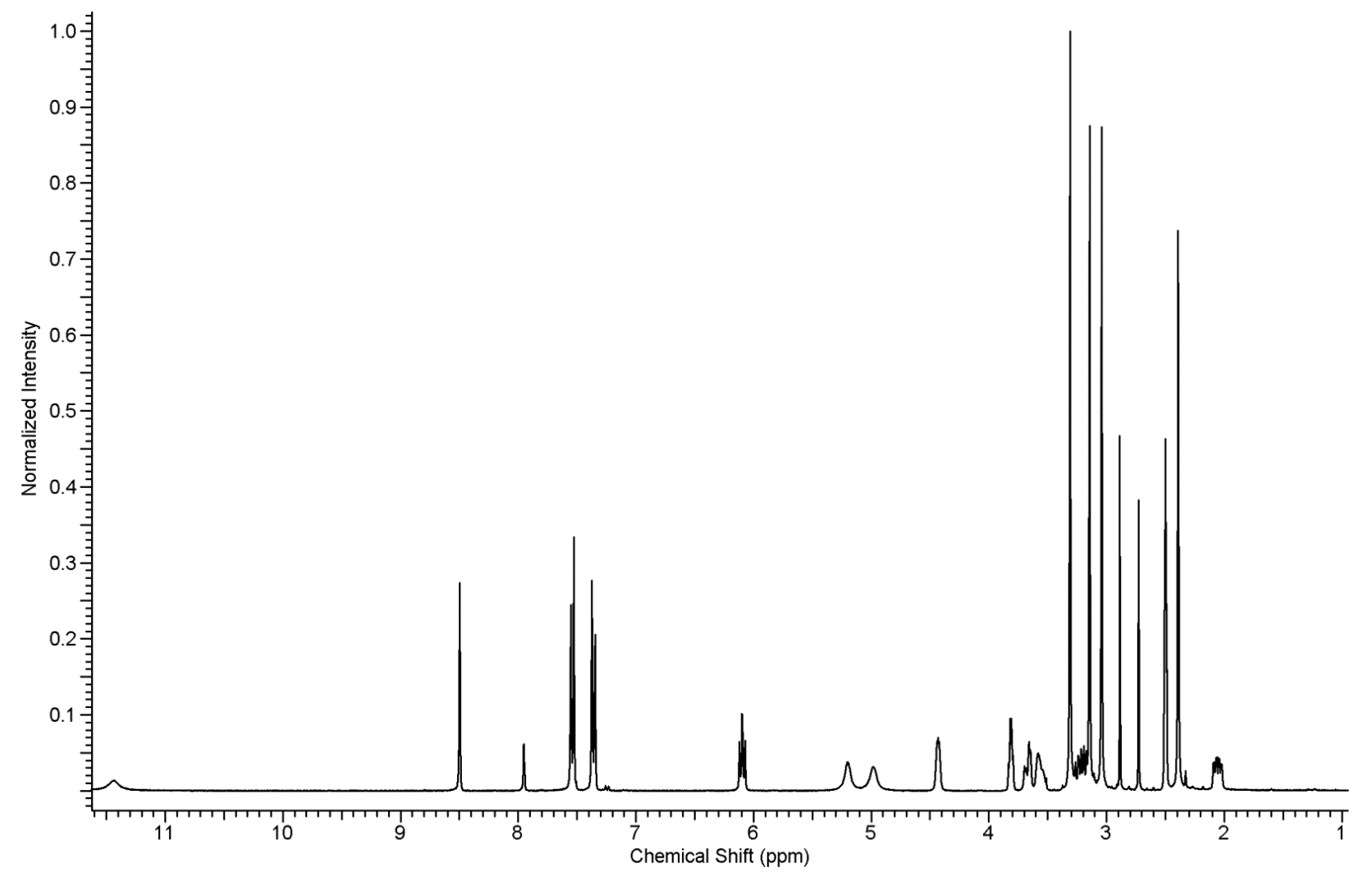


${ }^{1} \mathrm{H}$ NMR of N2-(N,N-Dimethylformamidine)-8-(4-(TBS-O-methyl) phenyl-

2'-deoxyguanosine (11)

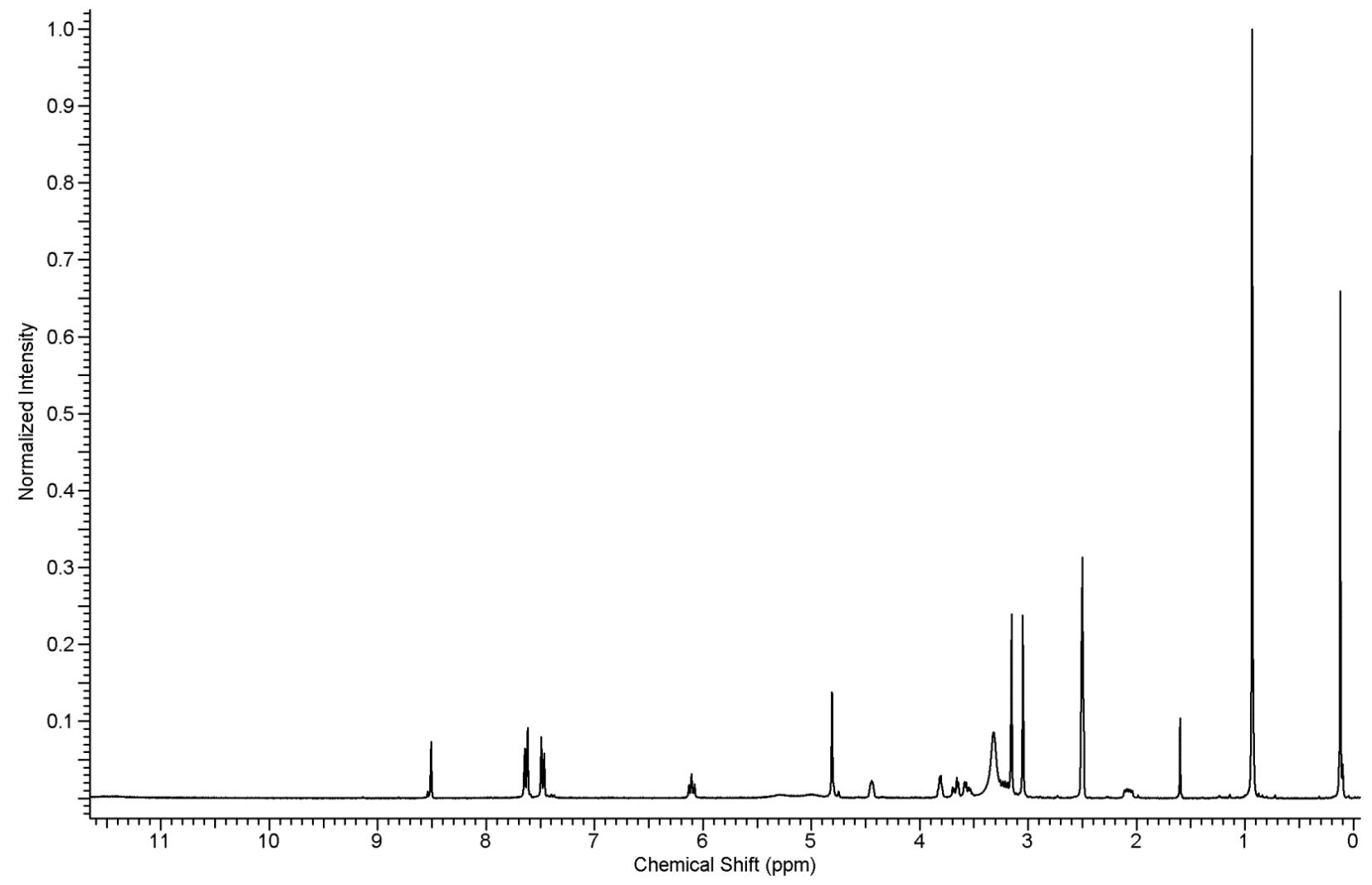


${ }^{1} \mathrm{H}$ NMR of N2-( $N, N$-Dimethylformamidine)-8-(4-methoxymethylphenyl)-2'-

deoxyguanosine (12)

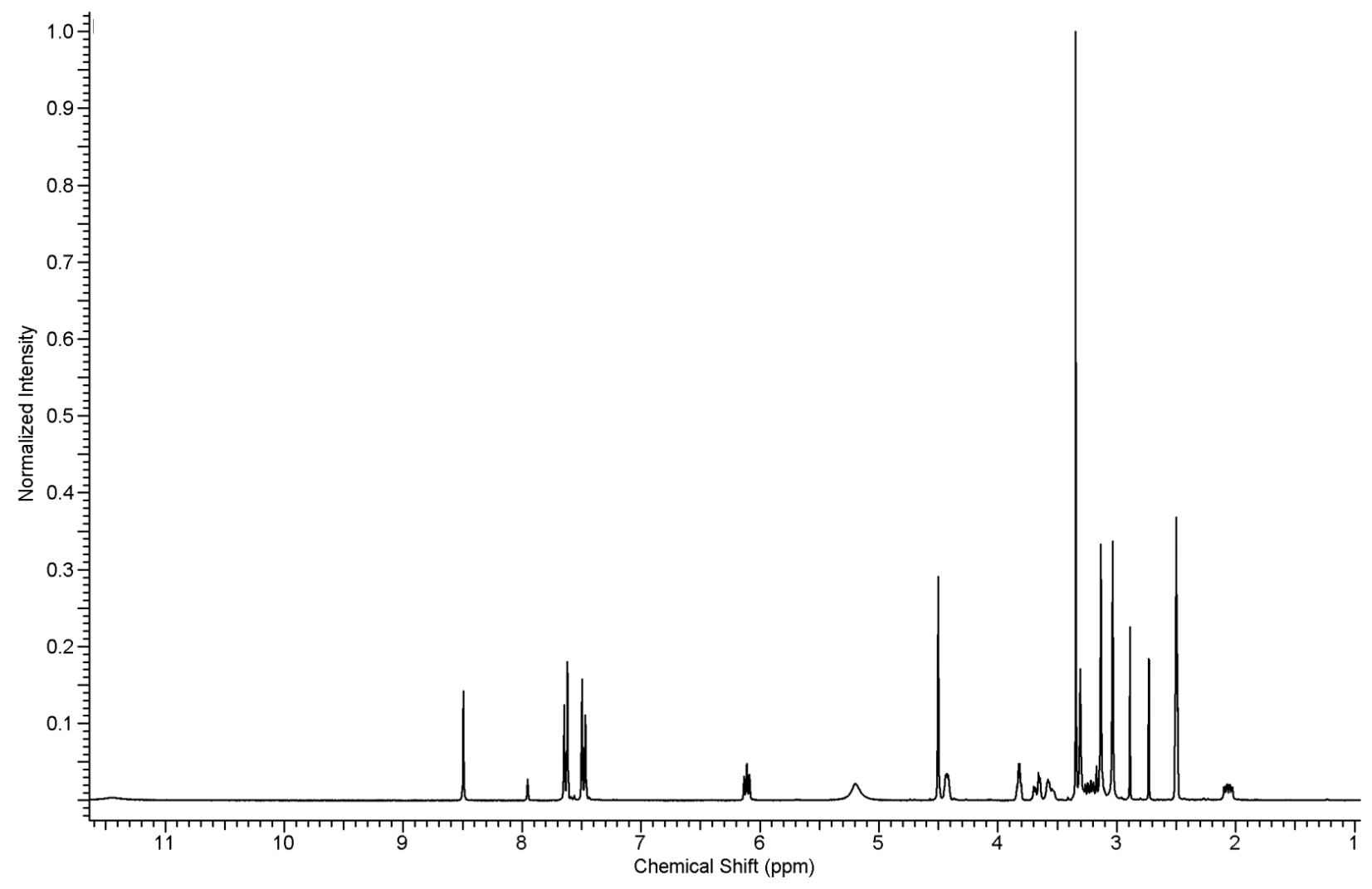


${ }^{1} \mathrm{H}$ NMR of N2-( $N, N$-Dimethylformamidine)-8-(4-carboxyphenyl)-2'-deoxyguanosine (13)

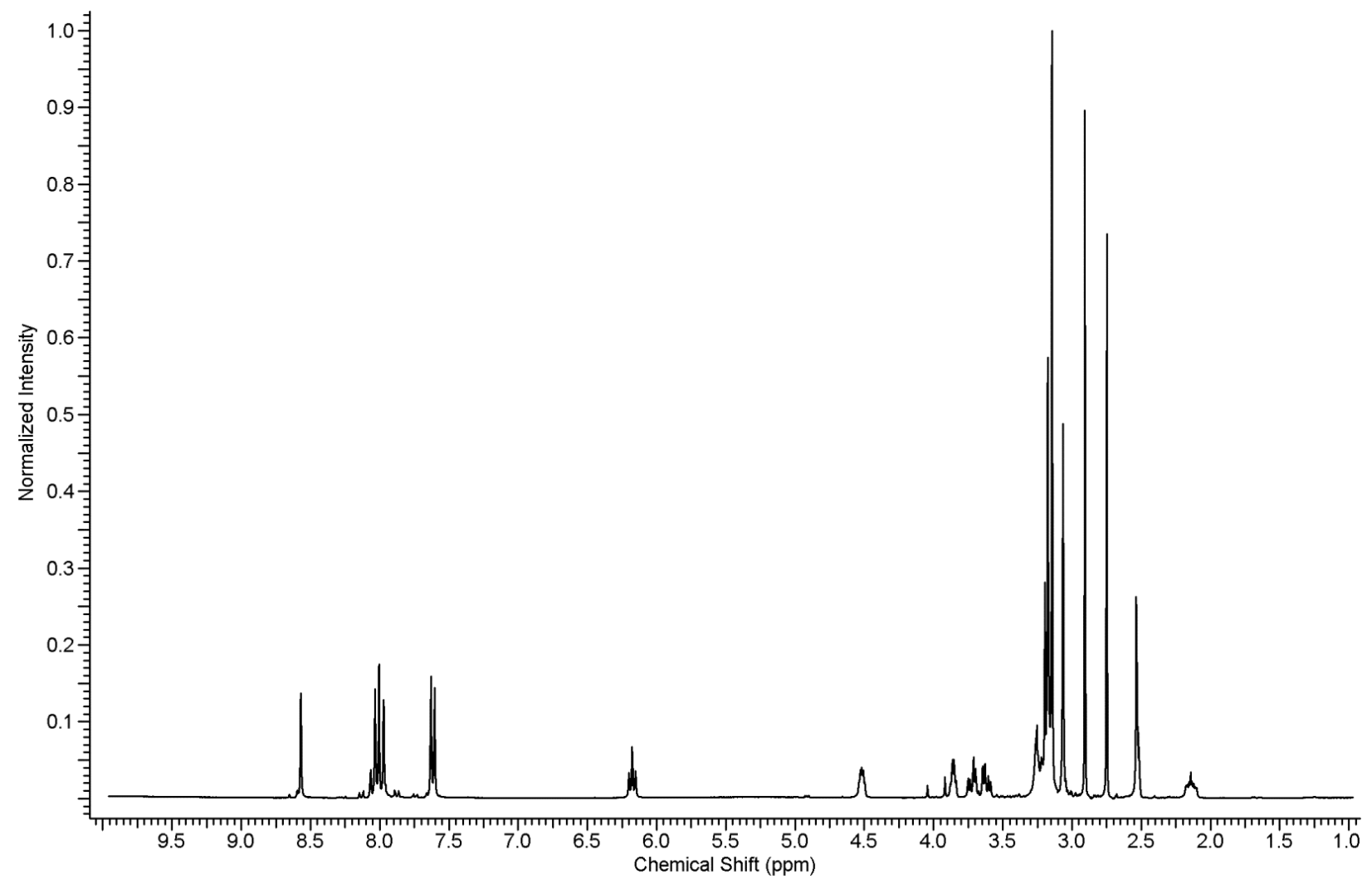


${ }^{1}$ H NMR of 5'-O-(4,4'-Dimethoxytrityl)- N2-(N,N-Dimethylformamidine)-8-phenyl-

2'-deoxyguanosine (14)

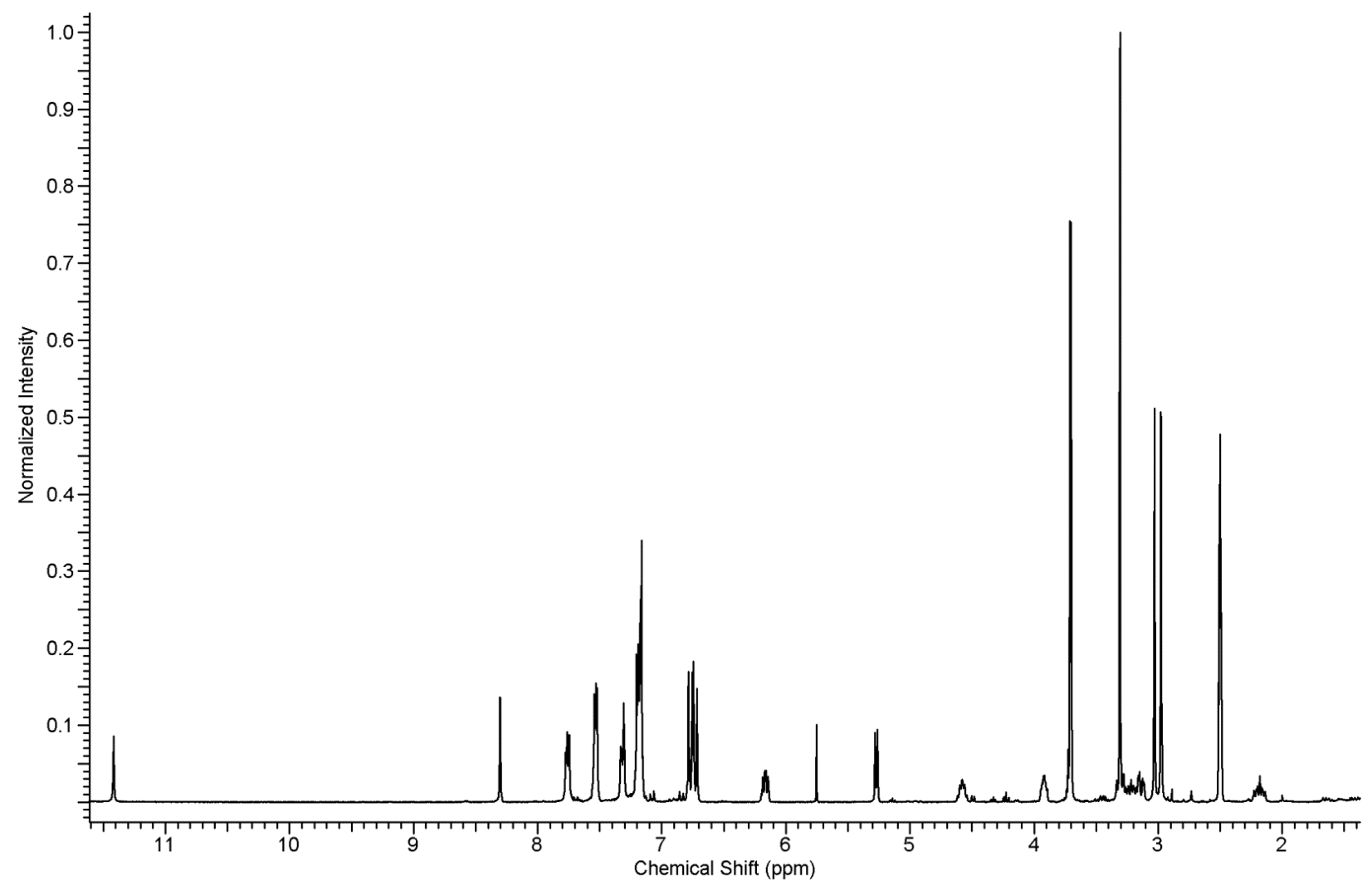


${ }^{1}$ H NMR of 5'-O-(4,4'-Dimethoxytrityl)- N2-(N,N-Dimethylformamidine)-8-p-tolyl-

2'-deoxyguanosine (15)

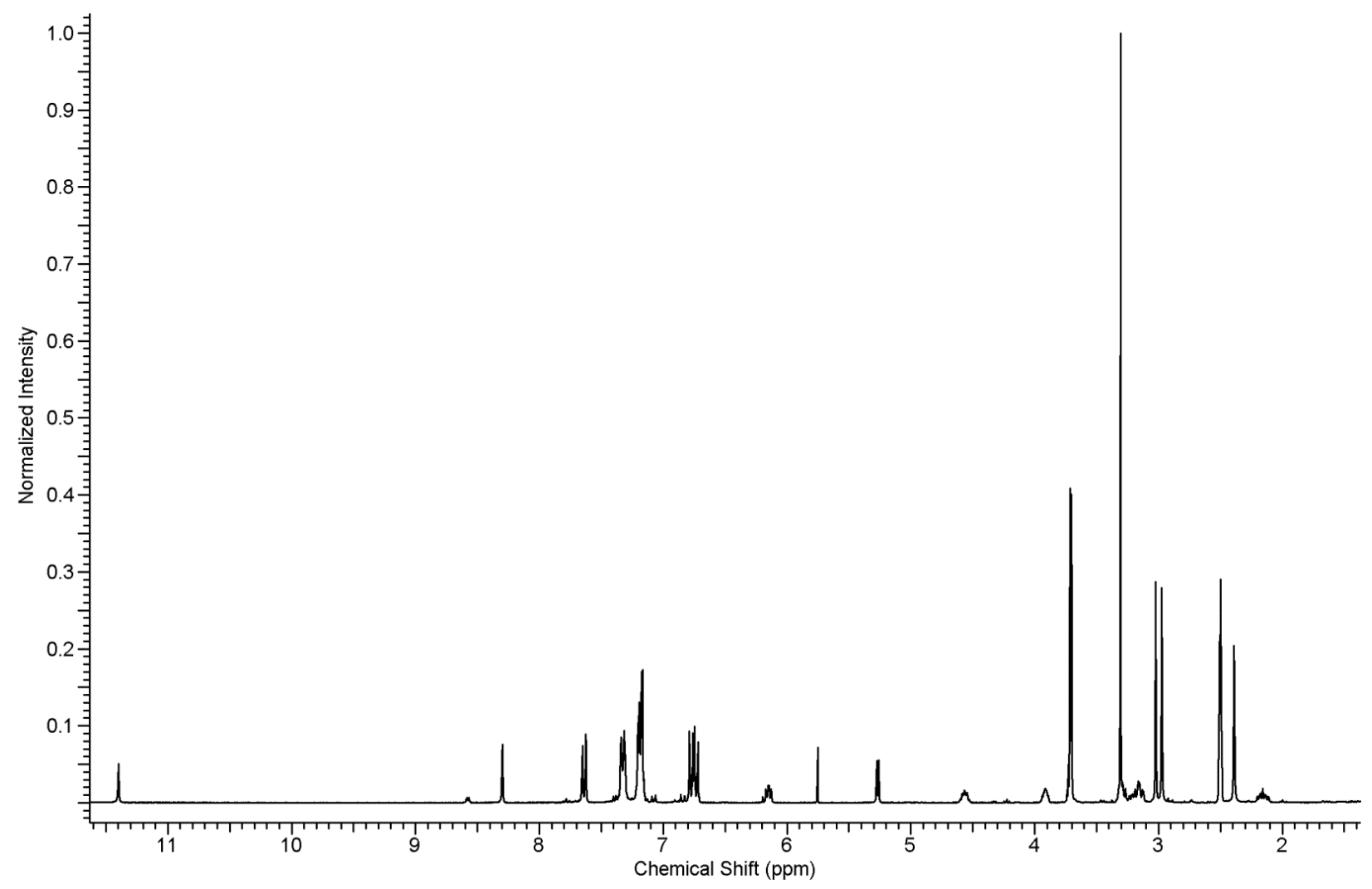


${ }^{1} \mathrm{H}$ NMR of 5'-O-(4,4'-Dimethoxytrityl)- N2-(N,N-Dimethylformamidine)-8-

(4-(TBS-O-methyl)phenyl-2'-deoxyguanosine (16)

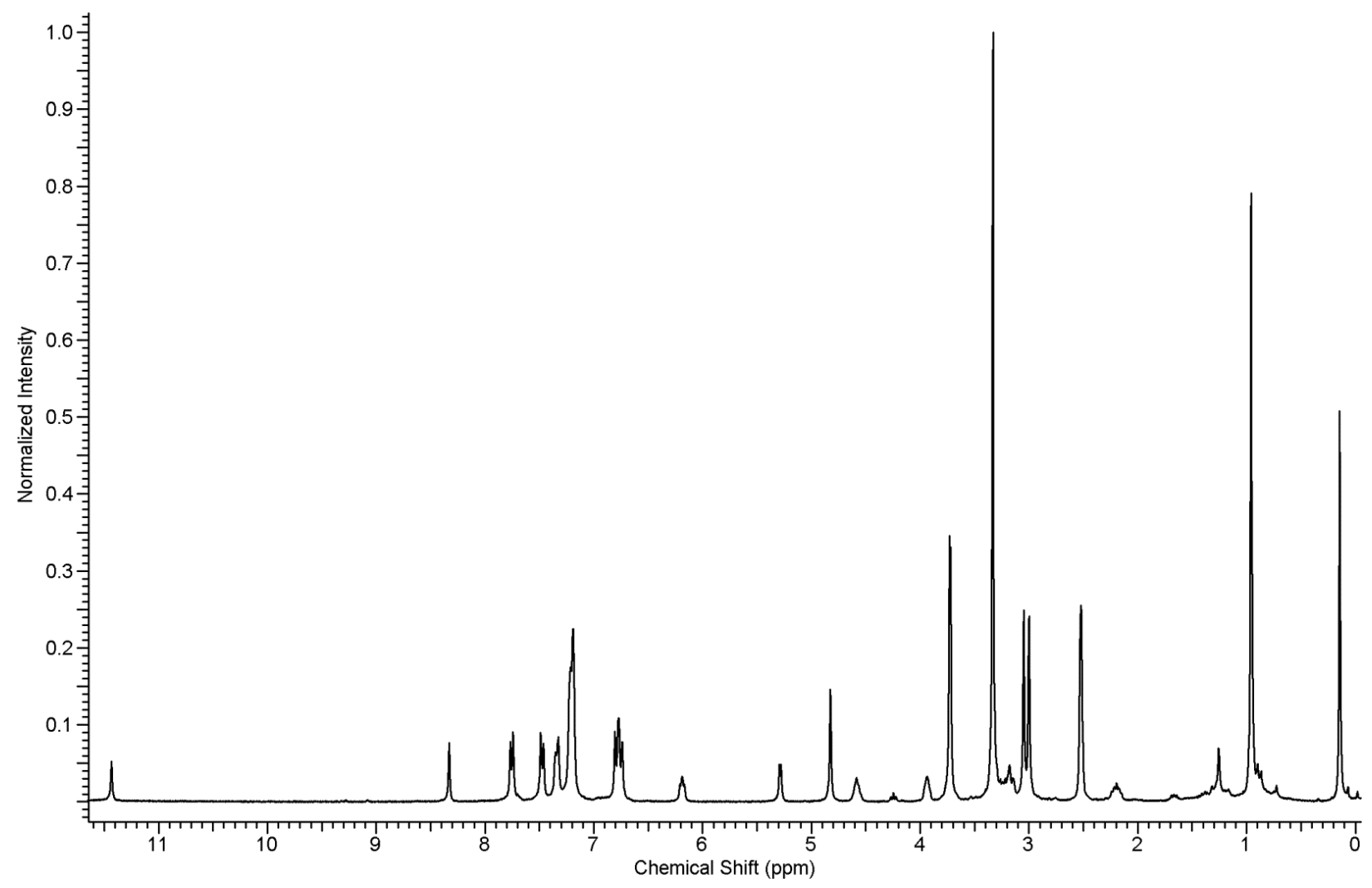


${ }^{1}$ H NMR of 5'-O-(4,4'-Dimethoxytrityl)- N2-(N,N-Dimethylformamidine)-8-

(4-methoxymethylphenyl)-2'-deoxyguanosine (17)

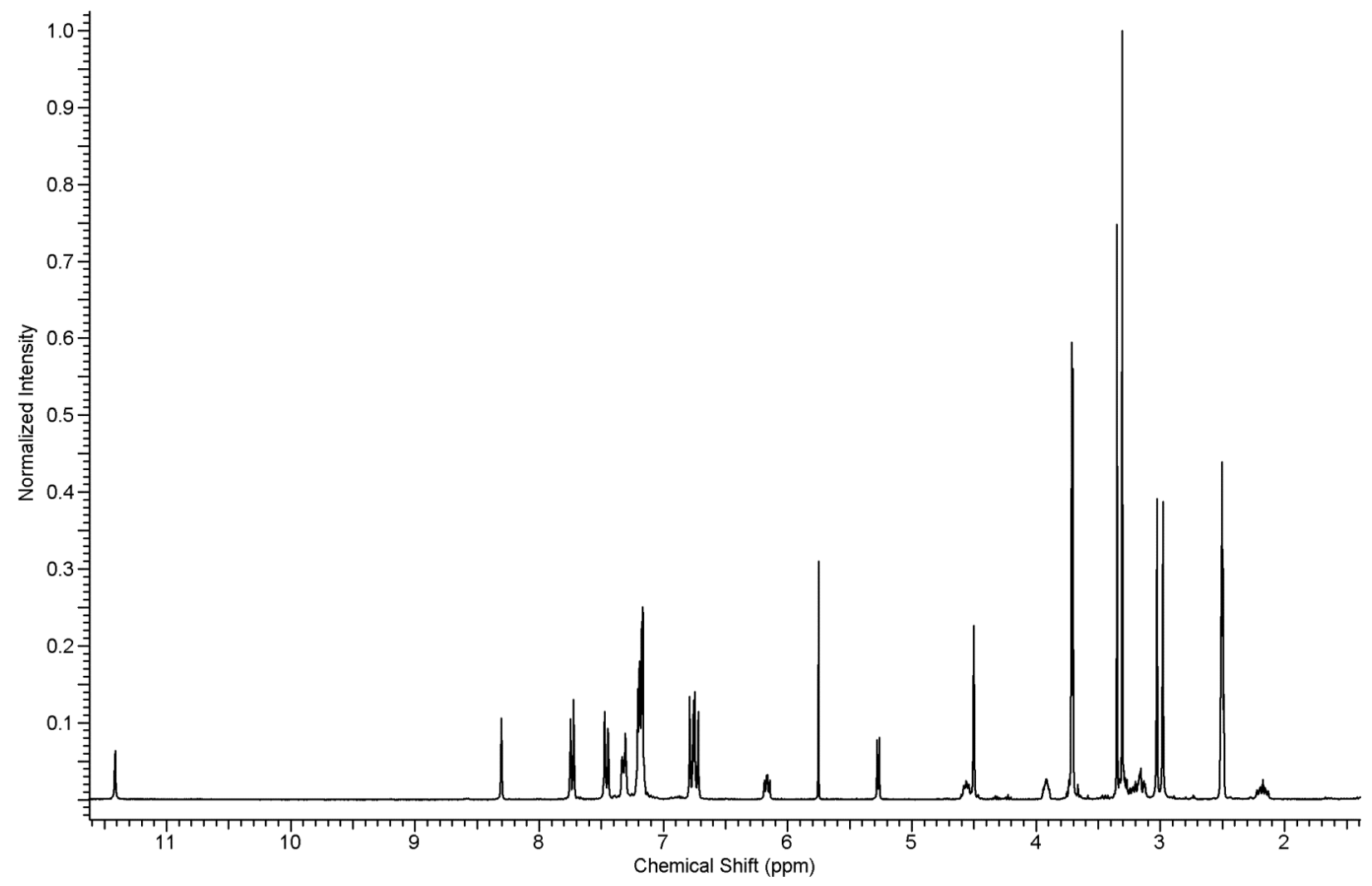


${ }^{1}$ H NMR of 5'-O-(4,4'-Dimethoxytrityl)- N2-( $N, N$-Dimethylformamidine)-8-

(4-carboxyphenyl)-2'-deoxyguanosine (18)

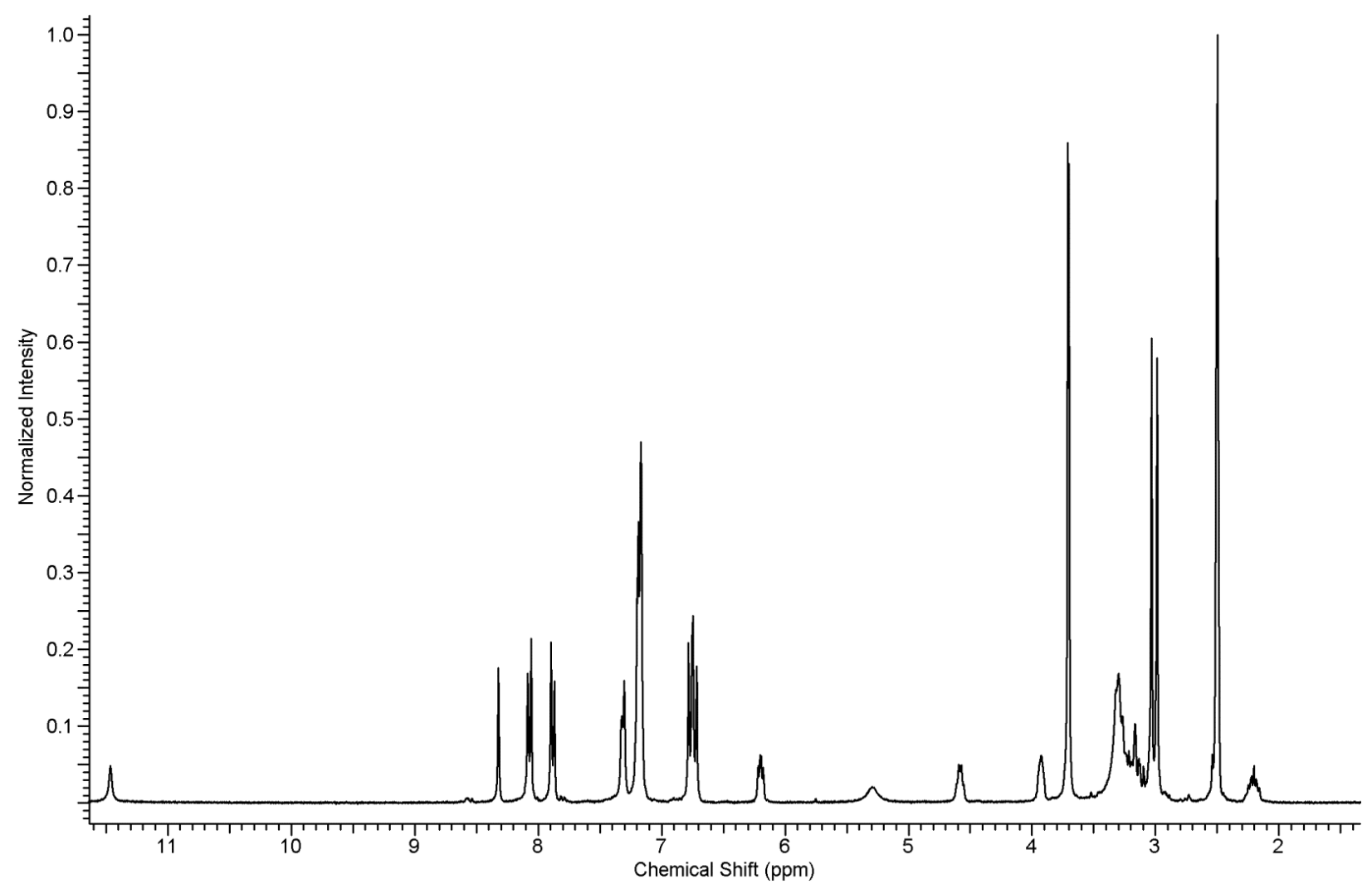


FPLC Chromatogram of the HP-CG

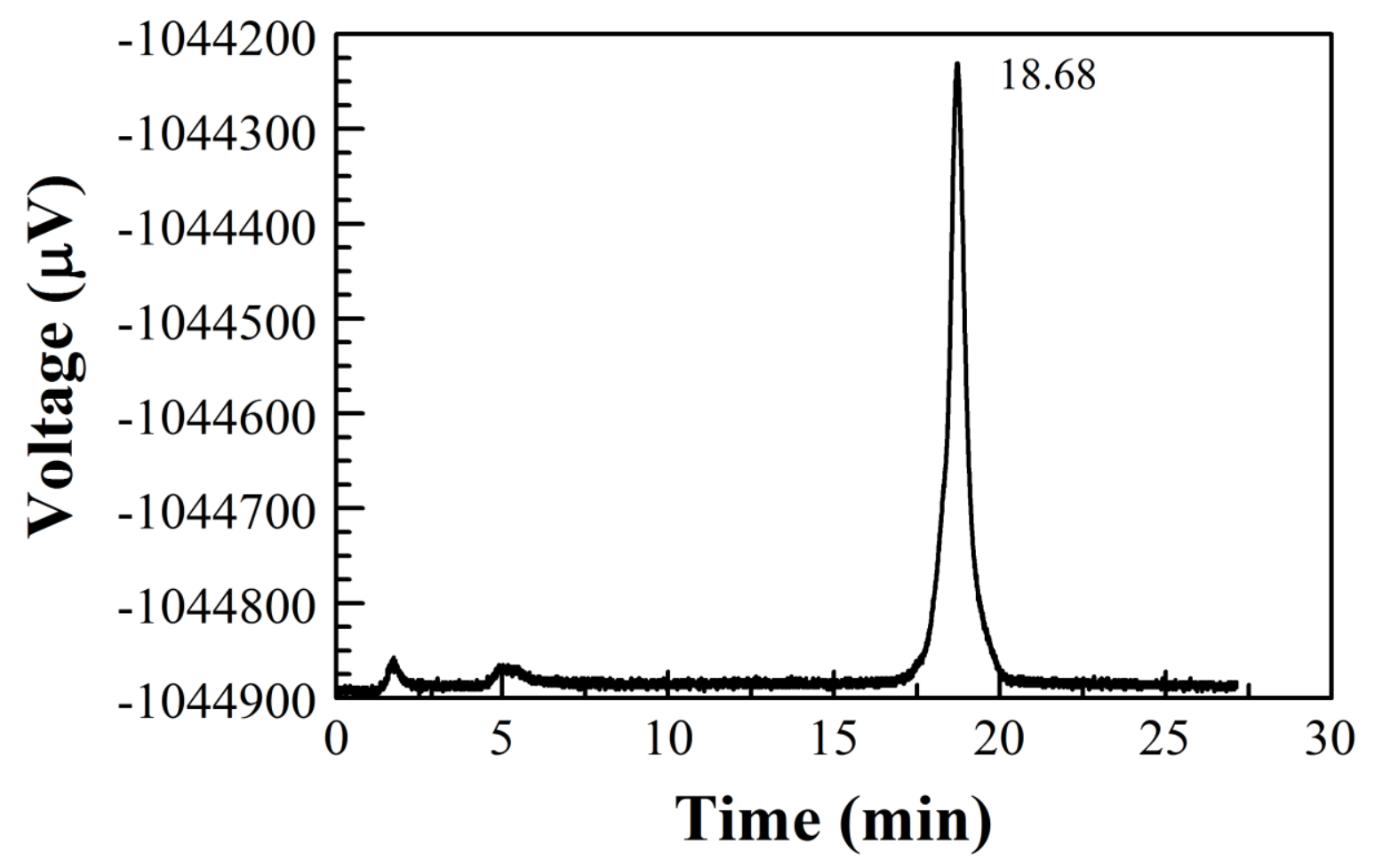


FPLC Chromatogram of the HP-CG ${ }^{8 T o l}$

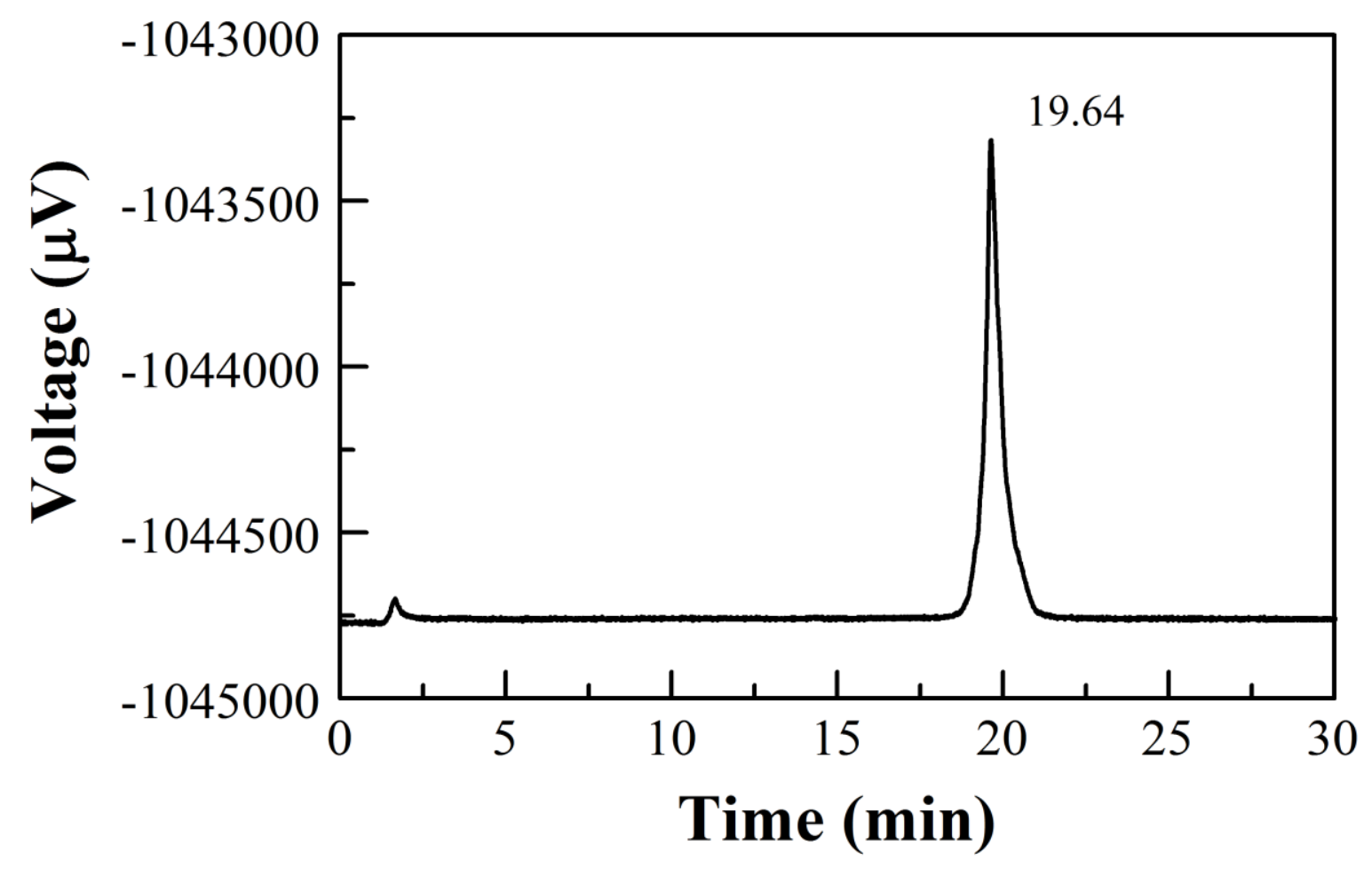


FPLC Chromatogram of the HP-CG ${ }^{8 H M P h}$

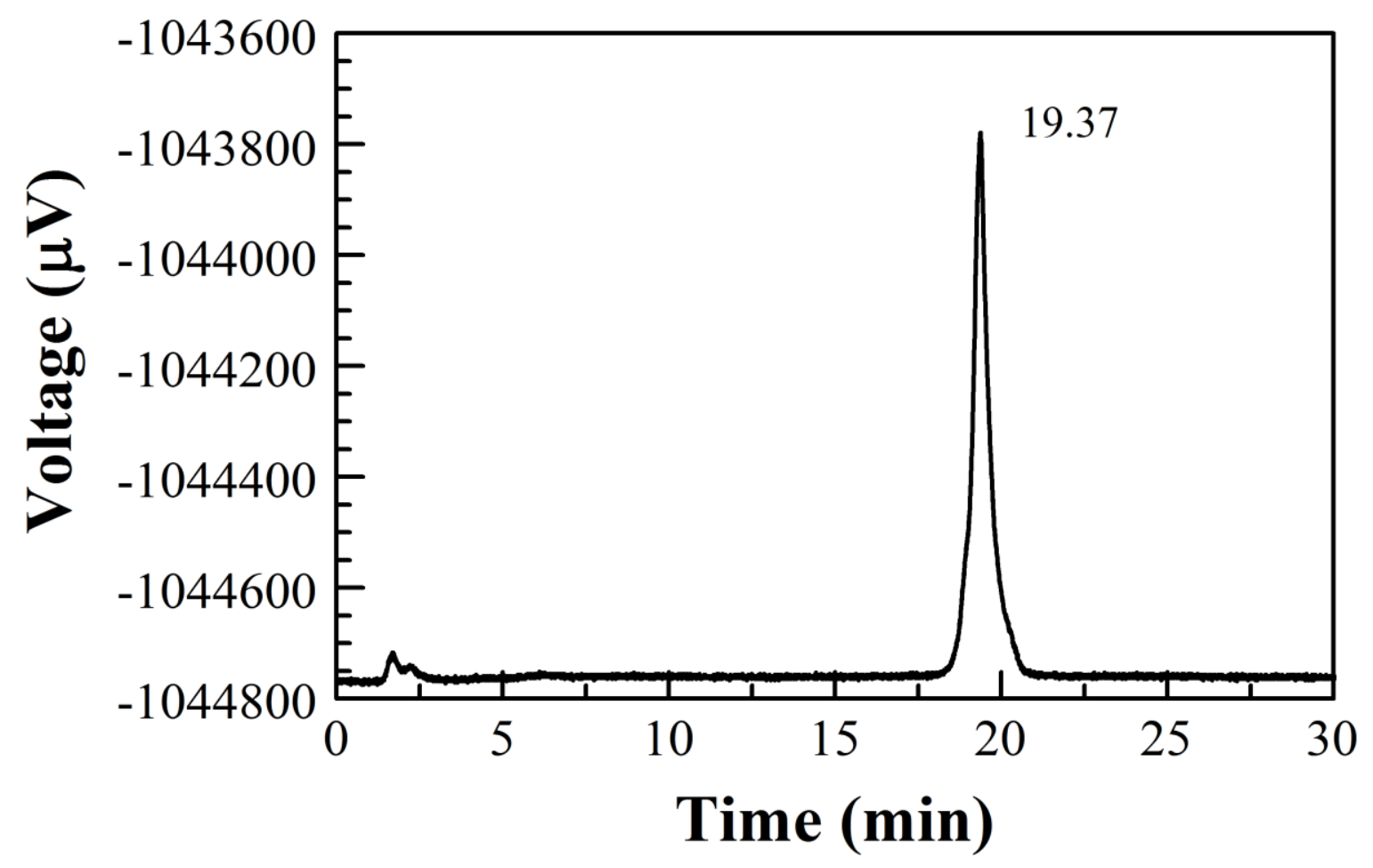


FPLC Chromatogram of the HP-CG ${ }^{8 M M P h}$

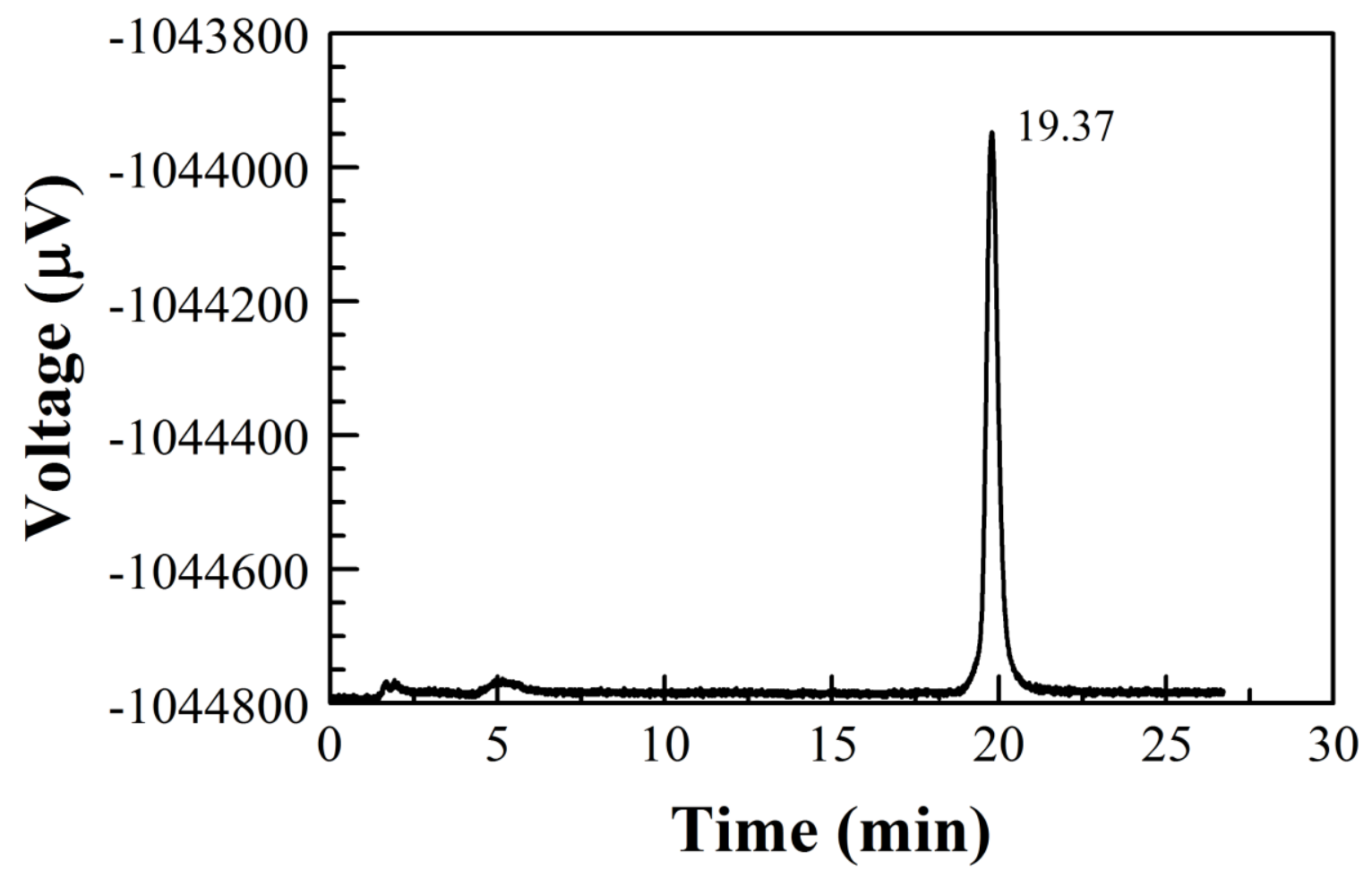


FPLC Chromatogram of the HP-CG ${ }^{8 \mathrm{CPh}}$

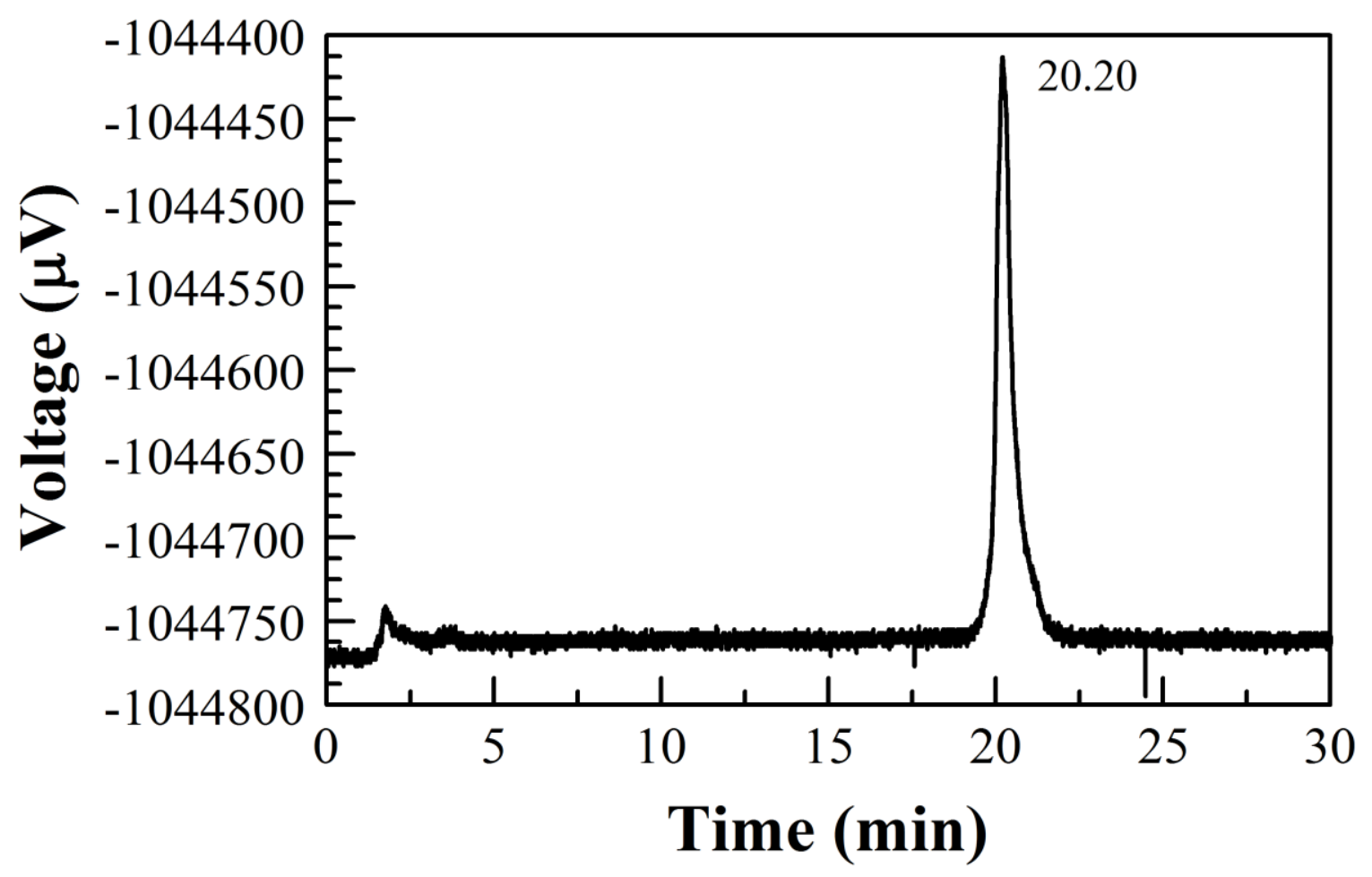


MS- Spectrum of HP-CG

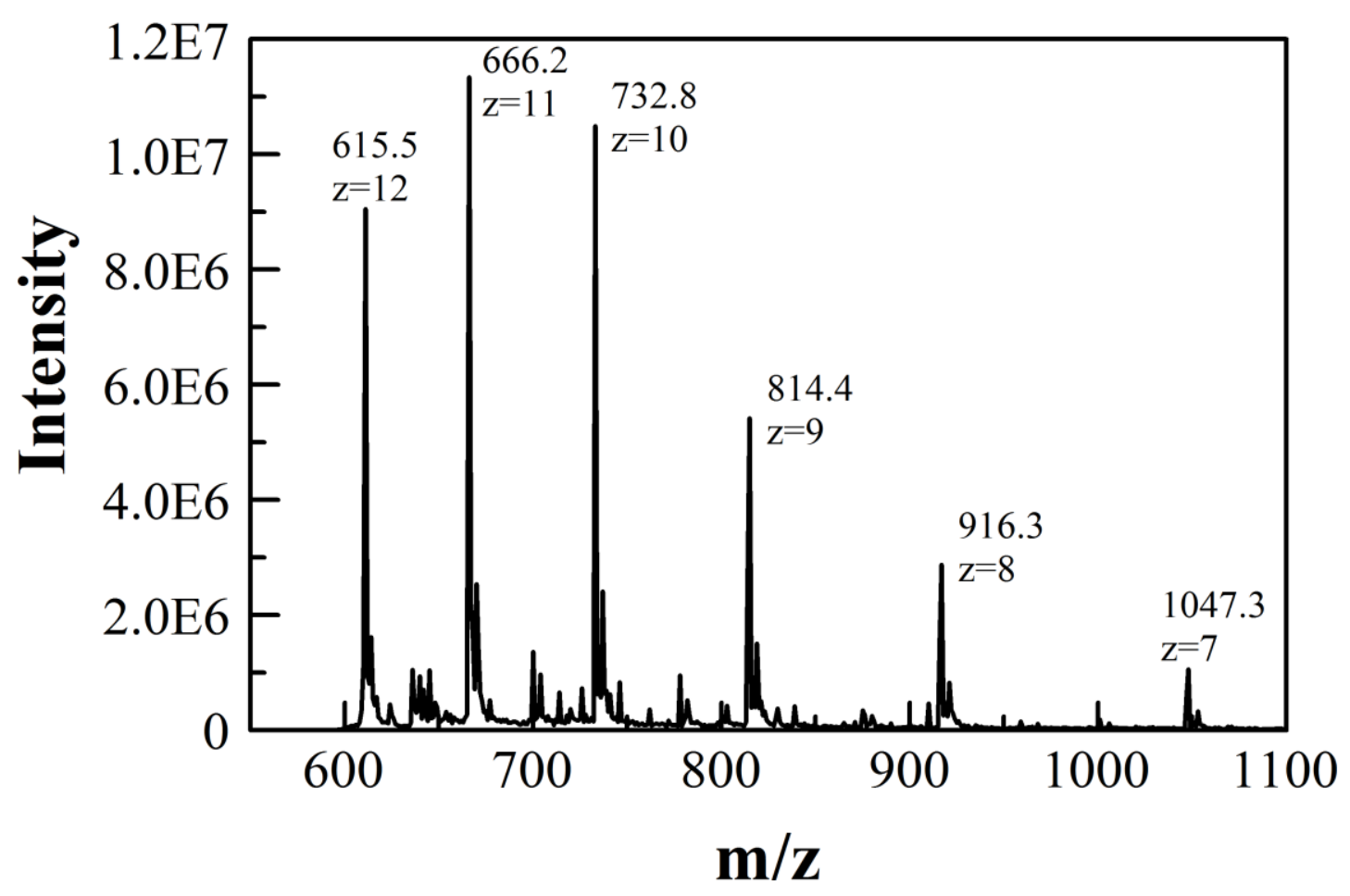


MS- $^{-}$Spectrum of HP-CG ${ }^{8 P h}$

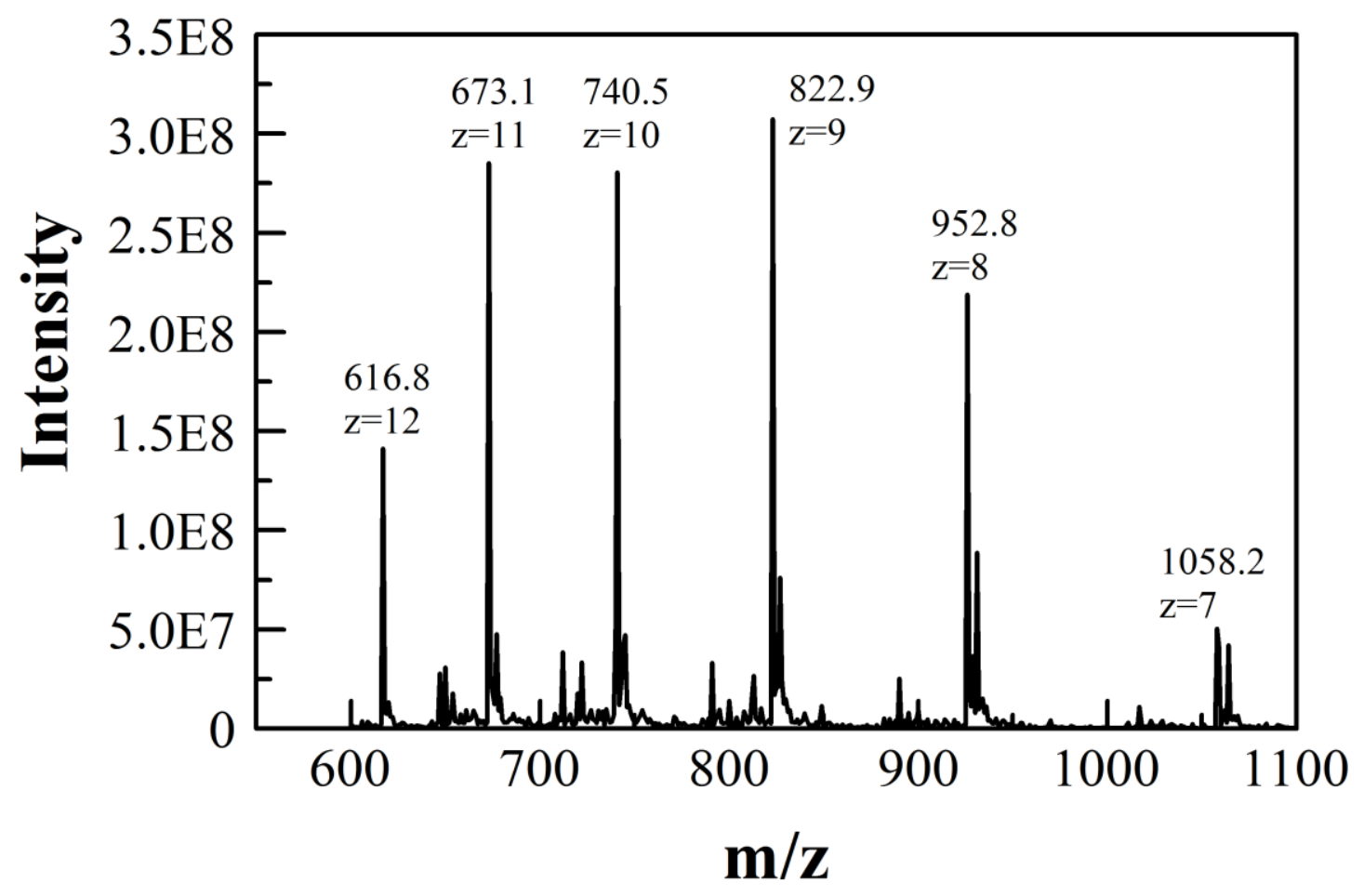


MS- Spectrum of HP-CG ${ }^{8 T o l}$

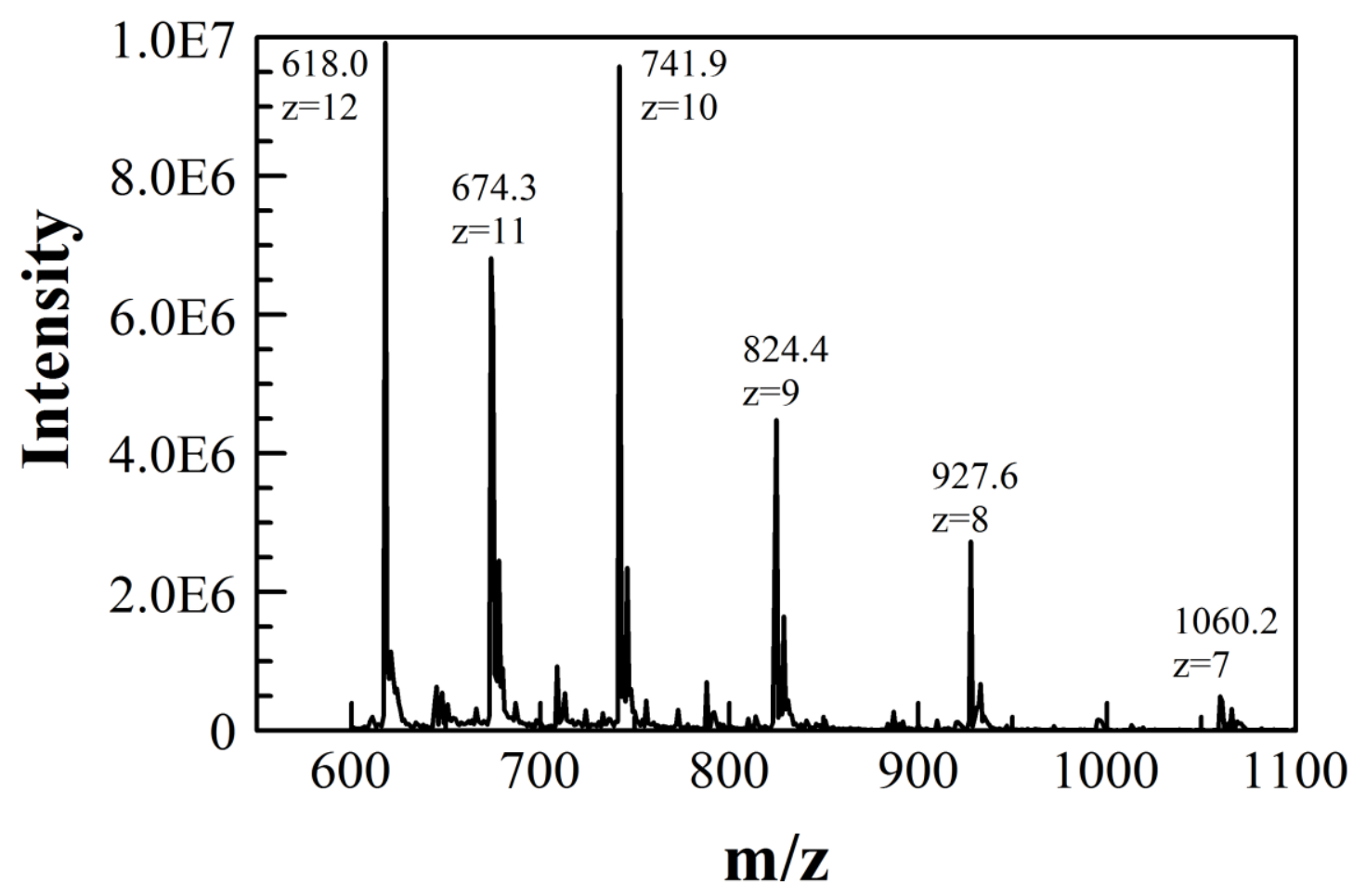


MS- Spectrum of HP-CG ${ }^{8 H M P h}$

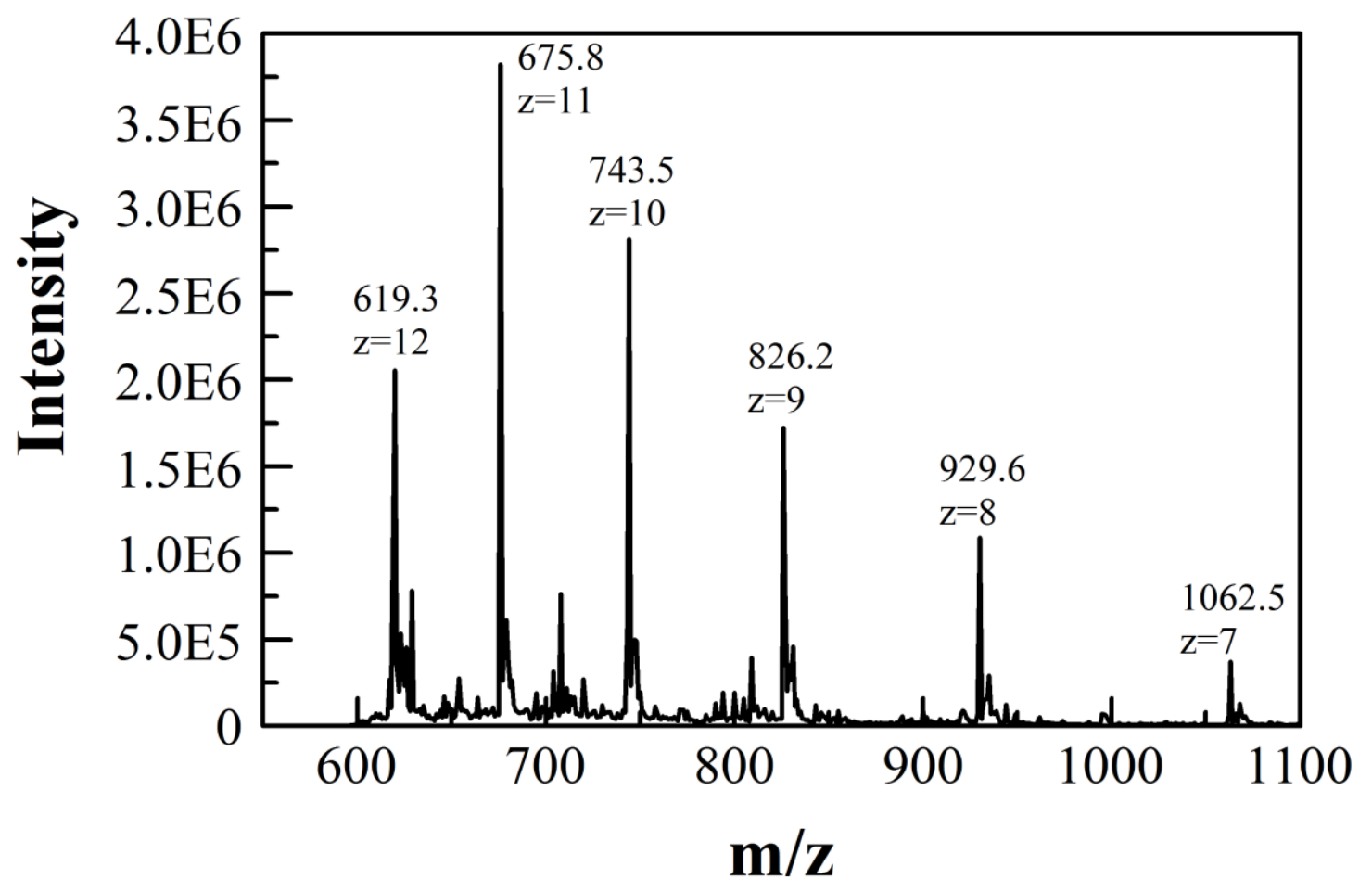


MS- Spectrum of HP-CG ${ }^{8 M M P h}$

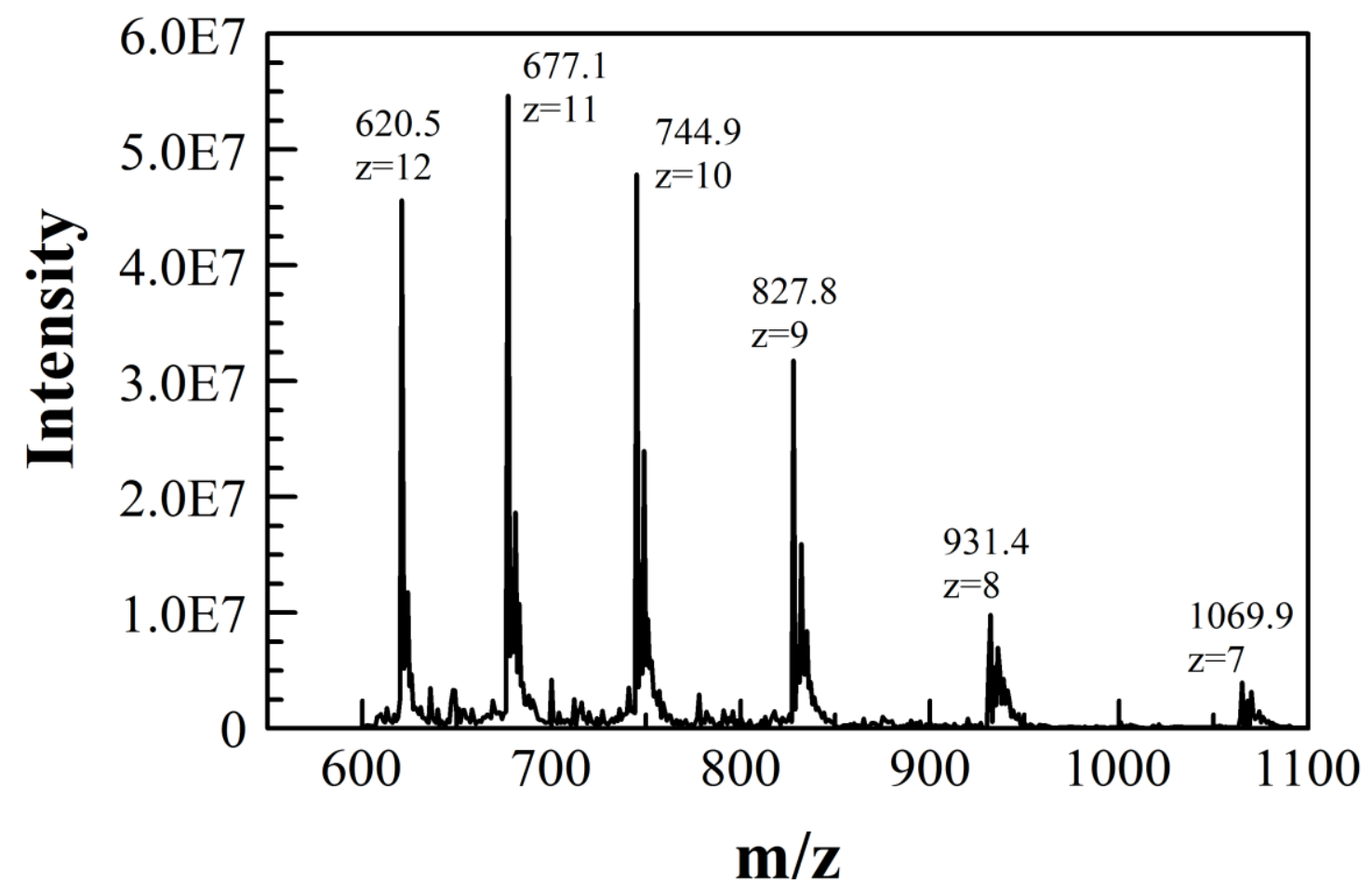


MS- Spectrum of HP-CG ${ }^{8 \mathrm{CPh}}$

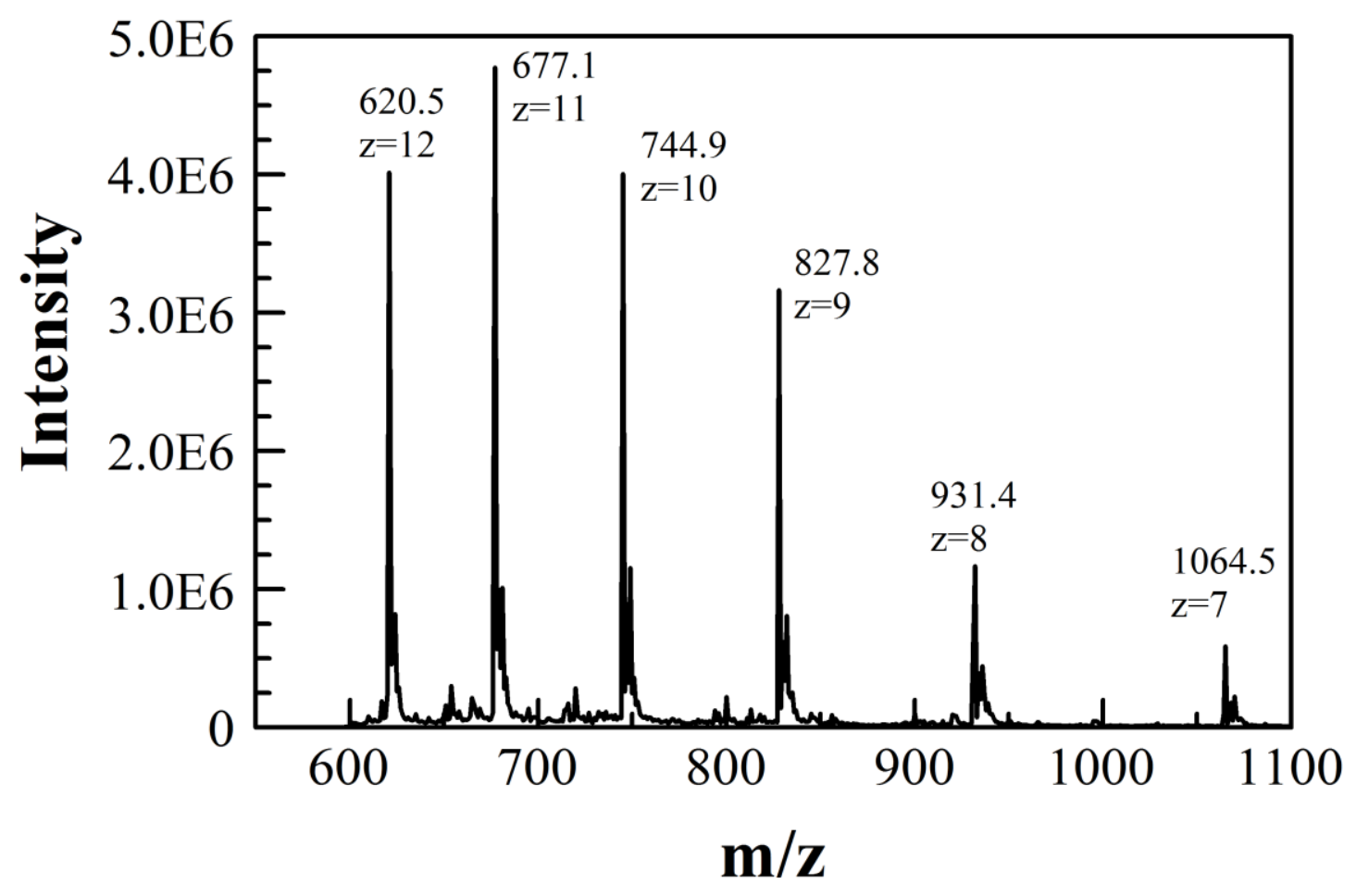


${ }^{1} \mathrm{H}$ NMR Spectrum of HP-CG in the B-DNA Conformation

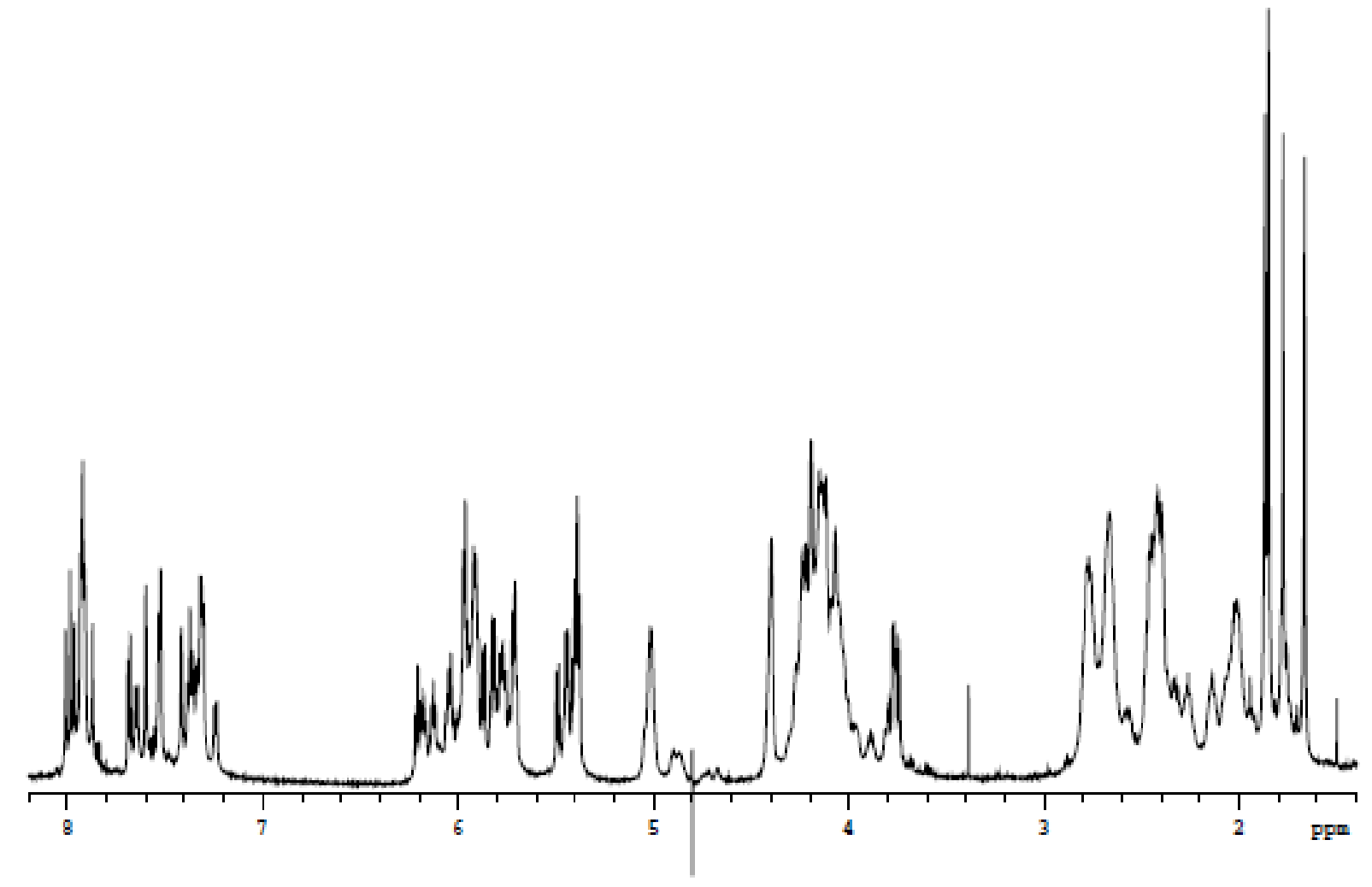


${ }^{1} \mathrm{H}-{ }^{1} \mathrm{H}$ gCOSY NMR Spectra of HP-CG in the B-DNA Conformation

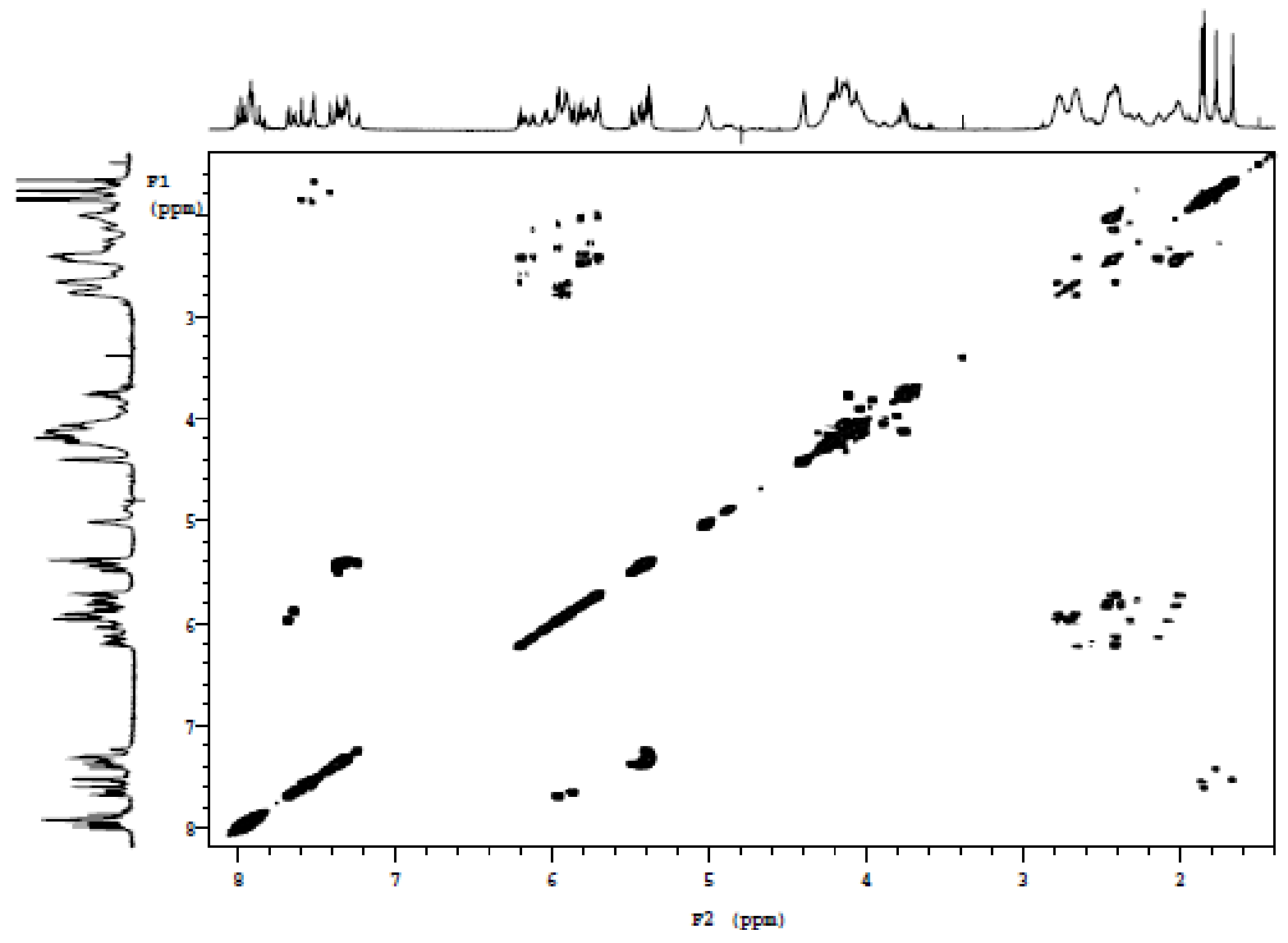


${ }^{1}{ }^{H}-{ }^{1} \mathrm{H}$ NOESY NMR Spectra of HP-CG in the B-DNA Conformation

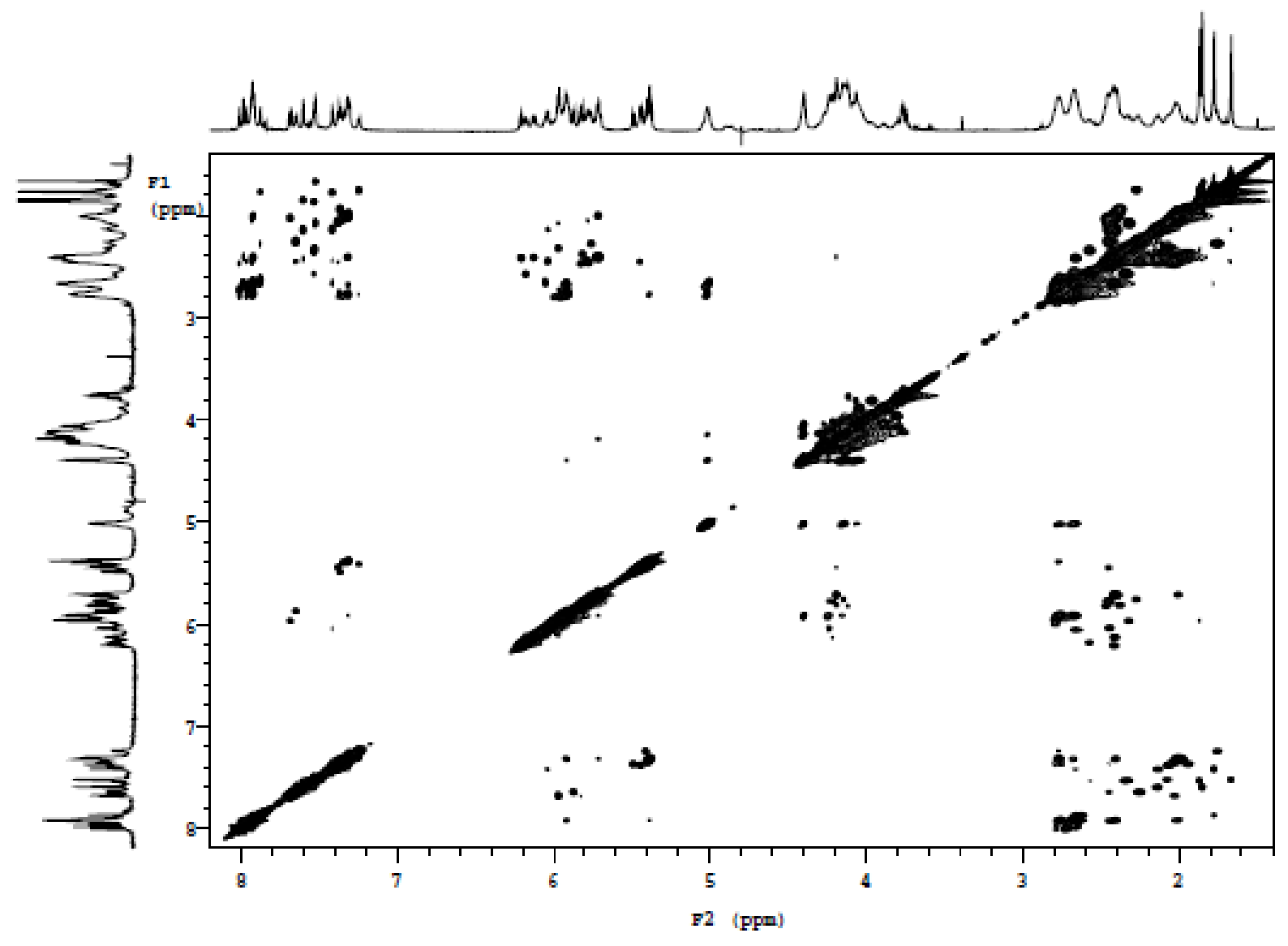


${ }^{1} \mathrm{H}$ NMR Spectrum of HP-CG ${ }^{8 \mathrm{Ph}}$ in the B-DNA Conformation

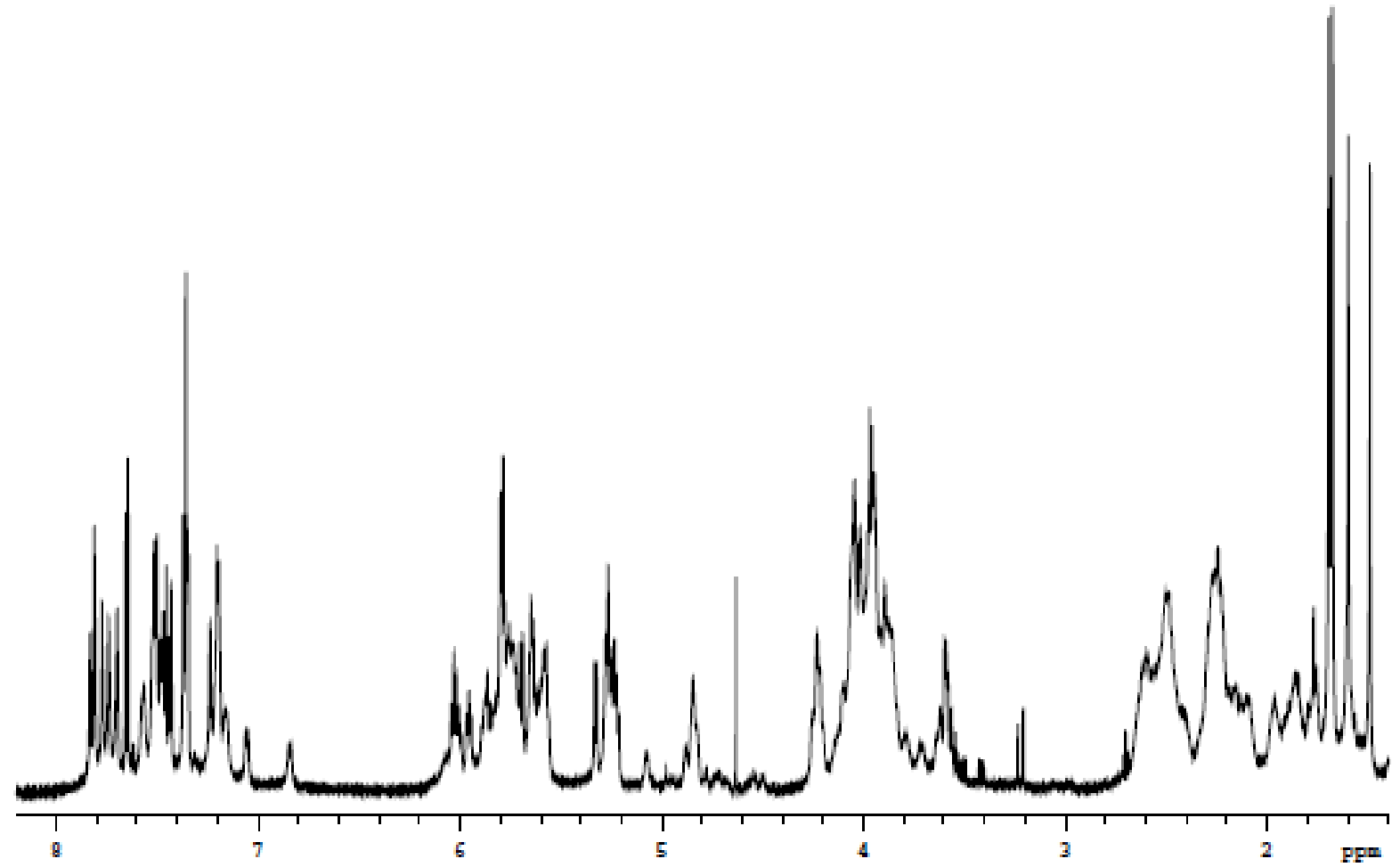


${ }^{1} \mathrm{H}-{ }^{1} \mathrm{H}$ gCOSY NMR Spectra of HP-CG ${ }^{8 \mathrm{Ph}}$ in the B-DNA Conformation

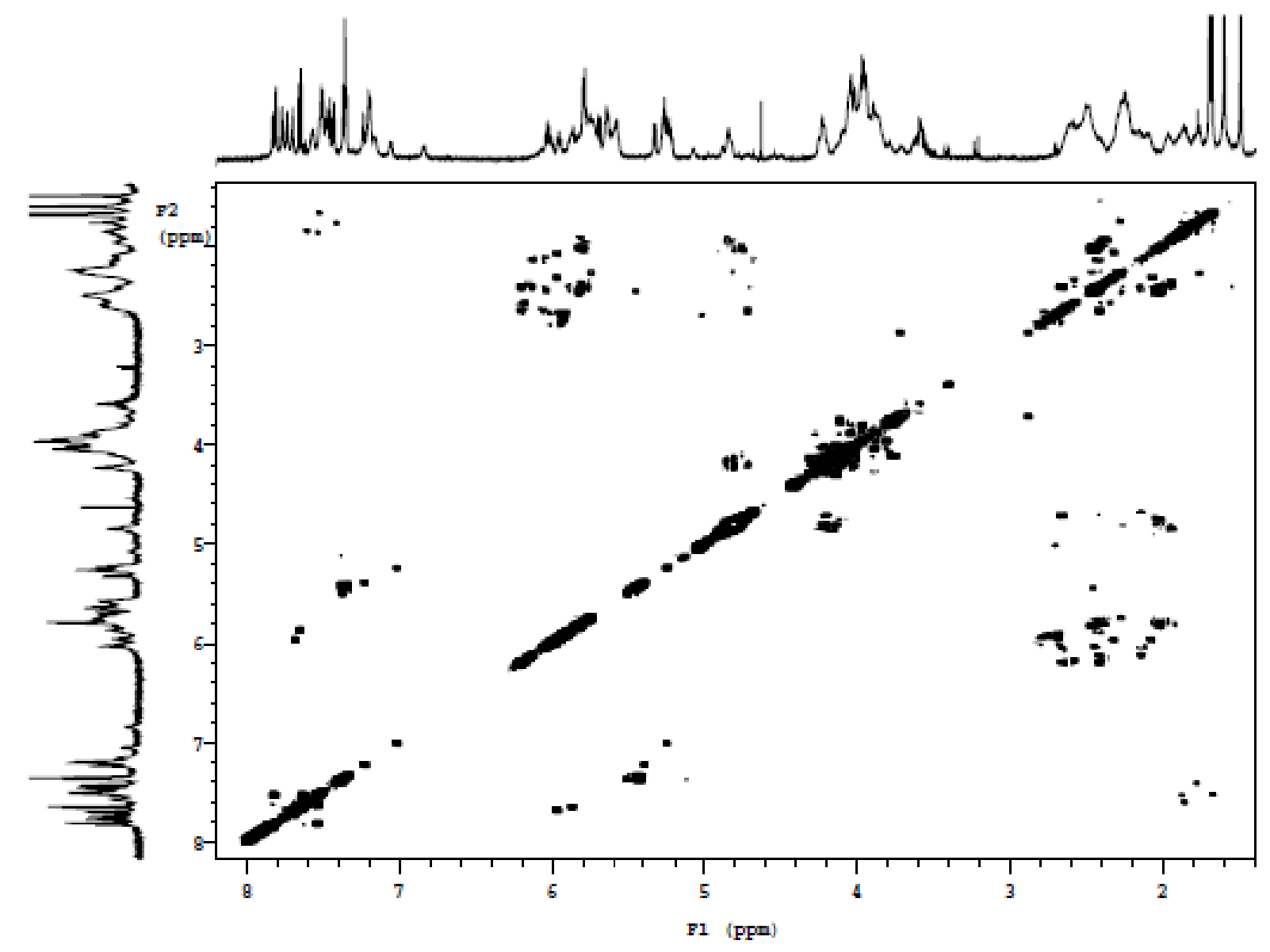


${ }^{1} \mathrm{H}^{1}{ }^{1} \mathrm{H}$ NOESY NMR Spectra of HP-CG ${ }^{8 \mathrm{Ph}}$ in the B-DNA Conformation

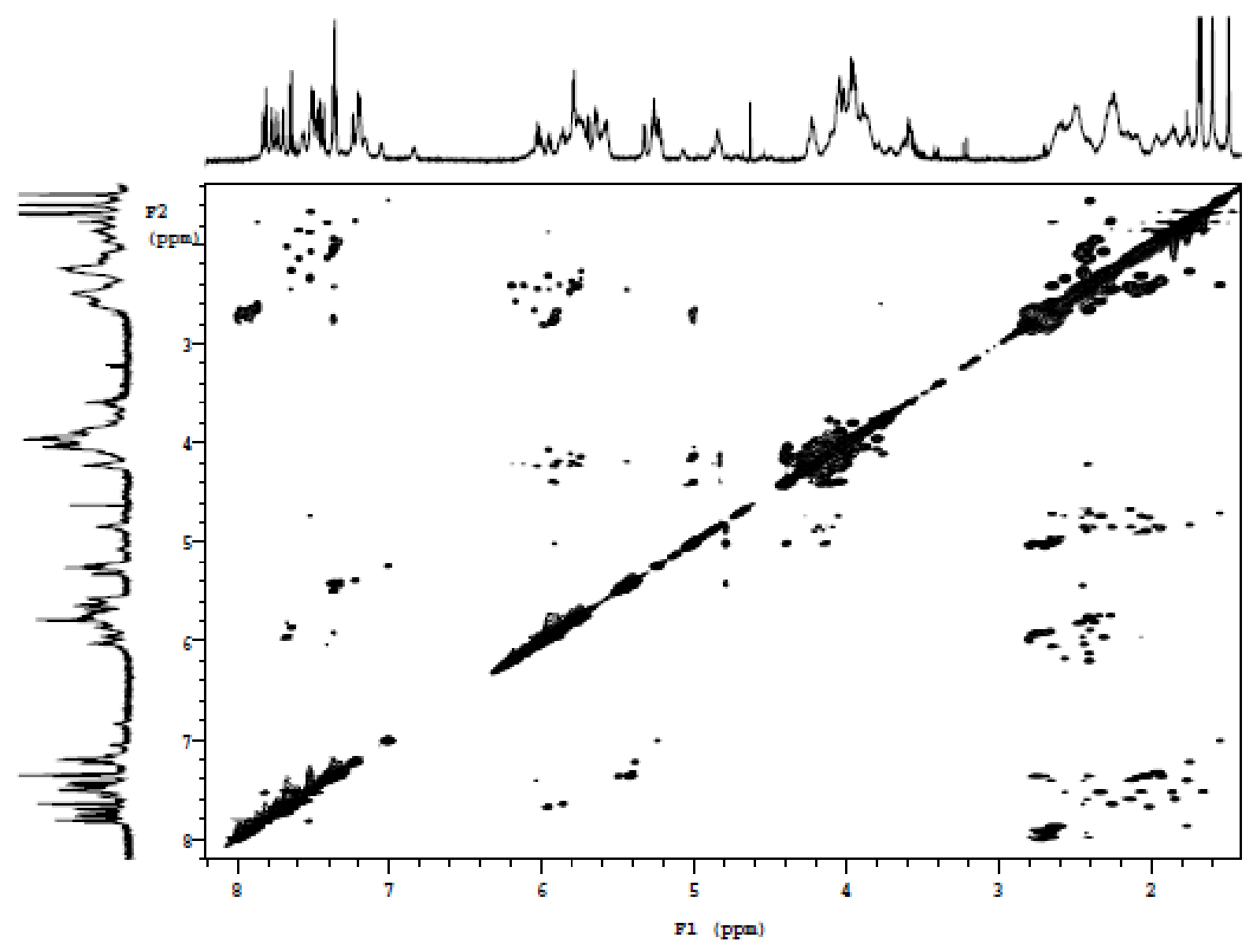


${ }^{1} \mathrm{H}$ NMR Spectrum of HP-CG ${ }^{8 \mathrm{Ph}}$ in the Z-DNA Conformation

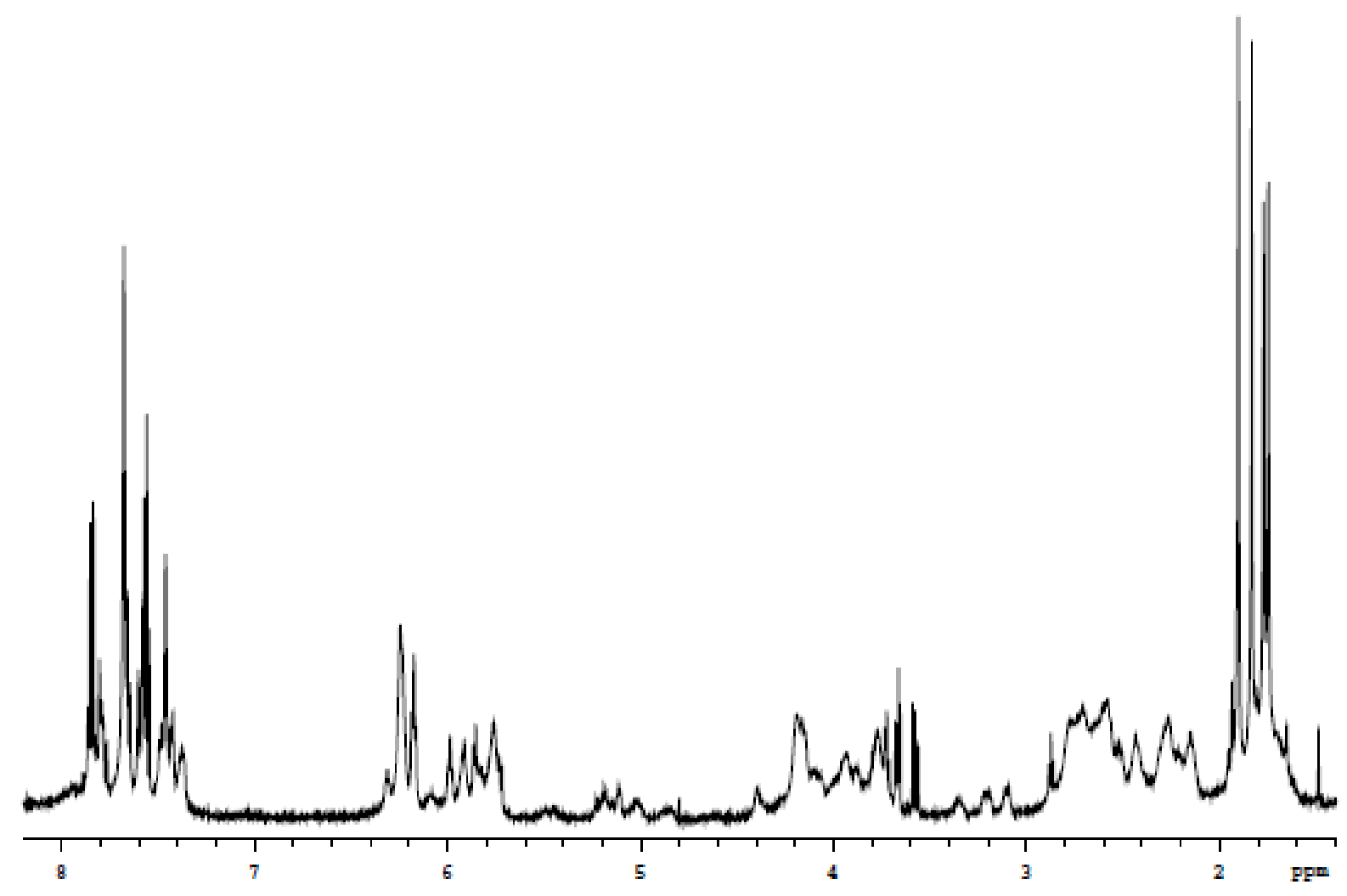


${ }^{1} \mathrm{H}-{ }^{1} \mathrm{H}$ gCOSY NMR Spectra of HP-CG ${ }^{8 \mathrm{Ph}}$ in the Z-DNA Conformation

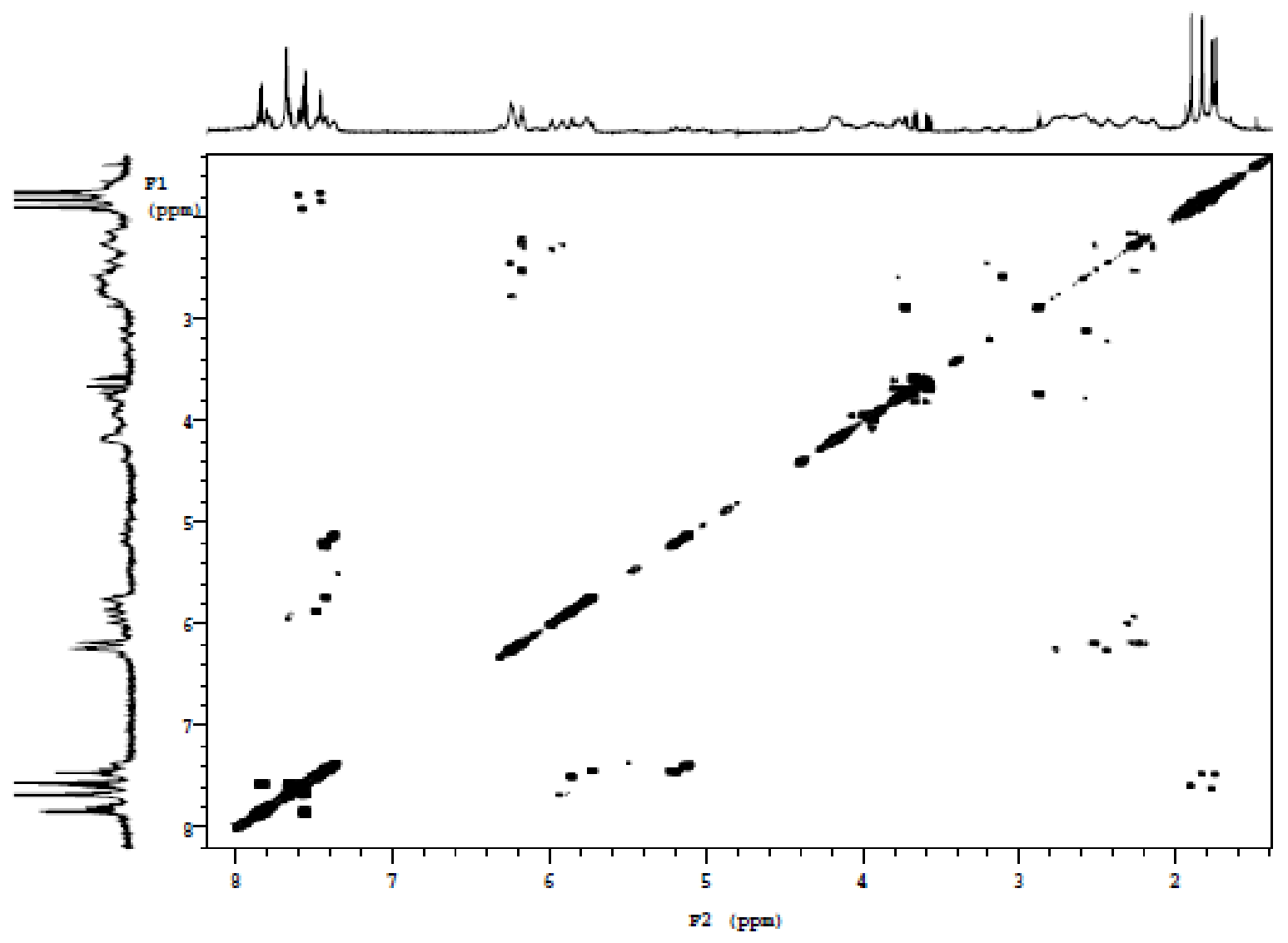


${ }^{1} \mathrm{H}^{1}{ }^{1} \mathrm{H}$ NOESY NMR Spectra of HP-CG ${ }^{8 \mathrm{Ph}}$ in the Z-DNA Conformation

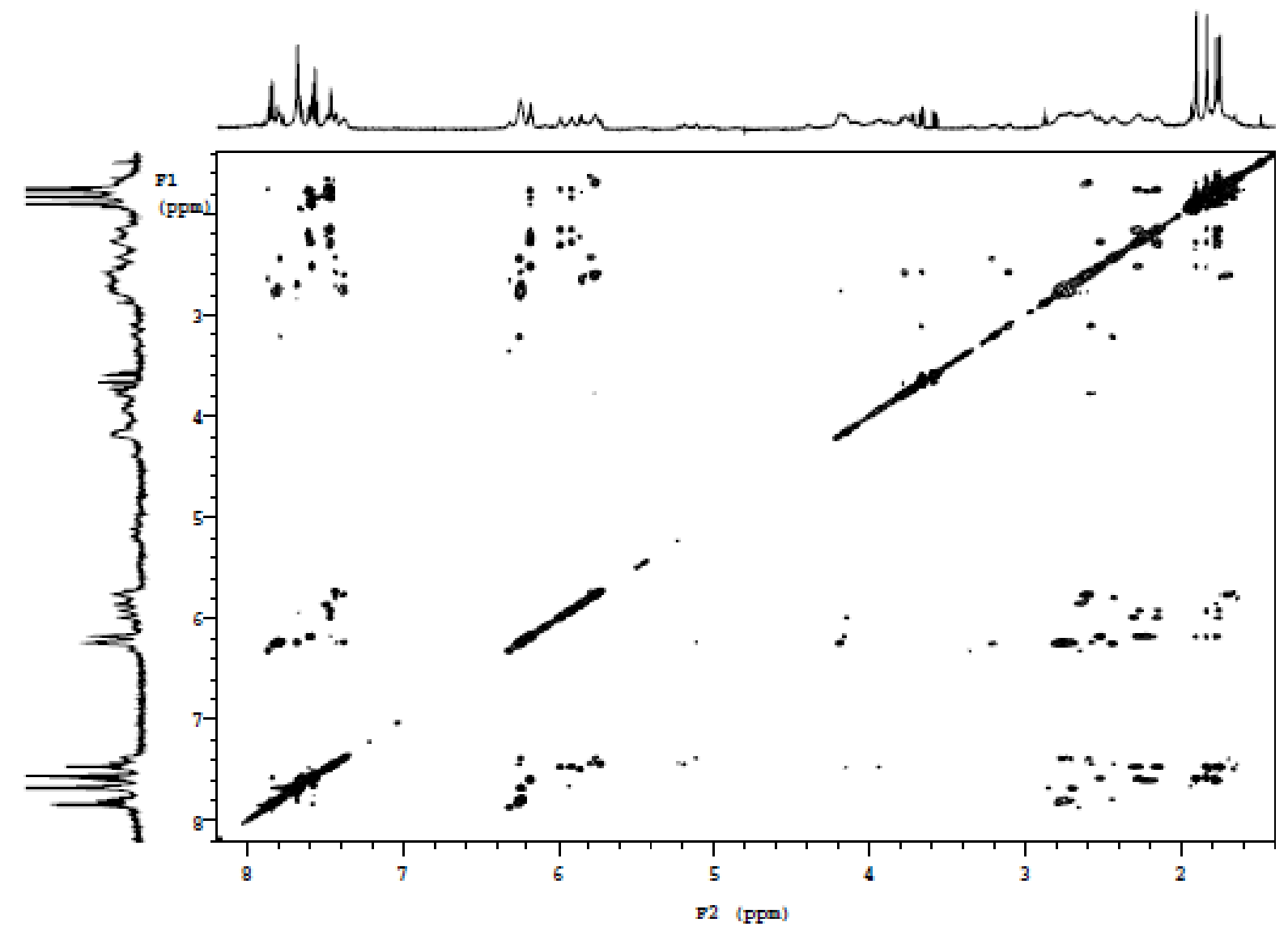


${ }^{1} \mathrm{H}$ NMR Spectrum of HP-CG ${ }^{8 \mathrm{~T} o l}$ in the B-DNA Conformation

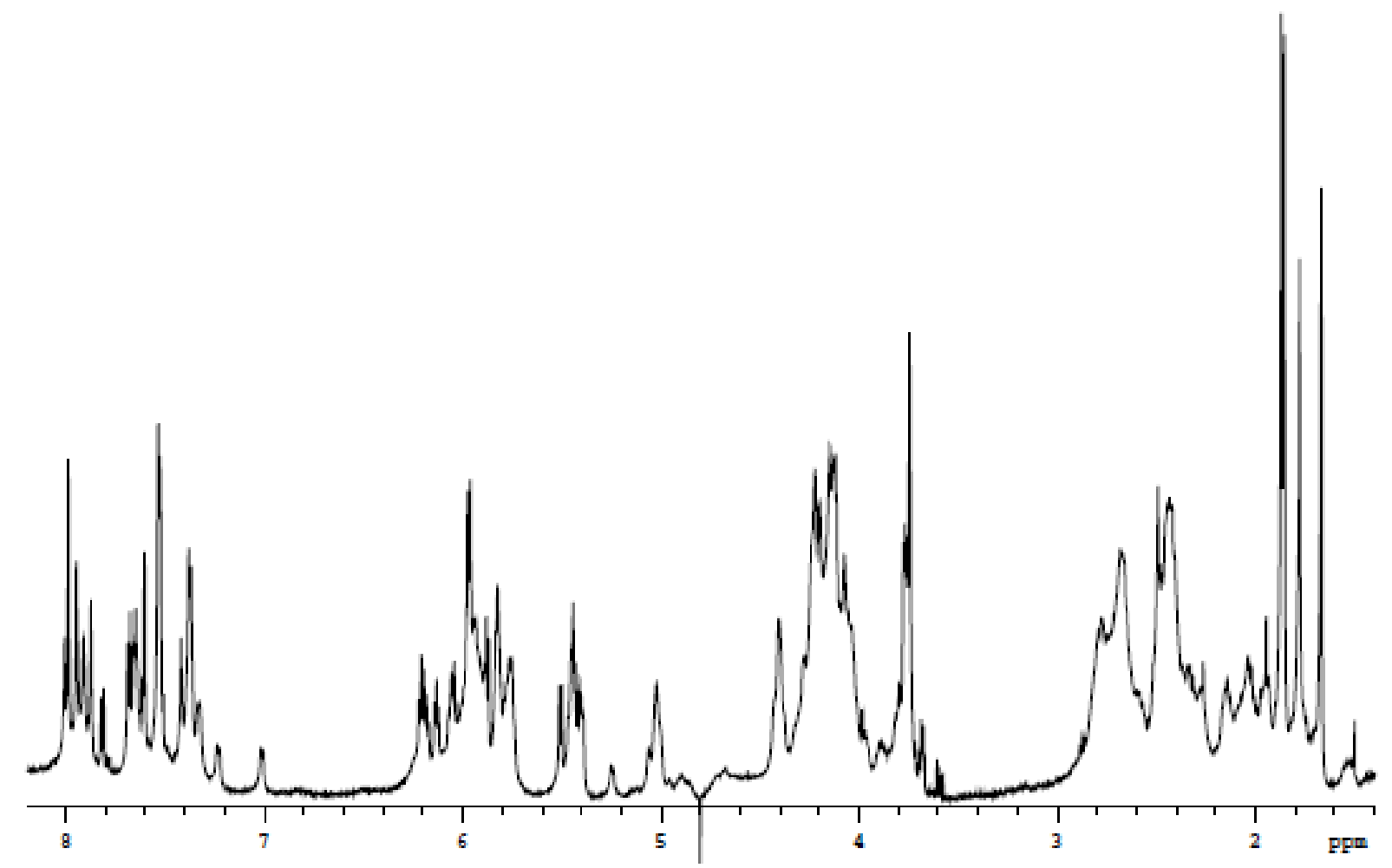


${ }^{1} \mathrm{H}^{1}{ }^{1} \mathrm{H}$ gCOSY NMR Spectra of HP-CG ${ }^{8 \mathrm{Tol}}$ in the B-DNA Conformation

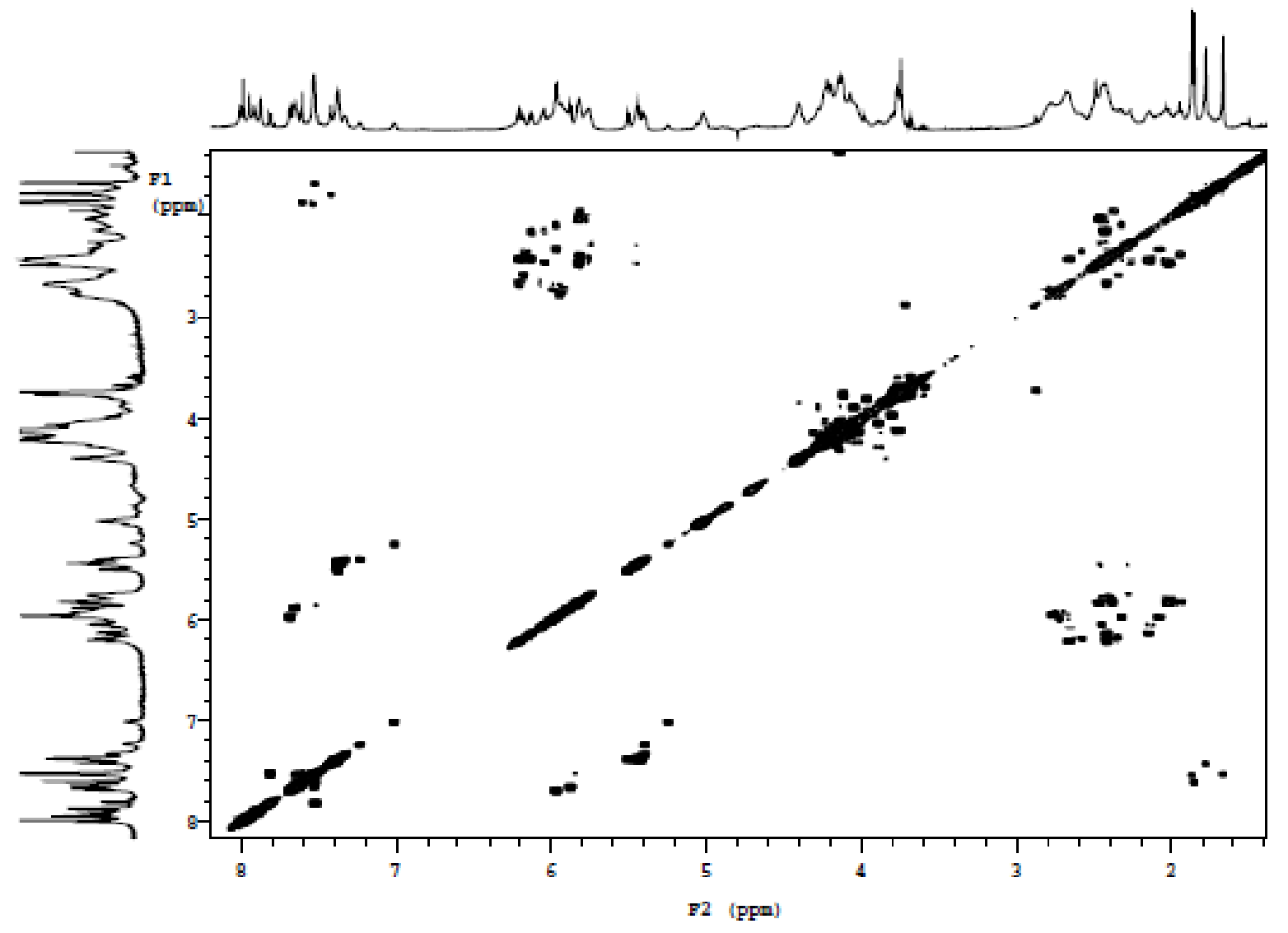


${ }^{1} \mathrm{H}-{ }^{1} \mathrm{H}$ NOESY NMR Spectra of HP-CG ${ }^{8 T o l}$ in the B-DNA Conformation

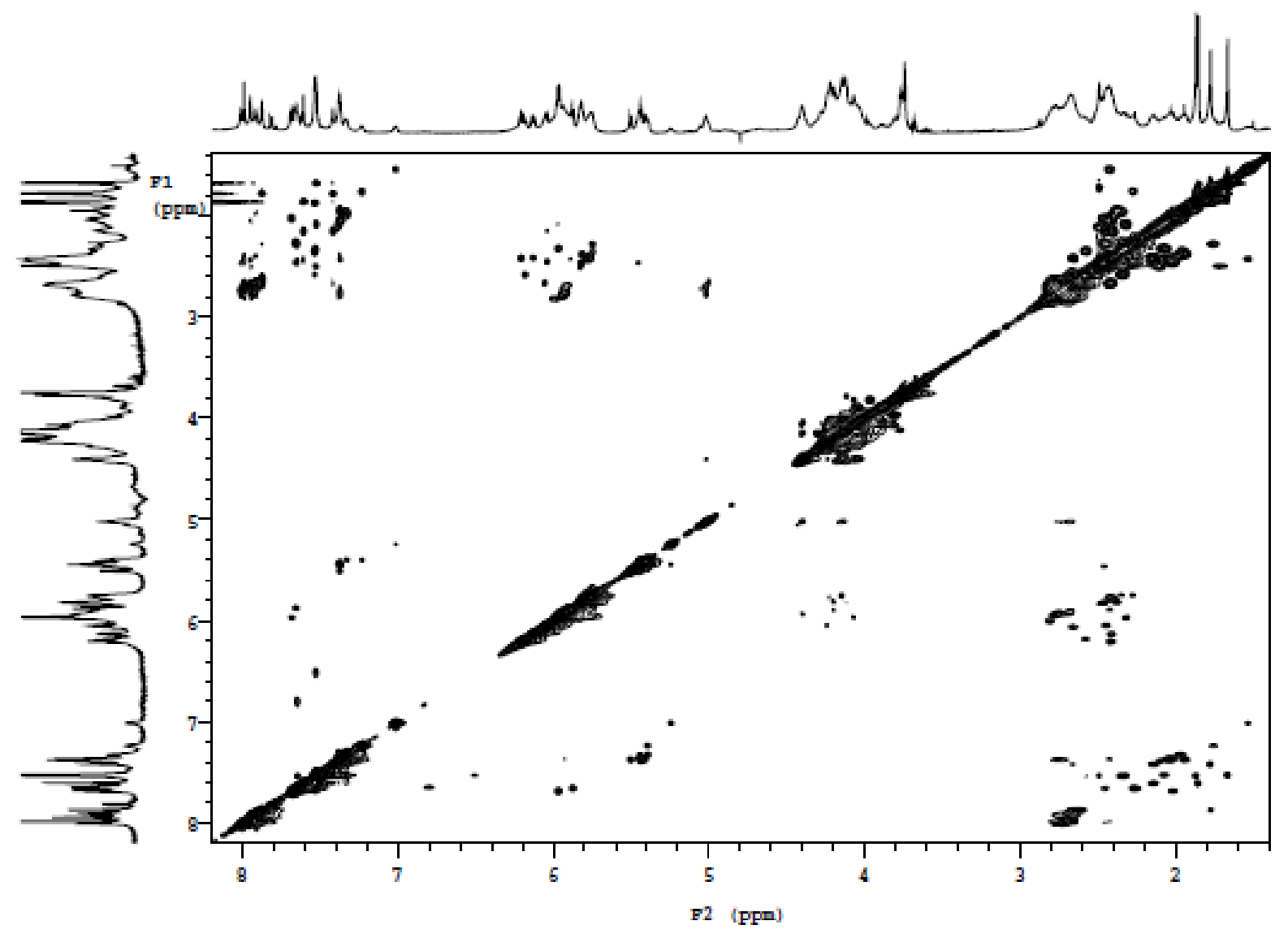


${ }^{1} \mathrm{H}$ NMR Spectrum of HP-CG ${ }^{8 T o l}$ in the Z-DNA Conformation

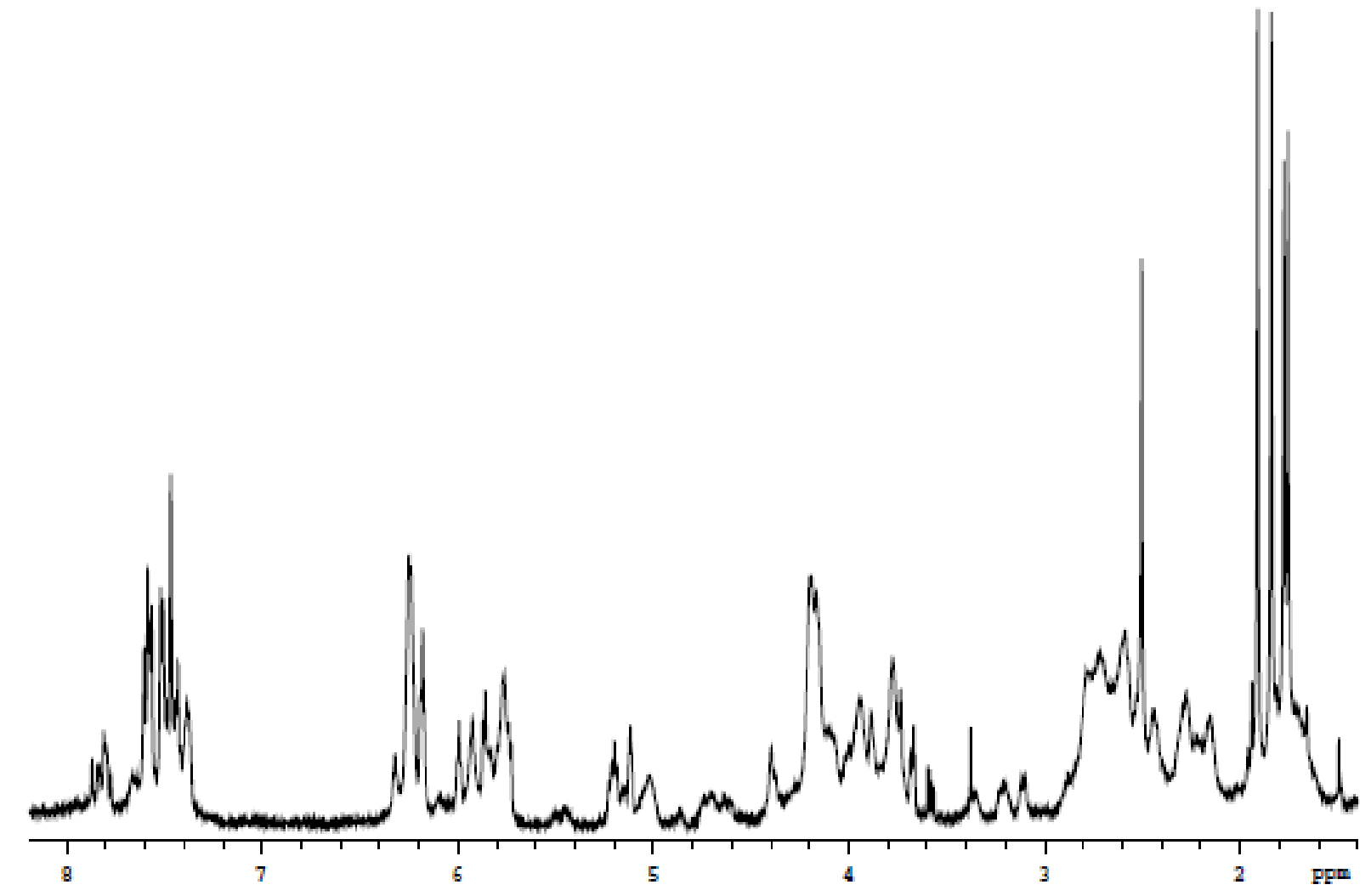


${ }^{1} \mathrm{H}^{1}{ }^{1} \mathrm{H}$ gCOSY NMR Spectra of HP-CG ${ }^{8 T o l}$ in the Z-DNA Conformation

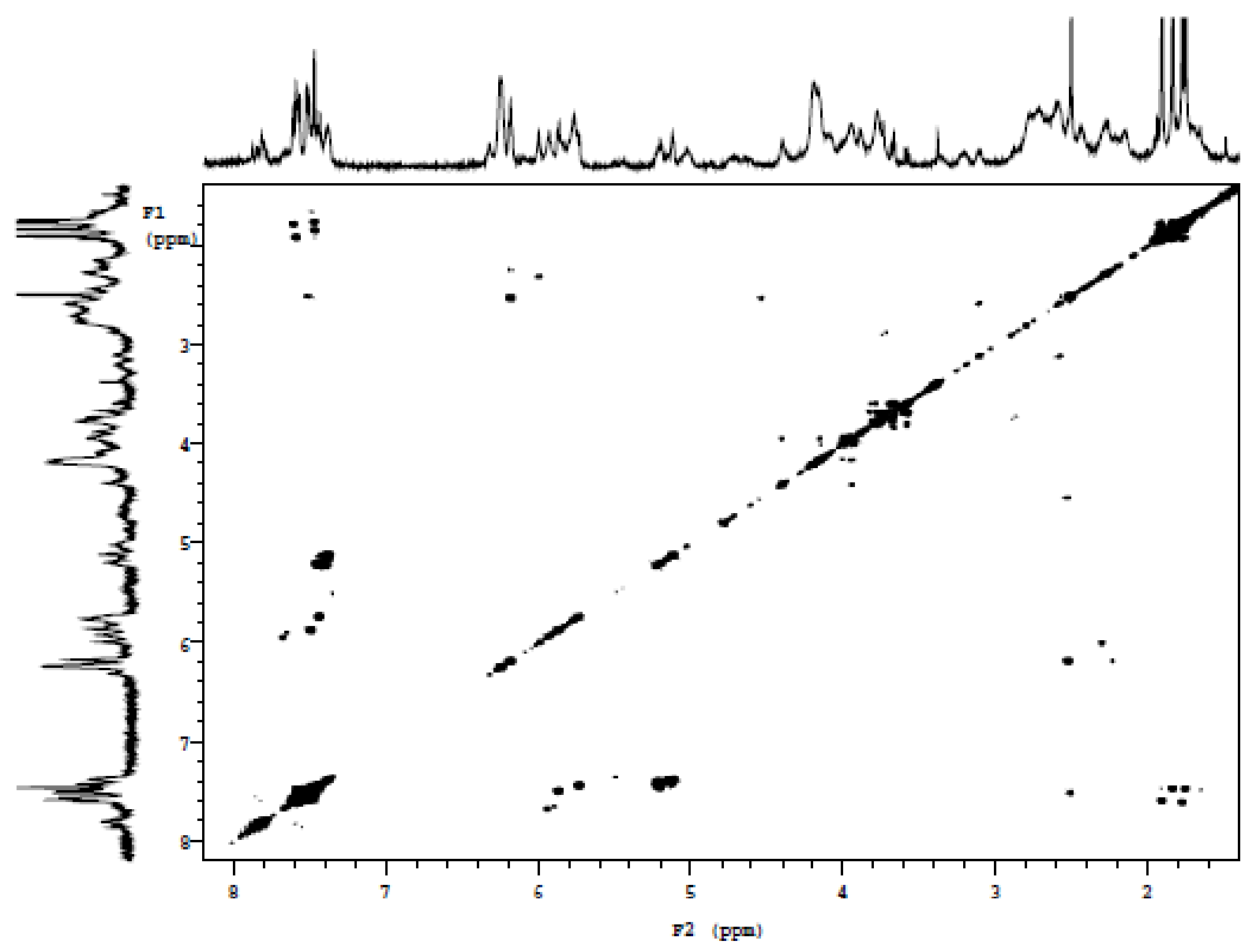


${ }^{1} \mathrm{H}^{1}{ }^{1} \mathrm{H}$ NOESY NMR Spectra of HP-CG ${ }^{8 T o l}$ in the Z-DNA Conformation

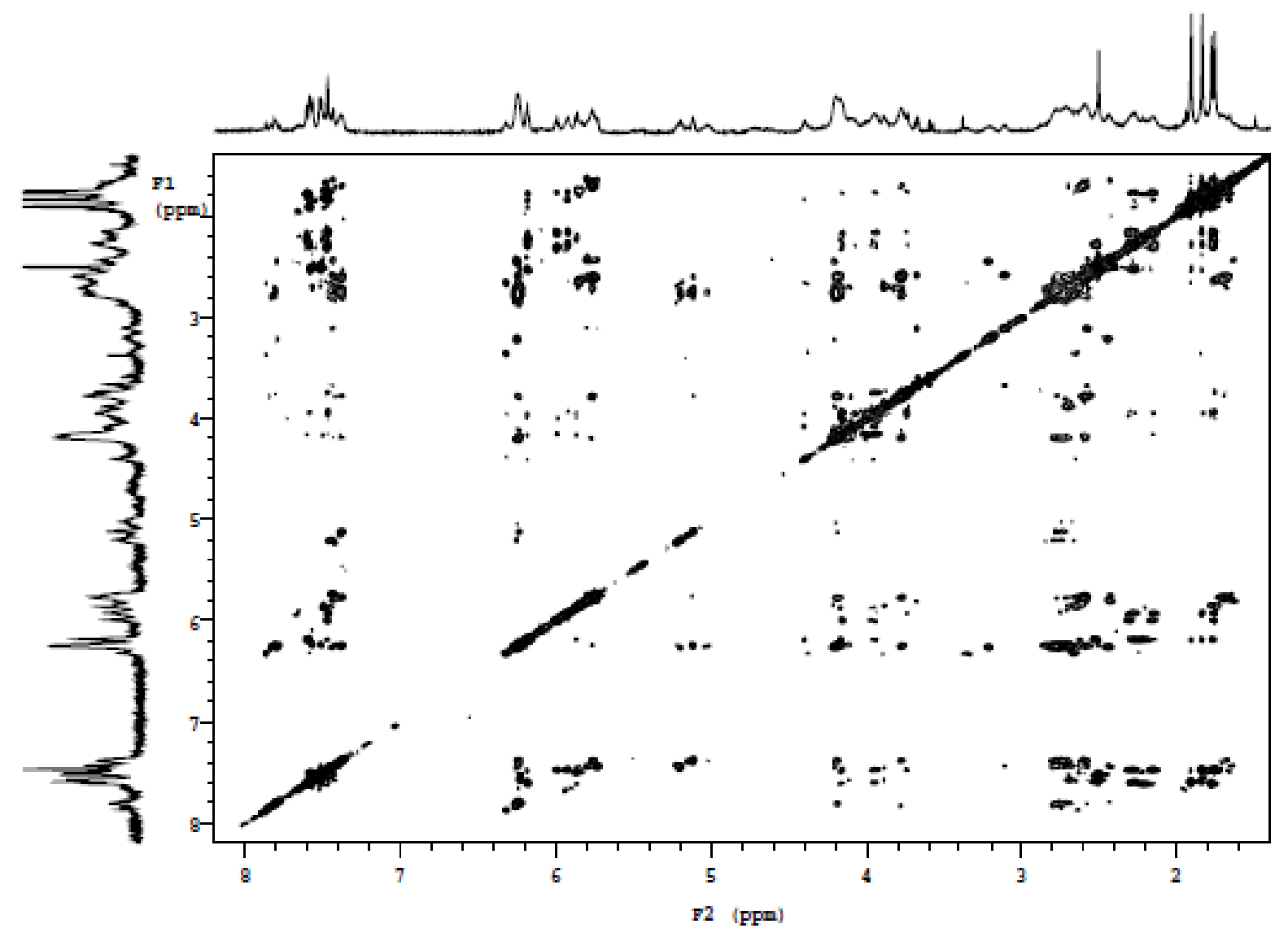


${ }^{1} \mathrm{H}$ NMR Spectrum of HP-CG ${ }^{8 \mathrm{HMPh}}$ in the B-DNA Conformation

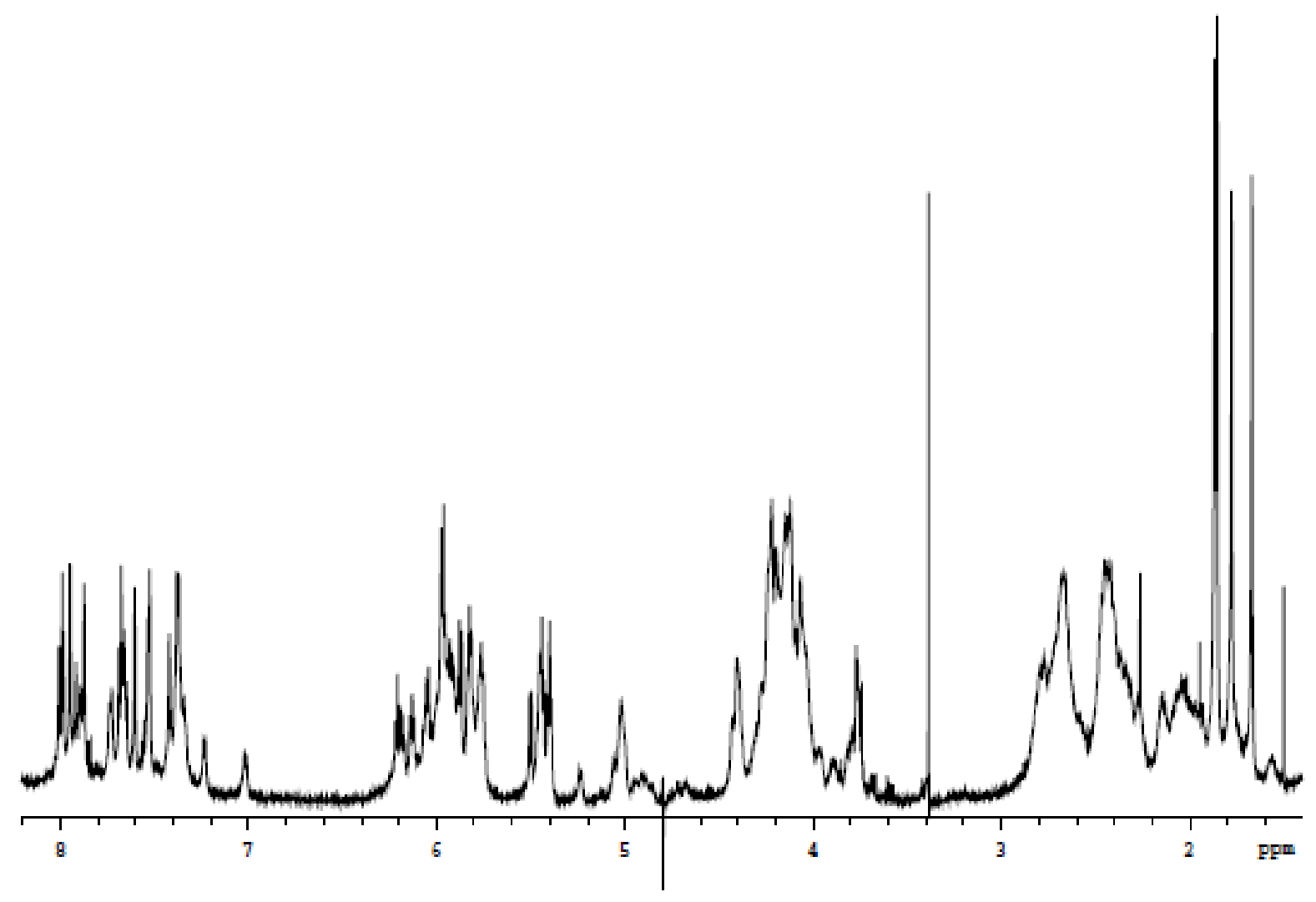


${ }^{1} \mathrm{H}-{ }^{1} \mathrm{H}$ gCOSY NMR Spectra of HP-CG ${ }^{8 H M P h}$ in the B-DNA Conformation

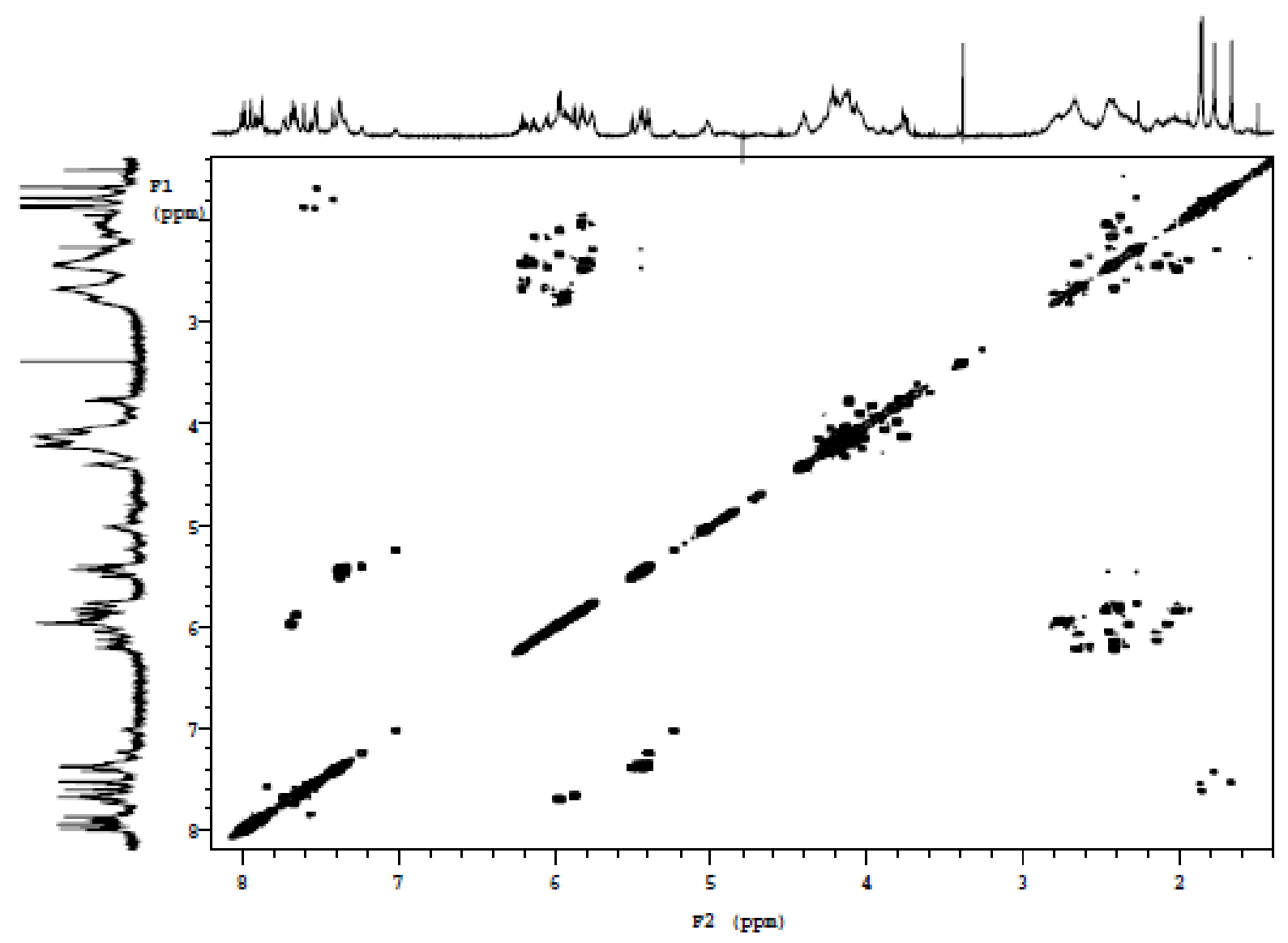


${ }^{1} \mathrm{H}^{1}{ }^{1} \mathrm{H}$ NOESY NMR Spectra of HP-CG ${ }^{8 H M P h}$ in the B-DNA Conformation

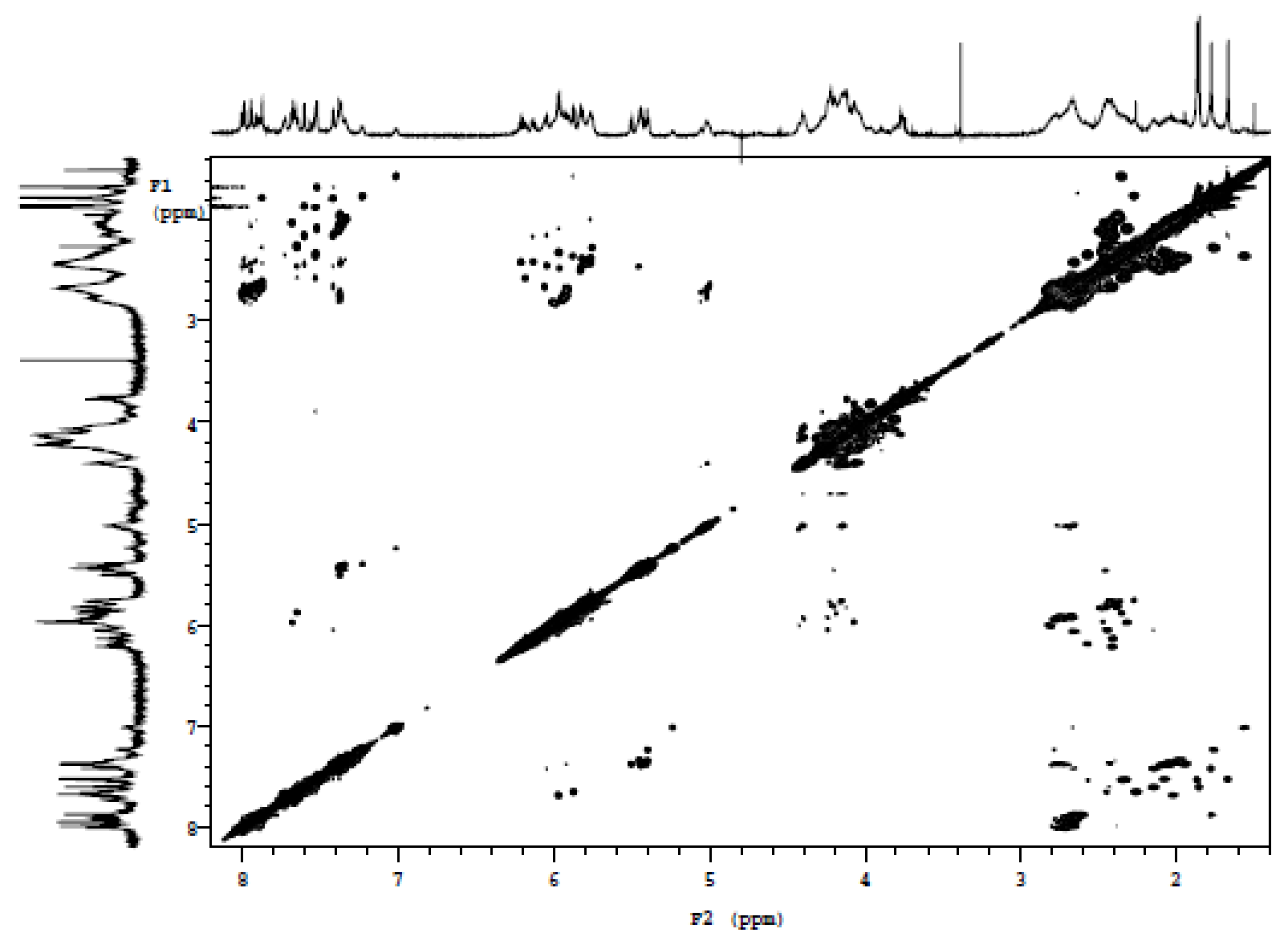


${ }^{1}$ H NMR Spectrum of HP-CG ${ }^{8 H M P h}$ in the Z-DNA Conformation

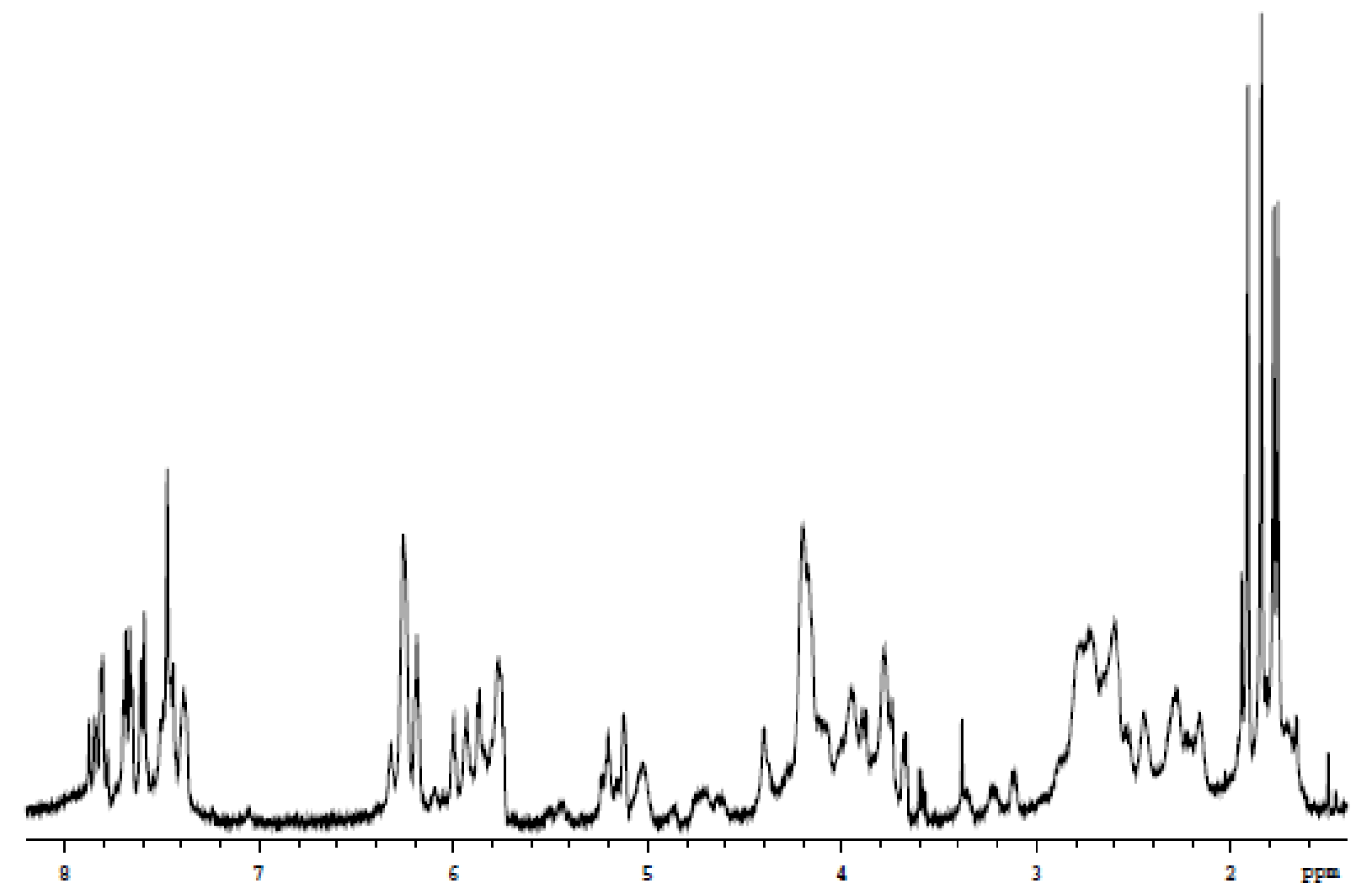


${ }^{1} \mathrm{H}^{1}{ }^{1} \mathrm{H}$ gCOSY NMR Spectra of HP-CG ${ }^{8 \mathrm{HMPh}}$ in the Z-DNA Conformation

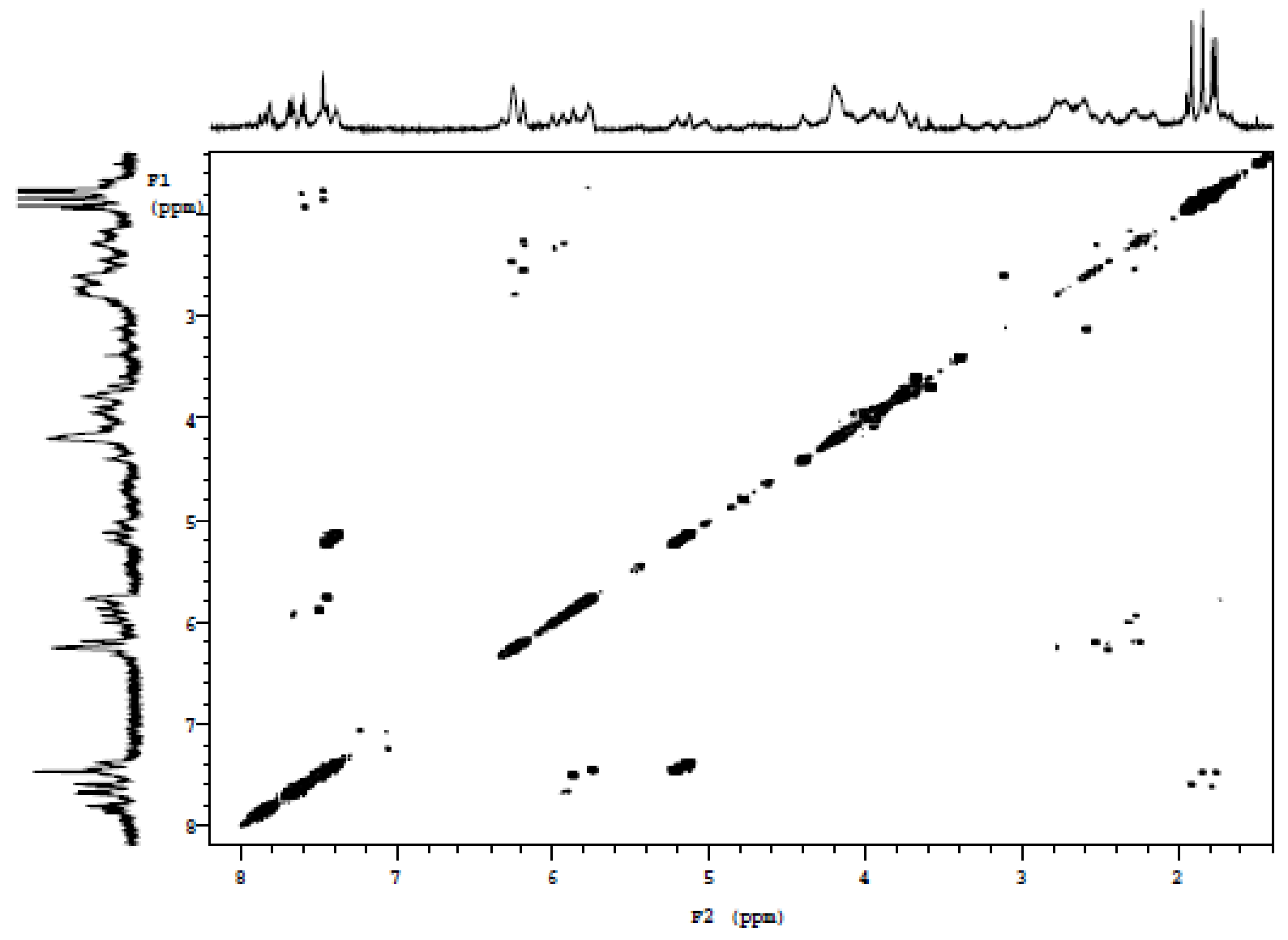


${ }^{1} \mathrm{H}^{1}{ }^{1} \mathrm{H}$ NOESY NMR Spectra of HP-CG ${ }^{8 H M P h}$ in the Z-DNA Conformation

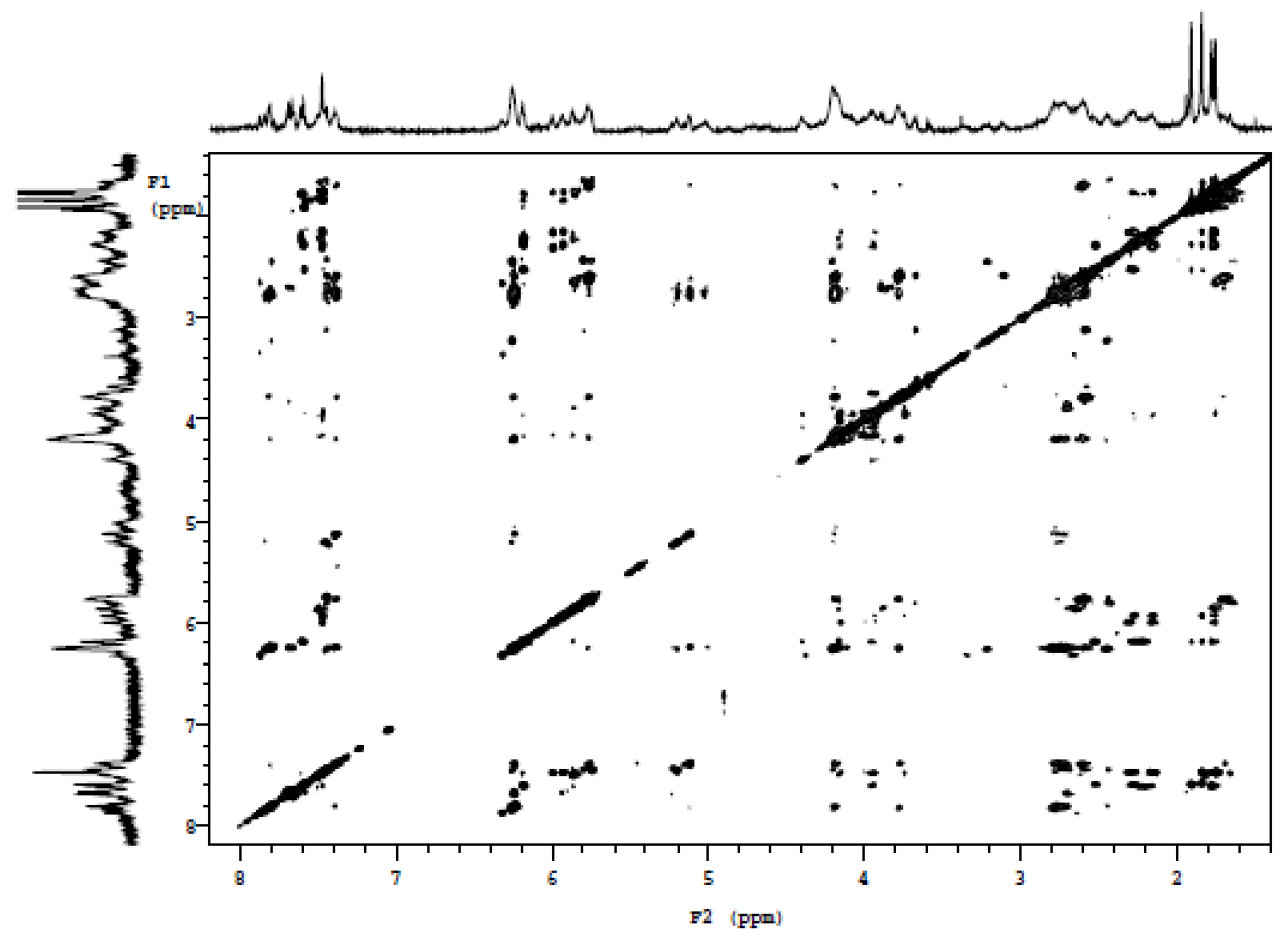


${ }^{1} \mathrm{H}$ NMR Spectrum of HP-CG ${ }^{8 M M P h}$ in the B-DNA Conformation

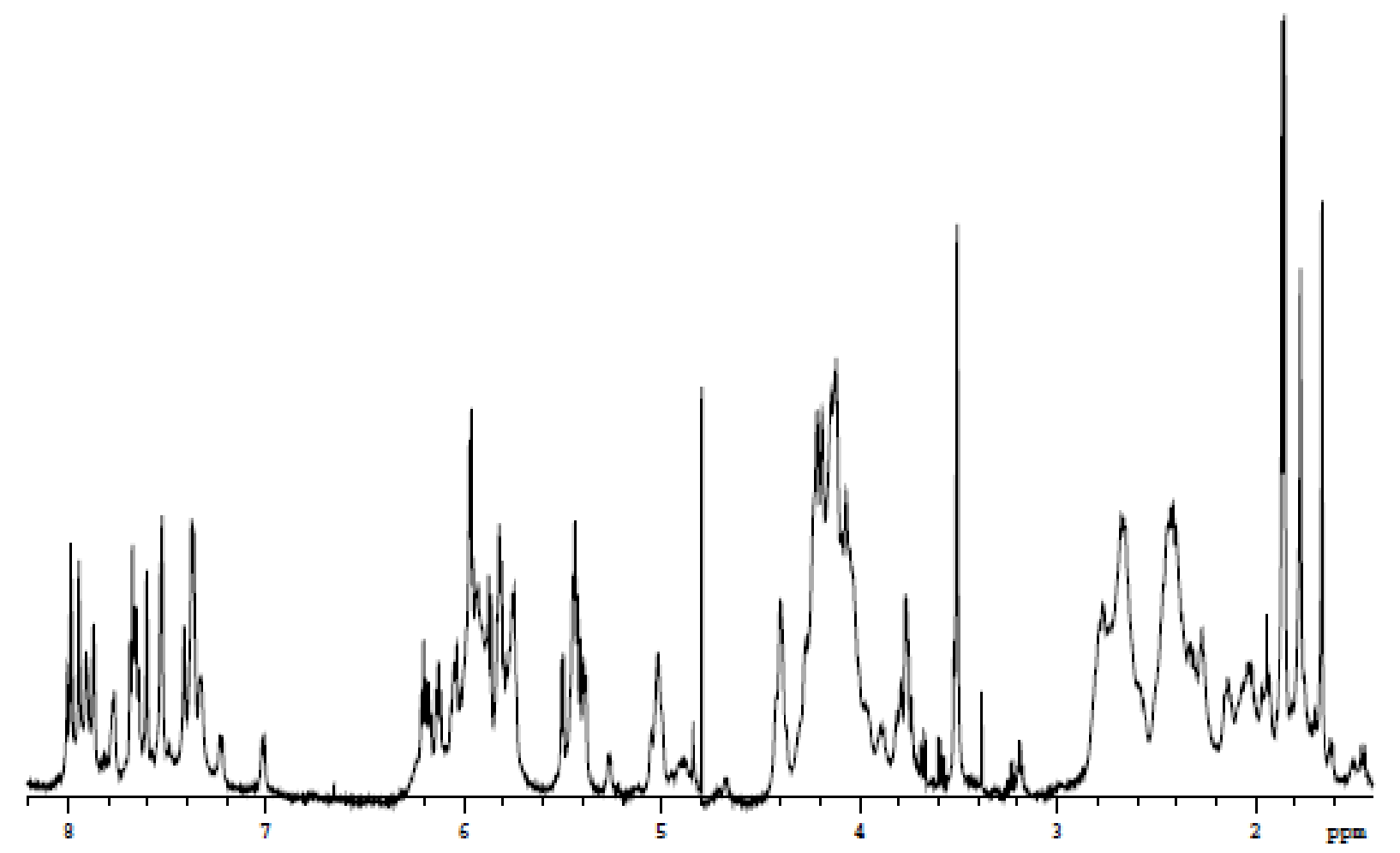


${ }^{1} \mathrm{H}-{ }^{1} \mathrm{H}$ gCOSY NMR Spectra of HP-CG ${ }^{8 M M P h}$ in the B-DNA Conformation

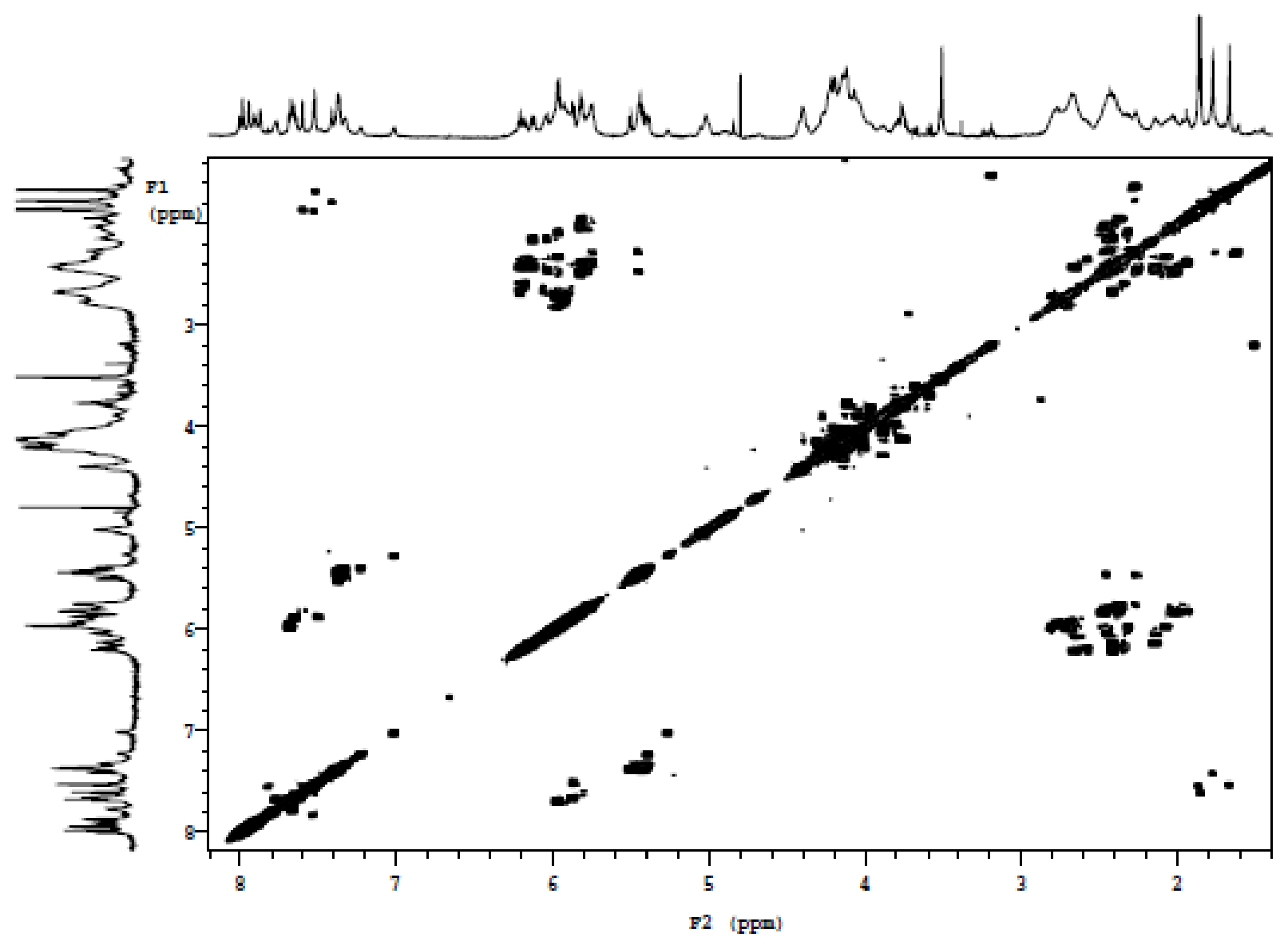




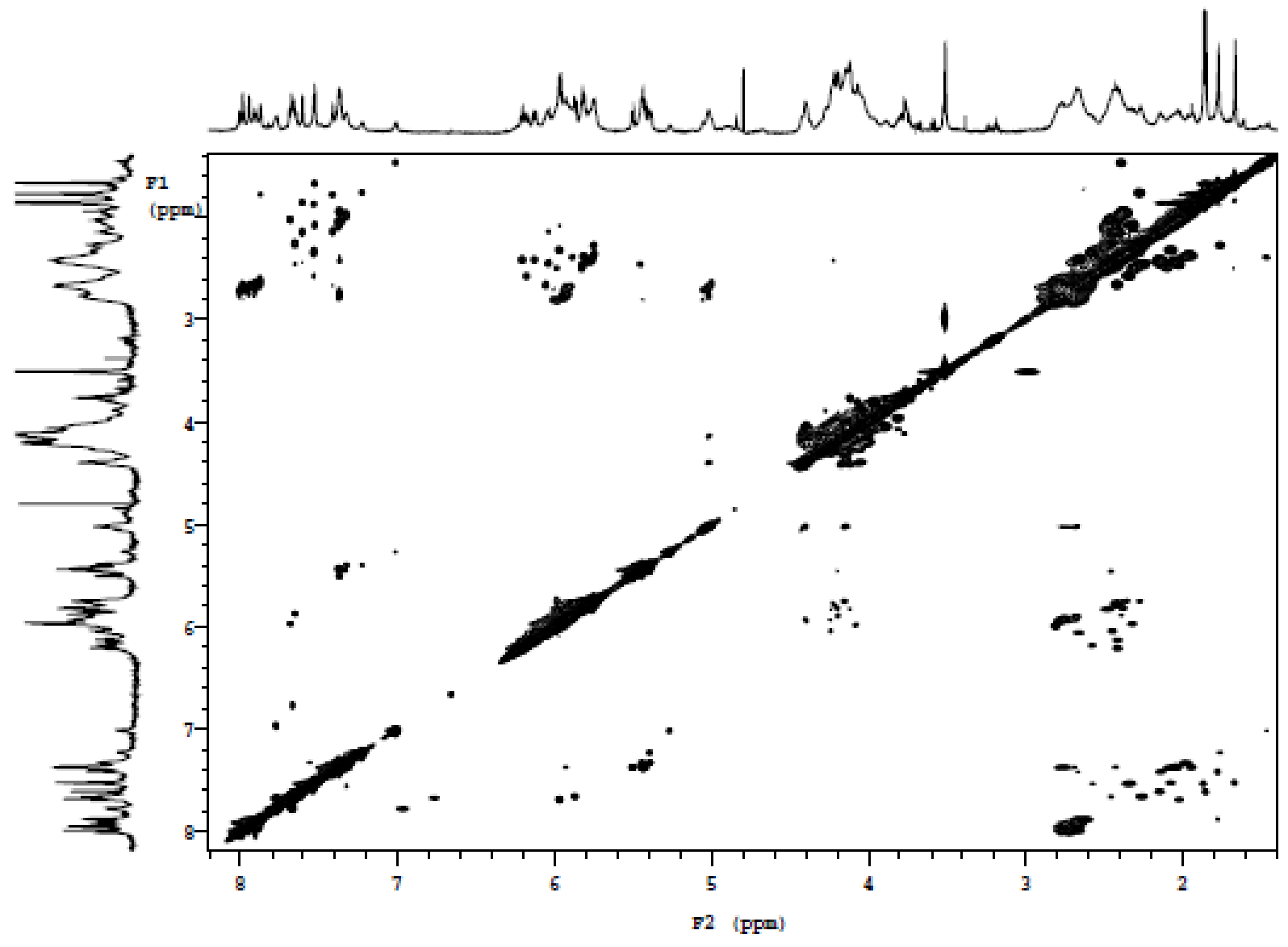


${ }^{1}$ H NMR Spectrum of HP-CG ${ }^{8 M M P h}$ in the Z-DNA Conformation

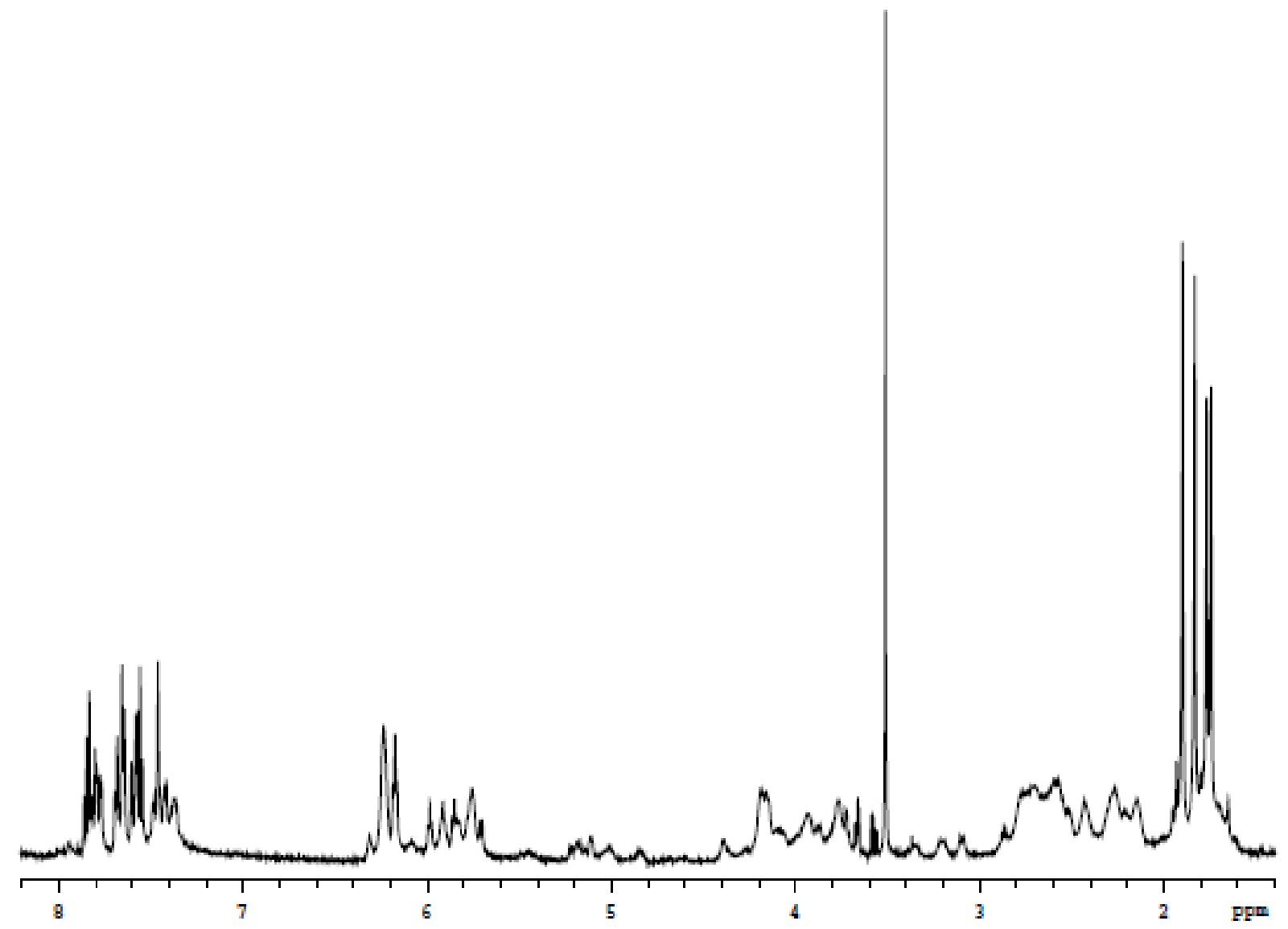


${ }^{1} \mathrm{H}-{ }^{1} \mathrm{H}$ gCOSY NMR Spectra of HP-CG ${ }^{8 M M P h}$ in the Z-DNA Conformation

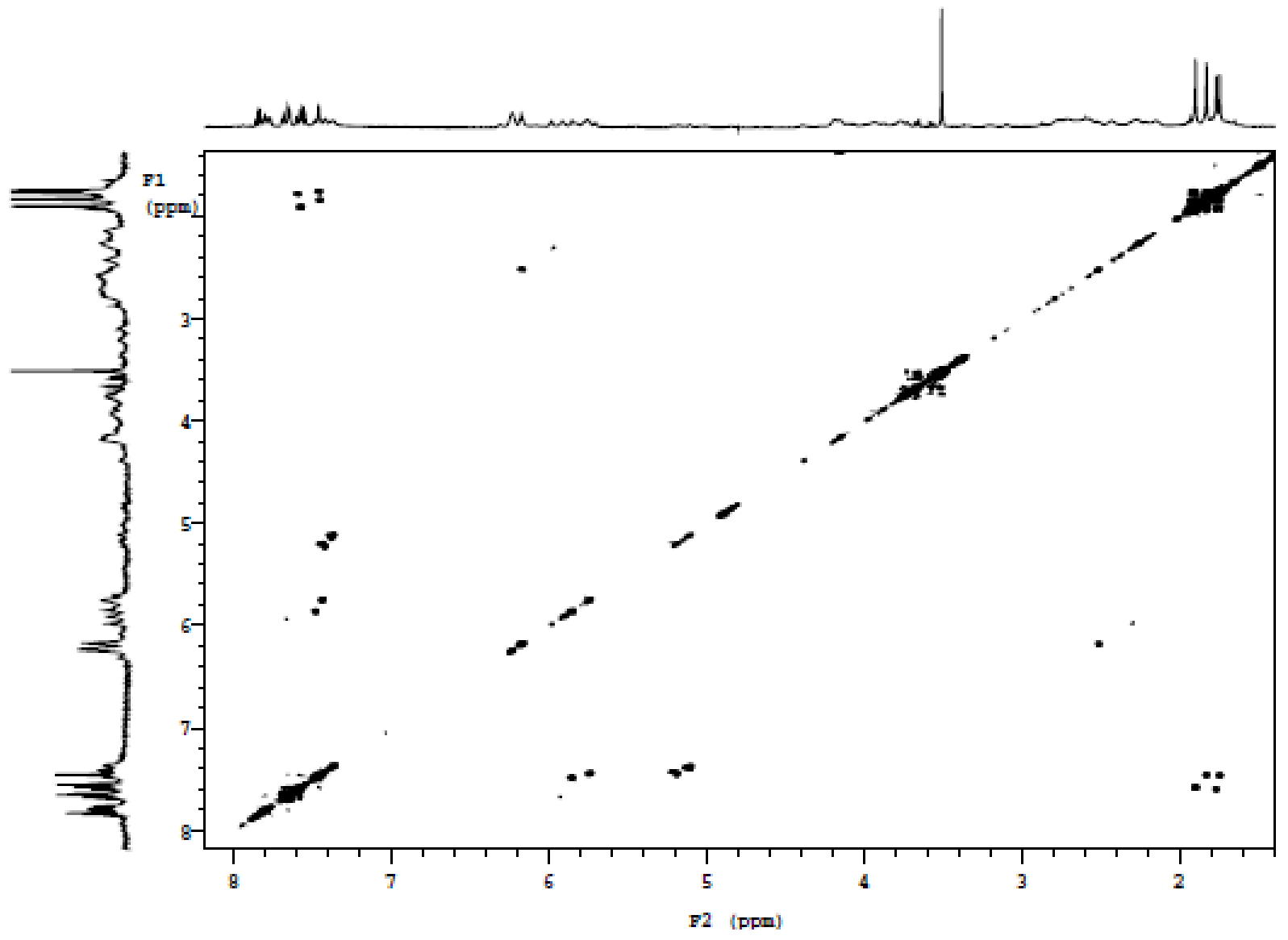


${ }^{1} \mathrm{H}^{1}{ }^{1} \mathrm{H}$ NOESY NMR Spectra of HP-CG ${ }^{8 M M P h}$ in the Z-DNA Conformation

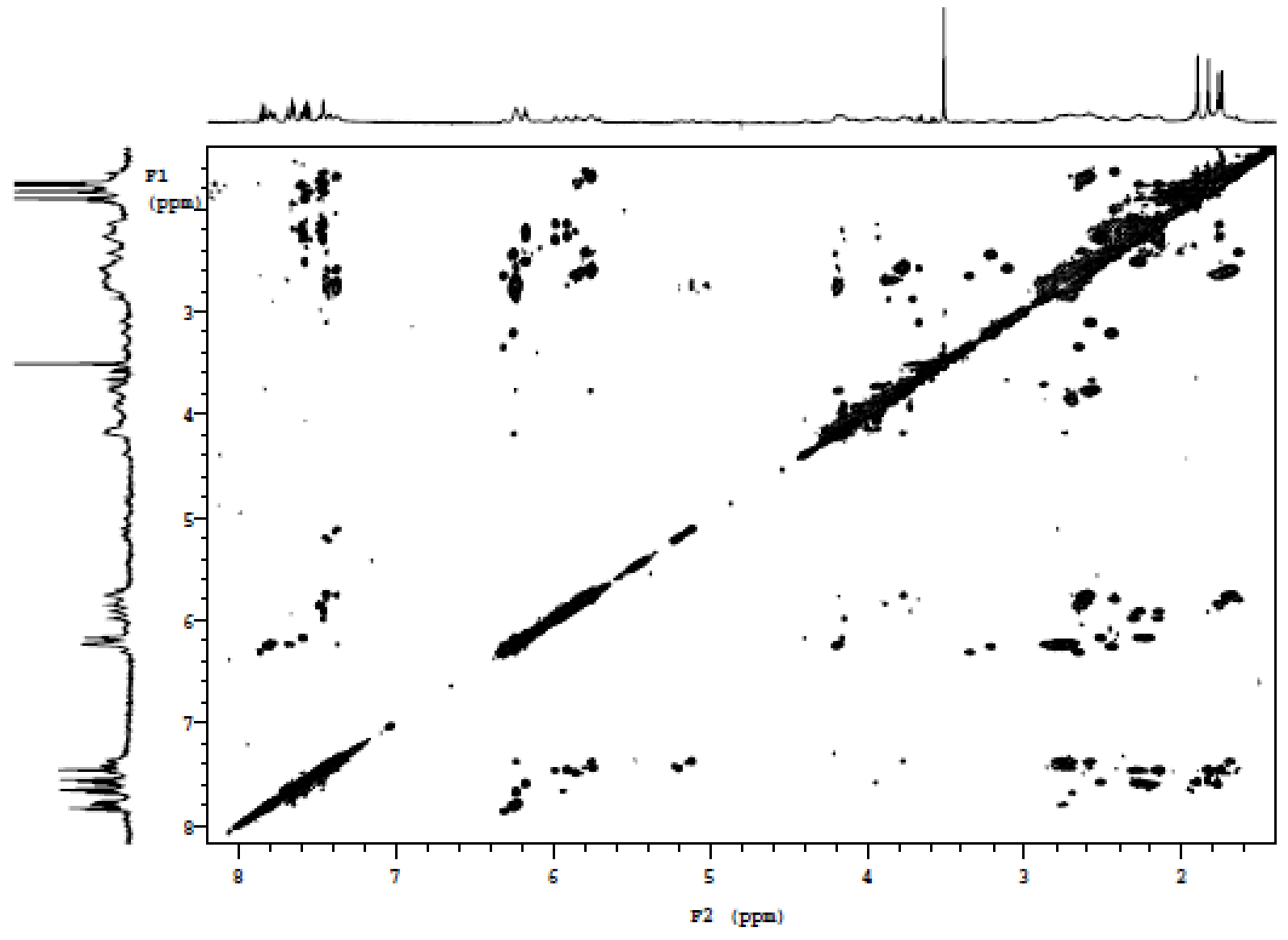


${ }^{1} \mathrm{H}$ NMR Spectrum of HP-CG ${ }^{8 \mathrm{CPh}}$ in the Z-DNA Conformation

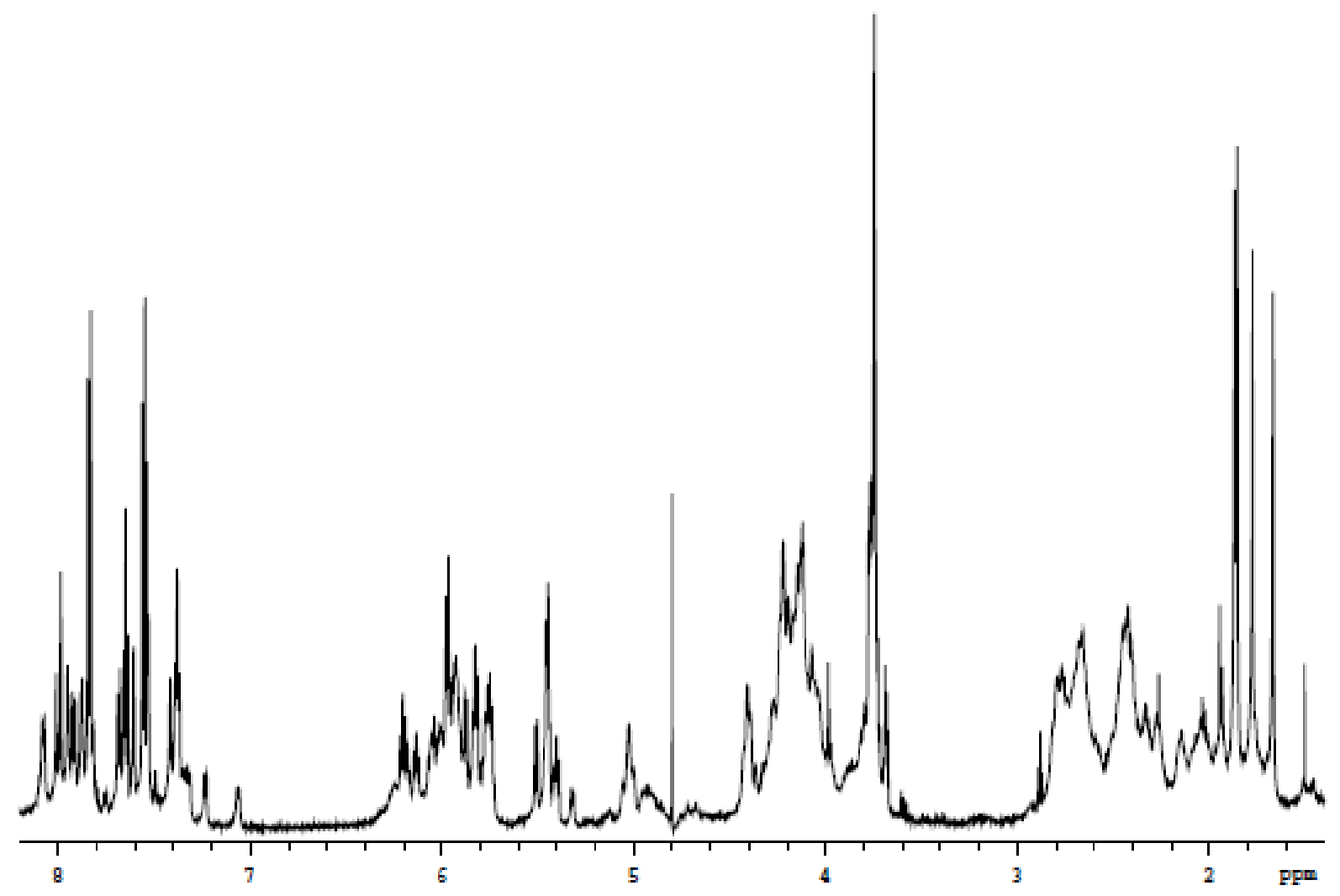


${ }^{1} \mathrm{H}-{ }^{1} \mathrm{H}$ gCOSY NMR Spectra of HP-CG ${ }^{8 \mathrm{CPh}}$ in the B-DNA Conformation

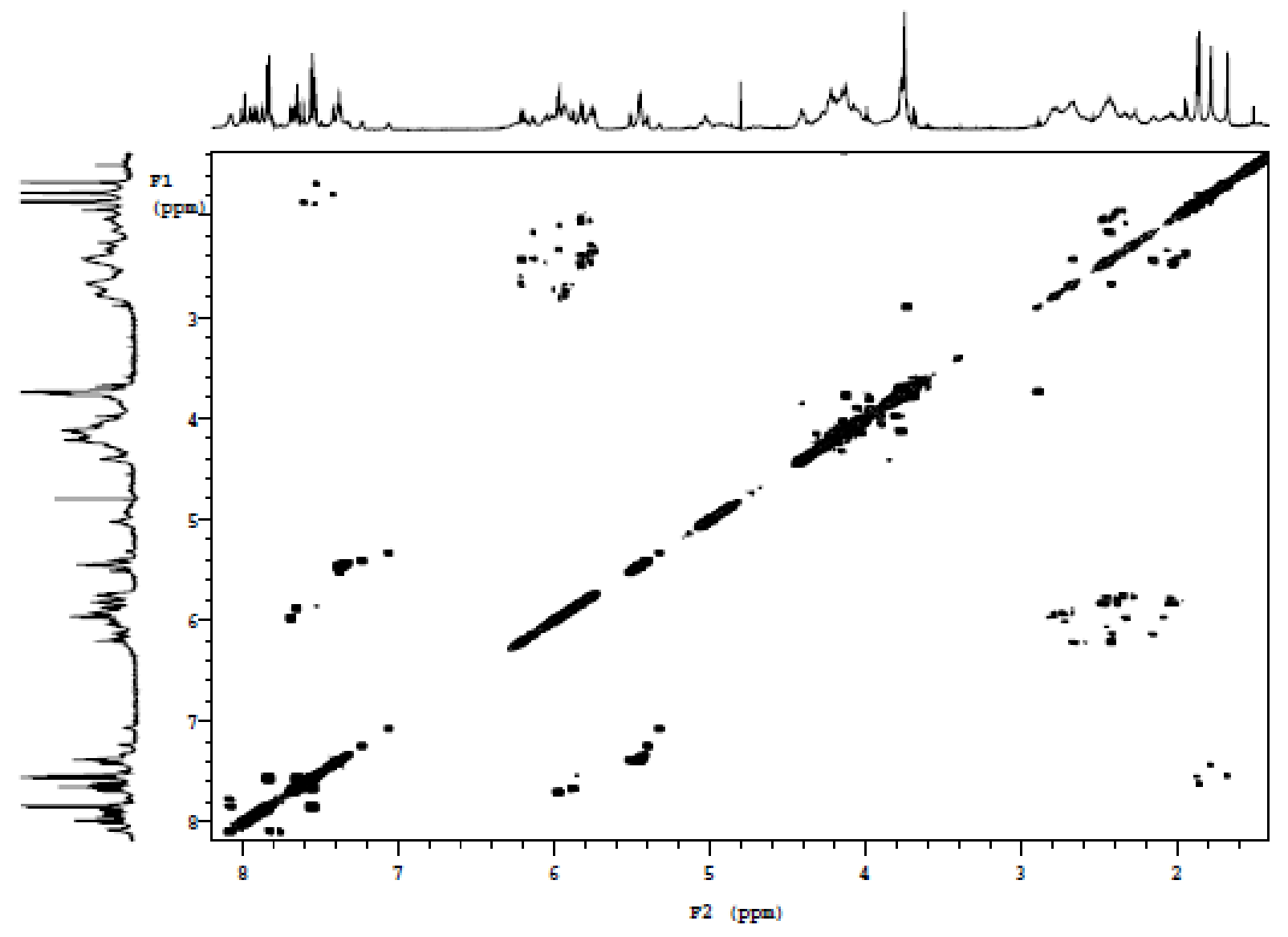


${ }^{1} \mathrm{H}^{1} \mathrm{H}$ NOESY NMR Spectra of HP-CG ${ }^{8 \mathrm{CPh}}$ in the B-DNA Conformation

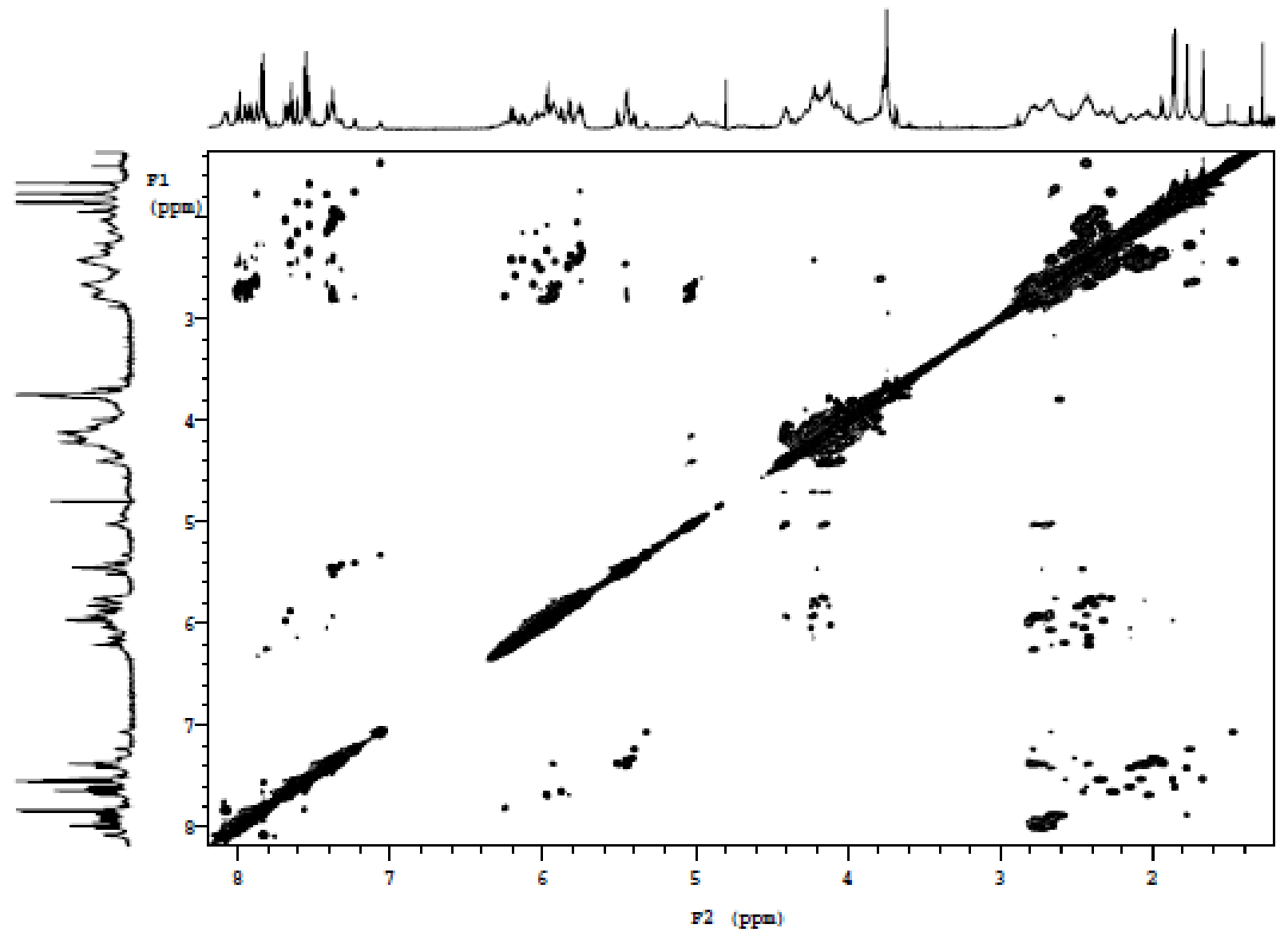


${ }^{1} \mathrm{H}$ NMR Spectrum of HP-CG ${ }^{8 \mathrm{CPh}}$ in the Z-DNA Conformation

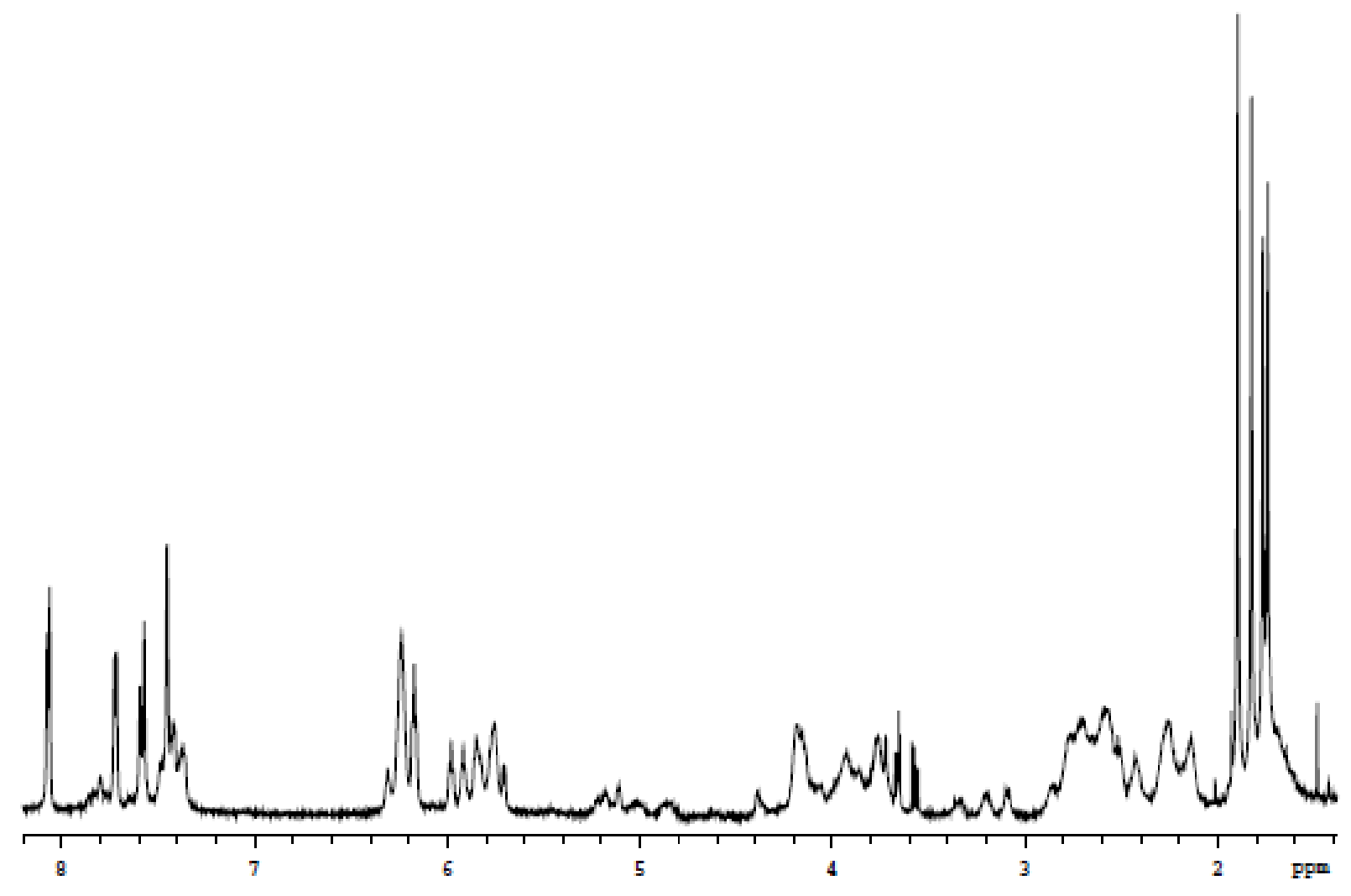


${ }^{1} \mathrm{H}-{ }^{1} \mathrm{H}$ gCOSY NMR Spectra of HP-CG ${ }^{8 \mathrm{CPh}}$ in the Z-DNA Conformation

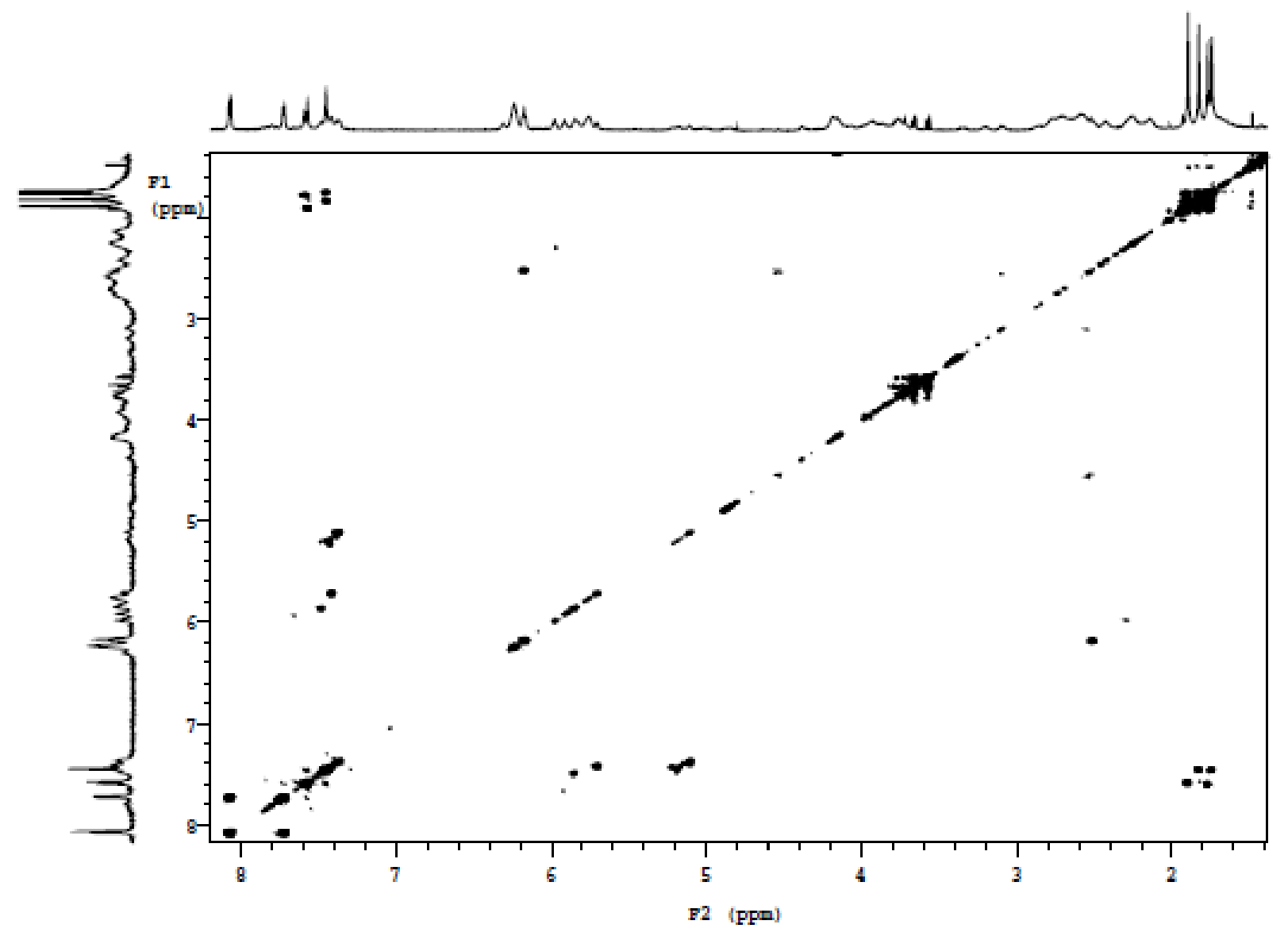


${ }^{1} \mathrm{H}^{1} \mathrm{H}$ NOESY NMR Spectra of HP-CG ${ }^{8 \mathrm{CPh}}$ in the Z-DNA Conformation

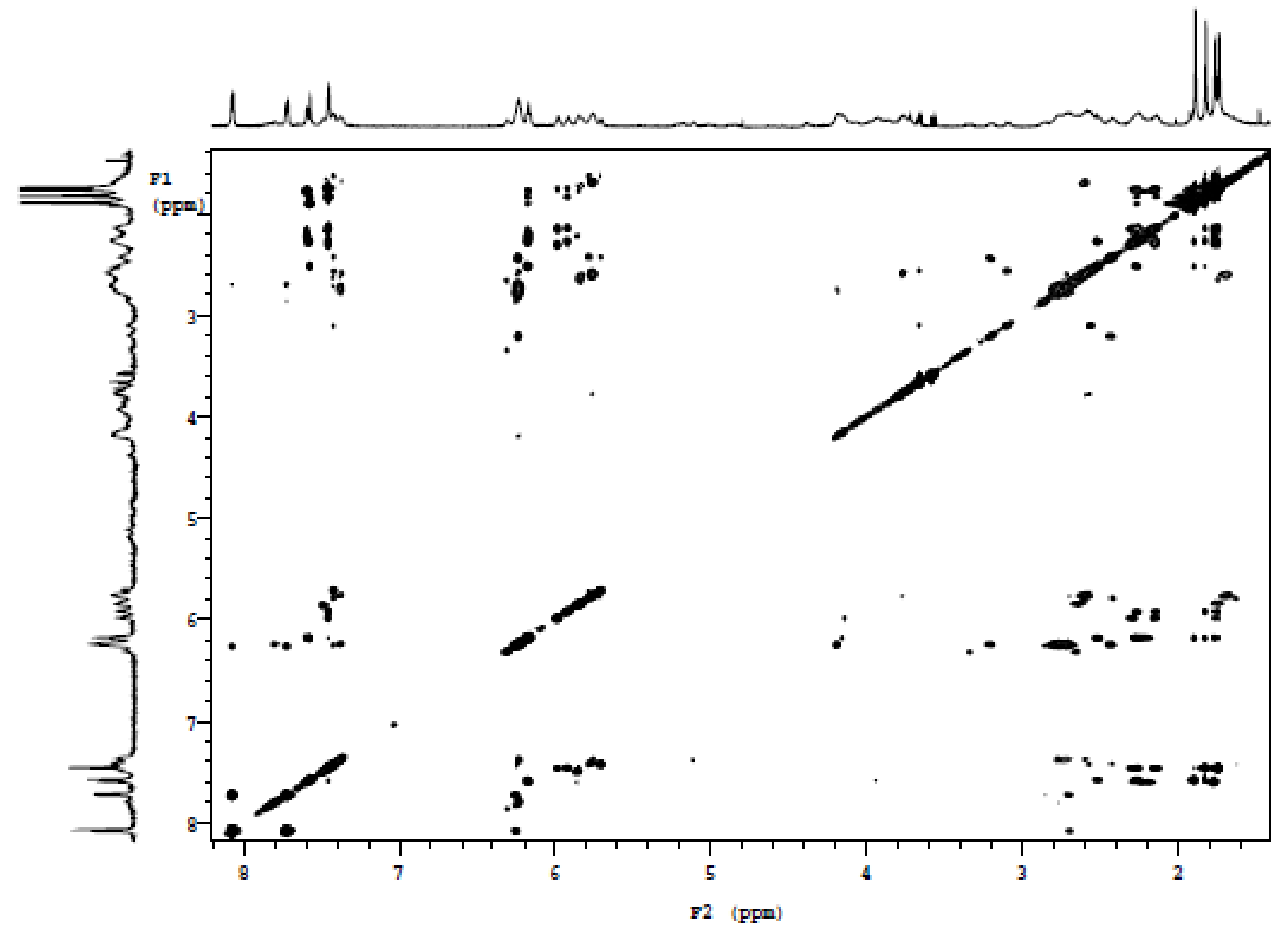

